90.

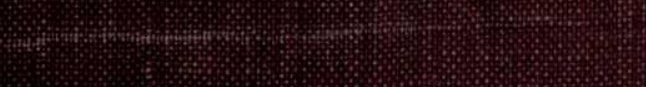

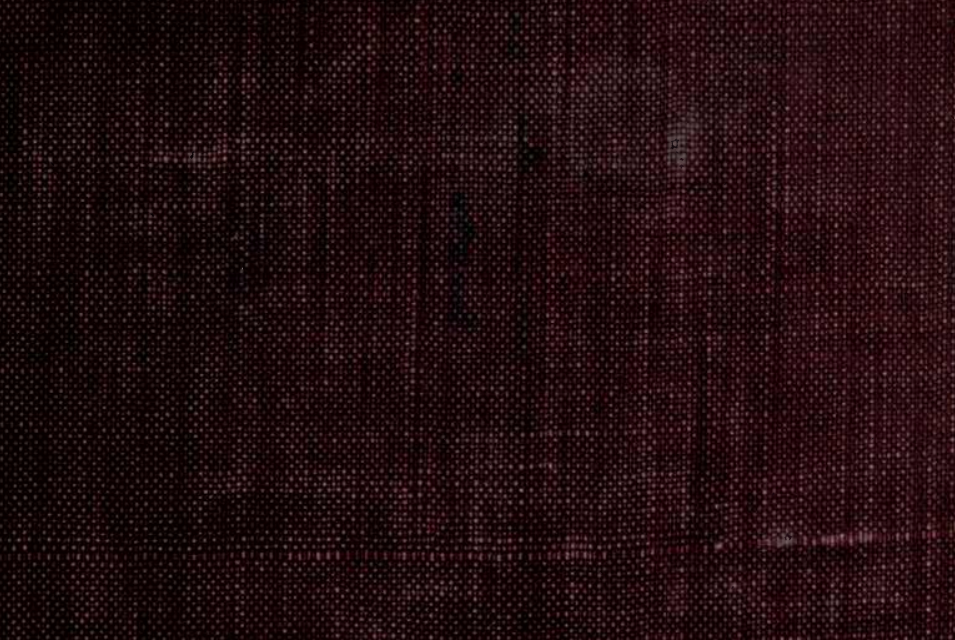

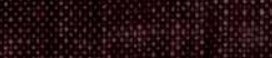

\& $800 \%$ \% 


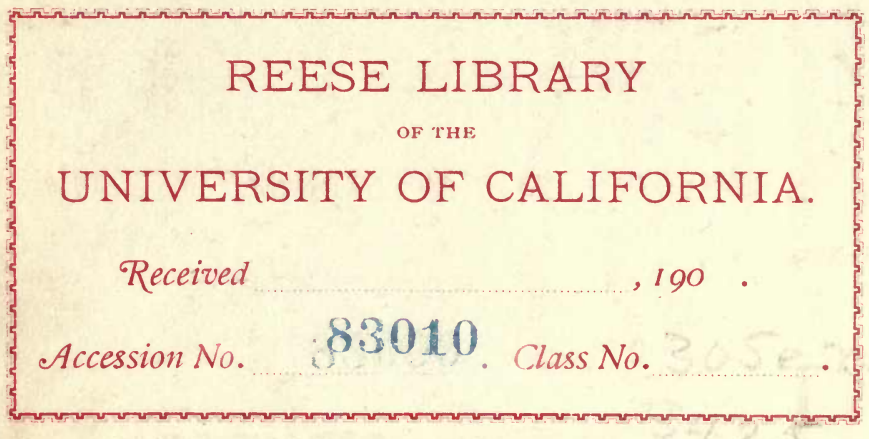




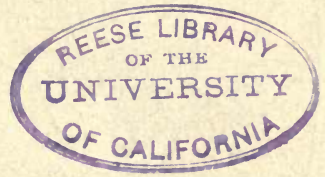




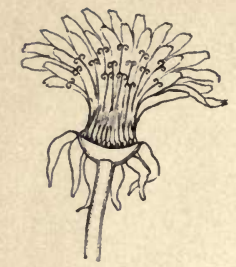

Fig. B
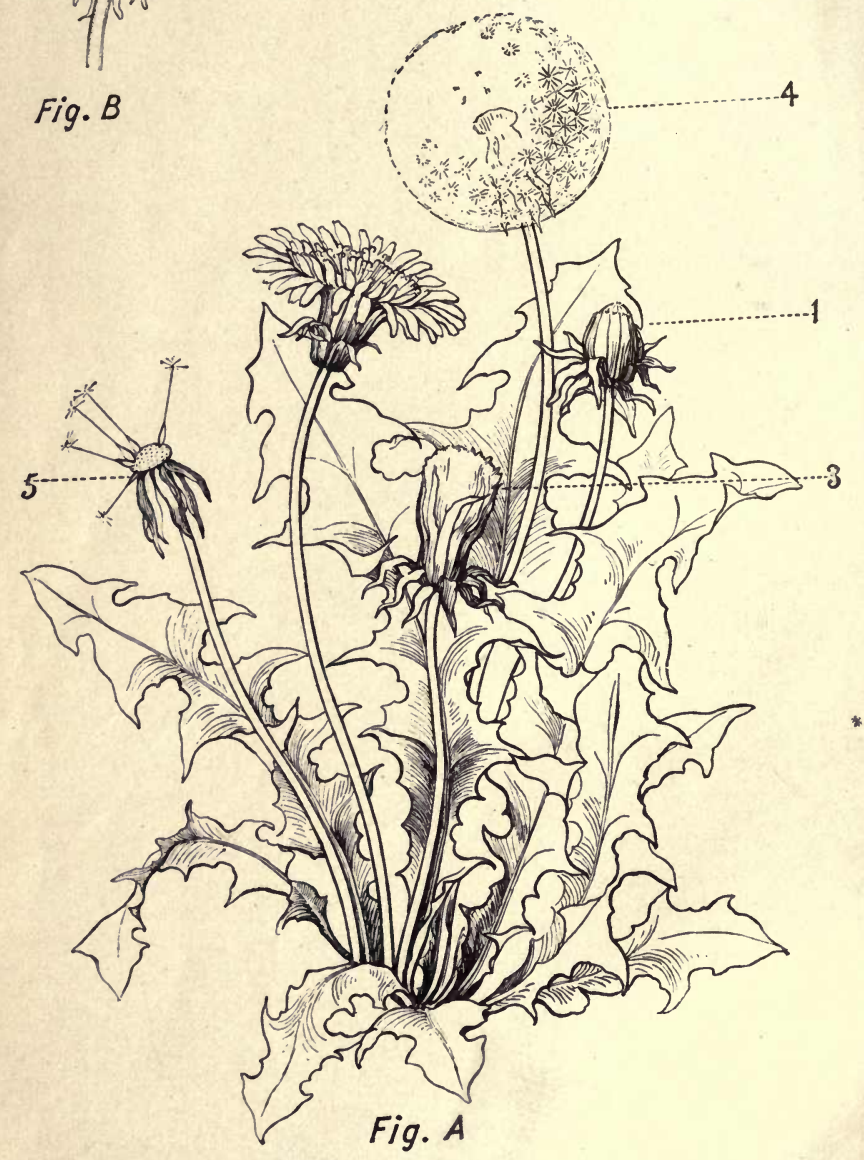

The Dandelion. 


\section{N A T URE S T U D Y}

AND

\section{T H E \\ C H I L D}

BY

CHARLES B. SCOTT, A.M.

Recently Instructor in Nature Study at the State Normal SCHOOL, OSWEGO, N.Y.

"And Nature, the old nurse, took

The child upon her knee,

Saying, "Here is a story-book

Thy father has written for thee."

LONGFELLOW

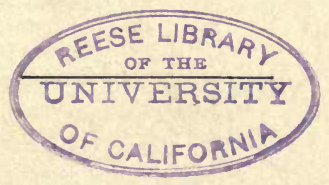

BOSTON, U.S.A.

D. C. HEATH \& CO., PUBLISHERS 
Copyright, 1900,

By D. C. Heath \& Co. 


\section{ANALYTICAL TABLE OF CONTENTS.}

\section{PART I. - AIM AND METHOD IN NATURE STUDY.}

\section{CHAPTER I.}

The Study of the Dandelion.

I. Advantage of beginning Discussion of Nature Study with a Concrete Illustration . . . . . . . . . 1

II. Study of Structure of Dandelion as an Isolated Thing

A. Investigation and description of parts . . . . . 3

B. Educational aim and value of such study . . . . 8

1. Broadens knowledge.

2. Cultivates interest in wayside weed.

3. Develops power of observation.

4. Develops power of expression.

III. Studx of Dandelion in its Relations to its Physical

Environment . . . . . . . . . . . . . 9

A. Structural or form relations . . . . . . . . 9

1. Comparison with other plants . . . . . 10

a. Buttercup.

b. Thistle.

c. Anemone.

2. Classification of the four plants ...... .

3. Educational aim or value of such study of form relations . . . . . . . . . . 14

a. Broadens knowledge.

$b$. May increase and broaden interest in plants.

c. May further develop power of observation.

$d$. May train to express better.

$e$. Develops power to compare, discriminate, and group or classify.

4. Will such study meet the needs of pupils in elementary schools? ......... 
III. Study of Dandelion (Continued) -

PAGE

B. Functional relations, or relations of dependence on and adaptation to physical environment . . . . . 15

1. Dependence on environment . . . . . . 15

2. Adaptation to environment . . . . . . . . 16

3. Educational aim and value of such study of life and function . . . . . . . . . . .

a. Interest is intensified and sympathy developed.

$b$. Appreciation of beauty - beauty of function and fitness as well as beauty of form and color - is cultivated.

c. Prepares for better understanding of unity of nature.

d. Gives a broader knowledge, a better insight into relations.

IV. Study of Higher Relations of Dandelion . . . . 31

A. Relation to man's physical nature . . . . . . 32

1. As a medicine and food.

2. As a weed to combat.

3. As a plaything for children.

B. Contributes to man's higher nature . . . . . .

1. Cultivates the appreciation of beauty.

2. By its life and symbolism appeals to ethical nature.

3. Is one of the pages of the "manuscript of God."

CHAPTER II.

The Study of the Rabbit.

I. INTRODUCTION . . . . . . . . . . . . 38

A. Relation to previous chapter . . . . . . . 38

B. Reasons for selecting rabbit . . . . . . . . . 39

C. Plan followed detormined by . . . . . . . 40

1. Aims.

2. Psychological laws.

3. Conditions, such as age and capacity of pupils.

D. Aims and material for study of rabbit . . . . . . 42

E. Helpful literature . . . . . . . . . . . . . 43

F. Order of lessons . . . . . . . . . . . . . . . . 45

G. Preparatory observational study of . . . . . 46

Positions.

Movements.

Eating.

Senses.

Cleanliness.

Breathing.

Burrowing.

Disposition. 
II. Lessons on RABbit . . . . . . . . . . . . 49

A. Lesson I. Homes and home life . . . . . . . 49

1. Aim and material needed.

2. Tame rabbit's home. Care of home.

Home life.

Summary.

3. Tame rabbit's original home.

Why domesticated?

Houses or burrows.

Home life.

Enemies.

- Food and damage they do.

- Summary.

4. Hare's or "wild rabbit's" home.

How distinguished from rabbit.

Home.

Home life.

5. General Summary and Expressive Work.

Oral or written.

Reading about rabbits.

6. Adapting the lesson.

B. Lesson II. Habits, positions, and movements . . . . 58

1. Positions.

When at rest.

When asleep.

When sitting.

When reaching.

Summary and Expressive Work.

2. Locomotion.

Walking.

Hopping.

Jumping.

Adaptation for locomotion.

Summary.

3. Playing, breathing, burrowing.

4. General Summary and Expressive Work.

Drawing positions.

Writing about habits observed.

C. Lesson III. Habits, feeding, washing, senses . . . . 64

1. Feeding.

Child's eating.

Rabbit's food.

Rabbit's eating.

Gnawing.

Adaptation.

Summary.

2. Drinking.

3. Washing.

4. Hearing, smelling, sight. 
II. Lessons on RabBit (Continued) -

C. Lesson III. (Continued) -

5. General Summary and Expressive Work.

Writing about habits.

Reading about habits.

D. Lesson IV. Reading related literature . . . . .

1. Aim.

2. Material.

3. Method.

E. Lesson V. Structure of body and limbs . . . . . 69

1. General appearance of rabbit.

2. Body, trunk, and head.

3. Tail and limbs.

4. Skeleton.

5. General Summary and Expressive Work.

Drawing.

Written description.

F. Lesson VI. Structure of head, ears, and teeth . .

1. Drawing head and appendages.

2. Head as whole.

3. Ears, eyes, nose, and "whiskers.

4. Mouth and teeth.

Mouth and lips.

Jaws.

Teeth.

Adaptation.

5. General Summary and Expressive Work.

Drawing.

Written description.

G. Lesson VII. Comparison and classification. "Gnawers" or Rodents . . . . . . . . . . . . .

1. Aim.

2. Material.

3. Method. Essentials in classification.

4. Comparison of different rabbits.

5. Comparison of rabbit and hare.

6. Comparison of rabbit and other rodents.

7. General Summary and Expressive Work.

H. Lesson VIII. Comparison and classification. Vertebrates and Mammals a

1. Comparison of rabbit and cat.

2. Comparison of rabbit with chicken and fish.

3. Comparison of rabbit and some invertebrate.

4. General Summary and Expressive Work.

I. Adapting Work OUtLined to other Grades . . 


\section{CHAPTER III.}

\section{What is Nature Study?}

I. Increasing Attention given to Science and Nature STUDY

A. In university and college.

B. In secondary schools.

C. In elementary schools.

II. Definition of Elementary Science. . . . . . . . . 91

A. Elementary - in aim, material, methods . . . . . . 91

B. Science, which is . . . . . . . . . . . 92

1. Knowledge, defined as

a. "Clear and certain perception."

b. "Familiarity gained by actual experience."

2. Classified - considered in its relations.

C. Three kinds of elementary science work which do not meet these conditions . . . . . . . . .

1. Gollege science. Science, but not elementary.

2. Reading "Nature Primers " and "Nature Readers." Elementary, but not science.

3. Glancing and sipping, not studying carefully. Not science, but may prepare for science.

D. A definite and graded course of work necessary . . . 96

III. Definition of Nature Study . . . . . . . . . . . 96

A. Term "nature study" better expresses spirit of work - 97

B. Is nature study . . . . . . . . . . . . . . . . 97

1. Personal contact with nature by each pupil.

2. Nature out-of-doors, as well as in schoolroom.

3. Life and action as well as form and structure.

C. Is nature study

1. Not mere reading or glancing.

2. Studied in its relations.

a. To the whole of which it is part.

b. To natural environment.

c. To past and future.

d. To other individuals, similar and dissimilar.

$e$. To causes and effects.

f. To man.

g. To the Creator.

h. To other school-work.

D. Nature studied .

1. By the child.

2. From the child's standpoint.

3. By the teacher with the children.

IV. ReAsons for Placing so much Emphasis on Definitions 


\section{CHAPTER IV.}

The Aim of Nature Study: to Develop the Individual Child.

I. Why introduce Nature Study in the School? Rather ask, Why stop Nature Study when the Child enters School? . . . . . . . . . . . 102

II. Importance of Aim in Method. . . . . . . . . 103

A. Importance of "why" to teacher.

B. Importance of "why" to pupil.

III. Aims of Nature Study . . . . . . . . . . . . . . 104

A. Practically the same as aims of education in general. . 104

B. Deals with the individual child . . . . . . . 105

C. Oldest recognized aim, the acquisition of knowledge or facts,

1. Has led to book-work and memorizing.

2. Knowledge thus gained "shall vanish away."

3. Value of knowledge gained by personal observation.

4. Value of "nature knowledge" to geography.

5. Weakness of knowledge as ultimate aim.

D. Development of intellectual power a higher aim

1. Shown by history of work in nature study.

2. Value of nature study as a means of developing power demonstrated.

3. Value, from this point of view, as a basis for expressive work of school.

E. Value of knowledge and power gained through nature study as a preparation for practical life . . . . . . 109

F. Importance of interest and sympathy as an aim . . . 110

1. Best seen when working with little children.

2. Mere power gained through nature study may do harm.

G. Higher aim is cultivation of appreciation of beauty . .

1. Beauty of function and adaptation as well as beauty of form and color.

2. Is a preparation for the study of literature and art.

3. Closely related is development of ethical nature.

H. Highest aim to lead from Nature to Nature's God . . 116

I. Résumé of aims . . . . . . . . . . 117

1. Considering development of individual child.

$a$. To awaken interest and cultivate sympathy with nature.

b. To develop æsthetic, ethical, and spiritual nature, and lead toward God. 
III. Aims of Nature (Continued) -

I. Résumé of Aims (Continued) -

c. To develop intellectual powers, and to form right habits.

d. To give knowledge of environment.

2. Considering school-work.

a. To give foundation for appreciation of literature and art.

b. To serve as a basis for the expressive work of the school.

c. To give knowledge, - a basis for geography and other studies.

\section{CHAPTER V.}

The Highest Aim: to Adapt the Child to His Environment.

I. Development of Individual Child Narrow as an UltiMATE АIM • • . • • • • . . . • • • • • • • 119

II. Highest Aim, Adaptation of Child to His Environment, 119

A. To nature, his physical environment.

B. To man, his intellectual environment.

C. To God, his spiritual environment.

III. Meaning of Adaptation to Environment

A. Has meant making our environment minister to our material needs.

B. Should include appropriation of beauties of nature, ministering to our higher needs.

C. Mere appropriation is partial, one-sided adaptation. We owe something to our environment.

D. Adaptation to environment means appreciation of what we receive from, and recognition and performance of what we owe to our environment, - to nature, man, and God.

IV. How Nature Study aIDs in Adaptation of Child to his

Environment . . . . . . . . . . . . 125

A. To his physical environment, - nature . . . . . . 125

1. Leads to appreciation of beauty of nature, beauty of function, and co-operation, as well as beauty of form and color.

2. Leads the child to cherish and care for nature.

B. To his intellectual environment, $-\operatorname{man} \cdot{ }^{\circ} \cdot{ }^{\circ} \cdot$.
1. Helps him appreciate what he receives from man.

a. Puts him in sympathetic attitude.

b. Nature becomes to child a symbol of man.

c. Appreciation of nature necessary for enjoyment of much in literature and art. 
IV. How Nature Study ams (Continued)-

B. To his intellectual environment, - $\operatorname{man}($ Continued) -

2. Helps him to realize what he owes to man, as well as to nature.

C. To his spiritual environment, - God

1. The child appreciates better the works and gifts and care or providence of God.

2. Can he do this without better realizing his duty toward God?

CHAPTER VI.

The Limitations of Nature Study. The Two Centres of Education: Nature and Man.

I. Nature Study cannot be made Basis of a Complete Education

II. Nature is but One Centre of Education. Man is the OTHER

A. Child must be related to nature, man, God.

B. Child is related to God through nature and man; hence,

C. All formal education may be grouped about two centres, - nature and man.

D. Education incomplete which neglects either nature study or man study.

III. Relative Importance of these Two Centres During Earlier and Later Periods of Elementary EduCAtioN . . . . . . . . . . . . . . .

A. Child world is a world of sense; hence nature study most important centre in earlier education.

B. Intellectual environment, - man study should be prominent in later education.

C. Application to school-work.

1. To nature study, history, and literature.

2. To work based on these, reading, writing, drawing, geography, arithmetic.

IV. Limitations of Nature Study

A. It provides for adequate study of but part of child's environment, - nature.

B. It does not give child the benefit of a knowledge of the experiences of the past.

C. It does not necessarily provide for adequate formal work in expressive studies. 


\section{CHAPTERS VII AND VIII.}

\section{Principles Determining Method in Nature Study.}

I. Method involves Consideration of Three Topics • • 144

A. The study of material, including

1. Presentation of matter to pupils.

2. Expression by pupils.

3. Relation to other school-work.

B. The selection of material for study.

C. The arrangement of material and formulation of a course of study.

II. Aims in Nature Study, Determining Method • • . 145

A. Résumé of aims already formulated.

B. Ultimate and mediate aims.

C. Importance of understanding aim.

D. Gare in stating aim.

III. Principles or Laws of Child Mind most Important ry METHOD

A. Sense perception

1. Importance.

2. Neglect of, in education of past.

B. Apperception

1. Definition.

2. Comparison with physiological assimilation.

3. Basis for other laws enumerated.

C. Interest

1. Relation to previous steps.

2. Comparison with appetite.

3. Value of sympathetic interest.

4. Direct and indirect interest.

5. Means of maintaining interest.

a. Apperceptive work.

b. Novelty.

c. Participation, or self-activity.

d. Personification, or imaginative work.

D. Imagination

1. Definition and kinds.

a. Reproductive imagination or memory.

$b$. Constructive imagination.

2. Memory.

a. Importance in education.

$b$. Means of training memory.

$1^{\prime}$. Laying foundation in sense-perception.

$2^{\prime}$. Importance of association in establishing relations.

$3{ }^{\prime}$. Necessity of repetition or drill. 
III. Principles or Laws (Continued) -

D. Imagination (Continued) -

3. Constructive imagination.

a. Importance in education.

b. Means of cultivating imagination.

$1^{\prime}$. Basing on sense-perception and apperception.

$2^{\prime}$. Giving imagination exercise.

$3^{\prime}$. Value of literature.

\section{(Chapter VIII.)}

E. Sequence . . . . . . . . . . . . 167

- 1. Definition and relation to apperception.

2. Precautions to insure sequence.

a. Laying good foundations.

$b$. Going step by step, not leaping.

c. Keeping to the line of thought, and aroiding digressions.

d. "Guarding the switches."

3. Use of the development or Socratic method.

4. Value of sequence for developing reasoning-powers.

F. Unity

1. Definition and relation to preceding principles.

2. Unity is ultimate psychological aim corresponding to the ultimate ethical aim, adaptation to environment.

3. Unity is psychological basis or reason for the greater educational value of the study of life, the best exemplification of physical unity.

4. Unity is brought out by questions "why" and "how," rather than by question "what."

5. Influence of unity on method.

a. How impress on child unity in his physical environment?

$b$. How impress on child unity of physical and intellectual environment ?

c. How impress unity of all environment?

d. How bring child into unity with environment ?

G. Expression ${ }^{1}$.

1. Definition and relation to preceding principles.

2. Function or objects.

a. To clarify the child's ideas.

b. To convey his ideas to other minds.

c. To enable him to get ideas from other minds.

1 See also Chapter XI. on "Nature Study and the Expressive Work of the School." 


\section{CHAPTERS IX AND $\mathrm{X}$.}

The Order and Method of Studying Material. Application of Principles.

I. Order of Study

A. How determined.

1. By aim.

2. By necessity of basing work on sense perception.

B. Order followed.

1. Name.

2. Relations to natural environment.

3. Habits and function (and life history?).

4. Adaptation to environment and to function, or structure (and life history ?).

5. Comparison and classification, or association and generalization.

6. Application.

II. Study of Name . . . . . . . . . . . . . . 193

III. Study of Relations to Natural Environment . • • 194

A. Importance from standpoint of unity.

B. Field lessons.

1. Purpose and value.

2. Conduct: determined by aim and conditions.

a. Lack of restraint among children.

b. Help from literature.

c. Studying what cannot be studied indoors.

d. Order.

e. Importance of definite aim, plan, and report.

IV. Study of Life, Habits, and Function .
A. Relation to previous step in study of animals, plants, minerals, physics.

B. Relation to study of life history.

C. Importance and educational value.

1. Interests and appeals to children.

2. Leads children to think.

3. Prepares for understanding of structure.

4. Correlates best with literature.

5. Gives best opportunity for individuality.

D. Suggestions for study of life, habits, and function.

\section{(Chapter X.)}

V. Study of Structure, or Properties, or of Adaptation to Environment and to Habits and Function • . 208 A. Relation to previous step and to next step.

B. Adapting to grade of children. 
V. Study of Structure (Continued)-

C. Studying details of structure or unimportant properties.

1. Study those which throw light on function or use.

2. Study those which aid in classification.

D. Dissecting animals and plants.

E. Use of microscope.

F. Order in studying and describing structure.

1. Similar to order followed in making a drawing.

2. Rules for determining order.

a. Study whole, then parts.

b. In studying parts, first relate to whole.

c. Work from base upward, from outside inward.

d. Emphasize parts which children can understand, and in which they are interested.

G. Use of drawing in studying structure.

1. Requires careful, exact observation.

2. Value of drawing before description.

3. Importance of analyzing object before drawing.

H. Use of technical terms.

1. Value: express ideas exactly and concisely.

2. Useful to children only when necessary to express their ideas.

3. Necessity of making meaning clear.

I. Relation to study of life history.

VI. Comparison and Classification, or Association and Generalization . . . . • . . . . . . . .

A. Relation to previous steps.

B. Purposes or objects.

1. To note resemblances and differences.

2. To distinguish essentials from non-essentials.

3. To recognize or abstract plan or principle.

4. To apply to other phenomena and arrange knowledge in groups, each represented by a type.

C. Relation to grade of children.

D. Suggestions for work in comparison and generalization.

1. Preparation in study of structure.

2. Selecting for study material which is typical.

3. Dwelling on resemblances rather than differences.

4. Emphasizing essentials and overlooking unimportant details.

5. Avoiding generalizations from very few particulars.

VII. Application . . . . . . . . . . . . . . . . . . 230

VIII. Modifying AND Adapting Above Order of Study. . . 232

IX. Application to Study of Minerals and Physics . . 234 


\section{CHAPTER XI.}

Nature Study and the Expressive Work of the School.

I. Importance of Demonstrating Value of Nature Study

IN OTHER SCHOOL-WORK . . . . . . . . . 236

II. VALUe of Nature Study in other School-Work . • 237

A. Definition of content studies and of formal or instrumental or expressive studies.

B. Importance of making content studies basis for expressive work.

C. Special value of nature study, as a content study, in work with young children.

D. Advantages of closely correlating nature study and expressive studies.

III. Objects of Expression or Expressive Work . . . .

A. To clarify our own ideas.

B. To convey our ideas to others.

C. To prepare us to gain ideas from others.

IV. Forms of Expression and Their Educational Valum in THe Elementary School . . . . . . . . . • . . 241

A. Motion or gesture . . . . . . . . . . 241

1. Function - to express action and direction.

2. Importance, with young children.

B. Music . . . . . . . . . . . . . . . . 242

1. Use depends on realization of aim.

2. Value for expressing and appealing to emotions.

C. Sewing . . . . . . . . . . . . . 244

1. Function - to express and fix form and color.

2. Limitations.

D. Moulding or modelling . . . . . . . . . . 244

1. Special value for expressing form.

2. Limitations.

E. Drawing .

1. Great value in nature study for expressing form ideas.

2. Advantages as an "eye language."

a. Is most natural means of expression.

b. Is clearest means of expression.

c. Is most exact means of expression.

d. Is most concise means of expression.

3. Drawing as a language of greater educational value than as a means of artistic training. 
V. Forms of Expression (Continued)-

F. Painting . . . . . . . . . . 250

1. Function - to express eolor.

2. Difficulties.

G. Language . . . . . . . . . . . .

1. Importance - the most general means of expression.

2. Difficulties in expressing by means of language.

3. Value - to express life, action, function, æsthetic, ethical, and spiritual ideas.

4. Varieties of language expression and their use:
a. Description - impersonal.
b. Narration - personal.
c. Personification - exercises imagination.

H. Résumé of relative use and value of above forms of expression . . . . . . . . . . .

V. Essentials in all Expression and Suggestion for ExPRESSIVE WORK . . . . . . . . . . . 255

A. Individuality . . . . . . . . . . . 256

B. Truthfulness . . . . . . . . . 258

C. Clearness . . . . . . . . . . . 261

D. Order . . . . . . . . . . . . . 262

VI. Limitations of Nature Study as a Basis for Expressive

WORK OF SCHOOL . . . . . . . . . . 263

\section{CHAPTER XII.}

Relation of Nature Study to Reading and Literature.

I. The Primary Reading-Lesson based on Nature Study, 265

A. Purpose .. . . . . . . . . . . 265

1. To help fix important ideas.

2. To give pupils practice in,

a. Expressing ideas in language.

$b$. Gaining ideas through language.

3. To serve as models for individual expressive work.

B. Essentials in primary reading-lessons . . . . . 267

1. Should contain best ideas in best form.

2. Should be in accord with principles already discussed.

a. Should be based on perception and apperception.

$b$. Should exercise imagination.

c. Should have sequence and unity.

3. Value of narration and personification.

4. Should be truthful, clear, and orderly. 
I. The Primary Reading-Lesson (Continued) -

C. Suggestions for primary reading-lessons . . . . . 268

1. Making them models for individual written work.

2. Keeping statements in order or sequence.

3. Supplementing ideas gained from children with higher and broader ideas.

4. Value of literary gems.

II. Necessity of basing Part of Reading Work on Man Study 273

III. Supplementary Reading based on Nature Study . • 273

A. Two classes of supplementary reading . . . . . 274

1. Reading for information.

2. Reading for inspiration-literature.

B. Reading for information . . . . . . . . 274

1. Purpose.

2. Characteristics.

3. Relation to nature study.

C. Reading for inspiration - literature . . . . . 275

1. Greater educational value.

2. Relation to nature study.

3. Necessity of reading real literature.

a. Avoiding mere rhyme or "jingle."

$b$. How select the best.

4. Value to children of reading what is above them rather than below them.

5. Manner of reading literature.

a. Determined by aim - inspiration.

$b$. Reading so as to give the thought.

c. Reading again and again.

$d$. Avoiding excessive analysis or dissection.

6. Value of literature to nature study.

\section{CHAPTER XIII.}

Relation of Nature Study to Geography and Arithmetic.

RELATION TO GEOGRAPHY.

I. Definition of Geography .

1. Must be real "earth study," based on sense-perception.

2. Must begin with what is nearest.

3. Physical geography must precede political geography.

4. Geography in German schools. 
I. Definition of Geography (Continued) - Pagx

B. Geography is study of the life of the earth . . . . 283

1. Not mere study of form and structure, the earth as it is.

2. Must include study of action and processes, the development of the earth.

II. Close Relation between Nature Study and Geography,

III. How can Nature Study be made most Helpful in GEOGRAPHY ? . . . . . . . . . . . . . 284

A. Practical importance of question . . . . . . . . 285

B. How can nature study in lower grades be made most helpful as a preparation for geography? . . . . 285

1. Physical environment of child includes:

a. The earth as a planet.

$b$. The earth itself and its three envelopes, land, water, air.

c. The inhabitants of the earth, - plants, animals, man.

2. Study of earth as a planet.

$a$. Conception too difficult for young children.

$b$. Preparatory observational work.

3. Study of earth itself, including earth forces, earth materials, earth forms.

a. Study of earth forces, beginning with water, air, and heat.

b. Study of earth materials, - water, air, minerals, rocks, soil.

- Study of earth forms, or forms of land and water.

4. Study of inhabitants of earth, - plants, animals, and man.

5. Necessity for man study, as well as nature study, as a basis for geography.

C. How can work in nature study in upper grades be made most helpful in geography?

1. Systematic study of relations between earth and other heavenly bodies.

2. Intensive study of minerals and rocks.

a. Those most abundant as earth materials.

$b$. Those of greatest economic importance.

3. Study of aërial envelope or weather study.

4. Emphasis on practical or economic aspects of plant and animal study and on physics.

IV. Nature Study must be more than an Adjunct to Geography. We MUST KeEP IN MiNd Higher AIMS AND Value of Nature Study 
I. Field of Arithmetic. Deals with Number and Size Relations (the "how-MUChNess") OF Things . . . 292

II. Relation of Arithmetic to Nature Study . . . . . . 293

A. In nature study, as pursued in elementary schools, number and size relations of minor importance as compared with form and function . . . . . .

B. Danger of forcing too close correlation between nature study and arithmetic . . . . . . . . . 294

1. Danger to nature study.

a. Emphasizes details (size and number) in nature study. which are accidental or of minor importance.

$b$. Sacrifices higher work, or loses sight of higher aims.

2. Danger to arithmetic.

a. May not provide for adequate drill.

C. Value of nature study in co-operation with arithmetic .

1. Furnishes material for concrete work in arithmetic.

2. Trains in exactness in observation, expression, and thought.

\section{CHAPTER XIV.}

Selection and Sequence of Material.

I. Selection of Material determined by

A. The aim.

B. The nature and development of the children.

C. The prevailing conditions.

II. Influence of Different Aims on Selection of MaTERIAL • . . . . . . . . . . . . . . . . . 297

A. Of interest as an aim. Importance of considering . . . 297

1. Interest of teacher.

2. Interest of children.

3. Interest of parents.

B. Of cultivation of higher nature as an aim . . . . .

1. Greater value of material showing life and action.

2. Application to plants, animals, minerals, physics.

C. Of development of intellectual power as an aim

1. Power must be developed by individual activity.

2. Importance of material which will admit of individual work. 
II. Influence of Different Aims (Continued) -

C. Of development of intellectual power as a aim.

3. Relative value for individual work of plants, animals, minerals, physics.

4. Development of power mainly dependent on method of study.

D. Of acquisition of knowledge as an aim

1. Knowledge of what material most helpful in other school-work.

a. Life sciences best prepare for literature.

b. Plants and animals best for free individual expressive work.

c. Physics and chemistry most exact and best correlate with arithmetic.

d. Knowledge most helpful in geography.

1'. Of "earth forces," - air, water, heat.

2 '. Of " earth-materials," - common minerals, rocks, and soil.

3 '. Of "earth inhabitants," particularly plants and animals of economic importance.

2. Knowledge of what material most helpful in subsequent science work.

$a$. Importance of material which is typical and of phenomena which best illustrate principles.

b. Importance of sequence in study of material.

c. Importance of beginning and ending with wholes and of relating parts to wholes.

3. Knowledge of what material of greatest practical value in life?

a. Utilitarian considerations have most weight in later school-years.

$b$. Practical value of physics and chemistry and of economic aspects of plant, animal, and mineral study.

III. Influence of Psychological Principles on Selection and Sequence of Material . . . . . . . . .

A. Dependence of children on sense-perception and apper-

1. Concrete material - plants, animals, minerals-

better for young children.

2. Forces-physics - reserved for older pupils.

3. Greater value of most common things.

B. Lack of permanence in interests and acquisitions of young children

1. Need of variety with young children.

2. Intensive study with older pupils.

3. Necessity for studying same topics again and again. 
III. Influence of Psychological Principles (Continued) - page

C. Arranging work in two cycles . . . . . . . . 316

1. First cycle - first four years - work extensive.

2. Second cycle - going over same ground intensively.

IV. Influence of Other Conditions on Selection and SeQuence of Material . . . . . . . . . . . 316

A. Of season and climate . . . . . . . . . . 316

1. Study life sciences when nature is awake.

a. Plants mainly in the spring.

$b$. Animals mainly in fall.

2. Study physical sciences during winter.

3. Some animal work (birds) in spring, and some plant work (seeds and fruits) in fall.

B. Of teacher

1. Of her interests.

2. Of her preparation for nature study.

a. Teachers usually best prepared for plant study and elementary physics.

b. Lack of preparation limits teacher to one or two lines of nature work at one time.

C. Of local school conditions . . . . . . . . . 318

1. Of time devoted to nature study. When time is very limited study:

$a$. Plants and elementary physies in lower grades.

$b$. Plants, animals, minerals, physics, in upper grades.

2. Of amount and character of previous work in nature study.

a. When beginning, best work done by younger pupils.

$b$. In beginning, better to introduce into lower grades alone than into upper grades alone.

c. When beginning, begin in all grades with foundation work.

3. Of tendency of pupils to drop out of school in intermediate grades.

$a$. Reason for arranging course in two cycles.

4. Of equipment for work.

a. Only home-made equipment essential.

$b$. Complex costly apparatus detrimental.

c. Science laboratory may be a detriment.

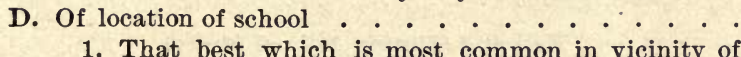
school.

2. That suggested in course of study which is most widely distributed.

3. Relative emphasis on topics influenced by local conditions and interests.

4. Material for study in cities. 


\section{CHAPTER XV.}

A Graded Course of Nature Study.

I. INTRODUCTORY . . . . . • . . . . . . . . . . 329

A. History of the course . . . . . . . . . . . . . 329

1. Gradually evolved from experience . . . . . . 329

2. Most of the work indicated done again and again . 330

B. Time required for the work . . . . . . . . . 330

C. Abridging and adapting the course . . . . . . 330

II. The Course of Study . . . . . . . . . . . . 331

A. First cycle - years one to four . . . . . . . . . . 331

B. Second cycle-years five to nine ....... . 336

\section{PART II. - DETAILED OUTLINES.}

SEPTEMBER.

\section{Fall Plant Study.}

The Common or Round Leaved Mallow . . . . . . 344

The Buttercup . . . . . . . . . . . . 361

OCTOBER.

The Dissemination of Seeds . . . . . . . . . 370

The Milkweed . . . . . . . . . . . . . . . . 371

The Dandelion . . . . . . . . . . . . . . . 381

Other plumed seeds . . . . . . . . . . . . . 385

The Maple Seed and other winged seeds . . . . 387

The Chestnut . . . . . . . . . . . . 393

Falling and Coloring of Leaves . . . . . . . . . 395

NOVEMBER.

The Study of Fruits . . . . . . . . . . . 400

The Apple . . . . . . . . . . . . . . . 402

DECEMBER.

The Pine. . . . . . . . . . . . . . . . . 410

Other Evergreens . . . . . . . . . . . . 425

SEPTEMBer.

Fall and Winter Animal Study.

OCTOBER.

Caterpillars and Butterflies . . . . . . . . . . 427

Grasshopper or Cricket . . . . . . . . . . 439 JANUARY.

The Cat . . . . . . . . . . . 449 
Winter Earth Study.

PAGE

WATER - ITS Forms AND WORK . . . . . . . . . . 462

Evaporation . . . . . . . . . . . . . 465

Condensation . . . . . . . . . . . . . . . 476

Forms of WAter . . . . . . . . . . . . . . . . . . 478

Frost . . . . . . . . . . . . . . 486

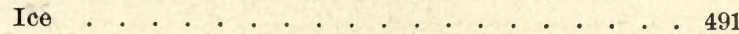

Snow . . . . . . . . . . . . . . . 494

The Work of Water in Soilmaking . . . . . . . 513

The Work of Streams . . . . . . . . . . . . 518

Spring Nature Study.

Aims and Opportunities . . . . . . . . . . . . 520

MARCH.

Spring Notes . . . . . . . . . . . 526

Tree Study . . . . . . . . . . . . . . . . 531

Bud Study . . . . . . . . . . . . . . 547

The Horse Chestnut Bud . . . . . . . . . . 551

The Lilac Bud . . . . . . . . . . . . . . 555

The Beech Bud . . . . . . . . . . . . . 560

The Elder Bud . . . . . . . . . . . . . . 561

Willow, Poplar, and Maple Buds . . . . . . . 562

APrIL.

Seeds and their Dissemination . . . . . . . 566

Planting the Seeds . . . . . . . . . . 569

The Germination of the Bean . . . . . . . . . 573

" " " "Pea . . . . . . . . . . 579

“ " " " Morning Glory . . . . . 583

MaY.

The Plant at Work . . . . . . . . . . . . 593

The Germination of the Bean, continued . . . . . . . 596

" " " "Morning Glory, continued . . . 602

The Horse Chestnut Bud . . . . . . . . . . . . . 609 JUNE.

The Flowers and Their Work . . . . . . . . . 613 



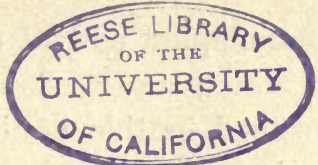 \\ NATURE STUDY.}

\section{CHAPTER I.}

THE STUDY OF THE DANDELION.

An Introduction to Nature Study.

"Flower in the crannied wall,

I pluck you out of the crannies;

Hold you here, root and all, in my hand, Little flower - but if I could understand What you are, root and all, and all in all, I should know what God and man is."

Tennyson.

IT seems wise, in beginning to consider nature study by and with the children, to illustrate by a concrete example much which will be discussed and elaborated in detail in succeeding chapters. In this preliminary study of some part or phase of nature, we can be helped to realize what is meant by nature study by and with children, as distinguished from natural science as commonly pursued by older pupils, and can see illustrated something of the method, and gain some idea of the aim and principles on which the method is based. After such preliminary concrete work we shall be better prepared for the discussion in succeeding chapters of defi- 
nitions, aims, and principles, and of the application of these to method.

The work as outlined in this preliminary chapter is not to be considered as a model or plan of work to be followed by the teacher in studying with her pupils the

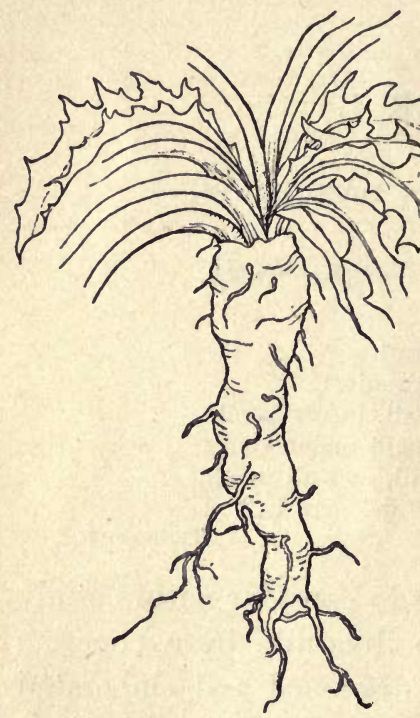

Fig. 1. Root of Dandelion. dandelion or any other plant. The chapter is intended to show the different points of view from which the dandelion may be approached, and the different ways in which it may be studied, and to compare the relative educational value of these different methods of study.

The dandelion is selected for this preliminary study because it is so familiar in many sections of the country, and can be obtained and studied during several months, and because its many interesting habits and adaptations of structure to work or function make it particularly good for illustrating method in nature study.

While an effort is made to illustrate by drawings all points of structure which are considered, drawings cannot take the place of the dandelion itself. This chapter 
will mean much more, be better understood and better appreciated, and will better prepare for later chapters, if the reader will take the book out-of-doors, and there, with the dandelions all about him, investigate for himself. There he will not only best understand the facts, but will discover the spirit in which nature should be approached.

We will dig up our dandelion, wash off the dirt, and describe it, as many of us have done in our work in botany.

We find that the root (see Fig. 1) is thick, long, and somewhat tapering (what the botanist calls a conical tap-root), and that it has some thread-like branches. When we cut it across (make a cross-section) we see that a milky liquid exudes, and discover that it has a central cylindrical axis, rather strong or tough, surrounded by a lighter-colored, less dense ring. (It is exogenous in structure.) We describe the dandelion root as a tap-root, cylindrical or conical, exogenous, containing a milky liquid.

As the plant has no distinct stem, it may be called stemless. It really has a very short stem, from which the leaves grow. What is commonly called the stem is the flower stem, not the plant stem.

The leaves seem to grow from the root (hence called radical), no two successive leaves (see frontispiece, Plate 1) growing from the same level (alternate). They are long and narrow (see Fig. 2), with large irregular lobes which are separated almost to the middle line (pinnatifid) and often inclined downward toward 
the base of the leaf (runcinate); and with a central vein running from base to point, or apex, sending out branches into the divisions on either side (feather veined or pinnately veined). The leaves are smooth on both upper and lower surfaces (glabrous). We can, then, describe the dandelion leaves concisely as radical,

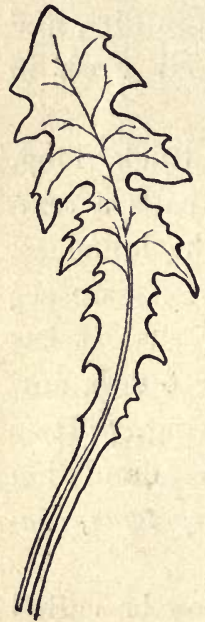

Fig. 2.

Leaf of Dandelion. alternate, runcinate, pinnately veined, glabrous.

The blossom (see frontispiece) has a leafless (naked) stem (called a scape), hollow, cylindrical, containing a milky liquid. It is enclosed in rows or concentric circles (usually three in number) of green, somewhat leaflike parts (called bracts, forming together the involucre), the divisions, or parts, overlapping like shingles on a roof (imbricated). The parts of the inner and upper row are long and narrow (linear), and nearly vertical (erect), while the parts of the other rows are somewhat shorter, and are bent outward and downward (reflexed). The yellow part of the dandelion blossom, surrounded by the involucre, is found, when examined carefully, to be composed of a large number (one hundred to three hundred) of similar parts. (See frontispiece, Fig. B.)

Each of these is fastened directly, that is, without any stem (hence called sessile), in the enlarged upper end (receptacle) of the flower-stem, or scape. Each 
(see Fig. 3), when carefully separated from the receptacle, is found to have at its base a small rounded body which, when examined with a magnifying-glass, is seen to consist of a minute sack (the ovary), enclosing a single seed (the seed and its enclosing sack forming when ripe an akene), with a very short stem above the ovary (called the beak). Extending upward and outward from the upper end of the beak are a great number of fine, soft hairs (the cluster of hairs being known as the pappus), in the position of and representing the outer part (the calyx) of ordinary flowers, such as the buttercup. (See Fig. 5.) Surrounded by these hairs, and attached, like them, to the upper end of the beak above the ovary (hence called epigynous, meaning upon or above the ovary), is the lar-

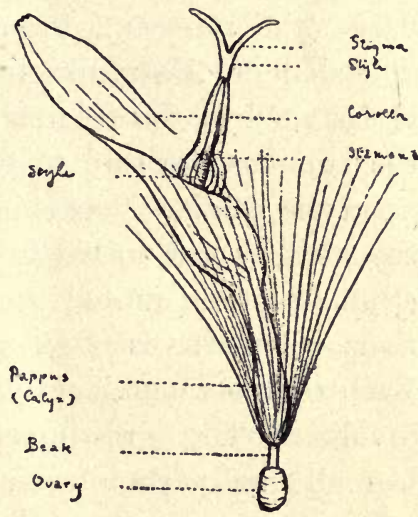

Fig. 3.

Flower of Dandelion Enlarged. Single Flower.

ger, more prominent division, the corolla. (Compare with same part in the buttercup, Fig. 5). This is much longer than the pappus, yellow, united at base into a short tube, and split open and spread out flat above into a long strap-shaped (ligulate) corolla, with usually five minute teeth at the upper end, indicating in a rudimentary way the division of the corolla into petals. (See Fig. 5.) An upward thread-like extension of the beak (called 
the style) passes through the tubular base of the corolla, separating above into two parts (two-cleft), the inner surface of the upper ends of these divisions being somewhat rough or spongy when the flower is fully developed. These roughish surfaces form the stigma. The ovary, style, and stigma taken together constitute the pistil of the little flower. Very careful examination with the magnifying-glass shows five minute thread-like parts (the stamens), forming a tube about the style. The slender, thread-like base (filament) of each stamen is fastened in the tubular base of the corolla. Hence the stamens are said to be epipetalous, meaning on or upon the petals. The enlarged upper parts (anthers) of the stamens are united to form a tube about the style. (Stamens thus united are syngenesious.) On the anthers when ripe is often a yellow powder (the pollen). Each of these similar yellow parts, surrounded by the involucre, and growing from pits in the receptacle, has all the parts of a complete flower, - calyx, corolla, stamens, and pistil. (Compare with the buttercup.) Hence each may be called a little flower, or a floret.

Flowers so arranged in clusters, growing directly from the receptacle, are said to be in a head. Because the dandelion is composed of many of these flowers or flower-like divisions, or florets, arranged in a head, surrounded by an involucre, it is called a composite flower.

We can describe the dandelion blossom, using the terms above defined, as: Growing on a naked, hollow 
scape, composite, with an involucre of (usually) three rows of imbricated linear green bracts, the inner longer row erect, the outer rows reflexed. Individual flowers arranged in a close head. Parts epigynous, borne on a short beak. Calyx a pappus of many fine white hairs. Corolla yellow, strap-shaped, with five teeth. Stamens five, epipetalous, syngenesious. Pistil one, with onecelled, one-seeded ovary (forming in fruit an akene), with a long style, two-cleft.

In the dandelion fruit, or matured flower, the stems usually grow much longer, and the hundreds of little seeds become loosened, ready to be detached from the little pits or pores in the enlarged end of the stem. Each seed (see frontispiece, Fig. D) is somewhat eggshaped, but flattened, has about its upper half a number of minute teeth pointing upward, and bears at its upper end a long hairy stem which separates into many spreading hairs. When spread out the stem and its parts somewhat resemble the handle and ribs of an open umbrella, with the seed fastened at the lower end of the handle. The hairy balls, or fruit, of the dandelion (see frontispiece, Fig. A, 4) may be described as spherical, open, hairy clusters.

We have studied and described the dandelion as a form or structure, and no more. Our description thus far might apply as well to a dandelion fashioned out of clay or glass as to the weeds which struggle in our yards and thrive by our roadsides, and smile back at the sun. We have not said a word, or apparently had a thought, about its life, - that which distinguishes the real dan- 
delion from its clay or glass counterfeit. We have considered the dandelion as something isolated from all the world, having no relations to anything else.

We have studied and described the plant somewhat carefully, with a free use of technical terms, but it would be most unwise, in work with children, to begin with such dissection and dry technical description. This study of structure is merely a basis for further work in this and subsequent chapters, and is not intended to serve as a model for teachers to follow in their work with children.

Incidentally, hitherto, we have seen the value of technical or scientific terms in describing structure concisely and exactly, and have learned, as we referred to the pictures to understand the descriptions in the text, that pictures illustrate flower structure much better than words can describe it.

But what can we gain from such a study? What is the educational aim or value of such study of mere form and structure?

First. We may widen our range of thought, and add to our previous store of information concerning the form of the dandelion, and the relation of its parts.

Second. We may gain an interest in the dandelion. The common, and perhaps despised, wayside weed becomes a complex and wonderful structure. It would become still more marvellous if we could study with the microscope its minute details; but this does not seem wise, nor even possible, for those for whom this book is planned. 
Third. We may learn, if we actually study the dandelion itself with care, and not merely read or hear about it, to develop our powers of observation.

Fourth. If we endeavor to speak about what we have observed, and are not content with repeating what others have told, we may learn, and particularly if we use technical terms, to express more clearly, exactly, and concisely what we have to say.

Theoretically, we can study the dandelion as an isolated thing. Practically, the youngest child in the kindergarten cannot avoid comparing the dandelion with other things he has seen; in fact, the same habit of comparing everything we see goes on continually throughout life. Assuming, therefore, that we have learned to recognize the dandelion as a plant, as distinguished from animals and minerals, and to associate it with other plants having flowers, we may begin to make suggestive comparisons.

Let us first select the buttercup for comparison with the dandelion. The two are alike in having roots, leaves, and flowers, but are unlike in the form and arrangement of these parts. Instead of one strong tap-root, such as the dandelion has (see Fig. 1), the buttercup has many rather slender roots, starting from the lower end of the stem (see Fig. 4). Its roots are multiple and fibrous. It has a distinct stem, to which many of the leaves are attached. This stem is cylindrical, and a careful study of a cross-section shows its structure to 
be, like that of the dandelion, exogenous. The leaves (see Fig. 5) are alternate, have distinct leaf-stalks (petioles), and have several veins branching out from the top of the leaf-stalk, somewhat as the fingers, when spread out fan-like, are attached to the main part, or

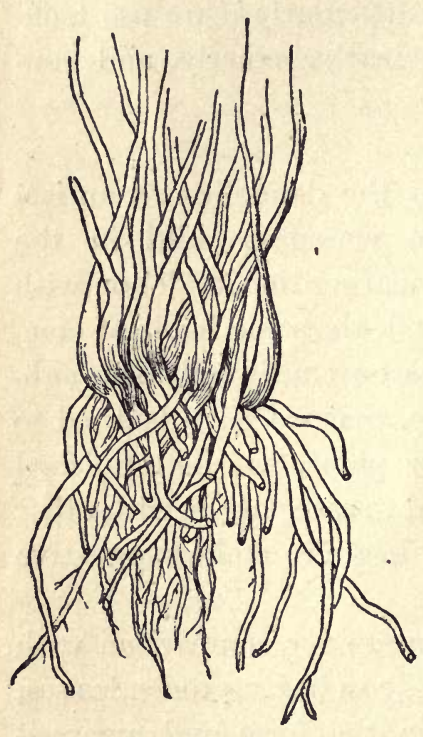

Fig. 4.

Roots of Buttercup.

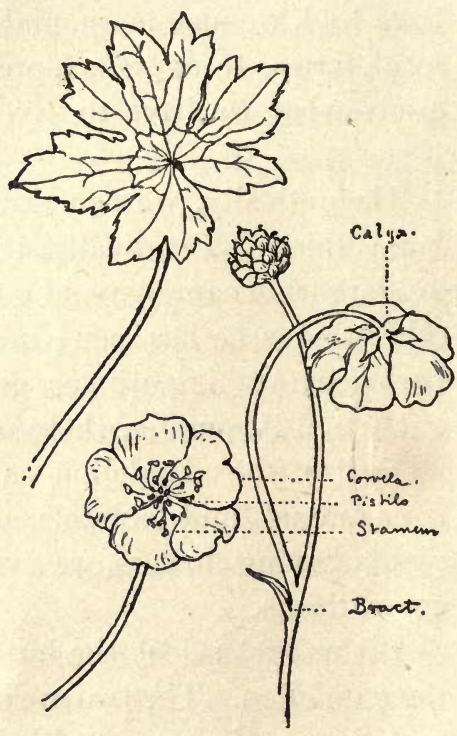

Fig. 5.

Buttercup Leaf, Flower, and Fruit.

palm, of the hand. Hence it is said to be palmately veined. The shape of the leaves, however, is entirely unlike that of the dandelion leaves.

When we examine the flower of the buttercup (see Figs. 5 and 6 ), the most important part of the plant in 
classification, we find that each flower is separate, with a distinct flower stem, instead of having, as in the dandelion, many minute flowers without stems crowded in a close cluster, or head. Each complete flower has an outer green calyx, somewhat cup- or saucer-shaped (calyx meaning a cup), with, usually, five divisions (the sepals). This corresponds in position to the pappus of the dandelion. If we could examine many kinds of composite flowers, we would find many gradations in form between the calyx of the buttercup and the pappus of the dandelion. Hence the botanist assumes that the two correspond, but are modified in the two plants, be-

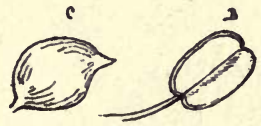

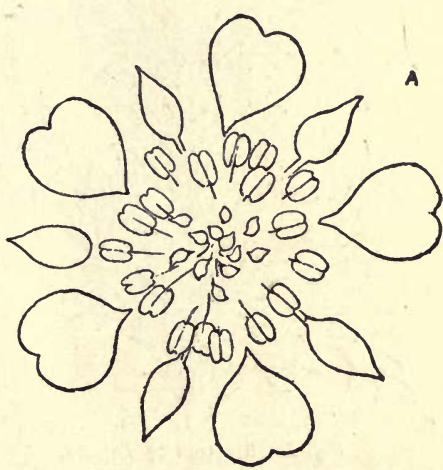

Fig. 6. Flower of Buttercup Dissected. cause they have a different work to do, or have different functions. The corolla, or "little crown," instead of being composed of one piece united into a tube at the base, as in the dandelion, consists of five or more yellow parts (the petals), together forming the most attractive and crowning feature of the flower. Within the corolla, and above the base of the petals, are many yellow parts (the stamens), each with its thread-like base (the filament) and enlarged upper part (the anther), but all 
separate, instead of being united to form a ring or tube, as in the dandelion. In the centre of the buttercup flower is a mass of green bodies which careful examination shows to be seed-vessels, or pistils, each containing one seed, but without any style, and without any hairy attachment above. Unlike the dandelion floret, in its

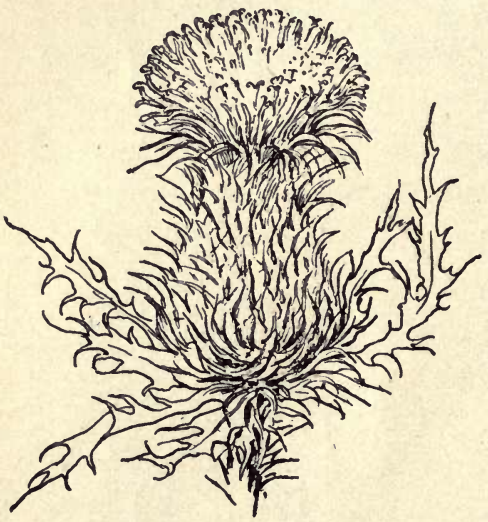

Fig. 7. Blossom of Thistle. great yellow cluster, each buttercup flower stands alone, growing directly from the upper end (receptacle) of the flower-stalk. The dandelion and buttercup flowers have the same parts, but the arrangement of these parts is very different in the two.

When we compare the dandelion and the buttercup with the common thistle (see Figs. 7 and 8) we find that the roots, stems, and leaves of all three are very unlike, and at first sight the flower of the thistle seems unlike those of the other two plants. A careful study, however, shows a cup-shaped, spiny involucre, similar in position, but not in appearance, to that of the dandelion, composed of many parts united or grown together. Within this spiny cup is a large number of little flowers (see Fig. 8), differing from those of the dandelion in shape, but like them in having a mi- 
nute one-seeded ovary, a pappus and corolla, five stamens with anthers grown together, and a long, slender style. The corolla is tube-shaped, with five long, slender teeth, not strap-shaped as in the dandelion.

If we continue by comparing the three already studied with the anemone, — wild anemone during spring or summer, and garden anemone (see Fig. 9) during the fall, - we find that the buttercup, while quite unlike the anemone in general appearance, has flowers with similar parts, but without a calyx, arranged in the same way.

We are led by this comparison to put the dandelion and thistle together, and the buttercup and anemone together. We learn from the books that the first two belong to the compo-

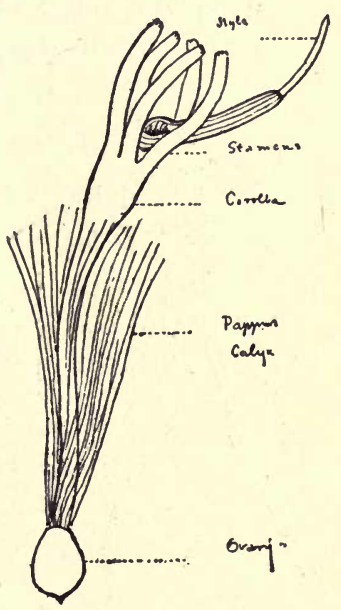

Fig. 8. Single Flower (Floret) of Thistle, Enlarged. site family of flowering plants, and the last two to the crowfoot family. We have compared our dandelion with other forms of plants, and placed it in a class with plants closely resembling it; that is, we have, to some extent, classified it.

What is the educational value of comparing and classifying different forms, as compared with the educational value of studying the dandelion as a form by itself, unrelated to other plant forms? 
First. We have broadened our knowledge of plant forms by studying several plants.

Second. We have increased our interest in the structure of plants by studying variations in form and structure.

Third. We have learned to use our powers of observation more accurately.
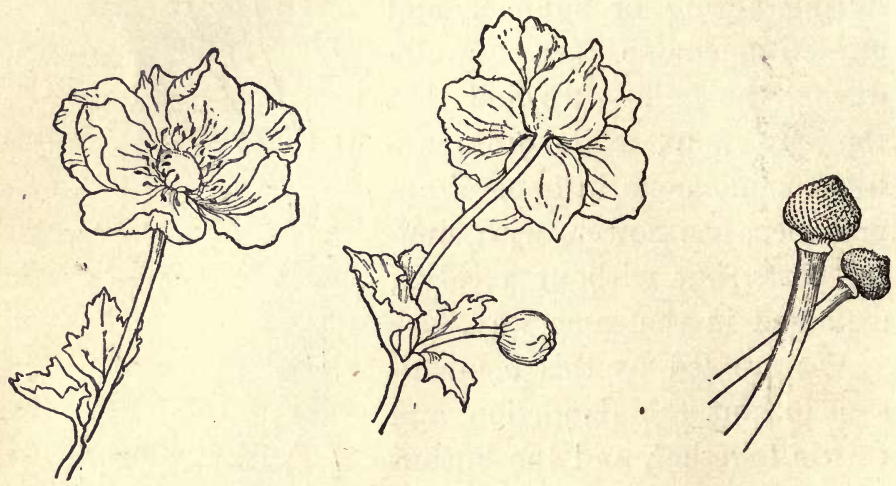

Fig. 9. Anemone Flower and Fruit.

Fourth. We have learned to express ourselves better; to increase our power of telling what we see and know.

Fifth. We have developed our power to compare, to discriminate between essentials and non-essentials in structure, to group and classify. We have learned to think, as well as to see and tell, and so to arrange or relate our thoughts that one thing shall stand in our minds as a type of many.

Yet even in studying the dandelion as a plant form in 
relation to other forms of plants, have we accomplished what will be of the highest educational value? Most of the work in botany in our secondary schools consists of this study and description of plant forms, and comparison with other forms, or tracing through an analytical key, and finding names, which is supposed to be comparison.

Will such work meet the needs of the boys and girls in the elementary schools? Is interest in nature, and power to see and compare and classify and describe, the highest pleasure or value they can get from nature study?

Is there anything better about the dandelion for the children to study than its form, and its relation to other plant forms, like and unlike it?

In addition to what we may call its form, or structural relations, it has other relations to its surroundings or environment. It is a living thing, dependent on its physical environment, - soil, moisture, air, sun; helped or harmed by these. It is adapted by form and structure and life-processes to get help from these and to give help to them in return. Let us study the relations between our dandelion and its physical environment, its dependence on its environment, its adaptation to its environment.

Our dandelion when separated from Mother Earth very soon wilts and dies, unless kept in a damp place or in water. It is dependent on the soil and on the moisture in the soil, and this moisture it must get from dew and rain and cloud. It thrives only where it can 
get the sunlight; opens its yellow eye to the sun each morning, and closes it at night; pushes its leaves up above the grass, and out from the shade of stone and fence; evidently it depends on the sun. If it is deprived of air, it dies, much as we should; it depends, then, on the air. The hairy sails on its seeds would be useless without wind to carry them along. It spreads in its flower a feast of nectar, which attracts hosts of insects. It certainly helps the insects; we shall find that the insects help it. The dandelion may be eaten by animals and destroyed by man. Our dandelion depends, then, on soil and dew and rain and clouds; on sun and air and wind; on insects and other animals; and on man. If we could study it thoroughly, we should find it more or less dependent on a host of other agencies ; in fact, on all, or nearly all, of its physical environment.

If it depends on these, it must be fitted to get help from its physical environment, or to struggle against it. Let us take up its parts in order, studying them not as mere forms, but as organs for sustaining life, investigating not merely their structure, but their special function and adaptation to their environment. Let us constantly ask not merely "What?", but "Why?" and "How?". We shall have to study carefully; not merely observe, but think.

Beginning with the roots, if we very carefully dig up from soft soil a root with all the earth about it, and cautiously wash off the soil by moving the mass back and forth in a pail of water, we shall discover many 
things that were overlooked before. (See Fig. 10.) When'we merely pull up or dig up a plant, and shake off the earth, we see very little of the root system. Besides the strong central root, or tap-root (shown in Fig. 1), we now discover a multitude of branches, many of them very minute, spreading widely in all directions.' What are they and the strong tap-root for? Any boy who has tried to pull dandelions will tell us that the strong root holds the plant firmly in the ground; it is almost impossible to pull it out. Of how little value the minute roots are for this purpose! If
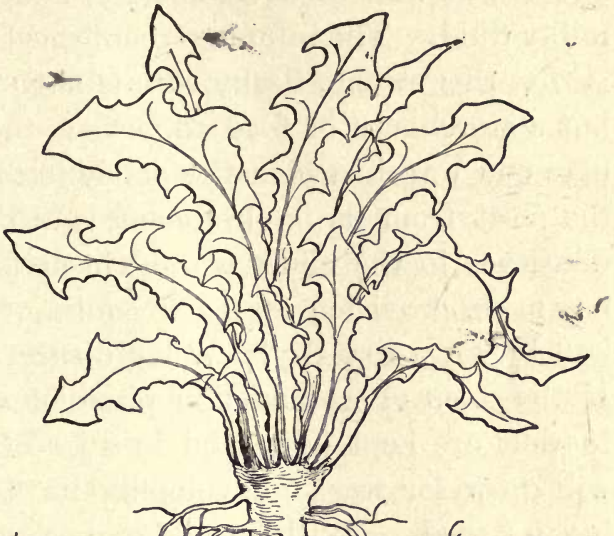

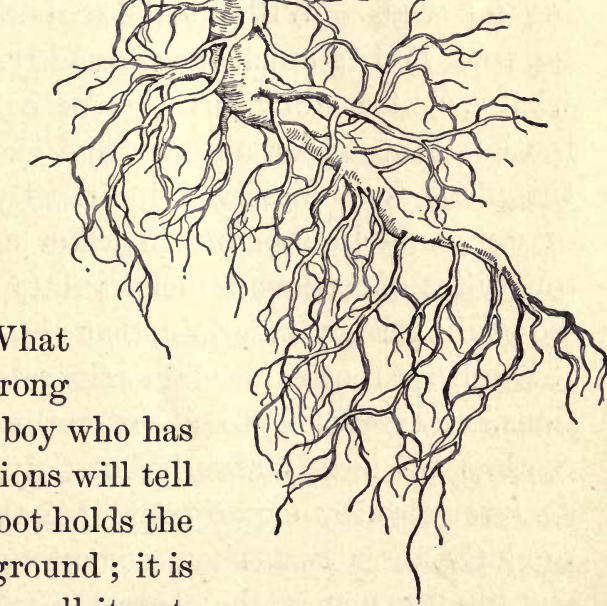

Fig. 10.

Roots and Rootlets of Dandelions. we dig up a root before the plant has gone to seed, it is full of milky juice. A root of a plant which has formed 
and ripened its seeds is spongy, and has little of the milky fluid. The inference, confirmed by careful study, is that this strong, fleshy root is not merely a holdfast, but a storehouse of food to perfect the seeds. We see here one way in which the dandelion is adapted to get the most from its environment, and one reason why it flourishes in the midst of and in spite of drought. It has made provision for such contingencies, has a store laid by for a dry day. What do the fine rootlets do? If the roots of a dandelion plant possessing these fine rootlets are kept immersed in a jar of water, the plant will grow for weeks, developing its flowers, and ripening its seeds. Without these rootlets, with only the tap-root, it dies much more quickly. This indicates what is confirmed by further experiments - that the fine rootlets take in or absorb from the soil moisture and the plant food dissolved in it. By keeping the roots of our dandelion plants in water containing measured quantities of various mineral substances dissolved in it, we could readily ascertain that the dandelion absorbed through its rootlets certain minerals in certain proportions, and refused to absorb other substances. The rootlets not merely absorb, but they select. We might discover also, by experiment, that the rootlets, and particularly their tips, show something akin to sensation and intelligence in the character and direction of their growth in the ground. The root tip is so sensitive that Darwin has compared it to the brain of lower animals. ${ }^{1}$

1 See Darwin's Power of Movemont in Plants; or Newell's Reader in Botany, Part 1, p. 34. 
The roots of the dandelion are then adapted to their environment:-

First. By having a strong, tough tap-root to serve as a holdfast.

Second. By having a thickened, somewhat fleshy root to serve as a storehouse for food.

Third. By having a multitude of hairy or fibrous rootlets, with many branches growing out in all directions, to absorb moisture and food from the soil ; these are fitted, by their manner of growth and sensitiveness, for their work of absorption.

The dandelion root is, then, more than a "cylindrical or conical tap-root, exogenous, with a milky liquid." It is a holdfast, a storehouse, a purveyor and absorber of food for the plant.

The leaves we have described as "radical, alternate, runcinate, pinnately veined, glabrous." Is that all? Let us ask not merely, "What are they?", but, "What do they do?". They grow from the upper end of the tap-root (apparently), forming together a circle: this is flat on the ground, or saucer-shaped; or, in high grass, cup- or cone-shaped. (See frontispiece.) The leaves alternate so as to leave few open spaces, yet do not cover one another. Nearly all of each leaf is exposed to the sun. If we watch them in a rainstorm we shall see that they are so arranged that nearly all of the rain which falls on them is directed downward and inward toward the root. The arrangement of veins (venation) aids in this. The veins are a system of troughs, or ditches, directing the water to the root. The leaves, then, are 
adapted by position, arrangement, and veining to direct water toward the roots.

Clustered between their broadened bases, often wrapped about by them, are tiny leaf and flower buds. The leaves help to protect these.

The leaves are not merely arranged so as to give each leaf as much sunlight as possible, but those in high grass grow up toward the sun, and those in shady places grow out from the shade toward the sun. Evidently they have some reason for seeking the sunlight.

If we cover a small growing dandelion plant with an inverted glass tumbler or fruit can, we soon discover, if the plant is in the sun, little drops of moisture on the inner surface of the glass ; if in the shade, the moisture appears more slowly. By preventing the passage of moisture from any part of the plant except the leaves (spreading paper over the ground under the leaves), we can show that the moisture comes from the leaves. We learn that the leaves throw out much of the moisture absorbed by the rootlets, and that the sun or sunlight aids them. They are adapted to throw out moisture by their form, - broad and thin, with a very large surface. By their position and arrangement, with nearly all of every leaf exposed to the sun, they get the greatest possible help from the sun. The skin (epidermis) with which they are covered prevents too rapid escape of moisture. Microscopic examination shows great numbers of little openings in the skin (breathing-pores, or stomata), which have the power of closing and opening, 
and thus regulating the escape of moisture in dry or wet weather.

It can be shown that the leaves breathe or respire for the plant in a way corresponding to our lungs, and that they also take in gaseous food from the air, and convert this and part of the water absorbed by the rootlets into starch and other plant foods. For the latter process they need the help of the sun. For this work they are adapted by their position and arrangement, exposing them to the sun, and by their form, with great extent of surface, through which the gases can pass, and on which the sunlight can act. Their effort to change position by bending away from the shade and toward the light, and their greater length in high grass or shaded places, aid them in getting help from the sun. The strong veins, with branches on each side, extending into the tip of each division or lobe, aid in lifting and supporting every part of each leaf in the sunlight, as well as in directing water to the roots, and in carrying water and dissolved food into every part of the leaf.

Now, the form and structure of the dandelion leaf mean something. We begin to see a reason for the structure in the adaptation to surroundings or environment.

The leaves of the dandelion are adapted by their position, arrangement, form, venation, and movements :-

First. To direct water to the roots.

Second. To protect buds at their base.

Third. To throw out water, with the aid of the sun.

Fourth. To breathe. 
Fifth. To absorb gases and make plant food, with the aid of the sun.

Wonderful as is the flower considered as a structure, it becomes much more wonderful when studied as a living thing, an organ with a work to do, an adaptation to work and environment.

In particular the slender, hollow flower stem is an admirable illustration of adaptation to work or function. In the bud it is very short, lengthening, as the flower develops, just enough to push the blossom above the grass, and later lengthening much more to lift the plumed seeds up where they will catch the wind. The length of the stem depends largely on the height of the grass or other plants about it; in tall grass it may push up two feet or more to lift flower and seed above surrounding plants. In the late autumn, when little is to be gained and much may be lost by lifting up the flower, the flower stem, or scape, remains very short. It bends away from shady places. Its structure, a hollow cylinder, gives the greatest strength and flexibility with the least material.

The scape not merely lifts the seeds up into the wind, but when they are ripe the rapid change in the form of its upper end, or receptacle, from a shallow cup to a somewhat flattened ball, causes the seeds attached to it to spread out into the hairy sphere, and exposes every seed with its little parachute to the wind. (See frontispiece. Compare Figs. A, 5, and B.)

The scape has one duty, to hold up the flower toward the sun, and where it will attract insects, and to lift up 
and spread out the seeds where they will catch the wind. When this work is done, it shrivels and dies.

No less interesting as a study in adaptation to environment is the involucre, with its rows of alternating, overlapping bracts. Note how all the rows of bracts protect the buds (see frontispiece, Fig. A, 1); how, as the flower develops, the outer rows are turned back or reflexed, while the inner row closes over and protects the flower at night, and often during storms, opening in the morning or when the sunshine returns; how finally it remains closed about the flower, sometimes for several days, while it is perfecting its seeds (see frontispiece, Fig. A, 3); how as the beak elongates and pushes up the pappus, this inner row of bracts also elongates and protects the developing seeds and their growing wings or parachutes, until the change in the form of the receptacle begins to push the seeds apart. Then the inner row of bracts is also reflexed.

The work of the involucre, to protect bud and flower and undeveloped seeds from excess of moisture and sudden changes in temperature, is now done, and, with the scape and receptacle, the bracts shrivel and die.

Is not the involucre more than "three rows of imbricated bracts, the inner row erect, the outer rows reflexed"? Is it not almost intelligent? Does not its structure embody a thought?

If we are not satisfied with describing the blossom and hairy fruit as two distinct things, but patiently watch the process by which the flower changes to fruit, constantly asking why and how, we shall learn much 
which we can never discover from a mere pulling to pieces for analysis and description. Let us mark several buds and flowers with a string or label, and note carefully, two or three times a day, the changes in them. We shall see the lengthening of the scape and the protective closing of the flower, and the changes in the length of the bracts. We may note the numerous insects which visit the blossom. We shall discover that after the blossom finally closes, the yellow part shrivels, is lifted up, and at last drops off. At the same time the hairy pappus is very gradually pushed up, at length protruding above the bracts (as in frontispiece, Fig. A, 3), the hairs of the pappus, lying pressed close together, separate, somewhat as an umbrella opens, the bracts are bent outward and downward or reflexed, and the hairy stems supporting the pappus of each flower diverge, and we have the spherical fruit of the dandelion. Why? How?

As we watch this in the wind, or imitate the children as they try to discover, by blowing the seeds, "what time it is," or whether "mother wants me," we see the seeds sail away, each with its little parachute, settle down, and gradually work down into the grass.

Are the yellow blossoms, the "seals of gold in the meadows," "bright as if Night had spilt her stars," are they merely "flowers arranged in a close head, with an involucre of three rows of imbricated bracts"? Why lifted up so high? Why such a bright color? Why and how do they open and close? How do they perfect their seeds, and lift up and spread out their 
fruit, the "spherical open hairy clusters" we have described?

Let us examine one little flower of the dandelion, asking constantly "why," and "how." Each seed has a little stem (the beak) connecting it with the parts of the flower above. Why? If we have watched the fruit develop, we have discovered that this beak lengthens, pushes up the pappus, forms the rays or radii of the sphere, and is the rope connecting each seed with its parachute.

Why does each dandelion flower have its outer part, or calyx, composed of little hairs, while in the buttercup it is composed of little green leaves? Each is fitted for its work. In the buttercup the calyx protects the parts within; in the dandelion the involucre protects, and the calyx has another duty, - to scatter the seeds.

What is the use of the other parts, - corolla, stamens, and style?

In the dandelion, as in all other flowering plants, seeds - that is, perfect seeds which will develop into plants - are formed, and only formed, by the union of the pollen (the yellow powder coming from the anther, or upper part of the stamens) with rudimentary seeds or ovules in the ovary, or lower part of the pistil. The grains of pollen must in some way pass from the anther to the upper portion of the style, called the stigma, from which some of the living matter (protoplasm) in the pollen grains works down through the style into the seed-box, or ovary, and unites with the rudimentary seeds there. Not until this process (fertilization) takes 
place will these rudimentary seeds begin to develop into real seeds, capable of forming new plants.

It is a law of nature that better seeds are produced when the pollen from one flower is carried to the stigma of another flower of the same kind; that is, when there is what is called cross-fertilization. Seeds may be formed - when the pollen of a flower gets on and pushes into the pistil of the same flower, but this process of self-fertilization is not apt to produce as healthy, vigorous seeds or plants as does cross-fertilization. It is to the interest of most flowers, including the dandelion, to prevent selffertilization, and secure cross-fertilization as much as is possible.

We shall find that the structure and changes in corolla, stamens, and pistil are arrangements or adaptations to insure cross-fertilization, if possible; otherwise, self-fertilization. In cross-fertilization the pollen is most commonly conveyed from the stamens of one flower to the stigmas of other flowers, either by insects or the wind. The dandelion hires the insects to carry her pollen from flower to flower.

The corolla has the special duty of attracting the insects by its bright color (one reason why the blossom is pushed up above the grass), and by the honey, or nectar, at its base. From the nectar and from the pollen, of which the dandelion and other flowers produce much more than they can use, the provident insects get their store of food. The bright-colored corolla is the signboard telling where these can be found. In getting them the insects brush off and carry on the hairs on 
various parts of their body more or less pollen, some of which adheres to the somewhat spongy and sticky surface of the stigmas of other flowers. The flower tries to prevent the pollen of any flower from coming in contact with, or adhering to, the stigma of the same flower, and to insure its adhering to the stigma of another flower.

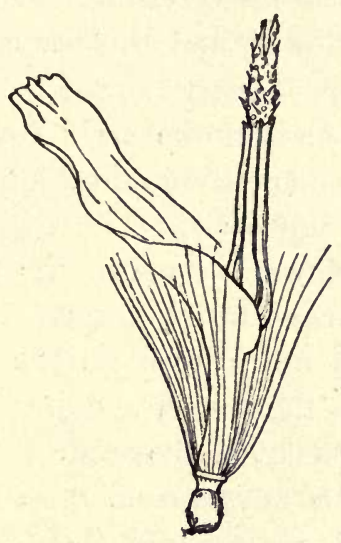

Fig. 11.

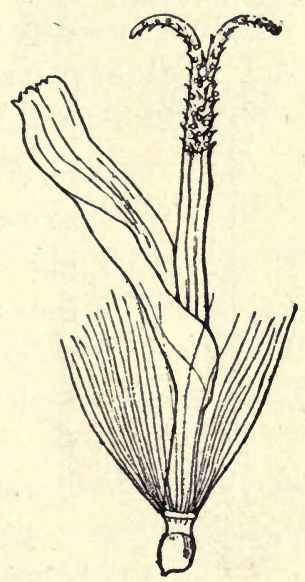

Fig. 12

Floret of Dandelion; Arrangement for Cross-Fertilizatron.

To insure this cross-fertilization, the anthers of the dandelion (see Fig. 11) ripen before the style or stigma is mature, and discharge the pollen into the tube formed by the union of the anthers. The style then lengthens, and minute hairs on it push or carry the pollen above the anther tube. Later the stigma ripens, and its two parts separate and curve outward (as in Fig. 12), each division having on its inner upper side the 
spongy, sticky surface on which the pollen must fall in order to develop. When the insects visit the flower in search of the nectar at the base of the corolla, and tome in contact with the pollen, they carry some of it away. Even if the pollen grains come in contact with the outer and under surface of the recurved stigma, the grains are not apt to adhere, and will not develop. When the insect visits a new dan-

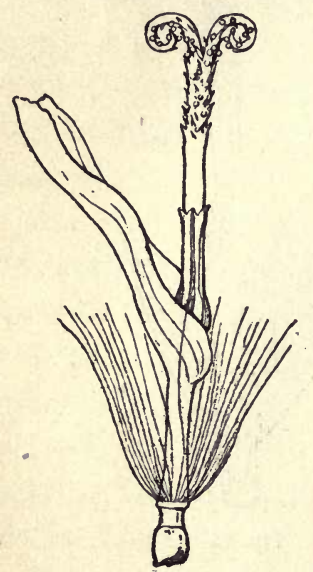

Fig. 13. Floret of Dandelion, Self-Fertilization. delion flower, and brushes against the upper inner surface of the forked end of the style (as it is almost compelled to do when pushing its proboscis, or mouth parts, into a flower), some of the pollen may adhere, develop, send its protoplasm down through the style, fertilize the ovule, and insure the development of the seed.

If, for any reason, cross-fertilization is not secured, then the two divisions of the style bend downward and outward (see Fig. 13), each curving into a circle, and bring their inner spongy surface in contact with the pollen above the anther tube, thus insuring self-fertilization and the development of their ovules.

When fertilization has been secured, the work of corolla, stamens, style, and stigma is about completed, and they soon shrivel, and are pushed off by the growth of the beak. 
In two days or more, depending on weather and temperature, after the florets have been fertilized, and the dandelion blossom has finally closed, the pappus of each flower is pushed, by the lengthening of the beak, above the enclosing involucre, the receptacle becomes convex instead of concave (compare Figs. B and A, 5 , in frontispiece), causing each pappus to separate from all the others, and the hairs to spread out like an umbrella inverted, and we have the "hairy open spherical head," each seed with its bal-

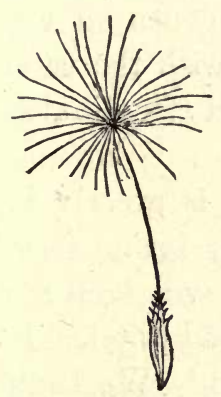

Fig. 14.

Seed of Dandelion. loon spread ready to catch the wind and sail away. The dandelion mother shows no favoritism. She gives each seed baby a choice seat on her tower, from which to view the world and take flight.

Mother Dandelion's care for her seeds does not end with the arrangements for their dispersal by the friendly wind. Not merely does she provide each seed with a balloon, or parachute, but to each she gives a set of grappling irons to anchor again to Mother Earth. If we examine carefully (see Fig. 14), we shall find about the upper end of each seed many little spines growing obliquely outward and upward. As the seed, after its flight in the air, settles down, these spines catch in the grass, and then the swaying of the parachute causes the seed to work deeper and deeper into the grass. If it alights on rock or hard soil, it is not so apt to catch, but may be carried farther, to a more promising landing-place. 
It would seem that Mother Nature or Mother Dandelion was thinking, when she gave the seed its color, how much better it would escape the sharp eyes of birds and insects if it had the color of the ground where it must rest for months.

When we study the dandelion in this way, asking "why" and "how" as well as "what," investigate the work of its parts as well as their structure, what do we gain from it? What is the educational value or aim of such a study of the functional relations of the dandelion to its environment, of its dependence on and adaptation to environment, as compared with the value of the previous study of its structure and structural or form relations?

First. Our interest in the dandelion is greatly increased. We have studied it not merely for its form, but as a plant endowed with life. We have given it a personality somewhat akin to ourselves, and watched its struggles and perseverance and triumphs. We begin to feel some sympathy for the domestic weed. This is particularly true of children, to whom living nature appeals so strongly.

Second. Our appreciation of the beauty of the dandelion, which may have begun with the study of structure, increases greatly as we learn to see not merely the beauty of form and color, but the far higher beauty of function and adaptation. "Handsome is that handsome does," is as true for the dandelion as for any of the human kind.

Third. We have laid some foundation for realizing 
the mutual dependence and helpfulness of all nature, and for comprehending the unity of nature. The dandelion has become more than something with root, leaves, flowers, and seeds. It has become a unit, with all its parts related, and a centre about which much of its physical environment has been grouped.

Fourth. We have learned to think as well as to see; to investigate the "why" and "how" as well as the "what" of the dandelion. We have learned somewhat better to see or think of things in all their relations, functional as well as structural, relations of dependence as well as relations of similarity and difference. We have developed somewhat our capacity for broad thinking.

We have studied the dandelion as an isolated form or structure; we have compared it with other forms of plants; we have considered its dependence on and adaptation to its surroundings. Have we exhausted its relations, - studied them all? Have we put into or obtained from the wayside weed all that may make its study of educational value, - all its content?

Does the dandelion have any relations to man, or any higher relations?' To our practical, matter-of-fact reader may come visions - or nightmares — of the intensely bitter dandelion tea administered in childhood days by mother or grandmother as a "spring medicine." Perhaps we remember with more pleasure the dandelion greens made from the young leaves. So the dandelion is of some use to man. 
It may be that we recall the persistent but often vain efforts to eradicate the dandelion from our lawn. Now that we understand better the resources of the plant, we are not much surprised that we were defeated in our struggle with it. Perhaps we have noticed how the dandelion accompanies man in his conquest over nature; seems to thrive best in the vicinity of man. It is, in some degree, dependent on or affected by man.

Are we still young enough, in heart, to enjoy telling time as we did in childhood, by seeing how many "blows" it takes to scatter all the seeds in a head; or, by a similar process trying to discover " whether mother wants us"? Perhaps we have not forgotten how to make dandelion curls and dandelion chains. The dandelions were close to us and dear to us in our childhood days.

Has the thought come to us that the despised wayside weed is more to man than medicine or food or a plantpest or a plaything; that it may have a higher function or use for man? Have we appreciated the beauty of its contrasting green and gold, and the exquisite delicacy of its cluster of seeds? Why is it, like hosts of other weeds, so pretty? Its beauty is not essential for seedmaking. Why is it that -

"Dandelion through the meadow makes

A royal road with seals of gold"?

Why is it that among the flowers, the

"Stars that in earth's firmament do shine," 
we find most frequently about our homes

\section{... "the dandelions, bright \\ As if night had spilt her stars"?}

Is it not because they are related to something higher in man than his physical or material nature? Have we really studied the dandelion with our children until we have helped them to appreciate its beauty; not only its beauty of color and form, but, far higher than these, its beauty of function and adaptation, the way in which it is fitted for and performs its work? The dandelion ministers to the rsthetic nature of the child. Indeed, unless the study leads to a fuller enjoyment of the beauty of nature, we have gained little from our nature study.

Longfellow has said, -

"In all places, then, and in all seasons, Flowers expand their light and soul-like wings, Teaching us, by most persuasive reasons, How akin they are to human things."

As we study the mutual dependence and mutual helpfulness of all parts of the plant, as we discover how they help and are helped by insects and wind and rain and sun, do no lessons come to us, and even more strongly to our children, concerning our relations to the world about us? How akin to the child are the dandelion and the violet, of which Lowell writes, -

"For the whole year long I see All the wonders of faithful Nature Still worked for the love of me; 
Winds wander, and dews drip earthward, Rain falls, suns rise and set, Earth whirls, and all but to prosper A poor little violet."

The dandelion is a symbol of man. Its life is full 9; of symbolism for the children. From the study of the plant, from what comes to the child through his eyes, the gateways to his soul, our boys and girls can better appreciate what they receive from their environment, and what they owe to it. Hans Andersen brings out these ethical lessons in "The Apple Branch," and in many other tales. Thus the dandelion may minister to the ethical nature of the child - and of his teacher.

We cannot do better than turn to Lowell's poem, "To the Dandelion": -

\section{TO THE DANDELION.}

Dear common flower, that grow'st beside the way,

- Fringing the dusty road with harmless gold,

First pledge of blithesome May,

Which children pluck, and, full of pride, uphold,

High-hearted buccaneers, o'erjoyed that they

An Eldorado in the grass have found,

Which not the rich earth's ample round

May match in wealth, thou art more dear to me

Than all the prouder Summer-blooms may be.

Gold such as thine ne'er drew the Spanish prow Through the primeval hush of Indian seas,

Nor wrinkled the lean brow

Of age, to rob the lover's heart of ease ;

'Tis the Spring's largess, which she scatters now

To rich and poor alike, with lavish hand,

Though most hearts never understand 
To take it at God's value, but pass by

The offered wealth with unrewarded eye.

Thou art my tropics and mine Italy;

To look at thee unlocks a warmer clime;

The eyes thou givest me

Are in the heart, and heed not space or time :

Not in mid June the golden-cuirassed bee

Feels a more Summer-like, warm ravishment

In the white lily's breezy tent,

His fragrant Sybaris, than I, when first

From the dark green thy yellow circles burst.

Then think I of deep shadows on the grass, Of meadows where in sun the cattle graze,

Where, as the breezes pass,

The gleaming rushes lean a thousand ways,

Of leaves that slumber in a cloudy mass,

Or whiten in the wind, of waters blue

That from the distance sparkle through

Some woodland gap, and of a sky above

Where one white cloud like a stray lamb doth move.

My childhood's earliest thoughts are linked with thee;

The sight of thee calls back the robin's song,

Who from the dark old tree

Beside the door, sang clearly all day long,

And I, secure in childish piety,

Listened as if I heard an angel sing

With news from Heaven, which he did bring

Fresh every day to my untainted ears,

When birds and flowers and I were happy peers.

Thou art the type of those meek charities Which make up half the nobleness of life,

Those cheap delights the wise

Pluck from the dusty wayside of earth's strife;

Words of frank cheer, glances of friendly eyes, 
Love's smallest coin, which yet to some may give The morsel that may keep alive

A starving heart, and teach it to behold Some glimpse of God where all before was cold.

Thy wingèd seeds, whereof the winds take care, Are like the words of poet and of sage

Which through the free heaven fare, And, now unheeded, in another age

Take root, and to the gladdened future bear That witness which the present would not heed, Bringing forth many a thought and deed, And, planted safely in the eternal sky, Bloom into stars which earth is guided by.

Full of deep love thou art, yet not more full Than all thy common brethren of the ground, Wherein, were we not dull, Some words of highest wisdom might be found; Yet earnest faith from day to day may cull Some syllables, which, rightly joined, can make

A spell to soothe life's bitterest ache, And ope Heaven's portals, which are near us still, Yea, nearer ever than the gates of Ill.

How like a prodigal doth nature seem, When thou, for all thy gold, so common art!

Thou teachest me to deem More sacredly of every human heart, Since each reflects in joy its scanty gleam Of Heaven, and could some wondrous secret show,

Did we but pay the love we owe, And with a child's undoubting wisdom look On all these living pages of God's book.

But let me read thy lesson right or no, Of one good gift from thee my heart is sure;

Old I shall never grow

While thou each year dost come to keep me pure 
With legends of my childhood; ah, we owe Well more than half life's holiness to these

Nature's first lowly influences, At thought of which the heart's glad doors burst ope, In dreariest days, to welcome peace and hope.

We cannot stop with the rsthetic beauty and the symbolism and ethical lessons of our wayside friend. Everything about it points to its Source. It is one of "these living pages of God's book," a leaf in the "manuscript of God." Its form and structure and plan, and, much more, its life and adaptation or fitness for its place, point to its Maker. Unless we, and our boys and girls, look from nature and through nature up to nature's God, our study of the dandelion or of nature has missed its highest value. In this highest spiritual relation we discover that which illumines and relates and unifies all else.

Perhaps we can now better understand and appreciate the thought from Tennyson with which we began, -

"Flower in the crannied wall,

I pluck you out of the crannies;

Hold you here, root and all, in my hand,

Little flower - but if I could understand

What you are, root and all, and all in all,

I should know what God and man is." 


\section{CHAPTER II.}

THE STUDY OF THE RABBIT.

An Introduction to Animal Study.

In the previous chapter we have studied the dandelion as a type of the plant. We have approached it from the morphological or structural point of view, because that is the phase of the plant which has been most emphasized in the plant study of the past, and most teachers and adult students are apt to look at the plant from that point of view. We have shown how much richer and higher content there is in the investigation of the life and relations of the dandelion than in mere analysis, description, and classification. From some consideration of aims in nature study, we have been led to urge that the order commonly followed and the work done by older students in their plant study be. modified in work with children, that they begin with and emphasize the observation of the life and function of the dandelion and its parts, proceeding from this to structure or adaptation, and finally to comparison and classification.

In this chapter we shall study the rabbit as a type of the animal. We will approach it from the standpoint 
of the child, not of the adult, and will follow the order of study indicated at the end of the previous chapter. This chapter is thus intended to illustrate, much more definitely than did Chapter I, method in nature study.

The domesticated rabbit is selected, because it is so common and so many children have made a pet of it and have observed its habits; because it can be easily obtained and kept and its life and habits can be readily observed in the schoolroom or school-yard; because a rich literature, mainly of folk-lore, has been gathered about the rabbit, and because it is an excellent type animal and starting-point for the study of its many relatives, the "gnawers" or rodents. Another good type animal easily studied is the cat.

Much of what follows is a gathering-up and summarizing of work in the writer's class in nature study methods in the Oswego State Normal school. The work of each class begins with a careful study of some common plant or animal, or both; this forms the concrete foundation for the work of the term. One class spent two weeks on the rabbit: observing (from live animals at the school) and writing about its habits; describing its structure and making drawings of the animal and of its parts ; comparing it with the squirrel, rat, cat, canary-bird, and other animals, and thus classifying it; and finally searching the library to ascertain what others had discovered and written about their friend, and to gather all the folk-lore and other literature related to the rabbit. This was followed by a very hasty discussion of aims in the rabbit study, and of the order 
to be followed in the work with the children. Each member of the class was then expected to prepare an outline, very definite and specific, for the study of the rabbit with children of a certain age or grade in school, different sections of the class preparing outlines for the different grades, from the first to the eighth. Later some time was spent discussing and criticising these outlines. The writer wishes to acknowledge his indebtedness to the members of his class for many helpful ideas and suggestions, and for much of the related literature.

The plan of work and method followed in studying the rabbit depend:

First. Upon the aim kept in mind: the cultivation of a sympathetic interest in the rabbit and in animal life, and through this a better appreciation of the beauties and uses and rights of the world of life; or a development of the intellect and intellectual powers of the child, training him to observe and think and express; or the acquisition of a mass of facts about the rabbit and animals in general. Aims in nature study are discussed in Chapters IV and V.

Second. Upon certain laws of mind : that the child depends upon his senses and mainly upon his eyes for real knowledge; that each new idea must be related to or incorporated with what is already in the child's mind before it becomes his mental possession; that the mind receives and retains ideas most readily when they are presented in order, step by step, each point clearly and deeply impressed before a new point is presented; that the child must arrange and give back, or express in some 
way, the ideas presented to him, to insure clear, definite ideas, and to develop the power of conveying ideas to others. These underlying psychological principles and their application are discussed in Chapters VII, VIII, IX, and $\mathrm{X}$.

Third. Upon such conditions as the age and capacity of the children, the material obtainable for study, and particularly for comparison, and the importance of correlating the rabbit study with and making it helpful in other school-work. These are discussed in Chapters XI, XII, and XIII.

On account of the dependence of the child on his senses, we avoid mere talking or reading about the rabbit, the first and greatest fault in much nature work, and make every effort to have him see as much as possible; we emphasize and begin with and build upon that which he can see, and omit or merely touch upon and leave till later that which cannot be seen. Because of the necessity of relating the rabbit study to what is already in the child's mind, we begin with that in the rabbit which is most closely related to the life of the child and most appeals to him, and dwell on its home and home-life, its need of protection and the care of its young, and other characteristics which show "how akin they are to human things." To meet the demand of the mind for continuity of thought, each lesson has a central thought, but is related to the lessons preceding and following; each lesson is divided into two or more somewhat distinct steps, and the steps and lessons are carefully summarized, thus clarifying and clinching the 
important facts and thoughts, upon which new work must be based. Provision is made for expressive work, to lead the child to arrange and thus clarify his ideas, to give teacher and child a means of testing the clearness of the ideas gained, and to make the rabbit study helpful in other school-work.

'The work has been planned for what are believed to be average schoolroom conditions. It is assumed that most teachers can, with some effort and trouble, obtain living rabbits, preferably from or through their pupils, and keep them or eare for them for a few days in the schoolroom or school-yard. Without the living rabbits the study is of comparatively little value. The work is planned for intermediate grades, about the fifth or sixth year in school; suggestions are given for adapting it to younger or older pupils. The lessons, including the related reading and expressive work, are supposed to occupy from three-quarters of an hour to an hour. Much better results will be gained from long lessons two or three times a week than from short lessons (fifteen or twenty minutes) daily.

OUTLINE FOR THE STUDY OF THE RABBIT.

AIM.

General Aim. To awaken a sympathetic interest in and love for all animal life, so that the children will be kind and gentle in their dealings with animals; to help the boys and girls gain some realization and appreciation of the beauty and unity of nature, and of the care and plan shown in nature. 
Minor Aims. To lead the children to observe the habits and structure of the rabbit, and see how they are adapted to its life and home; to enable them to gain definite knowledge which may be used in later work; to develop their powers of observation, expression, and thought.

\section{MATERIAL.}

Absolutely necessary are one or two living rabbits, in schoolroom or in school-yard, confined if necessary in boxes or cages enclosed in wire netting.

Helpful will be a box of sand in which the rabbits can dig or burrow, the skeleton or picture of the skeleton of a rabbit or of the rabbit's head, to show the gnawing and grinding teeth, and pictures illustrating their home and habits. Living or mounted specimens of at least two or three closely related animals, such as the squirrel, mouse, and rat, and of dissimilar animals, such as the cat, are necessary for good work in comparison and classification. Pictures will be helpful if the animals themselves cannot be obtained.

HELPFUL LITERATURE AND SUPPLEMENTARY READING.

1. Joel Chandler Harris's Nights with Uncle Remus.

2. Joel Chandler Harris's Daddy Jake the Runaway.

3. Cowper's Poems. Epitaph on a Hare and accompanying note.

4. Bret Harte's Poems. Battle Bunny.

5. La Fontaine's Fables. Translated by Elizur Wright. 
6. William Hamilton Gibson's Sharp Eyes. How Bunny writes his Autograph.

7. John Burroughs's A Year in the Fields. Winter Neighbors.

8. John Burroughs's Signs and Seasons. Winter Neighbors.

9. John Burroughs's Riverby. A Life of Fear.

10. St. Nicholas Magazine. Old volumes.

Nos. 1 and 2 contain negro folk-lore, in which "Brer Rabbit" plays a prominent part. They contain much excellent supplementary reading, which can be read or told to children of any age.

In many editions of Cowper's poems is a note accompanying his poem, "Epitaph on a Hare," in which he gives a most interesting account of pet hares which he kept for several years.

Bret Harte tells in "Battle Bunny" how at the battle of Malvern Hill "a white rabbit, which had been hopping hither and thither over the field swept by grape and musketry, took refuge among the skirmishers, in the breast of a corporal."

Among La Fontaine's Fables are such as: "The Hare and the Frogs," "The Ears of the Hare," "The Hare and the Partridge," "The Hare and the Tortoise."

In Sharp Eyes Gibson tells how Bunny makes his tracks. In his book Highways and Byways, Gibson has a beautiful picture of the rabbit at home, called "A Winter Rendezvous."

John Burroughs tells in Winter Neighbors, found in both No. 7 and No. 8, a little about a rabbit which took 
up his abode under the naturalist's study floor, and much more about equally interesting animal neighbors and visitors. In Riverby he tells of the life of fear led by the rabbits and hosts of other wild animals.

The old volumes of St. Nicholas contain many excellent and well-illustrated rabbit stories for children.

Much on the habits and structure of rabbits, good for reference or supplementary reading, but lacking, usually, in literary value, can be found in books on zoölogy and natural history, and in the natural history readers for children.

ORDER OF LESSONS.

Lesson I. Home and Home Life.

Lesson II. Habits. Positions and Movements.

Lesson III. Habits. Feeding, Washing, and Senses.

Lesson IV. Literature and Folk-lore Related to Life and Habit.

Lesson V. General External Structure. Body and Limbs.

Lesson VI. General External Structure. Head, Ears, Teeth.

Lesson VII. Comparison and Classification. "Gnawers" or Rodents.

Lesson VIII. Comparison and Classification. Vertebrates and Mammals.

\section{PREPARATORY WORK.}

Have two rabbits in a large wire cage in the schoolroom several days before beginning formal work. The 
observation of habits, on which much later work is based, requires time. Have, if possible, a large tray of sand in one corner of the schoolroom; occasionally let the rabbits out in the room.

Too much emphasis cannot be placed on the necessity of personal observation of the rabbit by the teacher, as

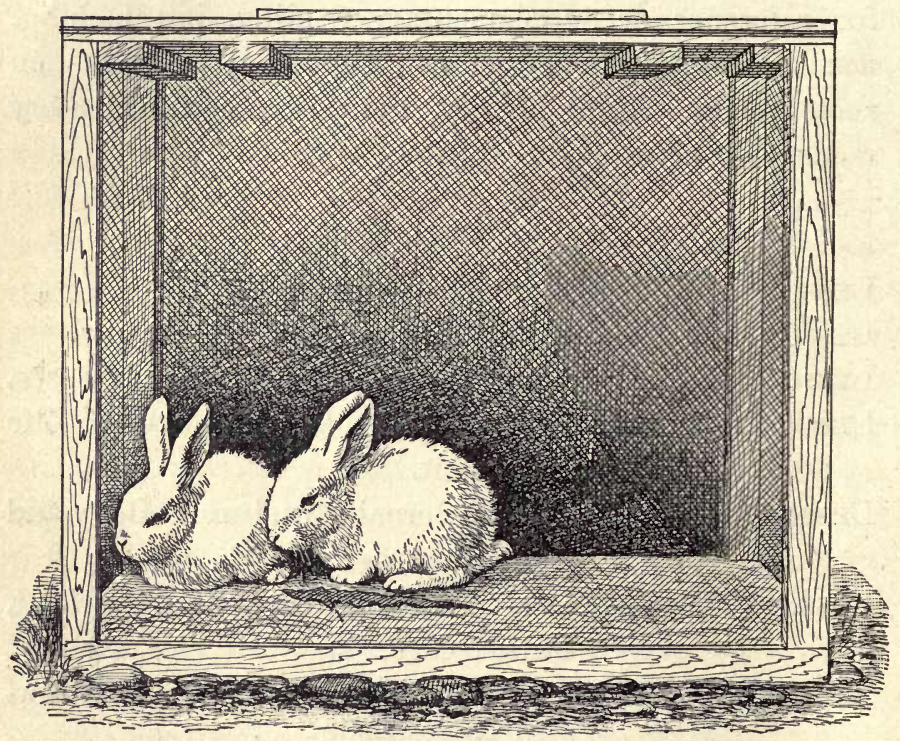

Fig. 15. Rabbits in Schoolroom Cage.

well as by the children. The teacher who prepares by merely reading about the rabbit cannot lead her children in observation. The teacher who depends on the book will almost certainly have pupils who depend on the teacher and book. 
Have pupils care for rabbits as far as possible. Feed three times a day. "In the morning give them a handful of hay or dry clover, and a little of such green food as is in season; about noon, some good oats or meal; at night, more green stuff and hay, if that which was given in the morning is all eaten. Rabbits are very fond of green food, but do not let them have too much, and care should be taken that this is quite dry. No green food is better for rabbits than parsley and the tops of carrots; the roots of the latter are eaten with much relish. Besides these, lettuce, the leaves - or better still, the stumps - of a cabbage, turnips and parsnips, can sometimes be given them." It is commonly believed that rabbits do not need water. They certainly do, at least when their food is dry, and when they have young rabbits to be fed.

Find out how many of the pupils have or have had rabbits, and get them to watch their pets at home, and come prepared to tell something definite they have discovered about them. Strongly emphasize the idea that only the observations of the children are desired, not what they have heard or read about the rabbit.

Dwell on observation of habits, the study of which requires most time. Much about structure will be learned incidentally; the definite study of points of structure can be left for the formal lessons. Direct the observations by placing on the blackboard or giving to the pupils, from day to day, such questions as the : 5 following, to be investigated whenever the children have or can be given opportunity :- 
Position. What is Bunny's position when lying down or sleeping? Where and how are his legs placed? His ears? Does he lie just as the cat, or dog, or cow, or horse does? Are his eyes tightly closed when he is asleep? How does he sit? How does he stand when watching or waiting for food, or when listening?

Movements. How does he move about his cage? About the room? (Observe carefully and tell exactly.) How many ways of moving about does he have? (Walking, hopping, and jumping.) Does he make much noise when he moves about? Why? Notice the kind of tracks he makes (in damp sand, or, in winter, in snow. See Gibson's Sharp Eyes.) How does he dig holes in the sand?

Eating. What does the rabbit eat? How? Have the children feed him. How does he gnaw the wood of his cage? Are his teeth like any of your teeth? Are they all alike? What is peculiar about his upper lip? (The cleft.) Watch him eating, and see the use of this kind of upper lip.

Senses. Watch the movements of the rabbit's ears, particularly when there is a sudden noise, and observe their position at different times. Does he move them as the horse does? What is the use of having them so large? Can he hear well? Can he see well? Watch Bunny's nose, particularly when food is brought near. Can he smell well?

Cleanliness. How do the rabbits keep clean? Watch them wash themselves and one another, and find exactly how they do it. Do they wash just as the cat does? 
Breathing. Put your hand on your chest, and notice how it moves when you breathe. When does the chest move out or expand? When move in or contract? How many times a minute? Watch the breathing of the rabbits, and compare it with your own.

Burrowing. If possible, give the rabbit a chance to burrow in the yard or in a box of earth, that pupils may see how he does it.

Disposition. Are the rabbits fond of one another? Watch and see what they do to and for one another. (Play and eat together, wash each other's faces, go to sleep close together. Do they fight one another? Are they gentle or rough? Are they timid or easily frightened? Are they trustful when we are kind to them? Are rabbits all alike in disposition, or does each have his own traits, just as boys and girls do? Try to discover the distinctive traits of disposition of the rabbits under observation. See also note by Cowper, referred to under Helpful Literature. The confidence of a wild rabbit in man is brought out in Bret Harte's "Battle Bunny."

\section{LESSON I.}

\section{Homes and Home Life.}

Special aim. To broaden the sympathy and knowledge of the children by helping them to see some of the points of similarity between the homes and home life of the rabbits and of themselves, leading them from the domesticated rabbits to the less familiar wild rabbits; to lay foundations for the study of habits. 
Aim given to the pupils: To-day we are going to find out all we can about Bunny's home.

Material needed. A box of earth in which Bunny can burrow, and pictures of wild rabbits in the woods, or even of the woods alone: pictures of the burrows of rabbits or other similar burrowing animals, such as the prairie dogs, will be helpful in impressing the ideas. Some beautiful pictures of rabbits at home can be found X in Gibson's Highways and Byways and Sharp Eyes.

SteP I. Domesticated rabbit's home.

To give the children the right point of view, it may be well to begin the lesson by asking some of the pupils, those with good homes, about their homes, bringing out briefly the necessity for protection from rain and cold, and for food and care; the special care given to the children, and, most of all, to the baby; the mutual love, helpfulness, and forbearance, which really make the home. Now let us study the rabbit's home. Its home is certainly not here in the school-room.

The homes of the rabbits. Where and how they are kept. (In cages or loose in yards.) The construction of the houses or eages, to insure protection, fresh air, and cleanliness. Use of cages in protecting rabbits from weather and from animals from which they cannot protect themselves. Contentment in these when Bunny is well fed and cared for. How they escape from them by gnawing the woodwork or burrowing under the walls. How, when loose, they sometimes make burrows for themselves, or hide under buildings or in brush piles or under low-branching shrubs and trees or in tall grass. 
Care of rabbits. Importance of cleanliness. Feeding them. What, how, when? Importance of often giving them their liberty, letting them run about. How they appreciate kindness shown them; how affectionate and trustful they sometimes become. (See Cowper's account of the treatment of his hares.)

Home life. How affectionate they usually are. How pleased to be with one another when placed together after separation. (It is often asserted that a rabbit, accustomed to the company of others, will pine and soon die if kept alone.) How they huddle together when resting or asleep. How they play and frolic together, particularly when let loose. Their scrupulous cleanliness, usually; how they wash themselves and one another. Their care of their young.

Summary. Have a definite oral summary with as few questions as possible, having two or more pupils tell all they can and as clearly as they can about each of the following points :

The homes of the tame rabbit.

How we should care for the rabbit, and how they show their gratitude for our kindness.

How the rabbits love and care for one another.

SteP 2. The homes from which the rabbits first came.

The rabbits were not always pets. Like the horse and cat and dog, and all our domestic animals and pets, they were once wild.

Why made a pet. Review those characteristics brought out in previous step, which make the rabbit a good pet; its tameness; its cleanliness; the comparative ease 
with which it can be cared for, on account of the nature and variety of its food. In Europe millions are raised every year and sold for food; their skins and fur are also largely used.

Their original homes. Wild rabbits have been found for thousands of years in the warmer parts of Europe, Asia, and Africa. No true rabbits occur in America, except those which have been brought here. What we call wild rabbits are really hares. Have these regions located by the pupils on the maps, if they are old enough to use maps. Try to picture the homes of the wild rabbits in the woods and fields, and their free life as compared with that of their tame cousins.

Their houses. They have no boys to make houses for them; they make their own by burrowing. The tame rabbit in a box of earth or loose in the yard may show how the rabbits dig their burrows. The burrows are said to be in a zigzag, to make it harder for other animals to get in; in the side of the hill, when possible, to facilitate the removal of the earth, and to have several openings for escape. Because of the social instincts of the rabbits, many burrows often communicate, forming a "warren," in which scores may live together. The mother often digs a special burrow for her young, trying to find a dry place in light sandy soil, enlarges the bottom for a "nursery," and pulling hair from her own body, makes, from it and dry leaves, a comfortable bed for her babies. It is said that she often remains with them two days without any food. When hunger compels her to go out, she carefully covers the opening. 
Their home life. "In its wild state the rabbit is an intelligent and amusing creature, full of odd little tricks, and given to playing the most ludicrous antics as it gambols about the warren in all the unrestrained joyousness of habitual freedom.

"At one time they are gravely pattering about the doors of their underground homes, occasionally sitting upright and gazing in every direction, as if fearful of a surprise, and all behaving with the supremest gravity. Next moment some one gets angry and stamps his feet fiercely on the ground as a preliminary observation before engaging in a regular fight. Suddenly a whole party rush off at full speed, scampering over the ground as if they meant to run a mile, at least, but unexpectedly stop short at an inviting tuft of herbage, and nibble it composedly as if they had not run a yard. Then a sudden panic will flash through the whole party, and with a rush and scurry every rabbit leaps into its burrow and vanishes from sight like magic. The spot that was so full of life but a moment since is now deserted and silent as if it had been uninhabited for ages; but in a few moments one little nose is seen cautiously poked out of a burrow, the head and ears follow, and in a very few minutes the frightened rabbits have come again into the light of day, and have recommenced their interrupted pastimes." (From Animate Creation.)

Their enemies. They are found in every direction: owls and hawks swoop down from above; weasels, foxes, hedgehogs, and the domestic cats catch them in or dig them from their burrows; man (the most 
cruel of all, because he kills them for mere sport and not to satisfy his hunger) chases them with hounds. Appropriate here will be a story illustrating the occasional sagacity of the rabbit in outwitting the hounds, or a story from Nights with Uncle Remus. See also $A$ Life of Fear in Burroughs's Riverby.

Their food and the damage they do. Often kill young trees by gnawing the bark. When abundant, are very destructive to vegetation, sometimes making it impossible to raise crops. In some countries, such as Australia, where they were introduced as pets and have multiplied enormously, great hunts, with hundreds of men, are organized, and the rabbits are killed by thousands.

Summary. Have several pupils summarize the points discussed, emphasizing their burrows, warrens, and home life.

STEP 3. The home of the hare (usually called the " wild rabbit") of our country.

Any of the pupils who have lived in the country or have passed much time in the woods can probably tell something about the "wild rabbit." Depend on them as much as possible.

How distinguished from rabbit. The hare always has longer ears, longer than the head; in the rabbit the ears are shorter than the head. The common species are considerably darker in color than the rabbit, at least in summer, the more common one being yellowish brown in summer and gray in winter (hence called by the early settlers "gray rabbit," a name still used); another reddish brown in summer and whitish in winter 
(pure white in the far north), with ears tipped with black. The "gray rabbit" can often be obtained at the markets in winter; it is largely used for food. Common in the west is the "Jack Rabbit."

Home. Occurs in most or all sections of the United States. Does not burrow, but only makes a slight depression in the ground, usually under a tuft of grass or fern or a low bush or a pile of brushwood, in which the hare lies so flatly pressed to the earth and so closely resembling in color the soil and dried herbage that it can hardly be distinguished from them. To this simple home, or "form" as it is called, the hare seems much attached.

Home life. Touch only on points different from rabbits. More solitary, not social in habits. Said to be more courageous. Sagacity in escaping from hounds and from its many other enemies. When hunted, often stands perfectly still or squats behind a clump of sod, being almost indistinguishable from its surroundings. Often destructive to trees and other vegetation. The article by Cowper, referred to under Helpful Literature, tells much about the life and habits of hares which had been domesticated.

STEP 4. Summary of whole lesson and expressive work.

Dwell in this final oral summary on the home and home life of the tame rabbit, and of the hare or American "wild rabbit;" these are nearer to the children, and it is more important that they should know and remember about them. The study of the true wild 
rabbit of other lands is of value, mainly, as a means of relating, and at the same time distinguishing, these two which occur about our homes.

As much of the matter in this lesson cannot be based on actual seeing by all the members of the class, it does not seem wise to ask all the pupils to write about the home of the rabbit. It may be well to have those who have kept rabbits write about "My Rabbit at Home." These papers may be read and preserved as written summaries. An excellent way of summarizing such a lesson may be to read and discuss with the pupils one or more of the articles suggested under Helpful Literature. The articles will serve to re-enforce and more deeply impress some of the thoughts, which may be more important than the mere facts, and the discussion may enable the teacher to test the real results of the lesson.

Adapting the lesson. Where the children "are full of the subject" of rabbits, tame and wild, it will be neccssary to extend this into two lessons. Where they know from observation considerable about the homes of tame rabbits and nothing about their wild cousins, it will be well to emphasize Step 1, and merely touch on Steps 2 and 3. Where they know little or nothing about rabbits, and the lesson is merely so much information given them by the teacher, it should certainly be condensed into one lesson. In such case, however, the reading suggested may occupy another lesson. 


\section{LESSON II.}

\section{Habits, Positions, and Movements.}

Aim. Much as given in Lesson I. We have learned about the homes and home life of the rabbits. To-day we will see how much' we have learned, and how much we can learn, with our own eyes, about their habits, and the ways in which their life resembles ours.

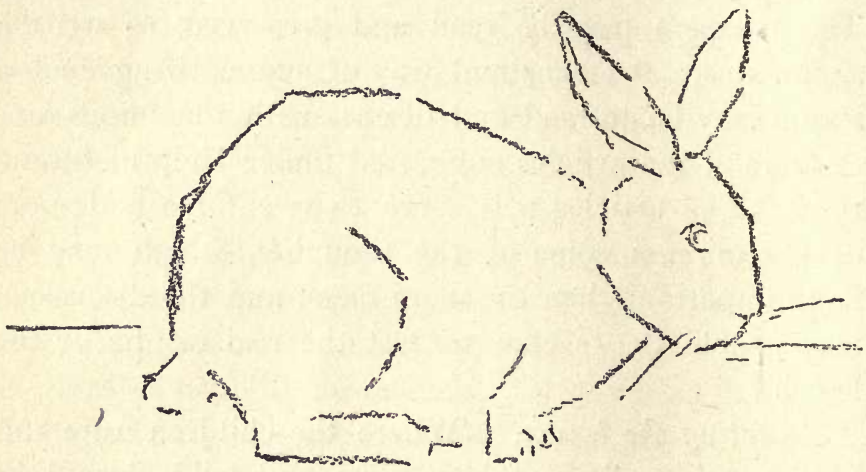

Fig. 16. Drawing of Rabbit, "blocked in."

Preparation. Previous observations. The success of Step 1 will depend almost entirely upon the definiteness of these preliminary observations.

SteP 1. Positions.

When at rest. Draws himself together into a furry ball, his back arched, with the highest point back of the middle, his head drawn in close to the body, his ears turned more or less backward, his eyes only partly closed, his feet under him so that they scarcely show.

When asleep. Sometimes in above position. More 
commonly he stretches his body out full length, turns on one side with his hind legs extended and his head resting on his fore paws, his ears lying back close to the body with the openings always turned outward, and with the eyes always, apparently, partly opened. Rabbits often sleep or rest close together, with their heads on one another.

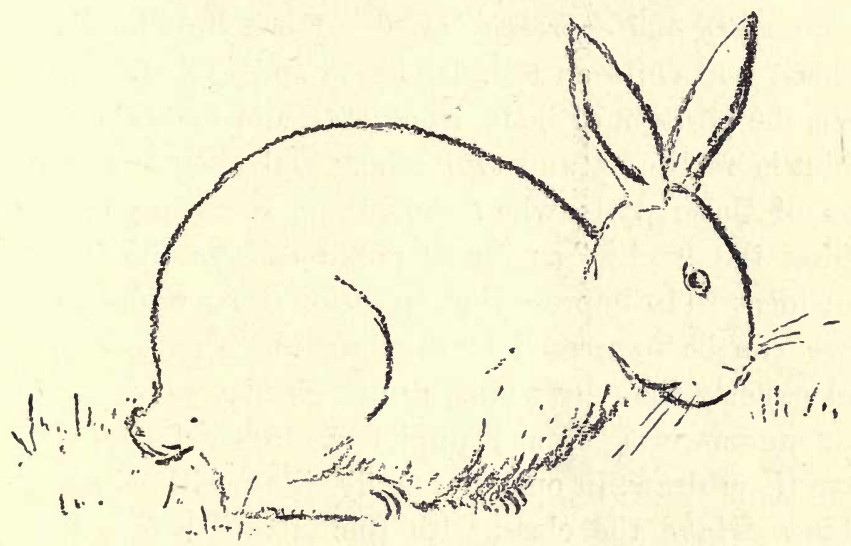

Fig. 17. Drawing of Rabbit, completed.

When sitting. Sits with the hind legs doubled under him and the fore legs straightened, thus raising the fore part of the body, and with the ears erect, or with the body resting on the hind legs and the fore legs quiet or used as hands. When feeding often assumes this position or the next.

When reaching for food or listening. Often stands with body stretched out full length, resting on the hind feet or toes, the head extending upward and forward. 
Compare the positions with those of the cat. Notice that their position, whether reclining or sitting, is usually such that they can spring up instantly, that the opening of their ears is always turned outward, that they hear very slight noises even when asleep, and that their eyes never seem to be entirely or tightly closed. Why is this so?

Summary and expressive work. For a summary have at least two children tell, as clearly and exactly as possible, the position of body, head, ears, and feet when the rabbit is reclining, and two others tell about the position of these parts when the rabbit is sitting up, all telling the "why" as far as possible. As the important ideas to be impressed are position or form ideas, and these can be expressed by drawing much more clearly and exactly than by words, drawings may serve as the best summaries. If any pupils can draw fairly well, have them draw, in outline merely, the positions of the rabbit. Have the class, with the rabbits before them for observation, tell the teacher how to draw the outline (only gross features, not details) of the rabbit on the blackboard. If the teacher pretends to know nothing about it, and compels them to observe exactly and express clearly, by drawing only what they tell her and as they tell her (but not carrying this so far as to discourage the children), this exercise may be made very profitable in helping both teacher and pupils to test the exactness of their observations and their power of expressing their ideas clearly.

This Step 1 is essential for giving the children the 
basic form ideas which will enable them to picture the rabbit, and serves as a foundation for the study of other habits and of structure.

STEP 2. Locomotion.

Walking. Watch Bunny in his cage, or where he has little room to move about. Have children recall, or better show, how they walk, moving the two legs alternately, and then how they walk on "all fours." Why do they move the right arm and left leg and the left arm and right leg together? The rabbit walks in the same way, but is apt to bring his two hind feet forward with a jump. Compare with walking of cat or horse or dog. Bunny does not walk much.

Hopping. His usual means of locomotion when not frightened or hurried. Best seen when rabbit is loose in the room. Have the children tell or show how they hop. If they hop on "all fours," they will hop as the rabbit does. The fore feet touch the floor one after the other, then the hind feet are quickly brought forward together.

Jumping. His means of movement when hurried or frightened. Notice how softly and quietly he comes down, and how his feet spread out. Can only be seen when he has room to jump. It is difficult to see just how he does it. How do the children jump? The rabbit does it in much the same way, moves his fore feet forward at the same time, then quickly brings his hind feet forward so that they are outside and in advance of the fore feet, making a jump of a yard or more. A little sand or even chalk-dust scattered on the floor over which 
the rabbit hops and jumps may show the marks he makes, which the children may often see in the snow.

Adaptation for locomotion. Which legs are the longer and stronger? Why? Why do the hind legs (the portion most readily seen) double backward, like the joint at our ankle, while our legs have the main joint, at the knee, doubled forward? Is there any advantage in this arrangement when the rabbit hops or jumps? Compare with cat, dog, and horse. Why is it easier for the rabbit to hop or jump than to walk? How are his feet and toes arranged and covered to prevent jar and noise when he moves?

Summary. As hopping is the main means of locomotion, so far as the children can usually observe, emphasize this. Have the pupils tell, and if necessary show, or illustrate, exactly how the rabbit hops, and tell what they can about walking and jumping. Have others tell, with the rabbits before them, how the legs, fore and hind, are fitted for hopping and jumping rapidly and noiselessly. Reading and discussing Gibson's How Bunny Writes His Autograph will further summarize and impress what they have observed.

STEP 3. Playing, breathing, burrowing.

Playing. Nothing probably will so impress on children the similarity between rabbits and themselves, "how akin they are to human things," as watching their frolics. The rabbits the writer observed had great frolics in the schoolroom after most of the pupils had left, playing "leap-frog," "tag," and other games, and acting like two happy, active children. 
Breathing. Have the pupils first describe how they themselves breathe, telling about the movements of the chest and sides, and noting how fast they breathe. They can then tell more intelligently what they have observed about the breathing of the rabbit, comparing with themselves. When do the rabbits - and they - breathe most rapidly? Why?

Burrowing. As this is so essential in the life of the wild rabbit and many other animals, it will be helpful if the pupils can see exactly how they burrow, digging with their fore feet, and pushing the earth away with their hind feet. Two or three pupils, preferably those who have rabbits, may be assigned this as a special topic for investigation and report. It is said that rabbits much prefer to make their burrows on hillsides. Why? Many of our hares, or so-called "wild rabbits," burrow under the snow in winter.

STEP 4. General summary and expressive work.

Not everything observed or discussed in the lesson can be or should be reviewed at the end, but those habits most important and most clearly observed. If the drawing of the rabbit in one or two most common positions is attempted, as suggested after Step 1, this can be the expressive work. If this seems impossible, perhaps the pupils ean write about those things studied in the lesson which they have seen most clearly, and therefore know most about. A good subject will be, "How Our Rabbit Rests and Plays," telling how the rabbit lies when resting, and how he sits, how he hops when playing, and how he breathes after playing. A 
broader subject with more scope for individual observations is, "What I Have Seen About the Rabbit's Habits." Insist that each pupil tell only what he has seen, and tell it as exactly as possible, looking at the rabbit or going to the rabbit, when necessary, to make sure of the truth of what he writes.

\section{LESSON III.}

Habits. . Feeding, Washing, and Senses.

Aim and preparation. As in Lesson II.

Material. Living rabbits which have not been fed for several hours. Food, such as cabbage and carrots, to show how they bite off food and how they gnaw. Water for them to drink.

STEP 1. Feeding.

Child's eating. Have children tell, and perhaps show, how they eat their food, biting it off with the sharp, flat biting teeth (incisors) in the front of their mouth, and grinding it with the broad, grinding teeth at the back. Have them feel the shape of the two kinds of teeth. They can eat almost any kind of food. Have them note that they move their jaws up and down and sideways when chewing.

Rabbit's food. Leaves, vegetables, bark, etc., not meat or grain, but food which must be bitten off.

Rabbit's eating. Have pupils tell everything already observed about the rabbit's way of eating. Give rabbits cabbage. Note how they often eat together from the same leaf. Note position, commonly reaching up 
or sitting on hind legs. How does the cleft upper lip aid them? How do they bite off the cabbage? Note carefully number and character (chisel-like sharpness) of front or incisor teeth in each jaw. The rabbit moves his lower jaw up and down and sideways, and from front to back, when he chews, much as the child moves his jaw. It is difficult to see the back or grinding teeth. If necessary, tell children that the rabbits have five or six grinding teeth in each half of each jaw. Compare with food and way of eating of cat or dog. Does the cat or dog have any teeth which rabbit does not have? (Canine or dog teeth.)

Gnawing. Perhaps pupils have already observed the rabbit gnawing the woodwork of his cage or home, or have discovered evidences of his gnawing power. Try to ascertain exactly how they do it, how they use their teeth in the process, and how the teeth are fitted for gnawing. They may gnaw the carrots.

Adaptation. How the rabbit is fitted for its food and way of eating. Reason for the long, chisel-shaped, sharp front teeth. Tell the children that the back of each incisor tooth is softer (composed of dentine) and wears away more rapidly than the front part (covered with enamel); this keeps them always sharp. As fast as they wear away they grow out from the jaw, so that their length usually remains about the same. Sometimes they grow more rapidly than they wear away; then the rabbit has a hard time, and may in time die, because his teeth become so long he cannot eat. Use of the cleft upper lip. Advantage of having the lower 
jaw move up and down and from side to side and from front to back, somewhat like our jaw, but moving more freely.

\section{Summary.}

Have pupils tell: -

How the rabbit's way of eating is like ours, and how different from it.

How the rabbit's teeth and lips are like our teeth and lips, and how they differ from them.

\section{SteP 2. Drinking.}

How does the child drink? Pours or sucks water into his mouth. How does the cat drink? Curves the tip of its tongue into the shape of a spoon, and laps or draws the liquid into the mouth. How does the rabbit drink?

\section{STEP 3. Washing.}

How do children wash? Need soap, towel, comb, brush. Do they keep as clean as Bunny? One great reason why he is a pet is because he keeps so clean. How does he do it without soap or towel? How many of the children have their hair well combed or brushed? How does Bunny's fur look? How does he keep it looking so well without comb or brush?

Bunny uses the bottom of his foot, with its stiff hairs, for brush and comb, and his tongue for a wash cloth or sponge. Licks with his tongue parts which cal be thus reached; washes face and other parts with paws; holds down ears with hind paw, and washes with tongue or front paw. 
This is an interesting step to the children, and will repay careful, patient observation.

Compare with the way in which cat washes herself. Very similar.

STEP 4. Hearing, smelling, sight.

Need of keen senses. To aid in escaping from enemies.

Hearing. Recall how people put their hands behind their ears to help them hear better, and how they turn their hands and ears toward the sound. Some of the pupils may have noticed how horses turn their ears toward the sound.

Note how the rabbits lift up their ears at a sudden sound, and how they are turned with the opening forward and outward. Try to test acuteness of hearing. Note position of ears when Bunny is quiet, resting or sleeping. Reason for having such large ears?

Sight. Eyes seem to be partly open, even when rabbit is sleeping. Why? Our eyes are in front and in sockets. Rabbit's eyes more at sides and are large, "bulging out" more. Why? It is said that the rabbit can see behind and at the side better than straight before him. It must be difficult to close the eyelids over eyes that are so large and protruding. (The belief that rabbits cannot shut their eyes is the basis of the story "Brother Rabbit and the Ginger Cakes" in Joel Chandler Harris's Daddy Jake.)

Smelling. Constant motion of nose. Watch nose when cabbage or similar food is brought near. Does the rabbit's sense of smell seem to be good?

Summary. How do Bunny's ears, eyes, and rase help him? 
STEP 5. General summary and expressive work.

Have pupils write about "How We and the Rabbits Eat, Drink, and Wash Ourselves," letting each tell most about what he is most interested in.

At this time pupils would enjoy and appreciate what Cowper tells about his hares:

\section{LESSON IV.}

Literature Related to Life and Habits.

Aim. To broaden and strengthen the ideas of the pupils by having them look at the rabbit and his life through the eyes of others.

Material. Any of the literature or folk-lore suggested under Helpful Literature will be appropriate and helpful. If this is not available, considerable on the habits of rabbits and of their relatives, such as the squirrels, can be found in the books on popular natural history, or in the Nature Readers.

Method. Do not let the class, as a class, read anything with distinct literary merit, such as "Battle Bunny" or anything like the dialect stories of Joel Chandler Harris. They will "murder" it, and miss most of the thought and beauty. Read these to them, or intrust such reading only to pupils who can do it fairly well. That which is merely supplementary reading and not literature may usually be read by the class with advantage.

A little discussed with them and related to their own observations is better than much merely read to them.

It may be well to discuss some of the superstitions 
connected with rabbits or hares : the carrying of a rabbit's foot in the belief, most prevalent among colored people, that it brings good luck; the fear of a hare or hare's foot among English fishermen, so that the mention of a hare's foot brings terror; a hare thrown into a boat will prevent it from going to sea, and a "hare running along the beach in front of all the fishermen's huts would shut them up as effectually during the day as if each were guarded by a regiment of soldiers;" the old belief that witches could turn themselves into hares.

LESSON V.

General External Structure. Body and Limbs.

Aim of this and succeeding lessons. To lead the child to broader conceptions and greater unity by helping him to see the plan of body of one animal and its adaptation to its life, and to discover this plan and adaptation to life in many related animals.

Aim, as given to pupils: To-day we will find out all that we can about the body and limbs of the rabbit.

Material. Living rabbit, as before. Skeleton, or picture of skeleton, of rabbit or some other quadruped.

STEP 1. General appearance.

Review position of rabbit and of legs and ears when he is reclining and when sitting, as studied in Lesson II. The best preparation for the study of structure is to have the teacher make on the blackboard a drawing of the rabbit in these two positions, drawing from the description and directions of the pupils; this exercise will compel the pupils to observe very carefully the form and 
relative position of the rabbit and of its main parts. After this drawing has been made and erased, if the pupils can draw the rabbit for themselves, drawing as exactly as they can, directly from the rabbit, the study and description of form or general external structure will be much simplified.

STEP 2. Body, trunk, head.

Body as whole. Form egg-shaped, or somewhat cylindrical when stretched out. Narrower and somewhat pointed at anterior end, like most boats and fishes.

Position commonly along or parallel with ground. Compare with usual position of children.

Compare size with that of other familiar animals, such as cat. Measure absolute length and height, and relative length of trunk and head.

Furry covering. Everywhere except on inside of ears and tip of nose. Beauty; softness and fineness (have pupils feel it) and color. Note color under feet. Variations in color in different individuals. Color becoming lighter in winter in hares. Use; to beautify and to protect from cold. Compare with clothing of children and furs worn in winter.

Two main divisions. Form and relative size, and relative position of trunk and head. Impress by sketching mere outline of the two. Each generally ovoidal. Head about one-third length of trunk, with its longer axis oblique (about $60^{\circ}$ ) to axis of trunk.

Step 3. Tail and limbs.

Tail. Position, direction, size, covering. Impress small size by contrasting with other animals. 
Limbs. Review what was learned in Lesson II. about usual means of locomotion, hopping and jumping. How many times as far can the rabbit jump as the child, keeping in mind their relative size.

Have children tell about their own legs and arms, their position, relative size, the direction of motion and comparative freedom of motion of arms and legs, the three divisions of each (upper arm, fore arm, and hand, and thigh, leg, and foot), and the direction of motion at the joints, at knee, ankle, elbow, and wrist. Have them note and show how, when ready to jump, they stand on their toes, with legs flexed at ankle and knee, and spring by suddenly straightening these joints.

Position and attachment and covering of legs of rabbit. Greater freedom and range of motion of fore legs. Greater size and strength of hind legs.

Parts of hind leg. Thigh, leg, and foot. Compare with child's leg. Thigh very short, with joint corresponding to child's knee close to the rabbit's body. Leg, corresponding to part of child's leg between knee and ankle, long and strong. Prominence of ankle joint. Part below the ankle joint, corresponding to child's ankle and foot, greatly lengthened. Cushion or pad near end of foot covered with brush-like hairs. How many toes on each hind foot? Are they movable? Do they spread out? Compare legs, toes, and claws with those of cat or dog.

Fore limbs. Relative size of parts and character of joints, as compared with similiar divisions of eflaks foré $A$ 
limbs. Number of toes and flexibility. Comparison of fore paws with child's hand.

Adaptation or "why." Use of limbs. Hind legs mainly for jumping or hopping, the rabbit's way of moving about. Fore legs mainly for grasping things, and sometimes for defence. Compare with uses of child's legs and arms. The former require strength, the latter freedom and range of motion. Legs adapted for jumping by their strength and character of joints and direction of bending. The lengthened foot gives a firmer support, and probably greater strength and quickness. The flexibility of the foot and toes, and cushion on the toes, lessen the jar and noise when alighting. The spreading of the toes and the hairy brush aid in making the step so noiseless, and assist in walking on the snow. In similar way study adaptation of fore leg.

Do not let this degenerate into a mere "guessing match." Base all study of adaptation on definite, careful observation of habits, structure, and use ; otherwise it is useless, or worse than useless.

In this study of adaptation, teacher and children are "thinking God's thoughts after Him" in a way which appeals very strongly to children, if it is properly done, based on what has come to them through their senses, not merely "preached" to them.

Step 4. Skeleton.

Have children discover, by feeling their own bodies, that each has a backbone, ribs, and a bony framework or skeleton, in arms and hands and legs and feet. Lead 
them to think and tell about some building which they have seen in process of erection. What is the use of the framework of the house? Of the skeleton or bones of the body?

Holding Bunny by the ears, have one or two children gently feel of his body. Does he have bones? A backbone? Ribs? Bones supporting hind legs and

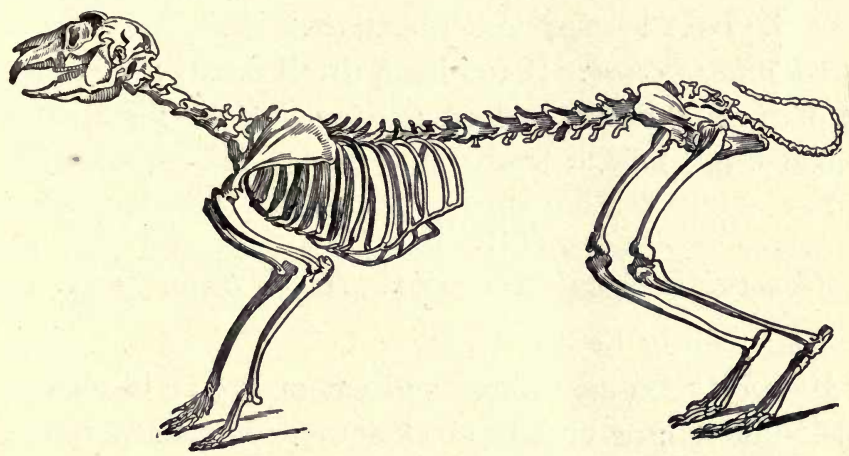

Fig. 18. Sheleton of Hare.

feet? Bones in fore leg and feet? What are they for?

With older pupils a skeleton of rabbit or other quadruped, or picture of a skeleton, will be helpful in impressing the plan of the bony framework. Compare with picture of human skeleton.

With young children touch very lightly on this step.

Step 5. General summary and expressive work.

A drawing of the rabbit, drawn with care by each child from nature, even though very crude, is the best 
way of reviewing, making clear and exact, clinching and expressing, the main points of structure.

If this seems too difficult, have them write about "What I Have Learned About the Rabbit's Body and Legs," or "The Parts of the Rabbit's Body and Legs, and How They are Fitted for His Life," or "Ways in Which the Rabbit's Body and Legs and My Body and Legs are Alike." The written work may be left until after the next lesson, which is short.

Adapting Lesson. If too long, dwell on structure and adaptation of limbs, and on existence of backbone and of bones in limbs.

\section{LESSON VI.}

General External Structure. Head, Ears, Teeth.

Aim. As in Lesson V.

Material. Living rabbit and cat or dog. If obtainable, skeleton, or picture of skeleton, of head of rabbit and of cat or dog, showing kinds, arrangement, and number of teeth.

Step 1. Drawing.

A drawing, made as carefully as possible by each pupil from nature, of head and neck, bringing out relative position and form or appearance of neck, head, ears, eyes, nose, and whiskers, will compel the pupils to observe much more carefully than if they merely tell or write about them, and will greatly aid in impressing these features upon the mind.

STEP 2. Head as whole.

Connected with body by short, flexible neck. Neck 
often looks as if string were tied about body where head joins it. Head somewhat egg-shaped, its axis oblique to axis of 'trunk, and about one-third as long, covered with fur, except inside of ears and tip of nose.

SteP 3. Ears, eyes, nose, and "whiskers."

Ears. Position : on top of head. Compare with position and freedom and range of movement of child's ears. Form: like a leaf rolled at base. May be well to have a piece of paper cut shape of ear and rolled in same way. Size : measure length, and compare with length of head. Covered with fur on outside, with hairs inside, longer and more numerous toward base. Network of veins on inside, giving pinkish tinge. More or less transparent, and apparently delicate, but quite strong, as shown by fact that rabbits are carried by their ears.

Eyes. Have pupils observe and tell about their own eyes, - their position in front of head, sunk in sockets, with upper and lower eyelids, with eyebrows and eyelashes, with a dark pupil in centre of eyeball, a colored part or iris about that, and the white of the eye around the iris.

Compare rabbit's eye with child's eye. Is on side of head, large, stands out from head, is usually pinkish, has parts corresponding to parts of child's eye, but somewhat difficult to see. Perhaps quick-eyed pupils can discover under the two eyelids a thin, membraneous "third eyelid," which covers the pupil somewhat when the eyelids are brought together, and is drawn down into the inner lower corner of the eye as the eye is 
opened. If they watch the movements of the eyes, they may observe that the rabbit can turn his eyeball toward his tail, and see behind him with little movement of the head.

Nose. Position : very freely movable, and almost constantly in motion. Small, as compared with most animals. Naked at tip (compare with cat or dog), with V-shaped partition between two openings, or nostrils.

"Whiskers." Position: at side of mouth and below eyes. Compare with cat's "whiskers." Are said to aid rabbit in feeling, and to tell him whether any opening his head may enter is large enough for his body to pass through.

Adaptation. Advantage of position, form, size, and freedom of movement of ears; use of hairs on inside. Advantage of having eyes on side of head; of having them stand out so far from head; use of "third eyelid" if rabbit does not shut his eyes.

Summary. With topics below written on blackboard, have pupils tell orally, with as few questions as possible, all they can about -

The head: position with reference to body, shape, size.

The ears: position, movements, shape, size, how adapted to rabbit's use.

The eyes: position, parts as compared with pupils' eye, how adapted to needs of rabbit.

The nose: position, movements, size, covering, openings. 
STEP 4. Mouth and teeth.

Mouth and lips. Position of mouth. Upper lip cleft up to nose. Why? Recall what pupils have observed about advantage of this when gnawing. Lower lip small.

Jaws. Have pupils note that we can move only our lower jaw, not our upper jaw, and can move it up and down, from side to side, and slightly, from front to back.

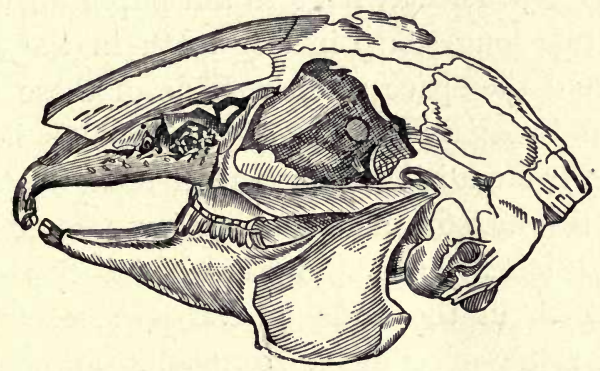

Fig. 19. Skull of Rabbit.

The up-and-down movement enables us to bite. How do the other movements aid us in grinding our food? Movements of rabbit's lower jaw are similar; but the movement from front to back, best seen when he is "chewing his cud," is greater.

Teeth. Have pupils ascertain and tell about the kinds of teeth in their own mouths: the chisel-shaped biting or incisor teeth in front of each jaw ; the longer, pointed teeth next to these, the dog teeth or canine teeth, one on each side of the incisors; several flat, rough grinding 
teeth, toward the end or side of the jaws. Use made by children of incisors and grinding teeth.

Examine teeth of cat or dog. Incisor teeth readily seen, but grinding teeth somewhat difficult to see. Great length of canine or dog teeth. Used and fitted for seizing and tearing animals and meat.

Examine teeth of rabbit, comparing with teeth of child, and of cat or dog. Back teeth will probably have to be studied from a skeleton, or picture of skeleton of head, or the teacher may have to tell pupils about them. Note the two long sharp incisor teeth in the front of each jaw, and the space at either side of these without any teeth. From a skeleton of the rabbit's head can be seen the two additional very small teeth back of and hidden by the incisors in the upper jaw (found only in rabbits and hares), and the five or six flat grooved grinding teeth in the ends of the jaws, each with a transverse ridge of enamel, so that it appears to be composed of two halves.

The provision made for keeping the incisor teeth sharp, and for replacing the parts worn away by gnawing, has been already given in Lesson III.

The character and number of the teeth are very important in classification; hence pains should be taken to have them thoroughly understood as a basis for the next lesson on classification.

Adaptation. See also Lesson III. The rabbit belongs to a group or order of animals called "gnawers." How is it adapted for gnawing? By cleft upper lip, free movement of lower jaw, and position, shape, size 
strength, arrangement of enamel, and manner of growth of teeth.

STEP 5. General summary and expressive work.

Making a drawing of head and parts externally visible is most exact and effective way of summarizing these. With this, or in place of it, can be an oral or written summary, telling briefly but exactly "How the Rabbit's Mouth and Teeth are Fitted for His Food."

\section{LESSON VII.}

Comparison and Classification. "Gnawers" or Rodents.

Aim. To broaden pupils' conceptions and lead to greater unity in their minds; to train them to compare, to discriminate between essentials and non-essentials, to understand plan and to discover similarity of plan amid great diversity in minor details; to make rabbit a type in the pupils' mind of a great order of animals, the "gnawers" or rodents.

Material. Living rabbit and cat or dog; hare (can often be obtained from meat market in winter), or picture of hare, showing incisor teeth; any other rodents, living, dead, or mounted, such as rat, mouse, squirrel (in winter can sometimes be obtained at market), gopher, prairie dog, or woodchuck; pictures of beavers, and of any carnivorous animals, showing canine teeth.

Essentials of classification. Classification is based on essential similarities, or similarity in plan, as distinguished from such minor characteristics as size, color, 
and markings ; two houses may be very similar in plan, and yet differ greatly in size, color, and markings, or trimmings or decorations. Hence it is wise to begin the comparison with two quite similar animals, to dwell on essential similarities rather than differences, and to emphasize these similarities, bring them into stronger relief, by contrasting these similar animals with those quite dissimilar. ${ }^{1}$

Comparison and classification require very careful questioning or development work by the teacher. Distinguishing between essentials and non-essentials requires knowledge and judgment; abstracting and applying plan demands some intellectual power. Hence in this work the pupils need considerable guidance and help.

1 The most essential features in the classification of the rabbit are :-

The bony skeleton and backbone or vertebral column, placing it among: the vertebrates.

The hairy covering or fur, placing it among the class of vertebrates called mammals.

The way in which it feeds and the character of the teeth, two large incisors, and the molars in each jaw, with no canine teeth, showing that it belongs with the order of mammals called "gnawers" or rodents.

The long ears, short tail, and two small accessory incisor teeth, hidden behind the large incisors of the upper jaw; these are characteristic of the family of hares (the leporidæ), including the rabbits.

The ears, shorter than the head, and the habit of burrowing in the ground, distinguish the rabbit from the hare.

These essential features are given here merely to assist the teacher and give point to the lessons which follow. They should be gained from the children, as a result of their observations and comparison, never merely given to the pupils. 
STEP 1. Comparison of different rabbits.

Have pupils compare size, color, and markings of the rabbits they have with others they have seen, to show that they may differ in these respects and still be rabbits ; that is, that size, color, and markings may not be important in classification. If they cannot compare many rabbits, compare the cats they have seen, to impress the same thought.

STEP 2. Comparison of rabbit and hare.

Have pupils compare with hare or picture of hare, bringing out similarity in general appearance and plan, in possession of backbone, in being covered with fur, in having teeth alike in number and character, and differences in length and color (?) of ears, and habit of burrowing in the ground. The pupils will tell of other points, but teacher should emphasize and clinch those above.

If slight comparison is made between the rabbit and hare and the cat, the essential similarities will be impressed by contrast.

STEP 3. Comparison of rabbit and other rodents.

Have pupils compare rabbit with squirrel, chipmunk, rat, mouse (small for most satisfactory work), muskrat, woodchuck, gopher, beaver, or other available gnawing animals, bringing out similarities in general plan, bony skeleton, possession of fur, and character of teeth, and the essential differences: such as the climbing habits, short ears, long, bushy tail, sharp claws, and greater comparative length of upper incisors in the squirrels; the burrowing habits, thick, clumsy body and short legs 
of the woodchuck; the similar habits and body and cheek-pouches of the prairie dog and gopher; the aquatic habits, webbed hind feet, and broad, flattened, scaly tail of the beaver; the aquatic and burrowing habits, long tail, musky odor, and color (brownish above, gray beneath) of the muskrat; and the omnivorous habits, long, naked (not covered with hair) tail, and narrow, pointed, lower incisor teeth of the rats and mice. Try to relate differences in structure to differences in habits.

The results will be much more satisfactory if the rabbits can be compared with two or more other rodents ; it is dangerous and wrong to encourage or allow the pupils to generalize from too few particulars, as they do when they assume the characteristics of rodents from the observation of two species.

STEP 4. General summary.

Gather up from the children, characteristics in which all studied (except the cat) are similar; general plan, backbone, fur, teeth. In what respects are all like the cat? In what respects do all differ from cat?

Write on the blackboard a list of points in which all the animals studied are like one another and unlike the cat. All animals having these characteristics are called "gnawers" or rodents. Write under this, gaining from pupils, distinctive characteristics of the different kinds of rodents studied. This tabular view appeals to the eye and greatly helps the memory. Have children make copy of it. 


\section{LESSON VIII.}

Comparison and Classification. Verterbrates and Mammals.

STEP 1. Comparison of rabbit and cat.

Review points in which all animals previously studied (except cat) are alike, points in which they are like the cat, points in which all differ from the cat. Cat differs in having a longer, more lithe body, incisor teeth more

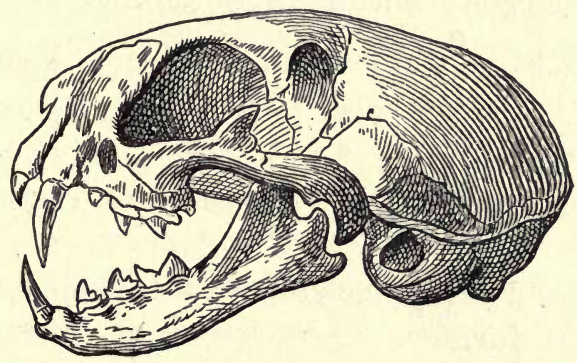

Fig. 20. Skull of Cat.

numerous, and not well fitted for gnawing, canine teeth long, conical, and pointed, grinding teeth with two or more rather sharp projections on their outer end, not well fitted for grinding, and claws strong and sharp. Relate differences in structure to differences in habits and food, to bring out the "why."

Compare cat with dog. Similar, but claws not so sharp. Why cannot dogs climb trees?

Compare rabbit and cat with any other carnivorous animals of which mounted specimens or good pictures, 
showing canine teeth, can be obtained. Relate peculiarities of structure to habits.

Gather from pupils, and write on the blackboard, a table such as the following:

\section{Gnawing Animals or} Rodents -

Have four long chisel-shaped incisor teeth.

Have no canine teeth.

Have flat-topped grinding teeth.

Gnaw and grind their food.
Flesh-Eating or Carnivorous Animals -

Have many (twelve) small incisor teeth.

Have four long pointed canine teeth.

Have grinding teeth with tops having points.

Tear and grind their food.

Rabbit, hare, rat, mouse, squirrel, woodchuck.

Cat, dog, fox, wolf, lion, tiger, skunk, wildcat, leopard, bear.

All have a bony skeleton and backbone, and are covered with fur.

STEP 2. Comparison of rabbit with chicken and fish.

These are selected because most children have discovered, when eating them, that they have a bony skeleton and backbone.

Chicken. Like rabbit in having bony skeleton and backbone. Different from rabbit and all the other animals studied in having two legs, a pair of wings, a hard mouth or bill, and in being covered with feathers.

Fish. Like rabbit in having bony skeleton and backbone. Differs from all animals already studied in having no legs, swimming in the water with its fins 
and tail, and in having its body covered with scales (generally) instead of fur or feathers.

All animals studied so far have skeleton and backbone.

STEP 3. Comparison of rabbit and some invertebrate animal.

Select any invertebrate animal which pupils have discovered, or can be led to discover, to be without internal skeleton; that is, without backbone or bones of any kind, such as the caterpillar, slug or shell-less snail, earthworm, or some insect.

How like other animals studied? Only in having life, and in being an animal instead of a plant, in having power to move itself, and a mouth to take in food. Differs from most in having no backbone or bones, and in having more than four legs.

All those with a backbone are called vertebrates. The others are invertebrates.

All vertebrates with more or less furry or hairy covering are called mammals. All with feathery covering and wings are birds; all with scaly covering (sometimes naked) and with fins are fishes.

STEP 4. Summary and expressive work.

Have pupils review both process and facts by having them write (assign different topics to different pupils) about: -

1. "What we learned from the comparison of different rabbits."

2. From the comparison of rabbit and hare.

3. Rabbit and squirrel. 


\section{Rabbit and cat.}

5. Rabbit, chicken, and fish.

6. Rabbit and caterpillar.

Written summaries are usually more definite and exact. Have these read and discussed in class.

Pupils can apply what they have learned about classification by writing the following lists of animals :-

1. A list of all the animals they can think of which are vertebrates.

2. A list of all the animals they can think of which are not vertebrates or are invertebrates.

3. A list of vertebrates which are also mammals.

4. A list of mammals which are also carnivorous animals.

5. A list of mammals which are also gnawers or rodents.

Why is our rabbit classed with the vertebrates? With the class mammals? With the order rodents? With the family of hares?

\section{ADAPTING WORK TO OTHER GRADES.}

\section{For Grades or Years One and Two.}

The work as planned will certainly occupy two weeks, forty-five minutes to an hour a day. Little folks could not do much of the work outlined; it would be difficult to keep them thoroughly interested in one topic so long. They are most dependent on their senses, must have work most closely related to their child-life, and have very little power of reasoning or of abstracting. 
With the children of the first or second year there should not be more than five lessons on the rabbit. After having the rabbit in the room a week, to get acquainted and answer the simpler questions given under Preparatory Work, the lessons could be divided as follows : -

Lesson I. Home and Home Life of Child and Tame Rabbit.

Lesson II. Habits. Movements and Playing of Child and Rabbit.

Lesson III. Habits. Food, Feeding, Washing, Hearing of Child and Rabbit.

Lesson IV: Structure and Adaptation. Limbs, Teeth, Ears of Child and Rabbit.

Lesson V. Bunny's Cousins. Squirrels, Rats, Mice.

For Grades or Years Three and Four.

Lesson I. Something of life of our own "wild rabbit" or hare, in addition to life of tame rabbit, dwelling on difference in life, rather than on differences in structure.

Lesson II. Careful study of one or two most common positions, of walking, hopping, and playing, and of breathing.

Lesson III. Much as given.

Lesson IV. Much as given.

Lesson V. Somewhat less detail. 
Lesson VI. Dwell on ears, jaw, and incisors, and on adaptation.

Lesson VII. Compare rabbit with two other rodents, with cat and with fish and chicken (or canary-bird), dwelling on clearly visible characteristics (the bony skeleton is not visible), and trying to impress clear idea of gnawing animals and of hairy or fur-covered animals.

\section{For Upper Grades.}

In grades five or six, for which this is planned, and with older pupils, the study of the rabbit may well be a veritable "introduction to animal study." . Beginning with the rabbit, the other rodents or mammals or vertebrates may well occupy for months the period which can be given to nature study. In the school with which the writer is connected such work, continued four or five months, three to five times a week, has aroused great interest and given very satisfactory results in grades six, seven, and eight. The boys in particular, at this age, are apt to take more interest in such animal study than in plant study. The work must, however, be observational, based on the careful observation of type animals, not mere reading and talking about animals. 


\section{CHAPTER "III.}

\section{WHAT IS NATURE STUDY?}

For many years a struggle has been going on in our higher institutions of learning between the upholders of the classics and of the sciences. One class has limited education almost entirely to the study of man and his languages, history, and literature, and to methods of exact reasoning, or mathematics. The other has advocated the study of man's surroundings, his physical environment, of the world in which man is placed and on which he so largely depends. The defenders of the classical education have been compelled to yield point after point to the champions of the scientific education. To-day we are coming to the conclusion that we can get the best well-rounded, liberal education by a compromise between the two opposing schools, in the study of man and nature.

From the higher seats of learning the struggle has passed into the secondary schools, the high schools and academies, where a similar compromise is being effected, or a sharp distinction made between the students taking classical and those pursuing scientific courses.

Our elementary schools have until recently confined their work to the human studies, or studies relating 
to man, to his language and other methods of conveying ideas, to his methods of exact reasoning, and to the way in which he has parcelled up the earth. Everything has been centred about man, as the universe was once supposed to be centred about the earth. Even geography, the study of which might well have brought the pupils into closest relation with their physical environment, has been, not a study of the earth, of our physical environment, but almost entirely a study of a description of the earth, and of a description, not to any great extent of physical forces, processes, and features, but very largely of the divisions made by man, and of the features due to man. The schools have placed all emphasis on the "essentials," reading, writing, and drawing, arithmetic and geography. The children in these schools have studied almost nothing of the other part of their environment, the physical world, which forms such a large part of their life.

To-day the old conflict is being waged in these elementary schools. The champions of science are urging the introduction from the beginning of the child's school-life of some study of the world of sense which lies about the child. This has been designated as elementary science, or nature study.

It seems wise at the very beginning to determine just what we mean by elementary science, or nature study. This will prevent ambiguity and misunderstanding in later discussions, 
The terms "elementary science" and " nature study" are both widely used. Elementary science is, perhaps, more exact, and therefore more scientific. Nature study has a less formidable sound, and better expresses the spirit in which the work should be undertaken. It seems much the better term, at least for the work in the first four or five years of the school course.

The former term includes two ideas. First, it is elementary, as distinguished from advanced. In the aim or purpose of the work, in the material selected, in the methods pursued, it is elementary; planned for and adapted to the needs and capacities of the pupils of elementary schools. In the second place, it is science, classified knowledge.

"Knowledge" our dictionary defines as "clear and certain perception," "familiarity gained by actual experience." In the very beginning we cannot emphasize too strongly the ideas involved in these definitions of knowledge, _ "clear and certain perception," "familiarity gained by actual experience." Let us analyze them. "Clear," - not hazy or foggy, but sharp and distinct; "certain," - not what we imagine or think we know, but what we are absolutely sure of ; "perception," - not what has come to us from others alone, from book or teacher, but the mental picture based upon what we have seen, or what we have apprehended with our own senses. Equally significant is the other definition. "Familiarity," - "intimate and frequent converse or association," like that among the members of a family; "gained," - acquired by effort, not merely 
absorbed ; "actual," - real, as distinguished from theoretical ; "experience," - "practical acquaintance by personal observation," "continued and varied observation," "personal trial and experiment."

How much of the stock of information possessed by the pupils in our schools will stand the test of these definitions of knowledge? How much is "clear and certain perception"? How much is "familiarity gained by actual experience"?

In the third place, elementary science is knowledge classified or studied in its relations, arranged and grouped by the children. Isolated facts of observation may be knowledge, they may be "clear and certain perceptions," but they are not science, they are not classified. Until these facts are related and grouped they are of comparatively little value to the mind. Unless they are tied up in assorted bundles, the mind that possesses them may be little more than a mental junk-shop. When they are properly related and grouped, each perception' suggests a host of related ideas, each fact or group of facts becomes typical of the great class to which it belongs.

Later we will discuss the various relations in which our physical environment can be considered.

To recapitulate, elementary science is :-

1st. Elementary, adapted in aim, plan, methods, and materials to the capacities and needs of the children in the elementary schools.

2d. Knowledge, "clear and certain perception," "familiarity gained by actual experience." 
3d. Classified, considered in its relations, and arranged and grouped (by the child, not merely by teacher or book) in accordance with the relations and the differences and similarities the child has discovered.

If this definition is correct, we can test the work being done under the name of elementary science by seeing how far it meets the requirements of the definition. Is it "elementary knowledge classified"?

We shall find in our schools and homes, or clamoring for admission, three general classes or kinds of science work, or so-called science, which do not meet these conditions.

Our university or college or high-school friend, interested in education, enthusiastic in his specialty, would have us introduce, or has already introduced, into our schools such work as he carries on with his students, with very little modification or adaptation to children. The botanist would have our little folks begin with the plant cell as the unit of plant life and structure, or with the lower forms of plants, such as pond scum, and work up step by step to the complex organism which the child calls a bean plant. This seems to the botanist the simplest, easiest, and only logical method of procedure. The mineralogist would have the children begin with the chemical elements of which minerals are composed, and build up the minerals and rocks, because to him a mineral means nothing unless he knows its components. Both overlook the fact that what is logical and simple for them may be illogical and incomprehensible to the child, and 
what is complex for them may be simple to the child: Both forget the long process of education, much of it unconscious, by which they learned to analyze the common things about them, before they could even understand that they were complex, much less resolve them into their components, or build them by a synthetic process from their components. The teachers of college and high-school students, discouraged by their lack of power to do careful work, and appreciating the need of a better training in exact, thorough scientific methods of study, may do, as did the writer, insist on the most careful, exact, detailed work, even in the primary grades, either not realizing, or forgetting, that the children's minds and hands and eyes are not fitted by nature for such work. This is science, but it is not elementary; it is not adapted in material and methods to the nature and needs of the children.

Other friends of our schools would place in the hands of our children beautiful and interesting books telling all about the wonders of the world about them. They would introduce into the homes and schools Nature Primers and Nature Readers, and Stories Mother Nature Told Her Children, from which the pupils can imbibe or absorb some of the facts, or what are supposed to be facts, concerning the world in which they live. These books may be good, they may be helpful, they may be elementary, well adapted to children; but this is not science, it is not even knowledge. It is not "clear and certain perception;" it is not "faniliarity gained by actual experience." 
A third class, with a better appreciation of the needs and capacities of the children, with a better understanding of the conditions of our schools, would have the children go to nature instead of the book, watch the swelling bud, the developing seed, the opening flower, note the flight and song of the bird, and peep into its nest, glance at the fly or grasshopper, admire the brilliant coloring of the butterfly. They would have our children, butterfly-like, sip a little here, a little there, taste in this place, in that place. This is better, very much better; where the child is surrounded by nature, almost immersed in nature, it may be an excellent means of arousing in him the interest and sympathy and spirit which are the first essentials in his best development. It may lead to knowledge, to fairly "clear and certain perception." It may lay the foundations for science ; it is on just such foundations that all science has arisen.

But if it stops with sipping and tasting, if the knowledge is simply taken in and not digested or assimilated, if it is not expressed in a form intelligible to others, it is only the beginning of science. Unless the phenomena are observed or studied in some order or sequence, unless their study prepares for and leads to a careful investigation of the relations of the various phenomena observed, unless it results in comparison, in some natural classification by the child, and, finally, in broader and broader generalizations and a better comprehension of the unity of nature, it is not science. The method, if it may be called a method, so prevalent in many of 
our schools, of studying without plan or sequence any. thing in nature which may be accessible or convenient, to-day a plant, to-morrow a bird, next day a stone, or the wind or weather, may interest the children, may develop and train the teachers, may be a preparation for elementary science; but it is not elementary science, it is not or does not result in "knowledge classified."

To get the best results in elementary science in our schools, we need a clear, definite plan or course of study, with its various parts closely related. The work of each grade should be adapted to the children of that grade, based on the work of the preceding grade, and should prepare for the next grade above. Then our work will become, in truth, elementary science.

The term "elementary science" refers mainly to the results of the work, classified knowledge: The term "nature study" has more reference to the materials considered and the methods pursued, and better expresses the spirit in which the work should be carried on. The materials are found in nature, our physical environment. The methods are the methods of nature, those by which we have always become acquainted with our surroundings since we first opened our eyes on this world of sense. The spirit in which we should study nature, the spirit in which children approach a constant companion or friend, is better indicated, to the children and teachers at least, by the simple "nature study," than by the somewhat high-sounding and formidable "elementary science." 
Nature study is first nature study, a study of our physical environment. It is not a study of books. Books may help, may tell us about nature, but they are not nature. It is not listening to the teacher as she tells about nature, or what purports to be nature. It is not merely gazing with awed attention at the interested, observant, bright boy of the class, as he tells what he has read, or even seen. This may be studying about nature; but it is not studying nature, it is not nature study.

Nature study is not merely a study of nature, but of nature under natural conditions, so far as this is possible. It is not merely schoolroom study. Nature belongs out-of-doors, and out-of-doors we must go to study many of her manifestations. Field lessons are a necessity for the best work. Nature constitutes much of the child's out-of-school environment. He is learning from nature, consciously or unconsciously, almost continually. Much of what he thus learns out of schoolhours in nature's school must be utilized in his nature study in school. When we confine nature study to the schoolroom and school-hours, we shut out the best part of nature.

The word science is apt to be associated in our mind with a laboratory, and an array of instruments and appliances. The laboratory for nature study is all outdoors; and the only instruments and appliances absolutely necessary are the seeing eye, the hearing ear, and the understanding heart.

Nature, real nature, is instinct with life and action; 
is living and developing and doing. The science in our educational institutions has been heretofore, very largely, a study of form and structure and plan. But nature is not mere form or structure.

We must study the life and life history of animals and plants, and the work performed by their various parts or organs, as well as their form and structure; the changes through which our rocks are passing or have passed, as well as their structure and components; the forces which are now affecting the earth, and the processes which have brought the earth to its present condition, as well as the present forms and features of the earth. Otherwise we study only a part of nature, and that side of it which is least adapted to our elementary schools, and of least value to our pupils.

Nature study is, in the second place, nature study. As has already been shown, it is not merely talking or reading about nature; it is not merely glancing at the beauties or sipping the sweets of nature. It is definite, orderly, systematic study of nature by each pupil and by the teacher.

Nature study is, furthermore, nature studied in its relations. Every phenomenon in nature stands in relation to a host of other phenomena. The dandelion in our hand is related to the whole plant, and to each part of the plant - a relation of mutual dependence and helpfulness. It is related to, and dependent upon, soil and rain and sunlight and wind. It is related to the insects which feed upon or fertilize it. It has a relation, of similarity or difference, to a host of other 
flowers. It contributes to the happiness or comfort of man, and has inspired the poet. It points up to its Maker and Protector. It has many other relations. To understand nature, we must keep in mind, investigate and arrange or group, these relations whose mutual actions and reactions constitute nature. These relations can be summed up as follows:-

First. To the whole of which it is a part, and to other parts of that whole. The flower or leaf is not merely a flower or leaf, but is related to the whole plant, and to every part of the plant. This brings out function, or use, and plan.

Second. To natural environment. The plant or animal is related to water and soil and food and air. This brings out life and function, and adaptation of structure to function or work, and impresses mutual dependence and co-operation.

Third. To past and future. The study of plant and animal is incomplete until we investigate its life history. The raindrop is but one stage in a long series of changes or transformations. The fragment of rock or of soil is most wonderful and instructive when considered as a history of the past, or a prophecy of the future.

Fourth. To other individuals, similar and dissimilar, $c_{/,}$ leading to comparison and classification.

Fifth. To other phenomena, bearing to it the rela- $c_{k}$ tions of cause and effect. These relations are prominent in physics and chemistry.

Sixth. To man, ministering to his spiritual, ethical, ? æsthetic, and material nature and needs. Nature must 
be studied in its relations to man's higher nature, leading to the best in literature and art, and in its utilitarian or practical relations.

Seventh. To the Creator. Nature reveals a Protector and Planner, and points to a purpose and first cause. Nature study misses its highest object and greatest value unless it leads to that which is above nature.

Eighth. To the school and to school-work: as a means of interesting and stimulating children; as a basis for expressive studies, — writing, reading, drawing, modelling, painting, arithmetic; as a preparation for and aid in geography and literature.

If the children study nature it must be from their standpoint, not from the standpoint of the mature mind. Those phases of nature must be studied which are nearest to the child and most strongly appeal to him. This is discussed more fully in later chapters.

It must be not merely a study of nature by the children, but a study of nature by the teacher with the children. In this work the teacher who depends on books in her preparation will have pupils who depend on their teacher. The teacher who studies nature with her children - fellow-investigators of truth - will inspire and be inspired by her pupils.

To sum up our definition of nature study, it is :-

NATURE - not books, not mere reading or listening ; nature under natural conditions; nature living and in action, not mere form and structure.

STUDIED - not glanced at or sipped, or talked about 
or read about, but studied, - a personal investigation.

In ITS ReLATIONs - to all the universe, - nature, man, and God.

BY THE CHILD - by each child individually, not merely by the teacher, or by bright or interested children.

From the Child's Standpoint - not merely from the standpoint of the mature mind.

Bx the TEACHER - not merely by the children.

With the ChILdRen - teachers and children fellow-investigators of truth.

It may seem that we have given undue prominence, and placed unnecessary emphasis, on definitions; but experience has shown this to be necessary. No matter how earnest the spirit of the teachers, and however honest their intention, the habits and training of a lifetime, which have too often made books crutches instead of helps, will assert themselves. Teachers will study, under the guise of nature study, anything and everything but nature. They will deliberately shut their eyes to nature, and confine their investigations within the covers of a book. They will cram their pupils' minds full of memorized facts and names and classifica. tion, and call that nature study. 


\section{CHAPTER IV.}

THE AIM OF NATURE STUDY: TO DEVELOP THE INDIVIDUAL CHILD.

The question is asked by many, "Why introduce nature study into our schools?" We might better ask, "Why stop nature study when the child enters our schools?" In the early life of the child, the world of nature is his world. With this world his senses bring him into closest relations. His earliest education is almost entirely in nature study, and by nature's methods, - an education of seeing and doing, of using his powers and developing them by using. Is there any reason why this should stop when he enters school? Is there any more natural way, any better way, of developing his powers than to follow the leadings of nature, help and train him to see and do more, and then to think and tell about what he has seen and done? Is there any knowledge which is more essential to him than a knowledge of his surroundings?

The burden of proof is on those who would stop nature study when the child enters school.

Before it is possible to discuss intelligently methods of work, it is necessary to consider somewhat carefully 
the aim or purpose of the work. The methods of work will depend very largely on the aim or purpose. Consciously or unconsciously every teacher will be influenced in her methods more by the final aim she keeps in view than by any other one factor.

This has been illustrated in the introductory chapters. If our aim is to study and describe the form of the dandelion, or if, back of this immediate aim, we think only of training our pupils to see and describe, we shall be satisfied with a mere pulling to pieces of the parts of the plant, and a description or drawing of what is observed. If we want our pupils to make the dandelion a type, or wish to train them to discriminate and compare and classify, we shall have them compare the structure of the dandelion with that of other plants. If we feel that our boys and girls should understand something of the life of the dandelion, should, through its study, be brought into more sympathetic, loving relations with nature, should better appreciate the beauty and symbolism of nature, should, through their dandelion study or nature study, have the higher side of their nature cultivated and developed, then we shall emphasize life and function and adaptation, and select from literature all the beautiful thoughts that we can find. Our aim will determine our method.

Method is simply the determination of aim, and the application of aim to conditions in accordance with the laws of the child mind. . Teachers who so thoroughly appreciate the aims, and particularly the highest aims, of nature study, or of education in general, that these 
aims are ever before them, and who are so in sympathy with children as to be guided in their work by the way in which their pupils see and feel and think and do, will not go far astray in their methods. Without this appreciation of aim and sympathetic study of children, the best methods degenerate into mere devices.

"Why" is the most important question for the pupil as well as for the teacher. The education of the past has been too largely a study of "what." In history and biography we have studied facts and events, revolutions and battles and leaders. In science we have studied form and structure, have emphasized mere identification and classification. We are learning that history is also a study of causes and results, of the working out of great truths or principles, of gradual development or evolution. In science we are beginning to investigate more carefully forces and agencies, to watch processes, to emphasize action and change, life and function and adaptation, of which form and structure are but the results or the expression.

One leading characteristic of the "new education" is the pre-eminence of "why," and the subordination of "what," or the looking beyond and through the "what" to the "why."

What is the aim of nature study? We shall find that it is practically the same as the aim of other studies, or of education in general.

More than is the case with most other studies, probably, science, or nature study, deals with the individual 
child, and aims to develop each child as an indıvidual. It places the material in the hands of each child, and expects him to see and think and tell for himself. Nature is many-sided; and when pupils observe for themselves, each will have a different point of view, will see a different side. The teacher will thereby be helped to realize the difficulty, the impossibility, and, finally, the viciousness, of teaching en masse, of teaching classes rather than individuals, and will recognize, respect, and at length encourage and develop, the individuality and self-reliance of the pupil.

In discussing aims it will be helpful to consider first the aims which have determined the character of much of the work in science, or nature study, in the past.

As men began to realize how dependent they were on the physical world about them, their physical environment, they were impressed with the necessity of becoming acquainted with that environment. The earliest recognized object of science, or nature study, or of study or education of any kind, was knowledge, the acquisition of facts.

As knowledge (using the term in the older and narrower sense), the acquisition of information or facts, was considered the great object of science or education in general, it was natural and inevitable to place great emphasis on the study of books as the storehouses of facts, and on memorizing as the simplest method of acquiring facts. For this reason most of the work in science and in all education was for centuries mere book-work. Even to-day in our schools the study of geography, which has been defined as the study of the 
physical environment of man, is very largely a mere memorizing of matter taken from books.

Our thoughtful teachers have long realized that knowledge thus gained through books alone, or through teachers and not through personal investigation, is exceedingly hazy and illusory. Too often it is not knowledge, but has only a misty semblance to it. Such knowledge "shall vanish away."

To science - that is, physical science - belongs the credit of most clearly demonstrating the haziness of the knowledge thus gained, and the weakness of this method of study. Science has introduced into our educational system the method of personal investigation, the laboratory method, as distinguished from the mere book or lecture method. Gradually the scientific method, or laboratory method, has been adopted in subjects not scientific, such as history and literature.

From this point of view, the introduction of nature study, of personal observation of nature, has been urged as the best preparation and basis for geography. It gives the children a knowledge, a genuine, personal knowledge, of the fundamental facts necessary for an intelligent study of geography.

Even with the laboratory method of ascertaining, making clear, and demonstrating facts, and assimilating the material gained, our teachers are learning that knowledge, accumulation of facts, as an ultimate aim in education, is exceedingly low, narrow, and unsatisfactory. No matter how clear or how well fixed in the mind the knowledge may be, we are learning that 
knowledge of our physical environment, or of anything else, is not necessarily power. We need more than knowledge, or more than this kind of knowledge.

The development of the intellectual powers of the child has become, or is becoming, the ultimate aim of many teachers ; and the acquisition of knowledge, or of facts, has become of secondary importance. We are more and more endeavoring in our schools, from university to kindergarten, to have our students get more than facts; we are striving to develop their intellectual powers, - of seeing or apprehending for themselves, of thinking or combining ideas in their relations, of expressing or conveying these ideas to others, and of doing or making their ideas active or effective.

The same development or evolution of ideals or aims has, consciously or unconsciously, determined the character of the work in nature study, or elementary science, in our schools. At first teachers placed all emphasis on the importance of a knowledge of the facts of the physical world; and the schools have been flooded with Nature Primers and Nature Readers, and Hours with Nature, good, bad, and indifferent, to meet the demand of the school-men and school-women. Too often the study of nature has stopped with the reading of these books. Unfortunately, in many schools we have not yet passed beyond this first stage in the introduction of nature study:

A host of teachers have, however, realized the importance of a higher aim, and are insisting on personal, 
individual investigation, as opposed to mere book-work, as a means of developing the powers of the pupils, training them to see and think and express for themselves.

Science work, or nature study, has given the pupils something to work with, something on which and with which to develop their powers, something definite and tangible which they can see and think about and tell about. Nature study is a content study, and a basis for formal or expressive work.

The results of science work, genuine science work, personal investigation, not mere book-work, - taught as a means of developing power, have demonstrated its great value. In hundreds of schools nature study has won and kept a place as an aid in developing the powers of the children. It has given not merely the clearer vision and more certain knowledge which come to those who walk by sight and not merely by faith, but the power, crystallizing into habit, of careful, exact observation; the corresponding power of clear and truthful expression in language or drawing, which must come when the impression is clear and exact, because based on interest and on actual observation; the habit of asking and seeking the "why" and "how" of the world around them; and, perhaps best of all; the marked improvement in individuality and self-reliance resulting from the consciousness of power.

More and more nature study is being, and has been, introduced into our schools as a basis for the expressive work of the school, - reading, writing, drawing, 
modelling. What the children see they talk about, write about, draw, mould, paint. Experience has demonstrated beyond possibility of doubt or question that when a portion of the time formerly given to the formal work in language, drawing, and other expressive studies has been devoted to nature study as a basis for these expressive studies, the work in these subjects has been greatly improved.

Nature study, considered as a means or method of acquiring a knowledge of our physical environment, and of developing power to control our environment and make it minister to our needs, is not merely an aid in other school-work, but is a preparation for practical life.

Our success in life as individuals depends to a very large extent on our knowledge of and power over our physical environment. Our dependence on physical forces and agencies becomes greater as civilization advances, and man learns to better control nature. The child of to-day must know more about steam and electricity than did the wise man of a century ago.

Our development as a race is very largely due to the fact that we have learned to harness natural forces, and make them do much of our work. With the aid of steam and electricity, the average man to-day can probably accomplish thirty times as much as did the man of a century ago.

The practical importance of a more careful study of science has long been recognized in higher institutions of learning, - in university, college, and high school. 
If science is considered necessary for the few students in these institutions, why is it not necessary for the many who never get beyond the elementary school?

Of inestimable value in life is the power, and the habit which results from the constant exercise of power, of investigating for ourselves, of separating the true from the false, of distinguishing between essentials and non-essentials. Under no other condition is this so important as in a republic. Nothing gives this power to children as does genuine science work, simply because in science work, or nature study, more than in any other work, children can study things with their own eyes, really investigate and distinguish for themselves.

The question now arises, "Is the development of intellectual power the ultimate aim, the highest object, of nature study, or of education in general?"

The mother and the teacher very soon realize that the acquisition of knowledge and the development of power in any study are largely dependent on the interest aroused. With intense interest there is scarcely a limit to what the child can learn and do. Without interest, comparatively little can be accomplished. The more carefully we study children, - and their fathers and mothers, - the more we shall be impressed with the fact that the knowledge acquired and the power developed under any conditions are, in general, directly proportional to the interest aroused.

Nature study is no exception to this rule. The first essential is to gain the interest of the child. His senses 
form the gateway to his world. His senses always respond to interest, the gate always opens; with interest aroused, with senses alert, every power of the child responds, and there is scarcely a limit to what he can do. Nature study will never succeed until the child is interested.

Are the awakening of interest, the development of power, and the acquisition of knowledge, the highest aims?

Of what value is power without something above it or back of it to direct and regulate it? Power may do harm as well as good. The possession of power may be a curse as well as a blessing.

Goethe has said, "Nothing in the world is so terrible as activity without insight."

We may develop the power of observation in our pupils. If they are thereby only better fitted to see the evil and the vile, have we helped them?

We may train them to express their ideas more clearly, exactly, and effectively, and to better convey to others what they have in their minds. Unless at the same time we store their minds with ideas worthy of expression, and give them an impetus toward better, higher, nobler thoughts, their greater power of expression may be a curse to themselves and to others.

We give our boys and girls greater power to calculate and think and reason. If this is to be used to cheat their fellows, to influence others for evil, have they and the world gained or lost?

The more we work with children, and particularly 
with little children, the more we get into sympathy with them and look through their eyes, the more fully we realize that there are higher aims in education than the development of power. When we get into the primary school or kindergarten, such an aim seems incongruous, utterly out of place. We see instinctively, if we love and understand children, that such an aim is beneath them. Why?

As the primary teacher studies with her children, and studies her children, she discovers the necessity. in all their work of interest, and of that highest form of interest, - sympathy. With perfect sympathy between herself and her children she has almost unlimited power over them. With the little folks in thorough sympathy with the bird or cat or plant they are studying, their power to see and think and tell is wonderfully increased.

This sympathy is peculiarly necessary in nature study. Without sympathy with nature, nature study may be even detrimental to the child, and disastrous in its effects on the child's environment.

If we merely aim to interest the children in nature, develop their powers of observation, expression, and thought, and give them a better knowledge of their physical environment, and stop there, the ultimate results may be of doubtful value. Our wild-flowers will be pulled up, our birds destroyed, our shade-trees mutilated ("sacrificed to the cause of science"), in the search for material. Our boys and girls may become, like many of their older brothers and sisters in the 
science classes of higher institutions, mere cold-blooded anatomists and collectors.

No; interest, power, knowledge, are not the highest aims in nature study. Preceding these, along with these, more important than these, must come the cultivation of the sympathies of the child. "Love is the fulfilling of the law" educationally as well as spiritually.

We shall find that we shall develop in the hearts of the children a sympathy with the world of nature in proportion as we lead them to care for or work for nature. We are apt to love best that for which we do the most, not merely, as is often assumed, that from which we receive the most. So keeping in view the cultivation of a sympathy and love of nature, we will give our children and pupils plants and animals to care for. A few seeds planted, watered, and watched over by the little folks, buds gathered and supplied with fresh water, a pet bird or kitten cared for by them, will be most helpful in developing a sympathy with the world of life.

Equally essential for the cultivation of sympathy with and love for nature is an understanding of what we receive from nature, an appreciation of what nature gives to and does for us.

Most closely related to the cultivation of sympathy with nature is the development of the resthetic sense in our pupils, the appreciation of the beauty of their environment.

By beauty we mean, as shown in Chapter I, not 
merely the beauty of form and color and structure, but the far higher beauty of function and adaptation, or fitness for work, and that highest manifestation of beauty shown in the unity of all nature. The old definition of beauty was "multitude in unity."

In nature, as among men, "handsome is that handsome does," and in nature study we have constant opportunities to lead our pupils to realize that everything has a work to do, and to see how well everything is adapted to its work. Whether we are studying plant or animal or stone or water or air, every part has a a work to do, is fitted for its work, is doing its work.

We may study the clouds simply to give the children a larger knowledge of the phenomena of nature. We may use the study of clouds as a means or method of sharpening the intellects or developing the powers of the children. But the cloud study will mean more when we dwell also on their beauty of form and color, bring out the story they tell of co-operation- of water and air and sun and wind, and give our pupils some idea of their place in the plan of nature, or of nature's Author.

We may analyze the dandelion, and learn all about its parts. We may study it in its relations to the past and future, investigate the work of its parts, and all the marvellous adaptations to insure fertilization and the formation of fruit. We may also dwell on its beauty of color and fragrance and function, and read with the children the beautiful poems inspired by the dandelion.

Which will do most for the child?

Wordsworth has said, - 
"For I have learned

To look on nature, not as in the hour

Of thoughtless youth; but hearing oftentimes

The still, sad music of humanity,

Nor harsh nor grating, though of ample power

To chasten and subdue. And I have felt

A presence that disturbs me with the joy

Of elevated thoughts; a sense sublime

Of something far more deeply interfused, Whose dwelling is the light of setting suns, And the round ocean, and the living air, And the blue sky, and in the mind of man :

A motion and a spirit, that impels

All thinking things, all objects of all thought,

And rolls through all things. Therefore am I still

A lover of the meadows and the woods,

And mountains; and of all that we behold

From this green earth; of all the mighty world

Of eye and ear, - both what they half create,

And what perceive; well pleased to recognize

In nature and the language of the sense,

The anchor of my purest thoughts, the nurse,

The guide, the guardian of my heart, and soul

Of all my moral being."

Considering the higher aim of nature study, we see the importance of correlating it with literature and art. Much of the most beautiful in literature and art has been inspired by nature ; and for an appreciation of this, nature study is the best preparation. If we do not give our pupils the beautiful thoughts which others have gained from nature, if we do not read with them the poets and other nature-loving writers, we miss one of our greatest opportunities in nature study.

Along with this appreciation of the beauty of their 
surroundings, will there not come to the children a better understanding and better performance of what they owe to their surroundings? Will they not be more careful of flower and bird and tree? And will not their ethical nature, their appreciation of duty, be thereby developed?

Have we reached yet the highest aim of nature study?

Is that interest complete which does not attract the child toward the Author of nature? Is that knowledge complete which does not see in nature and through nature the Creator? Is that power complete which does not enable the child to see through nature nature's God, to realize that in nature study he is "thinking God's thoughts after Him;" to read better this other book of revelation, to tell better the story of a Protector and Planner which nature tells him? Is that sympathy complete which does not bring our pupils into closer touch, into harmony with Him who has breathed into all things the breath of life? Is that appreciation of beauty, that æesthetic sense, best developed which does not look above beauty of form and color and structure to beauty of adaptation and function; above beauty of function to beauty of co-operation and mutual helpfulness; above beauty of co-operation to the unity of plan; above the plan to the Planner?

Let us review in order the aims which should control in the work in nature study. So far as it is possible to arrange in tabular form aims which are so closely re- 
lated and mutually dependent, which are all really subordinate to the great aim of nature study or education, character-building, we may summarize the aims of nature study, considering the development of the individual child, as : -

First. To awaken an interest and cultivate a sympathy with his physical environment.

Second. To cultivate the higher nature of the child, æsthetic, ethical, and spiritual, and lead him toward God.

Third. To develop his intellectual powers and form right habits.

Fourth. To lead the child to acquire a knowledge of his physical environment.

Considering the child in his relations to school, we may give as secondary or subordinate aims of nature study:-

First. To give the child an understanding and appreciation of nature which will enable him to enjoy and appreciate the literature and art which have been inspired by nature.

Second. To give the child clear impressions which shall serve as one basis for the expressive work of the school, - language, reading, drawing, modelling and arithmetic.

Third. To give the child a clear knowledge of his immediate physical environment which will serve as a basis for his work in geography, his study of his broader environment. 
We must ever keep in mind that all other aims are subordinate to one, the highest. The study of nature misses its highest purpose unless it leads the child from nature up to the Author of nature. Unless the seen points the child to the unseen, unless from care and protection he looks to a Protector, through function and purpose and plan he sees a Planner, nature has not revealed to teacher and pupils its greatest thought, its grandest lesson, - eternal law, eternal unity. 


\section{CHAPTER V.}

THE HIGHEST AIM OF NATURE STUDY: TO ADAPT THE CHILD TO HIS ENVIRONMENT.

In the previous chapter we have considered as the great aim of nature study or education in general the development of the individual child. If we stopped with the individual our outlook would be narrow. It is not until we think of the child in his relations to his environment that we get the broadest and highest views.

Even in discussing the development of the individual child, we have found that those aims are low which relate merely to the individual, and the aims become higher just in proportion as they bring the individual into closer relation with that outside himself. The acquisition of knowledge and development of power are comparatively low aims, because they relate to the individual. The cultivation of the sympathies, and of the æsthetic, ethical, and spiritual nature, is a higher aim, because it tends to bring the child into closer relations with his environment.

Now we want to consider the higher aim of nature study, - to perfect the relations between the child and 
his surroundings, or to adapt the child to his environment.

The environment of the child may be considered as threefold, - his physical environment, or nature; his intellectual environment, or man as an intellectual being; and his spiritual environment, or God. This division may be somewhat artificial, but it is very convenient. That education is incomplete which does not adapt the child to this threefold environment, - nature, man, God.

The question naturally arises, "What is meant by adaptation to environment?" In much of the work of the past we have assumed, or have seemed to assume, that adaptation to environment means learning about our environment, so that we can control it, or make it minister to our material needs or desires.

Too often we have considered almost entirely our material needs, and have looked on nature, man, and God as means for supplying these needs. This has been most apparent, perhaps, in our attitude toward nature. Nature has been considered almost entirely as a storehouse of purely material riches. Our natural resources have been material resources. Forests have been lumber and little more except to the few, "the children, women, and poets" as some one has grouped those who see in forests more than lumber. The birds have been the farmer's bane or the farmer's friends according to the state of knowledge, but not often, except to the group before named, the sweetest singers ever beard, sources of joy and inspiration. The flowers 
- most high-school teachers of botany have recollections of interviews with parents who did not want their children to waste their time studying such things.' They wanted their boys to learn something practical.

But nature can do much more than minister to our material wants. If we will but let her, she ministers to far higher needs. To the eye that sees she comes full of beauty, a solace and inspiration, a messenger from above. The sunset and clouds, the frost and snowflakes, the leaves and flowers, the hills and valleys, the birds and bees, appeal to that in man which is higher than the mere material. Not until we gain from nature these higher riches, not until we can appreciate her beauty and the story she tells, can we realize what nature can give us. These higher gifts of nature we can appropriate without much regard to deeds or titles. No one needs a title to make his own the riches of the sunset or the beauty of the landscape. The amount of this higher wealth which we can call our own is only limited by our capacity for receiving or appropriating.

I do not own an inch of land, But all $I$ see is mine; The orchards and the mowing-fields,

The lawns and gardens fine.

The winds my tax-collectors are,

They bring me tithes divine, Wild scents and subtle essences,

A tribute rare and free; And, more magnificent than all,

My window keeps for me

A glimpse of blue immensity,

A little strip of sea.

Lucy Larcom. 


\section{MY TENANTS.}

I never had a title-deed

To my estate. But little heed

Eyes give to me, when I walk by

My fields, to see who occupy.

Some clumsy men who lease and hire

And cut my trees to feed their fire,

Own all the land that I possess,

And tax my tenants to distress. :

And if I said I had been first, And, reaping, left for them the worst, That they were beggars at the hands

Of dwellers on my royal lands, With idle laugh of passing scorn As unto words of madness born, They would reply.

I do not care ;

They cannot crowd the charmèd air ; They cannot touch the bonds I hold On all that they have bought and sold.

They can waylay my faithful bees, Who, lulled to sleep, with fatal ease, Are robbed. Is one day's honey sweet Thus snatched? All summer round my feet In golden drifts from plumy wings, In shining drops on fragrant things, Free gift, it came to me. My corn, With burnished banners, morn by morn,

Comes out to meet and honor me; The glittering ranks spread royally Far as I walk. When hasty greed Tramples it down for food and seed, I, with a certain veiled delight, Hear half the crop is lost by blight.

Letter of law these may fulfil, Plant where they like, slay what they will, Count up their gains and make them great, Nevertheless, the whole estate 
Always belongs to me and mine.

We are the only royal line.

And though I have no title-deed,

My tenants pay me loyal heed

When our sweet fields I wander by

To see what strangers occupy.

Helen Hunt Jackson.

In our study of nature with the children, in aiming to adapt the children to their environment, we can scarcely emphasize too strongly this most important step in adaptation, the training of our children to appreciate and appropriate the higher riches all about them. Not until they appreciate, not only the utility or practical value, but the beauty and symbolism, of their environment, are they fitted or prepared for real adaptation to environment.

This training to appreciate and appropriate all that we receive or may receive is only partial, one-sided adaptation. Not until we realize that adaptation implies something more than appropriation, will complete adaptation be possible.

Man has lived beyond the time when he centred the universe about this little world. But he still, to a considerable extent, regards his environment as a mere adjunct and servant to his little self. We have adapted ourselves to our physical environment by stripping our land of its forests, our air of its birds, our waters of their fish, by using up in the most reckless manner our natural resources. Nature has been our slave, from whom we could take anything, to whom we owed nothing. We have often adapted ourselves to our intel- 
lectual environment by getting from our neighbor all we could, and giving him in return as little as possible. Our adaptation to our spiritual environment has been equally one-sided and selfish. Too often we have taken all, and given the least possible service in return.

We are learning that such adaptation is in the end unprofitable, unwise, utterly wrong. The farmer soon learns that he must give to his fields if he would get the most from them. We are discovering as a nation that we must protect our forests, and are just beginning to plant where we formerly used our energies in destroying our trees.

The growing recognition of the brotherhood of man, of the fact that we are to an extent our brother's keeper, is an appreciation of the same principle. We are realizing better than ever before that our fellows are not merely instruments, tools to be used for our own development or advancement, from whom we are to take all that we can get. We owe something to them. Men are slowly learning to appreciate that what they get from their fellow-men depends very largely on what they give to them.

We like to think that the same idea is modifying our understanding of our spiritual relations; that a larger proportion of mankind is realizing that the church, or religion, is not a plan for getting as much as possible from our spiritual environment, and giving as little as possible in return. Do not a greater number than ever before regard the church as an opportunity for larger service? We think so. 
Adaptation to environment means more than making our environment minister to our needs, getting from it all we possibly can, and giving the least possible return. We owe something to our environment, whether nature, man, or God; and adaptation is incomplete until we learn to recognize and perform what we owe.

We have considered as successive aims in nature study the acquisition of knowledge, or facts, the development of intellectual power, the awakening of interest, the cultivation of sympathy, the development of the higher nature, æsthetic, ethical, spiritual. We shall find that in the ultimate analysis these are all subordinate to the highest aim, - adaptation to environment. They all prepare for more complete adaptation to environment, to nature, man, and God.

The question now arises, How, through or by means of nature study, can the child be better adapted to his threefold environment?

The child is first brought into relation with the physical world. His early wants are physical. He gains everything through his senses, and they tell him only of his physical surroundings. Of his intellectual and spiritual environment he knows almost nothing at first. What he gains later comes directly or indirectly through the medium of his senses. In his earliest education we must use matter and methods which appeal most strongly to his senses. These we find in nature study.

The first step in adapting the child to his environ- 
ment is to lead him to appreciate what he receives from nature, and what he owes to nature.

To do this we must first open his eyes to the beauties of the world about him, - the beauty not merely of form and color, but the higher beauty of use or work or function, and adaptation to work. It is not enough to merely talk or read to him about the world of sense. We must help him to see how much of beauty there is in the most common things; how much they have to do, and how well they are fitted for their work. The most common plants, - the bean and pea and dandelion, the plantain and burdock and thistle, - the trees and buds and leaves, the birds and insects and fishes, the stones at our feet, are full of beauty and grace if we will but look for them. When the child has watched the bean and pea grow from seed to fruit, and noted how each part has a work, and how well it does its work; when he has seen the buds emerge from their protecting scales, throw out leaf and flower, and go to work; when he has discovered how the dandelion feeds and protects and ripens her seeds, and finally scatters them to the four winds of heaven; when he has listened to the song of the robin or bluebird, and peered into her nest as she has fed her little ones, - he appreciates, as he cannot be led to appreciate in any other way, the beauties of his natural environment.

As the child understands better the beauty of his surroundings, the beauty of being, and the higher beauty of doing; as he discovers how much he gets from nature, he realizes better that he owes something to the 
world about him. He protects where he once destroyed. He takes care of the flowers which before he trod upon. The birds are his friends. He is learning to love them as he understands how much they give him. He is adapting himself to his physical environment; not merely appropriating, but giving in return.

We have already referred, in Chapter IV, to the importance and necessity of leading the children to express their appreciation by action. As they take care of plant and animal they will appreciate and realize what they receive from and owe to them.

Every mother and teacher who has studied nature with her children from this standpoint, knows how marked, in this respect, is the effect on the minds of the children, on their attitude toward nature; how quickly they respond, how soon they are brought into touch or sympathy with nature. If our work in nature study in the elementary schools does no more than strengthen or fix this attitude toward nature, it does much. If it does less than this, it does little.

How can nature study help the child to appreciate what he receives from and owes to his intellectual environment, man?

As this right attitude toward. one part of his surroundings is fixed, as his sympathy with nature is broadened and deepened, it cannot but affect the attitude of the child toward the rest of his environment. He cannot learn to appreciate nature, and what he owes to nature, without being in a mental condition better to appreciate all of his surroundings. 
Furthermore, nature, rightly studied, is, to the child at least, a symbol of his higher surroundings. As he sees how much Mother Nature does for her children, how carefully she protects and feeds seed and bud, leaf and flower, how she looks after, plans for, and controls plant and animal and mineral, Mother Nature helps him to better understand how much his mother and friends have done for him.

As the child studies nature, he learns to appreciate better what has been the source and inspiration of much of the most beautiful in literature and art. Nature study opens his eyes to much of the most beautiful part of his intellectual environment. One who, like the writer, has begun his right sympathetic study of nature in his adult years, when he could understand the effect upon himself, can realize that an appreciation of nature opens a new world in literature. Much in Bryant, Wordsworth, Longfellow, Tennyson, Lowell, Whittier, Helen Hunt Jackson, Lucy Larcom, Burroughs, Thoreau, and a host of other writers, which before meant little, has become full of beauty, because he has some appreciation of the world of nature which inspired these writers, and has read something of the story which nature told them.

Not less is the child helped to appreciate many of the beauties of art. He who never studies the landscape about him or the clouds above him, who scarcely looks at the sunset or notices the trees or flowers or birds, is utterly incapable of really appreciating the pictures which these have inspired. 
Even more helpful is the right study of nature in leading the child to realize and perform what he owes to man, - his intellectual environment. He discovers that everything about him is doing, helping as well as being helped. The leaves, at first so carefully protected by scales and gum and fur, push out and go to work to help root and stem and flower, and soon begin to protect other buds and leaves. The flower, at first ministered to by every other part of the plant, learns as it unfolds that it has a work, a wonderful work, to do. From it new plants must come. The water is constantly helped and being helped. In the sky, in the stream, down under the ground, in plant and animal, it is always at work. Nature is a great mutual cooperation society, whose motto is, "Help and be helped." Is the child the only exception? or will he learn from nature the lesson that he not only receives much, but that he owes. much?

These lessons come with most force direct from Mother Nature herself. She is the best preacher. The lessons thus absorbed, imbibed by the children often unconsciously, make a far deeper impression than the "Thou shalt" and "Thou shalt not."

As the child is thus learning to appreciate nature and man better, will he not be lifted toward the Author of nature? Will not the protection and care which he sees in plant and animal lead his mind to a Protector? As he discovers in everything about him purpose and plan, will not his thoughts be lifted toward the Planner? Will not his better appreciation of the 
beauty and function and unity of his physical environment, and his better understanding of his human environment, help him to appreciate better what comes from the Author of all, - his spiritual environment?

And will the effect stop there? Can it? As the child sees the wisdom and power of the Creator shown in his works, as he begins to appreciate the beauty and unity in all nature, as he realizes something of the infinite care with which leaf and flower and seed are planned and protected, will he not be drawn toward the Protector and Planner? Will he not better appreciate and better perform what he owes to the God and Father of all?

Others have expressed so effectively this higher value or æsthetic content of nature study that it seems appropriate in concluding this discussion to quote from two of our poets.

GRACE AND HER FRIENDS.

Your walk is lonely, blue-eyed Grace,

Down the long forest-road to school, Where shadows troop, at dismal pace,

From sullen chasm to sunless pool. Are you not often, little maid, Beneath the sighing trees afraid?

"Afraid, - beneath the tall, strong trees, That bend their arms to shelter me, And whisper down, with dew and breeze,

Sweet sounds that float on lovingly, Till every gorge and chasm seems

Thrilled through and through with fairy dreams? 
"Fast to the slippery precipice

I see the nodding harebell cling:

In that blue eye no fear there is;

Its hold is firm, the frail, free thing !

The harebell's Guardian cares for me :

So I am in safe company.

"The woodbine clambers up the cliff, And seems to murmur, 'Little Grace, The sunshine were less welcome if

It brought not every day your face.'

Red leaves slip down from maples high, And touch my cheek as they flit by.

"I feel at home with everything

That has its dwelling in the wood;

With flowers that laugh, and birds that sing;

Companions beautiful and good, Brothers and sisters everywhere; And over all, our Father's care.

" In rose-time or in berry-time, When ripe seeds fall or buds peep out, While green the turf or white the rime,

There's something to be glad about: It makes my heart bound just to pass The sunbeams dancing on the grass.

"And when the bare rocks shut me in Where not a blade of grass will grow, My happy fancies soon begin

To warble music, rich and low, And paint what eyes could never see: My thoughts are company for me.

"What does it mean to be alone?

And how is any one afraid, Who feels the dear God on His throne, Sending His sunshine through the shade, 
Warming the damp sod into bloom, And smiling off the thicket's gloom ?

"At morning, down the wood-path cool The fluttering leaves make cheerful talk; After the stifled day at school, I hear, along my homeward walk, The airy wisdom of the wood, Far easiest to be understood.

"I whisper to the winds; I kiss

The rough old oak, and clasp his bark;

No farewell of the thrush I miss;

I lift the soft veil of the dark, And say to bird and breeze and tree, 'Good-night! Good friends you are to me !'"

O for boyhood's time of June, Crowding years in one brief moon, When all things I heard or saw, $\mathrm{Me}$, their master, waited for.

I was rich in flowers and trees; Humming birds and honey bees; For my sport the squirrel played, Plied the snouted mole his spade; For my taste the blackberry cone Purpled over hedge and stone.

Laughed the brook for my delight Through the day and through the night, Whispering at the garden wall, Talked with me from fall to fall. Mine the sand-rimmed pickerel pond, Mine the walnut slopes beyond, Mine on bending orchard trees Apples of Hesperides! Still, as my horizon grew, Larger grew my riches too. 
A lover's claim is mine on all

I see, to have and hold,

The rose light of perpetual hills,

And sunsets never cold.

Aloft on sky and mountain wall

Are God's great pictures hung.

Beauty seen is never lost,

God's colors all are fast.

The glory of this sunset heaven

Into my soul has passed.

WHITTIER. 


\section{CHAPTER VI.}

THE LIMITATIONS OF NATURE STUDY.

The Two Centres of Education: Nature and Man.

IN the two preceding chapters the aim of nature study has been discussed, and its educational value brought out. So strongly have these been emphasized, it may seem that the writer considers nature study allsufficient as a means of education; that, as has been said by another, "Nature studies contain in themselves the possibilities of a complete education, not excepting the fruits which have hitherto been ascribed to the humanities alone."

The educational 'value of nature study has been emphasized to bring into near and broad perspective a study which has been in the past very near the vanishing-point. In the great majority of schools to-day, nature study, the study of our immediate physical environment, is utterly ignored. There seems little danger for years to come that it will be made too prominent.

In the tendency seen in so many directions in our elementary schools to turn from "man study" (language, history, political geography) to nature study, there is a possibility, however, of going too far. The 
pendulum once started is apt to swing to the opposite extreme. Something of this has been seen in science work in higher institutions. From the old classical extreme, when a liberal education did not include any physical science, but was all language, mathematics, and history, the pendulum swung to the opposite extreme. Often a purely scientific education, without any attention to the humanities, has been regarded as the best. Today many of our universities and colleges recognize that a broad, liberal education requires a due proportion of science and the humanities. The conviction is growing that an education purely scientific may be even more narrow than one purely classical.

Nature study is not all-sufficient. It has its limitations. Nature study, or science, does not contain within itself the possibility of a complete or well-rounded elementary education. Harm may be done to the cause of education, and the progress of nature study may be retarded, by emphasizing it too strongly at the expense of other studies equally important.

As has already been said, the child's environment may be considered as threefold, - nature, man, and God. With his spiritual environment, God, he is brought into relation, at least in his formal education, only through his relations to nature and man. If it is true, as has been asserted in the preceding chapter, that the highest aim of education is to perfect the relation between the child and his environment, then the immediate object of formal education is to bring the child into right 
relations with nature and man. Behind, beyond, above this is the perfecting of the relations between the child and God.

We may group all formal education about the two centres, - nature and man. The child must study and be brought into better relations with both nature and man; if he is not, his adaptation to his environment is to that extent incomplete or imperfect.

If all his education consists in the study of man, his language, literature, history, geography, and methods of calculating and reasoning, - the education is narrow. It does not fit the child to understand, appreciate, or properly make use of or control, the physical world in which he lives. He is adapted to but part of his environment, and to that extent is only partly educated.

If the education of the child is limited to the study of his physical environment, nature study, or science, and the work growing out of this study, his preparation for life may be even more defective. If he has not studied man, his history, his literature and art, - that is, the use man has made of his physical surroundings, the beauty man has "half created, half perceived," in and from his environment, - if he knows nothing of man's conquest of nature, of man's social and political relations, and has learned nothing from the past experiences of man, then he cannot be adapted to his human environment, and is not well equipped for life with his fellow-men.

In so far as man neglects the sympathetic, reverent study of nature, his understanding of its Author will 
be defective or erroneous. In so far as he is ignorant of physical laws, he will fail to understand many spiritual laws of which physical laws are counterparts or downward extensions. In so far as he is unfamiliar with the phenomena of the physical world, he is unable to fully appreciate spiritual truths, or, at least, to convey spiritual truths in the most effective manner to those whose world is largely a physical world. The Great Teacher almost invariably used the simplest physical phenomena about him, those with which his hearers and all mankind were most familiar, - the sparrow, the lilies, the grain of corn, the mustard seed, — as the means or medium for conveying the highest spiritual truths. The teachers of to-day, whether in home or school or pulpit, and particularly those working with the little folks, who live so largely in a world of sense, can do no better than follow his example.

On the other hand, the study of nature alone, no matter how sympathetically and reverently pursued, does not give the child an adequate knowledge of his spiritual environment, does not fit him to appreciate all that he receives from God, nor to appreciate and perform all that he owes to God. In history he sees even higher manifestations of protection and care, of purpose and plan and a Planner, than in nature. Some comprehension of God's dealings with, and God's relations to, man are essential, and cannot be gained from nature study. It must come from and through "man study." Without this the child cannot be best adapted or related to his spiritual environment. 
A complete education, then, even in the elementary school, must provide for the study of these two parts of the child's environment. The work of the school must be grouped about the two centres, nature and man.

How can or should this be done? It is much easier to gather school-work about one centre, man, as has been largely done in the past. Are these two centres equally important, should they be made equally prominent, throughout the school-life of the child? A little study of the child and his relations to nature and man will help in answering these questions.

With nature, his physical environment, the child is brought into relation very largely through his senses. Nature (as we use the term) is primarily a world of sense. The child sees it, feels it, hears, tastes, smells it. The plants, animals, minerals, the flowers, birds, and insects, the rocks and soil, the water and clouds, appeal to the eye and ear. He begins to see and hear and feel them as soon as he is born. His earliest education in babyhood consists almost entirely in becoming familiar with nature, this world of sense, through his senses.

Nature thus indicates unmistakably that the earliest education of the child should be very largely centred about and based upon that which appeals to his senses. Building on what he sees, and therefore knows, he can not only develop his power of seeing, but can exercise the imagination with which he is so richly endowed. He gives to bird and flower every human attribute, and 
makes the brook and valley he has studied a startingpoint for wanderings by the great streams, and through the valleys of other lands.

Even in the earliest school-years not all his work, however, should be a study of nature. He must begin his study of man. But that must be largely limited to a study of man's relation to nature. From the study of what he can see, and therefore can understand, in his home and the home relations, he can pass to the homes of other children, - of Agoonack, the child of the north; of Gemila, the child of the desert.

Man, as an intellectual being, does not appeal to the little child. His early relations with mother are purely physical. He has little or nothing at first to give him any idea of man as a mind, or the possessor of an intellect; nothing to relate him to his intellectual environment. As he grows older, he begins to understand something of the mind of man, but through the medium of his sense perceptions. Not until several years after birth does he show much intellectual power. Not until then is he well fitted for the formal study of his intellectual environment. As his intellect develops, he is more closely related to the intellectual world about him; his intellectual environment becomes more important, and its study can and should be made more prominent.

If this is true, then the two centres of education are not equally important at all times, and should not be made equally prominent throughout the school course. In the earlier years of the school-life, nature should be 
made more prominent; in the later years, man becomes more important, and should be given more prominence.

Theoretically, perhaps, it may be difficult to tell just when the child's intellect is so well developed that he can pursue to the best advantage such studies as history and literature. As a practical question, however, these must be taken up not later than the fourth to the sixth year of school-life, or in the case of the average American child they will never be studied. Probably ninety per cent of our school-children never get beyond the eighth or ninth grade. Forty or fifty per cent end their school-life at the close of the fifth or sixth schoolyear.

The recognition of these two centres of education must largely determine the character of the work in nature study throughout the school course. At first the children must study nature just as they see it, putting all emphasis on personal observation, and on inference based on personal observation. Later, nature should be studied in its relation to man, - the discoveries man has made; the way in which he has grouped natural objects and phenomena, leading to systematic science; the use man has made and is making of nature, bringing out the practical side, mining, manufacturing, commerce, and correlating the work with geography and history; the thoughts which nature has inspired in other minds, leading to literature and art.

The work in the distinctively "man studies," such as history and literature, is similarly influenced by the recognition of these two centres. The earlier work in 
literature must be that relating to nature, or to man in his relations to nature. This the children can comprehend and appreciate. The earlier work in history will be a study of man's relation to nature, how he lives, and how much nature has helped man. For the social relations, except those grouped about the home, the little child is not ready. He knows nothing about them. $\mathrm{He}$ cannot understand the history of the intellectual and social struggles and development of mankind. That must come later.

The grouping of the child's school education about these two centres should be, and is to a considerable extent, recognized in all school-work. The expressive work of the school - reading, writing, drawing, moulding - must, in the earlier years, be largely based on what the child can see, and largely grouped about nature as a centre. Later he is better fitted to understand, talk, and read and write about his intellectual environment, man.

Geography must be at first physical geography, the study of the earth itself, beginning with the immediate physical environment of the child. Later he is prepared for political and commercial geography, the earth in its relations to man.

The first limitation of nature study depends on the fact that it includes an adequate study of but one part of our environment, - nature. Through nature study alone the child cannot be most closely related or best adapted to all his environment. Hence it cannot be made a basis for a complete, well-rounded education. 
The second limitation of the educational value of nature study, or science, depends on the fact that it does not provide for any adequate study of the experiences and examples of the past, and does not impress those lessons and truths which can be most readily and effectively gained from the study of human experiences and human examples.

The third limitation of nature study depends on the fact that while it may be, with history and literature, a basis for other studies of the school, — reading, writing, drawing, geography, and, to some extent, arithmetic, - it does not necessarily provide for adequate formal work in these studies. It is a content study. It gives matter or ideas. Through the other formal studies these ideas must be related and expressed. In nature study or literature or history, the essential thing is the idea; in the formal studies, the important thing is the form, means, or method of expressing or relating the ideas.

When the child has studied the robin, and is writing about it, the ideas he expresses are gained from nature study; but he must know something of language, of spelling and capitals and punctuation, to express these ideas properly.

It may be possible to make the formal studies such as language, drawing, and arithmetic - entirely incidental to the content studies, - science, literature, and history. In every lesson in nature study the child should be studying, often unconsciously, language.

Most lessons in history and literature may be made 
lessons in geography. The experienced, well-equipped, far-seeing teacher may possibly entirely dispense with definite, formal lessons in language, - spelling, capitals, punctuation, grammar, - drawing, geography, and arithmetic, and teach them as incidental to nature study, history, and literature.

But the average teacher cannot do it to advantagé. The inexperienced teacher is almost certain to fail in the attempt. In not a few schools the attempt has been made to teach all language work incidentally. The result has almost invariably been detrimental to the language work. In some schools arithmetic has thus been taught incidentally as an adjunct to nature study. Very rarely have the results been satisfactory.

In the average school, with average teachers, under average conditions, there must be more or less formal work in the formal or expressive studies, work supplementary to or independent of the work in these lines based on the content studies. The amount of this formal work which may be necessary depends on the wisdom, tact, experience, and breadth of the individual teacher.

The limitations of nature study depend, in the ultimate analysis, on the fact that it does not include any adequate study of one division of the child's environment, man; that it does not give the child the benefit of the experiences of the past; and that it does not, under average conditions, provide for adequate work in the formal studies of the school, particularly language, drawing, and arithmetic. 


\section{CHAPTER VII.}

PRINCIPLES DETERMINING METHOD IN NATURE STUDY.

THE discussion of almost any subject involves the consideration of three questions, _ "What?" "Why?" "How?" We have answered two of these questions.

The consideration of method involves three topics, the study of material, the selection of material, and the arrangement of material and formulation of a course in nature study. The term "method" is frequently restricted to the first of these, the method in studying material. This may be discussed under three main heads: First, the presentation of matter to the children; second, the expression by the children of what they have learned, involving a consideration of the methods of relating nature study to the expressive work of the school, - language, drawing, moulding, painting, music; third, the method of relating nature study to other schoolwork, particularly literature, geography, and arithmetic.

In this and the next chapters we propose to consider the principles which must largely determine all method; in the two chapters following these we can study the application of these principles in the presentation of matter to the children, taking up in later chapters the other phases of method. 
While our method must be determined by our appreciation of aim and understanding of children, it wili be modified by other elements. It seems wise, therefore, in discussing method, to consider in order:-

First. The aims of nature study or of education in general, discussed in Chapters IV and V.

Second. Those characteristics or laws of child nature and child development most important, or having the greatest influence, in determining method.

Third. The other conditions which may modify method. These affect more particularly the selection and arrangement of material. They are considered in Chapter XIV.

The ultimate aim, as discussed and formulated in Chapter V, is: To adapt the child to his threefold environment, - physical, intellectual, spiritual, _ or, stated more definitely, to train the child to appreciate what he receives from, and to recognize and perform what he owes to, nature, man, and God.

Considering the individual child, the following subordinate aims were formulated in Chapter IV, all included in the final aim, already stated :-

First. To awaken the interest and cultivate the sympathy of the child.

Second. To develop his higher nature, æsthetic, ethical, and spiritual, and lead toward God.

Third. To develop the intellectual powers of the child, and form right habits.

Fourth. To gain a knowledge of his environment. 
Subordinate to the general aims enumerated are others relating to the material. Each series of lessons and each lesson in nature study has as its.immediate aim the presentation of certain matter, and the developing of certain ideas and relations. The teacher is planning to study with her pupils the robin. The immediate aim may be to discover all they can about the robin. Back of that may be the emphasizing and clinching of those points of structure which will help the children to compare the robin with other birds. Back of this is the putting of the robin in its proper group or order of birds, relating this group to other orders of birds, comparing birds with other backboned animals, and finally finding their place in the animal kingdom. Above all these aims is the development of the powers of the child, - the powers of discrimination, judgment, and classification, and of reducing to unity. Highest of all is the training of the child to use these powers for the good of himself and of the universe of which he is a part. Each lesson should have an immediate aim or point, subordinate and well related to the aim of the series of lessons, and all planned and conducted with reference to the ultimate aim.

The relation of aim to method and of subordinate aims to general aim has been illustrated in the lessons on the rabbit, Chapter II.

The method of each individual teacher in presenting material to her pupils, or in selecting and arranging or relating topics for study, will be mainly determined by her power or habit of looking from and through imme- 
diate aims to the higher ultimate aim. If she can see little farther than the examination, she will find little place for nature study, and have little use for method. Her method will be a process of "cramming." If she thinks mainly or only of developing the intellectual powers of her pupils, - that is, the powers of observation, expression, and thought, - she will understand the uselessness of "cramming." She will insist on individual work, individual seeing and thinking and telling, but will neglect the highest aspects or content of nature study. Her method will be rigidly scientific. If she thinks only of preparing her pupils for practical life, of fitting them to earn their bread and butter, she will dwell on the economic relations of what she studies with her boys and girls. If she keeps ever before her the ultimate aim, the fitting and training of the children for the best possible relations with all their environment, nature, man, and God, she will find time and place in her plan of work for that which will appeal to and develop the higher nature of her pupils, as well as for that through which they may gain useful knowledge and develop power.

It is important that the pupil, as well as the teacher, have a definite aim. His aim may be immediate and narrow, while the teacher sees the higher aims; but, in general, the pupil will do definite work in proportion as he realizes a definite aim. The pupil who does not know the aim, is like the child who is taken out for a walk without any objective point. Both wander about aimlessly. The pupil who, at the beginning of the 
lesson, is impressed with the aim of the work in hand, who knows exactly what he is looking for or trying to do, like the child who knows he is going to grandma's or to the toy-store, is much more apt to go directly toward his destination. When they are asked to study the buttercup, most children will do very little. When they understand that each pupil is to see how much he can discover about the parts of the buttercup flower, what each part does, how it does it, how it is fitted for its work, each is much more apt to observe and think for himself.

The aim must be stated in such a form, however, as not to tell the pupils what they should discover for themselves. When the children are told, "To-day we are going outdoors to discover how and from what dirt or soil, is made," they are given something definite to do, and are apt to do and think much more than if they are told, "To-day we will find that rocks break down into soil or dirt, and that leaves decay to form soil." In the second case they do not go out to investigate for themselves, but simply to verify what the teacher has told them.

Now comes the question, What characteristics of the child mind are most marked or what laws of child development have the most weight in determining method?

In genuine nature study the child is studying under the most natural conditions. He is gaining knowledge for himself through his senses, the natural method. 
In no school-work do teachers have better opportunities for studying children. Experience has shown that nature study, more than any other work in the elementary school, leads the teacher to study her children and adapt her methods to them. In nature study, genuine nature study, teacher and pupils are working together, fellow-investigators of truth.

In such child study we discover certain characteristics or laws in the development of children (and almost equally marked in the adult) which determine method and require special consideration. These are :-

First. Sense-perception, as determining the medium through which, and the method by which, the child must originally gain his ideas or impressions or percepts.

Second. Apperception, as determining the means or method by which new ideas must be assimilated and incorporated with the old ideas, forming concepts or general notions.

Third. Interest, as determining the condition for and the method of gaining the most effective sense-perceptions, and of relating these percepts in apperception.

Fourth. Imagination, the power and process of forming mind pictures or mental images of what is seen or perceived (visualization), of recalling or reproducing these mind pictures (memory or reproductive imagination), and of modifying and combining the mental images of what has been perceived so as to picture what has not been perceived (constructive imagination).

Fifth. Sequence, the relating of ideas in a sieries, as 
determining, or rather expressing, the order in which the mind most readily receives and retains ideas or impressions.

Sixth. Unity, combining or merging diverse ideas into one, the condition to which the mind strives to reduce all ideas, and with which alone the mind is satisfied.

Seventh. Expression, as determining the means by which the child can convey his ideas to others, and at the same time fix or impress these ideas in his own mind, and gain power to get ideas from others.

By what we may call the law of sense-perception, we mean that the child must originally gain his ideas through his senses. All entirely new matter must come through his senses.

When we attempt to give the child new ideas through the artificial symbols which we call words, we often violate this law, and fail in our work. This law is of the greatest importance and widest application in science, or nature study. True science, or nature study, probably more than any other other line of work, must be founded and built upon sense-perception.

This is most essential in work in primary grades, and in any grade when beginning nature study. In later study, much can be founded or built upon the senseperceptions and the mental pictures gained in earlier work.

Just here special care is necessary. Unless teachers take every precaution, make sure that pupils see with their own eyes, instead of merely listening or absorbing, 
all later work will be weak, because built on weak foundations.

The education of the past has been almost entirely an education of listening and absorbing, and appropriating, not of seeing and getting for ourselves. Teachers have learned to depend on books. In the writer's experience with teachers, one of the most common questions has been, "Where can I find a book which will tell me all about it?" Teachers have given to their pupils, instead of leading the pupils to get for themselves. In nature study the first great struggle of teachers will be at this point, - to overcome the habits so firmly fixed; to allow the younger pupils, and encourage and compel the older pupils, to use and depend on their own senses, to really base their work on sense-perception.

The necessity of basing all nature study on senseperception, of laying the foundations in actual seeing and observation by each pupil, must greatly influence method; it must largely determine the selection of material and the order of study. Other things being equal, we must select for study that which can be best perceived or seen, and begin our study of anything with that which appeals most to the senses. This has been illustrated in Chapter II.

It must be remembered, also (as was brought out in Chapter III), that knowledge must be based not merely on sense-perception, but on "clear and certain perception." Too much emphasis cannot be placed on careful, exact observation, so far as the children are capable of exact work. 
The law of apperception is an expression for the fact that the mind receives and retains those ideas which are or can be related to what is already in the mind, and, further, that it changes what it thus retains, connects it with, and makes it like, what the mind had before.

What any one sees depends on what he has already seen, what is already in his mind. Looking at the leaves on a tree, the artist may see the shades of color and play of light and shade, and little more; the botanist may see the resemblance to leaves of related plants, or perhaps their special adaptation to their work or function; the child may see only the movements of the leaves in the wind, or their bright colors, or the wreath he once made from them. All may look at the same leaves, and yet each sees something different. Each sees with and through that which he has already seen.

In this respect the mind is much like the body. No matter how much or what kind of food is placed before or taken into the body, the body only retains that food which it can assimilate; that is, relate to and make like what is already a part of the body. Apperception is thus the mental equivalent of physiological assimilation.

In the ultimate analysis the laws that we have enumerated depend, very largely at least, on apperception. We have seen that sense-perception depends on apperception. Interest is based on apperception. The child is interested in that which appeals to him; that is, in that which can be related to something already in himself. This is the reason why children are so much 
more interested in life and action than in mere form and structure, and why young children are so much interested in nature's babies. Imagination can only use the material or ideas gained by perception, and modified and related by apperception. The law of sequence results from apperception. By sequence we mean bringing matter to the child step by step in such an order that each new idea may be most clearly apperceived, that is, seized by and correlated with the mass of ideas which the previous steps have either given to the mind or brought into consciousness. The law of unity is simply an expression for the tendency which the mind has to relate everything which it perceives. The more closely the relations are established in all directions, the more perfect is the resulting unity. We shall find later, in our discussion of expression, that methods of expression must be determined largely by reference to the same principle of apperception.

The law of apperception must, then, very largely determine methods in nature study. To get the best results, we must not merely bring the matter before the children where each child can see it, - that is, base our work on sense-perception, — but we must call up, bring into consciousness, by our questioning, or by encouraging the children to talk freely, what is already in their minds relating to the material; find out what the children already know, and take hold of and emphasize those ideas which will make the best foundation for the new matter we want to present. This is most essential when working with young pupils. The little 
folks see so much more in germinating seed or developing bud, when they have connected the plant babies with the babies in their homes, - the way in which their baby brothers are cared for and fed and grow.

In any work which requires the pupils to think rather than to merely see, our success as teachers will largely depend on our power and habit of calling up the apperceiving ideas or concepts of the children, and building on these. As illustrated in the study of the rabbit in Chapter II, pupils understand much better the movements and limbs and feeding and teeth of the rabbit when they are related to their own body and way of moving and eating.

We see the wisdom, considering this same principle of apperception, of reviewing at the beginning of each lesson those parts of previous lessons on which the new lesson must be built or based, of being sure of our foundations before beginning new work.

The law of interest, - that the mind most clearly receives or perceives, is most deeply impressed by and most strongly retains or apperceives, those ideas which excite or are accompanied by interest, - has been strongly emphasized in the discussion of aim. In general, the surest evidence of interest is attention. Until the teacher has attention she can accomplish comparatively little.

No matter how careful the teacher is to bring the material before the child, to make sure that he sees, and to build on the foundations already laid, on the 
apperceiving concepts in the child's mind, the ideas gained or the impressions made will not be most clear and strong unless the child is interested.

On the other hand, the more the work in nature study is based on sense-perception, on what appeals to the senses, and the more the new is built upon and related to the old, is based on apperception, the more, in general, will the child be interested. Interest, particularly sustained or habitual interest, is one of the surest evidences that work is being presented in accordance with psychological laws. Absence of interest shows, in general, that something is wrong; matter or method is not adapted to the children.

Just as apperception is the mental equivalent of physiological assimilation, so interest may be considered as the counterpart of appetite. With adults appetite and interest are oftentimes not considered essential. The body and mind of children will not get proper nourishment without appetite or interest.

With interest aroused and senses alert there is scarcely a limit to what the child can do. In no other work is interest more essential than in nature study. In no other study will the teacher be so apt to be impressed with the educational value of interest as when she and her children are studying nature together under natural conditions, and following natural methods. In much other school-work the conditions and methods are unnatural, and the importance of interest is not recognized or realized.

Sympathy is but a higher active form of interest. 
The more we can bring our pupils into sympathy with the dandelion and rabbit, with the world of life about them, the better the results. Sympathetic interest, as distinguished from mere intellectual curiosity, is a great aid in nature study.

As pupils grow older, we can depend more and more on what may be called secondary or indirect interests, the ambition to succeed or to prepare for life, the desire to please parents and others, the fear of the disgrace which failure may bring. This indirect interest is not so helpful nor important at any stage in education as immediate, direct interest.

A most practical question is, How can the children be interested, and how can they be kept interested?

As has been said, the first essential in gaining and maintaining interest is to present matter which the children can understand, for which they have apperceiving concepts, and to present it in such a way as to most clearly relate the new matter to the old.

Novelty or newness usually arouses or stimulates interest. Young children particularly are more interested in new things. For this reason they require frequent change. Their interest cannot be very long sustained in one thing. As children begin to think more, new ideas as well as new objects attract them, new points of view, new relations in which familiar objects are studied, new beauties of form and color and function and adaptation, unsuspected before. The commonest, most familiar things, such as the dandelion, become new, when thus studied in a new light. 
A third source of interest is participation, or selfactivity. Children are interested, in nature study or anything else, in proportion as the teacher leads them to see and think and do for themselves. The child who makes a new discovery with his own eyes, or works out for himself a new idea or thought, is much more interested by and because of this self-activity, than he who simply absorbs from book or teacher or fellow-pupil. In nature study the children are much more interested in material which they have gathered or cared for themselves. The more a teacher can lead her pupils to get and take care of their own plants or animals or stones, or make their own apparatus, the more will they be interested. The more the children discover for themselves new facts, the more they work out the "why" and "how" of what they have discovered, the more the pupils, rather than the teacher, compare and generalize and deduce principles or laws, the greater will be their interest.

The interest will be increased, more especially with young children, by emphasizing in nature study the human or personal element, and particularly the child element. We can study the plants and animals, not as mere things, but as beings with human or child attributes or characteristics. Even water and snow and frost, lifeless things, can oftentimes be endowed with human desires and sympathies. The poets thus personify flower and tree, and raindrop and stream. In the childhood of the race all mankind personified nature. The children naturally do the same. It is often 
most helpful to allow or encourage children to thus personify, beginning always with facts gained through perception and elaborated by apperception, but letting imagination add flesh to what might otherwise be dry bones. In the study of cotton, the cotton-pickers and their pickaninnies and homes and life are more interesting than the mere process of planting and cultivating and gathering cotton. The processes of lumbering mean most when the study is centred about the lumbermen, the human element. These give connection and life to the processes.

We come now to the place of imagination in determining method. When our boys and girls have seen what they can about the dandelion blossom, and, by relating what they have seen to what is already in their mind, have gained a fair idea of the number, size, form, and color of its parts, they should have a mental picture of the flower. If this picture is to be of much value, they should have the power of bringing it into the mind, or rather into consciousness, again, when the blossom is not before their eyes, repeating or reproducing it at some later time. But this power of repeating the image or mental picture is of comparatively little value if the pupils can only repeat it exactly as they first saw it. It is necessary to take from that picture some features not essential, such as the size of the yellow disk, which varies in different specimens, and to add points noticed in other dandelions, so that the children can gain the general idea or general notion of dandelion 
blossoms, as distinguished from that particular blossom. Or they may have to add to the picture of the flower those of the other parts of the plant to form a picture of the plant, or those of other stages of growth to understand its life history. Finally, as was shown in Chapter I, the images of the dandelion must be related to what the mind knows about its environment.

This process of relating to other mind pictures, omitting some features, adding others, combining and modifying, may be continued until we get the beautiful series of pictures embodied in Lowell's "To the Dandelion."

The power or the process of repeating or reproducing the images of what has been perceived and apperceived is memory. The power or process of relating and combining these images, selecting parts of some, adding to others, combining parts of several to form a mind picture of what has not been perceived, we call imagination. The distinction between memory and imagination as thus defined is not very sharp. Frequently imagination is considered as including both memory - then called reproductive imagination - and imagination proper, distinguished as constructive imagination. Both have a most important part in determining method in nature study or in any other subject.

We recognize the importance of memory, or reproductive imagination, in all education. The education of the past, and much of the education of to-day, has relied too much on memory of words rather than of sense-percepts, memory which has very little sense-per- 
ception back of it. Too often children have memorized facts, definitions, formulas, - words, words, words, with very little real content in them. Nature study, or science, is a protest against this kind or form of education. For words it would substitute real ideas, sharp, clear mental pictures, based primarily on sense-perception, and would use words as the means of clothing and expressing or gaining ideas.

In the reaction against too great dependence on word memory, there is often a tendency toward the opposite extreme. In emphasizing sense-perception, we are prone to overlook the importance of memory as an educational factor, and to neglect that necessary drill in reproducing what has been perceived and apperceived. This tendency is very evident in much of the elementary science work in our schools. It is often assumed that when children have seen and understood, little more is to be done. Seeing and understanding are or should be but the foundation and preparation for larger and broader seeing and understanding; and this larger view is only possible when children keep in mind or remember the essentials of what has been learned before, and constantly relate them to what is newly acquired.

To train the memory, - that is, to insure the repeating or reproduction in the mind of what has been seen or otherwise perceived, - nature points out three means or methods :

First. The original picture or impression should be as clear and sharp as it is possible to make it. The pupil who has examined a flower carefully will remem- 
ber much better than he who has merely glanced at it. What cannot be clearly seen by the children, such as the structure of the individual florets of the dandelion, is apt to be soon forgotten.

The clearness of the mind picture can be ascertained, and the power to recall it developed, by occasionally testing the power of the pupils to visualize; that is to - form a mind picture of what is not before their eyes. After looking intently at some simple object, such as a leaf or a piece of apparatus, the pupils should describe it, or draw it from memory. Occasionally it will be helpful to have the pupils make a "conceptional drawing" of some simple familiar object at home, such as a tea-kettle or a lamp, and afterward compare their diawing with the object, and correct errors.

Second. Each important idea should be related with many other ideas, so that it may be recalled through or by means of any one or more of these. What is isolated or stands by itself is soon forgotten. What has been seen about the dandelion will be remembered much better when the plant is studied, not as a mere isolated structure, unrelated to anything else, but as related to its environment, soil and sun, and wind and insects, and to other plants. Its green cup is better remembered when related to its habit of closing at night, or in a storm. Any point of structure is better remembered when related to its function. When the children understand what the veins do for a leaf, that they support and carry food to each part, they better remember the plan of veining and the fact that a branch vein extends to the 
apex of each division of a leaf. We see here another reason for emphasizing the "why" in nature study.

Third. That which is most important, and should therefore be remembered, must be frequently repeated or reviewed. Here we see the necessity for drill. Because of the first law of memory, stated above, the review will be most effective when the images are fresh and clear. Because of the second law, that review is best which emphasizes relations and not merely facts. Hence each lesson should close with a summary, gathering up, bringing together, and relating the important points brought out. The first step in each lesson should, in general, be a review of the previous lesson or lessons, or at least of those portions of previous lessons on which the new work depends. So, also, each step in a lesson should be reviewed and stated clearly before passing to another step. This summary tests the clearness of the impressions, brings out the relations of the ideas or facts, and helps to fix them in the mind by having them repeated.

Constructive imagination, or imagination proper as distinguished from memory, differs from the latter in that it not merely repeats the mental images of what has been seen or perceived, but takes from, adds to, combines and recombines them, forming a picture of what has not been seen. It is only through imagination that we are able to become acquainted with that great part of the universe of which our senses alone give us little direct knowledge. It is imagination which helps 
us to look into the future, just as memory enables us to recall the past.

Imagination plays a most important part in mature science, as Professor Tyndall has shown in his essay on the "Scientific Use of the Imagination." On imagination, applied to and tested by facts, controlled by reason, depend the grandest conceptions and generalizations of the human mind, - the law of gravitation, the nebular hypothesis, the theory of evolution.

On the other hand, imagination not based on facts, or not controlled or directed by reason, is exceedingly harmful.

In the reaction against the education of verbal memorizing and return to the natural education of seeing, there is a tendency to discredit the educational value of imagination. Not infrequently scientists aver that it is utterly wrong to encourage the children to put into nature anything they cannot see; that, for instance, the lessons in elementary science which emphasize or dwell on the idea of protection in the study of the buds of pussy-willow or horse-chestnut are absurd and unscientific. As a fact, without imagination we could get no conception of life processes, of which only the results can be directly perceived.

Nature, however, endows the child with a strong imagination, and indicates its importance as an aid in his education. Imagination is the instrument by which the child looks from and through his little world of sense to the greater universe beyond his childish senses, for which he must be prepared. Through his imagina- 
tion he modifies and combines the pictures which come to him through his senses, and thus gains higher, wider views, somewhat as he unites his letters to build words and form sentences. This faculty must be cultivated and directed, not neglected or deadened.

The practical question is asked, How can we most effectively use and cultivate the imagination in our work in nature study? Much of what has been said regarding the training of memory applies also to the cultivation of the imagination.

What is imagined or imaged must be based on and related to what is seen or perceived. The teacher who would train her pupils to picture what they have not seen must first lead them to combine into a clear picture what has been seen. They can only really imagine the lion and its habits when they have carefully studied the character and habits of such an animal as the cat. They can gain some idea of the Mississippi Valley through an examination of some brook or river-basin near their home. The pupils cannot imagine the processes by which sap is carried through the plant until they have seen experiments on capillarity and osmosis.

On the other hand, if we are to cultivate the imagination we must not stop with what is seen, but must frequently lead from what is perceived to what must be imagined. After studying the hairy seeds which the children can see, such as the dandelion and thistle and milkweed, it is wise to pass to the cotton-seed, with much longer hairs, which they must usually imagine. From the cotton-seed they can be led to picture the 
cotton-plant, the cotton-field, and perhaps the cottonpicking.

As describing or drawing from memory trains the memory, so describing or drawing what the children have read about, or have been told, but have never seen - that is, making a conceptional drawing - may help in cultivating the imagination. A description by the children of a cotton-field, or a drawing to represent the children's mind picture of the cotton-boll, shows teacher and pupil whether the picture in the mind of the pupil is clear and correct or vague, and tends to develop the power to picture or image or imagine.

Because the child can most readily imagine that which is most like what he already knows, it is easier for him to gain or form mental pictures of what is alive like himself, and of those things which are considered as having the attributes and relations with which he is familiar in his own life. Hence, as has been said before, it is natural, and often very helpful, for the child to personify; to endow animals and plants, and even lifeless nature, with human attributes. The more he thinks of them as living, working, helping, dependent, like himself, the better can he imagine and understand their life. Often he delights in imagining himself to be a leaf or plant or squirrel or raindrop, or in having these tell their own story.

One of the most effective aids in cultivating the imagination is literature. On the other hand, one of the main essentials for an appreciation of literature is a vivid imagination. The value of literature, as a means 
of broadening and uplifting the ideas and thoughts and pictures gained from nature study, is illustrated in the study of the dandelion in Chapter I. Lowell's "To the Dandelion" leads into a new world, if the reader has seen or experienced enough, and has an imagination sufficiently trained, to picture what the poet expresses. Genuine literature can be distinguished from mere prose or rhyme by the extent to which it gives broader, higher views, opens new vistas. That which merely gathers up what has been already perceived or apperceived, lacks one great essential of literature.

If we realize the importance of cultivating the imagination of our boys and girls, of leading from the seen to the broader, more uplifting unseen, if we appreciate the higher aims of nature study, the importance of cultivating the higher nature of our pupils, we will in our nature study make use of the best literature, and so study it with our pupils that they will be able to see something of the pictures the authors have seen. 


\section{CHAPTER VIII.}

PRINCIPLES DETERMINING METHOD IN NATURE STUDY (CONTINUED).

Having considered in the previous chapter the influence of sense-perception, apperception, interest, and imagination in determining method, we are prepared to discuss the relation to method of sequence, unity, and expression.

Sequence is but a continuation or repetition of the process of apperception. The mind, like the body, accomplishes most when it builds and is built in order, or proceeds step by step. Sequence is building in order, founding each new part on the previous part, relating each new step most closely to preceding steps.

To insure sequence, several precautions are necessary; certain errors, common in teaching, must be guarded against.

We must be sure that all necessary foundations are laid. The builder who discovers after he has partly finished the superstructure that he has forgotten or neglected to support some part, and is compelled to go back and strengthen or add to his foundation, always loses time, and usually has a weak structure. The teacher who continually finds that in previous lessons 
she has neglected to lay some of the foundations on which present work must be built, and who is frequently compelled to interrupt her advance work, and go back to lay the foundations for it, cannot do the best teaching.

In studying the dandelion, unless the children have observed out-of-doors the closing of the flower, the growing of leaves and flowers away from the shade and toward the light, and the arrangement of the leaves to catch the rain and direct it toward the root, a lesson on the relations of the dandelion to sun and rain is almost useless. No foundations have been laid for it. The value of sequence or continuity of thought in individual lessons and in series of lessons is illustrated in Chapter II on the study of the rabbit.

A second error often committed by teachers, and particularly by teachers of young children, consists in attempting to take several steps at once, or to jump from point to point. Adults learn to take long steps, to go up-stairs two or three steps at a time, to take great leaps. Children must first creep, then take short steps, and after a time learn to run and jump. Particularly when climbing (and education is a process of climbing) they must progress step by step. They can jump or fall downward, but not upward.

What is true of the bodies of children is equally true of their minds. The mind, however, is much later than the body in attaining the stage of development when it can habitually jump or leap.

The adult teacher habitually, but often unconsciously, makes mental jumps in her line of thought, paying little 
or no attention to the intervening steps. When the teacher assumes that her pupils can take the same leaps of thought that she does, she either fails entirely, or, if she is strong, pulls her pupils off their feet, and carries them along with her, instead of training them to walk for themselves.

Only as the teacher analyzes her leaps, goes back in her experience to the time when she had to go step by step, studies the steps by which her children progress, and then adapts herself to them and tries to keep step with them, will she be most successful in training her pupils to take longer steps, and finally to leap for themselves.

Such an analysis by the teacher of the successive steps by which she gained her ideas or attained her present state of knowledge is particularly essential in the case of the teacher whose education has been almost entirely an education of books. In mere book-work, pupils habitually make great leaps, accepting the ideas and conclusions of the author without looking at the steps which lead up to them. For this reason, and many others, the teacher should study nature, not merely books, in preparing for nature study; she can best prepare by studying with a child. She can then see just how the children creep and step in their observation and thought. The teacher who prepares for her lesson in nature study by merely reading what "the book says," will almost certainly fail in adapting her work to her pupils, and in leading them to see and think for themselves.

This tendency of the adult mind to leap is illustrated 
constantly. We associate the evaporation of water with the formation of rain and snow, and are apt to expect a child to do the same. If he does he merely takes the relation on faith, as we probably took it originally. Between the evaporation of water and the falling snow there is a long series of intermediate steps : the process and conditions of evaporation; condensation and the formation of water-dust, mist, fog, cloud, and raindrops; the process of freezing and crystallization, by which frost and the snowflakes are formed; perhaps also the work of heat and gravitation, of the sun and wind, in the formation of snow from evaporated water.

At times, of course, the path is too steep, or the climbing too difficult, for the children. Then the teacher must carry them. However, children are much better climbers, and need much less carrying, than the average teacher assumes or supposes. If allowed and encouraged to climb in their own way, they can do wonders.

The lack of sequence, of step by step progression, is a serious fault most prevalent in class-room work, particularly in nature study, in which, more than in most other studies, the teacher is usually left to plan her own work and determine her own order. In the writer's experience with teachers, he has found it helpful, in overcoming this fault, to have the teachers, in -planning and conducting their work, divide each lesson into two or more distinctly marked steps, and to have each step carefully reviewed and summarized by two or more pupils before passing to the next step. A lesson 
on the movements of the canary-bird may thus be divided into: step 1, position at rest; step 2, perching; step 3, hopping; step 4, swinging; step 5, flying. The teacher should get all that she can from the observations of the children about the position of the bird at rest, perhaps supplement this from her own observations, and have it gathered up or summarized by two or three pupils before asking them or even allowing them to tell about the perching of the canary. If such a plan is followed, the children soon learn to observe in some order, and are much more apt to be orderly in their oral and written expression.

In Chapter II this step by step progression and summarizing is frequently illustrated.

A third precaution necessary to insure sequence or continuity of thought is the avoidance of digressions. When the teacher has decided on her line of thought, she must be careful about wandering out of the path into the fields on either side. In no other study is the tendency or temptation to do this greater than in nature study. If pupils talk freely, as they should, they are apt to bring in much extraneous matter. It requires tact to keep them to the line of thought without discouraging them from expressing themselves.

The pupils can be more readily kept to the line of thought if told at the beginning of the lesson just what the aim or point of the lesson is. When they are deeply impressed, at the beginning, with the idea that "to-day we will try to discover how the snail-shells are made, and what becomes of them," or, "to-day we want 
to learn just how Mother Nature provides for the scattering of the dandelion seeds," they are not so apt to wander.

It must be remembered, however, that the thoughtful digressions by the pupils often indicate the line of thought which the children are following, which may be better for them than the line of thought the teacher has mapped out. Remembering that we are often most successful in leading children when we are apparently being led by them, it is frequently wise to follow out these digressions, when they are sincere and thoughtful, and see where they will take us.

In studying about the elm-tree, for instance; if the children persist in talking about the oriole's nest they found in the elm-tree near the school, the wise teacher may let them tell about the nest, - how and where it is fastened, how deep it is, - and may help the pupils to see that the birds understand, even better than the children, how flexible and tough the branches of the elm are, and how well fitted to support just such nests. The interest in the nest will help to fix these distinctive characteristics of the elm twigs.

Closely related to the avoidance of thoughtless digressions is the importance of "guarding the switches." There are certain points where pupils are most apt to get confused or wander off. These must be guarded with special care. Two "switches" which require special "guards" result from the tendency to depend on old ideas established in the mind, rather than on what the senses tell, and from the tendency to make too broad gen- 
eralizations. After studying the cricket or grasshopper (see Fig. 27, p. 229) and other insects, and having the idea impressed upon them that these animals have distinct head, thorax, and abdomen, nine children out of ten will think of and draw the crayfish or spider (see Figs. 22 and 23), when they begin to study them, as having a distinct head, although their eyes tell them that head and thorax are very closely united, without any neck. After studying the dandelion and thistle flowers as typical of the composites, nearly all pupils will assume that all compound flowers, such as the clover, are composites. The experienced teacher, who has been over the ground and located these "switches," will have the foresight to warn the pupils before they reach these points.

A common method of keeping children to a definite. line of thought is the Socratic method, or development method. By a series of skilful, well-related questions the child is led to see and to state just what the teacher wishes him to see and state.

This development method is often invaluable. In leading children to an abstraction or general truth, such as a rule in mathematics or grammar, or a grouping or classification in botany or zoölogy, or in helping the pupil to see relations which he can never work out for or by himself (as the fact that a potato is a modified stem, and that a thorn may be a modified leaf), it is most effective and necessary.

But in most science work the development method 
must be used cautiously. Close questioning has less place, probably, in science or nature study than in any other line of school-work, because in nature study pupils have concrete things to work with. Too much development work may be more harmful in science than in any other field. Every experiment and observation is, in general, a question asked of nature; and the answer to that question is usually in plain

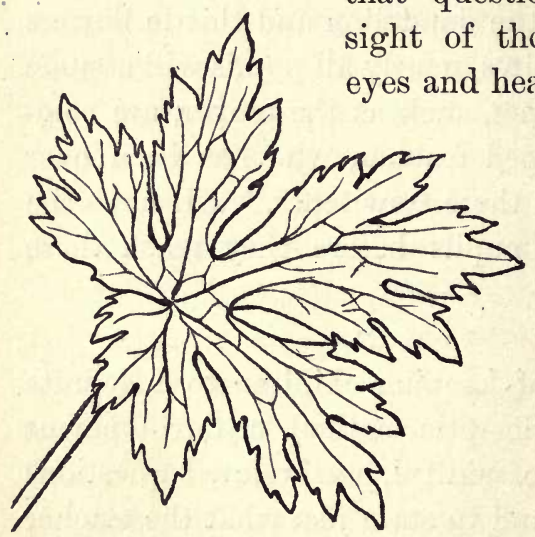

Fig. 21. has made sure that the pupil understands the question, the point of an experiment, the appearance of the leaf in his hand, and has the means for answering that question, it is better to give him opportunity to observe and think for himself, not to distract his attention and interfere with close observation by throwing questions at him.

The teacher may get from the children a good orderly description of the buttercup leaf (see Fig. 21) by asking such a series of questions as : What kind of a stem has it? How long? What is its shape? What is the shape of the broad part or blade of the leaf? How long? How wide? Where widest? What is its color? 
Is the color of the upper and lower surfaces similar? How are its veins arranged? How far out into the lobes do they extend? What kind of a margin does the leaf have? How many main parts? What kind of a base? But from such work pupils get little training in real connected observation and description, and no training in connected thinking. If they are really observing their leaves, they cannot listen to the constant string of questions; if they listen to the questions, they cannot observe. They cannot relate successive ideas about the leaf - and the essence of thinking is thus relating ideas for ourselves - because the teacher does all of the relating, such as it is, and drags her pupils with her. We cannot train children to observe and think by such a process any more successfully than we can teach babies to walk by carefully lifting their little feet one after the other, and pressing each down at the proper distance in front of the other.

To train the boys and girls in connected, related observation and description, it is much better, with the buttercup leaves in the hands of all the children, to ask one pupil to tell all that he can about his leaf, have a second and perhaps a third tell all about his own leaf, noting any differences or errors of observation or of statement, and adding as many new points as possible, and then have the class correct and complete the description. In beginning such work, it may be wise or necessary to have the pupils discover the features to be observed, and then, under the guidance of the teacher, arrange these in order, and formulate a plan for de- 
scription. Even more helpful in insuring individual connected observation may be a drawing, each pupil drawing, as exactly as possible, his own leaf. After such a drawing they will describe much better.

In the experience of the writer, scores of lessons in nature study have been spoiled, even when the teacher had her work well planned, and was well prepared, had excellent and abundant material, and wide-awake, observant pupils, by such questioning, making it impossible for the pupils to really observe or think for themselves.

In such a comparison as that between the dandelion and thistle suggested in Chapter I, the teacher may lead the pupils to make a clear, orderly comparison by asking a series of questions bringing out in order, point by point, the features in which the dandelion and thistle blossoms are similar. But after the pupils have carefully studied and have understood the flower of one of these plants, it is better for them to discover for themselves as many points of resemblance as they can, even though the work may not be quite so orderly. When they have noted all that they can, then the teacher can ask questions to bring out features unnoticed before, and can lead them to an orderly comparison.

In abstract work, as when leading pupils from many particulars to the demonstration of a rule or general principle in mathematics or grammar, or when gaining a definition in geography, close questioning may be most helpful, even absolutely necessary. In generalizations in science, as in classifying animals and plants, or leading pupils to distinguish characteristics essential in 
classification from those which are of minor importance, development work is invaluable. Care is necessary, however. Too often the questioning is so done that the child is shut in between two walls, as it were, compelled to go where the teacher wishes him to go by being led to bump his head, first against one wall and then against the other. He has followed a line of thought, it is true, but not his; he has not made it his own. He has simply bumped along, driven by or between the questions of the teacher.

This excessive use of questions illustrates an abuse, rather than a proper use, of the development method. But it is much too prevalent.

In general, the fewer and broader, and at the same time the clearer and sharper, the questions, the better the results, in getting pupils to think for themselves.

The teacher who leads her pupils to relate their ideas for themselves, to follow out a line of thought for themselves, will be much more successful in impressing ideas, and in developing the power and habit of logical thinking, than the teacher who compels her pupils to follow closely her own line of thought.

The next law which must determine method is the law of unity, - an expression for the tendency of the mind to relate and group and unify all its ideas.

In apperception, the combining of new percepts with the concepts already in the mind, we have the first step of the mind in the process of unifying. Sequence, the uniting of ideas in a series, illustrates an extension of 
this unifying process. The mind strives to continue indefinitely this process of unifying, or relating its knowledge or the phenomena about it, as when it refers many effects to one cause, or groups in one order or class, because of similarity in plan, great numbers of plants or animals.

The child is educated in proportion as he can and does relate the ideas gained; that is, in proportion as he recognizes in his environment, and realizes in himself, unity. The study of physical phenomena is of very little value, comparatively, unless the child can, to some extent, explain them and refer them to their causes. What he learns about plants and animals is almost useless unless he recognizes, and in some degree realizes, their relations and their unity. The facts of history amount to very little unless the child relates them, understands more or less of their causes, and appreciates to some extent the working out of principles or laws.

In the ultimate analysis all the aims of nature study which have been enumerated are, from a psychological standpoint, manifestations or resultants of this unifying tendency of the mind. The awakening of interest and sympathy, the cultivation of the rsthetic, ethical, and spiritual nature, the development of power, and the acquisition of knowledge, are all means or processes of establishing unity in the mind.

We have agreed in Chapter IV that the final aim of nature study or of education in general is to perfect the relations between the child and his environment, physical, intellectual, and spiritual. We want our child 
to appreciate what he receives from, and to realize and perform what he owes to, his environment, - nature, man, God. Thus can he be adapted to his environment. In formulating this aim, without any discussion of psychological laws, we naturally emphasized environment rather than the child, and dwelt on adaptation to environment. When we look at the question from a psychological standpoint, ask what is the ultimate aim of the mind, we find that the mind ever seeks to reduce to unity all its environment and itself, or to adapt its environment to itself. It discovers that phenomena at first very diverse are illustrations of the same principle, results of the action of the same agency or force; that animals, such as the vertebrates, at first showing almost infinite diversity, are built on the same plan. Thus it refers all physical changes to.a few agencies or forces, and groups all forms of life about a few types. The mind finds that physical phenomena and laws are analogous or identical with those of the intellectual and spiritual world. Thus it reduces to unity what is without itself, and then relates this to itself. We see, therefore, in this law of unity, the psychological warrant for the final aim of nature study or of education, before established on ethical grounds, the perfecting of the relations between the child and his environment, or the reducing to unity of the "I" and the "not I."

We express the same idea in spiritual terms when we say, with the Great Teacher, "Love is the fulfilling of the law." Love is unity. Recognizing the unifying tendency of the mind, and the importance of developing 
it, we see why interest and sympathy are so essential. They are the only means of establishing the greatest unity between the child and his environment.

In the law of unity we find the psychological basis for the greater educational value of the study of life, the most nearly perfect illustration or realization of physical unity. In a living plant or animal all parts are organized to co-operate with one another, to work as a unit in taking from environment, - from sunlight and soil and air, - and in giving to environment. Perfect physical life in plant or animal is perfect adaptation or perfect relation or complete physical unity between it and its environment, or that part of its environment to which it is adapted or related. As this unity becomes less complete, disease comes. When death ensues, unity ceases. The plant or animal is no longer a unit, but is disorganized, made up of isolated parts. In the study of death, of mere form and structure, the child does not see this unity, and his mind is not greatly aided in its unifying process. In the study of leaves or roots or stems or flowers, isolated and not related to the plant, this psychological demand for unity is not recognized nor satisfied.

From this standpoint we see also the psychological reason for emphasizing the study, in earlier years or lower grades, of life and living nature, and of forces and processes, and understand why the study of minerals or of mere form and structure is not so interesting to young children, and not so satisfactory in its results. If in earlier years children can study units, - the whole 
living plant, its development from seed to maturity, and growth or adaptation to environment; and living animals, caterpillars and butterflies, frogs' eggs, tadpoles and frogs, living birds or kittens or fish, - they learn to relate parts to wholes, to recognize the unity between plant or animal and its environment; and thus the unifying tendency of the mind is recognized and developed. After such preliminary work the mind more readily, and oftentimes necessarily or automatically, unifies what is not presented to it as units; relates the leaves or flowers to the plant, thinks of them, not as mere forms, but as parts of a whole, depending on and working for the whole plant.

The child who has studied the life of the dandelion, the development and work of root and leaves and flowers, the ripening of seeds, and the preparation and arrangement for their dissemination, the co-operation of plant and wind in scattering the seeds, who has compared the life and adaptations of the dandelion with those of two or three similar plants having similar adaptations, is much better prepared to unify or reduce to unity, and therefore much better educated, than the child who has simply described the form and gross structure of fifty isolated leaves or of a score of roots or flowers, or has dissected or analyzed and grouped by mere structural or morphological features a dozen plants.

In the same law of unity we see the reason for the greater educational value of the questions "why" and "how" as compared with "what." "What" is mere 
structure, and is isolated. "Why" and "how" relate the structure and thus help to unify. We may describe the form and structure, the "what," of the dandelion, and never think of it as related to anything else. When we ask "why" and "how," we begin to relate it to its environment. Why is it colored? To attract insects, to beautify the world. Why does it have the green cup, or involucre? To protect it from moisture, from sudden changes, or from insects. Why do the florets have hairs (the pappus) about the base? To catch the wind, and aid in scattering the seeds. Each "why" suggests a new relation, leads to a better realization of the co-operation and unity of nature.

How does the recognition of this unifying tendency in the mind, and of the importance of unity in the work, affect or determine the method of study?

First. We must endeavor to impress the idea of unity in the child's physical environment, nature.

Second. We must labor to make more complete his realization of the unity between his physical and intellectual environment, nature and man.

Third. We must strive to lead from nature and man to God ; to impress deeply on the child the unity of all parts of his environment, physical, intellectual, spiritual.

Fourth (and including the others). We must do all in our power to bring the child into the closest relations with all his environment, into unity with nature, man, and God. 
How can we impress on the child the idea of unity in his physical environment; that is, in the world of nature about him?

At first, perhaps, everything is unity to the babe. He has little power of analyzing. He soon, however, begins to separate his environment from himself, the "not I" from the "I." In time he distinguishes different parts of his environment, - mother, nurse, father, food. At first he doubtless sees a pussy as a whole, with little or no conscious analysis. Later he distinguishes head and body and tail and legs, and gradually minor divisions. This process of analysis, of separating into and distinguishing parts, is continued as he develops.

The problem at first is, not to give the child the idea of unity, but to keep that idea in his mind as and while he analyzes.

The development of the analyzing power in the race has been similar. The progress of knowledge has gradually compelled man to separate what was once called natural history, into many distinct sciences; - botany, zoölogy, chemistry, physics, each with a host of subdivisions. These distinct sciences, as such, have little place in work with young children. They must study nature much as their ancestors studied nature before these sciences existed, and as the children study nature before they enter school. This does not mean that they are merely to flit about and sip here and there, but that each thing studied may, and often should, become a centre for the study of much about it.

When we thus study the dandelion in its relations, 
investigate the co-operation of its parts, and their relations to their environment, — soil, wind, sun, insects, we are brought into contact with a large part of nature, and study portions of many sciences. The absorption of water and food by the roots leads us into physics, capillarity, and osmosis, though we may not use these terms. The transformation of this absorbed matter into "milk" is a chemical process, although the children may never hear the word chemical. Any observation or study of the insect visitors of the dandelion and of their work leads us into zoölogy.

We can emphasize the unity in our physical environment by studying plants and animals as units, and by studying the phenomena of nature in their relations. These relations have been enumerated in Chapter III.

These relations, so far as they need to be considered here, can be gathered into two general classes, relations of dependence (including causal relations), and relations of similarity and difference; the first functional, the second structural. As brought out in Chapter I, the dandelion has relations of dependence upon soil, air, wind, and water (rain, dew, clouds, frost, snow), sun, animals, and man; that is, these help or harm it, or are helped or harmed by it. It has a relation of similarity or difference to other plants (more particularly composites), more remotely to animals, most remotely to inorganic nature. It is like or unlike these in form, structure, or plan.

Which of these relations is most important? In the science of the past, as pursued in most educational 
institutions, and particularly in the study of botany and zoölogy in secondary schools, all emphasis has been placed on the relations of similarity and difference; and, as a result, great prominence has been given to comparison of form and structure, and to classification. It has apparently been assumed, oftentimes or usually, that comparison of form and structure, and classification based on these, were aimost the only method or means of unifying or reducing to unity this part of our phys-. ical environment. On the contrary, it is the functional relations which show the most complete unity. The structural relations are but the preparation for or result of functional relations. The similarity in plan, form, color, etc., depends on similarity in function or work.

If it is true, as has been asserted in previous pages, that the study of life and function is of greater educational value, at least in elementary schools, than the study of structure, then the functional relations, those of dependence, are more important than relations of similarity and difference in structure. While great emphasis must be placed on these functional relations in work with young children, as they grow older, more and more attention can and should be given to form and structure, and to structural relations.

The recognition of this principle will greatly influence the method in nature study in elementary schools. In accordance with this principle, children should begin their plant study with whole plants, and study these first in their functional relations. They can begin in 
the first and second grade (see Course of Study, Chapter $\mathrm{XV}$ ) with the study of such a plant as the mallow, or with the growth from seed to maturity of the bean or pea, and have impressed the mutual dependence of all parts, - roots, stems, leaves, flowers, fruit ; the dependence of the plant on soil, water, sun, and man; the dependence of man and animals on the plant; the dependence of all on the Creator. The form and structure of parts should be studied as adaptations to work. The comparisons should be at first a comparison of the ways in which the organs do their work, preparing for a comparison, later, of the ways in which they are fitted for their work; that is, for a comparison of form and structure, resulting in classification.

The children, young or old, should never begin their study of leaves by merely comparing their forms and veining and arrangement on the stem. In their study of the development of seeds and buds, the children should first have impressed the idea of the leaf as something related to the. whole plant, formed by and developing from the plant.(from seed or bud), dependent on the plant, working for the plant. Gradually other functional relations can be brought out. As the child begins to understand these functional relations he can begin to appreciate the arrangements the leaves have for doing their work. The veins will then be, not merely veins, but a framework to hold out to sun and rain, or channels and tubes to carry water. Their arrangement may then have a meaning. Later, in the third or fourth year, more attention can be given to the 
comparison of the forms of leaves; that is, to the formal study of relations of similarity and difference, connecting these, however, with function. This will prepare for comparison and classification, and the study of families and larger groups in the upper grades.

It is evident that it is neither wise nor possible to dwell on all the relations of everything studied. It becomes essential to select that material which will best illustrate these relations, and to which other material, not so carefully studied, can be related, or about which it can be grouped. The chapters on selection of material and formulation of courses of study (Chapters $\mathrm{XIV}$ and $\mathrm{XV}$ ) indicate the material which will best serve as centres for work in the different grades, and, at the same time, serve as foundations for later work.

How can we, in and by our methods in nature study, make more complete the unity between the physical and intellectual environment of the child?

Certainly not by separating the physical and intellectual as far as possible, that is by divorcing nature and all school-work as we have done in the past. Rather by uniting these as closely as possible, basing much of the school-work on nature study. The better the child realizes that school is out-of-doors as well as in the schoolroom, in plant and animal ànd stone, in cloud and sunset and waterfall, as well as in book, the more complete will be the unity between his physical and intellectual world. The more his nature study is correlated with and made a basis for his language work, 
drawing, reading, and literature, the more will the unifying tendency of the mind be satisfied.

The child and the poet see in the physical world much that symbolizes man and God. This symbolism of nature, rightly impressed and re-enforced by literature, will do much in leading to unity.

The methods of relating nature study to other schoolwork are discussed in Chapters XI, XII, and XIII.

How can we best impress on the child the unity of all his environment, of nature, man, and God? Not by mere preaching. Rather by leading him sympathetically, reverently, where he can read for himself the " one great loving thought written in hieroglyphs of bud and bloom." By taking the child to bud and leaf and flower, to nest and egg, where he can see for himself the lessons of protection and care, shown alike in the physical, intellectual, and spiritual, by nature, man, and God. By letting him absorb, day by day, week by week, year by year, naturally, and often unconsciously, the lessons of mutual dependence and mutual helpfulness, the lessons of slow but sure development, the lessons of patient waiting and preparation. By impressing the lessons of purpose and order and plan all about him, and thus leading to the Protector and Thinker and Planner and Director, the highest Unity.

How can we bring the child into closest unity with all his environment? The question has already been largely answered in Chapter IV. Only sympathy and 
love can bring unity. Love is the fulfilling of the law - of all law. The teacher who has led her pupils to regard nature reverently and sympathetically has done much to bring into unity the child and all his environment.

\section{THE PRIMROSE ON THE ROCK.}

A rock there is whose homely front

The passing traveller slights;

Yet there the glow-worms hang their lamps,

Like stars, at various heights :

And one coy primrose to that rock

The vernal breeze invites.

What hideous warfare hath been waged,

What kingdoms overthrown,

Since first I spied that primrose tuft

And marked it for my own;

A lasting link in Nature's chain

From highest heaven let down !

The flowers, still faithful to the stems,

Their fellowship renew ;

The stems are faithful to the root,

That worketh out of view ;

And to the rock the root adheres

In every fibre true.

Close clings to earth the living rock, Though threatening still to fall;

The earth is constant to her sphere, And God upholds them all :

So blooms this lowly plant, nor dreads Her annual funeral.

WORDSWORTH. 
What has been said heretofore about the characteristics or laws of the human mind applies to the child as an individual. The child or man alone on an island, shut off from all intercourse with his fellow-men, would be dependent on his senses for new percepts; would assimilate these by the process of apperception; would be most impressed by that in which he was most interested; would try to picture or imagine what he could not see by modifying and combining what he had seen; would combine his ideas, to a greater or less extent, in a series or sequence ; and would endeavor, with more or less perseverance and success, to unify his knowledge. His development would be much retarded and limited, however, by the fact that he could not exchange ideas with others, convey his ideas to others, and receive their ideas in return. Man is a social being, and must not merely get and unify ideas, but must impart and exchange ideas.

This brings us to the consideration of expression, the process or means by which ideas are conveyed to or received from other minds. By expression is meant not merely language, but any means of conveying or expressing ideas, - drawing, painting, moulding, sewing, music, gesture.

Expression has a threefold object or function:-

First. To clarify, make more clear and orderly, our ideas, by bringing them into consciousness, arranging them in order to be conveyed to others, and forcing us to recognize our own weaknesses, either in perceiving or relating facts. Expression, the attempt to convey 
our ideas to others, leads us to relate our knowledge, and put it in order much as an expected visitor leads the housekeeper to "put her house to rights." Teachers recognize this fact when they say, "We do not know what we know until we try to teach it."

Second. To convey ideas to others, and thus aid us in influencing others, or in adapting other minds to our mind. Assuming that we have ideas worth expressing, gained by and through the means already considered, we will be most successful in bringing others to our way of thinking, adapting this part of our environment to ourselves, in proportion as we can most effectively express our ideas.

Third. To give us a medium through which we can receive ideas from others, and thereby relate or adapt our mind to other minds. In general, the better we can express our own ideas, the better will we understand the ideas expressed by others.

The relation of nature study to the expressive work of the elementary school is considered in Chapter XI. 


\section{CHAPTER IX.}

THE ORDER AND METHOD OF STUDYING MATERIAL.

HAVING discussed the principles which must determine method, we are ready to consider the general order of study, the first step in the application of these principles.

The value of the study by children of the relation of . plants and animals to their natural environment, and of the study of life and habits, has been illustrated in Chapters I and II, and discussed in Chapter VIII. In Chapter II, on the study of the rabbit, were illustrated some of the advantages of beginning with home and habits, followed by the study of structure, comparison, and classification. The order will be largely determined by aim and the necessity of basing work on sense-perception and apperception. Emphasizing the higher aims, we begin with home, life, and habits, if they can be observed. If the conditions are such, as in study of starfish inland, that life and habits cannot be observed by pupils, then it is often better to begin with structure, that is, with what can be seen. The reasons for following the order below are further discussed in connection with the different steps.

In considering method we must give some atten- 
tion to each of the following steps in presenting matter:

1. Name.

2. Relation to natural environment.

3. Habits or function (and life history (?)) .

4. Structure (and life history (?)).

5. Comparison and classification, or association and generalization.

6. Application.

The first essential in studying anything is the name; the child should know what he is studying. A name which means nothing, is not based upon or does not suggest any concept or idea, is very difficult to relate or apperceive, and difficult therefore to remember. Whenever possible, the name should be related with an idea, with something which suggests the name, or from which the name originated. It is best to relate the name with something which the child can see. When the child has learned that aster means star, the starlike appearance of the flower will suggest the name. The names starfish, sunfish, trillium (triple or three, having parts in threes, sometimes called "trinity flower"), pyrite (firestone), milkweed, earthworm, bloodroot, Solomon's seal, painted cup, and a host of others, will be much more readily apperceived and recalled or remembered if the meaning of the name is explained to and impressed on the children.

Of course with children we will use the common names, when there are any, not the technical names. 
Harebell, buttercup, butter-and-eggs, sea-anemone, and earthworm mean much more, are more readily apperceived and remembered, and are much better for children, than their technical equivalents, campanula rotundifolia, ranunculus, linaria vulgaris, actinia, and lumbricus.

Frequently the name can be associated with some beautiful legend or story: trillium with the legend of the trinity flower; hyacinth with the old Greek legend of the boy friend of Apollo; narcissus with many old stories. The name may suggest a comparison or simile, the name iris suggesting the rainbow; the Jack-in-thepulpit always attracts the little folks because of the idea associated with its name.

Having provided that the pupils shall not merely hear the name, but if possible shall be interested in it, apperceive it clearly or associate it with an idea, and make it the beginning of a sequence, what is the next step, the first step in the study of that part of nature which we have named? If we wish to unify the child's ideas, we should first relate the thing studied to the whole of which it is part. We are studying it in the schoolroom; it does not belong there. The next step should be to relate it to its natural environment. Is it a mouse, bird, insect, fish, a plant, a whole in itself? Where was it found? Under what conditions? What are its relations to earth and sun and rain and plants and animals? If an animal, what about its home and home-life and habits? If a plant, how does it develop; in what kind of soil does it grow; do its leaves or flowers 
turn toward or follow the sun; do its flowers close at night; is it the home of any animals, caterpillars, insects, birds? Is it a leaf or flower or root or branch, or feather or shell, a part of something? To what did it belong? Of what was it a part? Where did it come from?

In the case of minerals, the relation to environment is not so intimate or evident, and therefore not so important or essential, as in animals and plants. Forces, studied in physics and in chemistry, have no environment; they are everywhere. But minerals and rocks can be considered as earth materials, and physical forces as earth forces. Particularly in earlier years, it is helpful thus to relate them very closely to the earth (and to geography), quartz and sandstone becoming the most abundant materials out of which Mother Nature has built the crust of the earth, and heat the force which she uses to change the earth's crust. Later, with mature pupils, minerals and rocks may be unified by grouping them according to their chemical composition, and forces related through the law of gravity or the law of conservation of energy.

By thus always relating all things studied to nature, to their natural environment, rather than studying them as isolated leaves or stones or snails in the schoolroom, unrelated to nature, we help the child to start his study with something akin to unity. The different things studied are brought together again in a subsequent step, comparison and classification, or generalization, and are thus more or less unified at the beginning and at the end. 
Remembering that the best foundation is sense-perception, actual seeing, by far the best way to relate to environment is to take the children out for a field lesson, to see grasshopper or cricket or caterpillar or ant or snail in its natural home; to see where and how buttercup and mallow and fern and elm grow; to gather the stones, and study the position and arrangement of rocks, and watch the work of rain and streams. A field lesson with a definite aim and definite work for each pupil, carefully planned, well conducted, well followed up afterwards and clinched, is, in general, worth half a dozen schoolroom lessons.

The higher value of out-of-door study of nature Emerson has expressed in his poem "Each and All": -

I thought the sparrow's note from heaven,

Singing at dawn on the alder bough;

I brought him home, in his nest, at even ;

He sings the song, but it cheers not now,

For I did not bring home the river and sky;-

He sang to my ear, - they sang to my eye.

The delicate shells lay on the shore;

The bubbles of the latest wave

Fresh pearls to their enamel gave,

And the bellowing of the savage sea

Greeted their safe escape to me.

I wiped away the weeds and foam,

I fetched my sea-born treasures home;

But the poor, unsightly, noisome things

Had left their beauty on the shore

With the sun and the sand and the wild uproar.

Then I said, "I covet truth;

Beauty is unripe childhood's cheat; 
I leave it behind with the games of youth:"As I spoke, beneath my feet The ground-pine curled its pretty wreath,

Running over the club-moss burrs;

I inhaled the violet's breath;

Around me stood the oaks and firs;

Pine-cones and acorns lay on the ground;

Over me soared the eternal sky,

Full of light and of deity ;

Again I saw, again I heard,

The rolling river, the morning bird;-

Beauty through my senses stole;

I yielded myself to the perfect whole.

The manner of conducting field lessons must be determined mainly by the aim and the conditions in such out-of-door work. The aim is to get in touch or harmony or unity with nature; to investigate the relation to natural environment of that bit of nature in which teacher and children are specially interested; to gain or study what cannot be studied or acquired in the schoolroom. The conditions are very different from those prevailing in the school. The pupils are at home, where they realize their natural privileges and rights, and where the teacher often has to become the pupil. They are more free, more natural, more difficult to restrain or control, or at least less amenable to schoolroom rules or methods of discipline. The surroundings attract and distract the pupils. There is so much about them, that it is much more difficult to gain their attention, keep them at work, or pin them down to special, definite work.

Nothing is more helpful in giving direction to an 
out-of-door lesson, in imbuing the children with the spirit of nature, than an introductory literary gem, or a short story. Parts of Bryant's "Forest Hymn" read as they have gathered under the trees may make a deeper impression than hours given to its study in school. Longfellow's "Autumn," or portions of Lowell's “Indian Summer Reverie," or "The Maple," may be the best prelude to the study in the meadows or park of the autumn leaves, may impress the thought of the perfect whole, the highest aim of the field lesson.

The purpose of the field lesson, it must be remembered, is to study, not mere form and structure, but processes and relations, life and dependence on and adaptation to environment. Structure can be studied better in the schoolroom, where the conditions are more favorable for definite work. In our work out-of-doors we should largely limit ourselves to what cannot be observed or cannot be studied as well indoors; such topics as the falling and coloring of leaves, the work of earthworms or frost, of rain or streams or waves, the formation of soil, the relation of leaves and flowers to the sun, the habits and homes of insects, birds, and other animals, the occurrence, form, color and other obvious characteristics of trees.

It is difficult, unnecessary, and unwise to attempt to maintain out-of-doors the order which is required in the school. Such order will defeat the purpose of the field lesson. On the other hand, a lesson in which no order is maintained, which degenerates into a frolic or picnic, is not merely of little value, but may bring discredit 
upon all the work in nature study, and tend to postpone the time when this natural method of studying the children's natural environment shall be followed in other subjects, such as local geography and history.

The secret of a successful field lesson is: A definite aim or object understood by each pupil as well as by the teacher, definite work for each pupil, followed by a definite report on and review of what is observed. In a field-lesson, with the freedom and lack of restraint, and with distracting surroundings, from which the schoolroom is largely free, definiteness in aim and plan is more important than it is in any other work.

The pupils should have, in the preceding lessons, enough to interest them in what they are to observe out-of-doors, and each pupil should know just what he is to investigate. It is helpful to have several points which all are to investigate and report upon orally, and, in addition, to give each pupil one or more questions upon which he is to report. If the reports can be in writing, so much the better.

After the pupils individually have done all they think they can do alone, with such suggestions here and there as the teacher may be able to give, it is often helpful for the teacher to gather the pupils about her in the field, and correct any serious errors. The definite review or summary will usually be more successful in the schoolroom.

If a field lesson with the class is or seems impossible, the teacher will find it helpful to go out occasionally with a few pupils after school or on Saturday. For the 
study of many things, such as ants, crickets, mallows, trees, birds, buttercups, stones, earthworms, dissemination of seeds, it may be necessary to go only a few hundred feet from the schoolhouse, even in the heart of a city, and may not require more than half an hour or an hour. A field lesson with the teacher and one pupil in attendance will lead the teacher to look at nature, to some extent, from the standpoint of her pupils, and aid her in adapting herself to her pupils.

Nothing so draws together teacher and pupils, making them fellow-students and fellow-investigators of truth, as well-conducted field lessons, where they are on the same plane, the teacher often becoming a pupil, the pupils, who are so much nearer to nature than their teacher, often becoming teachers.

Much concerning the natural environment or home of what is being studied can usually be drawn from the children. Many or most children have an unsuspected store of nature lore, like Whittier's "Barefoot Boy" :-

"Knowledge never learned of schools, Of the wild bee's morning chase, Of the wild-flower's time and place, Flight of fowl and habitude Of the tenants of the wood; How the tortoise bears his shell, How the woodchuck digs his cell, And the ground-mole sinks his well; How the robin feeds her young, How the oriole's nest is hung; Where the whitest lilies blow, Where the freshest berries grow, Where the groundnut trails its vine, 
Where the wood-grape's clusters shine;

Of the black wasp's cunning way,

Mason of his walls of clay;

And the architectural plans

Of gray hornet artisans !-

For, eschewing books and tasks,

Nature answers all he asks ;

Hand in hand with her he walks,

Face to face with her he talks,

Part and parcel of her joy,-

Blessings on the barefoot boy !"

The poorest student, the boy who takes no interest in his school-work and plays truant whenever he can, may be able to tell most. And here may be the opportunity of the teacher to interest and get a hold on that same bad boy.

If the children cannot relate to natural environment, if they have never seen what they are studying, the starfish or sea-urchin or coral, the cotton or cocoanut, the limestone or iron ore or coal, in its home, or where it naturally occurs, then the teacher may endeavor by picture or blackboard illustration or word picture to give the children some idea of its occurrence.

When the children know nothing about the occurrence of what they are studying, and it is difficult for them to gain any clear idea of it, as in the starfish, it is well to change the order of study, begin with what they can see, the structure of the thing itself. This will give a good foundation for future work; and the study of relation to environment may be taken up later, and more or less incidentally. 
All the work heretofore indicated may be considered as preparatory. Now comes the presentation of new matter in the schoolroom. With what shall we begin? Of course we want to build on the foundation laid in the preparatory work. How? By going on with the same line of thought or sequence; studying in the schoolroom habits, work or function, development or formation.

Have the pupils told a little about the habits of the animal they are studying, rabbit, crayfish, cricket, fish, canary, squirrel; not merely where it lives, but how it lives? Continue the study of life and habits by observing these in the schoolroom; how the animal moves, crawls, walks, flies, how and what it eats, how it breathes, how it sleeps. Read about those habits which cannot possibly be observed. Study carefully the use or work or function of the different parts, and the way in which they are used; that is their "why" and "how."

Have the children study in the schoolroom the development and the work of the plant and its parts. They have gathered buds in the early spring, noted the trees from which they came, and their position, and perhaps, arrangement on the branches. Have them put those buds in water, watch their development, discover the function of gummy or hairy covering and scales and stipules, and note, as the parts develop, how they are arranged, and why they are so arranged. Have they learned to recognize the mallow, discovered how well it is anchored in the ground, noted how its leaves face the sun from morning to night, and how its younger 
leaves and its flower close before dark? Study with them in the schoolroom the function and development of root and stem and leaf and flower (so well shown in the common mallow), the "why" and "how" which shall make them think, lift them up, and prepare them for the later more definite study of structure, the "what."

The pupils have learned where the limestone they have in their hands occurs, and perhaps how it breaks down or crumbles. Work out with the children the story of the formation of the limestone. Its fossils, shells, or corals may serve to connect it with animals of long ago from whose skeletons it was made. Its crystals may give the clew to the process by which it has been deposited from water.

Following the same line of thought, we can begin with the origin or sources of physical forces, heat or electricity, following with a study of their effects, what they do, their work or function.

The study of life history, of the development from seed or egg or larva or babyhood, of plant or animal, and the story of the formation of mineral or rock, may come at this stage, or may be placed later in the order of study. Where the story of life history must be told, it is better to have it after the study of structure. In many cases, as in the crayfish, the children cannot understand the story of development from the egg until they have a fair idea of the structure of the adult. Where development can be watched in the schoolroom, as in the case of caterpillars and butter- 
flies, it may be better to study life history before structure.

Much has been said in previous chapters of the greater educational value, particularly for children, of such investigation of the living, working side of nature, or of the function and story of plants and animals and rocks, as compared with the study of mere form or structure or morphology. It is in accordance with the law of apperception. Life and action are more like the child himself, appeal to him, can be better understood by him. Life and action and work, the story of development and formation, interest the children, and appeal to their sympathies and to their higher nature, because life and function, rather than structure, show the higher side of nature.

The observation of life and function and the study of development and formation lead to the questions "why" and "how," and compel the child to think and to relate what he is learning, and thus tend to unity. Until an animal or plant is studied alive, and as a living thing, with all its parts co-operating, it is not a unit, but a collection or aggregation of parts. When we know the story of a mineral or rock, the forces which have acted on it, and the changes through which it has gone, it becomes almost a thing of life, a connecting link between the past, present, and future.

The study of habit and function and development or formation is the best possible preparation for an understanding of structure. The child who has watched the cat drink milk or eat meat, or climb a tree, or sharpen 
its claws and draw them into their sheaths, is best fitted to understand the structure of tongue and teeth and claws. The structure will be related to function, each "what" associated with a "why" and "how." The pupil who has watched the development of the bud into the flower, and the formation of fruit and seeds by the flowers, who has seen how the calyx folds about and protects the other parts, how the corolla beautifies, how the pistil becomes the seed-box, who has learned that the corolla attracts insects, and that its markings and hairs guide insects to the nectar, is prepared to study the structure of the flower; in fact, he has been studying structure without knowing it. The structure of sandstone or limestone, its layers or crystals or fossils, is not only better understood when the child has seen how water deposits materials in layers, or watched the formation of crystals of alum or sugar, or learned how shells are deposited in mud and how the mud is hardened into stone, but the child cannot possibly understand their structure until he has learned the story of their formacion.

The study of habit and function relates best with literature and art. As has been said before, it is life and function and story which have appealed to the poet and artist. There is scarcely any literature of mere structure.

The investigation of habit and function and development gives the best opportunity for freedom and individuality in observation and expression. Every child in the class may carefully observe the habits of the 
canary in its cage in the schoolroom, how it hops and walks and perches, how it eats and drinks, how it sings, how it sleeps; and each has a different story to tell, or tells what he has seen in a way different from all the others. When they come to describe the structure of the canary, - its body and head and wings and tail and legs and feet, - all are telling about the same thing, and are apt to tell it in about the same order and words. The latter description will be more exact, but at the same time more stereotyped, less free and individual.

Much of what is here said about the value or content of the study of life and habits, and about the method of observing these, has been brought out concretely and clearly illustrated in the outline or plan for the study of the rabbit in Chapter II.

This study of life and habits in the schoolroom or at home requires time; it cannot be done in a day. The material should be before the pupils for several days, where they can watch it, and occasionally report what they have learned. They may watch the germination of the seeds in their window-boxes, or the development of the buds in the jars, or the movements and habits of the crickets or fish or snails or crayfish, for a week or more before they have a formal lesson. Much of this work will be done before or after school, or at home, if the children are interested. If there are several boxes or jars about the schoolroom, they ean watch or study these during school-hours without confusion. The study of relation to environment and habits is of little value unless based largely on personal observation by the chil- 
dren. Without this it degenerates into mere guessing, which is worse than nothing - is not only useless, but injurious.

The teacher may help or guide them by occasional definite questions, perhaps one or two a day, written on a corner of the blackboard ; such questions as, "Find out exactly how the caterpillar eats and what it has to eat with," or "How does the caterpillar crawl?" "With how many legs?" "Does it use them all in the same way?"

To lead each pupil to observe for himself, it may be well to urge the pupils not to tell others what they have observed. Sometimes it is helpful to have each one write an account of his observations, of what he himself has learned, before there is any class recitation.

The order in studying habits and function of plants or animals is not material. We should begin with those most easily observed and leave to the last those most difficult for the pupils to see. In gathering up the observations in the class or in writing, however, all that has been learned about any one topic, as eating, moving, or breathing, should be brought out or told before passing to a new topic.

Here, in connection with the life and function, is the place to bring in the literature. The literature, if well selected, and the study of life, react on each other most helpfully at this point. 


\section{CHAPTER X.}

THE ORDER AND METHOD OF STUDYING MATERIAL. (CONTINUED.)

THE next step in the presentation of matter in the schoolroom is the study of structure, - that in the plant or animal which adapts it to its environment and fits it for its work or function; and that in the rock which is the result of the action of the agencies by which it was formed.

While much of structure is studied in connection with previous work, it is studied incidentally. At this stage structure must be emphasized both as a means of reviewing and clinching and unifying or binding together what has been learned about habit and function and story, and as a basis for a subsequent step in the process of unification; that is, comparison and generalization, or classification. After the child has learned the work or function of the dandelion root, has discovered how firmly it holds the plant in the ground, has seen its store of "milk" and noticed the disappearance of the "milk" and the shrivelling of the root as the seeds ripen, has learned that the rootlets take up water, and food dissolved in the water, then he is not only prepared to study the form and structure of the root, 
but such study will review and clinch and bind together what he has learned about function. The long, conical, tough main root suggests its function, - to hold fast. The thickened, upper part is fitted for its work as a storehouse, until the storehouse is no longer needed. The fibrous branches have a work, - to absorb water and food from the soil. It is more than a fleshy, conical tap-root, as the botanist would describe it; it is a holdfast, a storehouse, an absorbent. Moreover, this same root may in the next step become a type of roots which have similar functions, and thus become a means of still further unifying the student's ideas.

The relation between the study of habit and of structure and many of the principles and ideas discussed in this chapter have been applied and illustrated in the outline for the study of the rabbit in Chapter II.

The study of habits and function is largely a process of analysis. If we stop with the study of the habits of the canary-bird, we have little idea of the bird as a structural whole or unit. The study of adaptation to function or of structure is largely a process of synthesis, of bringing together and reducing to unity what has been separated in the previous step.

If the study of structure is to be a means of reviewing and clinching function, and is to lead the child to think, we must constantly ask "why" and "how." What is the use of this? Why is this so? It is not enough to say that the grasshopper has very large hind legs. Why? It has a groove on each side of the abdomen. Why? To aid in breathing. How? But the 
"why" should not be asked until pupils have gained clear definite knowledge of the facts necessary to answer the question. Mere guessing at "why" is worse than useless.

If the study of structure is to prepare for comparison and classification, we must particularly emphasize those structural features which are most important in classification, - the peculiarities of the flowers and florets in the dandelion and of the teeth in the rabbit.

With younger pupils in the first or second grade of the school, for whom structure has little meaning or interest, and whose power of relating or unifying structural features is but slightly developed, the study may stop with the observation of function and story, the growth of plants and habits of animals, and what structure may naturally be brought out in connection with these. As the children grow older, structure becomes more and more important as a means of reviewing function and preparing for generalization; as a step in the sequence by which they should relate their ideas, reduce them to unity, or to some approach to unity.

The question often arises, "How far is it wise to take up with the children details of structure or properties obscure or difficult to understand?" In general, in the work with children of any grade, only those features of structure or those properties should be studied or emphasized which either throw light on function (including use to man) or aid in comparison and classification, so far as the children of that grade study or can understand these. For instance, in the study 
of the mineral mica (commonly but incorrectly called isinglass), its softness (easily scratched with the fingernail), lustre (the brilliant shine of its surface), cleavage (the property by virtue of which it breaks into very thin plates), elasticity, transparency, and infusibility are the properties which make it useful and distinguish it from other minerals. It has many other properties, mineralogical and chemical, which the child need not study at all, or may merely note without attempting to remember them. The youngest children can discover the function of the little hairs at the base of each little dandelion flower, or floret (the pappus), can see how they aid in disseminating the seed. Therefore they should note the presence and appearance of these hairs. The young children cannot understand the real function of the stamens, so it is not necessary nor wise, in this flower, where they are so indistinct, to ask the little folks to study the stamens.

"How far is it necessary or wise to dissect animals?" is a question often asked. Teachers dread dissection. A similiar question which might be asked with equal propriety, but which is not often considered, is, "How far is it necessary or wise to allow or encourage the pupils to tear into pieces plants?" The higher aim of nature study - that is, to develop a sympathy and love for nature, and particularly for life-must determine this. There should be very little study of dead animals during the first three or four years, and no dissection of any kind during the first five or six years. During the last two or possibly three years, particularly 
during the last year, some dissection may be wise, but should usually be done by the teacher. Animals which are domesticated or are pets, such as kittens, should never be dissected before, or for, or by the children.

During the first two or three years children should never be allowed to pull to pieces plants or flowers. In later grades they should do no more of this than is absolutely necessary. They should learn to reverence life, plant or animal.

Closely related is the question as to the advisability of using microscope or magnifying-glasses. Nature study should lead the child to study the world about him, and to use the instrument he has, - his own eyes. Compound microscopes open a new world. While they add to the interest and gratify curiosity, while they are helpful in studying pollen grains and butterfly scales, and the compound eyes of insects and the breathingpores of leaves, they are not necessary for work with children, and give them little of much educational value. Children do not understand much of what they see in a compound microscope with a high magnifying power, partly because they do not relate it to what they see with their unaided eyes, partly because such a microscope shows at any adjustment only a section of an object in the plane which is in focus, and they do not relate the different planes seen at different adjustments. Simple microscopes are helpful in work with pupils in the upper grades in bringing out details of structure. They should be used very sparingly and carefully with young children, as they are apt to strain the eyes. 
If the study of structure is to be most effective in producing a clear mental picture in which or to which parts and functions are related, it must be orderly. In previous steps there should be an order or sequence, but conditions must largely determine that order. In studying or describing form or structure the order must be determined by the order followed by the mind in making a mind picture of form or structure. We appreciate and realize best the process in mąking a mental picture when we attempt to draw from a description what we do not see, - a spider, for instance (see Fig. 22). If, as we stand before our pupils ready to make on the black-

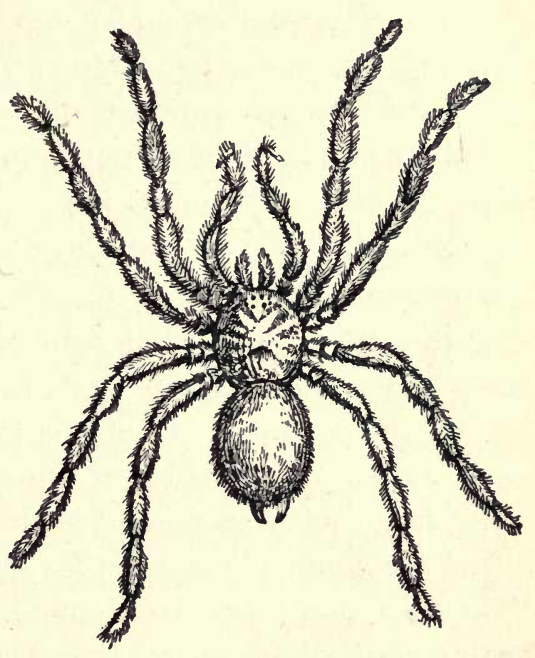

Fig. 22. Spider. board a picture of the spider from their description, we are told first that the spider has eight legs, or that it has several eyes, or that it has a pair of feelers (palps) in front of its head, we cannot draw, we cannot place the legs or eyes or feelers, or relate them to the whole spider. They must tell us first about the spider as a whole, and about its body, the part to which legs and 
eyes and palps must be related. If we are told that its body is an inch long, we can lay off that distance, or some multiple of it, on the blackboard. Next they might tell that it is about one-third as wide as long, rounded at the sides (oblong, some might say), divided by a neck into two parts, the first a little shorter than the second; both a little longer than wide, rounding toward either end. From such a description we might get a fair mental picture, and make a fair drawing, though we had never seen the spider. Now we want to add the appendages or other parts. It does not help us even now to be told that the spider has eight legs. We cannot relate them to the body. Where are they attached? we ask. Four fastened on each side of the first division of the body, the first pair back a little from the front end. Now we can place them in our drawing. If next they began to tell about the ends of the legs, we would be at a loss again. The bases of the legs are in place; the ends have not been related to the base, are off in space. First we must get some idea of the legs as a whole. They are long (an inch long), slender, the first two pairs projecting outward and forward, the last two backward. They taper toward the outer end, and have several (seven) joints. Now we can get and make a picture. When told, not merely that the spider has several eyes, but that the eyes are near the front of the upper surface of the first division, and are arranged in two rows running across, with four eyes in each row, we can draw without difficulty.

This will serve to illustrate the importance of the 
following rules, which will greatly help us in unifying our ideas of form or structure, and in gaining and conveying to others good mental pictures of form: As minerals are distinguished by their mineralogical and chemical properties rather than by their forms, these rules have little application in the study of minerals and rocks.

First. Study and describe the whole before taking up its divisions, the central or main part before considering appendages.

Second. In studying and describing parts or appendages, first relate them to the whole.

Another rule may be added, not so widely applicable, but helpful in insuring logical order or sequence. It will also prevent a useless waste of material, so common when pupils study without order. Those parts should be studied first which are most easily observed, such as the outer parts of the flower and the bark of a tree trunk, and those left to the last which are enclosed by other parts, and for the study of which other parts must be removed.

Third. In studying, work from the base upward, and from the outside inward.

To insist on a rigid compliance with these rules in every case would make our work mechanical. But it is helpful to keep them in mind, particularly in work with older children.

The order in studying structure, particularly with younger children, will be greatly influenced by the law of apperception, and the law of interest, so closely re- 


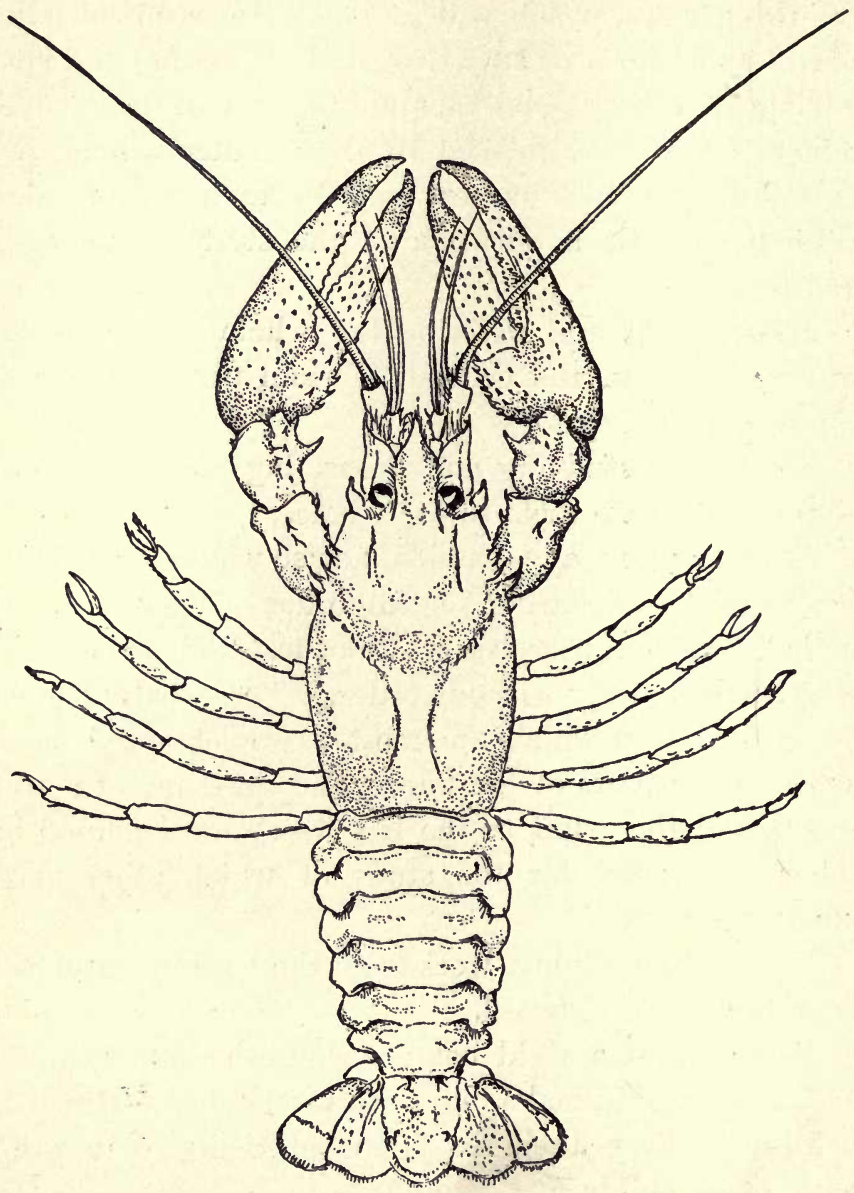

Fig. 23. Crayfish.

lated to it. The children will apperceive best and best build upon that in which they are interested. In 
studying the structure of the crayfish, for instance (see Fig. 23), if the children want to talk about its great "pinchers" first, let them do so, but not until they have studied the body and its divisions, and located the "pinchers" with reference to the body. From the "pinchers" they will naturally pass to the legs, and then to the swimmerets and tail fin, the parts by means of which the animal moves. Later can come eyes or feelers, large and small; the order is not material. The mouth parts, which are very difficult to see, and at best will not be understood, should be left to the last. If they begin the study of appendages with the large feelers or antennæ, take up next the small feelers most closely related to them. In studying the pea flower, if they are particularly interested in the little pod developing in the flower, it may be best to study this first, and consider the other parts in their relation to pod, to investigate the way in which they are formed so as to produce and protect the pod. We may then add another rule, subordinate to the others, which may influence the order in studying structure.

Fourth. Study first and emphasize those parts or properties in which the children are most interested, and which they can see best, and leave to the last what is most difficult to see or understand. We may find it best in studying limestone to begin with its effervescence with acid, or in studying mica to begin with its cleavage, or tendency to split into thin plates. These greatly interest the children.

What has been said about testing the order, clearness, 
and accuracy of a description by trying to draw from it, shows the value of drawing in the study of structure. The essentials in structure are the form and relative position of parts, and the best possible means of expressing these is drawing. As we have seen, we can at best get only an approximate and rather hazy picture of form from a word description. A few strokes with pencil or crayon will give us a better idea of crayfish or plant than we can possibly get from a word picture. When making a drawing of an object, we are compelled to observe much more carefully than when writing a description of it. We must notice the relative position and shape and size of every part we draw. On the other hand, nothing demonstrates so forcibly to ourselves, as well as to others, the lack of clearness in our ideas of form as the drawings we make. The youngest children see at a glance wherein the drawing they have made is incorrect or poor, when they do not and cannot see the deficiencies in a written description or word picture.

Remembering what was said in the previous chapter about the function and value of expression, we will find drawings most helpful in the study of structure in compelling pupils to observe carefully, and thus to gain clear ideas, and to express exactly, and thus convey those ideas to others, and in helping them to study and understand the drawings or pictures made by others.

It is an excellent plan, pursued in many schools, to place the object before the pupils without any previous study or description of structure, and tell them to draw it. These first drawings may be criticised and discussed 
individually or in class, and afterwards a second drawing made. After pupils have made a careful drawing, they are much better prepared to write a good description, if that is thought necessary. The drawing is frequently so much better than the word picture that it is not necessary or wise to ask for a written description. But it must be remembered that the most common, and usually the most convenient means of expression and communication is language; and children must learn to express by language as well as by drawings.

It is helpful to have each pupil make a drawing on the blackboard, and have the class select the best drawings, and tell why they are best. This makes them more careful and critical. The writer's experience has shown that even children in the first grade usually select the best drawings, and can tell why or wherein they are best.

We must remember that drawing from nature involves a more or less careful analysis of the thing drawn, a study of the relative position of its different parts. Pupils who have not been trained in this kind of drawing rarely have the power of careful analysis. If we simply place an object before the pupils, and tell them to draw, the results will be poor, particularly if the object is complex. The teacher must show her pupils how she draws it, lead them to analyze it with her, measuring (as when drawing the crayfish) the length of the body, and laying off this length, or some multiple of it, on the board, determining where the division line between the two main parts of the body comes, and meas- 
uring and representing the width at different points. Having represented the outline of the body, the details and appendages can be added. The teacher's drawing must always be erased to prevent copying, and the children asked to draw their crayfish in the same way.

At first pupils should draw only in outline, putting in very few details, as suggested in the drawing of the rabbit in Chapter II.

Whatever drawings the children make should be as careful and truthful as they are capable of making them. Otherwise the drawing may do more harm than good, tend to strengthen careless habits of observation and expression, and to fix in the child's mind incorrect forms.

It must be remembered that these drawings must express the ideas of the children, not those of the teacher, and must be examined and criticised from the standpoint of the pupil, not from that of the teacher. They must express the truth as the child sees it, and may be far from artistic. What is very poor from the standpoint of the artist or of the teacher may be very good when looked at through the child's eyes, regarded as the expression of his ideas.

The relation of drawing to nature study is farther considered in the chapter on expression (Chapter $\mathrm{XI})$.

In describing structure, scientists use a host of scientific or technical terms. How far is it necessary or wise to use them in work with children? This can be largely determined by a consideration of the use or 
function of scientific terms, and of the characteristics of the child mind.

Scientific terms are not mere "hard words," as the non-scientific are prone to regard them. They express in the most concise, clear, and exact form ideas or facts. When the botanist describes the leaf shown in Fig. 24 as, "pinnately compound, with odd leaflet, with nine leaflets, opposite, short petioled, stipellate, ovate, slightly acuminate at apex, entire, pinnately veined," he expresses with a few words what cannot be as clearly or exactly expressed in non-scientific or ordinary language with five, or perhaps ten, times as many words. From such a scientific. description, one familiar with the meaning of the terms used can make a fairly truthful drawing, and gain, of course, a fairly correct mental picture.

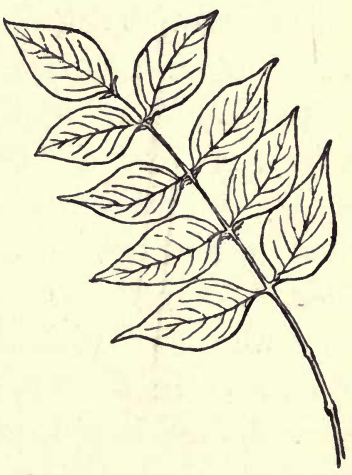

Fig. 24. Compound Leaf.

The main use of scientific terms is, then, to express facts in language as concise and exact as possible. Young children rarely need such terms, because their ideas are general rather than minutely exact. As children grow older their observations become, or should become, more careful and detailed, and they need exact terms to express them.

These should only be used so far as they are needed by the children to express their ideas. Children should 
never under any conditions be required to memorize a mere list of such words ; the terms, for instance, used in describing leaves. If, on the other hand, they can be first led to see or realize how helpful these terms are, they will be glad to get them and use them. Children even in the first grade, studying the bean, who have been given no technical terms, and have been encouraged to describe in their own ways, after struggling for two or three days to tell about the "two halves," or the "two thick white parts," or the "two pieces which cover the little bud," will welcome the word "cotyledon" as a friend, and use it freely and correctly. No other word expresses the idea. In the morningglory seed, where these cotyledons are so leaf-like, the children may call these parts seed-leaves, but not in the bean. After the children have gained an idea which they want to express in language, and have no word to express it, they need and will welcome the word, even though it is long. Until then they have no use for the technical term.

In general, the common terms, when they are exact in meaning, are much better for young children than the technical terms, - feelers better than antennæ, breathing-pores better than spiracles.

On the principle of apperception, scientific terms will mean more and be more readily remembered just in proportion as they are closely related to what is already in the child's mind. This can be done by always explaining their meaning. When the child knows that plumule means "little feather," and lanceolate means 
"lance-shaped," and micropyle (the opening in the skin of the seed through which the growing end of the embryo pushes) means "little gate," and calyx means "cup," and pinnately means "like a feather," they will remember the terms more readily, and use them more intelligently. If the oldest children know the meaning of a few root words, they can often form many words by combining these; such words, for instance, as epi, upon, and peri, around, and hypo, under, used in forming the botanical terms, epi-sepalous, epi-petalous, epigynous, perigynous, etc.

In the case of words describing forms, such as those relating to leaves, it will be found helpful to have charts prepared and hung up in the schoolroom showing the forms and the words together. These will keep the forms and the words expressing them constantly associated before the pupils' eyes. The pupils can refer to these charts to find the proper terms to express exactly the forms of the leaves or other objects they are studying.

As has been.said before, the story of life history, of development from germ to adult, may be brought out in connection with life and function, or after the study of structure. When the children can watch development, as of the tadpole into the frog, and of the caterpillar into the butterfly, this becomes a study of successive adaptations, or adaptations to different environments, and may well be studied in connection with habits as a preparation for structure. Where the story of life history is simply told to the children, it is best, in general, to leave it to the last, that is, until after 
structure, because some knowledge of structure will be necessary to understand life history, as in grasshopper or crayfish, and because the life history, being merely told to the children, will be hazy. What is hazy, the weak link in the chain, should be left to the last and made subordinate, so that later important steps will not depend on it.

We have studied plant or animal or stone as to : -

First. Its name and significance of name.

Second. Its relation to natural environment.

Third. Its habits and the functions of its parts (and its life history?).

Fourth. Its adaptation to function or its structure (and life history?).

In the endeavor to farther unify our knowledge, the object or phenomenon studied must now be compared with others like and unlike it, so that what is like it may be grouped with it, and what is unlike separated from it. Thus in time the things we have studied are not mere individuals, but types of classes, - the grasshopper of hundreds of insects, the robin of scores of birds, the buttercup or wild rose or lily-of-the-valley of groups or families of plants; and the experiments we perform explain many phenomena, - as the evaporation and condensation of water from the tea-kettle help the pupils to understand about the formation of dew and rain and mist and fog and cloud.

The purposes or objects of comparison or association, and of classification or generalization, are:- 
First. To train the child to note and study carefully resemblances and differences in objects before him. The young child usually sees differences most readily. For classification the teacher must emphasize resemblances and help him to see them.

Second. To lead him to distinguish the essential or important from the non-essential or unimportant in the form of plant or animal, or in the property of mineral, or in physical or chemical phenomena, and to relate or group or classify in accordance with essential resemblances and differences.

Third. To help him to recognize or abstract the general plan in plants and animals, and general principles or laws in physical phenomena, and to realize more and more a unity in apparent diversity.

Fourth. To lead him to apply his generalizations to other phenomena, and to arrange his knowledge in the most convenient form for ready reference; to "tie it up in assorted bundles ready for use," each bundle or group or class labelled and represented in the mind by a type. Thus the bee may represent the insects, or the membrane-winged insects; the robin or sparrow the birds, or the perchers; the cat the vertebrates, or the mammals or the flesh-eating (carnivorous) animals or the cat family, depending on the extent to which the knowledge has been assorted and grouped.

Lessons VII and VIII in the outline for the study of the rabbit, given in Chapter II, illustrate order and method in comparison and classification, and bring out the application of what is here presented. 
The work in association and comparison can and should be carried on from the very first with the little ones in the first grade. Gradually, certainly in the second year, they can begin to discriminate more carefully, pick out essentials, and see something of plan. Later, in the third or fourth grade, and in subsequent years, more emphasis should be placed on recognition of plan, and of principles or laws, and on definite classification.

Success in comparison and classification - that is, real classification by the pupils, not a mere memorizing of classification given by teacher or book - depends almost entirely on the character of the previous study of structure. If the teacher has required definite and exact observation, and if she has kept in view the classification to come later, and has emphasized those points of structure which she (but not the pupil) knows to be important in classification, there will be comparatively little difficulty when pupils are old enough for generalization. In comparing the crayfish and crab (see Figs. 23 and 25), to get the general notion of the class of animals (crustacea) to which both belong, the children will recognize the resemblance, if in the study of the crayfish the teacher has dwelt on plan, on the divisions and covering of the body and the number, position, and character of legs and other appendages. If she has been satisfied with a glance at form and color and length of parts, and paid little attention to plan, she will find that the children cannot classify for themselves. They have no foundation for it. If in the study of the rabbit 
blances, rather than differences, and to recognize similarity of plan or cause or law, we must endeavor to first associate or bring together and compare those objects which resemble one another, and then those which differ more. The results will be much better if we compare the crayfish with the lobster (see Fig. 26), and then with the crab to get the idea of crustacea, than if we first compare crayfish and crab, which are so different from each other.

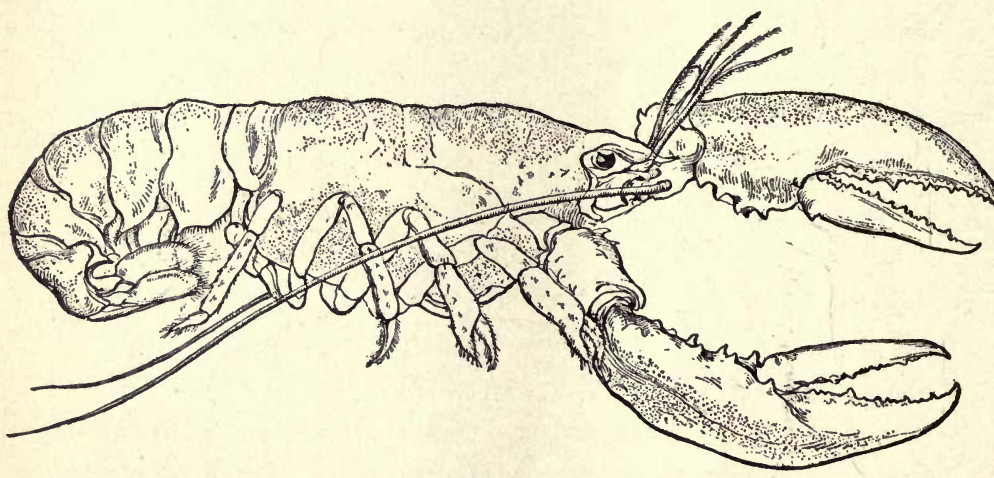

Fig. 26. Lobster.

After resemblances are seen they can be emphasized by contrasting animals which are similar with those which are dissimilar. After the children have discovered that crayfish and crab and lobster are alike in having two divisions of the body and five pairs of legs, they can be compared with the grasshopper (Fig. 27), which has three divisions of its body and three pairs of legs. This will bring into sharper relief, and prepare for the study of, the distinctive characteristics of crustacea. 
We will succeed in bringing into prominence in the pupil's mind the essentials in structure, or plan, or physical phenomena, and thus leading to classification or generalization, in proportion as we lead the pupils by our questions, to see and dwell on these essential features. If we encourage or allow a careful comparison of the multitude of details, often more or less accidental, such as color and minor markings, and length of parts, the association and comparison may have little result. In the comparison of dandelion and thistle (see

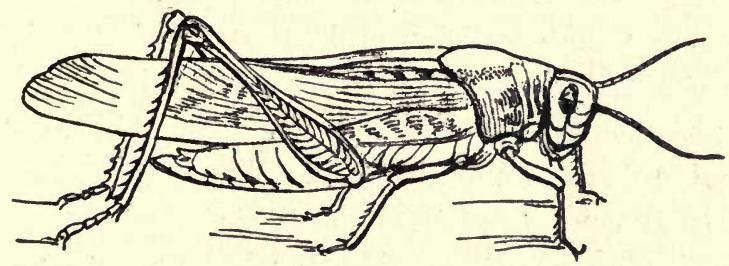

Fig, 27. Grasshopper.

Chapter I), we will gain little if we dwell on difference in calor, and in number of florets, and in length of parts. Only in proportion as the pupils dwell on the similarity of plan in the dandelion and thistle blossoms will they get an idea of the composite family of plants.

It will be seen that the process of abstraction and generalization requires the most careful work in development or questioning. In the previous steps the children, if properly taught, will accomplish much with very few questions. In generalization, particularly when made from few particulars, the pupils must be led by the teacher. 
One precaution is very necessary in the process of generalization. We must constantly resist the tendency to generalize from too few particulars. Broad generalizations based on very few particulars lead to careless, hasty, and often erroneous thinking. While schoolroom conditions will not admit of the study of the great number of particulars which must precede thoroughly scientific generalizations, we must be exceedingly careful about generalizing from one or two particulars. We must multiply experiments before deducing laws, and study as many plants or animals or minerals as the condition and interests of the children make possible before passing to classification.

We must not be satisfied when the children have worked out the generalization. These generalizations must be frequently applied to other plants and to other physical phenomena, so that the habit of working up to and making use of generalizations may be fixed.

This brings us to the last step in the method of presenting or studying material. We must apply what has been perceived and apperceived, and related and unified, to other phenomena. Thereby we cannot only fix and clinch in our mind what has been learned, but we can make it a means of further development and better adaptation, or broader unity.

When the children have learned about the conduction of heat, they should apply the knowledge to the explanation of a host of familiar facts, by studying such topics as clothing, storm-windows, stove-lifters. When 
they have discovered the distinctive characteristics of the composite family of plants, they should be led to gather and relate all the kinds of composites they can find. When they have learned how plants in the schoolroom develop, they should apply what has been gained in the investigation of the germination and development of several plants out-of-doors.

Here we can and should strongly emphasize (particularly with older pupils) practical applications. The study of the dandelion seeds, with their hairy' sails, may thus lead to the hairy cotton-seeds and the cultivation and process of manufacture and great value of cotton. From the flax we may pass to linen, and from the sheep to wool and to its manufacture and uses.

In connection with this step will come many opportunities for supplementary reading. In thus broadening the pupils' ideas, making what they have seen helpful in understanding what they cannot see, but must read about, such books as "Stories of Industry" and King's Geographical Readers are very valuable. (See also Chapter XII.)

What has been learned in the nature work should also be applied in other school-work. Nature study thus becomes the basis for physical geography, is very helpful in commercial geography, and throws much light on political geography. It may illumine much that the children read. It becomes a foundation for the expressive work of the school.

Teachers and pupils are prone to think that when a subject or topic has been completed, nothing more is to 
be done with it. Each thing completed, be it one fact or a broad generalization based on many facts, is but a means of apperceiving new ideas, a link in another sequence, a help in higher generalizations, a preparation for greater unity.

The applications of nature study in other schoolwork, and the methods of relating nature studies to other studies in the elementary schools, are considered in Chapters XI, XII, and XIII.

The question naturally arises, Is it always wise to follow from beginning to end this order of study, to consider each of these steps in studying any object? No, most decidedly. While this indicates the line of thought, the point at which we begin or end and the relative emphasis placed on different steps must be determined by the age of the children, the character and amount of preparatory work, the material available, and other conditions.

With young children we will place all emphasis on relation to environment, life, habits, and function, with very little comparison and application. Children are not ready for much work in the later steps. As the children become older, they are prepared for a more thorough study of structure, more work in classification, and can make a wider application of what they have learned. The older the children the more important in general are the later steps, which involve wider knowledge and require power of generalizing.

Where children have had nature work in the lower 
grades, much, but not all, of the earlier work can be done there, and in the upper grades the work can be built upon these foundations.

Where living animals or growing plants can be easily procured, the study of relation to environment and habits can and should be strongly emphasized even with older pupils. When only mounted specimens or pictures can be obtained, then comparatively little attention can be given to habits.

Closely related is the question as to the time to be devoted to the different steps, or to the whole work in the study of any topic. This must also be determined by the age of the children and by conditions. Children in primary grades may devote from one to four or five lessons to a plant or animal. It takes a very strong teacher to keep little folks interested in one thing longer than that. In the upper grades ten or fifteen or more lessons may be profitably devoted to the intensive study of such topics as corn, the rabbit and the family of "gnawers," the cat and the cat family, the pine and its relatives and their economic uses, coal, iron, etc.

The order of study as outlined is very generally applicable in the study of living or organic nature, plants and animals. Much the same line of thought can and should be followed in the study with children of inorganic nature, of minerals and rocks, and of physics and chemistry.

In studying such a rock as limestone, the first step after the children know what they are studying, and have noted the distinctive properties by which they can 
recognize it, is to relate it to its natural environment, to describe the places where and the conditions in which it is found, and, if possible, show how it is affected by its environment; how it crumbles or disintegrates and forms soil under the action of rain, air, roots; how it is worn away and carried along and deposited by waves and streams. If it is possible to study this reaction between the stone and its environment, which corresponds to habit in living nature, it will make much more intelligible the next step, the life history or story of the formation of the limestone. When the children see that the solid rock breaks down into mud, they will be better prepared to understand that it was formed from mud and animal remains. The story of the animals and other agencies which formed it, and of the process of formation, is largely recorded in its structure, and thus leads to and prepares for the study of the structure of limestone, its fossils and layers, and perhaps of its uses and adaptation to uses. From this we can pass to comparison with other limestone, perhaps with other lime rocks previously studied. The last step is the application, such as the relation of what has been studied to geography, the uses of limestone, and of materials made from it, and the processes of manufacturing lime.

A similar line of thought can be followed in the study of sandstone and shale and granite, and of such minerals as coal, the iron ores, quartz, graphite, and pyrite.

In studying physics and chemistry this order is not 
so applicable, and yet a similar line of thought can be advantageously followed, particularly with younger children. In the study of heat we can begin with its sources (leading and relating finally to the ultimate source, the sun), investigate next its work or function or effects (from which alone scientists, but not children, may gain some idea of what heat is, what may perhaps be termed its structure), and gradually, after many comparisons, generalize or determine laws or principles, and, lastly, apply these principles to the explanation of other phenomena. The line of thought is much like that followed in studying plants and animals. In work with gravitation, the pressure of liquids or of air, magnetism, and other physical forces or phenomena, a similar line of thought can be followed. 


\section{CHAPTER XI.}

NATURE STUDY AND THE EXPRESSIVE WORK OF THE SCHOOL.

WE have formulated the aims and discussed the psychological principles which must determine method in nature study, and have considered the application of these principles in the study of material.

We must now turn our thoughts to the relation of nature study to other school-work, and to the means and methods by which it can be made most helpful in such work.

In planning any work for elementary schools, the advocate of nature study must keep in mind the immediate object of these schools. That object, as recognized by most school officers and parents, is to teach reading, writing, arithmetic, geography, — "the essentials." Many teachers look little farther.

The educator who has deeper insight and a broader and higher outlook looks beyond these immediate objects to higher aims, - the development of the whole child, the building of character, the perfecting of the relations between the child and his environment, nature, man, and God.

The two objects are in no sense incompatible. 
Rightly considered, one is simply one means by which the other may be attained. The parent or teacher or school officer is perfectly right in believing that the children must be taught reading, writing, arithmetic, and geography, and right in opposing the introduction into our schools of anything which takes the place of these "essentials," or weakens the effective work in them.

While nature study has a most important place in our elementary schools, just as science has a place in higher educational institutions, independent of its relations to or effect on other school-work, the extent to which it makes and keeps a place in the average school, under average conditions as they exist at present, with average school officers and teachers, will depend very largely on the extent to which it is shown to be helpful in other school-work. The opposition to nature study by the stanch believers in "the three R's" will be best overcome by those who most conclusively demonstrate that nature study does not in any way take the place of the essentials, but, rightly taught, greatly helps them.

Nature study is simply a recognition of the dependence of the child on sense-perception. What comes through his senses makes the clearest and deepest impression, and forms the best foundation for expression in language, drawing, and reading, for geography and for other school-work.

The relation of the work of the elementary school to the two immediate centres of education, nature study 
and man study, and to the ultimate centre, God study, and the grouping of all school-work about these centres, were considered in Chapter VI.

All the studies of the elementary school may be divided, in a general way, into two classes: those which are directly concerned with nature and man and God, and those which are concerned with the means of conveying and relating what is learned about nature and man and God. In the first of these classes are included such studies as literature and art, history and science, and much of geography; in the latter, such studies as language, oral and written, drawing and arithmetic.

In literature and history we study man, his notable deeds and great thoughts and slow development. In science we study nature. Geography is a study of nature and of man's relation to nature. All of these have a value in themselves, dependent on what they contain, the knowledge or ideas or inspiration we get from them. So we call them content studies.

On the other hand, language and drawing have very little value in themselves, at least as they are and must be taught in the elementary schools; their value is determined by what we can do with them, what we can express or convey to others or gain from others through them. Hence they have been called instrumental or expressive studies. As the value of these studies depends mainly on what can be done with them (rather than on what they contain in themselves), and this is 
determined by their form or the relation of their parts, they have been called formal studies. Arithmetic expresses the quantity and proportion of things, and does this through or by means of the proper relations of the units used. Hence it is a formal or instrumental study.

This division into content studies and formal studies is somewhat artificial. Language and drawing may have much content, but not as studied in elementary schools. For such schools the classification is helpful.

In the schools of the past, and in not a few of the schools of to-day, all emphasis has been placed on the formal studies, - reading, writing, arithmetic. Even geography, mainly a content study, has often had most of the content taken from it. It has been a mere memorizing of a description of the earth's surface, rather than a real study of the earth's surface.

We are learning to-day the wisdom of placing more emphasis on content studies, not to take the place of formal studies, but to serve as a basis for these, and to make these more effective. We are discovering that when we take time, in the elementary school, to have our children gain ideas about their environment, nature, man, and God, they learn to express, to read and write and draw, in less time than when they gave all their attention to formal studies. They have ideas to express. Instead of merely studying about the instrumental studies, the pupils learn to use them by using them to express ideas, just as the carpenter learns to use his tools.

Not merely is the work in the expressive studies 
strengthened rather than weakened by devoting a portion of the time in elementary schools to content studies, such as science and history and literature, but, what is much more important, the children receive better, richer, more nutritious mental food, and are thereby broadened and developed. Before, they were fed too largely on something akin to husks, form or externals rather than content.

As has been said in previous chapters, nature study is particularly valuable as a content study and basis for work with children, because it appeals directly to their senses, through which the ideas of children must ultimately come. As the children grow older and have acquired through their senses a larger stock of ideas, or apperceiving concepts, more and more attention can be given to those studies which do not appeal so directly to the senses; to such studies as history and literature.

It is as a content study, serving as a basis for the formal or instrumental or expressive studies, that nature study will meet the least opposition. Teachers in communities opposed to "fads," so called, will find it wise to emphasize the value of nature study in reading, writing, drawing, and geography.

On the other hand, those children will get the most from nature study or any other distinctively content study who are led to express most carefully what they have learned. Their ideas are not clear until they are expressed. From any point of view it is wise to insist on careful expression, to correlate closely the content studies and the formal studies. 
The object of expression is threefold, as was shown in Chapter VIII :-

First. To make our own ideas more clear and orderly. Second. To convey our ideas to others, and enable us to influence them.

Third. To give us a means or medium through which we can receive ideas from others.

We must keep these in mind in our discussion of the relation of nature study to the expressive work of the school.

In much of our work in the past we have made use of only one form of expression, - language, oral and written. As we study the children we appreciate the fact that there are many other forms of expression, some of them much more expressive for the children than language. We find it necessary to consider the uses and relative value in nature study of these various forms of expression; viz.: -

$\begin{array}{ll}\text { Motion or Gesture. } & \text { Drawing. } \\ \text { Music. } & \text { Painting. } \\ \text { Sewing. } & \text { Language. } \\ \text { Moulding. } & \end{array}$

Long before the child can use a word he has learned to express his wants and feelings by gestures, or movements of his body. This is a most natural form of expression, which he continues to use throughout life. It is particularly effective in telling about action, position, and direction. Watch children use their hands, 
and see what they can tell with them, - ideas for which, oftentimes, they have no words.

In primary work particularly, where the children must depend so largely on their senses, we must not merely use material which appeals to their senses, but must make use of and encourage those forms of expression which make use of the senses, the different forms of what may be called sense-language. One of the simplest of these is gesture.

When the children cannot express in words, even the youngest can often tell much with hands and arms and legs. The writer remembers a lesson - one of many learned from a little three-year-old who had been much interested in some crayfish in a can. "When the little fellow was asked to tell how the crayfish moved, he struggled and floundered, trying to find words. When asked to show how the crayfish moved, his face lighted up instantly, and he soon demonstrated that he had very clear ideas of the mode of locomotion called "crawfishing." Some time later, when asked to tell how the earthworm moved, he "told" by wriggling wormlike on the floor.

The value of music as a means of expression in nature work will be recognized in proportion as the teacher realizes and keeps in view the higher aims of nature study, - the cultivation of the higher nature of the child, æsthetic, ethical, spiritual. The value of music in nature work will depend on the content teacher and pupils put into and get from their study of nature. 
If the main aim in the teacher's mind is to develop the purely intellectual powers of the child, the power to see and tell and think, to compare and discriminate and classify or generalize, then nature study and music will have as little relation as nature study and literature. If teachers are satisfied with the study of mere externals, general form or structure, then music is almost useless as a means of expressing the ideas gained.

If teacher and children go beyond form to the heart of nature, then nature is full of music, is instinct with thoughts which music can best or can only express. The play of the wind, the song of the birds, the ripple of the brook, the patter of the raindrops, the roll and roar of the waves, the singing of the tea-kettle, are all parts of the eternal symphony.

\section{The harp at Nature's advent strung Has never ceased to play; \\ The song the stars of morning sung Has never died away.}

WHITTIER.

After a lesson, a real wide-awake lesson, on the signs of spring, or on the bluebird, or on the nest with its blue eggs in the tree just outside the window, the teacher may find that a song will express more, and impress more of what is most important to express and impress, than a half-hour or hour spent in drawing the nest, or in writing about the swelling buds or the habits of the bluebird.

A song at the opening exercises of the school may be more expressive and more effective in increasing the 
children's sympathy with the world of life than hours of drawing or talking or writing.

Music and its strongest ally, poetry (the value of which is considered in discussing the relation of nature study to literature), are exceedingly helpful in cultivating the reverential attitude which will lead our pupils to join with nature in the hymn of praise to the Author of nature.

Nowhere is music, as a means of expression, so essential as in the primary grades.

Sewing has had a wide use in kindergarten and primary work. When the children can select for themselves the threads to match the color they wish to express, the sewing becomes helpful in color work. The stitching of the outline, if the work is not merely mechanical, may impress the form. Sewing also trains the pupil in doing orderly, careful, neat work. But its value as a means of expressing ideas is very limited. Little children can rarely make their own outlines; in general, they merely follow the outline pricked by the teacher or some one else. Hence there can be little individuality, and therefore little genuine expression, about such work. Furthermore, much fine work of this kind is trying to both the eyes and hands of the children.

Moulding or modelling in clay is perhaps the simplest and best means of expressing form which little children have. With clay the children can express the third dimension, depth, as well as length and breadth. 
Hence they can express with clay the form of solids exactly as they see them. In their sewing or drawing they can only outline solid forms.

The clay is so plastic that it can be very easily modified, and children are enabled to work readily toward a more nearly correct form. It is more difficult for the children to change their drawings.

On the other hand clay in the hands of young children is decidedly limited in its application as a means of expressing ideas. In general, they can only use it to express their form ideas of rather simple and gross objects. It is exceedingly difficult, if not impossible, for average children to express with clay anything but form ideas, or to show even the form of those things which are delicate. They can model the bean seed, but not the plant which develops from it. We may let them attempt thus to represent a horse or dog, but we see instinctively that we must not ask them to model a butterfly. The model of flower or butterfly is almost certain to be a caricature, which may be positively harmful in its effects.

In plant work moulding has the widest application. The form of seeds, buds, stems, roots, leaves, and fruits can be expressed or represented very exactly and clearly by means of clay models. In the study of animals there are not so many opportunities for modelling. This means of expression can be used very little in work with minerals or in physics, because form is of relatively little importance in these studies as they must be pursued in elementary schools. 
Drawing is a most helpful and important means of expressing what is gained in nature study. It is the most natural, the clearest, the most exact, and the most concise medium for expressing many of those ideas which come through the eyes. In the work in schools it can be used mainly for expressing form and relative position. Drawing cannot be used very largely by average school-children for telling about life and action and function.

Unless aided by drawing, nature study, or science, loses much of its value. On the other hand, nothing has done more than nature study to demonstrate the value of drawing in our elementary schools as a language or means of expression. As nature study has been introduced, and more emphasis placed on sense-perception, and particularly on the importance of using the eyes, more attention has been given to drawing as a means of expressing what is seen. Drawing is an eye language, in many respects the best eye language.

Mr. Henry T. Bailey, State Supervisor of Drawing of Massachusetts, has said, "The advocates of nature study, not the drawing-teachers, have had the honor of opening blind eyes to see drawing as a living language within the reach of all."

Drawing is a most natural form of expression. There is a natural relation, which appeals to the eye, between an object, such as a bud, and a drawing or picture of such an object, - a relation which any child of any nationality may discover. There is no natural relation between the object bud and the oral or written or 
printed word bud. The relation between ideas and the symbols which we call words must be gradually established in the mind of each child. No such practice is needed to establish the relation between ideas and the pictures representing them. Drawing is a natural universal language.

In the development of mankind drawing has preceded written language. The first writing was picture writing, and from pictures written language was gradually evolved. As children are more dependent upon their eyes than adults, so they find more helpful or necessary a means of expression, such as drawing, which appeals to their eyes.

Drawing is also the clearest way of expressing form ideas. It is, in general, impossible to describe any object in words as clearly as with a picture. We realize this when we compare the ideas we can gain from the clearest possible description of some simple object, such as a table or chair, with the ideas we can gain from even a crude sketch of the same object. The latter gives a very much clearer mind picture.

Form ideas can be expressed most exactly by drawing. It is impossible for any one, child or adult, to tell in words as exactly as by a drawing much of what he sees. Much more careful observation is necessary to make a fair drawing of an object, than to write what will be generally considered a fairly clear description of it, as any one will discover who makes the experiment. It is mainly because we do not observe carefully that we find difficulty in expressing by means of 
drawings. As soon as we learn to observe accurately, and to analyze carefully, the form of what we see, most of the difficulties in simple representative drawing vanish.

If language is the only means of expression used, the child soon learns that he cannot express his ideas exactly in words; therefore he does not observe exactly. If, on the other hand, the teacher insists on exact observation and exact word description, the child becomes discouraged. He is expected to do what is unnatural and exceedingly difficult.

Children, even in the first grade, can discover and often correct the errors they have made in their drawings. The experience of the writer has shown that the children in a first-grade room will almost always select the best drawings among several made on the blackboard by different pupils, and will usually know why or wherein they are best. They find much greater difficulty in selecting the best word description. It does not appeal to their eyes.

With the older pupils the best way to test the clearness and exactness of a description or word picture is to attempt to draw on the blackboard from the description, to interpret the word picture into the eye language. The pupils see at once the lack of clearness and exactness, as they cannot be made to see it in any other way.

Drawing is, furthermore, the most concise means of expressing form, size, and relative position. A few strokes of pencil or crayon may tell more than a long description. 
A drawing brings out the essentials and distinguishes them from the non-essentials, and shows the essential or important relations between parts. When we attempt to draw a leaf, we see the necessity of selecting for representation important features of the leaf, its length, breadth, and the position of the widest part, the position of the midrib, and the relation of other veins to this. After we get the skeleton, the essentials of the form, we can add as many details as seems wise. In making a drawing, we realize much more readily than in writing a description the advantage of first selecting important features, and of proceeding in order.

The value of drawing in connection with the study of structure is considered in Chapter X.

Drawing has been taught in our schools as a part of art education, or as an adjunct to form study. It will be much more helpful, both in school-work and as an aid in practical life, if more emphasis is placed on representation; if drawing is used more as a language, a means of expressing and clarifying and fixing the ideas gained in other subjects. The power of accurate representation and the power and habit of close observation gained by such work in drawing will, ultimately, be the best preparation for artistic development.

Mr. Henry T. Bailey, to whom reference has already been made, has said, "Drawing, as a language, has a permanent place in the school. Five hundred years ago it was the universal conviction that reading and writing were of no value to common people, and, moreover, that the masses could never acquire such profound 
learning. A similar conviction seems to have possessed us in these days regarding drawing. We now believe it criminal to allow any child to grow to adult age without the power to read and write; our successors - not five hundred years hence - will come to a similar conclusion about drawing - the oldest written language of the race, the only one now universally intelligible."

Painting is, of course, the best means of expressing color ideas. Language does this very imperfectly. Painting trains the color sense, and gives that nice discrimination of tint and light and shade which adds so much to the enjoyment of the beauty of the world about us.

But there are many practical difficulties which are likely to prevent a general use, in elementary schools, of color as a medium of expression. With the colored crayons, sometimes used, the children cannot express truthfully the colors of what they see. The colors of the crayons do not match the colors in nature. The pictures made by children with crayons are apt to be hideously false. With water-colors more truthful representations can be made; but the mechanical difficulties, in mixing and laying on the colors, and the expense of the equipment for water-color work, are likely to prove serious objections to the general introduction of watercolor painting.

Language is the highest, broadest, and most universal form or means of expression. It is the principal medium of communication between intelligent beings. It is the 
medium through which the child must acquire most of his knowledge of the great environment which is too distant to be perceived through the senses. It is, therefore, the most important form of expression.

But it is not, as we sometimes seem to assume, the only form of expression. It is not the most natural form of expression. It is not always with little children, the best medium for expressing ideas.

Language is a very difficult form of expression for children. Words are artifieial symbols. In talking, the child has to learn to use artificial symbols for each idea. In writing about what he sees, the child has to use another set of artificial symbols for each idea he tries to express. At first the effort to form these symbols, the written words, requires considerable muscular effort and control. When writing about what he has been told, but has not seen, the child has to interpret one set of artificial symbols, the spoken words, into another set of symbols even more artificial, the written words. That is, in telling what he has simply heard he writes the symbol of the symbol (both artificial) of an idea. Is it strange that the idea is sometimes lost during the operation?

On the other hand, language is a higher and more general means of expression. Language expresses, as nothing else can, life and action and function, the higher side of the child's environment. It expresses the higher relations, æsthetic, ethical, spiritual, as they cannot be expressed, by the child, through any other form or medium of expression. 
So far as we emphasize in nature study the life side, the forces and processes, the ideas must be expressed mainly by language. The child cannot tell how a bud develops, or how a stream wears away its banks, and carries and deposits the sediment, by a drawing or model or painting. He must tell it in words. On the other hand, he cannot tell the form or structure of the bud, the results of the work of the stream, its course or the slope of its banks, so well in words as by a drawing or model.

Drawing and modelling are particularly helpful in expressing what comes through the eyes. Language expresses also intellectual and spiritual ideas other than visual or physical or sensuous ideas. We have found it wise in earlier years, when children are so dependent on their senses, to emphasize that which appeals to and impresses the senses, and to leave until later years that which is not so immediately dependent on the senses and requires greater intellectual power. Is it not, then, wise and logical to emphasize in earlier education those forms of expression, such as moulding and drawing, which are adapted to express sense-perceptions, and to emphasize more in later education that form of expression, language, which best expresses those ideas with more intellectual, moral, and spiritual content?

Three varieties of language expression may be used in our nature work. The children may describe what they see, the horse-chestnut bud, for instance, impersonally in the third person. "The horse-chestnut bud" has a certain form and color and covering, with certain parts, 
and develops in a certain way. This is description. We may lead our pupils to tell about "our buds," or, better, "my bud ; " to tell what "we," or, better, "I," did and saw and thought, make it more personal. This is, or is closely akin to, narration, which includes more or less description. Or we may have the child personify the bud, either tell about it as a living thing with feelings like himself, or have the bud tell its own story, or imagine himself to be the bud.

In the first case, the bud is a somewhat abstract or generalized thing far removed from the child. In the second case, each child is telling about the concrete bud in his hands or before his eyes. In the third case, the bud is, for the time being, the child himself, not something outside of himself.

These three forms of language expression are illustrated in the "blackboard stories" given in Part II, in connection with the study of the mallow in the first grade.

Very much depends on the kind of language expression used. It is not necessary to ask any primary teacher who is in sympathy with little children which of the three is most expressive for the little folks, which is most natural, simple, and attractive. The little child naturally idealizes or personifies or endows with life much about him.

The more what is studied is brought near the pupils, the more the personal element is introduced in the expressive work, as well as in observation, the more free, natural, and individual are the results. It is almost always better to have the pupils in all grades tell in 
the first person what "I" or "we" did and saw and thought. The narrative or personal form is more exact, because it is more concrete or specialized. As the children generalize, and tell about "buds" instead of "my bud," "trees" instead of "the tree I studied," their language becomes less clear and exact.

On the other hand, in narration, and still more in personification, there is great opportunity for the use of the imagination, and the tendency is to give play to the fancy at the expense of truth and accuracy. This tendency can be corrected by having careful drawings made, the work in drawing preceding, if possible, the oral or written work; and by sometimes requiring, particularly from the older pupils and from those whose imagination is most active, impersonal descriptions, giving the "cold facts."

In determining the form of expression to be used in our nature work, we will call music to our aid to express emotions of joy and pleasure; we will sing about spring, about sunshine and happy birds. Language we will use to tell about life and action and habit; the development of the buds, the germination of seeds, the veauty and work of leaves and flowers. In this, literature, and particularly poetry, will greatly aid us. We will make use of the idea of apperception by having our pupils occasionally personify and write in the first person and not confine them to impersonal abstract description. We will have the children try to tell about the form and structure of buds and seeds and leaves and flowers, endeavor to make word pictures of them; 
but we will place more emphasis on the expression of form and structure by carefully made, truthful drawings, supplemented sometimes by clay models. We will paint only those things which show decided colors, or in which the color is distinctive or characteristic.

Having discussed the forms of expression, and their use or relative educational value in connection with nature study, we are ready to consider the essentials in all forms of expression, and some of the means or methods of realizing or attaining these.

The greatest essentials in all expression are:-

First. Individuality.

Second. Truthfulness.

Third. Clearness.

Fourth. Order or plan.

Expression, whatever its form, is not genuine expression unless it is individual, unless it tells that with which the individual pupil has been impressed. A mere copying of the ideas of others is not expression, but imitation.

Class reproduction, having all copy from the blackboard statements obtained from different members of the class, is, at best, imperfect expression. Often, for many pupils, it is not expression at all. It is easy, convenient, and, when the pupil is first learning to write, necessary. But the sooner we pass beyond such copying, and have each pupil express his own ideas gained through his own senses, the more will we develop the power of expression. 
Yet even class reproductions can be made very helpful in training pupils in individuality, truthfulness, clearness and order. If in such work the teacher accepts only those statements which the pupils who give them have discovered or verified for themselves, if she insists that each statement be accurate and as clear as the pupils can make it, and if she selects and arranges the statements so that there is a sequence in the resulting class reproduction, the work becomes an excellent preparation for individual work.

Lead each child to see and think for himself; then he will have something to express, and will not merely repeat what he has heard. Discourage in every way mere appropriation from others. It is a species of stealing, and children can be taught to consider it dishonorable.

Encourage the personal pronoun in the description. The expression is much more apt to be individual when it is personal. The child who tells about "my" leaf or flower or stone, or about what "I" did and saw and thought, is almost certain to tell his own observations in his own way.

Do not accustom the pupils too much to the pumping process, nor lead them always to depend on questions to draw them out. This weakens the pupils. Questions, clear, definite, logical, are necessary at first. They make the observations orderly and definite. If placed on the board, the pupils have time to think about them, to observe and answer more carefully. But the pupils are apt to see only enough to answer the questions. 
Naturally they all tell about or express the same things.

The more children can be led and taught to see and think with few questions, the more they will have to tell, and the more their powers of observation and expression will be developed. In the two or three best recitations - clearest and most definite and orderly the writer has ever heard, one in a second-grade room, the teacher did not ask half a dozen questions during the half-hour that the lesson continued.

An excellent way to develop individuality and selfreliance is to encourage the pupils to ask as well as to answer questions. The teacher may ask a question of a pupil, who has the privilege, if his answer is satisfactory, of questioning a second pupil. This may be continued as long as seems wise. The plan has shown very good results.

Respect the pupil's individuality in observation. No two persons ever see exactly the same thing. What they see depends largely on what they already have in their mind. If your pupils see somewhat differently from you, do not assume at once that they are wrong. Both may be right. You may be wrong. If there is a dispute about the facts, - this is the opportunity for arousing interest and stimulating the spirit of investigation, - let the pupils settle it by going to nature. Do not decide it for them.

Respect their individuality in expression. Let them express ideas in their own way, in the words most expressive to them. Your "grown-up" language often- 
times does not express their ideas. If you insist on their telling in your language, you deaden their power of expression and discourage them. Overlook little errors.

Remember, too, that language, and particularly written language, is a somewhat "grown-up" method of expression. Other methods are often more natural. Many a child full of ideas appears dull merely because he cannot express in words. Let him use gestures, or tell it with hand or chalk or pencil, and the ideas come out.

Develop individuality in expression. See in how many ways the children can tell about what they have seen. If a fact is told in a certain way, and this is repeated once or twice, most of the children will tell it in about the same words, and the language work will show that stereotyped sameness which proves that it is not genuine expression. Have the pupils draw objects in different positions or from different sides. This lessens the tendency to copy or imitate the drawings of others; and copying is not expression.

The great essential, then, in expression is individuality. If it is not individual, it is not genuine expression, but largely imitation.

Next in importance to individuality is truthfulness, telling the truth; the whole truth, so far as it is seen, and nothing but the truth. Considering the moral development of the child, too much emphasis cannot be placed on careful seeing and truthful telling.

The cultivation of the habit of careful personal inves- 
tigation and exact, clear statement has long been recognized as one of the most valuable results of the scientific studies in higher institutions. How much better and easier to form habits of truth-seeing and truth-telling during the earlier years of a child's life!

Cannot we, in our nature work, even in the kindergarten, lead our children to observe as carefully and express as exactly as they are capable of doing? More can be done in this kind of training in nature study than in any other line of work, simply because nature study gives better opportunity for personal observation or investigation. It is much more natural and much easier to tell exactly and clearly that which has come to us through our senses, than that which we have received from or through others.

For this training in seeing and telling the truth, the first essential is plenty of good material, so that each child can see for himself, and can correct for himself by reference to the material before him any errors he has made in observation or statement.

With the material, an apple, for instance, in his hand, our pupil says, "My apple is round like a ball." True, but not all the truth. At your question, "Is it exactly round like a ball?" even the little fellow in the first grade will look again, and may add,." "It has a hole in one end." Another look will bring out, "It has two holes, one at each end," much nearer the truth.

If you are satisfied with the first answer as describing the form of the apple (the term "round" is very indefinite and inexact, although much used), you accept 
a half-truth, a species of untruth, and allow or encourage untruthfulness.

If you correct the answer yourself, you miss an opportunity to help your pupils to be more truthful. It will often add much to the interest of the lesson, and sharpen the pupils' powers, if you encourage members of the class to watch for and correct statements which are not true or not clear.

Encourage in every way exact statements. Have the children count and measure. Discourage guessing and indefinite forms of statement, such as "about" and "I think." Any absolute misstatements should, of course, never pass unnoticed.

It must be remembered that language is a very diffcult and inexact way of expressing many ideas, such as those of form, size, and relative position. Drawing, painting, and modelling are often much more natural, simple, and exact forms of expressing truth than is language. Any child can tell the truth about the form of a seed or fruit much better with clay than in words. Furthermore, even the youngest child can recognize errors in drawing, when he cannot see wherein his word picture is wrong. Hence children can correct their own drawings.

As teachers, we may attach so much importance to sympathy and interest and an appreciation of the lessons and beauties of nature, that we neglect the careful individual work which is of the greatest value in the development of the powers of our pupils. On the other hand, we may emphasize exactness in detail so 
strongly as to deaden the interest and dull the eyes to beauty.

Cannot we keep in view both these aims, giving more and more prominence to exact observation, expression, and reasoning, as our pupils are older? We shall then find our nature study most effectively preparing for and aiding in the study of arithmetic, and developing careful, truthful men and women.

Not quite so important as individuality and truthfulness are clearness and order. In work with the youngest children clearness means expressing each idea so that it can be easily and correctly understood. Order means combining ideas so that their relations can be readily grasped or appreciated. As children grow older, and gain power to relate different or successive ideas, clearness depends more and more on order.

We cannot expect a little child to be very clear; he does not have sufficient command of language. Neither can we, at first, expect him to be very orderly; he does not well understand the relation of ideas. If we place too much emphasis on clearness, we discourage the child; we ask him to do what he does not have the power to do. If at first we emphasize order of thought too strongly, we lead him to copy our order, instead of developing in him the power to see things in their relations, and to arrange his ideas for himself.

Greater clearness can be gained by leading children to discuss one another's statements or drawings, and decide (not merely have the teacher decide) how they can be made more clear and truthful, or can be changed so 
as to be better understood. Special care must be taken in the use of such a word as round, often used incorrectly as equivalent to spherical, cylindrical, conical, or disk-shaped.

Clearness and order in expression depend, to a considerable extent, on clearness and order in observation. If the first is well planned, the second is likely to be orderly and definite.

Both order and clearness depend largely on the way in which the observation lesson is reviewed and the main points clinched before the reproduction is attempted. If there is a clear, careful summary at the close of each step in the lesson, and a general oral review at the close of the lesson, just before the written reproduction, it will greatly aid in making the written work clear and orderly.

It is often helpful to lead the class to decide on the order. The teacher can ask the children, "What shall we study first? Why? What next? Why?" Similar questions may be asked in the oral reproduction. The order thus decided upon may be written on the board, and will help the children in their oral or written reproduction.

The same plan can be followed to advantage in the drawing or other form of expression. "In drawing the bud, shall we draw the whole bud first, or a scale? Why? In modelling this apple, shall we make the apple first, and then show the pits, or make the pits first, and then shape the apple? Why?"

In written work the teacher can guide the pupils at 
first by the order of her questions, to which they write answers. Later, an outline, formed as much as possible by the children themselves, can be placed on the board as a guide. Gradually the outline can be made less and less detailed. In the intermediate grades the children can often, or usually, make their own individual outlines.

To insure orderly full oral expression, or to lead the pupils to tell all about what they are studying, it is helpful to have the pupils stand, in turn, before the class, with the material about which they are talking in their hands or before them, and tell all they can about it, or some part of it, without questions from the teacher. At first they may follow an outline on the blackboard, but should gradually learn to tell without such an outline.

In the primary work we can strongly emphasize individuality and truthfulness, and make somewhat subordinate clearness and order. We can place more emphasis on the latter in the intermediate grades, where the power of clear expression and orderly thought is better developed. Later, in the upper grades, we can ask our pupils to tell all about what they have studied and in as few words as possible ; that is, give more attention to complete, concise expression.

Nature study, it must be remembered, is but one basis for the expressive studies ; man study, including history and that part of literature which is not inspired by nature, is another basis. As was shown in Chapter 
VI, nature study is the best basis for expressive studies in the earlier years, when the children are so much more dependent on their senses; in later years, man study becomes more and more important.

Nature study and man study provide the material or content for the expressive studies. But there must also be systematic instruction and adequate drill in the formal work in these subjects, in formal language and drawing. In emphasizing the content we must not go to the other extreme, and neglect the form. The children must learn how to use the instrumental studies, must become familiar with the laws and principles without which they cannot make the best and most effective use of the instruments for expressing ideas, language, drawing, and other forms of expression.

Nature study will aid the expressive work of the school in proportion as it is closely correlated with the expressive studies, as the form of expression used is adapted to the nature and needs of the children and to the material studied, and as the essentials in all expression, individuality, truthfulness, clearness, and order, are kept constantly in mind. 


\section{CHAP'TER XII.}

RELATION OF NATURE STUDY TO READING AND LITERATURE.

THReE main objects of expression have been named: to make the ideas of pupils clear and orderly, to convey their ideas to others, and to enable them to gain ideas from others. In the preceding chapter we have considered the expressive work of the school mainly with reference to the first two objects. We have to discuss in the present chapter those phases of expressive work the special object of which is to enable us to use ideas gained from others. This is the main purpose of work in reading and literature.

In the primary grades the reading-lesson, related to nature study, is much like the individual language expression already considered, but is, in general, a class reproduction. What the children see they tell about, and their statements are written on the blackboard by the teacher for a reading-lesson. Frequently copies are made, by some duplicating process, for the use of each pupil.

Such reading-lessons serve a threefold purpose: they help to fix the important ideas gained by observation; they give the pupils practice in expressing ideas and in 
gaining ideas by means of language; and they serve as models for the children, or ideals toward which they may aim, in their individual written work. Hence such reading-lessons should contain and emphasize the important ideas or facts, should show the best work of the best members of the class, and should be models in both content and form.

Not infrequently such blackboard reading-lessons are entirely the work of the teacher, and not gained from the children. Then they lose much of their value, because they are not the expression of the ideas of the pupils. On the other hand, the lessons may be gained from the children, but the matter may be so poorly selected and expressed, and so lacking in sequence, that the lessons are anything but models in either content or form.

Care must be taken that the children do not, in their individual written work, merely copy or repeat what they have had in their reading-lesson; otherwise the reading-lesson may be a detriment to the individual expressive work. The reading-lesson should, if possible, come after the individual work, rather than precede it.

In the first grade the blackboard reading-lesson is the first step in training the children in written expression.

"Blackboard stories," based on what the children have seen in their nature work, gained from the children by careful questioning and written upon the blackboard by the teacher, are very helpful even before the little folks can read or write a word. They impress on the 
children the use and value of writing, and the fact that they can help "write stories;" they give them practice in expressing their ideas clearly, and can be made helpful in training the children to relate successive thoughts and statements, to keep a sequence in their work. Illustrations of such "blackboard stories" are given in the work outlined for the first grade in Part II. At first the pupils can merely copy what they see on the blackboard. The character of the blackboard readinglessons and the method pursued in these early steps in language expression have much to do with the character of the later expressive work of the pupils.

Such reading-lessons must be in accord with the principles laid down in Chapters VII and VIII. The matter must be based on sense-perception and on apperception, on what the children have seen and already know, and must interest the children. The lessons must call into play the imagination, not be confined to mere facts of sense. Each reading-lesson should have a sequence, a line of thought. Each should be a unit in itself, and at the same time, part of a larger unit, including a series of lessons.

What has been said in the preceding chapter about language expression, and about the essentials in all expression, applies to the primary reading-lesson as well as to the work of individual pupils.

A reading-lesson in the form of a story or narrative, or one in which what has been studied is personified, is better, in most cases, than a lesson which is purely descriptive. 
In the reading-lessons emphasis should be placed on life and action and processes, on function and cause, rather than on mere form and structure. The latter can be best expressed by means of drawings or pictures in connection with, or as part of, the lessons.

Many of these features of a good primary readinglesson are illustrated in Miss Bass's admirable reader, "Plant Life," as in the following lesson from that reader, -

\section{A DANDELION.}

Do you see me?

I am a yellow flower.

My name is Dandelion.

Do you think I am pretty?

You need not go far to find me.

I come near you.

You can see me on your way to school.

I love little boys and girls.

They love me too.

They are glad to see me.

I am bright like a star.

But I shine in the daytime.

You may call me a day-star.

I go to sleep at night.

I have a short stem.

I am not very tall.

Some day I shall not look as I do now.

You will hardly know methen.

The reading-lessons, growing out of the work of the class, cannot be markedly individual. They embody the best thoughts of the class, arranged, with the help 
of the teacher, in the best form, and often supplemented by thoughts gained from literature. The lessons should, however, be rigidly truthful or accurate, and should be models of clearness and order.

While the teacher should gain the lessons mainly from the pupils, she can, by her questions and suggestions, determine the character of the lessons, and can thus influence much of the expressive work of the individual pupils.

If the reading-lessons gained from the children are based on their observations; if they are truthful, clear, and orderly; if the children see that in these lessons the teacher accepts only the statements which tell in the clearest way what each child knows to be true; if they perceive that the teacher puts the statements in a certain order, and gradually understand the reason for that order, the children will be apt, in subsequent expressive work of their own, to follow their teacher's example.

If, on the other hand, the teacher accepts for these lessons any statement the children may make, whether based on observation or a mere guess, whether true or half true (the worst kind of a falsehood), whether clear or hazy, and writes these sentences on the blackboard just as the children happen to give them, without sequence or order, the lesson is not merely of little value as a reading-lesson, but is positively harmful to the children; it becomes a means of drilling them in telling in the wrong way what they have seen, a means of establishing bad habits of expression. 
The most common or general defect in the primary reading-lessons is lack of sequence or continuity of thought. Thinking is relating ideas, and it is only by relating ideas that children can learn to think. The successive ideas must be related, if they are to be fixed in the mind. It is comparatively easy to understand and remember ideas arranged in order, each related to the one preceding it and to the one following it. It is difficult to follow, and almost impossible to remember, a series of statements thrown together without sequence or order.

Arrange and keep the statements in logical order. If a pupil tells something not related to the previous statement, put it aside until a place can be found for it. With older primary pupils it may sometimes be wise to have the children tell all they can, without questions or any special attention to order, write these statements on the board, and, when the pupils have told all they can, arrange (with them, not for them) the statements in order or sequence, getting the children to fill in the gaps. This will give them practice in arranging or grouping ideas.

It is sometimes helpful to have the pupils criticise the statements as to exactness and clearness. Do they tell the truth, the whole truth (as far as they have seen it), and nothing but the truth? Are they as clear as they can be made?

So far as the reading-lesson is to train the children to express ideas and to fix the more important ideas which they have, we must get the statements from the chil- 
dren. But we must not stop here. A fountain cannot rise higher than its source. If we limit the children in their reading-lesson to their own ideas we narrow their horizon.

The teacher should introduce facts and thoughts which have not come from the children, but which grow out of or are naturally related to what they have seen and told. This is an opportunity to broaden the knowledge of the children by leading them from what they can see in their little world to what they must be told about the great world, and to give them the best and most beautiful thoughts from the poets and others about the birds and plants and clouds which the boys and girls have been observing.

In the reading-lesson about the hairy seeds of the dandelion or milkweed or thistle, the teacher can introduce something concerning the cotton-seeds with their hairy wings, and concerning the use man makes of the cotton hairs or fibres. In the lessons telling what the children have seen about the habits and nests and eggs of the bluebird, it may be well to add some of the habits which the sharper eyes of Thoreau or Burroughs have discovered. But care should be taken so to word this new matter that the children may be taught the importance and necessity of sharply distinguishing, in all their work, between that which they have gained for themselves and that which they have merely appropriated from others.

Very frequently we should introduce into these primary reading-lessons gems from the poets. But they 
should be gems, not mere rhymes or doggerel. The very best literature is not too good for the primary children. It is helpful to begin the lesson with a line or couplet or verse containing some beautiful thought which may give tone to the whole lesson.

A lesson gathering up some of the facts and thoughts the children have gained from their study of air and winds may begin with the verse from "The Child's World":

"The wonderful air is over me,

And the wonderful wind is shaking the tree;

It walks on the water and whirls the mills,

And talks to itself on the top of the hills."

Such an introductory thought is almost certain to give spirit and direction to the whole lesson.

A lesson on any flower may begin with the words of Henry Ward Beecher : "Flowers are the sweetest things God ever made and forgot to put a soul into." What the children read about grains, as they are studying wheat or oats in the fall, will mean much more if they can be given the thought of Lowell; he calls the grains "Four months' sunshine bound in sheaves." - When they are writing or reading about the uses of leaves, or about the leaf-miners and leaf-rollers, whose homes are in the leaves, how much may be added by quoting from Lowell :

"And there's never a leaf nor blade too mean To be some happy creature's palace."

Many illustrations of primary reading lessons based on nature study are given in Part II. 
It must be remembered that we are considering primary reading only so far as it is correlated with and based upon nature study. Part of the reading should be correlated with the other centre of education, man study; should be based on story-work, on what the children know of their home-life and the home relations, and on what they are told of the homes and lives of other children and other people. It is believed that nature study should be given more prominence than man study in work in the primary grades, because it appeals more directly to the children's senses, - the avenues through which little folks must gain their ideas, - and because nature study involves more selfactivity than story-work.

In the upper primary grades, and in grades above these, the reading-lessons cannot be based so directly on what the pupils observe, and the purpose of the reading-lesson becomes, more and more, to gain information and thoughts and inspiration, rather than to express in the best form what has been gained by the children through their senses. Close correlation of the reading with nature study or man study becomes more difficult and less important.

Now comes the time for supplementary reading as distinguished from what may be called expressive reading. This supplementary reading may be divided, in a general way, into two classes, - that which is mainly intended to broaden the knowledge, what may be designated as reading for information; and that which 
uplifts the pupils, gives them a higher as well as a broader outlook, develops their higher nature, what we may call reading for inspiration. These two classes, however, shade into one another.

Both of these are important; both are essential; neither should exclude the other.

The reading for information is distinctively practical ; it prepares for practical life. At the same time it may prepare for the reading for inspiration; the broader the knowledge we have of nature and man, the better are we prepared to appreciate and make our own the great thoughts which nature and man have inspired.

To this class of reading belong the information readers, the geographical readers, most nature readers, and most juvenile books which treat of travel and natural science. From all of these the pupils may get more or less broadening and uplifting, but their main value is as sources of information and means of broader acquaintance with man and nature.

One characteristic of most such books is that they are often or usually "adapted" to the children, "written down" to the supposed capacity of the boys and girls who are to read them. Comparatively little mental effort is required to understand them. Their content can usually be gained by one or two or three readings.

Nature study prepares for such reading by leading the pupils to gain, by the use of their senses and their mind, the foundation ideas on which these new and broader ideas must be built. It is only by the careful 
observation and study of the plants and animals and minerals and rocks about their own homes that children can be prepared for the clearest understanding of what they read about the rocks and life of other regions. Only after they have studied elementary mechanics and some of the first principles of electricity and magnetism, and have investigated the working of such simple machines as they have about their homes and school, can they intelligently read about the machinery and processes used in manufacturing.

In the second class of supplementary school reading, what has been designated as reading for inspiration, as distinguished from reading for information, are included the literature or classics of our language, or, more specifically, those portions of our literature which are so related to the work the pupils have done, and to the ideas they have gained, that the children can appreciate, and to some extent comprehend, their thought or content.

If it is true, as has been stated in Chapters IV and $\mathrm{V}$, that the great aim of nature study and of all education is to cultivate the higher nature of the child, æsthetic, ethical, and spiritual, and bring the child into sympathetic right relations with all his environment, nature, man, and God, then this second class of reading is much more important, educationally, than the first.

Much of the best literature has been inspired by nature, and can be best appreciated by those who are sympathetic students of nature. Longfellow has said, - 
"Art is the child of Nature; yes,

Her darling child, in whom we trace

The features of the mother's face,

Her aspect and her attitude,

All her majestic loveliness

Chastened and softened and subdued

Into a more attractive grace,

And with a human sense imbued :

$\mathrm{He}$ is the greatest artist, then,

Whether of pencil or of pen,

Who follows Nature."

If we keep constantly in mind the purpose of the literature used in connection with nature study, this will greatly influence or largely determine the selection of literature and the manner of reading or studying it. This purpose is, to give a larger content to ideas which the children have, to clarify their vision and extend their horizon, to help them see new beauties, think greater thoughts, have higher aspirations.

Teachers who realize the true purpose of literature will have little use for much or most of the so-called poetry with which our educational papers are often filled. Some of this may be useful. Facts and thoughts stated in rhyme, and with some rhythm or "jingle," are often more readily impressed on the memory. Most boys and girls remember much better the number of days in each month after they have "learned by heart" the doggerel, -

"Thirty days have September, April, June, and November;

All the rest have thirty-one 
Except February alone,

Which hath four and twenty-four,

And every fourth year one day more."

But teachers must not delude themselves and cheat their pupils with the idea that everything which is in rhyme is poetry, and therefore literature.

Mere rhyme we comprehend after one, or at most two or three, readings; we soon get from it about all the thought or content there is in it. The best literature, such a gem as Lowell's "Vision of Sir Launfal," we can read and reread, again and again, scores of times perhaps, and see new beauties and get new inspiration each time. This is perhaps the simplest test of real literature. If what we read awakens little thought, and a second and third and fourth careful, thoughtful rereading gives us little that is new, it is not literature, or, perhaps, it is so much beyond our comprehension that it is not the literature for us.

We can be sure of reading real literature to and with our pupils if we select from the writings of standard authors, those who by general consent have long been regarded as best worth reading. Any nature literature selected from such writers as Lowell, Emerson, Longfellow, Whittier, Bryant, Lucy Larcom, Tennyson, Wordsworth, we may consider as worth reading, if it is not utterly beyond the children. That which is selected from writers who are unknown or little known, may or may not be literature that is best worth reading.

In selecting literature it is well to keep in mind the 
old saying, "The greatest enemy of the best is the good." Much may be good, may be worth reading, but we have time in school for only the best; only the best is good enough for the children, whether young or old.

One reason for the use of so much mere rhyme and trash, instead of literature, is the feeling, so prevalent, that most real literature is beyond the comprehension of the pupils in our schools, and therefore of little value in school-work. Unless what is read is above the children, it has little value as a means of uplifting them. What children can readily comprehend with little effort cannot be very broadening.

Teachers who have attempted honestly and persistently to read or study real literature with their pupils, have learned that the children can be intensely interested in much which they cannot fully comprehend, and can get from it much more than is at first thought possible. Unless children have been so trained that it seems a hardship to think, and useless to attempt to understand what is not clear at first, they will read or listen intently to much which is somewhat beyond their comprehension.

A clear understanding of the aim or purpose of the reading of literature will largely determine the plan or method pursued. If the teacher wishes her pupils to get the thought, the inspiration, she will allow only those pupils to read it aloud who can best get and give the thought, or she will read it herself. When reading for information, it may be wise to have each one read 
aloud. When reading for inspiration, it is utterly wrong to permit a poor reader to mar a literary gem, and take from it most of its beauty.

Inspiration, like breathing, is a gradual process. If the teacher wants her pupils to get the most from the literature read, she will bring it before them again and again, or keep it before them, give them repeated opportunities to absorb it or breathe it in, just as she might try to get them to study, not merely glance at, the painting of a great artist. If it is literature, they may and should get much more from a second reading than from the first. It is wise to come back to it, think about it, discuss it again and again. The very best, never the mere rhymes, should be kept before the children, placed on the blackboard, copied in their written work, so that they will learn and remember it.

The aim, inspiration, will determine the way in which the literature is studied in and by the class. Many a literary gem has lost most of its beauty because too carefully analyzed, just as a flower loses its beauty when pulled to pieces. We may prepare the children for the understanding of a piece of literature by talking over with them beforehand some of the facts or thoughts which may be most difficult. After such preparation the children should, in general, listen, absorb, get the thought without interruption.

We can scarcely overestimate the value in nature study of genuine literature, rightly selected, carefully read, and rightly studied. Literature, more probably than anything else, will aid in attaining the highest 
aim of nature study, the cultivation of the higher nature of the child, æsthetic, ethical, spiritual. On the other hand, nature study is the best foundation, or the only foundation, for a real appreciation of much of the best literature. 


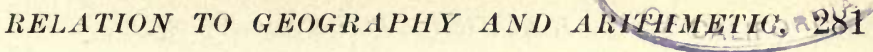

\section{CHAPTER XIII.}

RELATION OF NATURE STUDY TO GEOGRAPHY AND ARITHMETIC.

THE word geography means a description of the earth, and the study of geography has been literally a study of a description of the surface of the earth. Most of the geography of the past, in American schools, has been entirely, or almost entirely, book-work, a memorizing of the natural and political divisions of the earth's surface, and of the definitions of the forms of land and water, with much study, always from books, of cities, products and commerce and peoples.

Real earth study, actual observation of that part of the earth in which our boys and girls and their teachers live, has been almost unknown. Only within a few years have the better teachers in American schools realized the importance of careful observational study of home geography, as the only basis for any clear understanding or thorough study of the larger physical environment.

More and more we realize, in geography as in other studies, that sense-perception and observation must be the foundation or basis of school-work; that only through the careful observation of what is about us, what appeals to our senses, can we lay the best foundation, on 
which we can build by the process of apperception and with the aid of imagination.

Not until the boys and girls have studied carefully the valley or the brook which they can see, can they gain any fair understanding, or form a fairly clear mental picture, of the larger valley about which they must read, - the valley of the Mohawk or Hudson or Missouri. Only from an investigation of the way in which the brook near their home is wearing its banks and carrying away sediment, and is thus making its valley, can they understand how similar but greater valleys have been formed or are being changed. Only by noting the character and distribution of the rocks and soil of their homes can they hope to understand in some measure the materials with which other parts of the earth are covered, and on which the value of any region to man largely depends.

This observational study of our immediate physical environment is not merely the best foundation for an understanding of our larger physical environment, what is included in physical geography, but it is almost equally essential for an intelligent study of political geography. The character and rate of development and present condition of man in different parts of the earth have been greatly influenced or largely determined by physical environment. The phenomenal growth and the present condition of such cities as Chicago, Buffalo, and Duluth are due mainly to their location and to other physical conditions.

Geography must be more than a study of a descrip- 
tion of the surface of the earth. It must be genuine " earth study," actual "study of the physical environment of man," as it is rightly called in the Report of the Committee of Ten.

In our work in geography we have much to learn from the schools of Germany, where they pursue the three clearly differentiated lines of geography work, home geography (Heimath-kunde), folk study (Volkkunde), and earth study (Erd-kunde). Their field excursions, sometimes occupying several days, and their well-equipped geographical museums could be introduced with great profit into our American schools.

The physical geography of the past, like much of the science work, has been almost entirely a study of the mere form and structure of the earth as it is, of present physical conditions, with almost no consideration of the agencies and processes by which the earth eame to be as it is, and by which it is being constantly changed. We have seemed to regard the earth as a dead planet, like the moon, with its forms fixed and unchanging, with its valleys and hills and capes and bays ever the same. No conception can be more false. Every particle of soil at our feet, every raindrop, tells of change, past, present, future. The brooks and waves, the rills and pools in the street, tell of unceasing activity. Even the mineral world not merely is, but is becoming, is adapting itself. The seamed and jointed rock is everlasting only in name.

A river is much more than "a stream of water flowing through the land;" it is an always-working, never- 
resting agency, a most effective tool of the Creator. A valley is more than "low land between hills or mountains," as the geography has defined it; it is a story of action and change and adaptation.

Dr. Archibald Geikie has said, "The Life of the Earth is the central thought which runs through all that branch of science termed physical geography."

In geography, as in all nature study, we and our pupils must not merely observe physical features, but we must observe processes and changes, investigate life as well as structure. The greater educational value of the study of life and action, as compared with the study of mere form or structure, has been sufficiently emphasized in preceding chapters.

We see that nature study and geography are very closely related. During the earlier years of the child's life they are identical ; nature study is geography, physical geography, and the best preparation for political geography. As the child grows older, and the human element enters more largely into his life and schoolwork, both nature study and history become most helpful in his geography work: history showing what man has done on the earth; nature study showing the forces and materials with which he has worked; geography recording the results of the work of man and of the action of material forces on the surface of the earth.

Now comes the practical question, "How can nature study be made most helpful in geography; or, how can the two be most effectively correlated?" 
Friends of nature study must remember that the solution of the question is as important for nature study as for geography. As has already been stated, the value of nature study will be largely judged by its effects on " the essentials," reading, writing, arithmetic, and geography.

In considering the work in nature study as a preparation for and aid in geography, the need of a definite plan of work or course of study becomes most evident. The value of nature study to geography depends largely on the material selected for study. Hence the discussion in the following pages is largely limited to the selection of material.

It seems wise to consider the relation of nature study to geography first in the lower grades, where it is a preparation for and introduction to geography, and later in the upper grades.

What work in nature study in the earlier schoolyears will be most helpful in geography?

The child's physical environment includes:-

First. The earth as a member of the solar system and of the material universe.

Second. The earth itself and its three envelopes, land, water, air.

Third. The life of the earth, - plants, animals, man.

Of the earth as a member of the solar system, or in its relations to sun and moon and planets and stars, the child in the first three or four years of his school life can get no intelligent conception. It seems utterly useless 
for the teacher to attempt to teach the young child anything about the real relations of the earth and the heavenly bodies. To attempt to begin work in geography with little children, with a study of the earth as a planet, or with a discussion of the nebular hypothesis, is as absurd as it is to begin the study of plants in the elementary schools with the plant cell. Both are utterly beyond the grasp of little children. While such a beginning may be logical for the adult, it is illogical and unpsychological from the standpoint of the child.

But even in the primary grades foundations may be laid for some comprehension in later years of the relations of the earth to the other heavenly bodies. The children may learn to appreciate a little the beauty of the starry vault, and to recognize and name the more prominent planets, Venus, Mars, and Jupiter, and a few constellations and stars, and may read some of the myths connected with the heavens. They can observe, and perhaps record, the changes in the position of the sun, and in the position and appearance of the moon. After giving some attention to the heavens, during three - or four years, they may begin very cautiously to study a little about the real relation of the earth to the sun and moon, and later to planets and stars. They can observe and record from day to day the character of the weather, and the direction and force of the wind.

The study of the earth itself is most closely correlated with geography, as commonly pursued. The earth, the living, changing earth, may be considered under three heads :- 
First. Earth forces, those agencies which are changing the earth and fitting it for the habitation of man. Second. Earth materials, the matter on which these agencies or forces are acting.

Third. Earth forms, the effect of the action of the agencies or forces on the materials.

If we emphasize in earlier years the life side of nature study or geography, we shall dwell in our preparatory work in geography in the primary grades on the agencies acting on the earth, and first on those most easily seen by the child. From the child's point of view the most important earth forces are water, air, and heat. Water and air are not really forces, but merely vehicles upon and through which gravitation, heat, and other forces act; but from the child's point of view they are most active agencies, producing, with the aid of heat, most of the changes about him.

It is best to begin with water, in the forms of vapor, fog, clouds, mist, dew, rain, frost, snow, ice, streams, and waves, and study its forms and work. The study of water prepares for the study of air (including winds) and both lead up to heat and its effects and influence on the earth.

The order recommended is: during two or three winter months of the first school year, water; during the same period of the second year, air; during the winter of the third year, heat, including its sources and simplest effects; and during the fourth year, heat, studied in a much broader way, preparing for the study of physics in succeeding grades. 
In connection with this work, mainly indoors, some field study, during the spring or fall months, of the work of streams and waves in breaking down, carrying away, and depositing rocks and soil, and in forming gullies, valleys, hills, and other land forms, will be $\because$ ry helpful as a preparation for geography.

Air and water are earth materials as well as earth "rces. The study of other earth materials may begin during the second or third school-year, with those nearest the children, limestone, sandstone, granite, soil, depending largely on local conditions. All of these should be approached from the life side.

Fossil-bearing or fossiliferous limestone is particularly good for beginning mineral study. It is a history as well as a structure, a wonderfully interesting story which any child can read when properly directed.

Sandstone or any other stratified rock, and granite or any other crystalline rock, are stories written in stone.

The investigation of the formation and kinds of soil, approached in spring through the decaying leaves or the work of frost, is another gateway to the mineral world.

From such a study of earth forces, or of the agencies which have changed and are changing and shaping the earth, and of the materials on which these forces act, the children can get the best preparation for a comprehension of the forms of land and water. Then valleys and hills and bays and points and islands will have a significance which mere book-ivork or map-study or pictures or sand-table models can never give. 
Passing from what may be strictly called "earth study" to the life of the earth, the plants and animals do not appear to be so closely related to geography as is the mineral world. So far, however, as geography is the study of the earth as the abode of life, and particularly of man, our child must study the inhabitants of the earth even more than the earth itself.

Only as he observes the plants and animals about him can he, by apperception and imagination, fairly understand what he reads or learns in his geography about the life of other lands.

From the standpoint of geography, it is important that our children study in the earlier years that which will give them the clearest conception of plants and animals : -

First. As organisms in close relation to the earth, to soil, water, air, sun, to other plants and animals, and to man.

Second. As structures fitted for or adapted to their surroundings.

Third. As types of other plants and animals, some of which the children can see, many of which they can only read about.

Thus we will find best, as a preparation for geography, those plants and animals whose life, habits, and adaptation to environment are most easily observed, and whose life, structure, and plan are most typical.

Such study of our physical environment - we can call it nature study or geography, as we choose - can be carried on anywhere in any school. The conditions 
for such work are most unfavorable, in some respects, in the schools of great cities. In other schools, the teacher is limited only by her own lack of interest, energy, knowledge, or time.

The work outlined above prepares for but one side of geography, - physical geography. Keeping in view the other centre of school-work, man study, the children in the primary grades must also study a little about man, beginning with their own home, and continuing with the help of such books as Miss Andrews' "Seven Little Sisters" and "Each and All."

In the upper grades the work in nature study and geography must diverge much more. How can the work in science in these grades be made most helpful in geography?

Here we can give more attention to the systematic observation and record of the relations of the earth to other heavenly bodies. We can observe the northward or southward movements of the sun from week to week; the changes in the position and appearance of the moon, and its movements among the stars; the daily or nightly movements of stars or constellations, such as the motion of the Great Dipper about the pole star; the movements of the planets, Jupiter, Mars, and Venus, among the stars and with reference to the sun. Then what the pupils learn in geography about the relations of the earth, sun, moon, planets, and stars will mean something.

It seems wise to study much more carefully the com- 
mon earth materials, the most abundant rocks, - sandstones, shales, limestones, granites, - and to investigate to some extent their formation. From the common earth-forming rocks and minerals we can gradually pass to those of great economic importance, such as coal and iron ore, and thus aid in the study of economic geography.

In connection with the work in geography or nature study the children should give some attention to the changes in the aërial envelope of the earth. In the upper grades it is most helpful to have the pupils, individually or collectively, keep, on blackboard or on blanks, a record of the temperature, height of barometer, presence of frost or dew, direction and force of wind, cloudiness and rain or snowfall. In connection with this there may be some study of the daily weather maps, which can be obtained free by any school from the nearest station of the Weather Bureau, or from the office at Washington.

In the upper grades the work must be related more and more closely and directly to man. As political geography, or the earth as the abode of man, becomes more important, we shall find most helpful in geography a knowledge of those forces by which man has subdued the earth, of those minerals which he has found most useful, of the plants and animals which most aid in man's development, and of the uses man has made of forces, minerals, plants, and animals.

Hence the study of physics and chemistry, and the intensive study of such minerals as coal and iron, be- 
come more important in the upper grades. So also the economic aspects of plants and animals should be emphasized. In agricultural communities it may be wise to give considerable attention to soils and to agriculture as a basis for a broader study of related topics in geography. In manufacturing communities much attention can be given to such topics as silkworms and the manufacture of silk, or to cotton or flax and the manufacture of cotton and linen.

While nature study in the upper grades can thus be made helpful in geography, it must be much more than a mere preparation and foundation and ally for geography. Geography is pre-eminently practical in its aims. Nature study should be practical, and should be much more. In our attempt to correlate the two studies we must not overlook the higher aims of nature study.

The relation between nature study and arithmetic is not nearly so intimate as that between nature study and the other work of the elementary school, and it does not seem wise to attempt to correlate them closely.

Arithmetic has to do with the magnitude and number of things; the space or size relations and the number relations. In the study of plants and animals these are of relatively little importance as compared with the functional relations and form relations. The exact size of a tree or other plant, or the number of its branches, leaves, or flowers, is of little importance in investigating its life or structure. Much more essen- 
tial is an understanding of function and form and plan.

The number of parts, or the numerical plan, as the number of limbs in animals, or the occurrence of parts of plants in twos or threes or fives, is often important; but these number relations are so simple that they can scarcely be said to involve any work in arithmetic.

Quantitative physics and chemistry require much use of arithmetic, but the work in elementary schools must be largely qualitative, and hence makes comparatively little use of the space or number relations.

Elementary science or nature study will gain little from an attempt to force correlation between it and arithmetic. It may lose much.

When we require the children invariably to count the number of branches and leaves and buds and scales, to measure the length and breadth, and to calculate the area or volume, of what they are studying, to determine the proportion of branches which have developed, or of buds or leaves which have failed to mature, or the percentage of legs which turn forward, and the percentage which turn backward, this may be excellent practice in arithmetic, but it is, not infrequently, a positive hindrance to the nature study. Such work attracts the attention of pupils from important features to minor and often accidental details, takes their thought from the real spirit of the work, and has little or no relation to the higher aims of nature study. The autumn foliage may be considered as an opportunity to set the children at work determining the percentage of leaves which 
turn red, the percentage which turn yellow, the proportion which fall or remain on the trees, the ratio between the weight of leaves and the weight of loam or of ash they will form. But we cannot strongly emphasize this kind of work without sacrificing higher work, or losing sight of higher aims. When we reduce nature to ratio and proportion, we have made nature study of little value.

The arithmetic, as well as the nature study, will suffer from too close correlation between the two. Experience has shown that when this is attempted there is not, usually, adequate provision for the definite, thorough, systematic drill so essential in arithmetic.

Some correlation between nature study and arithmetic is helpful, particularly in primary grades. Nature study furnishes the material for the concrete work which is so necessary. All kinds of problems can be grouped about the seeds and buds and fruits and grains, the birds and other animals, the rocks and snow and water, the levers and pulleys and thermometers.

While arithmetic and nature study cannot be closely correlated directly, indirectly they may greatly aid each other. The special object, educationally, of arithmetic is to develop exactness in thinking and reasoning. One object of science work is to make pupils exact in observation, expression, and thought. The more we emphasize in our nature study exactness in the study of essentials, - exact seeing, truthful telling, careful generalizing and thinking, - the more closely will nature study and arithmetic co-operate, rather than correlate, 
in developing careful, accurate, truthful, upright men and women.

In this moral development, or training in habits of exactness and truthfulness, science work may be much more effective than arithmetic or mathematics. Scientific methods of observation and reasoning, involving exact observation of facts and conditions, careful comparison of these and discrimination between important and unimportant features, and cautious conclusions or generalizations based on them, have much wider application in life than has mathematical reasoning. The reasoning of life is largely inductive, not to any great extent deductive, as is most work in arithmetic. 


\section{CHAPTER XIV.}

THE SELECTION AND SEQUENCE OF MATERIAL.

The Formulation of a Course of Nature Study.

WhAT shall the children study? Nature is so vast! The world is so great! What shall we select from it all?

Shall the teacher take anything that happens to be convenient, - to-day a butterfly, to-morrow the clouds, the next day the daisy or the rain or a seed? Some teachers seem to assume that this is the way to study nature. But they discover that the children gain but little from work without definite aim, plan, or sequence. Such work may interest the children, but leaves in their minds little but a jumble of ideas, without order or coherence.

But what shall we select for study? By what principles shall we be guided in the selection of material?

This must be determined : -

First. By the aim of the work.

Second. By the nature and development of the children.

Third. By the prevailing conditions, such as season, preparation of teacher, character and amount of 
similar work previously done by the children, and location and environment of school.

As has already been said the general aim of all the work, and the special aim of each lesson, will largely determine the character of the work done. It will also greatly influence the selection of material.

Assuming that the teacher is striving to develop the higher nature of the children, and to bring them into the best relations with their surroundings, what should she study with them in beginning the work in nature study?

We have agreed (see Chapter IV) that the first aim, the first essential in nature study or any other work, is interest. We can find no safer guide than to study the interest of teacher, of child, of parent.

In beginning work in nature study, it will be found best for teachers to select some line of work in which they themselves are most interested, and with which they are most familiar. If any teacher is particularly interested in birds, she will be most successful in bird study with her pupils. If teachers are fond of flowers, they will be more apt to awaken in the minds of their pupils a similar fondness. If they have a pet eat or squirrel or rabbit, that will make an excellent beginning for their work in nature study. They will arouse in their pupils an interest in that in which they are interested. This interest, once awakened, will broaden until it includes other parts or phases of nature, and the interest and enthusiasm of the children will react on the teacher and broaden her interest. 
On the other hand, if teachers are compelled to take up, in the earlier work in nature study, material toward which they may have a decided aversion or antipathy, such as earthworms and spiders, this feeling is likely to be shared by the children, and will tend to make all the work in nature study distasteful.

Teachers who are beginning this work will find it wise to study and be largely guided by the interest of the children. If some child has a pet squirrel in which he and his playmates are interested, have him bring it to school, and let the children watch it for a few days, studying its habits, the use of its different parts, and the way in which they are fitted for the work they have to do. Their interest in the squirrel thus aroused, the teacher and children can read about its home in the woods, and study some of its relatives, - the other gnawing animals. Thus the squirrel may be the starting-point for a series of lessons on animals. Do the children come with a story of the robin's nest with its little blue eggs which they have discovered? That may be a good starting-point for the spring bird study. The wise, tactful teacher can, of course, stimulate and guide this interest by apparently following the children when she is really leading them.

In the earlier work in nature study the writer has always found the interest of the children to be the best guide in the selection of material. If it was found unusually difficult to interest the pupils in the material selected, then, in general, that was not the best material for those pupils. If they were unusually alert and 
enthusiastic, then it was well to take adwantage of their interest and study thoroughly. As the children studied nature more, their interest broadened, until they could be interested in almost anything.

It is wise to consider in the selection of material, particularly in begimning work in nature study, the interests and ideas of the parents. Nature study is, unfortunately, new in most schools, and, like all new things, will meet with much opposition and criticism. A wise teacher can very often disarm the critics by a proper selection of material for study. In the manufacturing town, comparatively few parents will object to having their children study about machinery or iron, or about the cotton from which they make their cloth. In a coal-mining region, the study in the school of coal and its formation and mining and transportation, may be welcomed by the stanchest believer in the three R's. In the country, the study of corn or wheat or oats, of fruit-trees, or of plant food and soil, or of insects, may not be regarded as a very dangerous innovation. The machinist would be much more apt to object to having his children "waste their time" on flowers and bugs and stones. The farmer could not see the sense in spending time in school on electricity and machinery, the value of which he could not see.

Later, when the children and parents have been interested, and the parents have learned that nature study helps in other work of the school, and develops and awakens their children, the teacher can select her material and plan her work with less reference to 
local conditions, and less allowance for parental criticisms.

The aim in nature study most closely related to interest is the cultivation of sympathy with or love for nature, and of sympathetic relations between the child and his environment. Interest and sympathy are steps in the development of the child's higher nature, æsthetic, ethical, spiritual, and are essential for the best adaptation of the child to his environment, - the highest aim of nature study.

Keeping in view these aims, we will select material which appeals to our pupils' sympathies and to their higher nature. Here we see the reason for emphasizing the study of life, of living plants and animals. Can we or our pupils sympathize ("feel with") with a stone or a force? Can we sympathize with a mere form or structure or with a dead animal? The study of minerals, and of physics and chemistry, the study of matter and force, while most essential as a basis for geography and a preparation for practical life, does not have as high an educational content for children, does not appeal as strongly to the child's higher nature, as does the study of life.

Seeds germinating, buds developing, flowers unfolding, or forming seed or fruit, are much better for study than dead seeds, undeveloped buds, flowers whose function is not shown. Other things being equal; those plants are best for study which, like the common mallow or dandelion or mustard or evening primrose, show 
at the same time all stages in the formation of leaves, flowers, and fruit. In these the child has before him, in a form most easily understood, the whole story of the development and work or function of each part of the plant. The plants possess this advantage over the animals, that all stages can be more readily studied at the same time.

In the animal study that material is best which can be most readily studied alive by the children, - the snails, fish, crayfish, and other aquatic animals, and the turtle, canary, and cat, which can most easily be kept alive in the schoolroom, the insects, birds, and domestic animals whose life and habits can be observed by the children out-of-doors. Animals such as starfish, corals, shells, and sponges, which cannot be seen alive, and are valuable chiefly as types, are not so good for study, particularly in the early work.

Those minerals and rocks are best which tell a story. The fossils in the limestone, the crystals, the ripple marks or mud cracks, all lead to a "how" and "why" which the children, properly directed, can work out for themselves, in which they will be greatly interested, by which they will be developed or educated. So, too, the minerals most useful to man, such as graphite or iron ore or coal or mica or asbestos, are excellent for study. They, too, have a "why."

The third aim of nature study, as summed up in Chapter IV, is the development of the power of seeing, thinking, and telling, and the formation of right habits, 
Power is capacity for action, and is only attained by action. Appreciation of the beautiful may be absorbed almost unconsciously, certainly without conscious effort, from surroundings. The development of the ethical and spiritual sense depends to a considerable extent on the environment. Appreciation of beauty, rsthetic, ethical, spiritual, may be imparted by the parent or teacher. But the development of intellectual power depends entirely on the individual. The parent or teacher can make the conditions favorable, but can do no more. The child cannot absorb power. He can only get it by action, by doing for himself.

Keeping before us this aim of nature study, we see the importance of individual work as distinguished from class work, and the necessity of selecting, when possible, material which can be placed in the hands of every pupil, which every child can study as an individual. Other things being equal, that material is best which is of such a nature, or is so abundant, that each pupil can study it independently; and those experiments are best which can be performed by each pupil individually. Specimens studied by the whole class together, or experiments performed before a class or by a few members of a class, are of less value in developing the individual. Such work is often necessary, but must be supplemented by work by the individual pupil.

For such individual work, requiring material in the hands of every pupil, plants and minerals are good. Plant material for each pupil can usually be easily obtained when needed, and minerals can be preserved and 
used for years. Animals cannot be so readily obtained or kept in the schoolroom in numbers sufficient for individual study, and few schools have facilities for much individual work in physics and chemistry.

The study of plants and animals is of special value for the development of the powers of observation, description, comparison, discrimination, and classification. As often pursued in higher institutions, the study of botany and zoölogy does little more than this.

The study of physies and chemistry constantly calls into action the reasoning powers. It is an investigation of "why," of cause and effect. It not merely develops the power of reasoning, but requires fairly well-develoned reasoning powers. Hence all but the merest rudiments of physics and chemistry must be postponed until the later years of the elementary school.

Aside from the possibility of doing individual work, the development of power in the children is much more dependent on the method of study and the sequence of topics than on the selection of material. These have been discussed in Chapter VIII.

We now come to the last and lowest aim of nature study, the acquisition of knowledge or facts, and to the influence of this aim in determining the selection of material for study.

By the emphasis placed on that course of study which will best develop the higher nature of the child, we have already answered the question, "What knowledge is of most worth?" But the selection of material 
must also be determined by utilitarian considerations. What knowledge will be most useful in other schoolwork? What knowledge will form the best foundation for later science work? What knowledge will be most useful in life?

First. From what material will the children gain the knowledge most helpful in other school-work?

The relation of nature study to other school-work is discussed in Chapters VI, XI, XII, and XIII, and need only be treated briefly in this connection.

We have already touched on the greater value of the life sciences as a preparation for literature and art. We will find a wealth of the best literature relating to plants and animals, particularly to plants, but comparatively little relating to minerals or physics; that is, to mere matter and force. There is much on streams and clouds and rain and frost and crystals; but the poets almost invariably treat these, not as mere matter and force, but as endowed with purpose and thought and other attributes of life. Lucy Larcom's "Rock and Rill" (given in footnote ${ }^{1}$ ) well illustrates this.

\section{ROCK AND RILL.}

"Into the sunshine out of shade!" The rill has heard the call, And, babbling low, her answer made,A laugh, 'twixt slip and fall.

Out from her cradle-roof of trees, Over the free, rough ground! The peaceful blue above she sees; The cheerful green around. 
The study of plants and animals, admitting of greater freedom and individuality in observation than does the study of minerals and physics, offers greater scope for expressive work in language, drawing, painting, and moulding. Plant study particularly can be correlated with any of the forms of expression. The gross structure of plants is much simpler than that of animals, and can be more readily understood and described in language. The forms and colors of plants are simpler than those of animals, and much more characteristic

A pleasant world for running streams

To steal unnoticed through,

At play with all the sweet sky-gleams,

And nothing else to do!

A rock has stopped the silent rill, And taught her how to speak:

He hinders her; she chides him still;

He loves her lispings weak.

And still he will not let her go:

But she may chide and sing, And over him her freshness throw,

Amid her murmuring.

The harebell sees herself no more

In waters clear at play;

Yet never she such azure wore,

Till wept on by the spray.

And many a woodland violet

Stays charmed upon the bank;

Her thoughtful blue eye brimming wet,

The rock and rill to thank.

The rill is blessing in her talk

What half she held a wrong, -

The happy trouble of the rock

That makes her life a song. 
than those of minerals. With plants, therefore, the problem of correlation is comparatively simple. The written descriptions of minerals and of experiments in physics are much more stereotyped, show less individuality, than the accounts of the environment, habits, life, and structure of plants and animals. On the other hand, the work in physics and chemistry may be much more exact, more quantitative, and correlate much better with arithmetic.

The relation of nature study to geography was discussed in Chapter XIII. This determines largely the choice of matter in minerals and physics during the first four years of the child's school-work.

As a basis or foundation for geography, we find most helpful in the earlier work in minerals those, five or six in number, most common in rocks, such as quartz, feldspar, hornblende, mica, calcite; and a few rocks, such as sandstone, shale, limestone, and granite, most abundant as earth-making materials. The study in the earlier years of water, air, and heat as earth forces (the forces which are nearest to the little children, and whose effects they can most easily understand) is the most useful as a foundation for geography, and the best preparation for future work in physics. In connection with these, such topics as soil-making or rock-disintegration, the work of rain and streams and waves, and the formation of valleys and hills and bays and points, - that is, the effects of the above forces on the materials, fulfil the other aims of nature study, and prepare for the best work in physical geography. 
Later, the study of minerals and rocks of economic importance, such as graphite, gypsum, pyrite, sulphur, of coal and of the iron ores, will be an excellent preparation for economic or commercial geography. Hundreds of minerals valuable to the collector and mineralogist on account of their rarity, are of no value in nature study in the schools, for the very reason that they are rare.

The selection of material for plant and animal study in the earlier years is largely determined by higher aims. During the later years of the course, utilitarian considerations must have more influence, and will lead to the choice of material of economic importance which will aid in the geography work: the grains, wheat, corn, rice, and their products; the fruits, apples, oranges, lemons; the cotton and flax plants, and the manufacture from them of cloth; the animals and animal products of greatest economic importance and most commonly referred to in the work in commercial geography.

In this way nature study will be an aid in physical and commercial geography. Man study, history, and related literature may be made equally helpful in political geography.

In considering the question, The study of what material will give the knowledge most helpful in subsequent science work? we will see the importance of selecting for study material which is typical of large classes or groups, and phenomena which illustrate and prepare for an understanding of principles. 
Other things being equal, the buttercup is much better as a type of the crowfoot family of flowering plants than is the columbine; the cranesbill is better than the "touch-me-not" as a type of the geranium family. The grasshopper is better as a type of insects than is the butterfly, although the butterfly may be better than the grasshopper for the study of life history or development.

This idea of the importance of studying types leads to the selection of such material as horsetails and ferns, rather difficult for study, and of corals, starfish, and sponges, which must almost always be studied from dead specimens and pictures. But they are important, in work with older pupils, because they are types of great classes of which the pupils should know something.

The laws of sequence and unity largely determine the selection and arrangement of material and the formulation of a course of study. It is essential that the material be so selected and arranged that there is a natural logical sequence, that each topic shall be considered with reference to what precedes and follows. The course in any one line of study - plants, animals, minerals, physics - should be a connected whole built up step by step. The work in all lines should be related and made mutually helpful as far as possible. New topics should not be undertaken until the foundations have been laid for their study by gaining the knowledge necessary for their comprehension. Limestone and fossil shells mean little until the children 
have studied snails, and know something about the way in which snail and clam shells are formed. Crystals mean almost nothing until the process of crystallization has been investigated. The dissemination of seeds will mean much more after the children have studied their formation or relation to the plant. When they have discovered how much the plant - roots, stem, leaves, flower - has done to make the seed, they. will appreciate better the various wonderful provisions by the mother plant for insuring the dispersion of her seed babies. 'The study of falling leaves in the autumn will mean much more if the children see during the winter how useful fallen leaves are in covering and keeping warm the buds and seeds, and the eggs and larvæ of animals, and discover in the spring how leaves enrich the soil by their decay, and how they feed other plants.

It is essential also that the earlier work should give the children a clear idea of wholes or units to which the parts, studied later, are readily related. It is much better, for instance, for the child to begin with the germination of a plant from the seed, to watch the gradual appearance and development of the parts, root, stem, leaf, flower, - and discover the relation, functional and structural, of all parts to the whole and to one another, than to begin with the study of leaves or flowers, all of which are parts, incomplete and separated from the whole to which they belong, and to which the child cannot or does not relate them.

It is equally helpful to come back to wholes or units after the study of parts, and so to review and relate the 
parts to the whole. For this reason the study of one or more plants as wholes is urged near the beginning and close of the school-year (in September and June), also the watching in the schoolroom of life history, or development from seed to the formation of seeds, of one or more kinds of plants during the spring months (April to June). This is particularly important during earlier years.

This principle, the necessity of considering parts in their relations to wholes, and of relating new matter to that previously studied, is exceedingly important educationally, and of wide application in influencing or determining the selection of material. The study of trees and of their changes throughout the year is very valuable, because nearly all the other plant study — buds, leaves, flowers, seeds, fruit - can be related to trees; and the plant study throughout the year is thus bound together and made a unit. If the children have studied in winter or early spring the horse-chestnut and maple and cherry trees, and follow this with a study of the buds, leaves, flowers, and fruit of the same trees when these are in condition for study, their work will be much better related, their ideas will be clearer, broader, and better fixed in their minds, and the pupils will be better prepared for understanding the great doctrine of gradual development, or evolution, than if they study the branches and bark of one tree, the buds of another, and any leaves, flowers, and fruits accessible, without reference or relation to what has been previously studied. 
Now comes the question, "The knowledge of what material will be of the greatest practical value in life, will best prepare for life?" The question has been largely answered already. The pupil is, in general, best prepared for life who is best prepared to do well what comes next, and to understand and appreciate what lies nearest.

During the earlier years of the elementary school, purely utilitarian considerations should have very little influence on the selection of material. This must be determined by higher aims. During the last three or four years of the elementary course, the years which end the school education of most of our children, this question of practical value must have more weight. Hence it seems wise, during these later years, to emphasize strongly the study of physics and chemistry, and of minerals and rocks of economic importance, and to dwell somewhat on the economic (agricultural, manufacturing, and commercial) aspects of plant and animal study. Remembering the higher aims of nature study, we must be careful, however, not to neglect the higher side of the work, æsthetic, ethical, spiritual ; not to place too much or too exclusive emphasis on purely utilitarian considerations.

Next to the influence of aim, the most important element in determining the selection of material is the stage of development of the child himself. In fact, the aim, to develop the whole child or to adapt the child to all his environment, and the nature of the child to 
be developed or adapted, are so closely related that it is almost impossible to separate them in the discussion.

The more important mental or psychological characteristics of the child, and the relation of these to method, were considered in Chapters VII and VIII. What was there presented applies to the selection and sequence of material as well as to other phases of method.

Remembering that all work with children must be based on sense-perception, apperception, and interest, too much emphasis cannot be placed on the importance of selecting for study material which each pupil can see or hear or feel and can study for himself, which is closely related to the every-day life of the boys and girls, and in which they are or can be interested. Remembering also that as children grow older they are not so directly dependent on sense-perception, and that they gain greater power to apply what has been learned through the senses, to combine and generalize, or to think and reason, we see the necessity of leaving until the later years those subjects, such as physics, which require considerable reasoning power.

The study of material, of plants, animals, and minerals, is, in general, the more concrete. They appeal directly to the senses. The baby can study a bud or a cat; he can do nothing with heat. Force studied in physics and chemistry is more abstract. It appeals to the senses indirectly through its effects. Little children cannot really study forces such as gravitation or heat, nor gain any real conception of them. Even adults 
find it most difficult or impossible to form a concept of a force only, as distinct from matter. Children can only conceive or express forces in terms of things which appeal to their senses. Gravitation becomes a giant. The work of frost is ascribed to Jack Frost. Although they realize that Giant Gravitation and Jack Frost do not and never did exist, they have no other way of conceiving and expressing force. They personify force for the same reason that their ancestors, in the childhood of the race, personified and deified the powers and phenomena of nature, the winds and thunderbolts.

For this reason it seems wise to emphasize in lower grades the study of things, plants, animals, and minerals, and to limit the work in physics during the earlier years in school to the study of water (rain, streams, waves, frost, steam) and air (currents, drafts, and winds), regarded as forces by the children because they do so much work. From this we can pass to the causes and effects of heat, phenomena with which the children are most familiar, and later take physics and chemistry as such, heat, gravitation, magnetism, electricity, sound, light, and chemical phenomena and forces.

It seems scarcely necessary to add that that is best for study which is most common and familiar. We are somewhat prone to think that we must go to distant lands to find wonderful and curious things. Nature study should, first of all, show the children the wonders at their doorstep, the treasures and beauties on which they have been treading for years. These they have seen and can see daily, Working with these, 
nature study can relate and make clear old perceptions, and add a host of new ideas.

The most common weeds, the pebbles in the street, or stones of the pavement, the rain and frost which they have seen so often, and yet have never seen, the most common birds, sparrows and canaries and robins, the flies and spiders so abundant all about them, are far better for study than the finer flowers or minerals from other localities, or the birds and insects of other lands. After the child has studied that which is nearest, he can make this a foundation for the study of what is more distant.

Teachers will find, as did the writer, that each year's experience with nature study will open their eyes to new and better material close to their schools or homes. At first they will think they must go or send miles for what they want. Later they will find just as good or better material in the trees under which they have walked for years, along the streets, in the back yards about the school. Even in great cities they will discover leaves and insects and stones in all sorts of places before overlooked.

The lack of permanence in the interests and acquisitions of children must influence the selection of material; or rather the variety of material and the time which should be devoted to its study. However intense the interest of the young child in any one thing, he does not want to study that thing very long. His nature demands and requires frequent change. If 
he does not get it he loses interest. After a change he may return to the old material with added interest. His interests are extensive, rather than intensive.

As the child grows older, as he gains a larger stock of facts, as he learns to relate these facts, and begins to realize the complex interrelations of nature, the dependence of each phenomenon upon all about it, his interests become more permanent, and he learns, or should learn, to concentrate his attention. Then he is fitted for more thorough, detailed work. His work should now become intensive rather than extensive. He should study much rather than many.

The mental acquisitions as well as the interests of young children lack permanence. Much of the work has to be repeated over and over again before it makes a lasting impression. This is less the case in what is gained through the senses, as in nature study, than in what is merely memorized. But the matter which is most essential needs to be presented and studied again and again. Particularly in parts of the work requiring considerable power of discriminating between essentials and non-essentials and some breadth of view, as in the grouping or classification of plants or animals, children will not grasp it all nor master it all at first, no matter how carefully the work is done. It must be repeated again and again, the children gaining more each time. For this reason it will be found helpful, particularly in the earlier years, to study important or difficult matter for two or sometimes three years, each successive year 
approaching them from a different standpoint, if possible, and studying them more thoroughly.

For these and other reasons to be discussed later, it seems wise to arrange much of the work in nature study in two cycles. During the first cycle, covering the first four years of the elementary school-course, the children can study nature extensively, - plants, animals, minerals, physics, whatever seems most essential and is within the comprehension of the children. During the second cycle, covering the remaining years of the elementary school-course, much of the same ground can be covered, but studied intensively, with much new work and more attention to structure and classification. The foundations already laid, and the greater maturity and better developed powers of the children, will make this work intelligible and helpful.

We come now to the third element affecting the selection and arrangement of material, the influence of physical and local conditions. Probably the physical conditions having the greatest and widest influence are the seasons and climate. This determines very largely the general character of the material which can be obtained for study. During part of the year - spring, summer, and autumn - plant and animal life is abundant. During the winter, late autumn, and early spring, in large sections of our country, organic nature is largely dormant. It seems wise and necessary to emphasize the study of living or organic nature, plants, and ani- 
mals, during the spring, summer, and autumn, and of inorganic or dead nature, minerals, physic, and chemistry, during the late fall, winter, and early spring. During the spring months the plant world is bursting into life, and attracting the attention and admiration of even the least observant. The material for showing development and life is then most abundant. In the autumn the plants are finishing their work, and preparing for their winter's rest. It seems wise, therefore, to emphasize plant study during the spring in all grades.

In the fall the material for animal study is at least as abundant and as easily obtained as in the spring. Some material, such as caterpillars and butterflies and many common insects, is much more abundant. Hence it seems wise to dwell on animal study during the fall months.

This assignment of subjects to the seasons cannot be rigid. Some phases of animal life, such as the return, nesting, life history, and songs of birds, and the development of frogs, must be studied in the spring. Much plant-work, such as the ripening and dissemination of seeds, the fruits and grains, can only be studied to advantage in the fall. The study of evergreens seems most seasonable in the winter because they are evergreens, and in the primary grades because of their relation to Christmas.

The work for each month will be largely determined by climatic conditions. The course of study given in the next chapter is planned to meet the climatic conditions of the extreme Northern United States, - Minnesota, 
Michigan, and Northern New York, - and is based on several years' experience in Minnesota and New York. It can be easily modified for and adapted to climatic conditions farther south.

The selection of material must be largely influenced by the teacher, her interests and education or preparation for such work.

We have already referred to the advantage in beginning work in nature study, of allowing and encouraging the teacher who is interested in any special line of nature study or science, to study with her pupils that in which she herself is interested. The teacher doing work in which she is interested, because she is interested, will accomplish much more than those doing the work merely because it is prescribed in the course of study.

The lack of preparation on the part of the teacher must be considered in selecting material, and planning a course in nature study. A most important question is, What can the teacher do? For what are the teachers best prepared?

Probably the greatest obstacle which the elementary schools will encounter in the introduction of nature study is the lack of preparation of the teacher for such work. It is wise to reduce to a minimum the difficulties of the teachers who are beginning such work.

The average teacher, doubtless, knows most about the plant world. Plants are probably the most noticed, best known; and most admired parts of the physical environment of mankind. People walk on the grass, they 
sit under the trees, they gather or care for or trample on the flowers ; buildings, food, clothing, and fuel come from plants. They are much more apt to observe plants because they are stationary, and can be observed more easily than the animals, and are more attractive than the stones. So a fair amount of plant lore is part of the stock of knowledge of most persons of average intelligence and education. They usually know more about plants than about animals, minerals, physics, or chemistry.

In our high schools, more attention has been given to botany and to physics than to any or all other sciences. The teacher with a high-school education is better prepared to teach these in her school.

Plants are cleaner and more attractive than animals, are more easily obtained, more easily preserved in the schoolroom, and, in general, are better for individual study by each pupil.

As has been said in the previous chapter, there is a rich store of literature relating to plant life as compared with that relating to other phases of nature; hence plant study correlates best with literature. The gross structure of plants is much simpler than that of animals, and can be more easily understood and described in language. The forms and colors of plants are simpler than those of animals, and more characteristic than those of minerals. Hence plant study correlates most readily with drawing and painting and moulding.

For these reasons plants will usually be found much the best for study when first introducing nature work 
into the schools. It will be found wise during the spring and fall months of the first year to limit the required work in nature study to plants, allowing teachers who wish to do so to study also birds in the spring, and insects and domestic animals in the fall.

Gradually, as teachers become accustomed to the nature study, and can prepare for the work, more animal study can be introduced, and then the study of minerals, physics, and chemistry, which will, in general, be found the most difficult.

Most teachers, even those who have never studied physics, have a sufficient stock of general information to study with their pupils common physical phenomena, such as water, air, and perhaps heat. These can best be studied during the winter.

The preparation or lack of preparation of the teachers for the science work must affect the distribution of the different phases of nature study throughout the year, or the emphasis on different kinds of work at different seasons. Botanists urge that the study of plants be pursued throughout the whole year, that much in the plant can be best studied during the winter. Much work in physics and meteorology can be best done or only done during the warm season. So it has been proposed that all lines of nature work should be carried on, each alternating with the others from day to day or week to week throughout the school-year. This greatly increases the labor of preparation on the part of the teacher. If the work is limited each season to one or two lines, teachers can more easily prepare and plan for 
it, and better obtain the needed material. Almost any teacher, no matter how well prepared, will get better results when she concentrates the attention of herself and her pupils on one or two lines of nature work at a time.

The selection and arrangement of material, and the course in nature study, must be greatly affected by conditions peculiar to each school, the time which is devoted to the work, the amount of previous work of this kind which pupils have done, the number of years they remain in school, and the apparatus available for work.

Where but little time, one or two periods a week, is given to nature study, it will be wise in beginning work in the four lowest grades to give most attention to plants, with very little animal work, during the fall, spring, and summer months ; and to physical phenomena or introductory work in physics - water, air, heat during the late fall and winter months. The plant-work will best bring out the higher side of the nature study, and the work in physics and minerals will be most useful in preparing for geography. In the last or upper. four or five grades plants can best be studied in the spring, with a little bird study; animals in the fall; and physics and chemistry, with perhaps a little work in minerals, during the winter. The plant and animal study will bring out the higher side of the work, and correlate with literature and geography. The work in physics, chemistry, and minerals will serve as a good preparation for practical life. 
Much depends on the character and amount of previous work in personal observation which the children have done. After a year or two of training they can accomplish much more. Experience has shown that, in beginning such work, the younger pupils, those in the lower four or five grades, do more and better work in nature study, absolutely, not relatively, than the pupils in the upper grades. With the older pupils the habit of going to books and depending on authority has become more firmly fixed. As one principal expressed it, "The power of seeing and thinking and telling for themselves has been educated out of them." The older children do not "see the sense" of spending so much time observing for themselves, when they can get it from a book in less time. They are apt, too, to feel, with their parents, that they come to school to study reading, writing, arithmetic, and geography, and not to study "flowers and stones and bugs." The younger children have not been so thoroughly educated away from nature, have not had their senses so atrophied by neglect, have not learned so thoroughly the lesson of dependence on book and teacher.

Where it is deemed impossible to introduce nature study into all grades, it will be found much more satisfactory and better to have the work in the lower grades alone than in the upper grades alone. Not merely will the pupils be more interested and do better work, but they will be better trained and prepared for nature study, or for any other work in the upper grades which requires pupils to see and think and tell and do for 
themselves. In the lower grades also it is much easier - to correlate nature study with other school-work than it is in the upper grades.

In beginning work it will be found best to begin at the beginning in all grades, except possibly the two highest grades, to take up in all grades the most elementary work as outlined (in the next chapter) for the lower grades, adapting it to the children. Thus good foundations will be laid for future work.

Statistics show that in American schools fifty per cent of the children do not remain in school more than four or five years. This must affect the arrangement of matter. It seems better to arrange the work so that those who thus leave shall have a broad general knowledge of the whole field, rather than a detailed knowledge, if this is possible for young children, of a small part of the field. This is another reason for the arrangement of the work in two cycles, referred to before, and shown in the next chapter.

Nature study differs from mature science in that it absolutely requires no laboratory except what nature provides, and no apparatus except the seeing eye, the hearing ear, the understanding heart, and the willing hand. The lack of equipment affects very slightly the selection of material, or the amount or character of work which can be done. Teachers, thinking of college and high-school laboratories and equipment for science work, are apt to feel that neither they nor their pupils can study this or do that in nature work with- 
out instruments or apparatus. They must remember that nature study is a study of what the Creator made, as he made it, by means which he has either given the children or given them power to get or make. A few cans or bottles or jelly-tumblers and simple boxes for planting seeds and keeping animals are necessary for plant and animal work. Work in physics requires the most apparatus ; but most of it can be made by teacher and older pupils at a slight expense with lamp-chimneys, bottles and corks, chalk-boxes, etc. This homemade apparatus is not only as good as the expensive pieces which must be bought or borrowed, but is mûch better for work with the children. An elaborate or costly equipment of apparatus is a great hindrance. Children think of the apparatus rather than the experiment or what it is intended to show, and assume that the complex apparatus is necessary for the experiment. In general, the more closely science work is related to other school-work, the better it is for both the science work and the school-work. A distinct science laboratory for the grammar grades may be a great help in leading the children to do definite, exact, scientific work. But such a laboratory is not at all essential even in upper grades, and if it makes a break between the science work and other school-work, may be a positive hindrance.

While the general plan of work must be determined by the aim, the nature and mental development of the children, and other conditions which have been dis- 
cussed, the exact material studied and the emphasis placed on different topics must depend, to a considerable extent, on the location and surroundings of the school.

In general, that is best for study in any locality, other things being equal, which is most common, and with which the children are most familiar. This is easiest to obtain. What is more important, it is best for the children. For the study of this the foundation is already laid by nature. The teacher can build best on this foundation, gradually building broader and higher. The daily contact out of school with what is studied in the school will strengthen and re-enforce the ideas gained. The children will thereby be led to see that school is everywhere. At the same time they will learn the importance of that which is nearest, and see better the possibilities in that which is simplest and most insignificant.

Most of the material considered in the course of study in the next chapter is to be found throughout almost the entire northern half of the country. Many species of plants, such as maple, elm, and oak, dandelion, mallow, thistle, mustard, and buttercup, differing in different localities only in minor characteristics, are found in most parts of the northern half of the United States east of the Rocky Mountains; and others, closely related or illustrating the same functional and structural features, in other sections. Among the animals, the birds, such as the robin, bluebird, sparrow, and oriole, the most common insects, such animals as the crayfish 
and earthworm, and certain species of fishes, frogs, turtles, and squirrels, are very widely distributed. Common minerals and rocks are widely scattered, or can be obtained at a slight expense, and preserved for study for years. In the Course of Study, as given in the next chapter, and in the directions and outlines in Part II, those plants, animals, minerals, or rocks are suggested and emphasized which are most common and most widely distributed.

While schools in widely separated sections may follow the same general plan, the pupils at the seashore should spend much more time on sea-life; the children in the school in a rocky region should learn much more about rocks and fossils and geology; boys and girls whose home is on a farm may study more carefully the soils and plant food and grains, while their city cousins are giving more attention to building-stones, or electricity, or other departments of physics, or to processes of manufacture, or methods of transportation, all following the same general plan, but adapting it to local conditions, local interests, and local needs. The study must not stop, however, with that which is just about them. From that which is near they must be led to that which is farther and broader and higher.

The schools in the country, in villages, or in small cities have the best environment for nature study; they are surrounded by, almost immersed in, nature. In the large cities the environment is not so favorable. But teachers in cities will find, as they gain experience, that material is much more abundant and accessible than 
they at first imagine. The back yards and stable yards and unused lots will furnish plants and animals in great profusion. Much can be raised in the schoolroom or school-yard. The study of the germination of seeds, of peas, beans, and corn, can be carried on anywhere where there is air and a fair amount of light. This is particularly good for city schools. When the children are interested and enlisted in the work of getting material, they will bring specimens almost without limit, - minerals and corals and shells and fruits from cabinets and garrets. In these days of rapid transportation, the electric cars carry teachers or pupils far out into the country in a few minutes, and enable them to bring the country into the city. The difficulty of getting material will be greatly lessened as we go to work and gain experience.

The experience of the writer in getting material for classes organized for the instruction of teachers in the nature-study work is probably typical. For such classes, where much work had to be brought into a short period of time, it was necessary to have a large supply - enough for each teacher - of the best illustrative material. For a year or two he thought it necessary to make long trips into the country. Gradually his trips were shortened. After two or three years' experience, he found material in the neighboring streets and yards, within a few blocks (although teaching in the heart of a city of 140,000 inhabitants) to meet nearly all the demands of his classes for plant study. It was somewhat more difficult to obtain material for 
animal study; but that obtainable near the school, such as grasshoppers, crickets, caterpillars, spiders, and earthworms and "thousand legs," supplied most of the needs of the class. For snails, fish, crayfish, and tadpoles it was necessary to make trips into the country, or to enlist the boys in the work of getting material.

In great cities it is much easier to get and keep material and apparatus for work with minerals and physics and chemistry. For this and for utilitarian reasons, the work in city schools is often practically limited to the study of physical sciences. The very fact that the children of cities are shut away from living nature, see almost nothing of the plant and animal life familiar to other children, makes it so much the more essential that they have some study of living nature, even if they study only the germination and development of peas and beans, watch the growth of flowering plants which can be kept in the schoolroom windows, and are led to investigate the habits of the omnipresent sparrows, flies, spiders, and mice. 


\section{CHAPTER XV.}

A GRADED COURSE OF NATURE STUDY.

THE following course of study illustrates the application of the principles enunciated in the preceding chapters. It is the result of several years of thought, experience, and experiment. The course in plant study was originally prepared by the writer (while teaching biological sciences in the high school, and directing science work in the elementary schools of St. Paul, Minn.) as part of the Report of the Conference on Natural History to the Committee of Ten, and was published in the "Report of the Committee of Ten." The course was immediately adopted in the schools of St. Paul, and has since been followed to a greater or less extent in many schools from New England to California. The work of the first four grades, in all subjects - plants, animals, minerals, and physics - and part of that for upper grades, was planned for the schools of St. Paul, when the writer was acting as Supervisor of Nature Study in those schools. The course was subsequently extended and somewhat modified for the Practice School connected with the State Normal School at Oswego, N.Y.

The course of study is not, therefore, based merely 
on educational theories, but has been gradually evolved from eight or nine years of experience with nature study in the elementary schools, and of study, - both in a great public-school system and in a normal school, - of the needs and conditions of such schools. Practically all of the work outlined for the first six or seven years has been done, most of it again and again, by practiceor pupil-teachers in the practice school of the Oswego Normal School. Most of the work outlined in the first cycle for the first four grades, and much of that for upper grades, was done by the teachers of. St. Paul.

The principles and ideas on which the selection, arrangement, and sequence of matter are based, have been discussed in Chapters XII. and XIII. In the practice school, nature study and its related work in expression (language, drawing, painting, and moulding) and literature are allotted throughout the year about one hour daily during years one to six, and one hour three times a week during years seven to nine. All the work is done by pupil-teachers.

The course, as outlined, covering so much ground, doubtless seems formidable for most schools. It must be remembered, however, that in the school for which the course is planned, much of the expressive work of the school is based on nature study, and that during the time devoted to nature study, work in writing, reading, drawing, painting, and moulding is done.

Where any systematic work is attempted, an hour a week, at the very least, should be devoted to observation work or presentation of matter, the related work 
in drawing, writing, and reading to be done at some other time. If less time is given to observation, very little will be accomplished.

To keep up the interest and obtain the best results, these observation lessons should not be less than twenty minutes, nor more than half an hour in length during the first three years; nor less than half an hour, no more than an hour, during the later years.

To facilitate the selection of matter and the arrang ment of shorter courses, which, although covering less ground, shall be in general accordance with the principles stated in preceding pages, and shall be logical and coherent, the topics in the accompanying course of study are printed in three styles of type: Those which are most important, and which, taken together, will form a coherent short course, are printed in heavy-faced type; those which, in addition to the topies in heavyfaced type, are considered essential for a longer course, are printed in ordinary type; those which may be considered as supplementary appear in italics.

In beginning systematic science work it is impossible of course to follow at first a graded course of study. The work outlined for the upper grades requires and is based upon the work in the lower grades. It is recommended that, in beginning systematic science work, during the first year all pupils in grades two to four follow the work outlined for the second year, and all pupils in grades above the fourth follow the work outlined for the third year, adding, in the upper grades, such topics as may seem wise. 


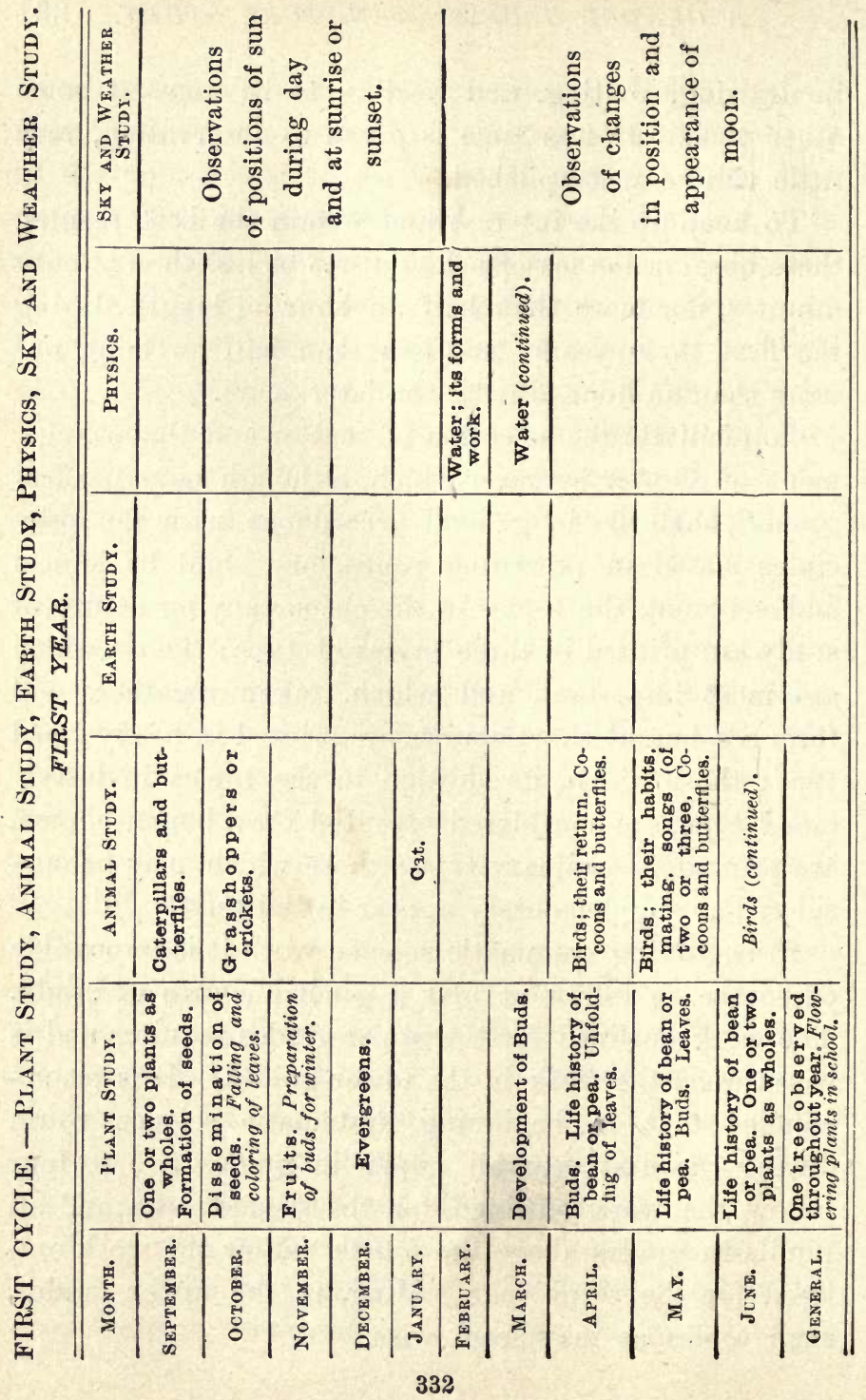




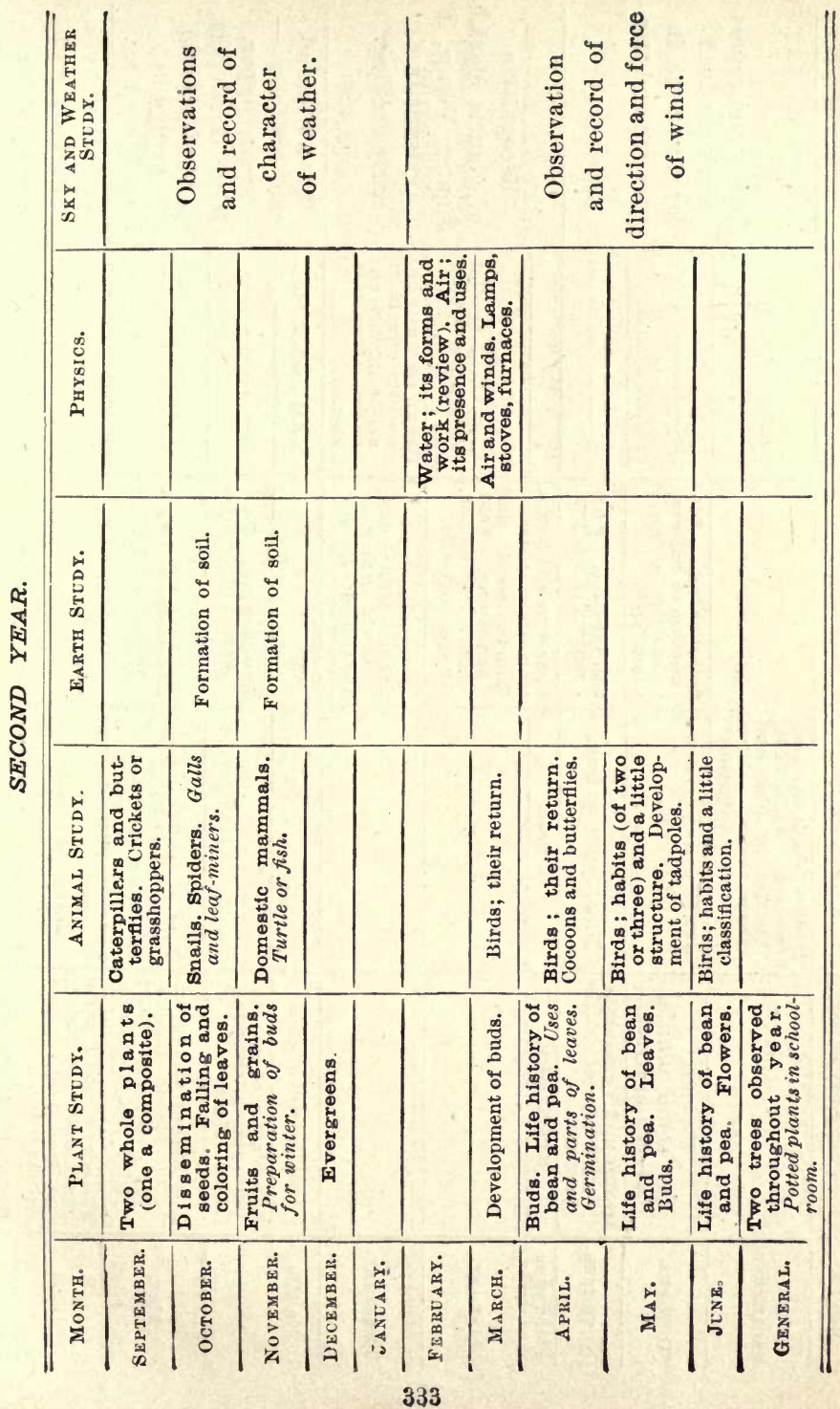




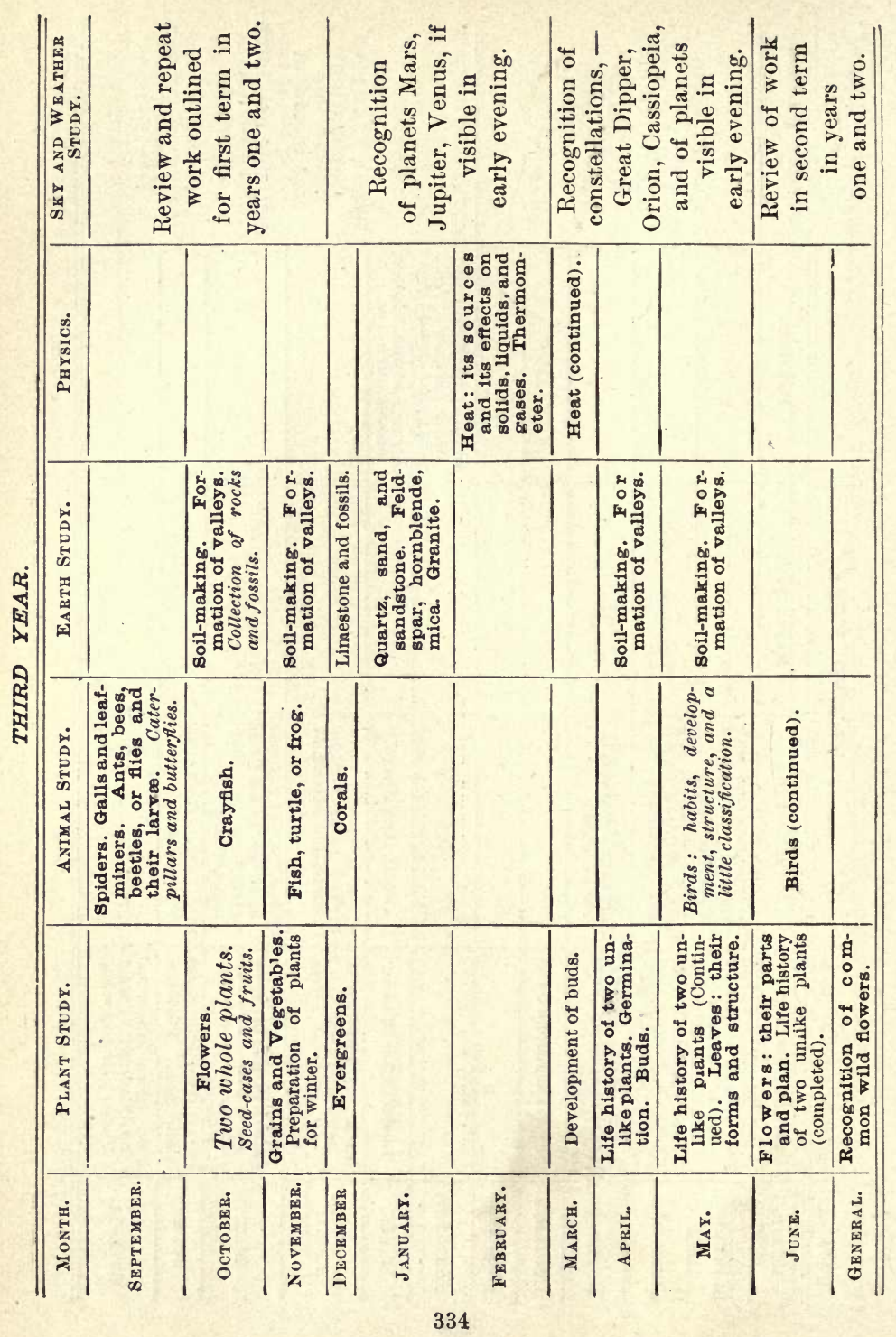




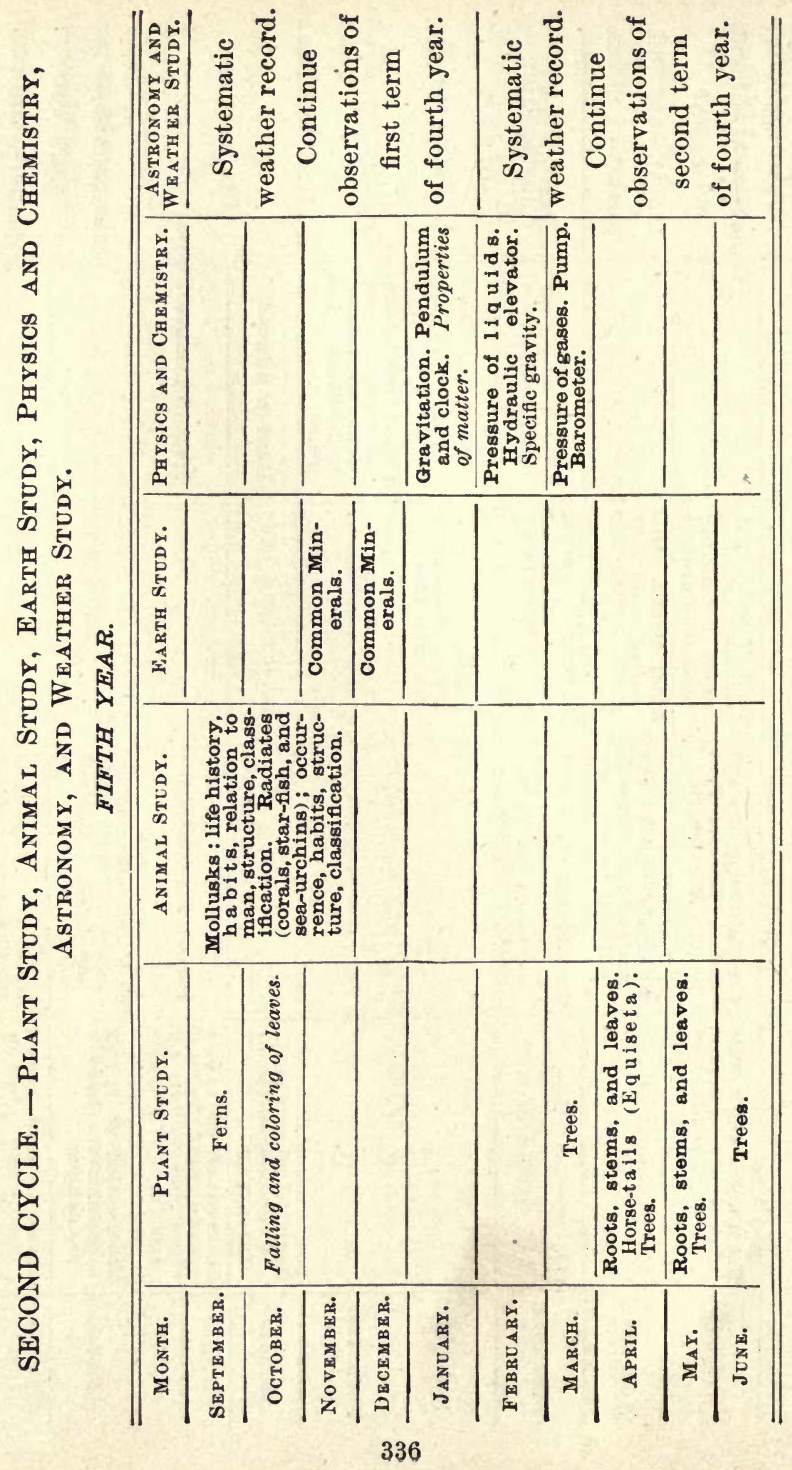




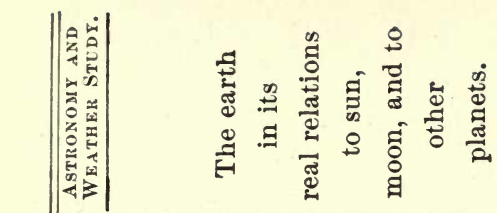

藏
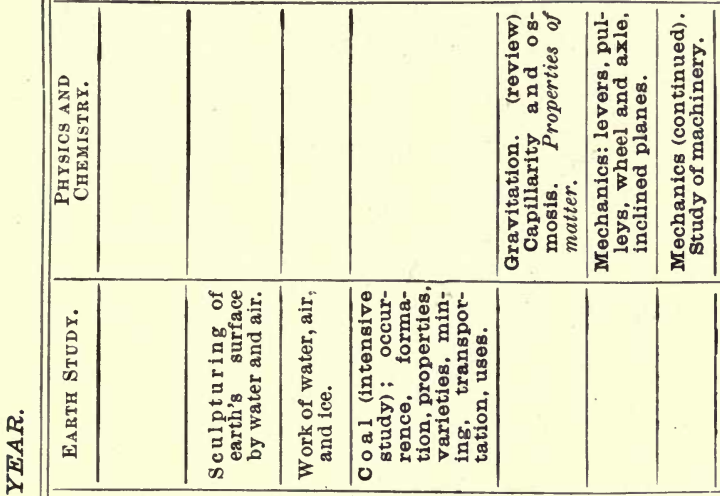

है

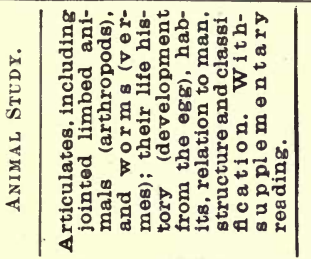

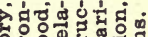
눈언대

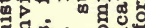
吅㐫 \&已) म 을

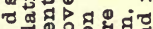

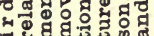
m

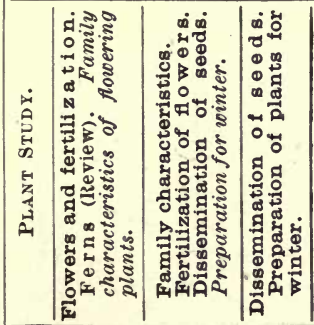

\begin{tabular}{|c|c|c|c|}
\hline 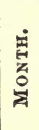 & 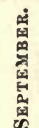 & 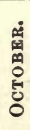 & 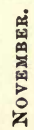 \\
\hline
\end{tabular}

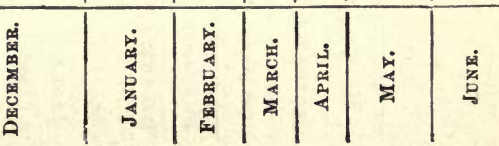




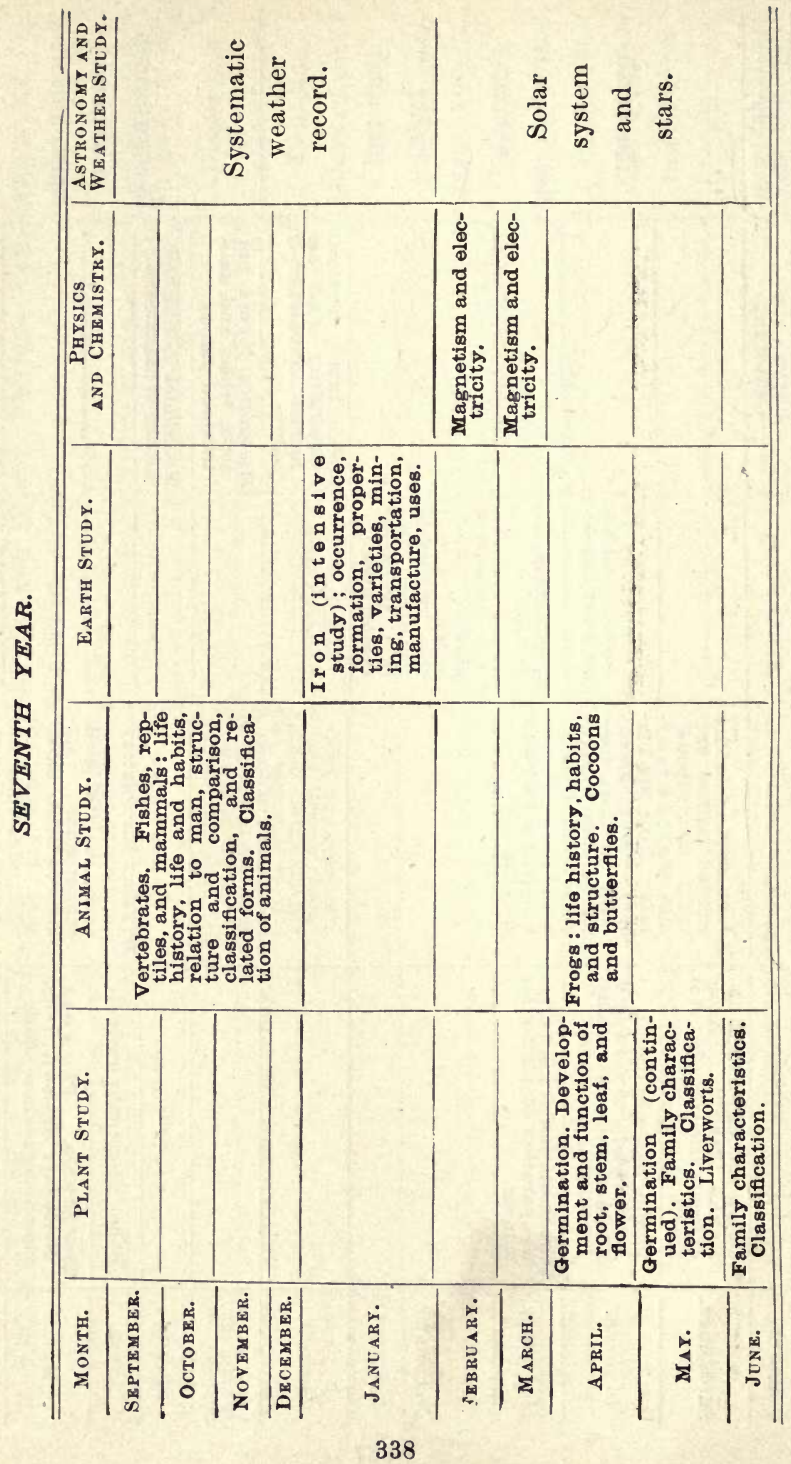




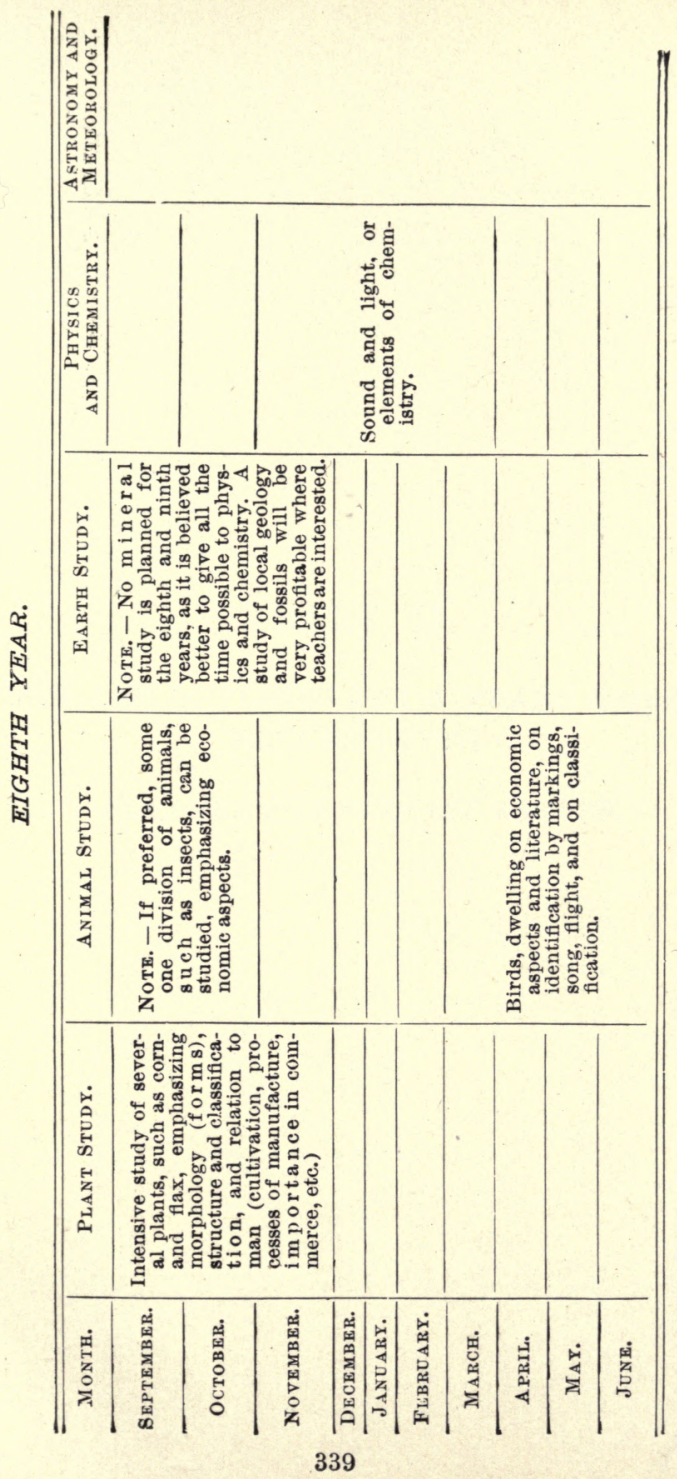




\section{PART II.}

DETAILED OUTLINES FOR A YEAR'S WORK IN NATURE STUDY.

PLANNED FOR PRIMARY GRADES. 



\title{
COURSE OF STUDY.
}

\author{
DETAILED OUTLINES FOR A YEAR'S WORK. PLANNED \\ PRIMARILY FOR PRIMARY SCHOOLS.
}

\section{FALL PLANT STUDY.}

Special Aim of Work. To inspire and develop an interest in the plant as something living, growing, and working, and not as a mere form or structure. To learn about the plant as a whole, the relation and work of its parts, and its life history, from the seed to the formation of the seed. To lead the child to see how well Mother Nature protects and cares for her children.

\section{SEPTEMBER. ।}

Work Indicated for the Month. One or two plants as wholes. The plant as an organism for making seeds.

Material. The mallow and buttereup are particularly good, and are common and easily obtained almost everywhere. Other common plants fairly good for this first study are the evening primrose, large-flowered mustard, and sweet pea, or other plants with large simple flowers, showing, at the same time, all stages in the formation of leaves, flowers, and fruit.

Dig up several plants very carefully from some place where the soil is soft, taking pains to dig deep, and to keep the soil about the roots. Transplant two or three of these to a box in the schoolroom, where the children can watch 
them. Wash off the dirt from two or three, by moving the plant, with the dirt about its roots, back and forth in a pail of water. These plants, with the fine rootlets preserved, will often grow for weeks in water in the schoolroom. If kept in glass jars, the children can easily study the root system. When plants are merely pulled from the ground, most of the roots - and all of the working-roots - are left in the ground. Small plants will thrive in the schoolroom much better than large ones.

THE COMMON OR ROUND-LEAVED MALLOW.

Occurrence. A common weed in and about door-yards, in rather good soil. Recognized by its roundish or kidneyshaped leaves (see Fig. 28), and by its small cheese-shaped fruit, - called "cheeses" by the children. The mallow is excellent for the first study, because the children are familiar with it, and because it has many interesting habits, such as the turning of its leaves toward the sun and the closing of its flowers at night.

\section{Order of Study.}

1. Name.

2. Relation to natural environment. Habits.

3. Function and structure, or work and adaptation to work, emphasizing protection, development, and mutual dependence.

4. Comparison. The mallow as a type of plants.

Preparatory Work Lead the children to talk about work they do at home, to tell how they help. Tell them that the mallow, like everything else, has a work to do, and that they are to find out about the work of the plant and of each of its parts.

To give direction to the thoughts of the children and the right spirit or tone to their work, read to them frequently, 


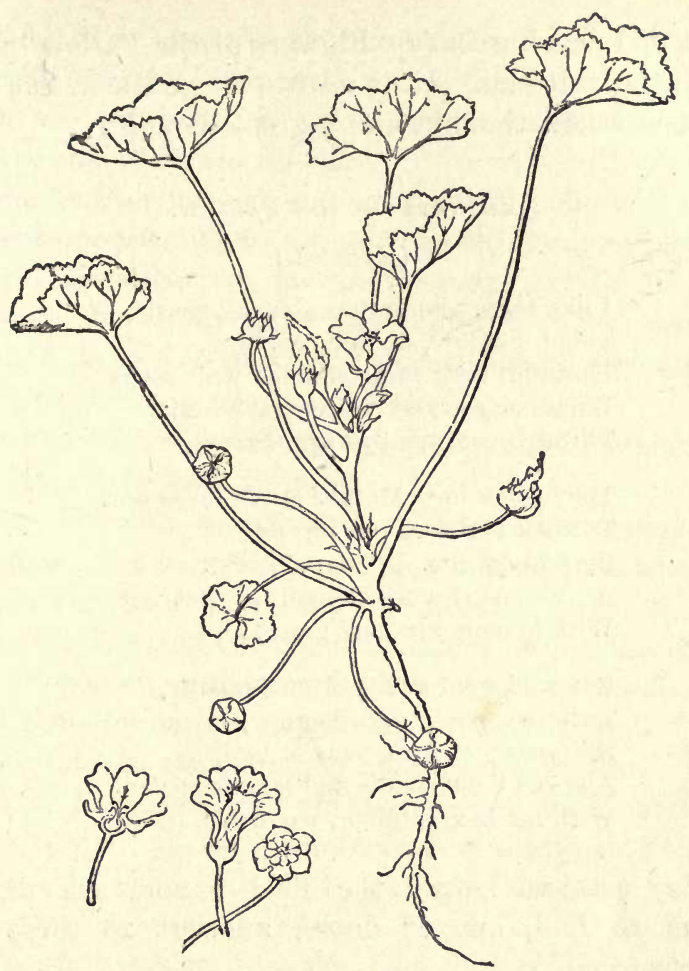

Fig. 28. The Mallow.

or, if they can read, write on the blackboard, and keep before them, something like the following:

"It was only a little plant ;

But on it did shine the sun,

The wind did caress, the birds did sing,

And it lived till its work was done.

It was only a little plant ;

But it took a gladsome part

In the great earth's life ; and at last

Earth clasped it to her heart," 
Part of Lucy Larcom's "Flowers of the Fallow" may be read to the children. It is a little above them, but it will give them a new thought and a great thought.

\section{Flowers of the Fallow.}

\section{(Adapted.)}

${ }^{66}$ I like these plants that you call weeds, -

Sedge, mallow, mullein, yarrow, -

That knit their roots and sift their seeds

Where any grassy wheel-track leads

Through country byways narrow.

They show how Mother Earth loves best

To deck her tired-out places ;

By flowery lips, in hours of rest, Against hard work she will protest

With homely airs and graces.

Her wildwood soil you may subdue, Tortured by hoe and harrow ; But leave her for a year or two, And see! she stands and laughs at you With mallow, mullein, yarrow."

A day or two before the field lesson, ask different children to find, out of doors, answers to these three questions :

First. Where does the mallow, or the "cheese," grow? Have each child tell where he (emphasize strongly the personal observation) saw it, and how he was sure that the plant he saw was the mallow.

Second. Find out whether the leaves of the mallow like the sun. Look at the leaves in the morning, on the way to school. Can they see the sun? Look again carefully at noon; and again in the afternoon, on the way home from school. (Sharp eyes will discover that the leaves turn toward the sun, and follow it from morning to night.) 
Third. How are the flowers of the mallow like little boys and girls? Look at them in the morning, at noon, and in the evening, and try to see how and when they go to sleep, and when they awake.

If the teacher tells these things herself, she will miss an excellent opportunity to interest the children, and set them to work investigating for themselves. It is helpful to encourage the children, or each child, to "find out" the answer to these "riddles" for themselves, and to tell what they discover to no one but the teacher.

The Field Lesson. When planning a field lesson, three points should be kept in mind:

First. The aim, to bring the children into sympathy or in touch with nature, through the study of that part of nature in which they have been interested.

Second. The conditions out of doors, where the children are at home, where they must have greater freedom than in the schoolroom, and where it is more difficult to keep them at definite work, and to hold their attention.

Third. The necessity of giving each child something definite to find out for himself, and of interesting the children so that each will try to find out the most and have the greatest number of discoveries to tell.

As a preparation for the field lesson, gather up the answers to the three "riddles."

Give to all of the members of the class such general questions as the following: What is the mallow good for? Is it just a good-for-nothing weed? (To bring out the fact of its covering the dirty waste places and beautifying the earth.) Does it stand up straight? or does it creep along the ground? How long does it grow? How much or how many times longer than the arm of the children?

Give to different children, or to different groups, such topics or questions as the following: 
Roots. Are the large plants hard to pull up? How held in the ground? Do the roots grow straight down? or do they grow out at the sides? Use of the branches of the roots? Pull up and bring to school two or three plants.

Leaves. Uses: To make the plant look pretty and to cover up, particularly at night or when it is cold, the flowers and "cheeses." Positions : Growing and turning up toward the light; when the grass is short, and the plant is not shaded, the stem is usually prostrate and the leaves near the ground. Arrangement: Covering the ground, with few or no open spaces, giving each large leaf the sunlight. Note how few leaves are covered by others, and how the young leaves are snugly placed in the space between the stem of the plant and the stem of the leaf, - in the axil of the large leaves. Have the children fold a piece of paper as the little leaves are folded, - like a fan. Does Mother Mallow take good care of her baby leaves? As the leaves grow larger and stronger, the plant spreads them out, lengthens their stem, and slowly pushes them up to work for themselves and for the rest of the plant. When it gets cold, they often fold up again, and snuggle down under the old leaves.

Flowers. Position: In the axils of the large leaves. Late in the fall, long after the frost has killed most of the other flowers, we can find the mallow flowers. How do the leaves protect the flowers from the cold? Where are the baby flowers? How are they kept warm?

Fruit, or "Cheeses." Position : Under the leaves. How kept warm? How are the baby cheeses covered? Look for the oldest "cheeses" you can find, those which have turned brown. Try to find some which fall or break very easily into pieces, each shaped something like a piece of an orange. Each of these three-sided pieces is a seed. 
Why does the plant-mother take such good care of the "cheeses"?

After the children have spent fifteen or twenty minutes at work in the field, it may be well to gather them together there, ascertain what they have discovered, and, with the material about them, correct their mistakes, and help them to see what they have not observed for themselves.

The general review of what they have learned can, how ever, be conducted much better in the schoolroom than ou of doors. Always review such a lesson with the plant be fore the children. Seeing the plant will refresh their memory; then, too, they will be able to tell many things, by pointing to the plant, which they, could not tell in words without the plant. Encourage them to tell all they can about what they have seen, with as few questions as possible.

Blackboard Reading Lesson, based on the Field Lesson After the oral review, what has been learned in the fie' lesson can be fixed by a blackboard reading lesson. Th statements should be obtained from the children, and shouls embody the important facts or thoughts gained out of doors. This will not only review and elinch what the children have learned out of doors, but will give them practice in expressing their ideas clearly and exactly, and in relating ideas, or putting their statements in sequence or order.

This reading lesson may be very simple, so that the children themselves can read it (if they can read at all); thus giving them practice in gaining ideas from the written words, as well as in expressing them in written words; or it may be made more complete, and may be read by the teacher, as a story. The fact that the little folks themselves have "made" the story will make it none the less interesting to them.

The main essentials in such reading lessons are: that 
they should be gained from the children as much as is possible, not merely written out by the teacher; should be based upon, but not limited by, what the children have seen; should generally be in a narrative form, or use personification, to appeal to the imagination of the little folks; and should be clear, truthful, connected, and orderly.

Some such stories as the following may be gained from the boys and girls, with help from the teacher, and read to them, rather than by them. If copies of such "stories" are made by the hektograph or other copying process, they will form excellent reading lessons for the children, later in their course.

\section{The Mallow and the Sun.}

We have seen so much about the mallow plant.

The leaves look at the sun in the morning.

John saw them.

They look at the sun when we go home from school.

Mary says she saw them.

The leaves of the mallow look at the sun all day.

They turn to the part of the sky where the sun is.

They grow up above the grass so that they can see the sun.

The mallow leaves must love the sun.

Can you tell why the leaves like the sun so well?

\section{The Mallow and the Ground.}

We went out doors to see how the mallow lives.

Henry tried to pull up a big mallow plant.

He could not. Its roots kept it in the ground.

Miss Grey pulled up a plant.

It had a big root and many little roots.

The little roots are its fingers.

Our fingers help us to hold fast.

The little roots spread out under the ground.

They help the big root to hold the mallow fast.

I think the mallow likes the ground.

Do you know why? 
We saw some very little roots.

They cannot hold much.

What do they do ?

\section{The Story the Mallow Leaf Told.}

Boys and girls think we mallow leaves do not do much.

But they do not know how much I do.

I cannot see that boys and girls do much.

What do I do?

Well, I look up at the sun and at the sky.

The sun makes me green.

I cover the ground with green.

I help make the earth pretty.

Did you ever think how the earth would look if there were no green leaves?

Just peep down here and see what else I do.

Isn't that pretty? See how pink it is !

That is a flower.

I cover it when the sun is too hot.

I cover it when it gets cold.

I hide it from Jack Frost.

I let it see the blue sky, and look at the sun when it is not too hot.

Can you see the baby flowers?

There they are way down where I grow from the stem

Don't I keep them snug and warm?

Now peep again.

No, you cannot eat that. That is not a cheese.

It is a box of seeds.

When the box gets old it turns brown and breaks.

Then the seeds fall out.

Can you find any old seed-box?

I have to take care of the seed-boxes too.

Don't I have much work to do ?

But this is not all.

Look again. Do you see those little green things?

Yes, they look like little green fans.

Those are baby leaves.

I rock them, and cover them, and help feed them.

I love them best of all. Do you know why ?

They will grow into more leaves like me.

They will help me with my work when I am old.

Now do you think I do not have any work to do ? 
IV. What Tommy Found about the Mallow Flowers.

I am in Miss Grey's room.

I went out with the boys and girls to see the home of the mallow. I saw lots of things.

Miss Grey said : "Tommy, you find out all you can about the flower and the cheese."

The flower is pretty, but it is bashful.

It hides under the leaves.

Some of the flowers are white. Some are pink.

The flower has a green coat.

I looked at a flower when it was almost dark.

It had closed up and gone to sleep.

It had its green coat over it.

It wakes up again when the sun shines.

I found lots of cheeses.

I ate some.

Mary said, "Oh, those are seed boxes !"

She found an old brown cheese, with some brown parts.

She said the brown parts were seeds.

I did not know that.

The above illustrate three forms of reading lessons, the narrative in the third person, the narrative in the first person, and personification, in which the plant tells its own story. Those who live and work with little children know how much they enjoy personifying what they are playing with or studying. The narrative in the first person gives less play to the fancy, and may be more careful and definite.

Study of the Mallow in the Schoolroom. Too much emphasis cannot be placed on the helpfulness and importance of the preparatory field lesson; without it there can be very little real study of the life of the mallow. A mere study of the form and structure of the plant is of little value to young children.

From the plant growing in earth and in water, in the schoolroom the protection and development of leaves and flowers can be observed, but not as well as out of doors. 
The parts of the plant must be approached from the standpoint of function; that is, each part should be studied as something having a work to do and as something fitted for its work. The little people can study only those adaptations of form to work which they can easily see and understand. The question "why" should be asked frequently, but not until they have seen something which will help them to answer it; mere guessing is worse than useless.

Plant as a whole. Occurrence: Length and height. (Use some standard of measurement with which the children are familiar, such as their hand or arm.) Position: creeping or upright. Why?

Roots. (Observed in water in glass jars.) One central main root, with many fine branches. Review what was learned about its use in the field lesson. If the attention of the children is called to the withered condition of a plant which has been pulled from the ground, leaving the fine rootlets behind, and has been placed in a jar of water, they will see that a plant will not live without the fine roots. Show them how a cotton string, loosely twisted, or a piece of yarn, draws up water. What is the use of the fine rootlets? To "drink for the plant." Show them how sugar and salt dissolve in water. Another use of the rootlets? To draw up from the ground the food for the plant, dissolved in water. Compare with the way in which children suck up liquids through a straw.

Have several children review and gather up orally, in their own way and language, what they have learned about the roots, somewhat as below :-

The mallow has one long, thick root.

This root has side roots.

They spread out under the ground.

They hold the plant fast in the ground.

The mallow has many fine roots. 
They are like threads.

Miss Grey showed us how a string draws up water.

We can suck up water with a straw.

The fine roots draw up water for the mallow.

We had a plant without any fine roots.

We put it in water, but it dried up.

It could not drink the water because it had no fine roots.

Miss Grey showed us how salt and sugar melt in water.

Some things in the ground melt in the water.

The roots drink these with the water.

They are the food of the plant.

So the fine roots get water and food for the plant.

In this oral review try to have the children tell all about each topic or division of a subject before allowing them to go on with another. Always have them tell observations or describe experiments before they give the conclusions based on those observations or experiments. This is inductive and scientific, and will help to correct the tendency, so common in children - and adults - to "jump to conclusions," to state conclusions, and overlook that on which these are, or should be, based.

On the clearness and thoroughness of this review will largely depend the clearness and permanence of the ideas gained.

Stem. Position: erect or creeping. Use or function : to fasten the leaves and flowers to the root; to carry food and water from the root to the leaves and flowers; to lift up the leaves and flowers where they can see the sun or get the light. Color, length, and shape (" round like a pencil," not merely "round"). Oral review and summary by at least two or three children.

Leaves. Review the uses of the leaves and their fondness for the sun, as noted in the field lesson. How has Mother Nature fitted them for their work?

What happens to a leaf when we break it from the stem? 
Leaves must get food and water from the root through the stem. Note how they are fastened to the stem, each large leaf growing separately from a different part and side of the stem. They must be lifted away from the stem, so that the leaves can see the sun. Call attention to the long green stem of the leaf, flat on the side turned upward, rounded on the other side, "like a pencil cut in two lengthways." Why so long? Why flattened, or slightly hollowed out, on the upper side? To leave a space for the baby leaves at its base. Notice the two little ears (stipules) at its base. They help to cover the young leaves when they are very small.

At the upper end of the leaf-stem is the broad, flat part, which we generally call the leaf. After the children have called it the "broad, flat part" for a time they will be glad to get a name for it. Comparing it with the flat, thin blade of a knife may help them to remember the special name given to it, the "blade" of the leaf. Why so broad? To form a blanket. Its shape - almost round, with a deep cut where it is fastened to the leaf-stem. Its scalloped edge (in many leaves), to make it look prettier. How held out flat with its face toward the sun? Have the children feel their hands and discover how their bones support their hands. What holds out the leaves of the mallow? The veins. Where do they start from, how many, how arranged? Call the attention of the boys and girls to the blood-vessels in their hands, and tell them that they carry the blood to and from all parts of the hand. The veins of the leaf also carry to all parts of the leaf the water and food taken in by the roots, and brought to the leaf-blade by the plant-stem and the leaf-stem.

The leaves have other work to do besides helping to beautify the plant and the world. To keep alive, what else do boys and girls have to do besides eating and drink- 
ing? What happens if they cannot breathe? Plants must breathe, too, and they breathe with and through their leaves. The leaves breathe the air much as we do. Part of the food of the plant comes from the air; and this the leaves take in, through thousands of little mouths, so small that we cannot see them. To make room for these mouths, the leaves have to be spread out a great deal, as we have to make the table large when there are many boys and girls to eat around it.

The leaves can take in this food best, and can best use it, when the sun is shining on them. Without any sunlight they and the plant would soon die. Hence each leaf loves the sun, and turns toward it.

To fix the parts and form of the leaf, it is helpful to have the children draw it, always and only from nature, with the leaf before them. They will draw more thoughtfully, and therefore more carefully, if led to think of the relation between work and form, or between function and structure. If they draw the leaf-stem as a single line, without thickness, as they will almost certainly do, ask them whether such a stem will hold up the blade when the wind blows. If they think, when they are drawing, of the use of the veins, they will be more apt to represent them correctly, as radiating from the end of the leaf-stem and reaching to the edge or margin of the leaf, so as to support and carry nourishment to all parts of the blade.

Before asking the children to draw, the teacher should draw the leaf on the blackboard before them, emphasizing those points about which the children are likely to make mistakes, such as the double line to represent the stem, and the relation to stem, direction, number, and length of the veins. This drawing must always be erased before the children begin to draw.

Flowers and Fruit. Approach the flower as a thing of 
beauty, the crowning glory of the plant; as something with a great work to do, the most important part of the plant. Do not, under any circumstances, have the little children pick the flower to pieces. It is one of the choicest, most perfect, most beautiful of the Creator's works ; and the little child, at least, should love, and cherish, and guard it as something almost sacred.

Study first the relation of the flower to the parts previously studied, - to the root, stem, and leaf. How does it depend on the root, and stem, and leaves for food? Where and how does it grow from the stem? From the angle between the flower-stem and the plant-stem (the axil of the leaf), usually in clusters of two or more. How are the young flowers protected by the leaves?

Have the children look carefully at the flower in different stages of development, - the very small bud just pushing up from the protecting care of the leaf, the fully developed bud not yet open, the open flower, and the old flower with the colored part withered or shrivelled.

Why is the flower-stem so short at first? Why does it grow longer as the flower gets ready to open?

Have the children tell all they can about the parts of the flower, - the green outer part with its five-pointed divisions; the pink part, also with five divisions; the little part in the middle, looking like a very small white Christmas-tree. Do not tear the flower to pieces, and do not allow the children to do so. What is the use of the green part?- To cover up the bud; to make a pretty outside dress for the flower. It is cut into five parts, so that it can easily fold over the baby flower, and just as easily open wide when the flower opens, much as a little girl's cape can be wrapped tightly about her or opened wide. We might call this the cape of the flower, but we do not. When the flower is open, this outside part is shaped like 
a little cup; so it is called the cup, or better, the calyx, a word which means "little cup." What does the pink part of the flower do? In the well-developed bud see how tightly it is twisted around the "little Christmas-tree." It must protect that. This is the prettiest part of the flower; so it is called the crown, or the corolla, a word which means "little crown," or "little garland." The use of the parts within the corolla, the stamens and stigmas, together forming the "little Christmas-tree," the children cannot see in the mallow, and cannot now understand; so it is better to say nothing about their functions.

Have one of the children carefully pull off the corolla from one or more of the old flowers in which it is withered and ready to drop off. What is there under the corolla, wrapped about by the green calyx? Compare it with the "cheeses," noting that the "cheeses" grow from the same place as do the flowers, on the same kind of a stem, and have wrapped about them the green calyx with its five parts. The children should "think out" for themselves the wonderful "secret" that the flowers make the "cheeses." That is their greatest work, - to make "cheeses" for the mallow.

Show the little folks the old brown fruits, or "cheeses," which are ripe, and ready to fall to pieces and drop their seeds. Tell them, or better, get them to tell, how important the seeds are to the mallow; how from the seeds the new plants must grow, when all the plants we have now have been killed by the cold.

Review the work and parts of the flower and fruit. A large picture of the flower on the blackboard will be very helpful in this review. The flowers of the single hollyhock or of the rose of Sharon are almost exactly like those of the mallow, but are one to two inches in diameter. Their size makes them helpful in reviewing the parts of the mallow flower. 
Review the work and parts of the whole plant as something for beautifying the world, and for making seeds which will grow and make the world more beautiful next year. How has each part helped in beautifying the world and in making seeds? How is each part made or fitted for its work?

"Flowers of the Fallow" may be read again, or parts of Longfellow's poem, "Flowers." They will be better understood now. The following from Wordsworth's "Primrose on the Rock" will now mean something, even to the little children, and will give them the best closing thought.

" The flowers, still faithful to the stems,

Their fellowship renew ;

The stems are faithful to the root,

That worketh out of view ;

And to the rock the root adheres

In every fibre true.

Close clings to earth the living rock,

Though threatening still to fall ;

The earth is constant to her sphere ;

And God upholds them all :

So blooms this lonely plant, nor dreads

- Her annual funeral."

The Mallow as a Type. After one plant has been studied somewhat carefully, another should be studied more rapidly, and the two compared. With little children the results will be better if the study of the second plant is completed before any comparison is attempted. If the parts of the second plant are compared with the corresponding parts of the first plant, before all of the second has been studied, the little, children are more apt to get the two plants confused. At least two plants should be studied before going on to another topic, such as dissemination of seeds. This will make the ideas of the children broader and more general. 
Excellent plants for comparison with the round-leaved mallow are the high mallow, an erect plant, two to three feet high, with lobed leaves, and similar but larger flowers, the common single hollyhock, an l the rose of Sharon.

Dividing the Work into Lessons. The ideas the children gain from the work will be much clearer and more deeply impressed, if each lesson is a unit in itself, with a definite aim, one central thought, and a careful summary at the close. When there is time, the following division of lessons is suggested :-

Lessson 1. Preparatory Work. Aim. To make the children familiar with the appearance of the mallow, and to put them in the right.attitude toward the plant as a living thing.

Lesson 2. Preparation for the field lesson. Aim. To gather up what the children have learned out of doors, and to prepare them for further definite out-of-door observation of the life of the plant.

Lesson 3. Field Lesson. Aim. To study the plant at work in its home.

Lesson 4. Review and summary of what was learned out of doors.

Lesson 5. What the roots and stems do, and how they are fitted for their work.

Lesson 6. What the leaves do, and how they are fitted for their work.

Lesson 7. What the flowers do, and how they are fitted for their work.

Lesson 8. Review. What the mallow plant does, and how it does it.

Possibly lessons 1 and 2, and lessons 5 and 6 , and lessons 7 and 8 , can be combined, and the number thus reduced to five. 


\section{THE BUTTERCUP. ${ }^{1}$}

The buttercup does not have the many interesting habits of the mallow (in the spring its flowers turn towards the sun, but not to any marked extent in the autumn). But it shows somewhat more clearly the spreading and branching of the roots, to get nourishment from the ground, the extension of the veins into every part of the leaves, to support and carry food to each division, and the protection of the young leaves by the older ones, and will give the children a better idea of the parts and plan of the flower.

Preparatory Work. The field lesson is not so indispensable in the work with the buttercup as in that with the mallow. All the class-work with the buttercup can be done in the sehoolroom.

But pains should be taken to have the boys and girls individually observe the plant out of doors in its home, find and report where it grows, how high it grows, how it lifts its bright flowers up above the leaves, while the modest dainty blossoms of the mallow hide below the leaves, look for "cheeses" or for seeds, and see how Mother Buttercup protects her baby leaves and flowers.

Dig up several plants, as directed before, selecting the youngest and most vigorous plants with flowers, and place some in window-boxes, and some in water in glass jars. The roots are usually interlaced, several plants being closely fastened together; at least two or three plants should be separated for study.

Preparatory Lesson. In the preparatory lesson the teacher may give the children the thought, "The buttercup catches the sun in its cup," and centre her work about this. Perhaps this poem may impress the thought of the

1 The plant studied is the tall buttercup, the most common species in Michigan, Minnesota, and New York. 
gold the jolliest and merriest of the flowers gets from the sun, and of the happiness he scatters about him :-

"A little yellow buttercup

Stood laughing in the sun ;

The grass and leaves all green around,

The summer just begun,

Its saucy little head abrim

With happiness and fun.

The flower smiled up, the sun beamed down,

As they for years had done,

Until as golden as his friend

The little flower had grown.

As summer passed and autumn came,

The flowers above him said,

'Come, buttercup, our work is done,

It's time to go to bed.'

'Not yet,' said he, ' the sun still smiles,

I'll wait till he has fled;

I yet some little seeds can form,

Some smiles about me shed.'

The merry buttercup laughed on,

And tossed his golden head."

Get the ideas of the children as to the meaning of the name "buttercup," and have them tell how the buttercup helps them to discover whether boys and girls like butter.

They may have observed that when it is found in fields and pastures the cows and horses eat the grass all around it, but rarely disturb this plant. Why? If the children taste of it (somewhat cautiously, as it has a decided "bite") they will discover one way in which Mother Nature protects her children. The cattle learn that the buttercup is a good thing to let alone.

Some of the sharper eyes may have discovered another of its secrets, - the fact that the long stems of the older leaves are enlarged, split open, and hollowed out at the 
base, making the snuggest kind of a cradle for the baby leaves and flowers. In the fall this is more difficult to discover than in the spring, as nearly all of the leaves and flowers have developed, and there are comparatively few babies to be cared for.

\section{SCHOOLROOM STUDY.}

Study of the Buttercup in the Schoolroom. Roots. Review the work of the roots, to hold fast and to absorb water and food. Why does the buttercup hold fast better than the mallow? Instead of one or two main roots, it has many, spreading out in all directions, each one quite tough. Call attention, too, to the great number of fine rootlets. What do they do?

Stems. Their work, to lift up the flowers and seeds, and to carry to them water and food. How much we would lose if the golden buttercups and all flowers were hidden under the leaves like the mallow ! How pleasant it is to find the mallow blossoms, and their modest, shy relatives hiding where they must be hunted for! Notice the many branches, to lift each flower where we can

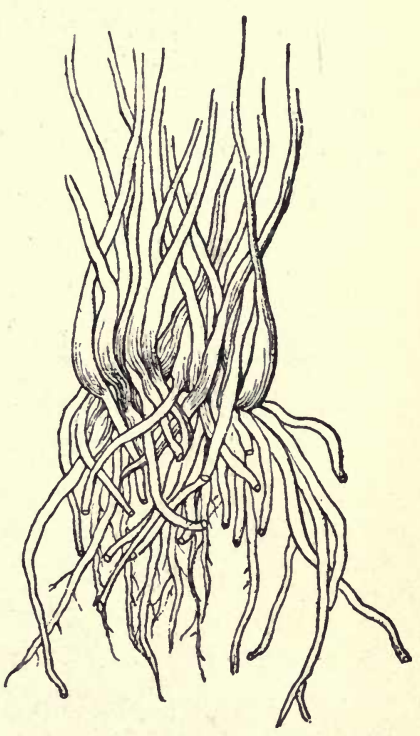

Fig. 29. Roots of Buttercup.

see it. The stem has some leaves, but they are much smaller than the leaves springing up from about its base. Their main work is to cover and protect the flower-buds, and to make the flowers look brighter from contrast with 
their green. In many plants, at this season, the stems have finished their work, and have dried up.

Leaves. Review the work of the mallow leaves: to make the plant and the world look pretty, to protect the flowers and the little leaves, to breathe and to take in food from the air.

Be sure that each child sees just how the young buttercup leaves and flower-buds are kept warm; they will not find many as pretty illustrations of protection.

Show them how much richer is the yellow of the flower when there are green leaves near it, and how much prettier the flowers look when hanging loosely and separated than when massed together. Perhaps even the little folks can get some hints from nature which may help them in arranging the flowers they gather

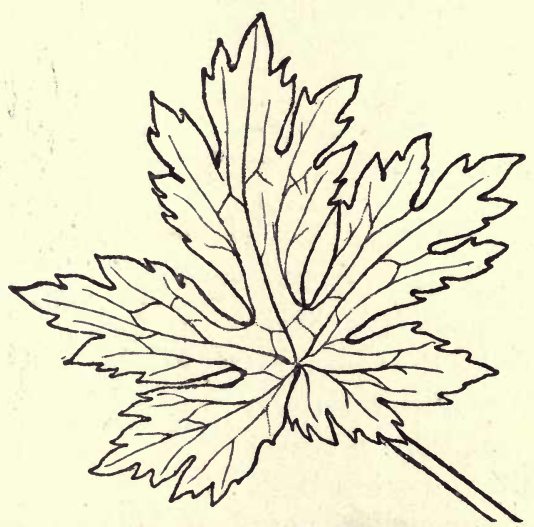

Fig. 30. Leaf of Buttercup.

Describe ihe leaves. They are too complex for little folks to draw; but their form may be impressed by having the pupils compare them with their hands, with the fingers outspread (do not give them the terms palmate or digitate 
now), by the teacher drawing the leaf on the blackboard at the direction of the children (represent first the plan of veining, then draw the divisions or lobes about the main veins or ribs), or by letting them make an impression in clay.

The large leaves come from around the base of the stem (they seem to come from the roots, and hence are called " root-leaves"), have very long stems, which are hollow and broad at the base, like a funnel split lengthways (Why?), and have a blade with five to seven divisions, or "fingers." Compare the veins with the bones in the fingers of the children; they will discover that each finger and each point has a vein to support it. Compare them also with the veins in their hands, or with the gas or water pipes in their houses, or with the ditches or drains in the fields.

Compare the stem-leaves, those growing on the stems which bear the flowers, with the root-leaves as to position, length of leaf-stem, parts, veins, and uses.

Perhaps the children can grasp a little of the thought that the earth is much prettier because there is such endless variety in the leaves of different plants. How much better it is that the leaves of the buttercup are so different from those of the mallow!

Flowers. The buttercup flowers are the golden cups from which the fairies take their favorite drink,- dew and honey.

" 'O where do you come from, bright flowers and fair,

That please with your colors and fragrance so rare, Glowing in sunshine, or sparkling with dew?'

'We are blooming for dear little children like you.'"

"The buttercup catches the sun in its chalice."

LOWELL.

Cannot we begin our study of the flower by putting and fastening in the hearts of the boys and girls thoughts like 
these? If they get and keep the idea that buttercups are fairy cups painted by the sun, or made of gold carried by the sunbeams straight from the golden sun, and that the flowers are here to bring happiness to boys and girls, and to men and women, will they be apt to pass them by so carelessly?

Review what has been done to make the flower; what the roots did, and how soil and water helped them; what the stems did; what the leaves did, and how sun and air helped them.

What can the flower do in return for all that has been done for it?

How it brightens the world! Like the dandelion, of which Lowell has written :-

"'Tis the Spring's largess, which she scatters now

To rich and poor alike, with lavish hand,

Though most hearts never understand

To take it at God's value, but pass by

The offered wealth with unrewarded eye."

But this is but a part of the work of the flower. To discover what else it does, the children, and their teacher, will have to use their eyes carefully. The story is all there, if we will but take the pains to read it.

Place a fully developed wide-open flower on each desk, eautioning the pupils to hold it by the stem, and not to hurt the flower. Have them observe it carefully, and tell all they can about it, with as few questions as possible.

Doubtless they will first notice and tell about the golden cup or saucer, made of five or more parts, each shaped like a fan (or some other object with which the children are familiar), bright yellow on its upper side, duller below. There is no difficulty in the buttercup in seeing why this is called the little crown, or the corclla, which means the 
same. Each golden fan is called a petal. The smallest child will understand and can tell what these do, or what they are good for.

The outer and lower five green parts ( these may be missing in some flowers, as they are apt to drop off when the flower is fully matured) together forming a star or rosette, constitute the little cup or calyx, each part, shaped like the bowl of a spoon, being called a sepal. What do these green parts do? A glance at the halfopened flowers or at the buds will show. When the other parts do not need to be covered or protected, the work of these green parts is done, and they fall off.

What else do the sharp eyes find? Many little yellow "things" about a green

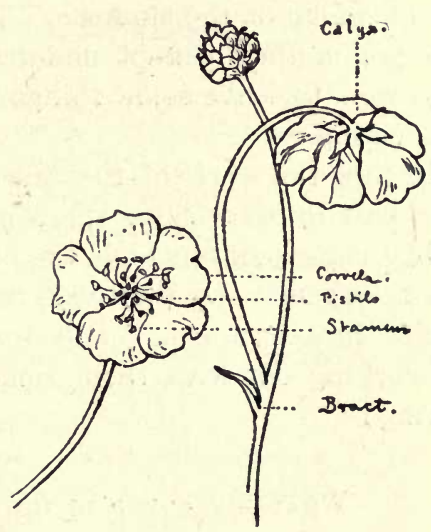

Fig. 31.

Flower and Fruit of Buttercup.

ball in the middle. The sharpest eyes will discover that each yellow "thing" has two parts, - a short stem with a ball on the top, and that the green ball in the middle is rough, or has points on it.

If the teacher has given to some children flowers in which this green ball is quite large, and to some, matured blossoms, from which the petals, but not the yellow threads or stamens, have fallen, they may discover that this green ball is, or develops into, a cluster of seeds. It is really a cluster of seed-vessels, each containing a seed; but the children are not ready for and cannot understand this distinction. This green ball is, then, made up of seeds; to the 
plant they are the most precious part of the flower. Why? Why are they placed in the middle of the flower?

The yellow "things" we can call "soldiers," placed there to guard the seeds. Older people call them stamens. The little folks like the idea of their being soldiers, and the thought will do them no harm. Note the yellow powder or pollen on the stamens. The real use of the stamens and pollen they cannot understand until they are older. It is well to leave some things unexplained, for future investigation.

Review the work of the flower and the special work of each part in beautifying the world and in making seeds.

The main points which the children have learned about the flower may be reviewed, fixed in the mind, and preserved in a form convenient for future reference and use by working out with them some such "story" as the following :

\section{What We found in the Buttercup Flower.}

We have studied the buttercups.

We never saw before how pretty they are.

They are yellow like butter.

They are yellow like the sun.

They look like gold cups.

Miss Grey says they get their gold from the sun.

The sunbeams bring it to them.

The fairies drink out of the gold cups.

When the cup spreads out it is like a saucer.

It has five parts.

Tommy's flower has seven parts.

Each part looks like a littie gold fan.

They make the flower look so pretty.

Under the gold parts we found a green star.

- It has five parts.

Each part looks like a spoon without a handle. 
In the baby fiower these parts are on the outside. They cover the pretty yellow parts when they are little. Mary's buttercup did not have the green parts. Miss Grey said they had fallen off.

Their work was done.

In the middle of the gold cup we found a little green ball.

It had little points on it.

Harry found a green ball without any gold cup.

It had many green parts.

Harry thought they were seeds.

We could not find anything else that looked like seeds.

Miss Grey said, "Yes, they are seeds."

There are many green seeds in the green ball.

The seeds are in the middle of the gold cup.

The gold cup and the parts of the green star take care of them.

The buttercup plant puts her seeds where they will be most safe.

We found some yellow things all around the green ball of seeds. They are so many we cannot count them.

Fanny says each yellow thing is like a pin.

It has a thin part like a thread, with a little ball on top.

They stand all around the seeds and take care of them.

Miss Grey says they have another work to do.

We will find out about it some time

Did you know the buttercup had so many things in it ?

Every little part has some work to do.

Do you know what the buttercup flower is good for?

It helps to make the world beautiful.

It helps to make boys and girls happy.

1t makes seeds for the buttercup plant.

And yet some folks think it is not good for anything.

Drawing and Color Work. The buttercup flower is so simple and symmetrical, it is excellent for the first work in drawing or painting flowers, much better than the mallow. 


\section{OCTOBER.}

Work Indicated for the Month. Preparation of the plants for winter. The dissemination of seeds. The falling and coloring of leaves.

\section{THE DISSEMINATION OF SEEDS.}

Aim. The general aim remains the same, - to inspire and develop an interest in the plant and love for it, as something living, growing, and working, and to lead the children to see how well Mother Nature cares for her children. The special aim has changed. We have been trying to discover how the plant lives, and how it makes its seeds; now we are to see how the plant prepares for winter, and particularly how it protects and scatters its seeds. Everything must be centred about the seed-vessels and the seeds; all else is subordinate and incidental.

Material. The milkweed furnishes one of the most exquisite illustrations of the way in which the plant-mother protects and provides for the scattering of her seed babies. The milkweed, thistle, and dandelion are the most common, and in many respects the best, examples of seeds with hairy wings. The burdocks, stick-seeds ("stick-tights" the children usually call them), and beggar-ticks (sometimes called by the children "pitchforks"), are the best examples of seeds provided with hook or barbs, by which they can cling to passing animals, and thus "steal a ride." The maple, ash, and linden trees, give their seed babies a wing by which they may fly quite a distance from their elevated home.

These should always be studied so as to bring out their relation to the plant-mother. Whenever it is possible, the children should see, not merely be told, that the seeds are 
formed from the flowers. The boys and girls should see the plant, or part of it, with the seeds growing on it, and should see the different stages in the formation of the seeds from the flower. In the thistle, dandelion, burdock, stick-seed, and beggar-tick these can usually be obtained at this season.

The teacher will find much helpful matter and many exquisite illustrations in Gibson's Sharp Eyes. Particularly good are the articles on "Seed Tramps," "Ballooning Seeds," and "Winter Grist for the Birds."

Plan of Work. Little children cannot, or at least they do not, think of "the seeds with hairy sails," or "the seeds with wings," or "the seeds with hooks." Such generali- zations are too abstract for them. They must gather each class about some concrete example. Hence we should first study such a plant as the milkweed, which is typical of the hairy-winged seeds, and gather about it two or three other seeds with hairy wings; then we can study with some care the burdock, and gather about it some of the hooked or barbed seeds. Later the ash may be the starting-point and centre for some study of the winged seeds. Afterwards the children can gather and sort many kinds of seeds, deciding for themselves whether they are carried about like the milkweed seeds, or like the burdock seeds, or like the maple-seeds, or whether they are not like any of them.

\section{THE MILKWEED.}

Bring into the schoolroom two or three milkweed stalks, one with leaves but no pods, the others with leaves, pods, and as much of the root or underground stem as can be obtained; if possible, have a stem with flowers or very small pods.

Name. Significance of name milkweed? 
Occurrence. How many have seen milkweeds growing? Where?

Life, Work, and Structure of Plant. Centre the interest and thoughts of the children about the pod, a wonderful cradle and treasure-casc. How have root, stem, leaves, and flowers helped to make the pod? Bring out briefly the special work of each. Dwell on the "milk" as the blood of the plant. Plants which have not made pods, or have not matured them, usually have at this season considerable "milk;" those in which the pods are fully matured usually have little or no "milk." The "milk" is used up in ripening the pods. Call attention to the height and strength of the stem, as compared with the stems of the plants previously studied. It must be strong to hold up such heavy pods. We will see, when we have studied the seeds, that it is much better for the seeds to be lifted up so high.

Why have the flowers dropped off? Why are stem and leaves turning yellow or brown? Their work is done. Those which have not made pods are much greener.

The Milkweed Pod. The result of the season's work: root, stem, leaves, flowers, soil, rain, sun, all have worked together during five or six months to make these pods. As Lowell writes in "The Changeling":

"For the whole year long I see

All the wonders of faithful Nature

Still worked for the love of me ;

Winds wander and dews drop earthward,

Rain falls, suns rise and set,

Earth whirls, and all but to prosper

A poor little violet."

Note the position of the pods, up near the top of the tall stem, and the peculiar way in which they are fastened to the stem. How easily they move when slightly dis- 
turbed! Each pod has a spring. The reason for this the children can discover later. Have the children tell about the shape of the pod (comparing with some object familiar to them), its color, softness, and perhaps the rows of soft spines on it, which make it look prettier. Along the outer side, always on the side away from the plant-stem, is, in the younger pods, a rather hard ridge along the middle of which a crease or crack develops as the pod ripens.

How the Milkweed Babies are Protected. Cannot we arouse in our little folks that "spirit of expectancy" which is the best preparation for one of those enthusiastic, earnest, wide-awake lessons the results of which "stick" in the little minds? Perhaps the lines below will aid in this :

\section{The Milkweed Case.}

"Cover and case, close locked together, Filled with a curious kind of feather; Open the box, you'll need no keyOlı ! pretty green case, did you grow fo ${ }^{-}$me?

'Twas only the other day I said, I must make my dolly a feather-bed; And here is the softest, fluffiest stuff, Silky and white and plenty enough."

Have the children study a pod partly opened. Isn't that beautiful? Neither teacher nor pupil will see many prettier objects. Are the little scales scattered about, as boys and girls sometimes throw their things, or does each scale have its place? Why arranged so carefully? Why does not Mother Milkweed tumble them in any way? (Never mind the moral; let the milkweed do the preaching.) Just under the crack in the cover the plant mother has not placed any little scales. Do you suppose she was afraid - some cold might creep in through the crack and chill the babies? In the small upper end of the pod we do not find the scales; there is only white, shining silk. 
If a ripe pod, which has opened, is hung in the schoolroom two or three days, it will begin to discharge its seeds, so that the children can see just how the plant-mother sends her seeds out into the world. They should also watch the process out of doors. The teacher cannot understand or appreciate the ways of Mother Milkweed until she has taken her book some Saturday, and spent an hour or two in a milkweed patch at sailing-time.

Now let us see how the babies are wrapped in their cradle. Compare constantly with the babies at home. Note how the blanket is wrapped all around the babies, with every crack closed up; how it opens at the right time, not too early, not too late, and at the right place, where there are no babies to feel the first cool drafts, and away from the stem, where the babies can first see out and get out. How soft and thick it is, the finest kind of a "comfortable"! How very smooth and soft is the part that comes against the wee babies! Perhaps some child can tell about the very soft flannel that mamma wraps next to the skin of the little baby at home. The outside wrappings need not be so soft. If any of the boys or girls have ever seen their mothers make a "comfortable," or have discovered the cotton inside of their " comfortable," have them tell about it. Then tear open the covering of the pod, and show them the spongy, cottony interior.

Is Mother Milkweed as careful about her babies as is the mother at home?

How the Milkweed Babies are Scattered. This lesson will mean comparatively little unless the children have watched the process, as urged on the preceding page.

Many of the children have brothers and sisters working, some in one factory or store, some in another, some scattered in distant cities or States. Why so scattered? They have gone where they could get work or could make a 
living. What would be the result if all the hundreds of seeds on each milkweed plant dropped down to the ground and began to grow together? Could they get soil enough or sun enough, or rain enough? Very few could grow or even live. Mother Milkweed knows this, so she gives each of her seed babies hairy wings or a balloon.

The upper scales or seeds, those toward the more pointed end of the pod, are on the outside and partly cover the others; so they must fly out first. The pod usually splits open at the top first. Note how the silky tail on each scale divides into two parts, and how its hairs spread apart, how the least wind shakes the pod until the seeds with their balloons are shaken out. Now we see why the pods are on springs, and why they open toward the outside. As the upper seeds escape, those below are pushed up and out by the drying and spreading of their hairs, and are slowly shaken out of the pod, one or two or a very few at a time.

How easily they sail away! How gently they drop to the ground! What comes to the help of the milkweed babies, and carries them along? Perhaps the children can see, in a large pod from which the seeds have been partly discharged, that each seed has a little saddle of its own, on which it rides like a child on horseback, with part of its tail on each side. The seeds are carried on a spindleshaped axis, fastened only at either end of the pod, so that it is free to swing, somewhat like a hammock. On the surface of this, extending from end to end, is a series of thin, narrow, projecting ridges; the edge of each of these is broken into scallops, forming the "saddles." Thus each seed is kept in place. In each "saddle" is a brown line which shows where the undeveloped seed was attached; here are the minute tubes through which the plant mother provided each baby with "milk." These little points are probably too difficult for the little folks, but 
seeing them will help the teacher to appreciate the perfection in every detail shown in the milkweed. They can be studied by older pupils.

This axis may be compared to a hammock, to the outside of which the seed babies cling. As the wind moves the pod back and forth on its spring, this hammock is twisted, and gradually brings up toward the opening in the cover those seeds which grow on the side of the hammock away from the opening. At the same time the pod is apt to double up, to bring the ends nearer together, and to make the opening "gape" more, as shown in the old dry pods.

If we select a large scale from a green pod, and carefully pinch off the "rim" from the broader or lower end, and press gently, the real baby, the little green plantlet, may be seen with a short stem and two leaves, lying face to face, but readily separated with a pin.

Division into Lessons. There should be at least three leasons, if the work is well done.

Lesson 1. The home of Mother Milkweed, and the making of the seed cradles.

Lesson 2. The milkweed cradle, and the way the seed babies are protected.

Lesson 3. The scattering of the milkweed babies.

Expressive Work. In Lesson 1, in which the matter is quite general and largely review, oral expression is the best.

In Lesson 2, the form and attachment of the pod is important, and can be best expressed by a clay model or a drawing of the pod. The teacher must make the object to be drawn as simple as possible, must remove from it everything except that which the children are to draw, and must place it in the position easiest to draw. Break off a few inches of the upper ends of two or three stems, removing the leaves and all but one pod, fasten these where and in 
the position in which the children can most clearly see and most easily represent stem, "spring," and pod, and have them model them in clay, or draw or paint them.

In Lesson 3, a careful drawing, somewhat enlarged, of the seed baby and its "tail," and a second drawing of the seed and its hairy sail or balloon, will help to impress the main thought of the lesson, the way in which the seeds are scattered.

Review Story. The essential thoughts and lessons for the children may be gathered up, and "clinched" or fixed in the minds of the little folks, by appealing to their imagination by a story somewhat like the following:

\section{The Milkweed Babies.}

\section{What I Heard and Saw in the Fields.}

One quiet afternoon last fall I walked out to a field not far from here, and sat down to watch all the pretty things I could see.

A brook ran through the field, near which was a family of waving and nodding ferns. You know how the ferns bend and nod, like little boys and girls when they get sleepy!

Off on the side of the hill was another family, each bright green, and tall, and slender, and straight, each gracefully bowing to the others. These milkweeds were not as dainty as the ferns; but they were just as pretty, in their way.

In a corner, not far away, was one - just one - buttercup, stretching itself up to look through the fence at the sun. Sometimes he would turn his bright face toward the fleecy clouds above him ; sometimes he would nod toward the ferns or the milkweeds.

I listened to the brook singing, and heard the wind whistling softly in the trees over me. Suddenly there was a whisper near me. I looked all about me, but could see nothing. When I moved it was quiet. I sat very still, and soon I heard it again. It seemed to come from the ferns. In one place they were growing around in a circle, and all seemed to be looking toward one who was nodding more than the others ; and the sound came from this fern. Now I could hear the words :

"Yes," the voice said, "yes, I have been watching that milkweed family up there all summer. They are not nearly as pretty as some 
of you ferns; but they have been working so hard, and live together so happily! Some of the grasses tell me that they can feel the milkweed roots growing, growing, growing ever so far under the ground. The buttercup says that the roots go down very deep in the ground, and leave the part of the earth near the top for the roots of the smaller plants; and that they work, work, work all the time, night and day. All summer they have been making milk. When the buttercup asked one of them what they were going to do with so much milk, it stopped work just long enough to say, 'You wait until next fall, and then you will see.'

"I have watched the stems growing up and carrying those thick, heavy leaves, so different from ours. I would think that they would get tired of such loads; but the more leaves they have to carry the better they seem to like it. When I asked them one day if they did not get tired, they looked so surprised. 'Tired ? We tired ? Why, that is what we are made for, to hold up and feed those leaves.' Then one of them said: 'But that is not all that we do. The most wonderful thing is going to happen next fall. We are getting ready loads and loads of milk for it.' When I asked what was going to happen, she laughed such a funny laugh, and only said, 'You wait until next fall, and then you will find out.' Now they have to carry those heavy green things at the top, - 'pods' they call them, - and they seem happier than ever. It is nice to have happy neighbors, even if you can't see what makes them so happy.

"The leaves, those thick, heavy ugly things, so different from the beautiful leaves that we ferns have - " Just then I heard another voice, so different from the first. I looked all about, and could see only a robin in the tree above us. The sound seemed to come from him. "Ugly! that's all you know. If you could be as high as I am, and could see how kind and thoughtful those leaves are, you would never call them ugly. They are thick, but that is because they carry so much milk to feed their little brothers and sisters with. They are large ; but that is because they have so much work to do, - and they do it tou. I wish you could see how carefully the larger leaves bend over the baby leaves which are nestled together above them, at the very top of the stem; and how warm they keep them at night, and in the daytime, too, when it is cold.1 Never again call the milkweed leaves ugly."

1 The little folks are intensely interested in seeing, not merely being told, how the upper leaves of the milkweed move up, toward night, to close over the "baby leaves," and spread out again in the morning. 

flew.

Just then the robin heard another bird calling him, and away he

For a time all was quiet. Soon there was a new voice, so bright, and happy, and full of sunshine, that I turned toward the buttercup, the most sunshiny thing I could see. The plants call him "Little Sunshine." But you shall hear for yourself.

"The milkweed leaves," said the buttercup, "told me a secret the other day. They seemed to be just dancing with joy, and I asked them what made them so happy. 'Why, don't you know,' said they. 'We thought everybody must know it. Don't you see these pretty flowers above us? For months and months we have been working for those, and waiting for those, and now, now' - how the leaves danced - ' they are here. But that isn't all. Something else is coming. When the flowers drop off - then, then - oh! won't it be wonderful." But that is all they would tell me. They went on dancing and laughing, but would not talk. I smiled and smiled at them until I suppose they thought they had to say something. Then one of the leaves added, 'Would you like to know, Little Sunshine ? It is a great secret, and we cannot tell any one. But you wait until next fall and you will find out.'

"I asked the flowers. One of them said, 'We would like to tell you, Little Sunshine; but it is a long, long story, and we are very busy making honey to feed these hungry bees. You wait until next fall and you will find out.'"'

As the buttercup was speaking some bees came towards him. He smiled at them - he smiles at everything, you know — and said, "I must see what I can do for these bees." Then all was quiet again.

By this time I wanted to find out for myself what made the milkweed leaves so happy. It was fall now, and perhaps I could see if I watched the milkweed carefully.

Very quietly I moved toward the milkweeds and sat down. At once I heard a new sound. At first I thought it was the rustling of the leaves, it was so low and gentle; but soon I could hear what seemed like hundreds of little voices. You may be sure I lay very quiet, and listened and listened. Many voices were saying so softly and gently, "Please can't we get out?" Others, and they sounded sleepy, said, "Oh, no! we are not ready yet. We want to stay a little longer. It is so soft and warm here in our cradle."

Cradles? Where were the cradles? I could not see any. The voices seemed to come from near the top of the milkweed stem, from some green things I had heard called milkweed pods. 
As I watched these some of the voices began to sound clearer. One green pod showed a little crack near the upper end. I peeped in, and-well, I cannot tell you what I saw; it was too pretty to tell about. I thought I had seen some pretty cradles, but that was the laintiest. It rocked back and forth so gently. It had the finest, smoothest lining. At first I could see inside only the softest, finest, whitest silk. I looked again, and then - well, maybe you won't believe me, but it is so; I saw them - there were in that cradle hundreds, yes hundreds of babies. Some, those near the top, were wide awake, and trying to get out; some were just waking up ; and some, those lower down, were sound asleep.

Some little folks that I know cannot sleep together, with only two in a bed, without sometimes pushing and pulling, and sometimes, I am afraid, quarrelling. But the little folks in this cradle were not quarrelling, or even pushing one another. Each had his place.

Those at the top began to sit up, and one peeped out. Then I saw that each had two legs, but I could not find any arms. I began to wonder how all those babies were going to get a living. They certainly could not go very far on those weak little legs. I could not see how they could even stand up on them. If they all settled down together, and all tried to grow as big as their mother - well, most of them would have to starve to death, or die because they could not get air to breathe. Poor babies ! they would have a hard time of it.

I watched the baby who was farthest out, and - what was the matter with his legs ? They seemed to be getting thicker and thicker. Suddenly out he jumped ; and his legs changed, right before my eyes, into - it would be hard for me to believe it if I had not seen it into wings, the daintiest, fluffiest, most beautiful wings; and away he went, carried by a puff of wind which happened along just then. Then another, and another, and another came out in the same way, spread its wings, and flew away.

I had been so interested watching the babies that I could see or hear nothing else. Now I heard all about me the funniest sounds. The stem of the milkweed was laughing, and at the same time telling the roots how the babies were flying away. The wonderful thing for which all had been working and waiting had happened at last. The milkweed leaves, every one of them, were dancing and singing, " Didn't we tell you so? Didn't we tell you all if you would wait until fall you would find out?" The robin was singing his happiest song. The ferns were nodding, and bowing, and dancing for joy. The buttercup was smiling and laughing and chuckling all at once. 
He looked so jolly and so funny I had to laugh myself ; I could not help it.

Suddenly all was still. I listened, but could hear nothing. I rubbed my eyes, as if $I$ had been asleep. There were the ferns, and the milkweeds, and the buttercup by the fence. Just flying away was a robin. But all was quiet.

Had my laugh frightened them? Or had I been asleep, and dreamed it all? I was never quite certain.

\section{THE DANDELION.}

Material. If two or three dandelion plants, with buds and flowers, are carefully dug up, as directed in connection with the study of the mallow, and are planted in the schoolroom, the children can see all stages in the formation, ripening, and scattering of the seeds. The writer has kept for six weeks, in jars of water in the schoolroom, dandelion plants from which all soil had been washed, and has thus studied with his pupils the growth and development of roots, leaves, flowers, and seeds. (See Chapter I. and Frontispiece.)

Life and Structure. This has been very carefully studied in Chapter I. Touch lightly on minor points of structure and details of life-history, most of which are too difficult for first-grade children. Mother Dandelion, like most other mothers, has some ways of caring for her babies which are more or less peculiar to herself. Dwell on these, rather than on the features in which all plant-mothers are alike. Some of these characteristic adaptations, easily discovered by even first-grade children, are:-

The storing up of "milk" in the root, which loses its "milk" and becomes spongy as the seeds ripen. Why?

The position of the flower-buds or "seed-cradles" in the bottom of the hollow at the middle of the rosette formed by the leaves. Why? 
The pushing up of the buds or "seed-cradles" by the lengthening of their stem. Why?

The green blankets (bracts) covering the buds, and the way in which Mother Dandelion turns them back so that the very small seed babies can feel the sunshine; at night these blankets are drawn over the babies again.

The bright yellow quilt which covers the seeds. Do not attempt, with the little folks, any detailed study of the parts of the flower or florets.

The closing of the seed-cradle, sometimes for several days. What can be going on inside?

Ripening and Scattering of Seeds. Observe with the children - do not merely tell them or observe for them such points as the following:

The lengthening of the flower-stem until the seed-cradle is pushed up far above the place where it was first seen.

The fading and pushing up and final dropping of the yellow quilt, and the appearance of a white silky blanket in its place.

The turning back of the green blanket, showing at last the many, many brown seed babies at the bottom of the cradle, each baby with one long white arm, like a hair, and with many long, hairlike fingers.

The changing of the cup or saucer (receptacle) in which the seeds are fastened into a flattened ball, shaped like a door-knob, causing the seeds and their arms and fingers to separate.

The way in which these arms and fingers spread apart until they form the beautiful hairy ball. Isn't it almost as pretty as the milkweed cradle, or hammock? It is much more dainty.

Now comes the helping wind,- or a "blow" from some little mouth, perhaps trying to learn whether mother wants her or what time it is, - and away go the seed babies, each 
with its arm and fingers changed to a balloon. Why did Mother Dandelion lift her seed babies up so high ? Why did Mother Milkweed make her seed cradles, or pods, so near the top of her stalk? Why did the milkweed pod gape open so wide? Why does the dandelion mother turn her cradle inside out, and change it into a hairy ball, when and not until her seed babies are ready to fly?

How many seeds there are? How far they go? Do you think the wind enjoys carrying the babies about? How gently they settle to the earth! There they will go to sleep. The trees will scatter their leaves over them, and Jack Frost will send a warm snow blanket for them. They will rest all winter long. Then what will happen next spring, when the rain taps, and the sun shines, and the birds sing?

\section{Review Story. - Dandelion Down.}

"Floss-Hair ran out to play in the sunshine among the dandelions. Grand mamma watched her from the doorway where she sat spinning, her little bright head in its halo of silky gold. Suddenly Floss-Hair paused, and turned a questioning glance towards the doorway.

"Grandmamma looked very lovely to Floss-Hair from where she stood. A silvery sunbeam danced around her spinning-wheel, so that she seemed to spin behind a veil of gossamer; and in her gray dress, with her quiet eyes smiling out from under her white, smooth hair, she was more than beautiful.

"Floss-Hair broke a downy seed-globe from its stalk, and blew it one, two, three times. The plumes fluttered around her in the air; not one was left on the stem. 'Grandmamma wants me,' she said, and ran back to the door. 'What was it stopped your play, little one?' -Why, there is scarcely a dandelion left there in the grass; and in their places are rows of round gray heads, standing up like ghosts. Why need flowers die, grandmamma?'

" Did you see where the seed-feathers went, Floss-Hair, when you blew them from the stem?'

" "Oh! into the air, to sail off on the clouds perhaps.?

"' No, no, dear ; some of them glided away to hide under the velvet 
grass of the lawn, where they will sleep all summer and all winter, and next spring will come out again, wide-awake young dandelions. And see there, the yellow-birds are taking the gray plumes to weave into the lining of their nests, and hundreds of little shivering birds will be thankful another year that the golden blossoms were changed to dandelion down.'

"So the dandelions are spinning silk to line the birds' nests with,' said Floss-Hair; 'and grandmamma sits and spins for me. Dear grandmamma, your hair is gray and soft like dandelion-down, - I hope no cruel wind will ever blow you away from me.' 'But, little one, my hair was once all fly-away gold like yours. Call me Dandelion-Down, the phantom of a little Floss-Hair that played among the meadow blossoms seventy years ago.'

" 'No, no, grandmamma, I will not call dandelion-down a ghost any more; it is a little, common yellow flower turned to an angel, scattering blessings about the world, like a white-haired grandmamma I know, who has kind words always ready to give everybody. If people could only be sure of growing good and lovely as they grow old !'

"The next spring little Floss-Hair strayed silently among the dandelions ; for the chair in the doorway was vacant, and the spinningwheel was still. But the child's heart was not wholly sad. Her memory was a nest of warm and tender thoughts, that seemed fluttering back to her from the dear, silver-haired friend, now one of the white angels of heaven."

Lucy Larcom.

\section{DIVISION INTO LESSONS.}

Lesson I. How the Dandelion Seeds are Made.

Step I. How the Milk is Stored for Flowers and Seeds.

Step II. How the Flower Buds are Protected.

Step III. How the Florets are Protected.

Step IV. How the Flower gets Help from the Sun.

Lesson II. How the Dandelion Seeds are Lifted Up and Scattered.

Step I. How the Flower is Lifted Up.

Step II. How the Corollas are Pushed off. 
Step III. How the Seed Balloons are Made. Step IV. How the Seeds Get Out of Their Cup. Step V. How the Wind Helps.

Lesson III. Supplementary Reading and Literature. A Dandelion. Florence Bass. In "Plant Life." To the Dandelion. Lowell. Portions can be read. A Dandelion. Louise M. Hodgkins. In "Fairyland of Flowers."

How West Wind Helped the Dandelion. Emilie Poulsson. In "In the Child's World."

The Apple Branch. Andersen. In "Classic Stories for Little Ones."

Hiawatha. The Four Winds. Legend of dandelion near end.

\section{OTHER PLUMED SEEDS.}

In connection with the seed study bring into the schoolroom the fall flowers, and watch them "go to seed."

This will help the children to appreciate the flowers, and make them familiar with their names.

After the dandelion the children may study other hairy winged seeds, - aster, golden-rod, clematis, - touching lightly on the history and prophecy which can be read in each seed, emphasizing their adaptation to their work and special preparation for dissemination, and gathering all about the milkweed or dandelion as a centre and a bond of union. (See Fig. 32.)

Encourage the children to collect and bring in all the seeds with hairs, like those of milkweed and dandelion, which they can find. They will find many at this season,

"When all the lovely wayside things Their white winged seeds are sowing." 

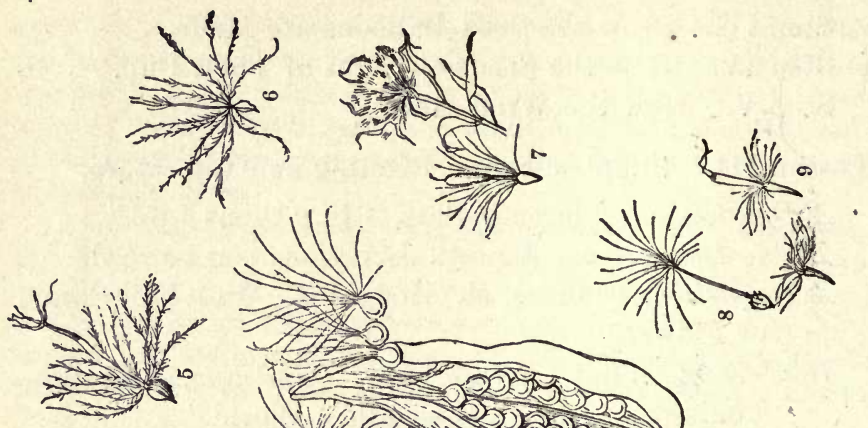

通
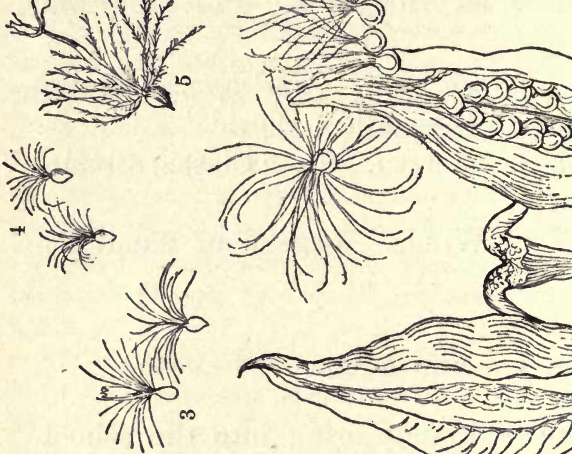

章

竞

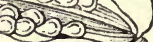

है
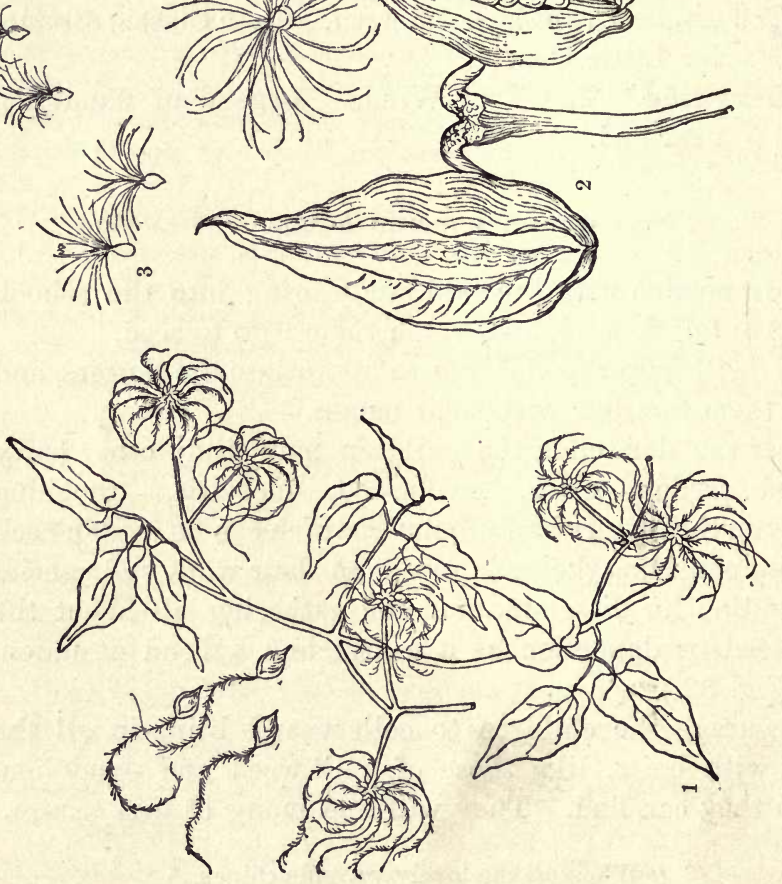

ร) 20

इ $\dot{\circ}^{\circ}$

a

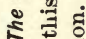

- $\div$

ले की

is

$+\widetilde{a}$

ฮ่

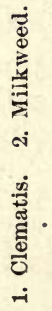


It will be most helpful to take the children out for a field lesson to study the "white winged seeds," such as those of the thistle, aster, golden-rod, and sow thistle.

"Oh, downy, dainty little wings,

Wild floating wings like silver spun,

That dance and glisten in the sun!

You airy things, you elfin things,

.That seed-time always brings,

$\mathrm{Oh}$, are you seeds that seek the earth,

The light of laughing flowers to spread ?

Or flitting fairies, that have birth

When autumn's flowers seem dead ?"

Adapted. Author not known.

THE MAPLE SEEDS AND OTHER WINGED SEEDS.

The maple seeds may be a type of these. They can be found in the grass under the maple trees. The seeds of the Norway maple remain on the trees until autumn.

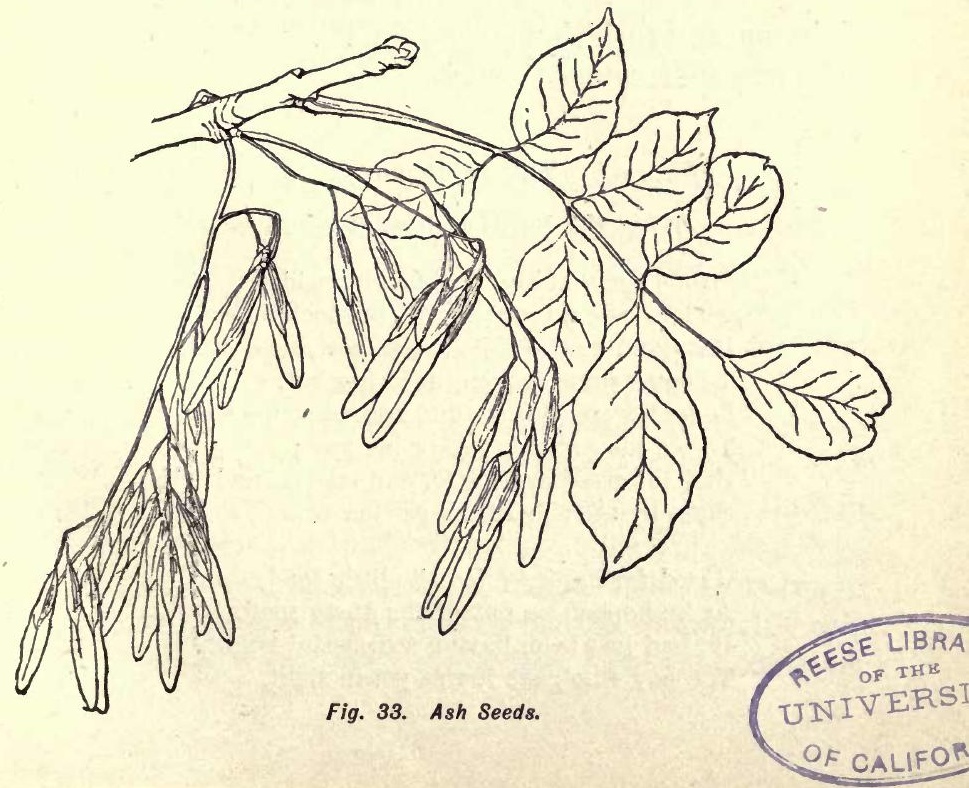


At this season the ash seeds may occasionally be fourd, still elinging to the tree. (See Fig. 33.) Note where and how they are fastened, how they separate from the mother tree, how they sail away. Gibson (see his "Sharp Eyes," article "The Ash Paddle and the Birch Bark") suggests that they furnished the Indians the models for their paddles.

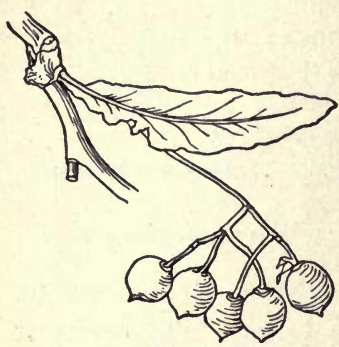

Fig. 34. Linden Seeds.

In the linden or basswood (see Fig. 34) the clusters of little spherical seeds, each cluster with a wing, often remain on the tree late in the winter.

The cones of the spruce, pine, hemlock, and other evergreens furnish many winter flyers. If the cones be gathered at this season they will soon open in the warm schoolroom, and furnish material for the study of other seed cradles and their winged babies.

\section{The Burdock.}

What the Burdock Was Good For. " ' ' Good for nothing,' the farmer said, As he made a sweep at the burdock's head; But then, he thought, it was best, no doubt, To come some day and root her out. So he lowered his scythe, and went his way, To see his corn, or gather his hay ; And the weed grew safe, and strong, and tall, Close by the side of the garden wall.

'Good for home,' cried the little toad, As he hopped up out of the dusty road. He had just been having a dreadful fright, The boy who gave it was yet in sight. 
Here it was cool, and dark, and green, The safest kind of a leafy screen.

The toad was happy ; 'For,' said he, 'The burdock was plainly meant for me.'

'Good for a prop,' the spider thought; And to and fro with care he wrought, Till he fastened it well to an evergreen, And spun his cables fine between.

'Twas a beautiful bridge - a triumph of skill, The flies came round, as idlers will ;

The spider lurked in his corner dim, The more that came, the better for him.

'Good for play,' said a child, perplexed To know what frolic was coming next. So she gathered the burrs that all despised, And her city playmates were quite surprised To see what a beautiful basket or chair Could be made, with a little time and care. They ranged their treasures about with pride, Anà played all day by the burdock's side."

A. S. R.

Will not this be a good thought with which to begin the study of the despised weed? Why not let the children play for a while with the burrs, and help to make "baskets and chairs" and other "treasures"? Then we will certainly have the sympathetic interest, which is the best foundation, the only real foundation, for work.

Study of Burdock Burr. It may be wise to begin with that about which the children know most, or in which they are most interested, the burr, and to centre about that all the study of hooked or barbed seeds. (See Fig. 35.)

After the boys and girls have played with the burrs, or have touched them to their clothes, and are thoroughly convinced of their "sticking" properties, have them discover 
- do not tell them - what makes the burrs stick. Note the stiff hairs, or the spines, each with an incurved hook at the outer end (compare with a fish-hook); their great number, and the way in which they project in all directions, and how they adhere. Draw on the blackboard, as directed by the pupils, or have them draw, an outline of a burr with two or more of the spines and hooks.

Have the children open a few of the ripest burrs, and discover the many seeds in each. These are another kind of "seed-cradle." They will almost certainly discover in some of the burrs little white grubs which have eaten some of the seeds (Haven't they as good right to them as we have to our grains and fruits?), and have taken possession of part of the cradle.

Formation of the Burr. Have a whole plant, showing roots, stem, leaves, flowers, in different stages of development, and the burrs. It is important to relate the burr to the whole of which it is a part.

Perhaps some of the children who have tried to pull it can tell how strongly it is fastened in the ground. If the farmer had cut it off, this great root would have gone to work at once, and have made more stems, and leaves, and flowers, and burrs. What a strong stem, and what great leaves! How much work they can do! They made it "cool, and dark, and green, the safest kind of a leafy screen," for the toad. Toward the upper part of the plant are smaller leaves. What are they good for? If the children are really seeing and thinking, not merely listening and absorbing, they will discover that between these and the stem the flower-buds nestle. Shall we call them the nurses of the buds?

With good material, the children should be able to see, with very little aid from the teacher, the stages in the development of flower-bud into flower and burr, and should 

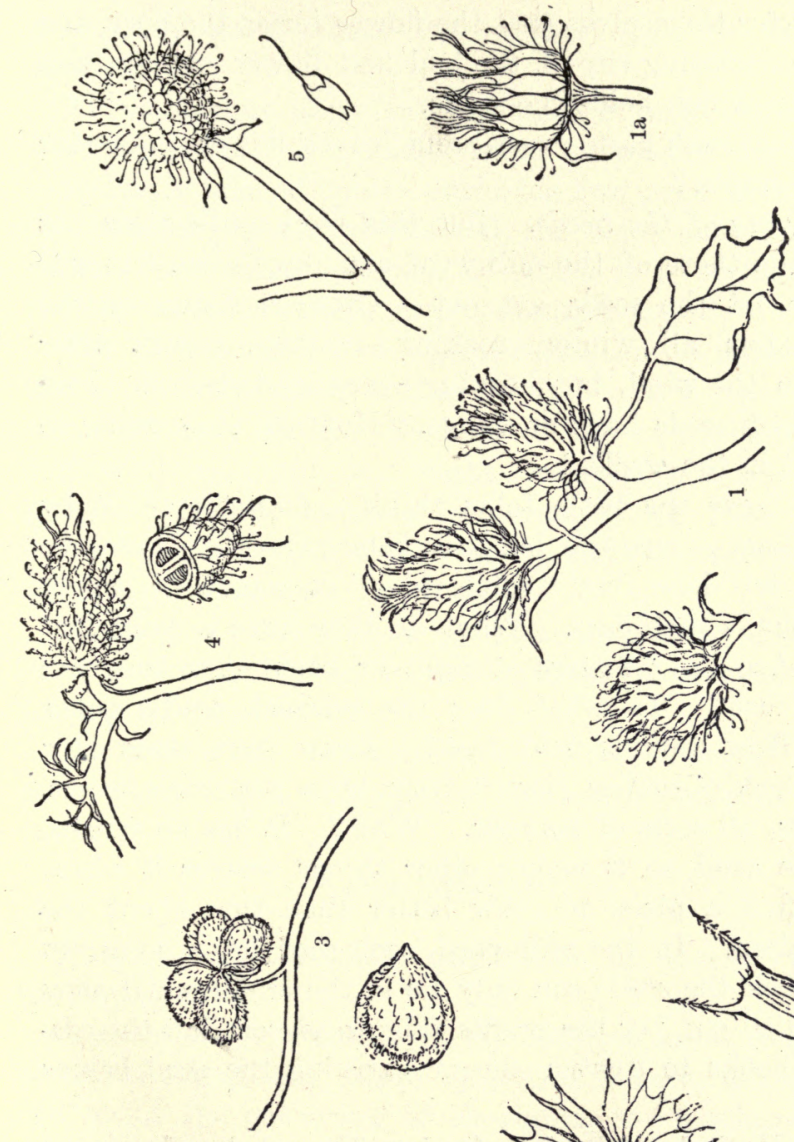

롤
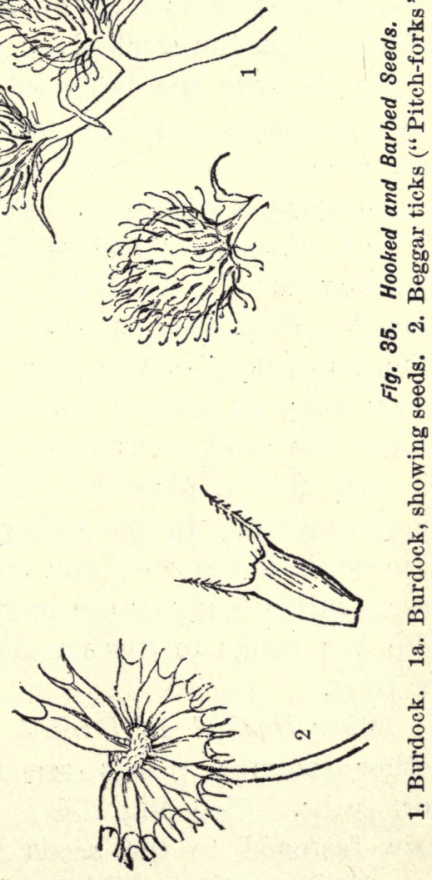

क्षे 
discover for themselves that the flower forms the burr, and that the enclosing cup of the bud and flower changes into the cradle which holds the seeds.

What has each part — root, stem, leaves, flower — done for the seed-cradle?

Scattering of the Seeds. But this seed-cradle does not open, as do those of the milkweed and dandelion. It will not even let the seeds get out. Often it hangs on the burdock-stem all winter, rocking, rocking, month after month, in the wind, but keeping every seed shut in. And the burdock seeds have no wings. How are they going to get about in the world ?

Try to have the little folks think - do not spoil it by telling them - how the burdock babies travel. Have the children tell how they "catch rides" on wagon or sleigh, or on father's shoulders. What do they have to hold fast with? Are their fingers straight or bent when they are holding fast? To what does the burdock cradle catch fast? How does it hold fast? Draw from them how the burdock "catches rides" from boys and girls, cows, dogs, eats, all sorts of animals. Why? It has no sails to catch the wind, so it makes other things scatter it where it may find a place to grow better than that about the mother-plant. In the milkweed each seed has a wing; in the burdock the seeds can only lie in the cradle until they are "spilled out," or the cradle falls to pieces; but the cradle has hooks to "catch rides," carrying the seed babies with it.

Other Hooked or Barbed Seeds. The seeds of several other common plants are scattered by means of hooks or barbs. (See Fig. 35.) In most of them the hooks are fastened to the seeds themselves, - or to what we must allow the children to call seeds, although the botanists may assure us that they consist of the seeds 
and other parts about it, - rather than to the seedcradles.

The cocklebur, abundant as a weed in many parts of the United States, has a rather large ellipsoidal seed-vessel, armed with hooked spines, enclosing two large seeds. Note the two long spines at one end, the many shorter hooked spines, the disagreeable odor by which it is protected, and the two cavities within, each containing a seed.

The burr-marigold, or beggar-ticks, can be found in all stages of development during the fall. Each ripened blossom has many seeds. Each seed has two stiff, pointed, barbed spines, giving it a slight resemblance to a two-tined pitchfork; hence the children commonly call them "pitchforks." In this, and in the equally common stick-seed, the seeds separate from the seed-cradle.

Sharp eyes will discover in fields and backyards many other hooked or barbed seeds. Interest the children in collecting all they can find.

The article and illustrations on "Seed Tramps," in Gibson's Sharp Eyes, will repay study, and be helpful in this work.

\section{THE CHESTNUT.}

Purpose. An exquisite illustration of another way of protecting seeds.

Suggestions for Study. If the children know something about "chestnutting," begin by getting them to tell all they can about the gathering of chestnuts, the teacher telling what the children do not know.

It may increase the interest to tell about another chestnut gatherer, the squirrel, and about his winter home and the store of food he collects.

If there are chestnut trees in the neighborhood, bring out some of the characteristics of the tree, its great spreading 
branches, and deep-green, large, rather long and narrow leaves, with long teeth scattered along the sides. Where do the chestnuts grow? How fastened to the tree? How arranged?

If the trees are not accessible, try to have a branch bearing leaves and burrs, so that the burrs can be related by the little folks to the tree.

The children will need little help in noting:

How the burrs like to keep together, two or three growing from one branch.

How tightly they are closed until the nuts are ripe, with an armor of sharp branching spines on all sides. What is the use of the spines?

How they burst open when the frost tells them that nutting time is here, revealing the two or three brown nuts within.

How the nuts are arranged and fastened in their cradle, and how easily they fall out when ripe.

How velvety and beautiful is the lining of the cradle. Did ever a baby have a softer, richer wrapping?

Perhaps some of the nuts will show the little hole through which another chestnut lover, the worm (or caterpillar), has made his way, and he may be discovered feasting within. Do you wonder that he is so fat, with such a store of food? Hasn't he as good right to it as we have?

The following, read with the children after they have seen all that they k, will add much to the study.

\section{Among the Nuts.}

"A wee little nut lay deep in its nest

Of satin and down, the softest and best ; And slept and grew, while its cradle rocked, As it hung in the boughs that interlocked. 
Now the house was small where the cradle lay, As it swung in the wind by night and day ; For a thicket of underbrush fenced it round, This little lone cot by the great sun browned.

The little nut grew, and ere long it found There was work outside on the soft green ground;

It must do its part so the world might know

It has tried one little seed to sow.

And soon the house that had kept it warm Was tossed about by the winter's storm; The stem was cracked, the old house fell, And the chestnut burr was an empty shell.

But the little seed, as it waiting lay,

Dreamed a wonderful dream from day to day,

Of how it should break its coat of brown, And live as a tree to grow up and down."

Author not known.

If all the chestnuts grew, how close together the trees would be; they could not live. The good tree mother makes more nuts than she can possibly need, and thus feeds the squirrels and - boys and girls.

Round out the thought by picturing the family gathered about the evening fire roasting the chestnuts, or by telling how the early settlers were kept from starvation by the store of nuts the trees had made for them.

\section{FALLING AND COLORING OF LEAVES.}

"October is the month of painted leaves. Their rich glow now flashes round the world. As fruit and leaves and the day itself aequire a bright tint just before they fall, so the year near its setting. October is its sunset sky; November, the later twilight." - Henry D. Thoreau, "Excursions." 
Our best literature abounds in tributes to autumn. Autumn tints and autumn fruits have ever appealed to artist and poet, and the child and the poet are near akin in their love of beauty and nearness to nature.

No more beautiful study can be desired than autumn leaves, beauty of color, beauty of use.

Their summer work is done. The tree no longer needs them to breathe, and throw out water, and make food. How beautiful is their leave-taking! They clothe their old mother with all the hues of sunset. Then quietly, contentedly, they slip away. Good Mother Nature knows what a burden to the tree they would be, how they would eatch the winter wind, and hold the snow. They have other work to do. They drop down - to die? Oh, no! To cover seeds and plants from the winter's cold. To nestle quietly through the months until in the spring and summer, water and air, the two great workers of the world, with their humble helpers, the worms, turn them into food, from which other plants make new leaves and flowers. Busy, busy leaves! Resting, yet always working, always helping.

Centre the study of the leaves about the maple tree, studied in early fall. Take the children out to visit this and other maples.

Let them revel among the leaves. Get them to collect and press the most beautiful, and decorate their rooms. Dwell on their beauty of color, and form, and use.

It matters little whether the children can draw and describe them exactly. It matters much whether they love them, and appreciate the beauty with which God has surrounded them, understand better the significance of this season of - death ? No, of transition, preparation for rest and for other work.

This will give the point of view the vantage-ground from 
which teacher and children can see so much in leaves. Our literature is full of beautiful thoughts about autumn. Give them to the children. They will understand more than we think. Much for the children can be found in the fol. lowing :

"There is a beautiful spirit breathing now

Its mellowed richness on the clustered trees, And, from a beaker full of richest dyes, Pouring new glory on the autumn woods, And dipping in warm light the pillared clouds."

LONGFELLOW.

"Softly breathes the west wind beside the ruddy forest, Taking leaf by leaf from the branches where he flies. Sweetly streams the sunshine, this third day of November, Through the golden haze of the quiet autumn skies."

BRYANT。

"One mass of sunshine glows the beech ;

, Great oaks, in scarlet drapery, reach

Across the crimson blackberry vine,

Toward purple ash and sombre pine.

Our forests that so lately stood

Like any green familiar wood,

Aladdin's wondrous tale repeat;

The trees drop jewels at our feet.

With every day some splendors strange!

With every hour some subtle change !

Of our plain world how could we guess

Such miracles of loveliness ?"

Lucy Larcom.

"What means these banners spread, These paths with royal red

So gayly carpeted ?

Comes there a prince to-day? 
Our earth such homage pays, So decks her dusty ways, And keeps such holidays, For one, and only one."

LOWELL。

Down to Sleep.

"I never knew before what beds,

Fragrant to smell, and soft to touch, The forest sifts and shapes and spreads;

I never knew before how much

Of human sound there is in such

Low tones as through the forest sweep

When all wild things lie 'down to sleep.'

Each day I find new coverlids

Tucked in, and more sweet eyes shut tight. Sometimes the viewless mother bids

Her ferns kneel down full in my sight.

I hear their chorus of ' Good-night;'

And half I smile and half I weep,

Listening while they lie "down to sleep." "

Helen Hunt Jackson.

How the Leaves Came Down.

"I'll tell you how the leaves came down," The great tree to her children said :

"You're getting sleepy, Yellow and Brown, Yes, very sleepy, little Red."

"Ah," begged each silly, pouting leaf, "Let us a little longer stay ;

Dear Father Tree, behold our grief ;

'Tis such a very pleasant day, We do not want to go away."

So just for one more merry day

To the great tree the leaflets clung, 
Frolicked and danced, and had their way,

Upon the autumn breezes swung, Whispering, all their sports among.

" Perhaps the great tree will forget, And let us stay until the spring, If we all beg, and coax, and fret." But the great tree did no such a thing; He smiled to hear their whispering.

" Come children all, to bed," he cried ; And, ere the leaves could urge their prayer, He shook his head, and far and wide, Fluttering and rustling everywhere, Down sped the leaflets through the air.

I saw them; on the ground they lay, Golden and red, a huddled swarm, Waiting till one from far away, White bedclothes heaped upon her arm, Should come to wrap them safe and warm.

The great bare tree looked down, and smiled. "Good-night, dear little leaves," he said, And from below each sleepy child Replied, " Good-night," and murmured, "It is so nice to go to bed."

Susan Coolidge. 


\section{NOVEMBER.}

Work for the Month. The final preparation of the plant for the winter. The work of the plant completed. What the plant gives to man.

\section{THE STUDY OF FRUITS.}

We have studied the plant as a whole, and in its relations to its surroundings, - to soil, water, air, and sun, We have investigated the relations of the parts - root, stem, leaf, and flower - to the whole plant and to each other, and have learned something of the special use or function of each.

As at this season seeds are being ripened, and scattered all about us, we have placed special emphasis on the seed, its formation, protection, and dissemination. During the bright October days our boys and girls have seen the dandelion and thistle and milkweed seeds, and hosts of others, flying through the air, and have learned, perhaps, in their manufacture of baskets and furniture out of burdock burrs, how and why they are scattered.

If the teacher has been wise, her pupils have talked and written about the seeds, and have made drawings of them. They have expressed that with which they have been impressed.

Has the little seed, for whose formation, protection, and dissemination all nature seems to be co-operating, led them to think? Has it interested them? Has it given them a glimpse of the great thought, of the purpose, back of it? Has the study of plant and flower and seed helped them to see a little more clearly and to tell a little more truthfully? Then the work has been a success, although not a name nor a fact of structure or classification is remembered.

But the bright October days have gone, and with them 
the sunshine and flowers and butterflies.

Perlouss the diays are gloomy; clouds have succeeded sunshine. The leaves are falling, and the branches are becoming bare. The milkweed is shrivelled and shapeless, its cradle empty, its seedbabies scattered. The plant world seems to be dying.

Is this the end? Can we study plants now? Yes; no better time for some phases of plant study. The work of the plant is completed. What has it done? What is the result of all its labor? The fruits have been gathered. With the result of it all — the fruits - in our hands, what better time for looking back?

We can study the fruit from three points of view :

First. In its relations to the tree, as the result of the work of the tree, aided by sun and rain and soil and many other of Mother Nature's helpers, and as a preparation by the tree and Mother Nature for the future.

Second. In its relations to man, - the ways in which man cares for and helps the tree, and the use he makes of the fruit. Here there is endless opportunity for observation and supplementary talks and stories and reading, - work which may be done at any time, during the winter. Such work should be based as much as possible on observation. Even when it is merely given as information, told the pupils, or read by them or to them, it will help them to look at the plant and the world in general more broadly, and will make the plant work more practical. We must remember that from the plants man gets all his food (directly or indirectly), all his clothing (directly or indirectly), all his fuel, all his light (except that from the heavenly bodies), and most of his tools, utensils, and building materials.

Third. In its relation to the Creator, the Thanksgiving thought. Whether we look backward to the work of the plant in the formation of the fruit, or forward to the preparation for winter and spring; whether we consider the 
fruit in its relation to its natural environment, or study its relation to man and the use man makes of it, the fruit study leads easily and logically to the great thought so natural at the time of the ingathering of the fruits, and prepares for the Thanksgiving Day which our forefathers established at this season. The fruit study should not merely interest the child, develop his powers of seeing and telling and thinking, give him a better knowledge of his surroundings, and a broader view of his relations, but, most important of all, should lift him up, lead to a better appreciation of his higher relations.

Special care will be necessary, in following out any of these lines of thought, to base the work, as far as possible, on individual observation by the children; and to draw out the little folks, lead them to give their thoughts, rather than merely listen to and absorb from the teacher. There is danger of such work degenerating into mere "talk," with little foundation in actual observation.

\section{THE APPLE.}

Material. An apple for every two pupils, or at least for every four pupils. Select apples which are regular in form, have a stem, and show most clearly the five pointed divisions of the calyx (forming a star at the "eye" end of the fruit) and many shrivelled threads (the remains of the stamens).

\section{LESSON I. OBSERVATION AND MOULDING OF APPLE.}

\section{Step I. Form and Color.}

The children will say "Round." Get a more exact statement, "Round like a ball." Is it exactly round like a ball ? "Has a hole or hollow in one side," some little one will say. "Only one hollow?" "Has a hole or hollow in two sides," or, better, in the top and bottom. 
In one hollow is the stem (the children will certainly call this also "round," but pin them down to a more exact statement, such as " round like a pencil"), green (or brown), hard and tough. In the other hollow, called the "eye," are five little brown pointed parts, looking together like a fivepointed star. (Often they are dried up; to make sure that the children see them, the teacher should point them out on an apple in which they show clearly.) In a hollow at the centre of the "eye" are, in many cases, many dry threads, some with little knobs at the end (the stamens).

Often in the pit at the eye end is a quantity of dry powder, the castings of the apple "worm" inside. Try to find another hole from which the "worm," or caterpillar, has probably escaped.

Note the character and variations of the coloring.

Step II. Moulding the Apple in Clay.

Emphasize thought that each child must copy the apple on his desk, and tell the truth about it as well as he can.

\section{LESSON II. OBSERVATION OF INTERIOR OF APPLE.}

Step I. Study of Cross-Section.

Give children apples divided midway between stem and eye. They can easily see the rather tough skin, the flesh sometimes showing a division into an outer and inner portion quite sharply distinguished, and the star-shaped core, consisting of five cavities, or "rooms," in each of which usually live one or two brown seeds.

\section{Step II. Drawing Cross-Section.}

Teacher draw first on blackboard, at direction of children, showing position of skin, core, and seeds. Why not call the drawing "The House the Apple Tree Built for Her Seeds." After showing the children how to draw the 
picture, erase, and have children draw on the blackboard, placing sections of apple so that all can clearly see them as they draw. Drawings made by the children on the blackboard on a large scale, with a free-arm movement, are better than little drawings made on slate or paper mainly with cramped finger movement.

Have the children select two or three of the best drawings, and tell why or wherein they are best. Teacher will find it wise to commend others which are best, not in the result, but in the effort made.

\section{Step III. Study of the Core.}

Split some of the cut halves lengthways through one of the divisions of the core. Notice how the "rooms" for the seeds are almost as long as the apple, extending from near the stem almost to the eye, but are very narrow; how smooth and shining, how thin and yet how tough, the walls are, how smooth the seeds are, and how easily they slip through the fingers.

\section{Step IV. The Uses of the Parts.}

Approach from the children's point of view. Centre all about the seeds. What is the use of the seeds to the apple tree? Why does Mother Nature or Mother Apple Tree place them in the centre of the apple, just as she placed the buttercup and mallow seeds in the centre of the flower? Why put them in rooms with these tough walls? Why do we not eat the apple core? The apple tree does not want her seeds eaten. Why give each seed or every two seeds a room? Why make seeds so smooth and slippery? Per haps to help them to slip out of our mouths. (It may also be a provision to facilitate their passage through the alimentary canal, their coat protecting them from the digestive fluids.) Why arrange the rooms so prettily in a star form? Mother Nature tries to make everything beautiful. 
Why put around the seeds the fleshy part of the apple, which we like to eat? Think how, when we have eaten the apple, we throw away the core and the seeds, and how the apple is sent all over the world. This is another way in which Mother Nature gets us to help her scatter her seeds. What is the use of the skin? (An apple in the schoolroom with a little of the skin removed will soon show the little folks how the skin keeps the apple from spoiling). What is the use of the stem? To fasten the apple to the tree. In the next lesson we will learn more about the use of the stem, and will hear about the story the eye tells us.

Step $V$. The Uses of the Apple.

First. To ripen, protect, and help to scatter the seeds.

Second. Trace in a wormy apple, from which the "worm" or caterpillar has not escaped, the burrow, beginning at the eye, and extending to and perhaps through the core. Show children the little creature who has crept into the home of the apple seeds. Tell them how a little moth lays an egg in the eye of the apple, this hatches into a caterpillar, who slowly eats his way to the core of the apple, and later makes another tunnel to the outside, creeps out, spins a cocoon (some of these may be found around the apple barrel), in which he sleeps all winter, and the next year turns into a moth. (See McCook's "Tenants of An Old Farm," Chapter VI.). If we ask this little creature why the apple was made, he will certainly tells us it was made for his home and his food and drink.

Third. For boys and girls. Let the children eat the apples.

LESSON III. HOW THE APPLE WAS MADE.

Step I. Growth of the Apple.

Tell how the apple tree burst into bloom last May. Try to picture its beauty and the fragrant feast it spread for the insects. 
Recall what they learned about the parts of the buttercup flower.

Draw a picture of the apple blossom; of its green cup, or calyx, with the five teeth around the edge; its white or pink crown, or corolla; its many thread-like stamens, growing within and around the sides of the cup, and the seed-box in the bottom of the calyx cup.

Tell them how the beautiful corolla blew off, how the cup and seed-box kept growing larger with thicker and thicker walls; how they pushed up the five teeth and the hair-like stamens until the little green apple was formed, with the calyx teeth and stamens making its eye, as we can see even in the ripe apple. So in this plant the calyx not only covers up the other parts of the flower when in bud, but helps to make, and forms part of, the fruit.

As long as the seeds were green the apple was sour and hard, so that nothing - except foolish children - would eat it. When the seeds were ripe, the apple became soft, and pleasant to the taste. Why? The bright color also serves to attract people and animals, who eat it, and aid in scattering the seeds.

\section{Step II. The Work of the Tree.}

How the roots worked all summer to get food and water to make these seeds and ripen this apple.

How the leaves worked. How much they did to beautify the tree, giving it its green color, contrasting with branches and sky and flowers and fruit. How they covered the flowers, the buds, and the young apples. How they took food from the air, and made everything which gives the apple its pleasant taste. How they breathed, and threw out water for the tree.

How the trunk and branches and stem of the apple helped, carrying the food from root and leaf to the bud and flower and fruit. 
How the flower helped. The work of the calyx in protecting the bud and making part of the fleshy portion of the apple. The work of the seed-box. The work of the corolla in beautifying the spring-time. The little folks cannot appreciate yet the function of corolla and stamens in fertilization.

\section{Step III. How Nature Helped.}

How the sun helped the leaves in their work, and painted flower and fruit.

How the air and wind brought food to the leaves, and gave life to the plant, as it does to us.

How clouds and rain brought water.

How the ground and soil upheld it, and gave it food.

\section{Step IV. Summary.}

A blackboard story, such as was suggested in the study of the mallow, will serve as an excellent review. A good subject is, "The Home of the Apple' Seeds, and How it was Made."

Some good literature will help to impress the thought, if not the facts, after such preliminary observation. Even little first-graders can get much from Bryant's "Planting of the Apple Tree." The first four verses are very appropriate.

LESSON IV. WHAT MAN DOES FOR THE APPLE TREE. WHAT THE APPLE TREE' GIVES TO MAN.

Step I. How Man Helps the Apple Tree. "Come, let us plant the apple tree, Cleave the tough greensward with the spade; Wide let its hollow bed be made; There gently lay the roots, and there Sift the dark mould with kindly care, 
And press it o'er them tenderly, As, round the sleeping infant's feet, We softly fold the cradle sheet;

So plant we the apple tree."

Bryant.

"6 'Take the fruit I give you,' says the bending tree;

'Nothing but a burden is it all to me!

Lighten ye my branches; let them toss in air !

Only leave me freedom next year's load to bear." "

Lucy Larcom.

How man plants the apple tree, and how he ploughs the earth about it so that its roots can get water and air.

How he fastens (grafts) branches to the trunks of other apple trees, thus getting better fruit. How he trims or prunes it so that the tree will not use up so much strength and food in making branches and leaves that it cannot make fruit, and so that the fruit can get the sunlight.

How he tries to keep away or destroy the worms or caterpillars.

How he gathers the apples, not waiting for the wind to shake them off, but picking them, and packing them in barrels, being careful not to bruise them, when he wishes to keep them all winter.

Step II. What the Apple Tree Gives to Man.

The beauty of the tree itself, when in blossom, one of the most beautiful sights we can see.

The shelter and shade under which boys and girls have always loved to swing and play.

The birds which sing, and nest, and raise their little ones among its leafy branches.

The fruit, the finest in the world, we think, sent from our country to all parts of the world.

The cider and vinegar made from its apples. 
Step III. Literature. "The Wayside Inn - An Apple Tree."

"I halted at a pleasant inn, As I my way was wending;

A golden apple was the sign

From knotty bough depending.

Mine host - it was an apple tree -

He smilingly received me, And spread his choicest, sweetest fruit,

To strengthen and relieve me.

Full many a little feathered guest

Came through his branches springing;

They hopped and flew from spray to spray,

Their notes of gladness singing.

Beneath his shade I laid me down,

And slumber sweet possessed me ;

The soft wind blowing through the leaves

With whispers low caressed me.

And when I rose, and would have paid

My host, so open-hearted, He only shook his lofty head;

I blessed him and departed."'

From the German. From Skinner's Arbor Day Manual.

LESSON V. THE THANKSGIVING THOUGHT.

Step I. Review. How the Apple was Made.

What the Tree has done.

What Nature has done.

What Man has done.

Step II. What God has done.

Has given sunshine and rain and a good season. Without these the apple crop fails. The tree and man can do nothing alone.

Directs and controls all. 
Step III. What We Should Do.

Appreciate better how much the apple means.

Enjoy better these simple, common gifts.

Share with others what has been made by all, - nature; man, and God working together.

Thank the Author of the garnered fruits.

"O painter of the fruits and flowers, We own Thy wise design, Whereby these human hands of ours

May share the work of Thine.

Apart from Thee we plant in vain

The root, and sow the seed; Thy early and Thy later rain,

Thy sun and dew, we need.

And still with reverent hands we cull

Thy gifts each year renewed;

The good is always beautiful,

The beautiful is good."

WhitTier.

DECEMBER WORK. THE EVERGREENS.

THE PINE.

Step I. The Pine at Home. Field Lesson.

Preparation. Recall fall work about coloring and falling of leaves, and have children tell how bare are the trees which were so beautiful last summer and fall. "We have some trees which do not drop all their leaf-helpers. Because they ever have green leaves we call them evergreens. To-day we shall see how beautiful they are, and how they are made so that they can keep their leaves all winter."

Take children out-doors to see pine tree. If this is im- 
possible, bring small tree into schoolroom, or (the very last resort) study picture of pine tree.

Tree as a Whole. Look at tree first from a distance of several hundred feet, where children cannot see details.

How beautiful its green above the white snow, particularly when decorated with freshly-fallen snow. How much more beautiful than the trees which have lost their leaves! Even little first graders can appreciate what Longfellow has said : -

"O hemlock tree! O hemlock tree! how faithful are thy branches !

Green not alone in summer-time,

But in the winter's frost and rime.

O hemlock tree ! O hemlock tree ! how faithful are thy branches !"

Note its form, tapering and pointed, or slender conical, or, in the children's language, round at the bottom, and coming to a point at the top, like a cornucopia or like the end of a lead-pencil. Compare form or outline with maple (ovoid), or elm (vase-shaped), or other trees not evergreen. Why does the pine (and other evergreens) have this shape? Does it eatch less wind than it would if broad at top?

Trunk. Going nearer to tree, note the trunk, reaching almost to the top, straight, tapering upward. Would this trunk make a good flagpole? Why? Have children represent direction and tapering of trunk by extending their arms straight above them, with hands together forming the tip of the trunk. Dwell on length and straightness.

Branches. They extend from the trunk almost horizontally, longest toward base. The clustered snow masses may show their flexibility (more marked in hemlock). If they do not, let children see how easily they bend. Let children represent horizontal branches by arms extending straight out from body. How hold arms to show position 
of branches when loaded with snow? How move them tc show how branches move when strong winds blow?

Summary. Perhaps the teacher can outline a tree in the snow, directed by class, drawing first the triangular outline, then the trunk, and lastly a few branches.

Dwell on the way the tree is fitted for winter :

By its bright green, so beautiful above the snow.

By its shape, eausing the snow to slide off, and not eatching so much wind.

By its long, strong trunk, holding it up.

By its branches growing straight out from the trunk, and bending easily when the snow falls on them, or the winds blow against them.

Step II. The Real Home of the Pine Tree.

Preparation. "Children, yesterday we went to see our pine tree at home. To-day we are going much farther, to a country which is almost covered with pines. But we must be sure first that we know the pines when we see them. So we are going to show what we know."

Teacher draw on blackboard pine tree, as directed by children. Erase, and have children draw from memory, or, better, from a small tree in the room, representing outline, trunk, and branches, but not leaves. Have children select best drawing made by the pupils, and tell why it is best.

Visit to the home of Hiawatha and of the pine trees. "Now we are going to take a 'make-believe' trip to the home of an Indian boy who lives among the pine trees. Shut your eyes, and try to think how it looks as I read to you."

"By the shores of Gitche Gumee,

By the shining Big-Sea-Water,

Stood the wigwam of Nokomis.

Dark behind it rose the forest, 
Rose the black and gloomy pine-trees,

Rose the firs with cones upon them;

There the wrinkled old Nokomis

Nursed the little Hiawatha,

Rocked him in his linden cradle,

Bedded soft in moss and rushes.

Round about the Indian village

Spread the meadows and the corn-fields,

And beyond them stood the forest,

Stood the groves of singing pine-trees,

Green in summer, white in winter,

Ever sighing, ever singing.

At the door on summer evenings

Sat the little Hiawatha ;

Heard the whispering of the pine-trees,

Heard the lapping of the water,

Sounds of music, words of wonder;

'Minne-wawa!' said the pine-trees,

'Mudway-aushka!' said the water."

Show children pictures of lakes with pines about them or of pine-covered hills or mountains. Tell them how the pine thrives in cold, windy countries. Then get children to tell how the pine is fitted for such countries and for winter.

\section{Step III. Branches and Leaves.}

Aim. To-day we will find other ways in which the pine is fitted for winter.

Material. Branches of pine and of some deciduous tree.

Branches. Recall what children observed about their direction and flexibility, expressing these ideas by arms of children, and comparing, in these respects, with branch of maple or other deciduous tree. 
Note general roughness of bark and smoothness and lighter color of extremities of branches, and of small twigs (those formed from last years buds). Note the pitch on broken end.

Leaves. Arrangement and form. The chararteristics of these are so obvious that children should see most of them

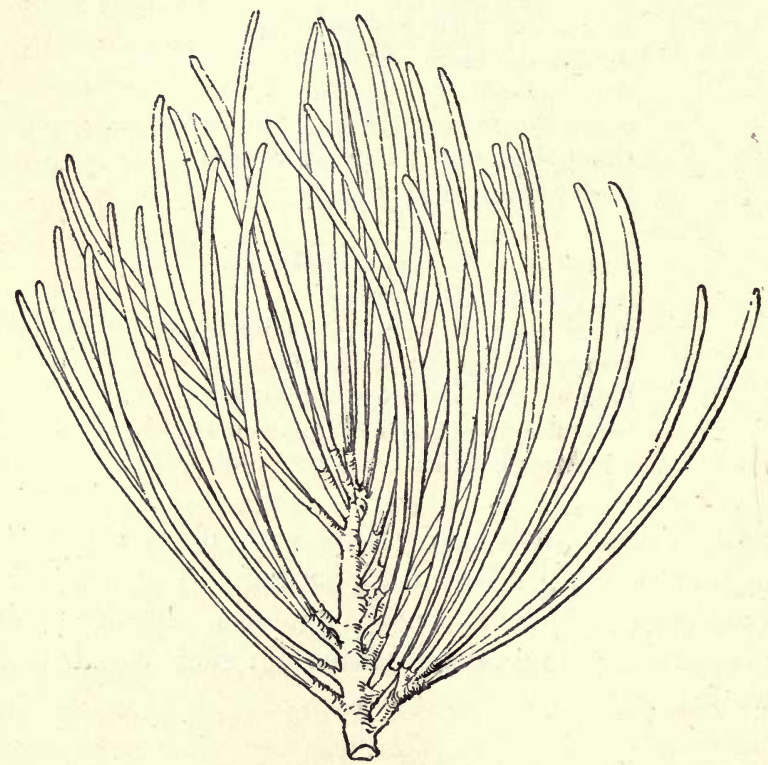

Fig. 36. Pine Needles.

with little questioning or help from the teacher. (See Fig. 36.) The best plan for insuring careful observation is for the teacher to place a twig, with two or three bundles of needles, where it can be seen by all, give children two or three minutes to observe it, and then draw it on the blackboard, as directed by the children, taking pains to get help from as many pupils as possible. 
After this drawing is erased, the children may be asked, "Now, who can tell me the most stories about the pine leaves?" When they have told all they can without questioning, then question for points not discovered or told by them.

Essential points to be impressed on the children are :-

The leaves, or bundles of leaves, are clustered in masses toward the ends of the branches, where all can get the sun. The leaves toward the base of the branches or twigs are loosely fastened (let children see how easily they pull or drop off) or have fallen off, leaving scars, and causing the roughness of the branch. The resulting balled appearance of the foliage is characteristic of the pine, by which it can be distinguished from other evergreens at a considerable distance. Probably little children cannot see this.

The leaves are fastened together in bundles, - two or three or five in a group, always alike in the same species,with a brownish cup or sheath around the base of each bundle. The bundles grow out from all sides of the twigs, causing the needles to point in many directions. Both of these features distinguish the pines from other evergreens.

The needles of each bundle are long (how long, as compared with children's fingers?) blue-green, each flattened on the side toward its companion needle, rounded toward the outside, and pointed, resembling, when there are two needles in each bundle, a lead-pencil split in two. The needles are thick and tough (test it) as compared with leaves of other trees.

Try to have the children summarize, without questions : the form, size, and color of the needles; their grouping in bundles, and the way in which they are bound together; their arrangement about and at the ends of the twigs.

Have children draw, only from material before them, a twig with two or at most three bundles of leaves. Fasten 
twig, with all but two or three bundles of needles removed, before each row of pupils, arranged in position easiest for drawing, that is, with needles not pointing toward or away from children.

Adaptation. Sprinkle snow, or salt, or pieces of paper or of chalk, on child's fingers, pressed together. Repeat, with fingers widely separated. How much more easily the little pieces drop down between the fingers! Why does the winter tree have leaves like needles, separated or with spaces be een, rather than like the leaves we have in summertime, when there is no snow? Have children blow on a piece of paper, noting how it "catches the wind," and bends. Cut into strips, with considerable space between. How much more easily the wind passes through! Why do the broad-leaved trees drop their leaves as the winds of winter come? Why does our pine have needle-like leaves? Get children to tell how they bundle up in winter, and have them show how much larger they look with coat and overcoat than in the thinner clothes they wear in summer or in the warm schoolroom. Why are the pine needles so much thicker and tougher than many summer leaves? Yes, the Pine Mother has dressed her leaves warmly. We will see how careful she is about her children when we study her seed-babies.

Literature. Read or, better, tell the story of the "Discontented Fir-tree," from Hans Andersen, substituting "pine-tree" for "fir-tree."

The children like this little conceit:-

"If Mother Nature patches the leaves of trees and vines, I'm sure she does her darning with the needles of the pines, They are so long and slender, and somewhere in full view, She has her threads of cobweb and a thimble made of dew."

Other literature which may be used with older chil dren :- 
"To a Pine-tree." Lowell.

"Growth of the Legend." Lowell.

"My Cathedral." Longfellow.

"Forest Hymn." Bryant.

Step IV. The Pine Tree's Cradle and Seed-babies.

Preparation. Have children tell about the babies at home, - how helpless they are, how warmly and carefully they are covered, how they are rocked to sleep in the cradle or on mamma's lap.

Recall fall work on protection and scattering of seeds, how the milkweed seeds were protected and scattered, how the maple seeds travelled about. Would you like to see how the Pine-mother takes care of her babies, and sends them out into the world?

Some one has said:-

"Tell me thy secret true,

Whispering pine ;

Tell me a story new,

Whispering pine."

- We shall find that what the pine is whispering about is her secret.

Position of Cradles. Show where and how cones are fastened, hanging usually near top of tree and toward ends of branches. What a place for a cradle! How it must rock in the wind! How can the babies be kept warm? Surely this is one cradle we think about when we sing :-

" Rock-a-by, babies, in the tree-top;

When the wind blows, the cradle will rock;

When the bough breaks, the cradle will fall;

Down come cradle and babies and all."

Cone Cradles. Note exquisite order of scales, every scale in place, how closely the scales are pressed together, and 
how cracks are sealed with pitch in freshly gathered immature cones. (See cone of spruce, Fig. 37, page 419). If cones are kept in schoolroom a few days, the scales curl back, disclosing the pockets in which the seed-babies are kept from rain and cold.

Seed-babies. Remove a few scales, and show how the seeds are placed, two at the base of each scale, each in a little pit, each with a wing ready for sailing-time. What a beautiful cradle, warm and snug! How much better to sleep with two together, so that they may have company! Shake the cradle, and see how gracefully the seeds circle downward, and how gently they drop to the floor.

Summary. Now we have discovered the secret the pine is whispering. Who can tell best: how the pine mother rocks her cradles and babies; how she keeps them warm, covers them up, and lets them out at the right time; how she helps them start out for themselves?

Expressive Work. Have children mould cone in clay, or draw in outline on black-board, fastened to a branch, with two or three seed-babies flying from it.

\section{Step $V$. What the Pine Does for Man.}

Beauty. What the pine and other evergreens add to winter. How beautiful their green above the white snow! How much prettier than the bare trees, which have lost their leaves!

Protection. Tell how evergreens are planted closely in rows to protect houses from the wind. The winter birds and rabbits like to nestle among the evergreens.

Food. Where the pines are abundant, the seeds are often used by people for food, particularly where the seeds are much larger than those we have (California pine nuts). Birds and squirrels are fond of them. Mother Pine - or Mother Nature, or God - must be thinking of this, when 

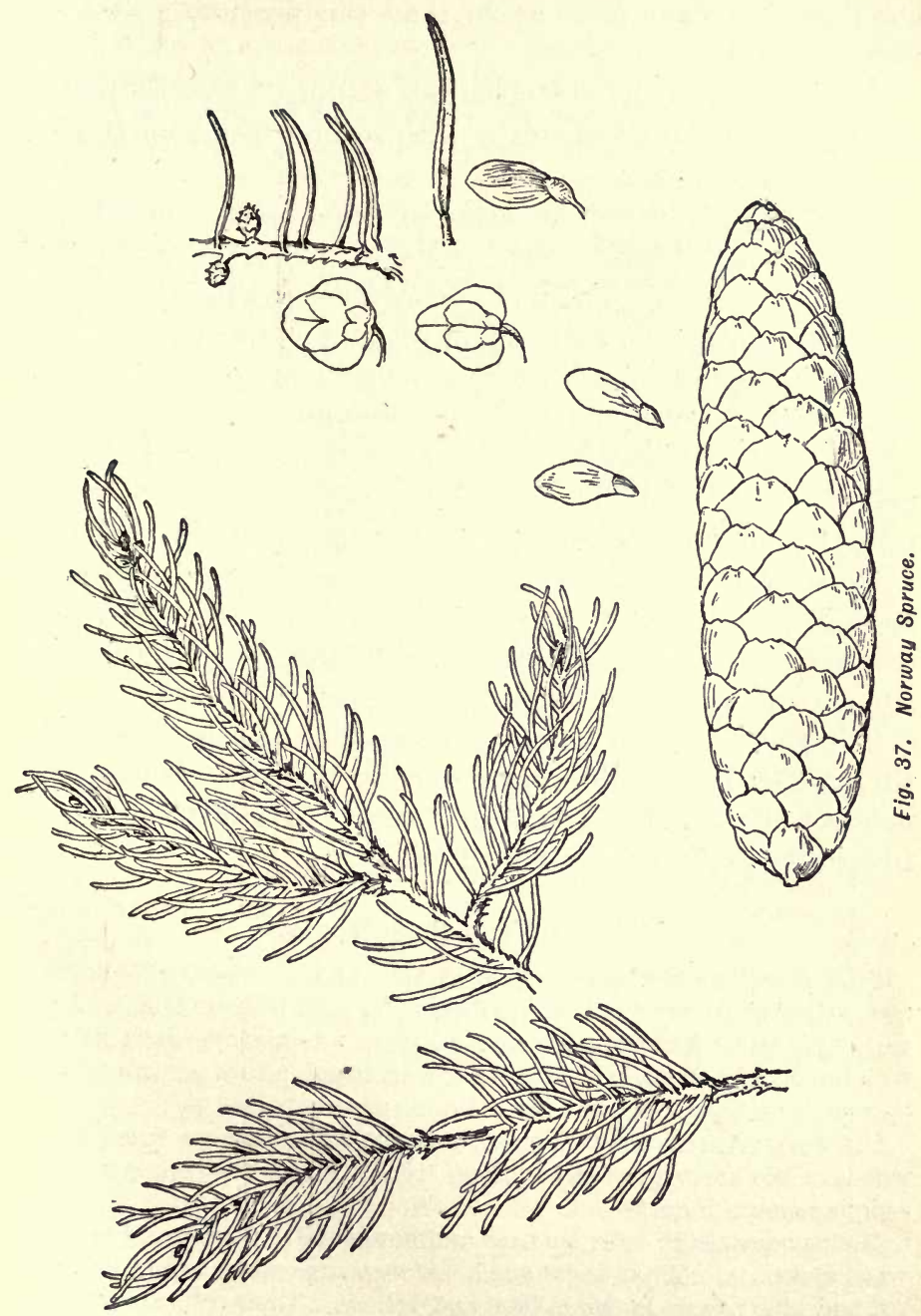

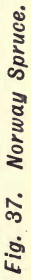


she makes so many more seeds than can possibly grow, thousands on a tree.

Resin. Read from "Hiawatha's Sailing," how he built his canoe, and filled its cracks with resin. Tell something of the uses of resin.

Lumber. Show objects made of pine wood,- matches, kindling-wood, boxes - and parts of buildings made of pine, - closets, doors, and door-frames, windows and window-frames. If children have seen carpenters building a house, talk about the parts made of pine. If possible, visit a carpenter-shop or lumber-yard.

$A$ Visit to a Lumber Forest. Here is the opportunity to make use of the children's imagination. A mere description of a pine forest and lumbering operations will mean litćle to them. Let them take an imaginary trip to the lumber woods, and tell what they do and see. Put all emphasis on the human element, the lumbermen and their life and work, rather than on the lumber.

The following, a portion of an outline for the study of the pine by little children, written by Miss Ella Mullins, a member of the writer's class in Nature Study Methods, well illustrates such an imaginary journey.

\section{A Trip to The Pine Woods.}

"Let us all go for a sleigh-ride to the lumber woods. While we are getting ready we shall sing, 'Jing-a-ling, the bells do ring.' Are we all ready? Are our ears covered from mischievous Jack Frost, who likes to pinch them? But we are each going to wear two roses, - winter roses, - so we shall not cover our faces.

Off we start, our bells ringing; and we ride until we come to a woods. We know what to call these trees. 'How do we know they are pine trees, John?'

Besides our sleigh-bells we hear another sound. Soon we discover what makes it. What do we see? A man dressed in bright red, or red and blue; there is one in blue and yellow. Their suits are warm; for they are made of flannel, like our blankets. The man we first 
saw has an axe; and he is cutting down a tree,- a great, tall, pine tree. While we are looking the tree comes down with a crash! We do not like to see it. You think it is not right to cut the tree? We ask the man why ie cut it down. He says - he smiles at us; I think he must have little children,- and know how they love the trees, 'That pine tree is happy now; it is going out into the world to make people happy by being of use to them, by helping them.' When we ask him how that is, he answers, "There is one from which I have just taken the branches; when the bark is off it will make something you boys have often seen. What is it? A mast for a vessel or a flag-pole. It will be happy because it will help to move the boats which carry coal to keep people warm, or grain to feed them. Over there is a pile of pine trees. Their branches have been taken off ; they have been cut into logs, and will soon be hauled to the river. In the spring, when the ice melts, the logs will float down, down for miles until they reach a saw-mill, where they will be cut into boards or beams or shingles, with which to build our houses. How could we get along without these, which the pine tree makes for us. But it could not be a mast to help move our coal and food, or a board to keep out the cold, or a shingle to keep out the rain, if it stayed as a tree here in the forest. It is glad to be made useful.'

We start for home along another road. What odd little houses those are! There are some men in front of them dressed like the one who was talking to us. They are called lumbermen, and these are their houses. The houses are long, not very wide, and are made of logs. These men, too, are kind, and invite us to come inside and get warm. We go in, and find one long room with no 'upstairs.' The tables are set ready for dinner. We see they have tin cups and tin plates, and have for dinner, bread and butter, potatoes, pork, beans, molasses, and coffee. All along the walls are shelves, something like the shelves in mamma's pantry at home, but wider. Let us look into this lower one. Why, there are blankets and comfortables and pillows on them; so this must be where the lumbermen sleep.

We must go outside to make room for the hungry men who are rushing in. We thank them, jump into our sleigh, tuck in the robes, and away we go. Are not these grand trees, as high as our church steeple? What long trunks, like masts, with branches toward the top. How they meet, and make a roof above us ! It makes me think of a church, - a church that God made. How quiet it is now that the men are not chopping or sawing! Here we are at the edge of the forest. One look backward, and away we go! Shall we sing again ? Here we are at home." 
Read to the older children the lines from Longfellow's "Building of the Ship:"

\section{"Long ago}

In the deer-haunted forests of Maine,

When upon mountain and plain

Lay the snow,

They fell - those lordly pines !

Those grand majestic pines !

'Mid shouts and cheers

The jaded steers,

Panting beneath the load,

Dragged down the weary winding road

Those captive kings, so straight and tall,

To be shorn of their streaming hair,

And, naked and bare,

To feel the stress and the strain

Of the wind and the reeling main,

Whose roar

Would remind them forevermore

Of their native forests they should not see again;

And everywhere

The slender, graceful spars

Poise aloft in the air, And at the mast-head, White, blue, and red,

A flag unrolls the stripes and stars.

Ah ! when the wanderer, lonely, friendless,

In foreign harbors shall behold

That flag unrolled,

'Twill be as a friendly hand

Stretched out from his native land,

Filling his heart with memories sweet and endless."

Try to have the children see, in imagination, the four scenes pictured by the poet - the pine tree in the "deerhaunted forest;" the cutting of the tree; the mast and ship in the storm at sea; the "slender, graceful spars" bearing so proudly, in a foreign port, the flag which attracts the wanderer. 
A Visit to A Saw-Mill. Another lesson may be devoted to an imaginary trip to the saw-mill, where our pine tree is sawed into boards.

\section{Step. VI. The Christmas Tree.}

\section{How The Pine Became The Christmas Tree.}

"Long, long ago, there were little pine trees in a forest in Ungarn, and they were very unhappy because they had to stay in the stormy winter, while all the flowers went to sleep till spring, and the birds flew away to the sunny south.

All the little pine trees wept and sighed together till the Wind heard them, and carried their voices down to Judea, where the dear Christ-Child lived.

When the Wind told Him the trouble of the little trees He was grieved, for He loved to have all things happy ; but 'The little pine trees must help something else before they can be helped,' said the Christ-Child ; for He knew all things.

So the Wind carried the words to the little pine trees, and they began to try to help something. When a great frost came, each tree spread out its branches as far as it could reach, and sheltered the grass and ferns from the bitter cold; and when a great snowstorm came, covering all the ground and trees, the little pine trees called to the poor snowbirds and said, 'Come, little birds, we have seeds for you to eat, and our arms shall keep the snow from you.'

When the Wind heard this, He flew to Judea again, and told the Christ-Child how the pine trees were helping.

So, when the Christ-Child heard this, He was glad ; for He loved all things to be good, and He came Himself to the little pine trees and blessed them. 'Dear little pine tree,' He said, touching them with His gentle hand, 'You have tried to help others, and you shall have the joy of always making happiness for little children. Every winter, when the frost and snow come, you shall have many beautiful things given you to give away to My little ones for My sake, if they have tried throughout the year to be loving and good.'

Then the little pine trees were glad, for they had learned how blessed a thing it is to give happiness.

And that was the way - says the German legend - that the dear Christ-Child gave us Christmas trees. But He does not wish us to think only of the pretty things we get from the tree, and so we may 
always see at the end of every branch of the Christmas tree a little Cross." - Selected.

Why not make the pine tree in the schoolroom a Christmas tree? What better closing thought and application of

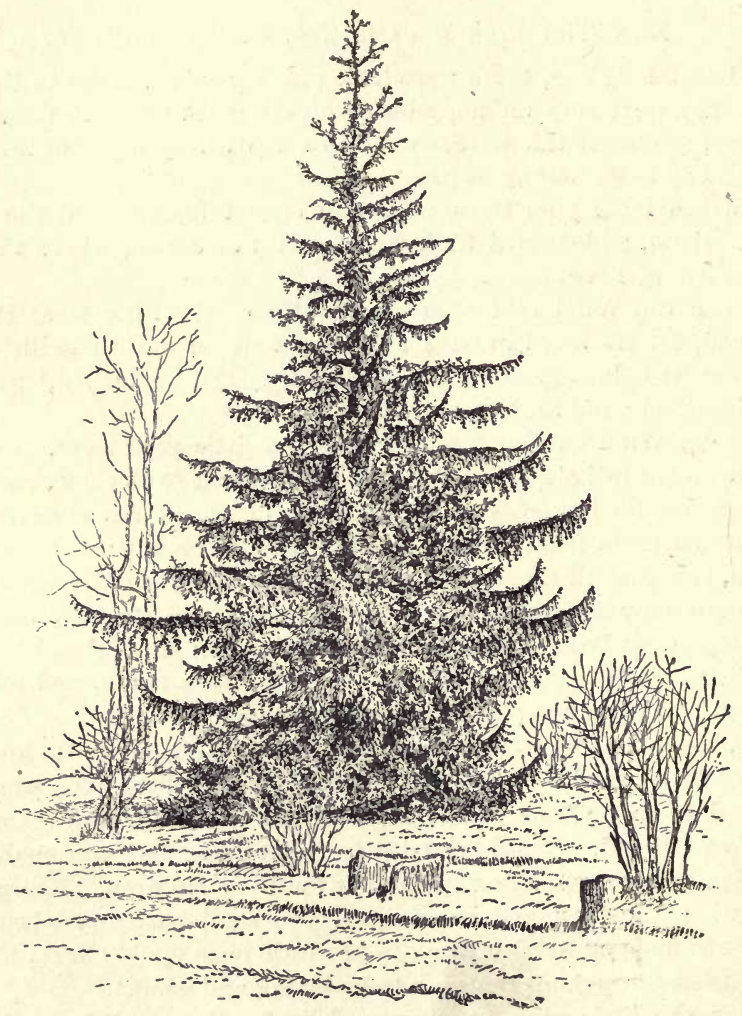

Fig. 38. A Norway Spruce.

our study of what the pine tree does for us? After such work, are not our children likely to think more of our 


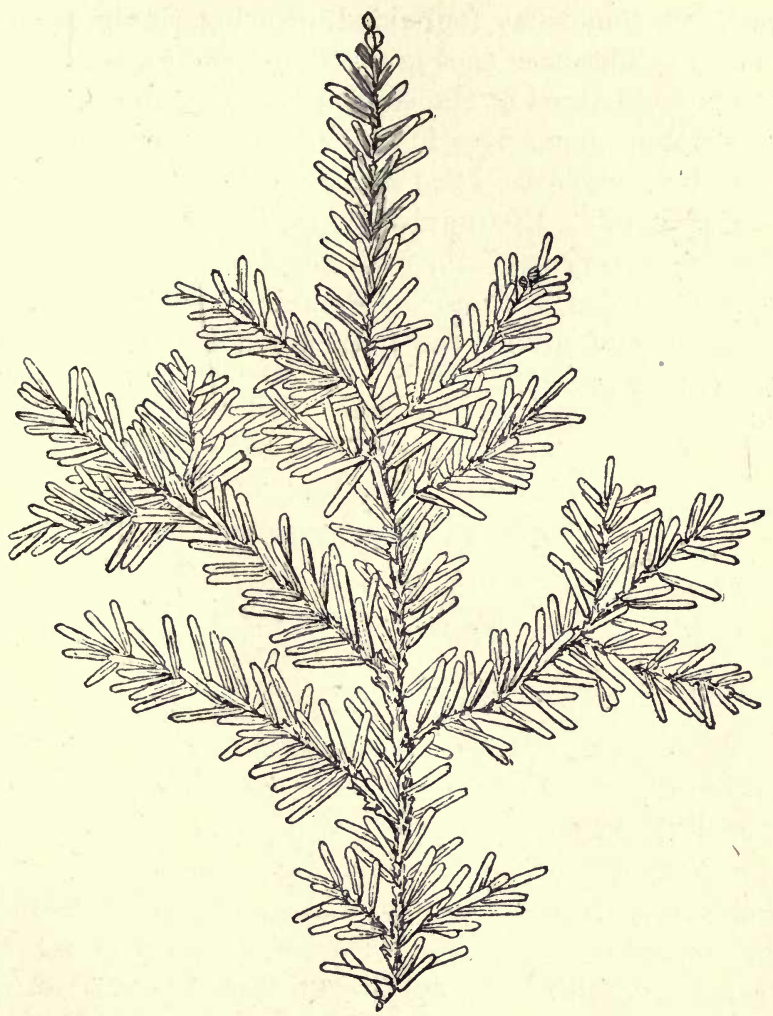

Fig. 39. The Hemlock Tree.

svergreens - and of trees - and to remember the lessons they teach?

\section{OTHEK FVERGREENS.}

Study one or two for comparison, dwelling on points in which they are like the pine, in being adapted to winter, and on those features which are most distinctive.

The Spruce. Recognized by its shorter leaves, needle. 
shaped, but somewhat four-sided, growing singly from all sides of the branches (not grouped in bundles, and not, to any extent, clustered at the ends of the branches), but tending to arrange themselves in two straggling rows, on either side of the branches. (See Fig. 38.)

The Hemlock. Distinguished by its short (half-inch), flat leaves, silvery beneath, with short leaf-stems, arranged on opposite sides of branches, making the leaves appear two-ranked, and giving the branches a blade-like appearance. (See Fig. 39). 


\section{FALL AND WINTER ANIMAL STUDY.}

Aim. To cultivate a sympathetic interest in the life and habits of animals, and to develop among the children a higher regard for life. Only living animals should be studied in the lower grades.

\section{SEPTEMBER WORK.}

Special Aim. To have children observe the life-history or development of an animal from egg to maturity.

CATERPILLARS AND BUTTERFLIES.

Material. One of the best is the milkweed caterpillar, naked (without hairs), stout, striped transversely with yellow, black, and white bands, bearing a pair of black threadlike projections near each end of the body. It is widely distributed, and can usually be found throughout the summer and early in September, feeding on milkweed leaves. Smaller, and therefore not so good for study, is the green "cabbage worm" found until late in October on cabbage, cauliflower, radish, horse-radish, and nasturtium plants. The three stages - larva, chrysalis, and adult - of the milkweed and cabbage caterpillars can be obtained in early fall, and their entire transformation observed.

The large green caterpillars of the cecropia, polyphemus, and promethea moths, found on woodbine, grape-vine, lilac, and many fruit and forest trees, are not attractive in appearance, but are excellent for showing the children the 
process of spinning the cocoon. They make the cocoon in the early fall, but do not transform to moths until spring.

The hairy caterpillars are more attractive. Among the prettiest are those of the tussock-moths characterized by the conspicuous tufts and pencils of bright-colored hairs on their backs. They are common in early fall on shade and fruit trees. The yellow woolly bear, covered with soft hairs of various shades of yellow or brown, is common; also the Isabella caterpillar, covered with stiff hairs ar-

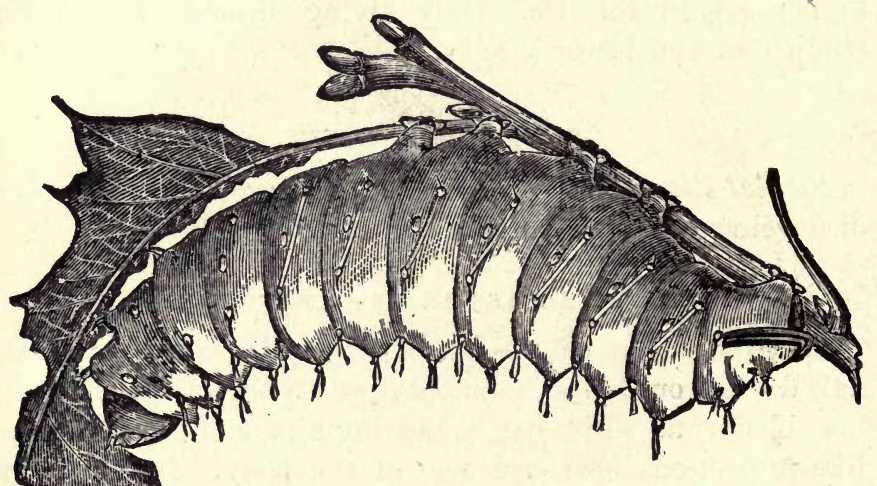

Eig. 40. Polyphemus Caterpillar.

ranged in tufts, the middle two-thirds of the body reddish brown, and either end black. These hairy caterpillars spin a cocoon, lining it with their hairs, but do not transform to moths until spring.

Care of the Caterpillars. Gather as early in the fall as possible. They can be most easily found during the warmer part of bright, sunshiny days. On cold days, and in early morning or late afternoon, they usually disappear.

Those brought in by the children are worth much more for study than those collected by the teacher. While 
gathering them, the children may learn considerable about their habits.

Keep in glass fruit jars or tumblers, covered with netting, or better, in a box with at least two sides made of wire netting, to allow circulation of air. If kept in box, place in bottom of box a vessel filled to a depth of three or four inches with moist, not wet, soil or moss. Sub-soil, which contains fewer disease-producing germs, or moss thoroughly boiled to kill the germs, is best.

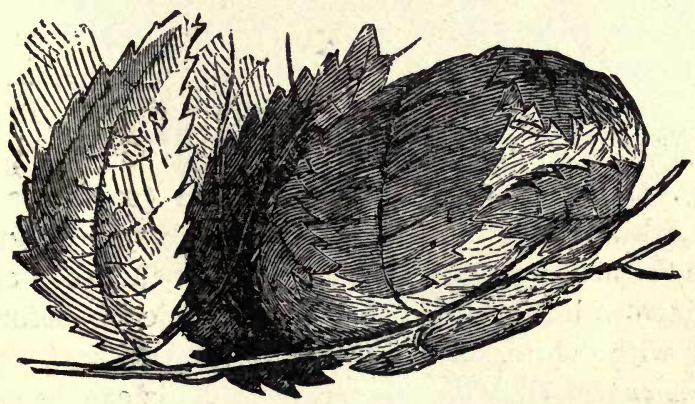

Fig. 41. Polyphemus Cocoon.

Keep a supply of fresh food,- milkweed leaves for the milkweed caterpillar; cabbage or some other cruciferous plant for the cabbage worm; maple, burdock, or plaintain leaves for the others. In general, every species should be supplied with the plant on which it was found feeding. Try to keep cages and food fresh and clean.

THE MILKWEED, OR DANAIS CATERPILLAR.

Preliminary Observations. Encourage and help children to watch them out-of-doors and at home. Keep in the schoolroom several days before formal work, and give children opportunities to observe their habits. Give one 
or two definite points for investigation, and report each day, such as :

Exactly how do they move? How climb on the netting? How many legs? How used?

How do they eat? How does their eating compare with ours?

How and where do they spin? How climb up the glass cases?

How does the caterpillar change to the chrysalis?

Relation to Environment. By whom discovered? Where found? On what feeding? How? Lead children to tell all that they have seen about this kind of caterpillar.

\section{Habits and Structure.}

Body. Shape, length (measure), rings (segments), and their markings and number. There are twelve segments, besides the head; segments two to eleven being each marked by a narrow black transverse band, bordered before and behind with white.

Movements. How do they crawl? This can be seen by putting them on a stalk of a leaf or of grass, or by watching them crawl on glass. Watch the movements of the feet. How many? Eight pairs. Fastened to which rings $(1,2,3$, not counting the head, $6,7,8,9,12)$. Notice the two kinds of legs, the first three pairs black, shiny, slender, and pointed, jointed (difficult to see); the other five pairs, soft thick pads, each divided in the middle. Study the large feet - best seen when crawling on glass or netting — and their working and use. How do they crawl? With which feet fasten themselves? How?

Notice movements of the hairlike projections near the head. For what do they use them?

Feeding. Keep them without food over night and feed just before children are to watch them. Notice how they 
FALL AND WINTER ANIMAL STUDY.

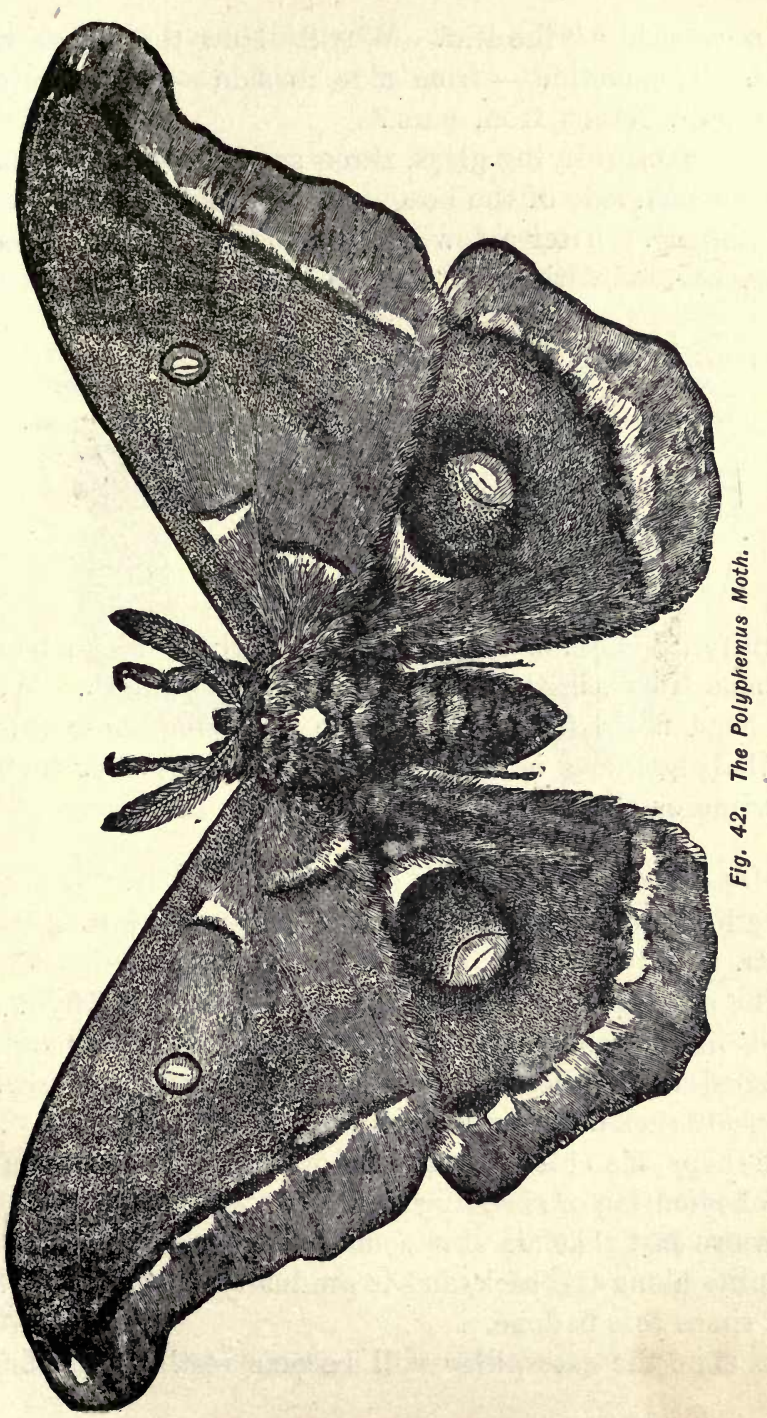


often "straddle" the leaf. Why? How they move their head. The motion - from side to side - of their jaws. Why so different from ours?

With a magnifying glass, three small black eyes can be seen on each side of the head, near the mouth.

Spinning. After a few hours the inside of the can becomes covered with silky threads like spider's web. With

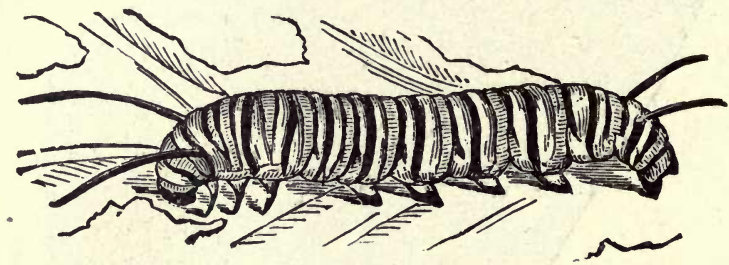

Fig. 43. Danais Caterpillar.

magnifying glass, or a very sharp eye, the silk can be seen to come from a little projection below the mouth. Watch the head move from side to side in laying these threads on the glass, and notice how the caterpillar uses them in crawling or climbing.

\section{Life History. Chrysalis and Adult.}

Tell about the egg, and its development into a caterpillar.

The eggs may possibly be obtained if the butterfly is confined in a cage with the milkweed plant. If patiently watched in' the fields, the butterflies can often be seen to lay their eggs on the milkweed leaves.

Perhaps the children may discover the caterpillar in the act of moulting or shedding his skin. He eats so much and grows so fast that his skin soon becomes too tight for him. It splits along the back, and is gradually pushed off. Several times this is done.

In time the caterpillar will become restless, and finally 
fasten himself, head downward, to the top of the can or box, bend his body like a fish-hook and hang perfectly quiet (Fig. 44).

If the children are fortunate, they may see how his skin splits open along the back, and a stout, bright green body appears within. At first this is distinctly ringed. Gradually the rings disappear, the body becomes smaller, several beautiful dots appear ("the green house with the gold nails," Mrs. Ballard calls it), and we have the chrysalis.

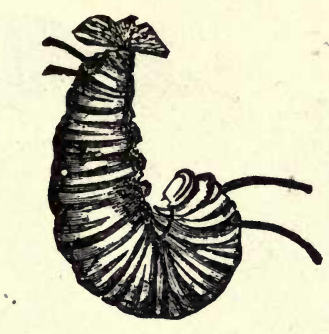

Fig. 44. Danais Caterpillar.

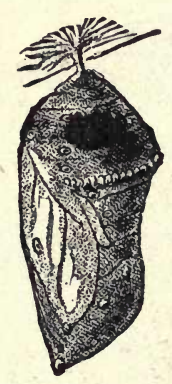

Fig. 45. Danais Chrysalis.

Tie a thread tightly around the black stem by which the chrysalis is suspended, and hang in the school where it touches nothing, and can be seen but not touched. After ten or fifteen days the boys and girls may see the chrysalis open, and may discover coming from it a large butterfly, with black body and brown wings, the latter with black border and veins, and with two rows of white spots near the outer ends.

Notice how the case splits, how the butterfly comes out, how small the wings are at first, and how they increase in size, how the form and size of the body change as the wings enlarge.

Isn't it a wonderful story? Is there a lesson in it? 


\section{Butterfly.}

Study the living butterfly, without handling it, its head and body (with two parts, thorax and abdomen), wings, legs, feelers, eyes and mouth parts.

How are the legs used? Are all of the same size? Why so weak? What an opportunity, in the wings, for a lesson on the beauties of our world. Note the scales on wings. Examine with magnifying glass.

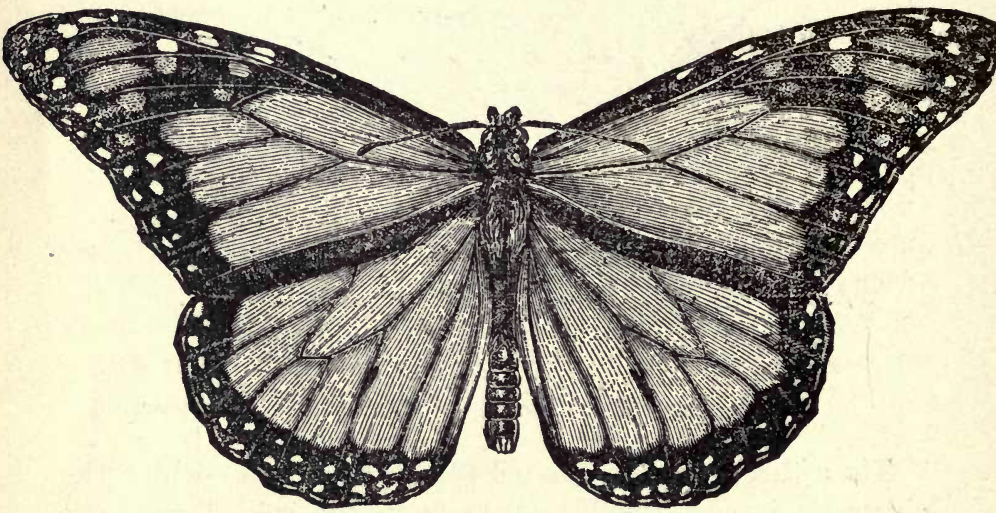

Fig. 46. Danais Archippus.

Give the butterfly a drop or two of sugar and water, or honey diluted with water, and see how it uncurls and uses its tongue. The sirup is sucked up through a tube in the tongue. Where does the butterfly get food out-of-doors? Why is its tongue so long?

\section{CABBAGE CATERPILLAR.}

If well fed these grow rapidly, and moult frequently, and are likely to form their chrysalids in the schoolroom. The caterpillar fastens itself by silken threads passed round 
its body, becomes shorter and thicker, casts off its skin, and changes to a chrysalis, the whole process taking about two days. The chrysalis can be found under stones, and attached to fences near cabbage patches infested with the worms. Those formed in August or September may develop into butterflies in two or three weeks. The butterflies, rather small, with white or yellowish wings spotted with black, can be seen until November. If several are caught with a net, and confined in a barrel with ends knocked out, and upper end covered with netting, and the barrel be

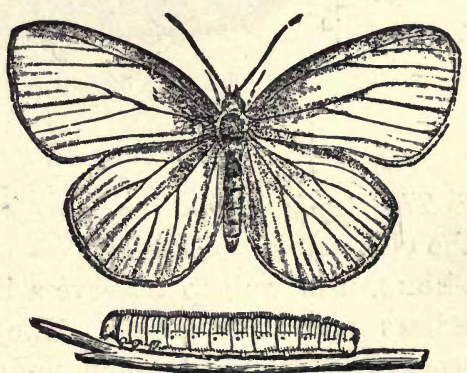

Fig. 47. Cabbage Butterfly and Caterpillar. placed over a cabbage plant, the butterflies will probably lay their eggs on the cabbage leaves. The hatching of the caterpillars from the eggs and the whole life-history can be observed.

POLYPHEMUS OR CECROPIA CATERPILLAR.

If confined in the fall, these usually begin to spin their cocoon ; and the process, often occupying several days, can be observed by teacher and children. The cocoons can be kept (in a cool place, not in the schoolroom) until the next spring, and the escape of the moth observed.

\section{THE HAIRY CATERPILLARS.}

The tussock-moth caterpillar, and the woolly bears thrive in confinement. The Isabella does not. All are most apt to form their cocoons in dark places; hence it is well to place in the cage with them pieces of bark or wood under 
which they can hide. Notice how they use their hairs in forming their cocoon, binding the hairs together with silk.

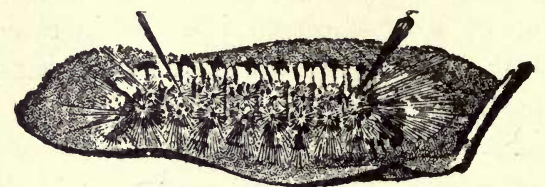

Fig. 48. Hickory Tussock Caterpillar.

THE HOMES OF CATERPILLARS.

The Apple Worm and Leaf Miners and Rollers. After the children have studied two or three of the larger caterpillars, it is well to observe a little about the small caterpillars and their homes. The little cocoon of the apple worm can often be found under the projecting pieces of bark on the apple tree or about the apple barrels. Many

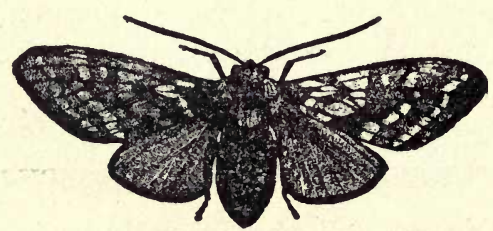

Fig. 49. Hickory Tussock Caterpillar.

leaves, such as yellow dock, show dark blotches or sinuous markings caused by minute caterpillars, called 'leaf-miners,' eating out the green matter between the upper and lower skin of the leaf. Both caterpillar and chrysalis may be seen on or in the leaves. Other caterpillars, the "leafrollers," roll the leaves of many plants (such as sumac) into tubes, and there feed, live, and make their chrysalids.

"And there's never a leaf or blade too mean

To be some happy creature's palace."

LOWELL. 


\section{THE SILKWORM.}

The caterpillar study may prepare the children to understand and appreciate what may be told or read to them about the silkworm and its cocoon and the manufacture of silk. This last step may serve to impress, particularly on fathers and mothers who may not be in entire sympathy with the nature study work, the practical aspects and value of such work. It will serve to relate the caterpillar spinners to the every-day life of the children.

\section{LITERATURE AND SUPPLEMENTARY READING.}

1. A Lesson of Faith, Margaret Gatty, in Gatty's "Parables from Nature" and in Poulson's "In the Child's World." Brings out the symbolism of the transformation from the ugly cabbage worm to the beautiful butterfly.

2. The Story of Pense. In Andrews's "Seven Little Sisters."

3. New Work for Pense. In Andrews's "Each and All."

Nos. 2 and 3 tell how Pense, the little Chinese girl, took care of the silkworms.

4. The Caterpillar. In Poulson's " Finger Plays."

A motion song, excellent as a means of reviewing and impressing what the little folks have seen about the life and movements of caterpillar and butterfly.

5. Complaint of a Chrysalis. In Ballard's "Moths and Butterflies."

6. Ballard's "Insect Lives, or Born in Prison."

BOOKS FOR TEACHERS.

1. Comstock's "Insect Life." The best book on insects for teachers.

2. Hyatt's "Insecta." Very good for the study of structure. 
3. Needham's "Zoölogy." Contains much helpful matter on the homes, life, and structure of insects and other animals, and is well adapted to the needs of teachers.

4. McCook's "Tenants of an Old Farm." Excellent for habits. 


\section{OCTOBER WORK.}

\section{GRASSHOPPER OR CRICKET.}

Special Aim. To observe and learn about habits and adaptation of structure to habits; to give some idea of the main parts and general plan of an insect.

Material and Care. Study either grasshopper or cricket carefully, and then compare, hastily, with the other. Crickets stand schoolroom conditions and confinement better; grasshoppers are apt to die when confined. Crickets can be most easily caught under stones; grasshoppers can be found, during the warmer sunny part of the day, in the open fields. During September and October, both can be obtained in different stages of development, - the young differing from the adults in size, in being stouter, with a larger head in proportion to their length, and in having short rudimentary wings.

Keep in schoolroom in wire-netting cage, or in boxes with top and bottom knocked out, and replaced by wire netting, or musquito netting, to allow free circulation of air. Place in vessels in bottom of box damp, not wet soil, an inch or more in depth, in which can be placed tufts of grass with the roots. A good insect cage can be made from a chalk-box, by taking out the top and bottom, except one to two inches at one end, and placing musquito netting or, better, wire netting over the open spaces. Keep the grasshoppers near the window, the crickets in a darker part of the room. Keep them away from the stove, radiator, or other source of heat. In general, the 'schoolroom conditions of insects and other animals kept in confinement should be made as much as possible like the out-door natural conditions. 
Preliminary Observations. Keep in schoolroom three or four days before any formal lessons, where children can observe habits and movements. Give each day definite points for observation, such as:

How does the grasshopper hold fast to the netting?

How does the grasshopper eat the grass? Watch his mouth. Watch his lips and jaws.

How does the grasshopper walk? How jump?

How does he use the "feelers" on top of his head? How does he use the little feelers at the sides of his mouth?

How does the grasshopper breathe? Compare with children's breathing.

Encourage the children to observe the grasshopper outof-doors, by giving questions for study, taking a little time after the opening exercises each day to have them tell what they have observed. Strongly emphasize idea that each child must tell only what he has seen. Discourage guessing. At this stage get all possible facts of observation, but leave the "whys" until later. Points for outdoor observation are suggested in Lesson $\mathrm{I}_{6}$

\section{PLAN FOR STUDY OF GRASSHOPPER.}

Lesson I. Life and habits out-of-doors.

Lesson II. Movements, feeding, breathing.

Lesson III. Adaptation to life and habits.

Lesson IV. General structure. Drawing grasshopper.

\section{LESSON I. OUT-DOOR LIFE OF GRASSHOPPER.}

Aim. To interest children in out-door life, and encourage out-door observation.

Step I. Literature. To direct the thoughts, read to them one of the following: 
“ Happy insect, what can be

In happiness compared with thee ?

Thou dost drink and dance and sing,

Happier than the happiest king.

All the fields which thou dost see,

All the plants belong to thee.

Man for thee does sow and plough,

Farmer he and landlord thou."

" Grasshopper green is a comical chap ;

He lives on the best of fare.

Bright little trousers, jacket, and cap,

These are his summer wear.

Out in the meadow he loves to go,

Playing away in the sun;

It's hopperty, skipperty, high and low,

Summer's the time for fun.

Grasshopper green has a quaint little house;

It's under the hedge so gay.

Grandmother Spider, as still as a mouse,

Watches him over the way.

Gladly he's calling the children, I know,

Out in the beautiful sun;

It's hopperty, skipperty, high and low,

Summer's the time for fun."

Selected.

Step II. Home of the grasshopper. Why called grasshopper? Where found? (Have each child tell where he or she has found them). Why do they like the grass? Do they like the sunlight? How do you know? Perhaps children have discovered that when pursued they often hide away in the grass close to the ground, lying very quietly, "playing possum." Are they found on anything besides the grass? How do "all the fields which thou dost see, all the plants belong to thee," the grasshopper?

Step III. How the grasshopper lives at home. How is he dressed ? Are all dressed alike? How many kinds have 
you seen? How does he get away when we try to catch him ? How far can he jump? How high? How does he fly? How far? How climb the grass? How hold on to the narrow leaves? Why is he happy? Does he hop around when it is cold or dark or wet? Where does he go then? When does he go to bed? Where? In what ways is the grasshopper's life like your life?

Step IV. Summary. For a review, or summary, read again one of the poems suggested in Step I., and have the children tell, from their observations as far as possible, what is meant.

LESSON II. HABITS, MOVEMENTS, FEEDING, BREATHING.

Aim. To have children see how much the grasshopper is like boys and girls.

Step I. Position and movements. Have children show how boys bend their legs when getting ready to jump, and how they jump. How far can they jump? As far as they are long? How does the grasshopper stand? How are his legs folded? How does he jump? How far? How far, compared with the length of his body? When the children jump, how do they hold their hands to keep from falling? How does the grasshopper hold his front legs?

Have children show how tightly they bend their fingers about objects to which they wish to hold fast. How does the grasshopper hold fast to the blade of grass? How does he "catch hold" when he jumps? Perhaps they can see the hooks on his feet when he is standing on the netting $\backslash$ of his cage. They may discover the cushion on his feet, to lessen the jar when he alights.

How do children move their legs when they walk? How does pussy move her legs? Alternately. How does our 
grasshopper move his legs when walking? Does he seem to like walking or jumping best? He is called (by Leigh Hunt) "Green little vaulter [or jumper] in the sunny grass." Is this a good name? Why?

Note how he uses his "feelers." Why called "feelers"?

If some of the large flying grasshoppers can be obtained, study the flying, noting how the inner wings unfold and spread out when flying, and how they are drawn back, when at rest, under the strong outer wings.

For a summary of this step, have children tell, or give statements for a blackboard reading lesson on, "How We and the Grasshopper Stand and Jump and Walk." Good as a beginning for the reading lesson is the above line from Hunt.

Step II. Feeding. Lead pupils to tell what kind of food children eat, how they hold it, and get it to their mouth, how they bite it, and in what direction their jaws move. Compare with grasshopper. He holds his food partly with his front legs, partly with two little arms (palps), one at either side of the mouth. His jaws move from side to side instead of up and down. Can he eat grass any better with jaws moving sideways than with jaws moving like ours?

Step III. Breathing. This may be too difficult for little "first graders." When the children breathe, where does their "breath" go in and out? Through nose and mouth. Have them place a hand on their chest. What do they feel when the "breath" goes in? When it comes out? The chest moves. Have them count to see how many times they breathe in a minute, or how fast they breathe. Watch the hinder half of the grasshopper's body. It gets smaller and larger, or moves somewhat as their chest does. How fast? Perhaps they can see the very small holes, seven on each side of the abdomen, through which the 
"breath" goes in and out. The process of breathing can be more easily seen in the cricket.

Step IV. Summary. Complete the reading lesson, adding "Eat and Breathe" to the title. Something like the following will review and clinch the main points:

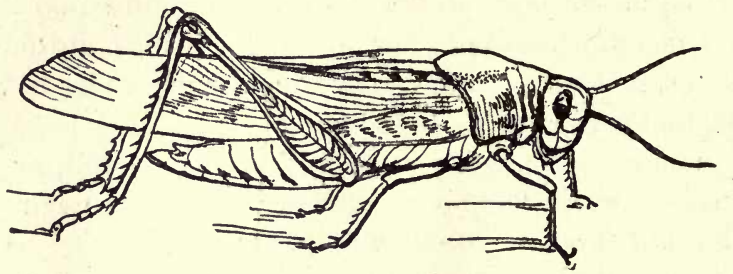

Fig. 50. Grasshopper.

How We and the Grasshopper Are Alike.

The grasshopper is happy.

We are happy too.

We live in houses.

He lives out-doors in the grass.

He loves the sun.

We love the sun too.

We bend our legs when we jump.

The grasshopper bends his legs too.

But he can jump better than we can,

He holds fast with his front legs.

He has hooks on his feet to help him hold fast.

We hold fast with our hands and fingers.

We hold our food in our hands.

'We bite it with our jaws (or teeth).

Our jaw (or teeth) moves up and down.

The grasshopper holds his food with his front legs.

His jaws (or teeth) move sideways.

The grasshopper breathes as we do.

The hind part of his body moves in and out.

We never knew before how much the grasshopper is like boys and girls. 
LESSON III. ADAPTATION TO LIFE AND HABITS.

Aim. To lead children to think about the "why" of common things about them.

Step I. How fitted for its home (Fig. 50). How its color, green or brown, like the grass, helps the grasshopper to hide, and protects it from birds and cats.

How its hard covering (compare with cabbage worm) protects it.

How it is made so that it can climb the grass blades, and hold fast to them. How much better for it to be able to jump over and between the tall grass blades!

Its head can turn to enable it to see around it. So its neck is soft and flexible, but is covered by the hard collar. Sometimes the sharp point of a blade of grass gets under this collar when the grasshopper jumps; this is apt to kill it.

Step II. How fitted for its movements. Why are the hind legs so large? How fitted for jumping?

How the front legs are fitted for holding.

How the feet are fitted for catching when they jump.

The head is very hard. It gets many hard blows when the grasshopper is jumping.

How the wings are fitted for their life. (Best seen in the large flying grasshoppers). How the delicate inner wings can be spread out for flying, or folded fan-like and protected under the tough outer wings.

Step III. How fitted for its food.

How made so that it can climb and hold on to the grass blades.

How its upper lip can be pulled up to uncover the teeth. How its jaws move sideways. Why?

How fitted to eat grass. 
Step IV. Closing thought. May not the story of Kepler's great words, adapted to the little folks, help to impress the thought, the great "why." When, after giving his life to the study of the heavens, he discovered the plan of the solar system, he exclaimed: "I thank Thee, O God, that Thou dost let me think Thy thoughts after Thee." Isn't that one great aim and privilege in nature study?

\section{LESSON IV. GENERAL STRUCTURE AND PLAN.}

Aim. To leave with children a definite idea of the plan and main parts of the grasshopper, as a foundation for study of, and comparison with, other animals.

Step I. Blackboard drawing by teacher.

Teacher should draw, at direction of children, an outline of the grasshopper, side view, showing three parts of body, segments of abdomen, wings, three pairs of legs, feelers, and large eyes. The teacher should take pains to show children how she draws. The process is more important than the resulting picture.

Step II. Drawing by children. Cover drawing on blackboard, and have children draw grasshopper as large as possible. Emphasize idea that each must draw, from the grasshopper, exactly what he sees. Have insects where all can look at them while drawing.

Let children select best, that is, most truthful drawings, and tell wherein they are best.

Step III. Parts of grasshopper. With the large blackboard drawings and the grasshoppers before the children, bring out the plan of the grasshopper's body; that it has three parts to the body, - head, thorax, and abdomen (give the children the terms); that it has three pairs of legs, and has wings on the thorax, and that its hind legs are larger than the others; that its head has a mouth with jaws, two 
large eyes, and two feelers, and that its abdomen has several parts or rings.

Put all emphasis in this lesson on simple facts of plan and structure which the children can see. Do not ask why, or allow them to discuss the "whys"; it will detract from the main thought.

Additional topics suggested.

Review story. Helpful for review will be "The Story Our Grasshopper Told," told by the teacher, with occasional questions, bringing out, from the grasshopper's point of view, his home and happy, merry home life; telling about his "hopperty, skipperty, high and low, summer's the time for fun" existence, and showing how well he is fitted for his home and life, just as well as boys and girls are fitted for their home and life. The children can fill in gaps left by the teacher.

Literature. For literature, read to the children Cowper's "The Grasshopper," or Leigh Hunt's "Ode to a Grasshopper." They are difficult; but, after studying the grasshopper, even little "first graders" may get more from them than we imagine. Portions of Cowper's "The Cricket" and Dickens's "Cricket on the Hearth," or "Waiting," in Mrs. Gatty's "Parables from Nature," can be read to the children. The nature readers have considerable on the grasshoppers and crickets.

Comparison. If comparison is made with the cricket, bring out such points as the following:

Both are happy, merry fellows.

Both live in the fields.

Their ways of moving, feeding, and breathing are similar.

The crickets are fitted for life in the dark, under stones, or in the ground.

Both have the same parts, differing in color and form.

Perhaps the children can discover how the cricket chirps. 
The outer wings are raised, and the inner edge of one rubbed or scraped rapidly over the inner edge of the other.

Bring out main differences, - color, feelers, wings, threadlike stylets at either side of end of abdomen.

Life history. With the live insects before the children, in different stages of development, tell them the life history of the grasshopper: how the mother bores a hole in the ground (with the pointed "egg-placers" on the end of her abdomen), and lays in it many eggs; how these hatch into little grasshoppers, much like their mother, but with large head and no wings; how, as each of these grows, its skin becomes too tight, and splits open, and the grasshopper comes out with a new coat, at first soft, but soon hardening; how he thus gets a new suit of clothes several times, each time becoming larger, and with longer wings; how at last the full-grown grasshopper comes out and stops growing.

\section{Books for the Teacher.}

1. Morse's "First Book of Zoölogy" is helpful in the study of structure.

2. McCook's "Tenants of an Old Farm" has several excellent chapters on the habits of crickets.

3. Hyatt's "Insecta" is good as a guide for the study of structure. 


\section{JANUARY WORK.1}

THE CAT.

Aim. To cultivate a sympathetic attitude toward animal life ; to interest children in the careful observation of the domestic animals; to lay foundations for a better understanding of the animals of which the cat is a type.

Preparatory Work. Some days before beginning formal study, ask the children to watch their kitties at home, and to find out and tell the teacher, perhaps immediately after the opening exercises each morning, exactly what their kitty does and how she does it. For a few days before the lessons, and during the lessons, it is well to have a cat in the schoolroom. Give the children definite questions such as :

How does the cat drink milk? How use her iongue when drinking?

How does pussy eat? How does she use her claws and her teeth when eating?

How does she play? How does she jump when trying to eatch anything? How roll on the floor?

How does she lie when resting or asleep? How place her feet?

How is it that kitty can walk quietly? What does she have under her feet to aid her in walking quietly?

Is she a good climber? What aids her in climbing?

How does kitty wash herself without water, soap, or

1 This is recommended for midwinter work because the plant work leaves little time for it in the fall, and because it seems wise to introduce in winter some study which has more of the human interest, and appeals more to the children's sympathies, than does the study of the forms of water. 
cloth? How wash her face? her ears? her paws? How does she keep her fur smooth?

How do her eyes look in the dark? Can she move her ears? How much?

How does she show when she is pleased? How does she show when she is angry?

How does the mother cat take care of her kittens? How carry them, feed them, wash them ?

If the children can be led to consider their individual discoveries as great secrets, to be told only to the teacher, the interest will be increased, and individual observation stimulated.

LESSONS I. AND II. WHY WE HAVE THE KITTY IN OUR HOME.

Preparation. To put the little folks in the right attitude, sing with them or to them, "I love little Pussy, her soat is so warm," or read to them something like the following :

\section{MY DEAR KITTY.}

"Have you seen my little kitty?

Her fur is soft as silk, And every day I feed her

With bread and sweet new milk.

Her feet they are like velvet,

As she goes pat, pat along, And her soft and gentle purring

Is like a pleasant song.

Her ears are small and downy, Her neck and breast are white, Her eyes are like two tiny lamps

To light her in the night.

I have no little sisters

To walk with, or to play; But my pretty kitty loves me

Almost as well as they. 
And often we run races, And play at hide and seek;

Or she will climb the cherry tree, And through the branches peep.

I have never hurt my kitty, Or harassed her or teased, For she is God's own creature, And He would not be pleased."

Author not known.

Did the girl in this poem love her kitty? Why? Because kitty was so pretty; because she purred when she was pleased (kitty's way of talking or singing); because she was such a good "playmate;" because she was "God's creature." How did the girl take care of her kitty? Fed her, played with her, was kind to her.

Presentation. With kitty in the room, in the arms of the child to whom she belongs, bring out, by questioning the children, the reasons why we like to have kitty in our homes, and why and how we care for her.

How pretty she is. Her soft fur, "as soft as silk." Her color and markings. Her eyes.

How she likes our company. How she shows that she likes to be with us. Rubs herself against us, or jumps into our lap. Likes to be stroked and petted. How gentle she is with baby.

How kitty talks to us. How she purs when pleased or happy. How she asks for something to eat. How she asks to have the door opened. How she speaks when displeased or angry. How she spits when the dogs frighten her. Tell how kitty's mewing has often warned and saved people in danger, as in a burning house, or has told mother that her baby had wandered into danger.

How kitty plays with us. Rolling a ball. Playing with a string. Trying to catch her tail. Running racess. Play- 
ing hide and seek. Perhaps some of the children can tell how they dress kitty and play doll with her.

How kitty is like us. She has life, just as we do. She enjoys or suffers, and can be happy or unhappy. She likes to play, and likes to be petted and loved, as we do. She is "God's creature," just as we are.

How we care for kitty. Feed her, give her a soft, warm place to sleep, pet her, treat her kindly.

Summary. Read again "My Dear Kitty," encouraging children to discuss it somewhat, to tell what it means.

LESSONS III. AND IV. HABITS. DRINKING, EATING, WASHING, SLEEPING.

Aim. Tell children "To-day we are going to find other ways in which kitty is like us, other things she does which boys and girls do."

Preparation. Read to the children something like the following :

"Oh ! here is Miss Pussy,

She is drinking her milk ;

Her coat is as soft

And as glossy as silk.

She sips it all up,

With her little lip-lap,

Then, wiping her nose,

Lies down for a nap."

Author not known.

Presentation. Have children see in schoolroom as much as possible. Have them tell with as few questions as possible.

Drinking. How do we drink? Lift the cup to our lips and let the water run into our mouth. Have child show how. Watch the cat drink milk. The cat cannot lift up 
the saucer of milk. How does she drink? How does she get the milk into her mouth? How use her tongue?

Eating. Have a child eat an apple before the class. How - with what teeth - do we bite? How - with what teeth - do we chew? Watch kitty eat. How does kitty bite off her food, like bread? How does she chew the meat? How does she use her teeth ?' How do we hold things (apples) when we are eating them? How does kitty hold her food, such as meat? Perhaps they can see how kitty chews or tears the meat with the sharp teeth on either side of her mouth. (This may be too difficult for the little folks.) Touch lightly on the other side of the cat's life, - her fondness for birds and mice, and the way she catches and eats them.

Washing. What parts do we get dirty when eating? Our face and hands. What should we do after eating? What does kitty do after her meal? How does she wash her face? Her paws? Her ears? How does she clean and brush her fur?

Sleeping. After dinner kitty is often ready for a nap. Where does she like to sleep? In places soft, or warm, or both. How does she lie when asleep? How curl up? How place her paws and nose and tail? Does she sleep soundly? or does she awake easily? How keep warm, when åsleep, without any clothes or any "covers" over her?

Summary and Reproduction. A blackboard lesson on "My Kitty's Dinner," or a story by the teacher on "A Day in My Kitty's Life," the teacher giving the children frequent opportunities to fill in gaps in the story, thus testing what they have learned about kitty's talking, playing, eating, drinking, washing, and sleeping. 
LESSONS V. AND VI. HABITS, MOVEMENTS, AND SENSES.

Walking. Have children watch pussy walk on the dosk or on the teacher's arm. How quietly kitty walks. Can we walk as quietly? How her toes, each with a soft pad at the end, spread out, much as our fingers spread out when we walk on our hands and feet. How her claws are drawn in. How she moves her legs alternately, much as the children do when walkiug "on all-fours."

Running. Much like walking, but faster. Who ean run the faster, - kitty, or boys and girls?

Climbing. How quickly kitty climbs trees or posts to get away from the dogs. How does she do it? How do children use hands and fingers when climbing? Show children how kitty can extend or retract her claws. Make her climb up the extended arm. Note how curved and pointed the claws are. How does kitty climb down the tree trunk? Can we climb as well as kitty?

Jumping. Have children show how they jump (bend and suddenly straighten the legs) when standing, and how they jump when "on all-fours." Let kitty jump from arm or table. Note how she pushes with her hind legs, and how softly she alights on her fore legs. How far can she jump? Can we jump as well or as far?

Creeping. This posture may be seen when kitty is getting ready to spring at a ball with which she is playing. Notice how she pushes her front legs forward and her hind legs somewbat backward, doubling them, and how close to the ground her body is brought; how she creeps along; how her tail moves; and how quickly she springs.

Grasping. Have children tell and show how they use their arms, hands, and fingers in picking up and holding things. With which legs does kitty seize the ball or string when playing. Does she hold the ball tightly? How? 
Note how quick and free (moving in all directions) are the motions of the fore legs as compared with those of the hind legs. In many ways kitty's fore legs are used like our arms.

Seeing and Hearing. Talk about kitty's habit of prowling around at night, and her power of seeing in the dark, when we can see little or nothing. Show, if possible, the acuteness of her hearing.

Summary. An oral review, centring it about the thought, "Ways in which kitty is smarter than we are," bringing out how and why (thinking of the plan or construction of her body) kitty can walk, run, climb, creep, and jump better than boys and girls can.

LESSONS VII., VIII., AND IX. HOW KITTY IS FITTED FOR HER LIFE.

Aim. To lead and help the children to see the "why" and "how" of what they observe. Tell the children: We have seen how kitty lives, and have learned that she does some things that we would find it hard to do, and can do some things much better than we can. Let us write these on the blackboard:

She keeps warm without any clothes or any "covers" at night. She drinks milk without a spoon or cup.

She eats meat without a knife to cut it, or a fork to hold it.

She washes herself without water or soap or wash-cloth.

She keeps her hair smooth without brush or comb.

She keeps herself just as clean as we do.

She does all these things without any hands.

She can run faster than we can.

She can jump farther than we can.

She can climb trees better than we can.

To-day we will try to find out how kitty's body is made (or how God has made kitty's body), so that she can do these things so well. 
Presentation. Have cat in the schoolroom, where children can study her parts, and compare with the parts of their own body.

Kitty's Fur or Clothes. Have children observe how soft and warm it feels, how thick the hair is, how it is colored on different parts of the body. Have them tell how the hairs sometimes come out; that is, how kitty sheds her fur. After they have observed all they can about the fur, and not until then, discuss with them how the fur keeps kitty warm, how it makes her look so much prettier (compare with cat which has lost part of her fur), how the fur is changed, the old hairs dropping out (before they get long enough to tangle, like the children's hair), and the fine soft hairs taking their placc.

Kitty's Legs and Feet. Constantly compare children and kitty.

Use. Have a child show how children bend their legs, and how they stand on their toes, when getting ready to jump, how they straighten their legs as they jump, and how they bend and straighten their legs when they walk. What is the use of the bends or joints in their legs? Note how kitty bends and straightens her hind legs when she jumps or walks. Her hind legs are kept bent, and she always stands on her toes ready to jump.

Structure. Help children to note the parts and joints of their own legs, - the upper leg, knee joint, lower leg, anklejoint, foot, toes, and nails. Compare with (apparently) corresponding parts of kitty's hind leg, the long upper leg, the upper joint (apparently corresponding to our knee, but bending backward instead of forward), the lower leg, anklejoint (apparently), and toes and claws, with no heel and little foot. (The cat really has a short upper leg, concealed by the flesh of the body, and the knee-joint, bending like ours, but close to the body. What seems to be the knee really 
corresponds to our ankle-joint, and the part below is the foot, much elongated. But the children cannot understand this; and it is better to have them compare the parts which are to them - and to most adults - analogous.) Call their attention, if necessary, to the cushion on each toe, and to the way kitty pushes out and draws in her sharp-pointed claws. (See Figs. 51 and 52.)

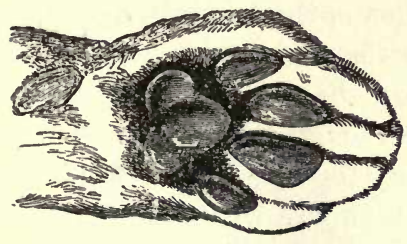

Fig. 51. Cat's Paw, under side, showing Pads

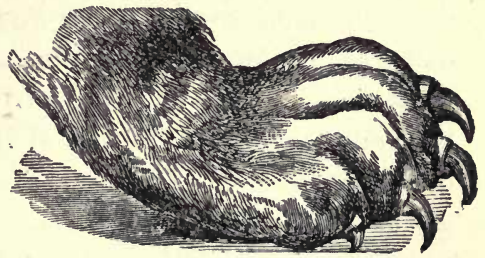

Fig. 52. Cat's Paw, showing the Claws.

Have children tell about the parts in their own arms,upper arm, elbow-joint, lower arm, wrist-joint, hand, fingers and nails. Compare with corresponding parts of kitty's fore legs, noting particularly their freedom of motion in all directions (compare with hind legs), and the toes with cushions and retractile claws.

Adaptation. After, not before, observing as carefully as possible, discuss adaptation with children. How are the hind legs fitted for pushing the body when the cat walks. Compare with way in which children push their sleds, with their feet extending behind the sled. How fitted for jumping? How are the fore legs fitted for quickly catching or grasping ball or string, or her food? What do both legs have which help kitty to climb so well, or to hold her food, or to keep away the dog - or the children? Why do not the sharp claws eatch in the carpet when she walks? What do the feet have to help her in 
walking so quietly? How are the feet fitted to wash and brush and comb her fur and head and face?

Teeth and Tongue. Use. Have a child show, as he eats an apple, how he bites it with the teeth in front of his mouth, pushes it around with his tongue, and chews it with teeth in the back or at the sides of the mouth. Feed kitty (potato or something to bite, meat to tear, and milk to drink), and see how she bites, chews, tears, and drinks. Ask children to watch, as she eats, the teeth in the sides or back of her mouth and to see how she uses her tongue.

Structure. Have children feel their teeth, and examine the teeth of one another, and tell about the sharp and wide or chisel-shaped biting teeth in front, and the broad flat grinding teeth at the sides. Compare with kitty's teeth. (See Fig. 53.) The front biting teeth are similar, but not

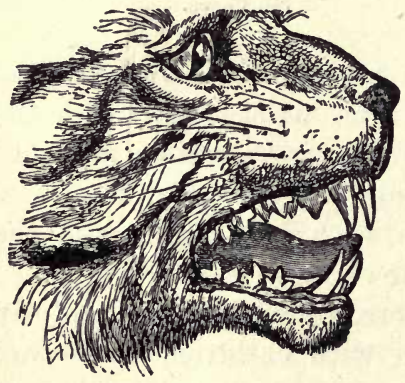

Fig. 53. Cat's Teeth. so wide or large, the grinding teeth have sharp points, and between the biting and grinding teeth, on each side of each jaw, is a long sharp-pointed tooth (four in all), with which kitty seizes and tears meat. We can call them "tearing teeth," or "meat teeth," or, when the children have noticed their length in the dog, dog teeth. Tell the pupils that Mother Nature has not given children these sharp-pointed "meat teeth," because she does not want little children to eat much meat. As they get older (like the teacher), and need meat, they get their "meat teeth" or "tearing teeth."

Tell the children, if they cannot see it, that kitty can bend her tongue into a form somewhat like a spoon, and that the upper side of her tongue is rough. The tongue of 
a child is smooth. Perhaps some children can tell how the cat's tongue feels when she licks their hand.

Adaptation. How are kitty's teeth nitted for eating and tearing meat? How are they fitted for biting? How is her tongue fitted for lapping milk? How is her tongue fitted for washing and brushing and combing herself?

Eyes and Ears. Use. Have a child show how he uses his eyes: how he turns them toward the object he is observing; how he protects them by closing the eyelids; how the pupils get smaller when looking toward a bright light,

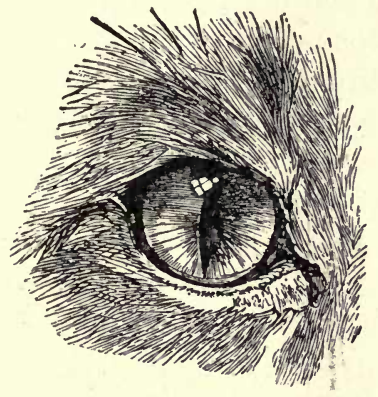

Eig. 54. Cat's Eye in Daytime.

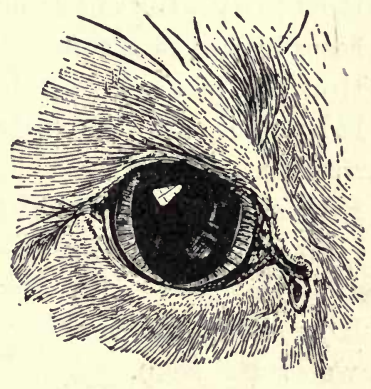

Fig. 55. Cat's Eye at Night.

and larger when turned away from the light. Have another pupil show how his ears are used: how he does not hear so well when his fingers are in his ears; how he turns his ear toward a sound when it is faint. Compare with the eyes and ears of the cat, dwelling on the great size of the pupil of the cat's eye (See Figs. 54 and 55), (cannot some of the pupils observe the cat at home, and tell how large this opening is, when their cat is in a dark place?) and the movements of the ears?

Structure. Study, first in children and then in cat, the position, lids, pupil, colored part and white of the eyes, and the position and appearance of the ears. 
Adaptation. Show how important it is that the cat should hear well at all times, and should be able to see well in the dark. Compare the pupil of the eye to a window shade which determines how much light shall come in, almost closing when the light is very bright, and opening when the light is dim. Why can the cat open the pupil of its eye wider than we can? Try to show how the movements of the cat's ears help him to hear better.

Summary. Have children tell, or prepare a reading-lesson telling :-

How kitty's fur is her clothing and her "covers."

How kitty has a spoon - her tongue.

How she has knives - her sharp-edged biting teeth.

How she has forks - her sharp-pointed tearing teeth and her claws.

How she has wash-cloths - her tongue and paws.

How she has a brush - her tongue; and comb - her feet.

How she gets from her mouth what is as good for her as water and soap.

How her legs are made for jumping.

How her feet are made for climbing.

How her eyes and ears help her.

\section{LESSON X. KITTY'S COUSINS.}

Aim. To give children a little idea of similarities and differences in animals. To make the cat something of a type of many animals. Tell the children: "To-day we will see how kitty is like and unlike us, and how she is like and unlike other animals we know."

Preparation. Try to have children see that we can recognize those who are brothers and sisters or belong to the same family:- 
Because they act or talk alike.

Because they look alike.

Because they are dressed alike.

We know plants or animals of the same kind:-

Because they look alike.

Because they have the same parts.

How kitty's body is like ours. Help children to see and tell how we use sticks to support weak plants, to keep the window curtains stiff, and to hold the panes of glass. Have them note how soft their flesh is, and feel the bones in their hands, arms, legs, chest, head, neck, and back. Of what use are they? Have some one gently try to discover where the cat has bones, emphasizing the back-bone and the bones that support the legs and feet. So the cat's body is like ours in having a backbone and other bones. Draw from them other similarities : the two main parts, body and head, the four limbs, the mouth with tongue and teeth. Bring these similarities into stronger relief by contrasting our body and the cat's body with those of the butterfly and grasshopper. The latter have no bones, three parts to the body, six legs.

How kitty is like the dog. Have a dog for comparison. Both have backbone and other bones, furry covering, four legs, and dog teeth or "meat teeth;" both are fond of meat.

How kitty is like other animals. Compare with any animal with which children are familiar, - rabbit or horse.

Summary. Make a iist of all the animals known to the children, which are :-

Like the cat in having bones or a backbone.

Like the cat in having Lairy or furry covering.

Like the cat in having long sharp-pointed dog teeth, or " meat teeth." 


\section{WINTER EARTH STUDY.}

\section{WATER.-ITS FORMS AND WORK.}

Time. Begin in January or February, continuing through March, and review or apply in April and May.

Aim. To interest children in the observation of the common things about them, and help them to appreciate the value and beauty of such a commom thing as water.

To prepare for a better comprehension of the co-operation and unity shown in nature.

To serve as a basis for geography work by helping children to study and understand the story and work of fog, clouds, dew, rain, frost, ice, and snow.

Order of study.

First. Useful properties and uses of water.

Second. Evaporation.

Third. Condensation.

Fourth. Forms of water, - water-dust, fog, mist, clouds, frost, ice, snow, dew, rain.

Fifth. Work of water in soil-making and in shaping the land.

The order is determined by the principle that we should begin with what can be most easily seen, and can be most readily related to the children's lives and experiences. They can see the useful properties of water, know considerable about the common or obvious uses of water, and can observe in the schoolroom the process of evaporation and condensation. 
USEFUL PROPERTIES AND USES OF WATER.

\section{What Water does.}

Dissolves things. Show the children that water dissolves ("Melts," or "Makes them go away," or "Makes them so we cannot see them," the children are likely to say) salt, sugar, snow, ice, alum, and other substances. Show them that heat helps the water to dissolve these more quickly.

Have children ask about and bring some of the incrustation usually formed in tea-kettles, and talk about its formation. Water may dissolve rocks, but very slowly. Water is the great solvent of nature. Heat and soap aid it.

Floats and carries things. Show children the power water has to float things, - wood, paper, leaves, saw-dust; to hold them in suspension, such as chalk-dust or mud; and to earry them along. Show how sand and even stones can be carried along by moving water.

Soaks into things. Show, with sponge and wood and chalk and sandstone, how water soaks into objects even when we can see no holes into which it ean enter. This helps it dissolve and carry along what is not on the outside of objects.

Review and summary. Try to have each step reviewed and "clinched" before passing to next step. At the end, try to have two or three children tell " the three things that water does." The retention of the ideas gained depends largely on the clearness, definiteness, and frequency of the summaries.

\section{The Uses of Water.}

Importance of "Why." This should be an application of the previous work. The work will mean much more if the children are constantly asked, "Why is water used for this?" and if they are led to relate each use to one or 
more of the useful properties previously brought out. Merely naming the various uses of water is of little value. Our children should think, not merely see and talk.

Uses to man. Used in the home to dissolve salt and sugar; to prepare tea, coffee, oatmeal; to boil vegetables and meat; to wash hands, clothes, food, house. Try to bring out the "why" in each case (mainly because of its dissolving and penetrating power). In which eases does heat help it?

Used in the body (as drink) to dissolve our food, and to cleanse the body by carrying away injurious things.

Used out-doors (rain) to wash roofs, sidewalks, fences, and to clean the streets by carrying away mud, leaves, sticks. Used to float boats, and help man to travel, and to carry things from place to place. Why? (Mainly because of its floating-power.)

To impress the thought of the usefulness of water to man, it may be well to tell how water is cherished, and how springs and wells are valued, in arid regions. (See the story of Gemila in Andrews's " Seven Little Sisters.")

Uses to animals. The only drink of animals. The home of fishes and frogs, and hosts of other animals. The roads by which they travel from place to place.

Uses to plants. Water washes them outside and inside. Water is their only drink. Water dissolves some of the soil, and gets from it and brings to the plants the food that their roots drink in.

Uses to the earth. How it carries along mud, sand, leaves. How it washes the earth and even the air. How it refreshes and brightens everything. This can be studied and discussed more fully in April and May.

Review and summary. Impress the thought of the dependence of everything on water. How useful and helpful it is. And yet we have only begun to study about its uses. 
A blackboard story on "How Water Helps Us" may gather up the most essential points. Below is such a reading lesson, as used by a teacher in a room where the children (five-year olds), were just learning to read, and could recognize but few words :

“Water helps us.

Water helps everyone.

We drink water.

We wash with water.

Fish live in water.

Water carries boats.

Water carries stones and sand."

If the children can write, cannot they be divided into groups, each with a different topic? The teacher may tell a story about "What a Pail of Water Did," having the children help her from time to time. It may be better to bring into the schoolroom a pail of water, and have the little folks tell, one by one, "What this pail of water can do and how it can do it," each giving such statements as these: "It can help me wash my hands by dissolving and carrying away the dirt;" "It can help mother get breakfast by dissolving the coffee;" "It can wash the steps by carrying away the dirt." How alert and interested the little folks are if such a review is sometimes turned into a game of "story-match," on the plan of a spelling-match, the children dividing into two groups, and successive children from alternate sides trying to tell a new story about "What the pail of water can do," taking their seats when they fail.

\section{EVAPORATION.}

Order of study. Be sure that evaporation is understood before making any reference to the opposite process, condensation. Do not be in a hurry to use the term "erapor- 
ate." When the children have the idea clearly, and have talked about "water going away," or "going into the air," " going so we cannot see it," or " changing into vapor," they will be glad to get, and will properly use, the word "e-vaporate." Begin with boiling and rapid evaporation in the schoolroom, because this is most easily seen. Follow this by a study of slow evaporation, first in the schoolroom, and later at home or out-doors. Last apply to explain every-day phenomena.

Apparatus. The form of alcohol stove shown in Fig. 56 has proven most convenient for this work and for later

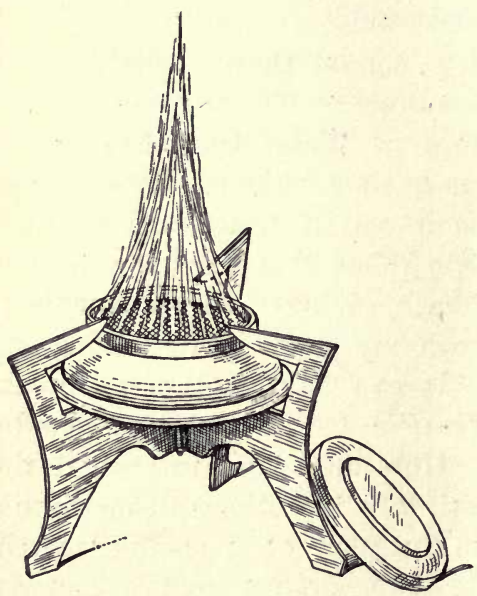

Fig. 56. Alcohol Lamp. study of air and heat. It can be obtained from, or ordered through, any hardware dealer for about twenty-five cents. Six or eight ounces of strong alcohol will be needed. If diluted with water, it will not burn well. Be careful not to have alcohol bottle near a flame, and not to pour alcohol on the hot alcohol stove. The other apparatus can be obtained anywhere.

Important points. Merely performing experiments before children does not necessarily lead them to observe important points ; they are apt to be most attracted by the apparatus and the flame. An experiment is, or should be, " a question asked of nature;" and we must be certain that the children understand what the question is. They must not be told the answer, what they should discover for them- 
selves; but their interest should be centred about the question, and their attention directed to what will help them to answer the question. The important points are :

First. The fact or process of evaporation, the turning of water into water-dust, which we can see, and into vapor, which we cannot see.

Second. The effect of heat in causing or increasing evaporation.

Third. The effect of a large surface in increasing evaporation.

Fourth. The effect of currents or winds in increasing evaporation.

Special pains must be taken to make these clear, and to "clinch" them in the summaries, oral or written.

Preliminary study of alcohol stove. To guard against or lessen the tendency to watch the apparatus rather than the experiment, it is well to take a little time to study with the children the stove and the way it is used. Then impress the idea that they are to watch what is done and what happens.

RAPID EVAPORATION, OR BOILING.

Step I. What does the water do? Heat a little water in a shallow dish (lid of jelly glass, or baking-powder can), over alcohol stove. Direct attention and observation to the water. "We want to see what happens to the water." The children, even the youngest, can observe, and tell that "Miss Grey put the water in a tin lid." "She put the lid over the stove." "The flame went up around the dish." "The water got warm." "Little bubbles came in the water." "Some bubbles were at the side." "Some bubbles were at the bottom." "The bubbles dance up and down." "Soon the water all went away." "No water was left in lid." 
Repeat experiment, putting in a tin cup a small quantity of water, which the children have measured in a bottle, heat for a time, observing as before, and have children measure again.

Clinch the observation and thought. "The water goes away."

Step II. What makes the water go away? Repeat one or both experiments, extinguishing the flame, and relighting it two or three times, that the children may see that "the water stops making bubbles" when the fire is blown out, and begins again when the fire is lighted. At this stage the children can probably only see that the fire or flame "makes the water go away." They may not be ready for the generalization (which must be based on many observations to mean much). "Heat makes the water go away."

Step III. What becomes of the water? Boil water in tin cup. Children, if really observing, will see the "smoke" (as they are apt to call it) or "steam" coming from the boiling water. Invert funnel over cup. The "steam" can be seen much more clearly coming from narrowed opening of funnel. They may state that the water makes or turns into "steam." Hold a dry tumbler or a slate or plate over the open cup, and later over the inverted funnel. What gathers on the inner or lower surface? Make sure that the children see the minute drops of water. Impress idea that what they call "steam" is made up of little drops of water.

Show the children how a piece of chalk can be broken into smaller and smaller pieces until it becomes as fine as the chalk dust below the blackboard. So heat or fire breaks up water first into bubbles, then into smaller and smaller drops. This can be shown by heating the dry tin lid, and pouring a few drops of water on it, letting the children see how the water breaks into little drops, which dance about 
until they disappear. They at last become so small that they are like the chalk dust. We cannot see one drop alone, but we can see many together. So we can call themwhat? Water dust. (Water dust is the more exact term for what is popularly called "steam." Steam, correctly speaking, is water vapor, and is invisible. The term "steam," referring to water dust, is so generally used in the children's homes that it does not seem wise to insist that the children shall not use it. Tell them we like better the name "water dust.") If they persist in calling water dust "smoke," show them, with a match, that smoke is made when things burn, and that it makes a tin or saucer black, while water dust is made when water boils, and it makes the tin wet.

After having children tell, as well as they can, what they did and what they saw, impress by repetition the idea that:

The fire turns the water into little drops.

The drops get small like dust.

Many drops together look like smoke.

Then we call it water dust.

Other people call it steam.

Call attention to the fact that water dust cannot be followed or seen far from the alcohol stove. It seems to "go into the air." Show children how chalk dust when scattered by blowing on it also "goes into the air." When the little drops of water dust become so small and so scattered that they cannot be seen we call them vapor. Impress the idea :

When water dust is so fine that we cannot see it, it is called vapor.

Now - and not before - the children are ready for the terms "e-vapor-ate," "to turn into vapor," and "e-vaporation," "turning into vapor." 
The important fact, the making of water dust, may be impressed by the teacher drawing on the blackboard, as directed by the children, the cup, funnel, and water dust, and then having the children draw it from the apparatus " at work," not from her drawing. Some analysis with the children of the direction and length of the lines used to represent cup and funnel will bring better results.

Step IV. Summary and expressive work. After the children have observed for themselves, - and not before, - it is helpful to call on the imagination to help clothe the facts of observation with life and additional interest. We may have them play at housekeeping, and tell how and for what they use water. Children are so made, - and we cannot and do not want to make them over, - that they delight in personification and in the life of the fire sprites and the water fairies. After personal observation by the boys and girls the fairies are helpful; they serve to impress and to relate what the senses have shown the children, and to give a larger content and a more attractive aspect to the world of sense. But if we call in the fairies before asking and directing the children to see and think for themselves, they are likely to interfere with the self activity of the children. The fairies are good helpers or companions in their place, but are poor guides or leaders. The following "story" illustrates how the sprites and fairies may help.

\section{How the Tea-Kettle Boiled.}

"'Jane, put some water in the tea-kettle.'

"Then Jane poked up the fire-sprites; and very soon the waterdrops bubbled, and the little fire-sprites said that there was water in the tea-kettle, and they put their arms around it.

"The water drops began to sing and dance; and the little drops at the top wondered what was the matter, and they went down to see. The drops at the bottom went up to the top singing, 'Ring tum, ring 
tum re,' and just then a little boy came in the room, and asked Jane what it was, and Jane said it was the tea-kettle singing."

\section{LAURA CoOke,}

Longfellow School, St. Paul, Minn.

Second Grade.

In any blackboard reading lesson, and, so far as possible, in individual written work by the children, tell -

First. What we did.

Second. What we or I saw.

Third. What we or I thought.

If this order is habitually followed, the children are more apt to think for themselves, and to base their conclusions on what they have seen. If told in the first person, as far as possible, class reproduction is apt to be more thoughtful and the pupil's work more individual.

The following are copies of individual reproduction papers written by two third-grade pupils in the Practice School of the Oswego Normal School. The papers are given just as written by the children, but with errors in spelling corrected. Two papers are given, written at the same time by two pupils in the same room, to illustrate how a teacher may impress on her class the general order to be followed in their papers and yet secure individual work.

\section{How Water Boils.}

"Miss Schiller placed a tin cup full of water over the alcohol lamp. Then she put some little pieces of paper in the cup. When the water began to boil, the little pieces of paper began to go up and down just like they were playing tag. The water near the heat got hot first. The warm water came up, and then the papers went up. When the cold water went down the papers went down. It was just like a current."

Addie Proud.

\section{How Water Borls.}

"Miss Schiller lighted the alcohol lamp, and put a cup of cold water over it. Then she put a few bits of paper in the tin cup. When the water boiled we seen the little pieces of paper goingr up and down the 
current. The little pieces of paper looked as if they were playing tag. The water nearest the flame got warm first. Then it rose. It took the little pieces of paper up with it. As soon as the hot water went up, the cold water took its place. Cold water is heavier than warm water."

Agnes Taylor.

\section{SLOW EVAPORATION OR DRYING.}

Step I. What slow evaporation is. Put vessel containing a very little water near stove or radiator, but not over fire. Place wet handkerchief or sponge, or paper or slate, in a warm place in a vessel, or under such conditions that pupils can easily observe and prove that water dust comes from them. Impress thought that drying is a slow evaporation. Get from children many illustrations of slow evaporation in schoolroom, at home, out-doors.

Step II. What helps slow evaporation or drying. Place, a measured quantity of water in vessel in warm part of room and in similar vessel in place not so warm. After an hour or two, or on the following day, measure. Place water in sunlight and in shade, and measure as before. Why the difference? After children have told as well as they can, what we did and what we saw, they can "think out" one answer to the question, What helps slow evaporation? Cannot they be helped to tell a story, and follow an order somewhat like this: "John put a cupful of water near the stove. Harry put a cupful of water near the door. It was warmer near the stove. We left them there all night. This morning John's cup was empty. Harry's cup was almost full. The water near the stove had all evaporated. Mary thought the warm stove made the water evaporate faster. We all thought so. James put some water in the sun, and some where the sun did not shine. The water in the sun evaporated faster. The warm sun helped it. So we think that water evaporates fastest where it is warmest. Heat helps slow evaporation." 
Below is a reading lesson copied from the blackboard in a second-grade room in the Practice School connected with the Oswego Normal School. It was gained from the children by good questioning by the teacher, Miss Bessie Bloomfield. It is a good illustration of such a lesson, - definite, clear, with successive statements well related, beginning with statements of experiments and observations, ending with the conclusions or generalizations.

\section{EVAPORATION.}

We put some water in a cup on Friday.

We put the cup in the window.

Monday there was not so much in the cup.

The water went away into the air.

Who took the water?

The air fairies took the water.

The water evaporated.

Friday we put a cup of water on the window and one on the radiator.

The air fairies took water from both cups.

Which cup had the least water in it on Monday?

The cup in the warm place had the least water in it on Monday.

Why did the cup in the warm place have the least water in it ?

The heat fairies helped the air fairies to take the water from the cup in the warm place.

If the heat fairies help the air fairies, the water goes away quicker.

Apply to such phenomena as the drying of wet clothes by placing them near stove or radiator, and the drying of sidewalks, striving to impress the ideas: Heat helps to dry wet things by making the water in them evaporate.

Place a measured small quantity of water in a narrow, deep vessel, a fruit jar, and the same quantity in a broad, shallow vessel, like a plate, and put both in a warm place. Put a small quantity of water in a vessel near the blackboard, and spread the same on the blackboard. Wet two handkerchiefs, and place near radiator, one spread out " to 
dry," one in a compact mass. These experiments will help the children to discover a second answer to the question: What helps slow evaporation or drying? "Water evaporates faster when it is spread out thin." "Things dry best when they are spread out." Apply this to the drying of the slate, and of clothes before the stove or on the line, and of the streets and sidewalks and roofs.

Show how much more quickly a damp cloth dries, or the ink on the paper dries, when cloth or paper are shaken. Have two or three children slightly wet both hands, and blow on one hand or move one hand rapidly, while the other is held still. Which dries more quickly? Try to dry two cloths, - one where the air is quiet, the other where there is a decided draft or wind. Which dries most rapidly? Water evaporates fastest, or things dry most quickly, when they are moving or when there is a wind. Apply this to drying of clothes on a line when wind is blowing, and to drying of walks and streets when it is windy. The relation of wind to drying is difficult for little folks, and is of minor importance. We can give them the idea, and let it digest. In a year or two it will mean more to them. It may be illustrated by the carrying of dust by the wind.

Cannot they understand something of the reasons for the three answers they have discovered to the questions asked them? Heat helps things to dry, or causes water to evaporate, more quickly, by breaking it up into very small drops of water dust, and scattering them through the air. The more the water is spread out, and the more shallow it is, the more easily the water dust can get into the air; the more the water is moved through the air, and the more the air blows over the water, the more it can take up and carry away the drops of water dust.

Step III. Blackboard review. An excellent way of reviewing and impressing the work already done, and at the 
same time keeping the children interested and alert, is to have a blackboard story, gained from the children as much as possible, on some such subject as, "Mother's Helpers on Wash-day." Tell who helped gather the clothes, how the fire and stove and boiler helped warm the water, how the water helped by dissolving and carrying away the dirt, how the soap helped, how the clothes-line helped by keeping the clothes spread out, how the sun helped by turning the water into water dust, how the wind helped by carrying away the water dust and vapor. Illustrations, though very crude, representing the boiler, wash-tub, and clothes on the line, will add much to the interest and impressiveness of the review.

The following illustrates an individual paper on :-

\section{What Makes Water Evaporate.}

One day our teacher, Miss Morrow, took some water, and put in the basin, and then set it on the table for two or three days. And one day Miss Morrow passed it around for the children to look at. And when we looked at it, it had all evaporated, and there were only a few drops left.

It had all dried up, and gone into steam. We cannot see the steam, but we can see the water dust.

The next time Miss Morrow took some water again, and put it in the basin, and set it on a chair by the register, and it evaporated quicker because there was more heat. The last time Miss Morrow took some water again, and put it in a kettle, and placed the kettle on a little stove; and it evaporated still more quickly, because there was more heat than anywhere else.

Ramsey School, St. Paul, Minn.

Edith Bambauer, Third Grade.

Step IV. The use of evaporation. Everywhere, in school, at home, out doors, over land and over the lakes and rivers, water is being turned into water dust and vapor, and is going into the air. Why is water always evaporating? Touch on the fact that evaporation helps the water to get 
away from the dirt and mud and all other impurities in it. Evaporation makes the water pure, leaves the dirt behind, and sends the pure water into the air and the sky. What becomes of this water? What does it do in the sky? Tomorrow we will begin to find out.

\section{CONDENSATION.}

Important points. What condensation is - the changing of water dust or vapor into water. Cold - or the absence or lessening of heat - as the cause of condensation. Common phenomena due to condensation.

Step I. How water dust can be turned into water. Boil water in tin cup over alcohol stove. Hold over it a slate or plate or tumbler, which has been slightly warmed, and then a similar vessel which has been placed out on the window-sill to cool. Water forms or collects more quickly on the cold vessel. Repeat the same experiment with a funnel inverted over the cup. Place on radiator, or near stove, a pan partly filled with water, covered with glass. Note how the drops of water collect on lower surface of glass. Cool the glass, and note the result. Cold, or cold things, make water dust turn into water. Compare with the way in which children like to get close together when it is cold, and thus help to keep one another warm.

Step II. How vapor can be turned into water dust and into water. When water is boiling vigorously in a teakettle, no water dust can be seen very near the end of the spout. The water in the spout is changed into vapor by the heat, and turns to water dust after it has escaped from the kettle, and has been cooled. Cold objects will condense this vapor into water dust or water. Heat a little water in a tightly closed vessel with small opening - such as the little oil-can used, with sewing-machines - to show 
formation of water dust from invisible vapor. Place boil ing water in the open window or other cool place. Th area and amount of water dust will be much increased because more vapor is condensed to water dust. A tin pail filled with ice-water, or better, with finely pounded ice and salt (three or four parts of ice to one part of salt), held over boiling water, will cause a great increase in the amount of water dust produced from the condensation of vapor. The condensation of vapor to water dust and to water can be illustrated by brushing together chalk dust scattered on white paper, first into little piles and then into larger masses.

Step III. What condensation is. What causes it. Gather up definitely the results of the experiments and illustrations in Steps I and II.

Step IV. Applications. The water dust coming from mouths of children and horses on cold days. Why not seen in schoolroom? The water collected on surface of pitcher of ice-water, or on water pipes, or on window panes, due to condensation of vapor in air. The steam (distinguish from smoke) from boilers of factories, seen so much more clearly on cold days. "Wash-day" at home in winter time usually illustrates condensation well. Try to lead children to observe and explain the escape of water dust from the boiler and wash-tub, the water on the windows and walls and ceiling of the kitchen, the cloud of water dust, like fog, with which the kitchen is often filled when the cold air rushes in from open door or window. Leave the wider applications of condensation, illustrated in formation of fog, mist, cloud, dew, rain, frost, snow, and ice, until these topics can be studied carefully.

Step $V$. Review and summary. Continue the blackboard story about "Mother's Helpers on Wash-day," with a chapter on "The Journey of the Water Helpers," telling 
how, after the water fairies had helped mother, the heat helped them start on a journey; how they let go of one another's hands, grew lighter and lighter, and flew away from the water; how some of them flew against the cold windows and against the cool ceiling, and what happened to them there; how others flew out-doors and went up, up, up, toward the blue sky and the bright sun - we will discover later where they went and what they did. Or the teacher can tell a story about "What We Saw on WashDay," bringing in as many applications as possible of evaporation and condensation, and often calling on the children to complete or supplement or explain the story.

\section{FORMS OF WATER.}

Order of study. The study of the forms of water will mean little unless preceded by the observational study of evaporation and condensation. There are three sequences in the work, - water dust, "steam," fog, mist, cloud, or the water-dust forms of water; water dust, frost, snow, ice, or the solid forms of water; water dust, dew, rain, or the liquid forms of water. So far as possible, it is best to take up the topies in the order given above, but the order will be modified by weather conditions. If we have a foggy or misty morning, we must take advantage of it to impress on the children, perhaps by an out-door lesson, the characteristics of fog, dropping other water study for a time. Then when we come regularly, to the study of fog, the children will have ideas to build upon, even if there is no opportunity to observe fog at the time. When the snow crystals, or the frost work on the windows, are particularly good, stop and study them. A wise, tactful teacher will so interest her children, that even little "first-graders" will be on the lookout when out of school, and will observe fog and rain and clouds and snow and ice. 
Important points. The temptation is particularly strong in this study to depend on talk, and pretty stories, and poems, and on the imagination of the children, rather than to build on the only sure foundation, - - on what the children have seen. In the writer's experience, nine teachers out of ten are prone to talk about Jack Frost and his beautiful pictures, without making any effort, or taking any pains, to watch, or to have their children watch, the artist at work, or to see how his pictures are made; too often they do not even look at the frost-work on the windows. Many teachers will expatiate on the beauties of the snowflakes; and have their pupils sing about them, and draw them, and sew them (from pictures in the books), without devoting fifteen minutes to real observation of their exquisite forms. Talk and stories and poems mean little, particularly to children, unless based on, or preceded by, sense-perception. Begin always with what children ean see. Relate the rain-drops and frost crystals and snowflakes to the children's life and experiences, and often endow them with the human attributes - desire to be useful, sociability, perseverance - which appeal to children. Then, and not until then, appeal to the imagination; but let the land of sense, and the life and experiences of the children, furnish the materials out of which fairyland is evolved, and peopled with the fairies of the air.

We must also endeavor to impress on the children something of the beauty and unity revealed in the forms of water, - the unity of cause, all being illustrations and results of evaporation and condensation; the unity of function or work, all having a work to do, and existing to do that work ; the unity of co-operation, all working together, all unceasingly helping and being helped; the beauty which the Greeks defined as "multitude in unity" and of which Emerson has written : 
"O'er me soared the eternal sky,

Full of light and deity ;

Beauty through my senses stole;

I yielded myself to the perfect whole."

WATER DUST, STEAM, FOG, MIST, CLOUDS.

Steam. Repeat, if need be, the work already outlined for the study in the schoolroom, of water dust and steam, dwelling on the way they are formed, the conditions necessary for formation (water, heat, cold), the depositing of water on objects held in them, and their appearance. Observe and talk about appearance and formation of children's "breath" on cold mornings. The best preparations for an understanding of fog and clouds, is to watch carefully the mass of steam rising from a manufactory or locomotive, noting how it rises in the still air, or is driven by the wind; how filmy or fleecy it is; how it partly obscures objects behind when it is in thin masses, and hides them when piled together; how the white masses often roll and tumble over one another, like children or kittens at play; how beautiful it may be, particularly when the clear blue sky forms a background. The children who have happened to be surrounded by steam when an engine was "blowing off steam" can tell how damp it was, and how "foggy" it looked all around them. Some of them may have seen, or may be led to notice, the way in which the steam may be lit up toward evening by the city lights or by a fire. Older children, at least, may discover how much better steam shows in the morning or evening than during the warmer part of the day, or on a cold day than on a warm day. Why? The observation at home of what happens on wash-day may aid in an understanding of fog and clouds. 
Fog. Fogs or mists can often be observed in low, marshy places, or over still water on the quiet mornings or evenings of spring or summer. Interest children in watching for them. What do these mists look like? How do they feel? Are the things covered with mist damp or dry? Why? Where do the fogs appear? Why in damp places? Why in low places or valleys? Why not on hill-tops? What happens to them as the sun rises higher in the morning? What change takes place as the sun sets? Why? Are they most often seen on cold or warm mornings or evenings? Why? On quiet or windy days? Why? The writer has asked such questions frequently of second-year children, and found that they had observed many such phenomena (when interested in them by their study of water), and were not merely eager to tell what they had seen, but able to tell clearly the "whys." Many "book-learned" teachers could not do as well. If teachers and children are so fortunate as to have a foggy morning, drop other water study, and make the most of the fog. Note particularly its dampness, and try to observe how it rises or disappears as the day gets warmer or the wind appears. It may be well to tell about effects of fogs on sea-coasts and in London.

For review, tell the story of "The Fog, the Sun, and the Wind." Because of their rare occurrence in most places, fogs are of minor importance as compared with clouds, and have much less content.

Clouds. Begin with observation of clouds, not mere talk about clouds. Much can be seen from school windows, more by taking children out for a field lesson, most by interesting them in watching the clouds for several days before any formal cloud study is attempted in school, and guiding them by a few sinple, definite questions. Good topics for such individual or class observations are: 
Movements of the Clouds. How they rush along with the wind, sometimes rolling and tumbling over one another like children out of school.

Forms and changes. How the children enjoy finding in the sky mountains and palaces and forts and trees and animals! How interested they are in their shifting and changing forms! To many a child whose eyes have been directed and guided cloudward the sky has become a veritable fairyland; the sunset has disclosed glimpses of heaven, with its pearly gates and golden streets and glittering towers and winged messengers.

Kinds. Large and small, white, gray, blue, dark, sometimes fleecy or feathery like the water dust or steam (feather or cirrus clouds), sometimes darker and denser, like many hills piled together (wool-pack or cumulus clouds), sometimes in layers one above the other, or side by side, like the boards in the floor (layer or stratus clouds), sometimes black with rain coming from them (rain or nimbus clouds), sometimes covering the whole sky with a gray veil, like fog.

Beauty. Due to light fleecy or "piled-up" appearance, contrasting with the deep blue sky behind them, to the endless variations in form and color, to the rich hues at sunset or sunrise. Perhaps the children can tell something about the clouds in the moonlight. How much they add to the sky and to the world and to our life, if we will but look upward!

Relation to "steam" and fog. Bring out ways in which clouds are like steam or water dust, and like fog, leading up to idea that clouds are masses of water dust high in air. Tell children how people on the tops of mountains can often see the clouds on the mountain side below them, looking like great masses of water dust or fog; how as they go down the mountain side they get into the clouds, which are 
just like fog, and as they go farther down they pass out of the fog, and see the clouds above them.

A verse from Lowell may help to impress the humble relationships of the clouds, the high destiny of the water dust :

" For countless services I'm fit, Of use, of pleasure, and of gain, But lightly from all bonds I flit,

Nor lose my mirth, nor feel a strain ;

From mill or wash-tub I escape,

And take in heaven my proper shape."

Uses. Dwell on their esthetic use, to beautify the world. The clouds are also blankets, or like an umbrella or parasol to people on the earth. They catch and hold many of the hot sunbeams in summer, thus making it cooler for us. At other times they keep the earth from getting cold too quickly, much as our clothes keep us warm when the air is cold. The third great use of clouds, to produce, by the condensation of their water dust, rain and snow, can be touched on here, and brought out again in the later work.

Literature. Some of the following may serve as an introduction to the out-of-door observation of clouds. Read to the children, or recited by the little folks as they are together watching the sky, they may give direction to their thoughts. Portions of Shelley's "The Cloud" will mean much, even to little folks, after they have observed and enjoyed the clouds.

\section{Cloudlets.}

"Little white cloudlets up in the sky, Say, are you snowy ships sailing on high? Or are you downy sheep running to find Shelter away from the rude blowing wind ?" 


\section{Little Clouds.}

"High above us, slowly sailing, Little clouds so soft and white, You are like the wings of angels, Watching o'er us day and night."

\section{RaIN Shower.}

"Plump little baby clouds, Dimpled and soft, Rock in their air-cradles, Swinging aloft.

Snowy cloud mothers, With broad bosom white, Watch o'er the baby clouds Slumbering light.

Tired little baby clouds

Dreaming of fears, Turn in their air-cradles, Dropping soft tears.

Great snowy mother clouds, Brooding o'er all, Let their warm mother tears Tenderly fall."

Author not known.

\section{A Journey to Cloudland and Back.}

"Some little drops of water

Whose home was in the sea, To go upon a journey

Once happened to agree.

They had a cloud for carriage, And drove a playful breeze, And over town and country They rode along at ease.

But, oh, there were so many, That soon the carriage broke, 
And to the ground came tumbling

The frightened little folk.

Then through the moss and grasses

They were compelled to roam

Until a brooklet found them, And carried them all home."

Selected.

The Cloud.

"I bring fresh showers for the thirsting flowers, From the seas and the streams ;

I bear light shade for the leaves when laid

In their noonday dreams.

From my wings are shaken the dews that waken

The sweet buds every one, When rocked to rest on their mother's breast,

As she dances about the sun.

I sift the snow on the mountains below; And their great pines groan aghast; And all the night 'tis my pillow white, While I sleep in the arms of the blast.

I am the daughter of earth and water, And the nursling of the sky;

I pass through the pores of the ocean and shores; I change, but I cannot die."

Percy Bysshe Shelley.

BLACKBOARD READING LESSON.

The following reading lesson, copied from the blackboard in a second-grade room in the Practice School of the Oswego State Normal School, was prepared, largely gained from the children by questioning, by Miss Bessie Bloomfield. It illustrates the right spirit in the cloud study, and shows how individuality can be encouraged and preserved, even in a class reproduction. 


\section{Clouds.}

"We have all seen the clouds.

Some of us have seen pictures in the clouds.

Jamie saw a little golden cloud.

The sun shone on the cloud, and made it golden.

John saw a little silvery cloud.

The moon shone on the cloud, and made it silvery.

A little star shone through this cloud.

Winifred and Albert have seen clouds that look like mountains.

The clouds have work to do.

They wear their dark dresses when they do their work.

They send us rain and snow.

The clouds are bunches of water dust."

WATER DUST, FROST, ICE, SNOW.

Preparation. Review by experiment the conditions necessary for making water dust: water; some heat to evaporate it; some cold to condense it. Show how much more rapidly it is formed when the vapor is shut in so that it cannot scatter through the air, and when the air is therefore full of vapor. This can be shown by placing a bottle of ice-water on a cork or block of wood in a saucer containing a little warm water, and inverting over the saucer and bottle, a glass jar, or tin can.

\section{FROST.}

Formation. Use the same apparatus as is described above. Use a wide-mouthed bottle, such as a quinine bottle, and fill with a mixture of finely pounded ice and salt, about one-quarter salt and three-quarters ice. Good results can be obtained with a half-pound baking-powder can (with the paper removed from part of it), to contain ice and salt, and, inverted over it, a two-quart tin fruit- or coffeecan (with a nail-hole in it). Show children that the ice is used to make the bottle or can cool, and the salt to help 
the ice. Invert larger jar or can over bottle and saucer, as before, and heat gently over alcohol stove. Soon frost will form on the surface of the bottle or can which contains the ice and salt. Watch the process very carefully, removing the inverted jar frequently. Note how the minute particles of frost form; how they grow, some pushing away from the surface of the bottle, some sending out arms over the bottle; how the arms often interlace; how the frost crystals glisten; how cold they feel, and how they melt, showing that they are made of water or ice. If the same experiment is repeated, but without the inverted jar or can, children can see that the frost forms best where there is much moisture, and where it cannot scatter through the air, and can explain why frost forms most quickly in low places and on quiet nights. A wooden water-pail filled or partly filled with a mixture of finely pounded ice and salt soon becomes coated with frost. The star-like frost crystals, resembling minute snowflakes usually form freely; they should be observed with a magnifying-glass, a reading-glass if obtainable.

Perhaps the children can tell where frost forms on the windows at home, - most abundantly in or near the kitchen or washroom or bath-room, where there is plenty of moisture or water dust. Why?

Observation of frost work. Whenever frost work on windows is particularly good, stop other nature work to study the frost pictures with the children. If it is possible to see how the frost work grows or spreads over the window-panes, or to get one or two children to watch it at home and tell about it, much will be gained. Try to find some of the little star-like crystals (as a preparation for snow study). Note how the arms or branches crowd together, and push out from the glass (as a preparation for the study of the formation of ice). How the children 
enjoy finding leaves and ferns and trees and church spires and fairy palaces and little villages in the frost pictures!

"These winter nights against my window-pane

Nature with busy pencil draws designs

Of ferns and blossoms, and fine spray of pines,

Oak-leaf and acorn and fantastic vines,

Which she will make when summer comes again."

T. B. AlDrich.

Observe, when possible, the frost on grass, walks, and fences, even if the opportunity to do so does not not come until weeks after the regular frost study. It is only by frequently reviewing and applying what has been learned, that it can be fixed in the minds of the children. If at any time during the winter, trees and other objects become - incased in ice, as after a sleety rain, much can be.impressed about the beauty of the frost-work.

"'Then he flew to the mountain, and powdered its crest; He lit on the trees, and their boughs he dressed In diamond beads; and over the breast

Of the quivering lake he spread A coat of mail, that it need not fear The downward point of many a spear, That he hung on its margin, far and near,

Where a rock could rear its head."

Hannah F. Gould.

The Work of Jack Frost. Now - after the children have observed for themselves - they are ready for Jack Frost, whose work they have been studying. Now he is not likely to lead them far astray; what they have seen will guide their fancy, and direct somewhat their imagination. How much interest he adds to their work!

How shall we picture Jack Frost to the little folks? Shall we give them the "Frost Spirit" of Whittier, who blasts the fields, and smites the leaves, the spirit with the 
"fearful breath," who bows the pines and the "torpid touch," who chains the streams, a veritable angel of death ? Or shall we picture him as a jolly little elf, full of pranks, pinching our fingers, nipping our ears, and yet one of our best friends, and one of Mother Nature's greatest helpers and most useful messengers?

He pinches our ears, but he brings the roses to our cheeks and the sparkle to our eyes. Mother Nature sends him to tell us to dress warmly, and to get warm by keeping our hands and feet and heart and blood at work. No lazy boys and girls for him! And yet, when night comes, and we are tucked in warm and snug, how he makes us sleep!

He chills the water dust, but how he changes it! At his touch water dust covers our windows with fairy pictures and silver stars, dresses the grass with diamonds, decks the trees and fences with glittering moss, even spreads over the blue sky a feathery, filmy lace, for the feathery (cirrus) clouds that we enjoy so much are made of little ice crystals which Jack Frost forms high in the air. There he works, even in summer time. We shall find that all the snowflakes are made by him.

His touch stilled the brook; but it was the loving, restful touch of Mother Nature, not the "torpid touch" of the angel of death. The little brook felt it, -

"And built a roof

'Neath which he could house him winter-proof;

All night by the white stars' frosty gleams

He groined his arches, and matched his beams;

Slender and clear were his crystal spars

As the lashes of light that trim the stars.

He sculptured every summer delight

In his halls and chambers out of sight ;

Sometimes his tinkling waters slipt

Down through a frost-leaved forest crypt,

Long, sparkling aisles of steel-stemmed trees

Bending to counterfeit a breeze; 
He had caught the nodding bullrush tops, And hung them thickly with diamond drops, That crystalled the beams of moon and sun, And made a star of every one. No mortal builder's rare device Could match this winter palace of ice."

LOWELL: Vision of Sir Launfal.

Jack Frost breathes on trees and flowers, and bids them "lie down to sleep." Their work is done. They need rest, to prepare for the larger, more beautiful life of the spring. Only to the tardy ones, who have delayed their work, or to the plant-lives whom man has brought from the lands where Nature uses gentler messengers, does he sometimes come with a "fearful breath." He sometimes "smites the leaves," but not until their work on the tree is done, and another work calls them to the ground. To the tree they might bring harm, by catching the winds, and holding up the "cold burdens" of winter. To Mother Nature's seed-babies and insect children they bring a covering, over which Jack Frost soon gently drops the snow.

"I never knew before what beds, Fragrant to smell, and soft to touch,

The forest sifts and shapes and spreads.

I never knew before how much

Of human sound there is in such

Low tones as through the forest sweep

When all wild things ' lie down to sleep.'

Each day I find new coverlids

Tucked in, and more sweet eyes shut tight; 
Sometimes the viewless mother bids Her ferns kneel down, full in my sight; I hear the chorus of 'Good-night ;' And half I smile, and half I weep, Listening while they 'lie down to sleep.' ",

Helen Hunt Jackson.

ICE.

Formation. Place shallow pan with very cold water on ledge outside of window, on north side of building if possible, at least where sun does not shine. Let children observe, through a reading-glass if possible, the forming of the ice crystals. If it is a fairly cold winter day, some time (ten minutes or more) may be required for the formation of crystals.

A wooden water-pail, nearly filled with finely pounded ice and salt, and covered with a pane of glass, can be used to show in the schoolroom the formation of ice crystals and ice. If a small tin fruit-can and a glass fruit-jar, each filled with ice-water, be placed in the pail, with the ice well packed around each, the tin can will show the formation of the needle-shaped crystals ; and the translucent deposit of ice on the inside of the glass jar will reveal many forms already seen in the frost, and show that ice is simply thick frost. The children can watch the process through the pane of glass, removing it occasionally. The ice crystals do not form so readily if the water is jarred or is in motion.

Have pupils observe and tell about the shape, size, and color of a single needle-like crystal, and compare with the simple frost crystals they may have observed. Watch and tell how the crystals come together and interlace.

Examine pan of ice which has been on window ledge two or three hours. The tracing of crystals may still be seen on the top, but below it is a compact mass. If pan 
is used with very small hole in bottom, through which water may trickle very slowly, masses of needle-shaped crystals may be formed projecting in from the sides.

Place pan first examined out on window ledge, and leave several hours until children can see that the crystal needles have become wedged and joined together to form the solid ice. Try to have children observe outdoors or at home the appearance and formation of ice.

After such observational study of ice crystals and ice, even the little folks enjoy and appreciate the beauty of portions of the selection from Lowell's "Vision of Sir Launfal."

Cannot the children see something of the formation, growth, and beauty of the icicles? An old pan or can, perforated so that the water may escape from it slowly, suspended outside the window on a cold day, may show the little folks something of the formation of icicles, from dripping water slowly congealing and constantly lengthening downward (or sometimes upward), and adding new layers. This will not merely add to the children's appreciation of common things, but may prepare for an understanding of the way Mother Nature decorates her underground palaces in limestone caves with similar, but even more beautiful forms, frozen in stone.

Expansion of ise. Fill a bottle or other glass or earthenware vessel with water, and place out on window ledge over night, or place in the freezing mixture of pounded ice and salt. The pressure of the ice crystals, all trying to lengthen and thicken as they interlace, causes the ice to expand, or "get bigger," as the children say, cracking the vessel in which the water is, if it is not very strong, or pushing up, as when water freezes in a strong pail. Apply to bursting of pitchers, water-pipes, etc., in cold weather. If the water is kept running, it is not so apt to freeze. Why? 
Work and use. How Jack Frost uses ice for his heavier, more solid decorations on houses and trees! How it sparkles in the sunlight, and glistens in the moonlight. How it bridges the brooks and rivers, and covers the lakes and ponds! How it brings to us all the sport of sliding and skating! How the cold of winter is stored up in the ice (expressed from the children's point of view) and kept in our ice-houses until summer, when it cools our water, and keeps our milk sweet, and helps us take care of our food! In places where much ice is cut, it may be well to study something of the process of cutting and storing ice. An inspection of an ice-box or refrigator in use, or of a cold-storage room, will impress strongly the usefulness of ice.

The breaking of pitchers and bursting of water-pipes seem to be pure mischief on the part of Jack Frost. But this is only another illustration of the fact that apparent evils are often great blessings in disguise. This " mischief" of Jack Frost, the expanding of ice as it freezes, makes the ice lighter, and causes it to float on the top of the water. If it did not expand, or if it contracted, as most substances do as they change from the liquid to the solid state, our lakes and streams would become solid masses of ice, from bottom to top, which the summer's sun could never melt. This same expansion is the main agent in breaking up our rocks into soil. The water which has soaked into rocks and stones expands as it freezes, making them finer and finer each winter, so that the plant roots can go through them, and get the food they need. Jack Frost is thus one of the best friends of the farmer. The farmer who ploughs in the fall knows that Jack Frost is going to keep on ploughing for him all winter. This work of frost and ice can be best studied in the spring. It is discussed under the topic: "Work of water in soilmaking." (See page 513.) 


\section{sNow.}

Aim and order of study. In the snow study more, perhaps, than in any other work with the forms of water, the main aim is esthetic, the appreciation of beauty. The snow has always appealed to the poets and nature lovers, and there is much excellent literature which should be used to impress the best thoughts in the study of snow.

Begin with what children can see, - the observation of snow, its beauty and purity in masses, the beauty it gives to nature, its falling, and the forms of the snow crystals. Leave until the last the story of the formation of snow, because it must be largely told to the children, only based indirectly on sense-perception.

\section{ORDER OF LESSONS.}

Lesson I. Field Lesson. Out-door Observation of Snow. Lesson II. Review and Summary of Field Lesson.

Lessons III. and IV. Uses of Snow.

Lesson V. Formation or Story of Snow.

\section{LESSON I. FIELD LESSON.}

Note. A few moments of well-directed observation outdoors will impress more deeply the beauty and work of snow than a much longer time in the schoolroom. The essentials in a successful field lesson are: the right spirit, a sympathetic, appreciative observation of what cannot be so well seen indoors; definite work for each pupil, adapted to their capacities; a careful review indoors, to fix the important facts discovered, and to impress the right attitude toward the outdoor world.

If it seems impossible to take the children outdoors, much can be seen from the school windows. Snow-flakes collected on a black cloth wrapped closely around a tin 
pail containing a freezing mixture of ice and salt, will usually keep their form several minutes in the schoolroom; a pane of glass should be placed over them to protect from the effects of the warm breath of the children.

Preparation. Read to the children and discuss briefly, with them, one of the following:

"Tiny little snow-flakes,

In the air so high, Are you little angels

Floating in the sky?

Robed so white and spotless,

Flying like a dove, Are you little creatures

From the world above?

Whirling on the sidewalks,

Dancing in the street,

Kissing all the faces

Of the children sweet;

Loading all the housetops,

Powdering all the trees,

Cunning little snow-flakes,

Little busy bees."

\section{Lucy Larcom.}

"Softly from the sky is falling

Snow-flakes white as lilies fair;

Gently to each other calling

As they float down through the air.

Softly, softly, oh, so softly,

Do they come from dizzy heights;

Gently; gently, oh so gently !

Do they lay a blanket white.

Over all the many housetops,

Over shrubs and tall, tall trees, Over hills and fields and meadows,

Hiding stones and restless leaves."

EMma Louise Clapp: 
" Little fairy people, Dancing in the sky, Dressed in soft white raiment, As they downward fly, Play with little children, Kiss their cheeks so red, Keep the flowers cosy In their earthly bed, Robe the world in beauty

In a single night, Covering trees and houses Till they sparkle bright." WINIFREd Marsh.

Draw on the blackboard pictures of two or three simple forms of snow-flakes, impressing on children that the snowflakes drawn are starlike, glistening white, with six arms.

Divide the children into three groups, - the first to watch the falling of the snow-flakes; the second to find out all they can about the snow covering and the beauty it gives to the world; the third to study the crystals.

To the tirst group give a few such questions as: How do the snow-flakes fly? Like birds? Like kites? Do they play or dance about, or do they come straight down, as stones do? Do they come fast or slow? How do they feel when they light on your hand? How are they like angels? Like "little busy. bees"? Like "little fairy people"? Like "little ships in the air"?

Try to have the second group notice how the snow forms a carpet for the earth and how the flakes catch, one by one, on the trees.

"And when a snow-flake finds a tree,

'Good-day !' it says, 'Good-day to thee !'

'Thou art so bare and lonely, dear, I'll rest and call my playmates here.'",

How do they drape the trees? How does the snow look on the evergreen tree? On which side of the trees is there 
the most snow? Can you tell from which direction the snow fell on the trees? How? Can you find any snow curtains or snow lace? Can you find any snow caps on the posts? How does the snow look on the fences? On the roofs and chimneys? How does it look where the sun shines on it? Try to find all the ways in which the snow makes the world beautiful.

The special work of the third group - and it should include some of the "sharp eyes" - is to see how many kinds of snow-flakes they can discover and show to their teacher. A large magnifying-glass, such as a reading-glass, will greatly help them in their search. They can see best the flakes which fall on their clothes, or, better, on a black cloth or umbrella.

Conduct of field lesson. Let the children scatter somewhat, the teacher helping the weaker ones by questions, but throwing the observational work on the children as much as possible. After a few minutes gather them together, and try to have all of them see what different pupils have discovered individually. Clear up disputed or uncertain points.

Will they not appreciate better now one of the poems already given? Some of them may see what Lowell means when he writes:

"Every pine and fir and hemlock

Wears ermine too dear for an earl ;

And the poorest twig on the elm tree

Is ridged inch deep with pearl."

Perhaps some one can sing to them before they go indoors (to the tune of "Sing a Song of Sixpence") :-

" Sing a song of snow-flakes

Dancing through the air!

See them whirling, playing,

Falling everywhere. 
Tiny little snow-flakes, Sparkling, clear, and white,

May we all as gentle be,

To those we love as bright.

Sing a song of snow-flakes

From the world above, Softly, softly falling, -

Are they full of love?

Beautiful white fairies,

Dressed in silver spray,

Happy little snow-flakes all

Merrily at play."

Adelle J. Gray.

\section{LESSON II. - REVIEW, OF FIELD LESSON.}

Have children tell as much as they can about each of the three topics, - how the snow-flakes fall; how the snowflakes make the world beautiful; how the snow-flakes look. Try to keep the thought on one topic at a time, finishing that before discussing another.

The children may be helped by reading with them again one of the poems given in Lesson I., or "A Snow Song," given at the end of this lesson, or by reading to them portions of Bryant's "Little People of the Snow."

One or more stories or blackboard reading lessons, somewhat like those below, will be helpful. With little firstgrade children it may be helpful to read these to the children, after they have told what they can. Second-grade children can aid in preparing these lessons; that is, many of the statements can be gained from the children by questioning. These "stories," either written on the blackboard or copied with the hektograph, should then be used as reading lessons. Third-grade boys and girls should be able, with some help, to write some such stories for themselves, making the work as individual as possible. 
Instead of writing about how the snow-flakes look, it may be best for each child who looked carefully at a snow-flake, and thinks he can remember it, to make a drawing of it. Special pains must be taken to have the children draw, as carefully and truthfully as they can, only what each child saw for himself. Discourage and frown upon mere copying. It is, in such work, a species of untruth.

\section{The Snow-Fairies.}

\section{How the Snow-Fairies Come.}

We all went outdoors.

We saw the snow-flakes fall.

They were like little birds.

We called the snow-flakes snow-fairies.

They come from cloud-land.

They fly so softly.

They dance up and down.

The wind makes them dance.

They play like boys and girls.

They fall so gently.

We could not feel them fall.

We love the snow-fairies.

II. How the Snow-Fairies Make the Earth Beautiful.

The snow-fairies fall on the trees.

They cover some trees with lace.

The snow-fairies say to the trees:

\section{"Thou art so bare and lonely, dear, I'll rest and call my playmates here."}

The snow-fairies look so white on the evergreen trees.

They make white caps on the posts.

They cover the dark earth.

They make a white dress for Mother Earth.

They shine in the sunlight.

The snow-fairies make the earth beautiful.

Mother Earth loves the snow-fairies. 
III. How the Snow-flakes Look.

Mary looked at the snow-flakes.

She had a glass which made them look big.

She says they look like stars.

John says they are thin, like paper.

The snow-flakes are white, as white as they can be.

They shine so when the sun looks at them.

Many snow-flakes have six arms.

Some have only four arms.

Miss Grey says some arms fell off.

Some arms have many little fingers.

Mary thinks Jack Frost made the snow-flakes up in cloud-land. The snow-flakes are so pure and beautiful.

Literature.

\section{A SNow-Song.}

"There's a wonderful weaver

High up in the air,

And he weaves a white mantle

For cold Earth to wear.

With the wind for his shuttle,

The cloud for his loom,

How he weaves, how he weaves,

In the light, in the gloom !

$\mathrm{Oh}$ ! with finest of lace

He decks bush and tree;

On the broad barren meadows

A cover lays he ;

Then a quaint cap he places

On pillar and post,

And he changes the pump

To a silent, grim ghost.

But this wonderful weaver

Grows weary at last, And the shuttle lies idle

'That once flew so fast.

Then the sun peeps abroad

On the work he has done, And cries, ' I'll unravel it all.

Just for fun.'," 
LESSON III. USES OF SNOW. WHAT THE SNOW DOES FOR US.

Preparation. Sing at the morning exercises or before the lesson a coasting or sleighing song.

Step I. How the snow makes the world beautiful for us.

Try to impress the thought that the beauty which the snow gives to the world is so much added to our life.

Step II. How the snow brings happiness to boys and girls.

Have children tell about their favorite winter sports. Ask them why they like winter. Name and count the sports and pleasures which the snow gives to children,snow-balling, making snow men, coasting, sleighing, etc.

Step III. How the snow helps grown people.

How snow aids us in travelling about and in carrying things. How much more easily we can travel, and how much heavier loads we can carry, when there is vlenty of snow. How much snow helps the lumbermen.

Step IV. How the snow helps the Esquimos.

Try to give the children some idea of the land where there is snow all the year round, and of the usefulness of snow to the people who live there. Picture the life of Agoonac (see Jane Andrew's "Seven Little Sisters" and "Each and All"), the way she dresses to keep warm, her house - often made of ice or snow - and the sled in which she is pulled by the dogs over miles of ice and snow.

Step $V$. Expression.

Have children draw Esquimo house or sled, or model the Esquimo hut. If they can build outdoors, at recess or noon, an Esquimo house of snow, so much the better. 
LESSON IV. THE USES OF SNOW. HOW SNOW PROTECTS.

Step I. How snow keeps man warm.

Review the story of the snow house in which Agoonac lived. Have children tell or tell them how people pile the snow around their houses to keep them warm. Tell how people have kept warm for days buried under deep snow. Compare snow with cotton in "comfortables."

Step II. How snow keeps animals warm.

Read the following, and picture the rabbit burrowing under the snow :

"The woods and fields are buried deep

Under the snow ;

The hedges lie in a tangled heap

Under the snow ;

And the little gray rabbits under them creep,

While the twittering sparrows cunningly peep

From the sheltering briars, and cosily sleep

Under the snow."

JoHN H. Bonner.

Step III. How snow keeps the plants warm.

Perhaps some of the children can tell how their fathers bury vegetables to keep them through the winter. They should certainly be able to understand by this time, and be ready to tell, that snow is the cover that Mother Nature sends to protect her plants, and particularly her plant babies. Recall how Mother Nature sends the leaves in the fall to cover seeds and buds, and hosts of animals, and how, a little later, she often spreads over them her snow mantle.

Literature.

\section{Putting the World to Bed.}

"The little snow people are hurrying down

From their home in the clouds overhead; They are working as hard as ever they' can, Putting the world to bed. 
Every tree in a soft fleecy nightgown they clothe;

Each part has its night-cap of white.

And o'er the cold ground a thick cover they spread

Before they say good-night.

And so they come eagerly sliding down,

With a swift and silent tread,

Always as busy as busy can be,

Putting the world to bed."

Esther W. Buxton.

"Little snow-flakes falling lightly,

Little snow-flakes falling whitely,

Cover up the sleeping flowers,

Keep them warm through winter hours.

Do you know

Why the snow

Is hurrying through the garden so ?

Just to spread

A nice soft bed

For the little sleepy flowers' head,

To cuddle up the baby ferns, and smooth the lily's sheet, And tuck a warm white blanket down around the roses' feet."

\section{The Baby Ferns.}

" $\mathrm{Oh}$ ! what shall we do the long winter through ?

The! baby ferns wept when the mother slept.

The wind whistled bleak, the woodland was drear;

On each baby cheek there glistened a tear.

Then down from the clouds, like a flutter of wings,

There came a whole crowd of tiny white things,

That trooped in a heap where the baby ferns lay,

And put them to sleep that bleak winter day.

Tucked under the snow in their little brown hoods, Not a thing will they know, these babes in the woods, Till some day in spring, when the bobolinks sing, They will open their eyes to the bluest of skies." 


\section{LESSON V. FORMATION OR STORY OF SNOW.}

Step I. Formation of frost.

Review briefly what children observed about formation of frost, - the evaporation of water, its condensation to water dust, the freezing of these to form frost crystals.

Step II. Formation of clouds.

Review briefly what was observed about formation of water dust, steam, or fog, and clouds.

Step III. Formation of snow-flakes.

Now cannot we take the children, in imagination, to cloudland, and tell them - or get them to tell - how the snow-flakes are made? In the sky the snow-flakes have plenty of room to form perfect crystals. The frost and ice crystals are crowded together. Try to follow the journey of a drop of water from the tea-kettle to the clouds, its change to a snow-flake, and its trip back to us.

"Pretty little snow-flake, Shining like a star,

Did you come to find us From some world afar?

Nay, my home was nearer,

Dear, than you suppose ;

From the kitchen kettle

Through the air I rose.

I longed in chilly cloudland

To see you once again ;

And so I flew, a snow-flake,

To your window pane."

Literature.

The SNow-flake.

"It was a little snow-flake With tiny winglets furled;

Its warm cloud mother held it fast Above the sleeping world. 
All night the wild wind blustered,

And blew o'er land and sea ;

But the little snow-flake cuddled close,

As safe as safe could be.

Then came the cold gray morning,

And the great cloud mother said.

'Now every little snow-flake

Must proudly lift her head,

And through the air go sailing

Till it finds a place to alight,

For I must weave a coverlet

To clothe the world in white.'

The little snow-flake fluttered,

And gave a wee, wee sigh ;

But fifty million other flakes

Came floating softly by ;

And the wise cloud mothers sent them

To keep the world's bread warm, Through many a winter sunset,

Through many a night of storm." .

Margaret E. Sangster.

Little Ships in the Air.

"Flakes of snow with sails so white,

Drifting down the wintry skies,

Tell me where your route begins,

Say which way your harbor lies.

In the clouds, the roomy clouds,

Arching earth with shadowy dome,

There's the port from which we sail,

There is tiny snow-flake's home.

And the cargo that you take

From these cloudy ports above, -

Is it always meant to bless,

Sent in anger or in love?

Warmth for all the tender roots,

Warmth for every living thing,

Water for the river's flow,

This the cargo that we bring. 
Who's the master that you serve,

Bids you lift your tiny sails,

Brings you safely to the earth,

Guides you through the wintry gales ?

He who tells the birds to sing,

He who sends the April flowers,

He who ripens all the fruit,

That great Master, He is ours."

E. A. RAND.

WATER DUST, DEW, RAIN.

Water dust. Begin again with experiments showing formation of vapor and water dust. Show how this is condensed into drops, impressing the importance of cold by showing how much more rapidly the drops of water are formed when a cold slate or glass or plate is used than when a warm object is placed in the vapor or water dust. Dew and rain are thus readily formed in the schoolroom.

A jar or pitcher of ice-water in the room may show the condensation of water on its surface. If the air of the schoolroom is too dry, place a bottle of ice-water on a cork or block in a saucer containing a little warm water, and invert over the bottle a glass jar. Heating this slightly over the alcohol stove will cause a more rapid evaporation of the water in the saucer, and insure the condensation of dew on the surface of the cold bottle. To form water dust we find necessary water, some heat to cause evaporation, some cold to cause condensation.

Dew. Apply these conditions to explanations of dew. It forms in low, damp places, or near the sea or lakes or rivers when there may be no dew on the hills or away from water. Why? It forms in the evening, not usually in the daytime. Why? Dew is most apt to form when there is little or no wind. Why? It is a little more apt to form on clear nights than on cloudy nights. Why? Touch on the uses of dew. Many regions depend largely 
on it for the water for plants. Regions of heavy dews are usually fertile. regions, and do not find rain so necessary. In Gen. ii. 5 and 6, we read: "The Lord God had not caused it to rain upon the earth . . .; but there went up a mist from the earth and watered the whole face of the ground."

Dew can be best studied in spring or early summer, when its work, its value to plants and to man, and the beauty of its jewels glistening in the morning sun, can be seen and appreciated by the children.

\section{WATER JeWELS.}

"A million little diamonds

Twinkled on the trees;

And all the little maidens said,

'A jewel, if you please!'

But when they held their hand outstretched

To catch the diamonds gay,

A million little sunbeams came,

And stole them all away."

Mrs. M. I. Butts.

\section{Help One Another.}

" ' Help one another,' the dewdrop cried,

Seeing another drop close to its side;

' The warm south wind would dry me away,

And I should be gone ere noon to-day;

But I'll help you, and you help me,

And we'll make a brook and run to the sea.' ",

Rain. Formation. In the schoolroom; on the kitchen windows or walls on wash-day; in the sky. Conditions necessary, - evaporation from water or damp places; water dust and vapor in the air; cold to make it condense. Cold may be due to cold slate; cold window or walls; cold hills or mountains up or against which the moist air may blow; cold regions of the air high above the earth, into which water dust and vapor may rise; cold countries 
to which the warmer moist air may be carried by the winds. Each of these ways in which rain may be formed can be related to experiments on rain-making in the schoolroom. The little folks will not comprehend it all; but, if the work is based on actual experiments, on what they have seen, well directed and reviewed, they will have foundations for a clear understanding of the subject a year or two later in their geography work.

Falling. Try to watch and study with the children the falling of the rain: the home from which it comes, the dark clouds or the dull leaden sky; the way it comes to us, - steady or irregularly, fast or slow, straight down or oblique ; its helper, - the wind, and the way the wind drives the drops; the course it takes, - following branches and tree-trunks, dripping from the leaves, falling from the roofs, rushing through the gutters; the voices of the rain, - the patter on the window, the splashing in the pools, the clattering on the roof, the roaring down the gutter, the gurgling and gushing from the spout.

Work. Begin with what children can see. How it washes trees and plants and buildings. How it beats the ground, stirring mud and sand, and carrying them along. How it wears channels, making them deeper and wider. How it rushes along, always doing something, always seeking lower places where it may find the brook or river or lake. How it leaves much of its load when it enters a quiet pool, dropping stones and sand, and carrying the mud farther. How it sinks into the earth.

"Still the earth

Drinks the unstinted bounty of the clouds -

Drinks for her cottage wells, her woodland brooks -

Drinks for the springing trout, the toiling bee,

And brooding bird - drinks for her tender flowers,

Tall oaks, and all the herbage of the hills."

Bryant. 
Follow the rain in imagination into the earth. How it drives out the frost, softens the ground, moistens seeds and roots! How the seeds welcome it! How the roots drink it in! How soon the buds begin to grow! How the spring flowers waken, and stretch themselves, and push upward.

" The friendly clouds drop down spring violets, And summer columbines, and all the flowers That tuft the woodland floor, or overarch The streamlet: - spiky grass for genial June, Brown harvests for the waiting husbandman, And for the woods a deluge of fresh leaves."

Bryant.

Review story. Now, after the children have used their eyes, they are ready to follow the journey of the rain-drops, to become rain-drops themselves: to start in spring or brook or river or sea; listen to the call of the beckoning sunbeams; rise in their filmy vapor dresses to cloudland, vapor and water dust playing tag and hide-and-seek with one another; ride in the wind chariots; laugh at the sun; race and frolic until they see the thirsting ground, and hear the sleepy call of the seeds and buds; join hands, with the help of the cooling breezes, drop, gently, slowly, faster and faster, toward the welcoming earth; dance on the trees, scamper over the roofs, tumble along the ground; perhaps run and rush toward the brooks, to help them in their spring cleaning and freshening; perhaps sink into the ground, to help the flowers; perhaps rest quietly in some pool, or perch on the shoulders of some child, until called back toward the smiling sun; but singing, laughing, gurgling, always helping, always seeking the home from which they started.

Literature. An excellent review story entitled, "Aqua, the Water Baby" can be found in "The Story Hour" by Kate Douglas Wiggin. 
Helpful literature, parts of which even little folks in the first grade enjoy, can be found in -

"Shower and Flower." Lucy Larcom.

"Rain in Summer." Longfellow.

"A Rain Dream." Bryant.

The following poems are added, as they are excellent summaries of the work done:

\section{A Rhyme for a Rainy Day.}

"With pitter-patter, pitter-patter, on my window-pane, Tapped clipper little visitors, the tiny drops of rain ; They did not ask to enter, but in liquid tones I heard This story, which, as told to me, I tell you, word for word:

'Within a cool, deep well we lived, quite happy, side by side, Until an empty bucket came, and asked us out to ride ; Then springing in, away we went, drawn up into the air, And a pretty china pitcher stood waiting for us there.

Beneath that pitcher's brim we thought much happiness to see; But soon a lump of ice popped in, with whom we can't agree ; For though Ice claimed relationship before it married Frost, With such a hard, cold-hearted thing all sympathy was lost.

Ice tried to steal our heart away ; but Air was on our side, And when it felt how cold we were, it just sat down and cried. You might have seen the tears upon the pitcher where they pressed,

Till Ice itself was forced to melt, and mingle with the rest.

But next I have to tell you of a most amazing thing,Above a blazing fire we were made to sit and sing, Till Bubbles brought the message up, that Heat would set us free ; When, boiling hard, we just steamed off, and gained our liberty !

We bounded off with motion swift, but met a colder wind, Which blew so fast that everything grew cloudy to our mind. We cared not to go higher then, we felt a heavy chill, And down we came quite suddenly upon your window-sill.", 


\section{The Drop and the Cloud.}

"In a mountain spring, a crystal drop

Came trembling up to the glassy top : It came from the dark, cool depths of earth, And the sunlight kissed it at its birth.

Far up in the azure realms of sky The clouds of summer were sailing by ; And the little drop looked up and said, As it saw the glory overhead, ' Oh, would that to me the boon were given To move in the shining ranks of heaven!'

And oft again, in its downward course, As it hurried from its mountain source,A bubble, borne by the brimming brook To many a wild and shadowed nook, Or loitered slow with the wayward stream,It thought of its childhood's sky-born dream. But on and away the waters flow Through woodland and meadow far below, Over sandy plain and snowy bank, And through swamps and jungles dense and rank ; Imprisoned long within rocky walls, Now plunging down over dizzy falls, That turn the wheels of the busy mill, Now white with foam, now dark and still, Till at length a river, deep and wide, It flowed where cities stood by its side; And at last the river reached the sea, And the dream and the dreamer ceased to be. The drop was lost in the heaving deep Where all the rivers of earth must sleep.

But the sun that kissed the new-born drop, And whose floods of sunbeams never stop, Had not forgotten his little child, Born of a mist in the mountain wild ; And he loosed his threads of golden light, And up from a wave of snowy white 
The drop was lifted so tenderly

It never knew when it left the sea, But found itself drawn up to the sky, Afloat in the heavens, soft and high, As free as the winds of airy space, As fair as the morning's tender grace.

One tranquil eve, 'mid the purple ones . That shine in the light of setting suns, It saw far down on the distant earth The forest spring where it had its birth, And all of the winding way it went, With many a murmur of discontent ; And the early dream came back again, As the thoughts of youth come back to men : That thread of silver that ever turned Away from the skies for which it yearned, That wandering life of fall and foam That seemed to lead it away from home,It now could see was the very road That led it up to its blest abode."

L. D. Brewsier : St. Nicholas, April, 1883.

\section{THE UNITY OF NATURE.}

Have teacher and children gained something of this thought?

"Thus the Seer,

With vision clear,

Sees forms appear and disappear,

In the perpetual round of strange,

Mysterious change,

From birth to death, from death to birth,

From earth to heaven, from heaven to earth :

Till glimpses more sublime

Of things, unseen before,

Unto his wondering eyes reveal

The universe, as an immeasurable wheel

Turning forevermore

In the rapid rushing river of Time." 
THE WORK OF WATER IN SOIL-MAKING.

This topic forms an excellent transition to the spring plant work, a preparation for the observation of the work of rain and running water and an introduction to real earth study, or geography. . It can be best stried in March, April, or May.

\section{THE BREAKING OF ROCKS TO MAKE SOIL.}

Evidences. Rocks which are splitting or crumbling to pieces are usually not difficult to find at this season, in the fields or in old stone walls or foundations. Bring into schoolroom, and show that the rock is not everlasting.

After the children are thus shown what to look for, an out-door lesson may reveal many examples of "rotting" rock. Visit, if possible, a rocky cliff or a bluff, or a street cutting, or an old stone wall. . Note the cracks and holes through which water can enter. Often roots can be seen penetrating the rocks. Bring back to school the best, that is, the most "rotten," specimens.

Causes. Review, by an experiment if possible, what was learned about the expansion of water when it freezes. Show how water soaks into rocks such as slate, and even into those which seem solid, like the stone window ledges. When this water freezes what may it do? Jack Frost is the greatest agent in breaking up rocks, and in making the soil which the plants must have. Shall we complain if he cracks a few pitchers in which we have carelessly left water?

Some of the specimens may show how the frost is helped by the growth of the roots, which push into the cracks.

Show children the limestone incrustation from the teakettle which must have been lissolved in the water, and was deposited when the water evaporated. So water dissolves 
even rock a little. Show how muriatic acid (obtained from drug-store) placed in the water helps it dissolve such rocks as mortar, limestone, and marble. Most water in the ground contains a little acid. Many rocks, such as mortar, sandstone, and granite, consist of insoluble grains held together by parts which are soluble. When the latter dissolves, the other portions fall apart and make soil.

If the school is near a large body of water, with a pebbly beach, the children can easily see how the stones are rolled back and forth, and gradually worn into soil, by the waves.

\section{THE DECAY OF LEAVES TO MAKE SOIL.}

Evidences. This can be best seen after there have been some weeks of spring weather. Collect, or better, have the children collect, and bring to school, leaves or leaf mould in different stages of disintegration. Note their dampness, and the earthworms usually abundant among them. Collect also some leaves from dry places, which have not disintegrated.

Recall the story as studied last fall of the work of the leaves for the trees during the summer, of their coloring in the autumn to make the world beautiful, of their falling to cover the seeds and buds (and the baby earthworms) through the winter's cold. Now they have another work, - to make food, the very best food, for the plants' roots. They are changing into something which will be drawn in by the roots, travel up to the buds, and help to make new leaves and flowers and seeds.

Causes. Compare the wet and dry leaves. Compare the decayed leaves with those collected and pressed last fall. Surely water had much to do in turning the leaves into food for the plants. The earthworms helped by chewing them, and breaking them into pieces. 


\section{HOW THE CHILDREN STUDIED SOIL-MAKING.}

The following account, written by Mrs. C. L. Place, then teacher of geography at the Teachers' Training School at St. Paul, Minn., will show how one teacher conducted a field lesson.

"The children of the second grade had watched the opening of the buds, and had talked of the beauty and use of the leaves whose growth they were watching, when the question arose as to what became of the leaves after they fell from the trees. Their teacher said they should go with her next day, and find out for themselves.

That night each child took home a little note, asking if he might go with his class to the river for a field lesson; and at the time for opening school the next afternoon, the whole class boarded the street-car.

After a half hour's ride, the point was reached where the teacher had found the conditions favorable for the lesson on the formation of soils. Down to a grove at the foot of the bluffs the class went, and at once the dead fallen leaves attracted the children's notice. The teacher's only directions were to dig, and as soon as anyone thought he had found the answer to whisper it to her; on no account was he to tell anyone else what he thought he had discovered.

Like little beavers, too busy to think of running off to play, they digged. Then one after another, with a cry of delight, ran to whisper to the teacher. She went from group to group, directing this one to a better place to dig, encouraging that one by telling him that his answer was in plain sight; and after about fifteen minutes of hard working and thinking, every child had discovered for himself, and had told the teacher, that the leaves 'broke all up, and mixed with the sand, and made dirt.'

Into each basket was put a bit of loam in process of making, to prove to parents the new-found fact. Then the children were led along the foot of the bluff, talking of the strange fact, until the sand attracted their attention. The teacher said, 'I wonder where the sandy soil comes from;' and as she spoke she picked up a piece of the soft sandstone, and crumbled it in her fingers. Instantly the answer came, 'Why, the rocks crumble and make it.' A little farther on the eager scientists came upon a pile of clay soil, with limestone bits at the foot of limestone cliffs. One child said, 'Here is 
another kind of soil.' - 'Yes, clay. I'wonder if we can find how this is made.' A glance up the cliff, and more quickly, because of the discovery regarding the sand, the children told this story. As they climbed the bluffs their attention was called to the condition of the rocks near the top; and the children described just how they were constantly breaking off, and tumbling to pieces at the foot, split up by water and Jack Frost.

The next day their pieces of rock and samples of soils furnished the text of an enthusiastic recitation, after which they wrote interesting and thoroughly individual accounts of their trip, which was not a picnic, but a live, earnest lesson."

\section{THE WORK OF RAIN AND OF RUNNING WATER.}

Our children have learned of the value of water in their homes and in the air and sky. Perhaps they have discovered how water and frost make the soil, by breaking up the rocks, and hastening the decay of the leaves. Water is also the greatest agent in shaping the earth, in carving its hills, and in digging its valleys. Cannot we give the boys and girls in the upper primary grades some idea of what water is doing on and in the ground, and how it is doing it, and thereby lay further foundations for real earth study when they reach the geography work in later years?

In no one line of work is there greater need and opportunity for out-of-door study than in geography, and probably no season is better for this than April and May. The soil is in a condition to be easily affected by the spring rains, and the erosive forces at work, and the effect of these forces, can be seen almost anywhere. These excursions need not be to any great distance; often a trip of a block or two will bring the party to a hill or valley or brook, a cut or ditch or mud-puddle, affording excellent opportunities for the study of the action of water in erosion, transportation, and deposit.

The boys and girls in the elementary schools, and particularly in the lower grades, will have their geographical 
concepts made much clearer and broader. They will have a better understanding of the forms of land and water, and a much better conception of the earth as a thing of change and development, and of the forces producing these changes. Each ravine and valley, the brook meandering through the plain, even the little stream or pool or mud-puddle formed by the spring rains, will be, not an isolated fact, a mere "what," but, to the observant out-of-door pupil, will become part of a great whole, will constantly suggest the questions "why?" and "how?" and will be a story full of interest and value.

\section{SUGGESTIONS FOR THE STUDY OF THE WORK OF RAIN.}

Visit after a rain-storm a bank or cut where the soil is sandy or loose. If possible have some of the children watch the rain at work, so that they can tell what it has done and how it has done it. The action of the rain may be imitated by pouring water from a watering-pot slowly down the bank or incline.

In what kinds of soil are the deeper furrows made by the rain streams (rills)? Why? Are the deepest furrows made where the bank is steep, or where it is more nearly horizontal? Why? What kinds or sizes of soil or other material are carried farthest by these rills, the fine or the coarse? Why? What kind or size of material is moved the least? Why? Are the furrows straight or winding? Why? When the furrows open into a little pool, what kind or size of material is deposited near the edge of the pool? What material is carried into the deeper parts of the pool? Why? After a rain, what makes the water in the pool "muddy"? As the pool dries up, what kind of soil covers the surface where the pool has been? Why is it covered with fine mud? What kind of soil do you find under the mud near the edge of the pond? Why? 
THE WORK OF STREAMS.

A visit to a brook, to observe the work of streams in wearing away, carrying, and depositing material, will supplement the rain study. Observe such points as the following:

The velocity of the current. Swiftest in level or "steep" parts of the stream? In the middle, or at the sides? On the outside of a curve, or the inside? In narrow or wide places? In shallow or deep places? Why? Compare water in a curve to a wheel going around. Which part goes most rapidly, the hub or the tire? How does the velocity affect the power the stream has of wearing away the earth, and of carrying along mud, sand, or stones? Experiment and see.

The wearing away, or erosion, by the stream. Show how it wears away deposits of soil placed in it. Where does the strean wear most, on the outside or inside of curves? Why? In what kind of soil does it wear most rapidly? What makes the stream wind about so?

The carrying or transportation by the stream. Throw in soil containing mud, sand, pebbles. Which drops first? Which is carried farthest? Show by experiment differences in carrying-power in slow-flowing and swift-flowing parts of the stream. Narrow or partly fill a portion of stream, so as to increase its velocity, and note result on the character of the bottom. Note appearance of bottom in swift and slow parts of stream. The former is usually sandy or stony, the latter muddy. Why?

The deposits by the streams. Where, how, and why bars, islands, points, and shallows are formed.

What the stream is making. Try to find illustrations on a small scale, and to describe or define and explain the 
formation of brook-basins, valleys, hills, slopes, plains, points, deltas, bars, islands, rapids, straits, bays, shallows.

Important points to impress.

The stream, like the water in the air, is always at work.

The stream picks up, carries along, and drops mud, sand, stones.

The swifter the stream, the more work it does.

The less room the stream has, the swifter it is.

The finer and lighter the soil, the more easily it is picked up and carried along.

The stream cuts its own path, and makes the path change and curve or wind.

It makes its own bars and islands and points.

It may make its own valley if it has time enough.

Streams have dug many valleys, little and great, and left the hills standing between them.

Water has made the country look as it does.

Water has given the country most of its beauty.

Literature. The following bring out something of the work of streams, and may help to make streams mean more to the children than "bodies of water flowing through the land."

"The Brooklet and the Wave." Longfellow.

"To my Brooklet." Longfellow.

"Mad River." Longfellow.

"The Boy and the Brook." Longfellow.

"Songo River." Longfellow.

"Friend Brook." Lucy Larcom.

"The Rivulet." Lucy Larcom.

"The Brook that ran into the Sea." Lucy Larcom.

"Rock and Rill." Lucy Larcom.

"The Brook." Tennyson. 


\section{SPRING NATURE STUDY.}

\section{AIMS AND OPPORTUNITIES. A LOOK AHEAD.}

THe best season for beginning or emphasizing nature study is the spring. Nature then attracts the attention of the least observant, invites the least interested. Even those who are almost nature-blind at other seasons notice the evidences of renewed life in the spring, - the developing seed, bud, leaf, and flower, the return of the birds, the activity of rain and stream.

We have agreed that in nature study, as, indeed, in all education, the first essential is to interest the children. In spring, if at no other time, they are interested, deeply, intensely interested.

At this season none of them need be urged to use their eyes. They do need to be directed, inspired, helped to carefully observe and study, not merely glance at, the beauties of nature, and lifted up to discover the lessons which nature teaches.

A great advantage in the spring is the abundance of material; plants are particularly good, because the material is usually so abundant that there is opportunity for individual study by each pupil. The pupils of even the most shut-in and unenlightened (by sunlight) city schools can plant seeds, and study germination, and can usually get a few branches or even weeds, to watch the development of buds or the protection and unfolding of leaves.

In the spring there is greater opportunity for the study of life; and children are interested in life, development, and 
growth. From their very nature they are most attracted by that which is most thoroughly alive. When does nature so throb and pulsate with life as in spring days? We can fairly see the plants grow. The birds bubble over with the joy of living.

Our little children must study, before all else, life, development, and function or use. It is more interesting. It is better adapted to their nature. It develops a sympathy and love for nature. It leads the children to think, as well as to see, to ask " why " and " how," as well as "what." It is the best possible preparation for the subsequent study of form, structure, and classification.

We have agreed that when we have interested our children in nature we want to develop a sympathy and love for nature. Can we sympathize with a form? Can we love a mere structure? Can our children?

Let us understand, then, that in our spring work with our boys and girls, we are going to study life, not mere form, use, or function, not mere structure. We will see how the buds develop, not merely tear them apart. We will watch the seed germinate, and form root and stem and leaf and flower. We will peer into the cradle of the baby leaf, watch it creep out and get ready for work, try to understand a little about its work and the ways in which it is fitted to do its work. We will see how and why the plant so carefully guards the flower, and learn something as to the work of the flower.

\section{PREPARING FOR SPRING.}

"Ah, March ! we know thou art

Kind-hearted, spite of ugly looks and threats, And, out-of-sight, art nursing April's violets."

H. H.

March is the month when we must lay or strengthen our foundations, and make preparation for later work in nature 
study. In April and May and June nature brings so much before our eyes that we scarcely know what to select from the riches bestowed upon us. In March we get only glimpses of what is to come.

It behooves us as teachers to so prepare ourselves and our pupils during this month connecting winter and spring, that, when the plants and animals finally arouse themselves, we may all see and fecl and enjoy and appreciate, and to some extent understand or comprehend.

If we leave the spring work until April we will be sure to find ourselves behind Mother Nature, and will get more and more behind as spring hurries away before the summer.

How can we lay the foundation for the work of the next three months? By studying, with our boys and girls, that from which and through which spring comes, investigating the very beginnings in the annual awakening. March forms the background which brings into sharper relief the life and thought and beauty of the months that succeed her.

How shall we prepare for spring? By absorbing, cultivating, inspiring, instilling in ourselves and in our pupils, just as much of the spirit of spring as we and they can take in. After all, spring will be to you and me what you and I make of it. We will not thoroughly enjoy and appreciate this season of awakenings, and we certainly cannot lead our children to get the most out of this brightest volume in the year-book of nature, unless we have spring in our hearts.

Why not begin, on one of these wintry days in early March, with a talk on winter, a talk not to the children, but with the children? Do we like winter? Why? Write on the blackboard a list of all the reasons why we enjoy winter. Do some of the children hate (to express it as the children are apt to do) this season of cold and snow? Why? Are we tired of winter? Why? Make another list.

Show how helpful to man winter is, how necessary is the 
cold and the ice and the snow, or the rain, which this season brings; how the chilly winds carry snow and rain where they are most needed; how the ice wedges break up the soil for the farmer, and the rain and snow prepare the ground for the spring; how the cold invigorates us, and the wind brings us pure air.

Have a reading lesson on the blackboard, or have the children write about, "Why We Like Winter," or "How the Winter Helps Us."

We can have one or more lessons leading the children to think and talk (with the thinking first) about the use of winter to the plants. Perhaps we can begin with the use of sleep to the children or the reason for having vacations. On these topics the smallest "tot" will have ideas, or apperceiving concepts as the psychologists like to call them, on which many new ideas can be based or built. Think of the winter as the season when plants, and many or most animals, sleep and rest, and gain strength and vigor for another year's work.

Talk about the preparation of plants for the winter: the falling of leaves, development and protection of buds (show branches with buds, as they have spent the winter); the disappearances of parts above ground, in grasses, bulbs, and similar plants, and the storing up of nourishment in parts below ground; the formation of seeds by plants which are killed each autumn by the cold. Show how the wind has scattered the leaves, and brought the snow to serve as a cover and protection, and how Mother Nature has given a thick bark to the trees and other plants which grow above the snow.

Read to and with the children the poem below. Try to get, to absorb and express, and impart to the children, the spirit of the poem. 
Talking in Their Sleep.

“' 'You think I'm dead,'

The apple tree said,

'Because I have never a leaf to show,

Because I stoop,

And my branches droop,

And the dull gray mosses over me grow!

But I'm all alive in trunk and shoot;

The buds of next May

I fold away-

But I pity the withered grass at my root.'

'You think I'm dead,'

The quick grass said,

'Because I have parted with stem and blade !

But under the ground

I am safe and sound

With the snow's thick blanket over me laid,

I'm all alive and ready to shoot.

Should the spring of the year

Come dancing here-

But I pity the flowers without branch or root.'

'Y.ou think I'm dead,'

A soft voice said,

' Because not a branch or root I own.

I never have died,

But close I hide

In a plumy seed that the wind has sown,

Patient I wait through the long winter hours ;

You will see me again-

I shall laugh at you then,

Out of the eyes of a hundred flowers.' ",

Edith M. Thомas in St. Nicholas.

-We are ready now for some real science, real observation as distinguished from talking. What we have had is nature study; but our scientific friends will not let us call it science because - they will tell us - there is too much poetry and 
Imagination about it. But it is from and through just such work that science has developed through the centuries, and Nature (by which we mean the Author of Nature) has endowed our little folks with an appreciation and love of poetry and a rich store of imagination. If our work conforms somewhat to the development of the race and to the nature of the child, we are not apt to go very far wrong. We are trying to train and develop and enrich and broaden the minds of our children, not merely to make scientists.

The study of the spring awakening is, to the children at least, who have not lost the seeing eye, the hearing ear, the understanding heart, a study of protection and care. The buds are exquisite lessons, wonderful stories, of protection from storm and cold. The seeds tell of care, of preparation months before for the growth of the baby plant. Every young leaf, wrapped about and within its fellow, protects, and is protected. Every flower but lives to care for and ripen the seeds hidden far within. What better nature thought can we give our children? What better means of impressing this thought than bud and seed, leaf and flower?

This thought of protection appeals most strongly to the little ones. A little later, as they see how bud and scale and leaf are each in place, how the flowers and the parts of the flower are planned, the lessons of order and plan and purpose will begin to dawn on them.

Our boys and girls who are watching the buds unfold are absorbing unconsciously, with the thoughts of care and order, another lesson scarcely less important. They are peering into the beginnings, and gaining the thought of development.

Hereafter is that bud so likely to be to them "only a bud"? or will they begin to see the future stored up in it? May the bud not lead some of them to realize the impor- 
tance of the beginning in which for them lies the future? May it not be the little leaven which may impress the idea of growth, development, evolution, the great thought in the education and life of to-day? Don't preach. Let the bud do it. Some may hear.

Shall we stop here? Can we stop here? To the child, as to the poet, the book of nature is a revelation. To the child - just from home and mother - protection without a protector is inconceivable, is beyond his experience. In guiding him in his study of this other divine book, shall we sharpen his spiritual as well as his mental vision? Can we, as true teachers, do less? Or shall we, through the lessons of protection and care, lift him to a Protector and Carer, through order and plan and purpose lead him to a Planner?

Cannot we begin our spring study with the thought from Tennyson, with which we began our study of the dandelion in Chapter I. of this book?

"Flower in the crannied wall,

I pluck you out of the crannies ; -

Hold you here, root and all, in my hand,

Little flower - but if I could understand

What you are, root and all, and all in all,

I should know what God and man is." m

SPRING NOTES.

Now that we have our background, we can turn from winter, and look toward spring. Have the children gather and record spring notes. If they cannot write, they can report from day to day orally; and their best discoveries can be recorded by the teacher, and form a basis for reading lessons, or can be preserved on the blackboard. If they write, camnot they keep a diary, recording - always in the first person - what signs of spring each sees from 
day to day? Do not be too critical about spelling. The interest and idea are most important. Encourage them to sketch or draw, however crude the results may be. Urge careful observation. Discourage guessing. Inspire a little rivalry in making new discoveries. In case of dispute, make them settle it by looking again. Do not decide for them, and thus deaden interest. Insist that they be sure, as sure as little folks can be. They are apt to see scores of bluebirds and robins before their teacher can discover one. They are not necessarily telling untruths. If the teacher has, as she should do, aroused a spirit of expectancy, their imagination may be quicker than their eyes. It is our work not to deaden their imagination, but to develop their senses, and cultivate a habit of using and trusting their senses, that they may form a basis for and develop what we call the scientific imagination.

The record of a few actual observations made in the spring of 1899, which is given below, may be suggestive.

\section{Our Spring Calendar.}

March 15. Jennie says she saw some pussy willow-buds yesterday, and that the pussies were just peeping out. Her brother brought them from the woods back of the fair-ground. So spring must be coming.

March 16. Jennie brought some of the pussies to school, so that we could all see them. She says they have been in the house two days. Some of the pussies are "way out" now.

March 17. Harry picked some "pussies" this morning, and brought them to school. The fur is about half-way out. Tom says he saw a whole lot of crows. His papa said that is a sign of spring. He says a few crows stay here all winter, but not so many.

March 20. It is so cold this morning that it seems like winter. The pussies must be cold. But they have such warm coats. One of the boys says he saw a robin. But he is not sure how a robin looks. So we will not put it in our calendar as a "sure" story. March 31. It is ręal warm to-day. We do not need mittens on our hands. So winter must be going away. Eleanor says she saw 
a robin to-day. It was in the top of a tree, and it flew away. Her papa saw it first, then she saw it. She knew it was a robin because she saw its red breast. Her papa said it sang like a robin. It said "Cheer up, cheer up."

Edward saw a woodpecker. He was not sure it was a woodpecker, but his father said it was. It had some red on its head and some stripes along its back.

April 3. Eleanor saw two robins this morning. She looked out of the window when she got up, and she saw them in the cherry tree. She saw their red breasts.

April 5. Jack saw a bluebird to-day. It was in the top of $\ell$ tree. He says it had a blue back and its breast was dark. Miss Grey says the bluebird has a brown breast. Jack says it had such a sweet song. He cannot tell how it sounded. "It was something like a whistle.

Harry found some horse-chestnuts which were beginning to grow. He brought two to school for us to see. The shell was cracked. Each horse-chestnut had a little point which was growing out through a hole in the shell. The horse-chestnuts know that spring is coming.

Jennie says the peony-plants in her yard are coming out of the ground. They are light green. They are as high as her thumb is long.

With older children there may be a "Bird Calendar," recording the arrival and doings of the birds, or a "Tree Calendar," telling about the changes in two or three trees near the school, or a "Flower Calendar," with a record of the first finding of the spring flowers. The record may be in charge of two or three pupils, supervised, of course, by the teacher.

Be ready with something bringing in the "spirit of spring." Sing about spring in the opening exercises. When several pupils report the. first bluebird, read with them something like the lines below.

\section{The Bluebird.}

"I know the song that the bluebird is singing Out in the apple tree where he is swinging. 
Brave little fellow! the skies may be dreary, Nothing cares he while his heart is so cheery. Hark! how the music leaps out from his throat! Hark! was there ever so merry a note?

Listen awhile, and you'll hear what he's saying Up in the apple tree swinging and swaying, 'Dear little blossoms down under the snow, You must be weary of winter, I know ; Hark while I sing you a message of cheer ; Summer is coming, and springtime is here. Little white snowdrop! I pray you arise; Bright yellow crocus! come open your eyes ; Sweet little violets hid from the cold, Put on your mantles of purple and gold ; Daffodils! daffodils! say, do you hear? Summer is coming and springtime is here.' "

Author not known.

Write part of it on the blackboard, and have children copy it for their writing-lesson. Let some or all commit it to memory. Continue the spring notes as long as the children are interested. They may be varied by having the class together make a little book, to be hung on the wall, recording the discoveries of a week or two, each pupil contributing a leaf with his own observations, written in his - not the teacher's - best style, and, when possible, illustrated.

\section{INDIVIDUAL SPRING NOTES. PAPERS BY CHILDREN.}

The boys and girls in the third grade may keep individual "spring notes," in place of the "Spring Calendar," recording the observations of the class, or, better, supplementing that record. In the writer's experience even second-grade pupils - or many of them - have kept such individual spring notes with excellent results.

The following papers are given, just as written by the children, but with errors in spelling and capitals corrected, to illustrate how some of these notes have been kept. 
Where two papers are given under one title, the two were written by pupils in the same room at the same time. They are given to show the possibility of individual work, even with young children.

\section{Signs of SpRing.}

"It is coming spring. I have seen robins in the trees. The flowers are coming up from the garden. There are crocuses in the garden. Spring is coming, for I saw a robin. I saw two robins up in the trees. I saw pussy willows. I got some sap in a bottle. I saw some white maple sap flowing from the trees. I saw a pussy willow bud taking off its brown coat. I saw a crow to-day. I saw ar maple tree down by my house growing. I saw a baby beach-bud opening (?) I saw a black crow in the air. I saw two crows. I saw a robin singing."

\section{Charlie Mimmack.}

"I saw a robin. The robin had a red breast. I know that spring is coming for the crows are out. The pussy willow buds are out too. The maple trees' buds are opening too. I saw some sap flowing from a maple tree. The pear buds are opening too. The crows are black. They are flying all around."

Oswego, March 14, 1898. LEON Brown, Second Grade, Practice School.

\section{How I Know Spring is Here.}

"I know spring is here, because I saw a baby daffodil all in bloom and the air smells sweet and I saw a robin. I knew it was a robin because it had a golden breast and I knew it by its song and I tapped a maple tree and tasted the sap. The pussy willows are most all out. I saw a crocus and hyacinth in the garden."

Carrie R. Coleman, Oswego, March 22, 1898. Second Grade, Practice School.

\section{Spring Notes.}

"I was going down the shop yard. I saw some pussy willows and some crocuses. I noticed that the rose bushes are green. I saw some acorns half way in the ground beginning to grow. I noticed that the weeds are beginning to grow in the sand. And I saw that the moss was growing on the bank.

"When I was going to school this morning I saw a robin. I no- 
ticed that the grass is getting green. I saw a chicken hawk. I noticed a little girl planting some seeds. I noticed that the days are longer. I noticed some cows eating grass. I saw a man take off the storm windows and the storm doors. I saw some chickens digging in the ground for worms.

"I noticed that the trees have buds on them. I saw some lilies coming up from the ground. I noticed some long pussy willows. Their color was pink. I saw some birds and two doves. I noticed a boy plant some flowers in his pots. We planted some seeds. I noticed that the water is all going away and the mud is drying up."

Annie Kovec,

St. Paul, Minn., Aprit, 1893. Third Grade, Adams School.

\section{WORK FOR MARCH.}

TREE STUDY.

Value as an introduction to bud study. The only logical way to begin bud study is to become familiar with the trees or shrubs of which the buds are a part. If the little folks in the first grade can begin their study of the lilac buds by getting a fair idea of the particular lilac bush from which their buds, or part of them, come - can visit it, if possible - they have a centre to which to relate all that they observe about the lilac buds. If they not merely watch the buds develop in the schoolroom, until the leaves unfold, but continue their observation of the lilac bush during the spring months, see the lengthening of the leafy branch formed from each bud and the growth of its leaves, note the first appearance of the little flower cluster, looking like a minute bunch of grapes, and study its changes until the flowers unfold, fade, drop off, and disclose the little green nut-like seed-cases, - always relating each step to what has been learned before, - they will not merely understand about the buds and all that come from them, but will have a connected, more or less unified idea of the life history of the lilac. This will be more nearly complete if the obser- 
vations on the lilac are continued in the fall, until new buds are formed, and the leaves drop off, thus completing the cycle of development.

Value in unifying all plant study. Frequently teachers and children study, in their spring plant work, the buds of some plants, the leaves of others, and the flowers of others. In the fall they may study seeds and fruits which have no relation to the spring work. If they can begin in March or April with two or more trees or shrubs or even herbs, such as house-plants or garden-plants or common weeds, and watch their development until the close of the school year (sometimes continuing the work in the fall), all parts of the plant study become correlated and unified; the children do not think of leaves merely as leaves, or of flowers as flowers, but of all as parts of the plant, all with a common origin, all working together. The study of germination, watching the development of a seed until it forms seeds, is also a great aid in continuity of thought and in securing unity in the plant work. While it is best to study the whole development of some buds, it is interesting and helpful to observe stages in the development of others, to impress certain thoughts, or illustrate certain phases of plant life. The early stages of the pussy willow show protection, and the early stages of the elder bud show clearly order and plan. It may be well to study these, even if their later development cannot be observed.

Value from esthetic and economic point of view. Trees have a rich esthetic content; their value as ornaments and educators in our cities is more and more recognized. Nothing else in the plant world compares with our trees in their grandeur. How much we can add to the lives of our pupils if we ean help them to appreciate and enjoy trees! Trees have ever appealed to nature lovers. They have a 
rich literature and art, for an appreciation of which tree study is the best preparation. Americans are understanding better, as the years pass, the economic value of trees. Nature study should lead and prepare our children to cherish and better care for our trees.

What trees give to us. As our children study the tree as a form, and learn the features by which they can recognize it, they must also think of it as a life adding much to our lives.

As we prepare them for a field study of some tree, or as we stand with them about the tree, cannot we give breadth to their thoughts, give a larger outlook or uplook by reading to them or discussing with them thoughts like these?-

\section{"What plant we in this apple tree?}

Buds, which the breath of summer days

Shall lengthen into leafy sprays ;

Boughs, where the thrush, ${ }^{1}$ with crimson breast,

Shall haunt and sing and hide her nest;

We plant upon the summer lea

A shadow for the noontide hour,

A shelter from the summer shower,

When we plant the apple tree."

\section{Bryant.}

If a maple is selected for study, break a twig or puncture the bark a day or two beforehand, so that the children can see the flow of the sap. Then tell them something of the use man makes of the sap of the sugar maple. If the elm or oak is observed, introduce the study by telling some story associated with an historic elm or oak. Associate the evergreen with Christmas and the chestnut or hickory with the nuts we - and the squirrels - gathered last fall, and enjoyed during the winter. The bare branches of the fruit tree mean so much more when the children's fancy 
can see the fruit which hung from them last year. Give the tree a " human interest."

Aids in tree study. Very helpful in recognizing our trees are the excellent photographs, showing the whole tree in foliage and the details of bark and leaf, published by the Forest Tree Photo-Reproduction Co., Chicago. The writer has found the following books most generally helpful to teachers in their tree study:

Flagg's "A Year among the Trees." Educational Publishing Co.

Matthews's “Trees by their Leaves." D. Appleton \& Co.

Newell's “Lessons in Botany, Part II." Ginn \& Co.

The first is an introduction to trees, an aid in understanding and appreciating the beauty of trees, and the greatness of man's indebtedness to them. The titles of a few sections - "Autumn Woods," "The Colors of Trees," "Trees in Poetry" - will indicate the character of the book.

The second book, while written by a tree lover, and not a mere classifier and labeller, and containing much which may lead to a fuller enjoyment of our forests, is particularly helpful in identifying trees by their leaves.

Miss Newell's book has excellent descriptions and illustrations of the flowers and fruit of our most common shade and fruit trees, - with much other matter on common "Flowers and Fruits," - written with special reference to the needs of teachers. Seven years' use has proven its value to teachers.

Plan and order of study. Select two or more trees or shrubs near the school. Two or three are better than one, because the children can compare and contrast them, thus 
fixing their distinctive characteristics. Always centre the work about one tree or shrub, observing that as carefully as possible, using the others for contrast. For the little folks in the first grade, a shrub like the lilac, or a small tree, is better than a large tree. A great tree is a great mass for little eyes to see, and a great unit for little minds to comprehend as a unit. After they have watched the development of a seed into a plant, with root, stems, leaves, flowers, and fruit, they may be better able to grasp the idea of the oneness of the great tree. Then, too, the little folks can more easily watch the development of a shrub or of a small tree.

Select a tree standing alone, as much as possible, and one fairly typical. Begin with the tree or shrub in the winter state, when there are no leaves to distract the attention from the plan, and try to observe it first at a distance, a hundred feet or more, where the children cannot see the details of bark or buds. Note its shape or outline, if this is characteristic, not merely accidental (have children trace it in the air with their finger), vase-shaped or umbrellashaped in the elm, egg-shaped in most maples, cone-shaped in most evergreens, narrow cylindrical or "pencil-shaped" in the Lombardy poplar. Impress shape by contrasting with other trees in sight. Observe comparative height of trunk and character of branching; trunk extending to top with branches horizontal, longest below, in the cone-shaped evergreens; in the elm the trunk soon lost in branches, which fork or bifurcate again and again, curving outward and downward, and bearing much fine spray; in the maples the trunk extending up one-third to two-thirds of the length of the tree (longest in young trees), with lower branches often nearly horizontal (unless the tree has been "trimmed up"), and upper branches more and more nearly vertical (the branching varying somewhat in different species of 
maple); in the horse-chestnut the form usually somewhat egg-shaped, with the branching varying greatly. The lilac seems to have no definite form and no plan of branching.

Going nearer to the tree, observe the bark, - its color on trunk, branches, and twigs (silvery gray or ash-colored, dark or slate-colored, brown, green, etc.); its smoothness or roughness, and the way in which it cracks or splits (finely or coarsely, vertically, horizontally, or diagonally, with the pieces between the cracks remaining flat or curling at the sides or ends); and the similarities or differences between bark on trunk, on branches, and on twigs. .

Note also characteristics of buds, - position (at end of branches or on side); arrangement (in pairs - called opposite, or one at a place - called alternate); size and shape (large, small, fleshy, slender, round, flat); color and covering, if at all marked or characteristic.

Adapting work to children. No primary teacher will ask or expect her pupils to observe or remember all these features about any one tree. She will select and impress those most characteristic, the number noted largely depending on the age of the children. The little folks in the first grade can learn to recognize the elm tree in the winter state by its vase or umbrella shape, its branches corresponding to the ribs of the umbrella, and by the amount of fine, drooping spray. The horse-chestnut they can tell by its thick branches and very large sticky brown buds on the ends of the twigs. Even the little kindergarten children can tell evergreens by their color, their conical shape, and their trunk extending to the top of the tree, and can distinguish the pine by its long needles, two or three or five together, and the hemlock by its short, flat leaves, silvery beneath. These same little folks may observe other features of the same trees later in the spring, one or two at a 
time. Older primary children may note and remember a larger number of characteristics. Children do not distinguish their playmates merely by one feature, - the form of their noses or the color of their eyes, - but by many features in combination. If we can train them to know trees, not by one feature, such as leaves, but by many, and to ana-

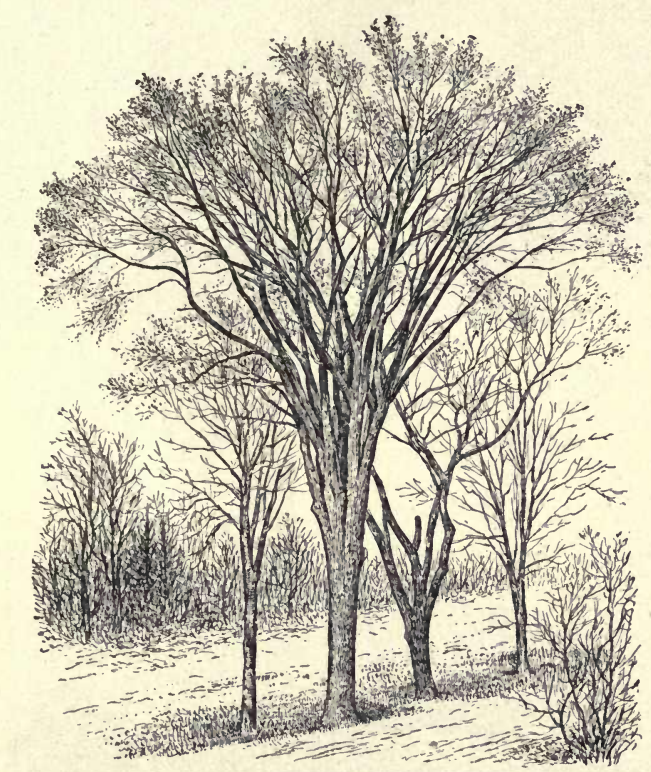

Fig. 58. American or White Elm.

lyze their knowledge so that they can tell how and why they know each tree or plant, much will be gained.

As the trees develop, and leaves, flowers, and fruit appear, the children should discover new characteristies, and relate them to what they have already learned, so that the idea or concept or general notion elm tree, or maple, or lilac bush, comes to have a larger and larger content. 
DISTINCTIVE CHARACTERISTICS ${ }^{1}$ OF COMMON TREES.

The trees named and illustrated include the most common and typical trees in northern and eastern United States. American Elm. (See Fig. 58.) Vase shaped or parasol or umbrella shaped. Trunk divides into two branches, and

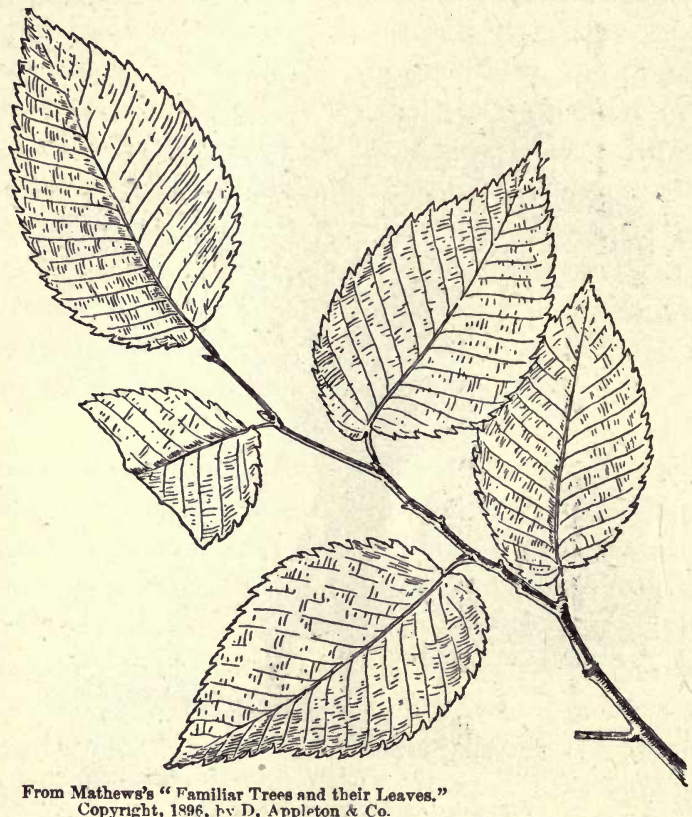

Fig. 59. Leaves of American or White Elm.

each branch forks or bifurcates (usually) several times. Bark rough on trunk and branches, smooth on twigs. Twigs, buds, and leaves alternating in two rows along opposite sides of branch (alternate, two-ranked). Leaves as in Fig. 5\%.

1 These are the characteristics of mature trees standing where they have had room to develop normally. Young trees, and trees crowded together, may not show the same outline or general plan of branching. 

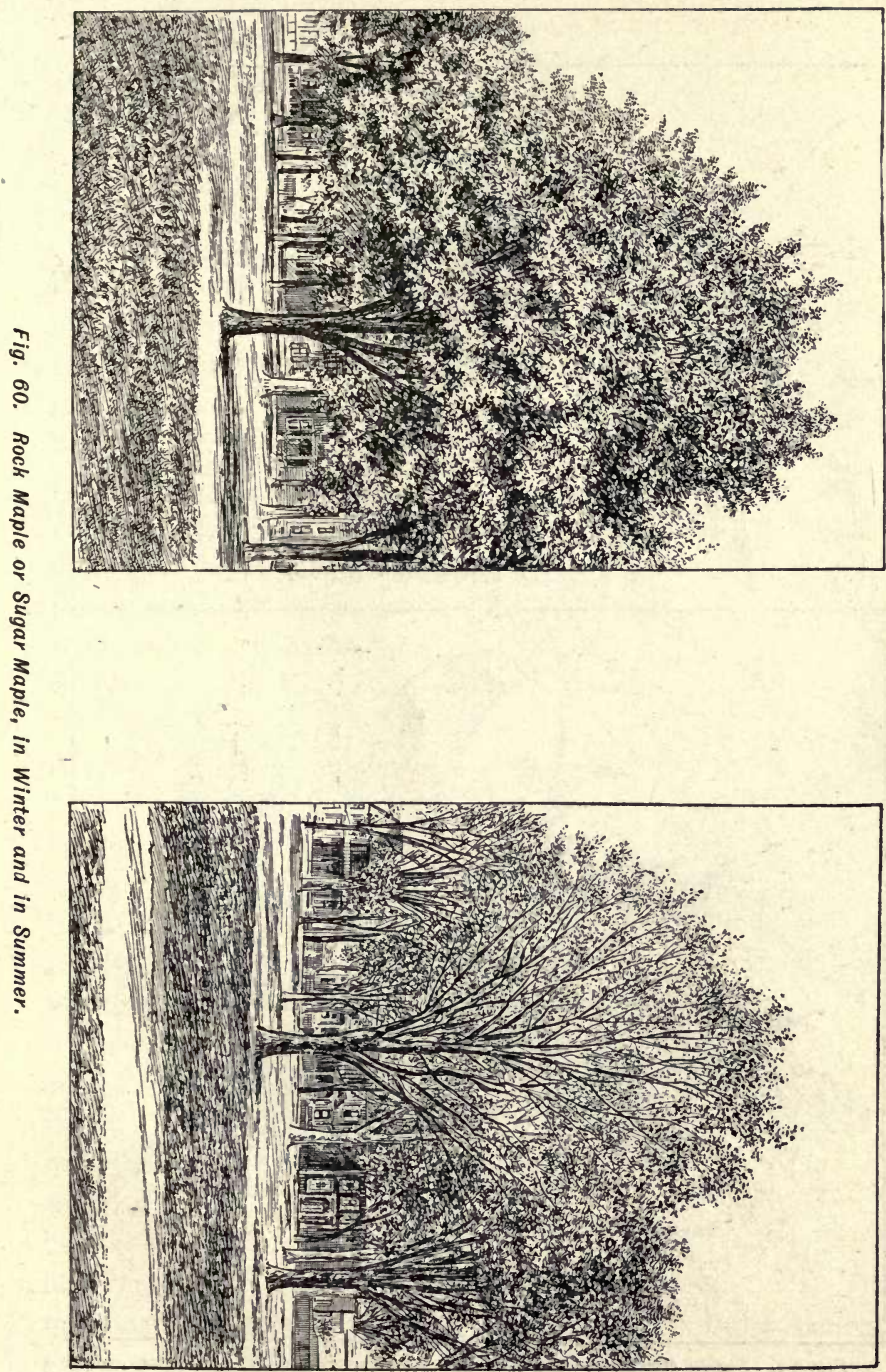


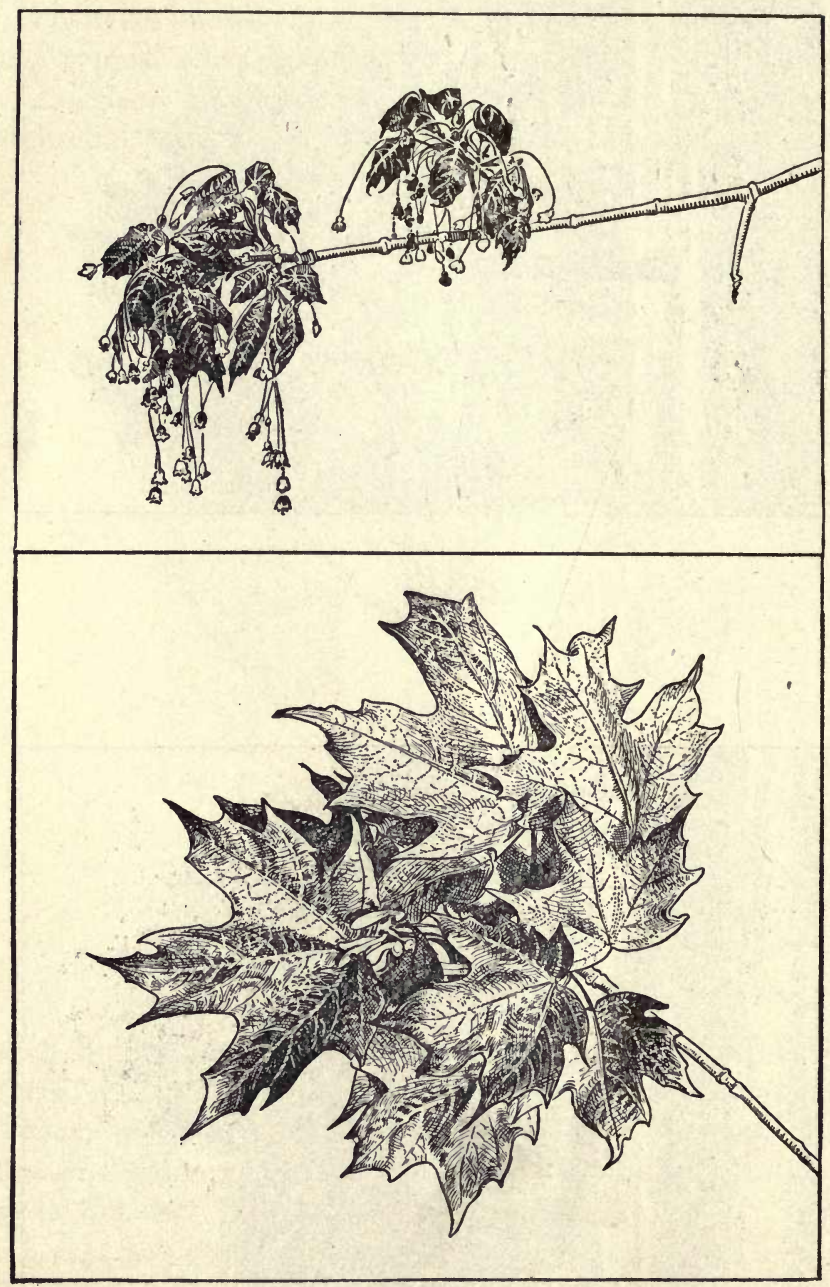

Fig. 61. Sugar Maple: Flowers, Fruit, Leaves, and Leaf Development. 
Rock or Sugar Maple. (See Fig. 60.) Ovoid or egg shaped. Trunk extending one third to onehalf the height of tree. Lower branches nearly horizontal, upper branches more and more nearly vertical. Bark rough on trunk and on largest branches. Twigs, buds, and leaves in pairs (opposite). Leaves and flowers as in Fig. 61.

White or Silver Leafed Maple. Form a longer or higher ovoid. Outline more ragged or irregular than in sugar maple because of projecting branches. B r a n e hes more numerous. Bark with wider strips on trunk, smooth and light gray

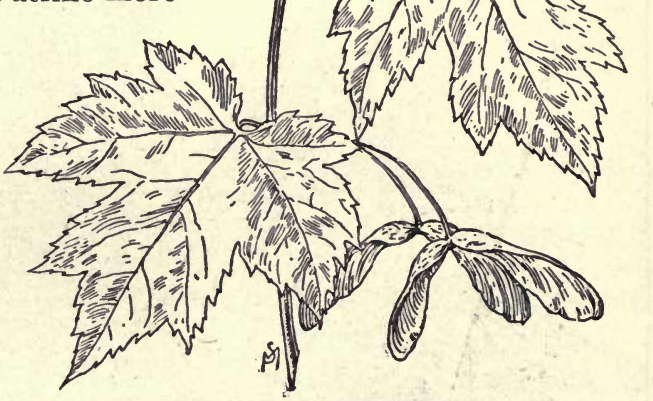
From Mathews's "Familinr Trees and their Lesves," Copyrijht, 1896, by D. Appleton .. Co.

Fig. 62. White or Silver Maple. on most branches. Leaves as in Fig. 62, light beneath. Otherwise resembling sugar or rock maple. 

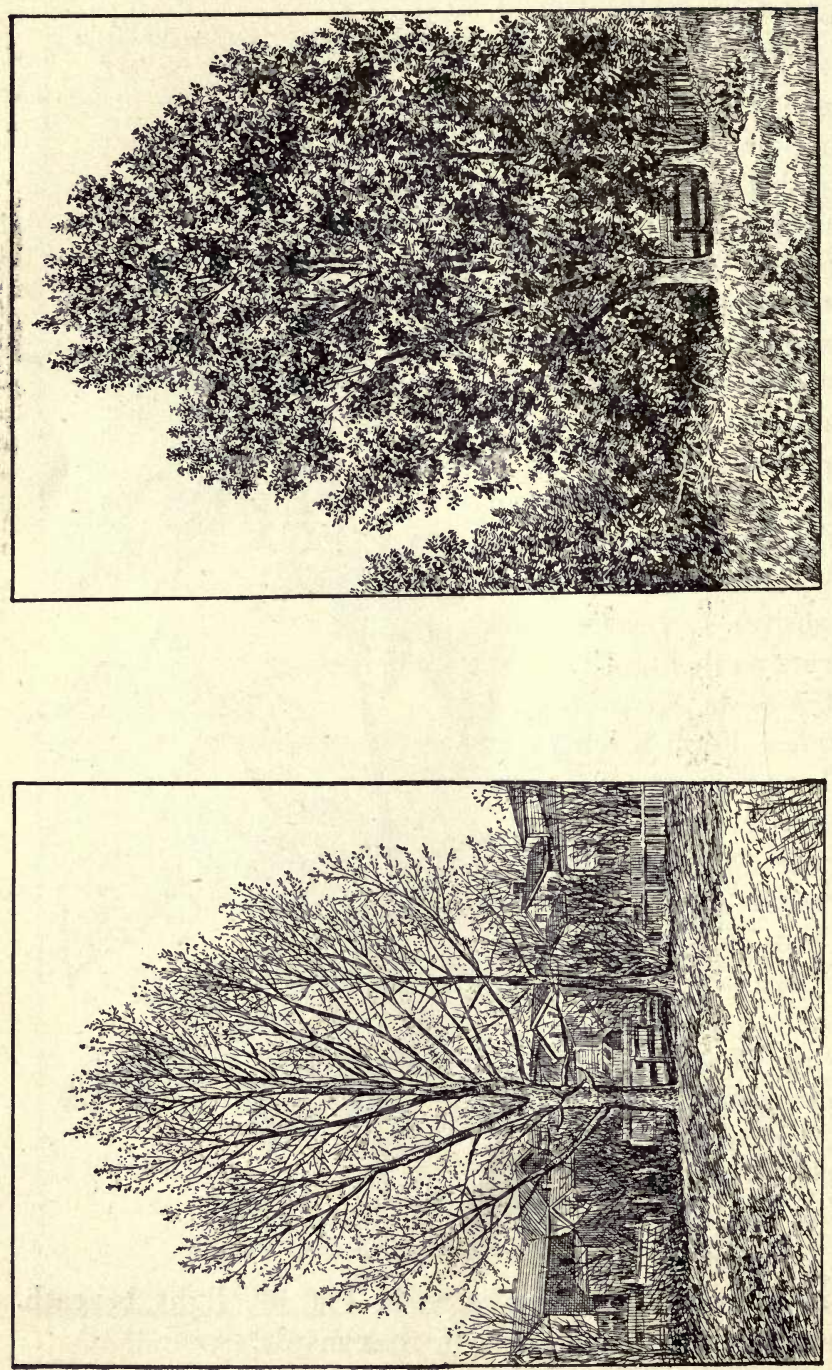

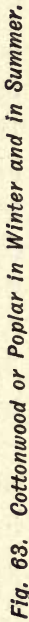


Horse-Chestnut. Form usually ovoid, not as regular as maple, and usually more pointed at top. Trunk sometimes extends almost to top, often short, and divided into three main branches. Branches without plan, very thick, and irregular in growth. Twigs with many large, opposite, crescent-shaped scars. Very large, brown, sticky buds, the large buds always on the ends of branches, the buds on sides of branches, smaller and in pairs.

Poplar. Lombardy poplar, distinguished by its slender spire shape, with trunk extending to top, and branches almost vertical, and numerous and short. Common poplar (cottonwood) as in Fig. 63. Trunk rather rough, light-colored. Branches, except largest ones, smooth, yellowish. Buds quite large, at ends of twigs gummy. Leaf as in Fig. 64.

Birch. The silver or white birch (see Fig. 65) is readily distinguished by the many fine drooping branches. The outline is usually cylindrical or slightly conical, with a dis-

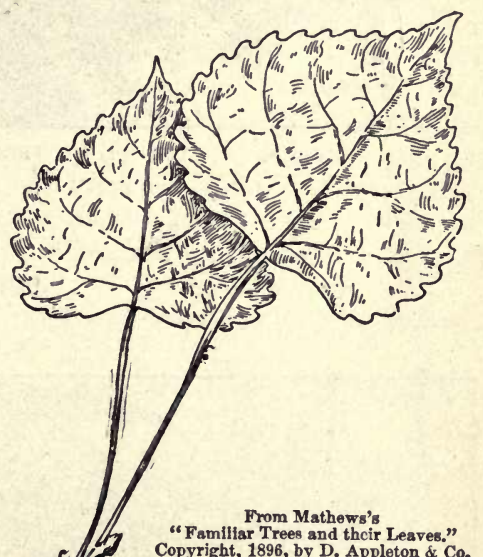

Copyright, 1896, by D. Appleton \& Co.

Fig. 64. Cottonwood Leaf.

tinct trunk, often extending almost to the top. Bark smooth, white, peeling off around the trunk. Branches nearly horizontal, flexible. Leaves as in Fig. 66. Short green catkins show early.

Evergreens. The pine and spruce and hemlock are described and figured in the study of evergreens in December. (See page 410 and Figs. 36, 37, and 38.) 


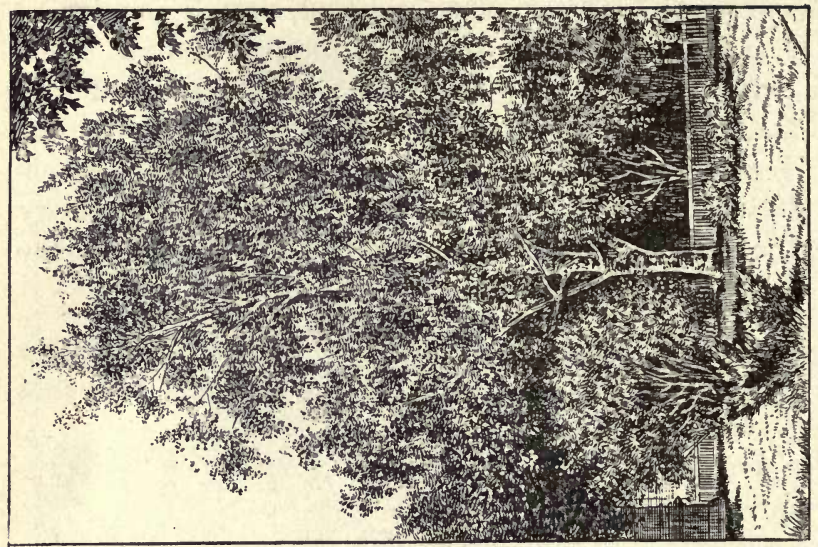

ह 


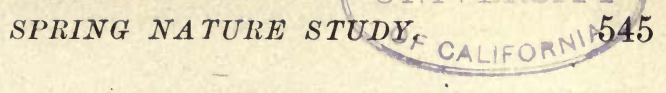

CHILDREN'S PAPERS ON TREES.

\section{Our Field Lesson. 1}

"Yesterday we went out on a field lesson to see the horse-chestnut tree. The shape of the horse-chestrut tree is like a cone. The horsechestnut tree is forty or fifty feet high. The trunk does not go up to the top of the tree. It goes up half way, and then the branches spread out. The branches of the elm tree are better than the horse-chestnut tree, because the birds can build their nests in the elm better than they can in the horse-chestnut. The branches of the horse-chestnut are thicker than the elm. The branches of the horse-chestnut tree are not as graceful as the elm."

Genevieve Hourigan.

"We went out for a fleld lesson April 5, 1898, to see the horsechestnut tree. It is shaped like a honey cone. (Probably confuses cone with bee-hive. C. B. S.) It is not the same height as the elm. Its trunk does not go all the way up the tree; it branches out. Its branches point up straight (?). Its branches are thick. It points up to the sky. The elm is more graceful. I know it by the twigs, because the buds are on the ends. When the sun shines the buds get sticky. It is thicker than the elm."

Grace Miller,

Third Grade, Practice School.

Oswego, April 6, 1898.

\section{The Birch Tree.}

"We went for a field lesson yesterday morning to study the birch tree. The bark of the birch tree is smooth at the top. On the top the color is white and gray, inside it is black. At the bottom it is rough and it is gray.

The tree is about forty feet high. The branches are spreading in every direction. There are a great many branches on the tree.

The leaves are green and small. They are shaped like a harp. There are a great many many twigs on the branches.

The catkins make the tree look very pretty. The catkins are shaped like worms.

The bark on the top is thin, and at the bottom it is very thick. When the bark of the lilac is taken off, it comes off straight. But

1 Two papers are given, written by children in the same room, at the same time, to show what can be gained in the way of individual written work, as distinguished from class reproduction. 
when you pull the bark of the birch tree, it don't come off like the lilac bark. The Indians make canoes and wigwams out of birch bark."

Bella Millington, Fourth Grade, Practice School.

Oswego, May 17, 1896.

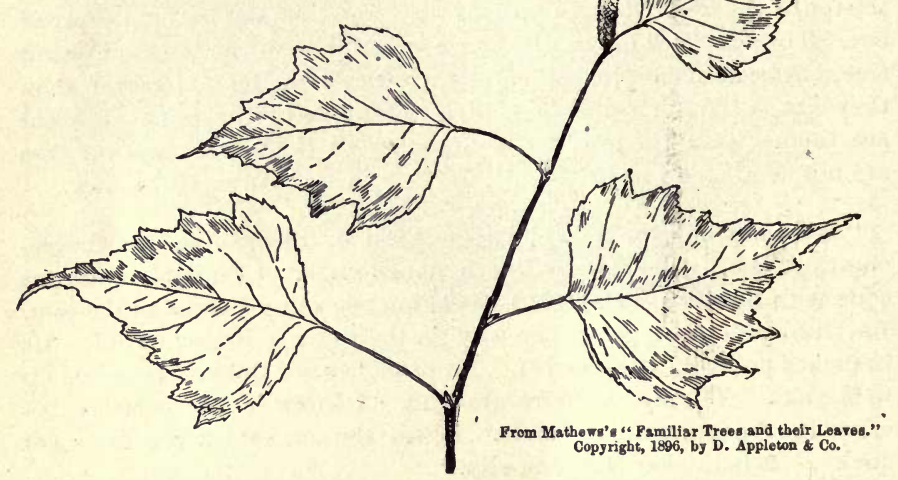

Fig. 66. White or Gray Birch.

Comparison of Lombardy Poplar, Birch, and Oak Trees.

"The poplar tree is cone-shaped and the birch tree is cylindrical-shaped. The poplar tree is a very tall tree, while the birch is a small tree. The branches of the poplar are larger around than the birch. The branches of the poplar are perpendicular. The branches of the birch are oblique. The bark of the poplar is a dark brown, the bark of the birch is a grayish white. The bark of the poplar is soft, I can scratch it with my finger-nail. The birch tree bark is smoother than the poplar tree. The poplar twig is hard and cannot bend, the birch branch can bend. It is like elastic rubber. The oak tree takes two and one-half pairs of arms to go around. It is cone-shaped (?). The oak tree is larger than any other tree around the trunk. The oak tree is dark blackish gray, it is rough. It has large branches and smaller branches, they have a great many trees and acorns. The oak tree is about one hundred feet high."

Marguerite Bruneau, Fourth Grade, Practice School.

Oswego, May 2, 1898. 


\section{BUD STUDY.}

In many parts of the country the tree buds do not develop until April or even May, and it may seem wiser to postpone the study of buds until the children can see them develop naturally out-of-doors. But during these months of awakening, many other things must be studied; the germination of seeds, the unfolding of the leaves, the development of the flowers, all come and must be studied then, or not at all.

It seems best to study the buds in March, as much as possible. This can be readily done by "forcing" them. The branches of almost any tree or shrub can be made to bud out, and form fairly perfect leaves and flowers, if kept in fresh water in a warm (not hot) room. The water should be changed daily. If the water is warm the buds develop more rapidly. It is well to trim off the lower end of the branches to be immersed in water with a sharp knife, making a clean, smooth cut, and to repeat this trimming every few days. It is said that buds will develop more rapidly if the cutting is done under water.

In this way buds can be made to develop in the schoolroom, where the pupils can watch the whole process. There is a very great advantage in this; it is much better than simply studying the buds before and after they develop on the trees. The children see Mother Nature at work. They set the gum about the bud softening, the scales spreading, the leaves unrolling, perhaps the flowers developing. One who has not thus watched the bud cannot understand how intensely interesting it is; very much better than tearing the bud open.

What better introduction can the children have to the study of life and life processes? What better study of protection and care? The children see how exquisitely the 
parts of the bud are cared for. They see how carefully the younger are protected by the older, how the flowers are enwrapped by the more hardy leaves and scales. They see the work of each part. What better illustrations of the order of nature and of the value of order? The children see each scale and leaf in its place, see each part develop in order, and see how much is gained by having everything in order.

" Earth is crammed with heaven, And every bush afire with God, But only he who sees

Puts off his shoes."

Elizabeth Barrett Browning.

As early as possible, in March, gather or have the children bring branches. These can often be obtained at the time of the spring pruning or trimming. If selected intelligently, their removal may be a help rather than an injury to the tree. Special care may be necessary to prevent the children from mutilating trees or shrubbery. The bud study should lead the boys and girls to be more careful about injuring the trees.

Particularly good for March study with the primary children are the buds of the lilac, horse-chestnut, beech, and linden (and in the West the buds of the box elder and of the red-berried, brown-pithed elder, or "elder-berry") and those of the pussy willow, poplar, or balm of Gilead (or cottonwood in the West), and red or white maple. Those in the first group are leaf-buds or leaf and flower buds, and present few difficulties, even to first-year children. The buds of the last group are flower buds, the leaves developing later, and are too difficult to study in any detail in the primary grades. The children gan enjoy the beauty of the early buds of pussy willow, poplar, and red maple, and can observe the flowers of all merely as stages in the 
formation of the seeds, which mature early. The elm flowers are very small, and should be observed only in connection with the study of the elm tree.

It is much better to have but two or at most three kinds under observation at one time, always centering the work about one. Too many varieties are distracting. A few branches of each kind are better than many. The teacher should set the example for the children by using no more material than is necessary.

It is well to encourage the children to watch some branches at home. This will often interest parents, as well as children, and may forestall criticisms in regard to "the nonsense taught at school."

The children should watch carefully the unfolding of the buds, noting all changes, but should never pick them to pieces. They can gain little knowledge, and will lose much of the spirit of bud study or nature study, if they are encouraged or allowed to pull apart these plant cradles, or dissect the babies within. Each day one or two questions may be asked which can be answered only by a study of the buds. Greater interest can be aroused by encouraging the more observant children to consider their discoveries as secrets, to be kept or imparted only to the teacher, thus stimulating the others.

The following may be helpful as an introduction to bud study:

A March Bud.

"Perhaps you may think, because I am buttoned And folded and wrapped in my little cloak so, That I always dress this way in all sorts of weather, With never a frill or a ruffle to show.

But it's only because I have come out so early, That only Jack Frost and the winds are astir. They're hard on the dresses, but under my wrappings Is my pretty new party dress hidden with fur. 
You'll see, if you come to Miss April's spring party, It's airy and dainty, a beautiful dress ! Jack Frost's not invited - he's a jolly good playmate But he's rather too rough for a party, I guess."

\section{Author not known.}

The Tree Buds.

" Rock-a-by, baby,

$\mathrm{Up}$ in a tree,

Rock-a-by, baby,

What can we see ?

Little brown cradles?

Yes, that is all ;

Little brown cradles

Never will fall.

Where are the babies?

$\mathrm{Oh}$ ! they are there, Tucked in their blankets

Away from the air.

Dear little nurslings,

Quiet all day,

In their green nightgowns

Folded away.

North wind is piping

Loud lullaby.

He couldn't soften

His voice, did he try.

Sleep till the springtime

Brightens the sky.

Little leaf babies

We love you. Good-by.'

Kate L. Brown. 


\section{THE HORSE-CHESTNUT BUD.}

No more exquisite illustration of protection can be found. While the lilac bud is more simple, and its parts and plan more easily understood, it is not as good as the horse-chestnut bud to show how daintily and wonderfully Mother Nature may care for her plant babies.

It develops very slowly, requiring four weeks or more to unfold its leaves. It should be gathered in February or early in March.

Important points for early observation are: the position of the buds, the large buds at the ends of the branches, with smaller ones in pairs along the sides; the egg-shaped form, brown color, and sticky varnish ; the horse-shoe shaped scars in pairs, each with three to seven dots, somewhat like nail-holes in the horse-shoe, and the ring-like scars. Do not ask or tell the children how these are formed. Let them find out for themselves, - a "secret" to stimulate interest and observation.

A drawing of a twig, showing buds and scars, made by the teacher as directed by the children, followed by drawings by each child, made from nature, not copied from the teacher's picture, will greatly aid in securing careful observation. The children can express by drawing more exactly than by words.

A week or two later gather up what has been observed. The large terminal bud has swollen and lengthened, showing green above and within the scaly covering. The varnish (the waterproof of the plant babies) is disappearing. Why? The brown coat has separated, disclosing several pairs of scales, each pair filling the cracks between the two scales below and without it, the outer scales (overcoat) short, thick, tough (Why ?); those next within them longer, thinner, more delicate in texture, brown where exposed, 
green where covered (Why?); the innermost green and thin. The projecting green tip is covered with wool, and shows lines or ribs, like cords, meeting below. As this lengthens, slowly, very slowly,

\section{"The grey hoss-chestnut's leetle hands unfold, Softer'n a baby's be at three days old."}

These hands are the centre of interest. Do not take away the joy of discovery by telling the little folks what they are or will become.

Continue observations a week or more, giving, from day to day, such questions as these: What grows out of the woolly ball? What do the hands turn into? What do the fingers make? What is between the hands? What happens to the scales? The woolly ball lengthens, the two hands push up and separate, the fingers spread apart and unfold, each showing that it is a leaflet (or "leaf" as the children will call it), doubled along the midrib, with the midrib turned outward, and the thin edges toward the centre of the bud. Why? Within these are two smaller hands, placed between the edges of the other two, and sometimes enclosing a third pair of hands. In the thick, "fat" buds there is, in the very centre, a green mass like a very small bunch of grapes. Let the children discover later what it is. As the hands push up, the inner green scales also lengthen almost as fast, keeping around them. Why?

Another week of observation will show that the hands have changed into leaves, each of the five or seven fingers forming a division or part. Probably the successive pairs of hands or leaves have been separated by the lengthening of the green stem. The outer scales have dropped off, and the inner scales can be easily removed. Each scale leaves a scar, and all together leave a ring around the lower end of the stem formed from the bud. Pull off a few of the leaves, 
showing the semi-circular scar each forms, with a dot within it for earch leaflet of the leaf removed.

Now the children (even in the first grade) can "think out" for themselves the meaning and story of the scars on the branches. Each horse-shoe shaped scar shows where a leaf fell off. Each ring shows where the bud scales fell off. By counting the number of rings, beginning at the tips of the branches, we can tell how many sets of scales have fallen off; that is, how many buds have helped to form the branch, or how many years that branch or twig has been growing.

The later development of the leaves and the growth of the little "bunch of grapes" in the centre can be best observed out-doors in May and June.

The following papers illustrate individual or free reproduction by the children. All are given as originally written by the children, with errors in spelling and capitals and serious grammatical errors corrected :

\section{How Mother Nature Cares for the Horse-Chestnut Buds.}

"Mother Nature cares for the buds because they are like children to ber as babies are to their mother. The sticky varnish helps the little buds because it keeps out the rain. The buds that are on the sides are smaller than the bud that is on the top because those that are on the top get more air and light than those that are on the sides."

Clark Robson,

Second Grade, Practice School.

\section{Horse-Chestuet Buds.}

"We went down to the park to see a horse-chestnut tree. The tree was in the southeast corner. The trunk of the tree was four feet around but it was not as high as the trees near it. It had a rough gray bark. I counted eleven branches that were big. The buds grow on the ends of the small branches. The buds are shaped like a pear. I counted ten scales on my bud. The color of the scales is brown. The stuff that is on it is varnish. The varnish is used to 
keep the water out of it and that keeps the buds from rotting. If it was flat at the top it would leak through. The scars are right below the bud and they tell me leaves were there."

James Brady,

Third Grade, Practice School.

\section{The Horse-Chestnut Bud.}

"Some of the buds are on the top and some are on the sides. The buds that are on the top are called terminal buds and the buds on the sides are called lateral buds. The color of my buds is a dark brown and on the top of some of the buds is a little black. The size of my bud is larger than the common size of buds on other trees. The form of my bud is like an egg. The parts of my buds are scales and there are ten scales on my bud. The color of my scales is a dark brown. The under scales are smaller than the upper scales. On the scales is sticky varnish and the varnish helps to make the scales stick together."

Essie Lanphear,

Fourth Grade, Practice School.

\section{The Horse-Chestnut Bud.}

"My home is an end of a branch. I lived in a little cradle. When the wind blows I rock back and forth. When spring comes I push out my head. The sunshine wakes me up. I throw off my blanket. Then my little green leaves begin to come out. I have three sets of scales. When I wake up I push my little head out. At first my head is small. When summer comes it grows bigger. At first the norse-chestnut bud is brownish like. My scales are (covered) with varnish a kind of sticky stuff. My flower is in the middle because that is the safest place. My flower has the most care of all other. My outer scales are the strongest. My scales overlap. The sun wakes me up."

\section{Clarence McElver.}

Third Grade, Practice School,

\section{My Horse-Chestnet Bud.}

" My twig looks like a sling shot. My bud is out around it. It is all fur. My horse-chestnut bud has a good many scales. The scales are brown. Under the brown scales there are green scales. They cover the little fur cloak. The little fur coat is white. It is very soft and smooth. On the outside of the bud it is very sticky. 
Some of our class said it was varnish and some said it was a sticky substance. On the outside on the sticky brown scales they have come off and they looked like petals of a flower. On my bud the scales have come off. The scales wrap the little leaves to protect the leaves. A little blossom is all wrapped up inside of the scales. My bud is very soft and smooth."

JOSEPHINE HART,

Third Grade, Practice School.

\section{What was in my Horse-Chestndt Bud.}

" When we looked at the other horse-chestnut buds then we looked at these. The scales were all turned back. All the little leaves are covered with cotton batting. The cotton batting flies away. Sometimes they have seven or five leaves. The lilac has only one leaflet. Some of them are front some back, some are left, some are right (Refers to opposite arrangement of leaves, C. B. S.) It (the leaflet) is shaped like a blade of a knife. All the leaves (leaflets) are fastened to the same place. It is rough on both sides of the horse-chestnut leaf. The color of it is green. The leaves give the tree a new green dress. It has one rib down through the middle of the leaves. There are little veins."

Lorenzo Carleton, Third Grade, Practice School.

THE DEVELOPMENT OF THE LILAC BUD.

This is one of the best for early study. It is widely distributed, and easily obtained. While the lilac buds are not as pretty as some others, they are so simple, their plan is so clear, and their parts so distinct, that any, child can understand them, and through them be helped to understand more difficult buds.

For the first study, the large buds on the young shoots springing from the ground are good, as they usually have only leaves. A little later can be studied the thicker buds near the upper part of the lilac bush, containing both leaves and flowers.

Begin with the buds at home, on the shrub, as already urged. Select some bush for special study, - one visible from schoolroom windows may be best, - and note its 
characteristics : its appearance, usually bushy, with many trunks and spreading irregular branches, but sometimes tree-like; its height, comparing with the height of the children or some other childish standard; and the arrangement of its branches, in pairs, or "two together" as the children say, often forking at the end.

Note the position of the buds, on the sides of the branches the larger buds usually near the ends, and their arrangement in pairs like the branches, successive pairs separated from and perpendicular to one another. (Have the children express with their fingers position, and form ideas which they cannot put into words.) The children will certainly see the little "seat" on which each bud is perched, and may discover the rings about the branches.

Have children describe the form and size of the bud, if not in words, with their hand and fingers, or with a drawing or clay model. It may be helpful to compare it to a tent, perhaps, Hiawatha's tent made to shed the rain. Even first-grade children can observe carefully, and can express quite exactly, if encouraged to tell in their own way, not always expected to express in words, ideas for which they have no words.

Note from day to day the changes in the form and size of the buds, and the gradual spreading apart of the enclosing scales. The children will discover that the scales, like the branches and buds, are opposite in arrangement, in pairs, each pair perpendicular to the pair below or without and above or within it. Why so arranged? Why do the outer scales cover the cracks between the inner scales? As the unfolding continues, compare arrangement of scales and of the leaves within. The same plan is found throughout the whole plant. Every branch, bud, scale, and leaf has its place. Why? 
Compare the outer two or three pairs of scales (the "overcoat") with the two or three pairs between them. Why so much thicker and harder? Notice outer and inner surfaces. Why so different?

Constantly relate to the life and care of the baby which some of the children may have at home, thus giving to the lilac bud a " human interest."

Note how much longer, softer, and greener the scales are the farther they are from the outside. Why? How many pairs of scales before we come to the leaves? The inner scales are so leaf-like that it is difficult at first to tell which are seales and which are leaves. Scales finally drop off. Leaves do not (until much later in the season).

In the lilac the scales are simply modified leaves, which Mother Nature has made tough and thick to protect the soft, delicate true leaves within. After once opening, do they ever draw together over the young leaves at night, or when cold, to protect them?

When the leaves can care for themselves, and also for the young leaves which keep developing within, the work of the scales is done, and they gradually drop off. Note the mark or scar left by each, and the set or cluster of scars, arranged in a ring about the branch, left by all of the scales of one bud.

After the bud has developed enough for the children to see that it will form a branch, compare this ring at the base of the bud with the other rings previously observed on the branches, and see if the children cannot work out for themselves the idea that each ring marks the base of a former bud, and the length of branch between successive rings shows the amount formed from the bud of each year. By the number of these rings the age of the branch can be told.

The leaves in the interior differ from the scales in being 
more distinctly veined, and in having or forming a stem. Note how carefully they are packed. As the scales fall off, the central axis or stem to which they are fastened and the stem of each leaf lengthens, and we have a leafy branch.

While the children are watching the development of the buds, and after the glimpses of the interior of the cradle have added new interest to the undeveloped bud, have them draw a branch with three or four pairs of buds, or stitch it on a card, or perhaps paint it. Fasten a small, simple branch where all can see it. When children are drawing, place a branch up before each row, where all can readily see it, and see it always in the same position. If a branch is placed on desk, do not let them handle it, as they are almost certain to draw part in one position and part in another, thus drawing incorrectly. The teacher should first draw it on the board, under the direction of the children as much as possible, to show them how to draw it, and to aid them in selecting those points which are most important, but should erase this drawing before the pupils begin to draw, emphasizing that each must draw as truthfully as he can only the branch he is looking at. Little folks will draw best on the board with large, free motions. It is helpful to have the pupils select the best of these blackboard drawings, and tell why or wherein they are best. The wise teacher will also recognize those which show the greatest or best effort, even though the result be poor. Later have the children draw, on a large scale, one bud on its seat, or make a clay model, showing, as exactly as they can, its shape and markings.

It may be well, when working with older pupils, to cut a branch into sections about an inch long, one for each pupil, and have them study and describe the structure of the stem, the bark, with its outer light-colored layer, and 
inner somewhat fibrous green part, the denser wood, and the spongy pith or the pith cavity in the centre. The bark protects, the wood supports or upholds. How is each fitted for its work? Show, by testing with weights, the supporting power of paper, some rolled tightly, and some rolled so as to form a hollow cylinder, how much better it is to have the wood in a hollow cylinder, rather than to have the same amount of material in a solid rod of much less diameter.

The buds containing flowers are quite similar to the leaf buds, but have in their centre, wrapped about by the leaves, a mass resembling a very minute bunch of grapes. Each little ball is a flower. Why does Mother Nature or Mother Lilac place the flowers in the centre, the best protected part of the bud? The lilac has reason to be proud of her blossoms. Some time we may learn another reason why the lilac and other plants take the very best care of their flowers. The flower buds may form flowers in the schoolroom, if kept in warm water.

This study of the lilac may take two or three weeks, alternating with the "spring notes," or with the study of the forms of water, or with other bud or tree study.

When the children have observed the whole development of the lilac, it will be helpful, for a review, to go back to the undeveloped bud, and have the children tell about the use of all the parts and the way in which they are fitted for their work. For the younger pupils the teacher may tell in story form the life of the lilac bud, or let the lilac bud tell, in imagination, its own story, the children supplying, as far as they can, the leading facts and incidents. This review is most important; properly conducted, it serves to bind together and clinch what might otherwise be disconnected and of comparatively little educational value. The success of the review, and the final results of the work, will depend on the extent to which the teacher 
has led the children to see and think and tell for themselves rather than to merely glance and listen or absorb, and on the faithfulness with which she has reviewed and related the essentials in all previous work before taking each new step.

The study of the later development should be continued in A pril, May, and June, studying the formation and main parts (calyx, corolla, stamens, pistil) of the flower, and the formation and characteristics of the seeds.

THE BEECH BUD.

Like the horse chestnut, the beech bud develops slowly. Its plan is rather complex, difficult for little children to understand ; but they can enjoy its beauty, and the story of protection and plan which it tells.

The buds are not arranged in pairs, as in lilac or horse chestnut, but each bud is attached separately; and they are arranged in two rows, on opposite sides of the stem. Beginning at the lower end of a fairly straight twig, the second bud is above and half way around the stem from the first; the third is directly above the first, that is, on the same side of the stem; the fourth above the second; the fifth above the third. This arrangement is called alternate (applied to all buds which are attached singly, not in pairs or whorls), and two-ranked, that is, in two rows. This two-ranked arrangement, contrasted with the opposite arrangement of the lilac and horse chestnut, will give the children a good idea of order and plan in nature. There are other plans of alternate arrangement, - five-ranked, eight-ranked, etc., - but they are too difficult for primary children.

The long, slender, tapering buds and their development are illustrated below. Perhaps the children can see how symmetrically the scales are arranged on the undeveloped 
buds. As the buds develop, and the brown scales spread out, the children will see how thin the scales are, and will discover the fur along their edges to keep out the rain or snow. When the outer scales drop off, leaving a distinct ring-scar they will see, in many buds, flattened silky masses, somewhat like the little " bunch of grapes" in the lilac and horse chestnut. Let the children discover in their later observations of the tree that these form flowers, and from some of them the beech-nuts develop. Do not tell them. Between these flower clusters, often enclosed by additional brown or brown-tipped scales, are several slender, silky, light green masses. Let the children find out what they are. As they expand, each leaf is seen to be enclosed between two narrow, delicate scales, and to be covered with silky hairs. Each leaf is folded lengthways along the midrib, and plaited somewhat like a fan. Cut a piece of paper the shape of a leaf, mark on it the midrib and veins, and show how the leaf is folded and plaited along the veins. All the scales are modified stipules, but it is doubtful whether little children will understand this. To older pupils it may mean much, showing how nature uses the same part for many purposes.

The buds of the linden or basswood are somewhat like those of the beech in arrangement and plan. They are tworanked; their scales are modified stipules, more leaflike than in the beech; the leaves are doubled, but not plaited. They are much simpler than the beech, but not so beautiful.

\section{THE ELDER AND BOX-ELDER BUDS.}

In both, the buds, scales, and leaves are opposite. Both may contain flowers with the leaves. In both the leaves are compound, each leaf composed of several parts or leaflets. In these the scales are modified leaves, and frequently all gradations can be found between the scales and the compound leaves; that is, the outer pair of scales may be short, 
brown, and woody, the next somewhat greener, the next green, and with the upper end slightly cut into divisions, resembling the fingers, and the next bearing quite long, fingerlike divisions resembling the leaflets.

\section{THE BUDS OF PUSSY WILLOW, POPLAR, AND MAPLE.}

The early stages of the "pussy willow" have been observed in many primary rooms. But few teachers have carried the observation beyond the first stages; they have been satisfied with the study of their beauty, their softness, and the way they are protected, without helping the children to see why they are so warmly clothed.

Gather twigs from several willow shrubs, as thus we are more likely to get some buds containing stamens and others containing pistils, the two kinds growing on different plants. Keep them in a cool place, occasionally trimming off the lower ends of the twigs. In two or three weeks some of the buds will probably develop into pistillate catkins and others into staminate catkins.

Centre the attention on the green pistillate catkins until the children can clearly see the bottle-shaped pistils, or seed-boxes, and the seeds which they contain. Then they will better understand why Mother Willow so carefully protects these buds. When the yellow staminate catkins are ripe, a shake will discharge the "willow gold-dust." Tell the little folks that this yellow powder, or pollen, helps to make the seeds, that the seeds cannot be made without it. How it helps, it is scarcely possible to make them understand at this early stage. The process of fertilization will mean more, and be better understood in higher grades, when the children have studied flowers more.

Willow twigs kept in water usually form fibrous rootlets, growing from the joints, or nodes, of the branches. The observation of the way in which these first appear, and of 
their growth, may prepare for the observation of the early growth of the root from the seeds.

The buds of the poplar, and particularly of the cottonwood, form long catkins, which show very clearly the clusters of stamens and pistils and the stages in the development of the seeds. The staminate catkins are worth observing just for their rich colors.

The flower buds of the white and red maples develop naturally in March or April, the white maple earliest. The flowers are difficult for young children to understand, until they have had consideraule study of larger flowers. But they are attractive in color (those of the white maple varying from green to reddish yellow, and those of the red maple from yellow to scarlet), and show clearly the stages in the development of the winged seeds from the flowers.

This study of tree flowers will be helpful in impressing on the children the fact of the existence of many kinds of flowers which they have never noticed, the function of flowers in the formation of seeds, and perhaps the fact that the important parts of the flowers, in seed-making, are the pistils and stamens, not merely or mainly the colored calyx, or corolla, usually regarded as the flower.

Newell's "Outlines of Lessons in Botany" (Ginn \& Co., Boston) will be found most helpful in bud study. Part I. (price \$0.55) has much on leaf buds. Part II. (price $\$ 0.90)$ relates to flowers and flower buds and to fruits.

\section{CHILDREN'S PAPERS ON BUDS.}

\section{The Leaf Bud of the Elm.1}

"The home of the little leaf bud is on the elm tree. The brothers and sisters never quarrel. The leaf buds are arranged one on the top of the twig and one on the right and one on the left side lower down.

1 These two papers were written by children in the same room. They illustrate the possibility of getting individual work while following the same general line of thought. 
The leaf bud of the elm is smaller than the horse chestnut. They are shaped like an ear of corn. The covering of the bud is the scales. The scales are a light green and the tops of the scales are brown. The smaller scales are outside. The scales are shaped like a blade of grass. The scales are pointed at the top and about a quarter of an inch wide. The horse-chestnut scales are thicker and wider than the elm and covered with varnish. The leaves of the little bud are inside of the scales. The leaves are folded in the middle. We found around each little leaf two little scales. They were taking care of the little baby leaf."

Jessie Cardwell.

"The leaf buds live in the elm tree. They open about the middle of May. They are smaller than the horse-chestnut bud. The horsechestnut bud opens in April. The horse-chestnut bud has a warmer coat than the elm bud. The elm bud does not need such a warm coat because they open when the weather is warm. The biggest bud is on the top of the branch, then there is one on the right side, then one on the left side, then another on the right side, then another on the left side. The elm is taller than the horse-chestnut tree. The elm is got rougher bark than the horse chestnut. It has more branches than the horse chestnut. The scales on the elm are light yellow."

John Scruton,

Third Grade, Practice School.

\section{SELECTIONS ON BUDS.}

\section{Pussy Willow.}

The brook is brimmed with melting suow,

The maple sap is running, And on the highest elm a crow

His coal-black wings is sunning.

A close green bud the mayflower lies, Upon its mossy pillow ;

And sweet and low the south wind blows, And thro' the brown fields calling goes,

'Come Pussy! Pussy Willow !

Within your close brown wrapper stir,

Come out and show your silver fur !

Come Pussy! Pussy Willow !' 
Soon red will bud the maple trees,

The blue birds will be singing, And yellow tassels in the breeze

Be from the poplars swinging, And rosy will the mayflower be

Upon its mossy pillow.

But you must come the first of all, -

'Come Pussy !' is the south wind's call,

'Come Pussy! Pussy Willow!'

A fairy gift to children dear,

The downy firstling of the year,

'Come Pussy! Pussy Willow !'"

\section{WAKING UP.}

"Millions of cradles up in the trees

Rock to and fro in the gentle breeze;

Tucked in these bud-cradles snug and warm

The little green leaves sleep, safe from harm.

April sings low as she passes by,

- Dear little leaves the summer is nigh ;

Open your eyes, from your cradles creep,

Wake up, little leaves, wake up from sleep I'

Millions of leaves from their cradle-beds Slowly and timidly raise their heads; They see the sun, and they love it so They back no more to their cradles go.

Stronger and stronger they grow each hour, Bathing in sunshine and soft spring shower; They stretch themselves out on every side, Saying, 'Dear me ! but this world is wide.'

They gaze and gaze on the deep blue sky, They watch the white clouds go sailing by, The winds sing songs till for very glee The leaves are dancing on every tree." 


\title{
WORK FOR APRIL.
}

\section{SEEDS AND THEIR GERMINATION.}

\begin{abstract}
"Whether we look or whether we listen, We hear life murmur, or see it glisten; Every clod feels a stir of might, An instinct within it that reaches and towers, And, groping blindly above it for light, Climbs to a soul in grass and flowers."
\end{abstract}

LOWELL.

Ethical Value. No other phase of plant life, not even the development of buds, has so much in it for the little children as the germination of seeds. They are babies together, - the seeds and the little folks, - and the children are drawn to them, have a fellow feeling, appreciate their struggles and difficulties, enter into their work, rejoice at their success, enjoy the brightness and beauty they shed about them, join in the "Well done" when the work of the seed is finished, and other seeds have been formed.

If they really study the life of the seed and seedling, not merely their form and structure, may not our boys and girls see in the short life of the seed an epitome of their longer life? Perhaps. Much depends on what the teacher sees in the seed and plant - and in her boys and girls.

IMPORTANCE OF STUDY OF DEVELOPMENT FROM BEGINNINGS.

The study of the germination and life-history of the plant is very important from another point of view. The children should, from the very beginning, study the plant as a whole, and think of root, stem, leaves, and flowers, not as distinct things, but in their relation to the whole.

The little plant coming from the seed, with tiny root, stem and leaves, the baby can comprehend and think of as a whole. If he first studies it when it is full grown, he does 
not see the whole, but the parts. If he watches it develop from seed to maturity, his idea of the "wholeness" grows with the plant.

The study of the plant as a whole includes its whole lifehistory, as well as all its parts. The child does not know the whole plant until he has studied the development of the whole and of each part.

This study of development is equally essential, to the child, to an understanding of the relations of the parts to the whole. The child who has seen roots form and branch, and buds appear, enlarge, unfold, and produce stem and leaves and other buds, need not be told how these are related to the plant. When he has observed the roots reach down into the ground, and watched the leaves spread out, and the flowers form fruit and seeds, he has the clearest possible idea of the work of each part for the whole.

This will aid not merely in future work with plants, but also in animal study. The knowledge of life history and the idea of development are as important in the study of animals as in that of plants. For many reasons the life history of animals cannot be so readily observed as that of plants, so the fundamental idea of life history and development must be obtained from plants.

This study of life and life history may be supplemented and broadened by observing one or more trees throughout the year, and making the tree study a means of connecting and correlating all the other plant work.

\section{PRACTICAL ADVANTAGES OF SEED STUDY.}

In addition to the educational value, the study of germination has practical advantages. Seeds - the more common, the better - are easily obtained anywhere at a very slight expense. They can be raised - during their first month or two at least - in any schoolroom or home in the most 
crowded part of a great city, in any place where air and water can be had. Sunlight is not a necessity, although, of course, plants thrive better, and are more apt to reach maturity, when they get sunlight.

If more attention is given to the study of seeds and leaves and buds, it will lessen the destruction of the wild flowers, which has been and will be one of the serious results of the growing interest in plant study. Teachers and others are apt to think that the study of plants means the study of flowers, and their first efforts to cultivate a love for nature and for the beautiful in nature too often result in almost exterminating for miles around the most beautiful gifts of nature, the flowers.

OPPORTUNITIES FOR ACTIVE WORK IN NATURE STUDY.

Seeds can be planted by the children in their homes. The writer has seen beans and peas and morning glories shedding their refining influence in the windows and scanty dooryards of scores of very humble eity homes, the only verdure to be seen, planted and cared for because the children had become interested in them at school.

Seed study furnishes one of the best opportunities for carrying on what we may call active work in nature study; getting the children to do something for nature, to take care of the plants. One of the most gratifying experiences in the writer's work in interesting children in nature study, resulted from an experiment in this line. He offered one spring to give sweet-pea seeds to any pupils who would agree to plant and care for them. Scores of girls asked for them, but only one boy ventured to get them. The next year, when the same offer was made nearly a hundred boys, as well as an increased number of girls, asked for sweet peas or nasturtiums. Each summer scores of hitherto barren dooryards were brightened by the flowers. This did 
more than anything else the writer ever attempted to give children a positive interest in nature and nature study and a larger enjoyment of the beauties of nature.

\section{PLANTING THE SEEDS.}

Get fresh beans and peas grown last season. For the study of the seed itself, Lima or other large beans and as large peas as can be obtained, are best. For planting, get the early dwarf varieties of beans and peas. They mature more rapidly, and if planted in April and given sunshine, will form flowers, pods, and seeds before the closing of school in June.

Plant not more than an inch deep nor less than an inch apart, in sandy loam, not too sandy, not too heavy. They will not thrive or mature in sand; in soil made of clay, or in leaf mould, the beans are almost certain to sour and decay.

Window boxes six or eight inches deep, or deep flowerpots, give the roots needed room.

During the first week or two the seeds will grow as well in the dark as in the light. After this time they should be in sunny windows. If this is impossible, try, two or three times a week, to put them where they will have a sun bath for several hours. In sunless windows peas grow better than beans. Beans are more apt to decay. The seeds should not be near a stove or radiator.

Teachers are apt to have their first planting, particularly of beans, decay, because kept too wet. For the first ten days it is well to wet slightly every afternoon, and cover tightly for the night with several thicknesses of newspaper. This will prevent too rapid drying or sudden changes in temperature. After the plants are an inch high it is unnecessary.

For the children of the first grade, it will be best to limit the study of germination at first to one kind of plant, the bean or pea. The bean is somewhat more simple. 
Perhaps in the second, and certainly in the third grade, the germination of bean and pea can be observed together and constantly compared. Later this may be supplemented - at least in grades above the second - by such seeds as the pumpkin or squash, sunflower, maple (if it can be found germinating out-of-doors), and morning-glory or four-o'clock. Always plant, when possible, early dwarf varieties. They thrive best in the schoolroom, and mature before the end of the school year. The corn is very difficult to understand; and it seems wise to leave the study of corn, wheat, oats, and similar seeds, until later years.

If possible, have each child plant his own seeds. Several can have a large flower-pot together, or the dirt in the window box can be marked off in squares. The holes into which the children are to drop the seeds can be made with a lead pencil. The children will enjoy watering the seeds, under direction. (Not too wet, remember.) The resulting sense of ownership will add much to their interest.

Plant plenty of seeds, several for each pupil. Many will decay. If too crowded in the window boxes they can be easily thinned out. Most teachers do not provide enough material to do the best work.

Encourage the pupils to plant and watch the seeds at home, and to report results at school.

Plant some seeds (peas thrive best) on damp - not wet - paper, in covered jelly tumblers or fruit jars, or on sponges in open tumblers, the lower part of the sponge touching - not immersed in - water in the bottom of the glass. These will show the children how the roots are formed, how they branch and produce root-hairs, how. they grow and get nourishment. These points cannot be studied on plants in the ground. With the little children it is not wise to pull up the plants. They should learn, first of all, to love and cherish and care for them. 
Have children watch, from day to day, the seeds in the tumblers, and later those in the window boxes, giving them questions to direct their observations. When they have something to tell, have a lesson.

\section{APRIL LITERATURE.}

\section{An April Welcome.}

"Come up April, through the valley,

In your robes of beauty drest,

Come and wake your flowery children

From their wintry beds of rest;

Come and overblow them softly,

With the sweet breath of the south;

Drop upon them, warm and loving,

Tenderest kisses of your mouth.

Touch them with your rosy fingers,

Wake them with your pleasant tread,

Push away the leaf-brown covers

Over all their faces spread;

Tell them how the sun is waiting

Longer daily in the skies,

Looking for the bright uplifting

Of their softly-fringèd eyes."

Pheebe Cary.

\section{The Seed.}

"As wonderful things are hidden away

In the heart of a little brown seed, As ever were found in the fairy net

of which children sometimes read.

Over the pretty shining coat

We sprinkle the earth so brown, And the sunshine warms its lowly bed,

And the rain comes dropping down.

Patter, patter, the soft, warm rain,

Knocks at the tiny door ;

And two little heads come peeping out,

Like a story in fairy lore." 


\section{Waiting to Grow.}

"Little white snowdrop just waking up,

Violet, daisy, and sweet buttercup,

Are under the leaves and the ice and the snow, Waiting, waiting to grow.

Think what a host of queer little seeds, Of flowers and mosses and ferns and weeds, Are under the leaves and the ice and the snow, Waiting, waiting to grow.

Only a month, or a few weeks more, Will they be waiting behind the door, Listen and watch and wait below, Waiting, waiting to grow.

Nothing so small or hidden so well That God cannot find it, and presently tell His sun where to shine and His rain where to go, Helping, helping them grow."

The Little Plant.

(From the "Plant Baby and Its Friends.")

"In the heart of a seed, Buried deep, so deep, A dear little plant Lay fast asleep.

'Wake,' said the sunshine,

'And creep to the light.'

'Wake,' said the voice of the raill-drops bright.

The little plant heard, And it rose to see What the wonderful Outside world might be."

- Kate.L. Brown. 
THE GERMINATION OF THE BEAN.

A Series of Lessons planned for First-Year Children.

LESSON I. PLANTING THE BEANS.

Read and discuss with the children "An April Welcome" or "Waiting to Grow."

Tell them that we have something we want Spring to wake up. Tell about the Bean Mother who was like the "old woman who lived in a shoe, who had so many children she didn't know what to do;" only she knew what to do; how she placed her seed-babies, five or six together, in seed cradles, each seed fastened tightly to the cradle (show picture of bean pod); how she wrapped each baby in a coat; how when Jack Frost came the cradles turned from a beautiful green or yellow to brown, and the babies all went to sleep; how some one took them out of their dry cradles, and took care of them all winter. We have them here.

It is time for them to wake up. They want to grow. How can we help them? What do boys and girls need to grow? What do our beans need? Talk about necessity of food, water, air, sunshine, care. Have children plant the beans. It is best to have portions of the box or flower pots assigned to each child or group of children. It will add to the sense of ownership and hence to the interest.

Sing with or to the children or read and discuss with them (from "Songs for Little Children" by Eleanor Smith):

"Wake," says the sunshine,

"It's time to get up ;

Wake, pretty daisy and sweet buttercup.

Why, you've been sleeping the whole winter long.

Hark ! hark ! don't you hear ? 'Tis the blue-bird's first song." 
Summary. Get from children such statements as those below, write on blackboard, and read to or with them or have thein read.

Mother Nature told Mother Bean that winter was coming.

Mother Bean made a cradle for her babies.

She put five babies in a cradle.

She put a coat on each baby.

The cold did not hurt them.

They slept all winter.

Now they want to wake up.

We will help them. We have put them in the ground.

The dirt and the sun and the water will help.

LESSON II. WAKING UP.

Preparatory observations. Have children examine each day the seeds in the glasses. Help them, so far as necessary, in observing how the seed swells, how the coat wrinkles and then becomes smooth, how and where the little white pointed "foot" comes out, how fast it grows (measure), how its branches first appear as knobs and how they grow, how it splits and sometimes pushes off the coat of the seed-baby, how the "foot" insists on growing downward and will not grow upward. To show latter, place, in a moist saucer, bean with "foot" (or "radicle" or "caulicle") half an inch or more in length, pinning it through the cotyledons to a cork with the point of the radicle upward, and cover with an inverted tumbler, so that the air around it will keep moist. In a few hours the radicle will bend downward. If again fastened with point upward, it will again bend downward. The pea is somewhat better than the bean for this and similar experiments.

When the children have. considerable to tell, have a lesson. A week or more may intervene between Lesson I. and Lesson II. 
Waking up. Read again or sing " 'Wake,' Says the Sunshine" or "The Little Plant." Talk about how boys and girls wake up, how they open their eyes, perhaps have a "stretch," push out their feet and hands, push off the "covers." Relate to bean. If children can be shown soaked Lima beans, they can see more clearly the opening (micropyle, meaning "little gate") in the skin through which the "foot" is pushed. Months ago Mother Nature or Mother Bean placed that opening or thin place in the skin just where the tender "foot" would begin to push out. Note how the foot bends or doubles on itself, somewhat like a fishhook. Give name, radicle (or, if preferred, "little root").

Have children describe bean and foot and coat, so that teacher can draw it on blackboard as it looked when first seen and also after it had grown a little.

Blackboard summary.

Our baby bean has waked up.

We have seen it (or them) grow bigger.

It has pushed out a little foot.

The foot came out of a hole in the skin.

Mother Bean made the hole just over the foot.

The foot has a point like a pencil.

It made the skin crack.

We saw it grow longer and longer.

We call the foot the radicle.

Miss Grey made the foot point up.

It soon turned down.

It will not grow up.

It always grows down.

LESSON III. PUSHING OUT OF THE GROUND.

Preparatory observations. Continue observations on beans in glasses. Note how the root lengthens, and how the branches form, lengthen, and perhaps branch again, and how the stem, bearing two folded green leaves, pushes 
out from between the two thick halves or cotyledons of the bean, and always grows upward, not downward.

Watch also the seeds planted in the earth. Note how they come up out of the ground, always with the radicle, or part of the stem below the cotyledons, arched; how this arch, acting like a wedge, pushes apart the soil, and sometimes lifts up large pieces of dirt; how, as it grows, it pulls the cotyledons backward out of the ground, with their lower (now upper) or united ends always uppermost; how the seed coat is pushed off, or splits and drops off; how the arched stem slowly straightens, turning the cotyledons upward; how the little bud or plumule with its two folded leaves grows out from between the cotyledons, turns greener and begins to unfold.

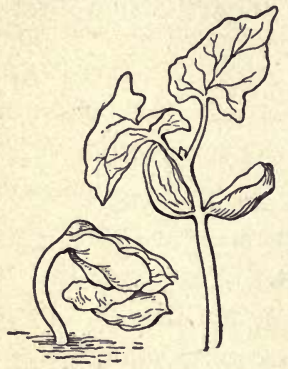

Fig. 67. Germination of Bean.

After the children have observed and understand the facts fairly well, ask why the stem is bent - to push more readily through the ground, to make a path for the cotyledons and delicate bud and leaves between them; and why the cotyledons are pulled out backward - to . keep the soil from injuring the bud.

Summary. Draw on the blackboard, directed by children as far as possible, two or three stages in the early growth of the bean in the soil. Perhaps some of the children can draw these after the teacher has shown them how. They should not copy the teacher's drawing, but should draw from a growing bean. Pictures made by the children on blackboard on a large scale with a free-arm movement are much better for the little folks than little cramped pic- 
tures on paper or slate. Outlines showing the seed pushing out of the ground, pricked by the teacher, and sewed by the children, may help in impressing the appearance of the seed as it comes up into the "wonderful outside world."

\section{LESSON IV. GETTING FOOD.}

Preparatory observations. Continue observations on growth and branching of roots in glasses. Dig up carefully one of the plants in the ground (do not pull it up), with all the soil about its roots, place in water, and move gently back and forth to wash off the dirt without breaking off the fine roots. Observe the root system.

Watch the changes in the thick cotyledons. They spread apart after their work of protecting the bud is done. Is that all their work? Note how they wrinkle and shrivel, getting smaller and dryer. In from four to six weeks they drop off. Cut off cotyledons from two or three young plants in glass jars. In a few days these plants die, while those with the cotyledons may thrive.

How Mother Bean feeds her babies. Talk about how mother must feed the baby, and how the children go to their mother when hungry. Some of them may bring some lunch to school in a bag. How does the bag look when they have eaten the lunch? How does an orange look when they have sucked out the juice? Wrinkled up. Try to have them see and tell that the cotyledons are the lunch boxes, filled with the best kind of food, which Mother Bean placed there for the baby plant to feed on until it was old enough to get food for itself. As it grows, it uses up this food, "sucks it in," and the lunch boxes wrinkle and shrivel up; when the food is all gone they drop off. If the lunch boxes are taken away before the baby can get food in some other way it dies. 
How Baby Bean gets its own food. As the baby at home gets older it begins to reach out, and tries to get things to eat and drink. So the plant baby, as its "foot" (shall we call it "hand" now ?) grows and forms branches, or "fingers," begins to get food for itself. Its food is in the ground. Its root always grows first (Why?). It grows down (Why always down?) and branches out and forms many threadlike "fingers" spreading in all directions. Why? By the time the two lunch boxes are empty the baby plant can get its own food and take care of itself. Emphasize fact that we must help the plant by giving it water and good soil, soil with plenty of plant food in it.

Summary. A baby that is old enough to get its own food is old enough to talk, and tell its own story. Cannot the teacher, with the help of the children, draw from the plants "The Story Our Bean Babies Told," have a bean tell how much Mother Bean and Mother Nature did for her, and how she is learning to do and work for herself?

\section{LESSON V. THE BEAN BABIES IN THEIR CRADLE.}

Now the children are ready to study the bean itself, from which the babies came. If they begin with beans before observing their germination they will not understand them. They have now seen each part, - coat, caulicle, cotyledons, plumule, - develop, and have learned by observation what each does. Now each part means something to them.

By the latter part of April beans in the pod can usually be obtained at the market. Show one or two to the children, open and show the beans in their green cradle, noting how they are fastened and arranged, each in its place.

Give children large beans,-Lima beans are best,- - soaked over night, and have them find coat (and micropyle if pos- 
sible), caulicle, cotyledons, and plumule or little bud with its two leaves so carefully folded.

Hans Andersen's story "Five Out of One Shell," read to the children, will be appreciated.

The observation of the formation of leaves, flowers, and fruit should be continued during May and June.
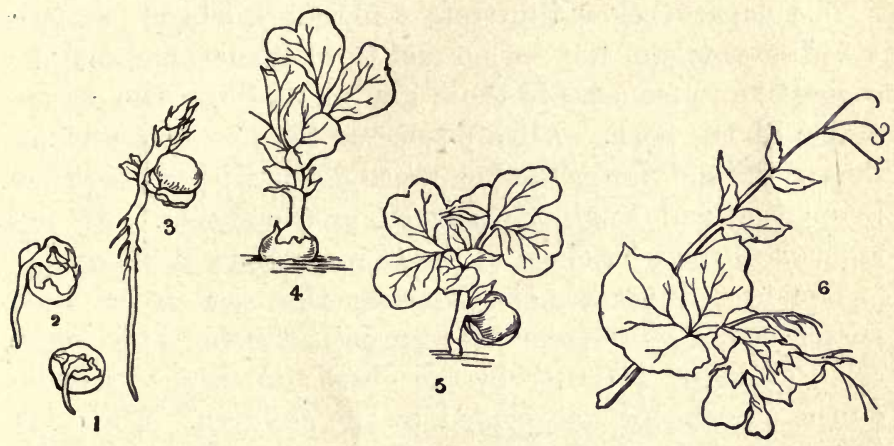

Fig. 68. Germination of Pea

GERMINATION OF PEA.

The early development of the pea is quite similar to that of the bean. The parts are not so large or distinct; the plumule is very small, and more complex than that of the bean; the cotyledons do not turn green, and often remain in the ground. But the pea is more certain to thrive in the schoolroom, and grows somewhat more rapidly. The differences between the early stages of the germination of the bean and pea are particularly interesting for observation. Notice the difference in the leaves, the leaves of the pea being composed of several leaflets and tendrils, fastened to a central stem or axis; the large parts at the base of each leaf stem (the stipules), and the way they fold about and 
protect the young leaves; the growth and use of the tendrils, the "fingers of the pea," as the children often call them, and their manner of twining. The pea is much better than the bean for the experiments on root growth suggested in connection with the study of the roots of the bean.

\section{WRITTEN WORK OF PUPILS. GERMINATION OF BEAN.}

The papers below illustrate different kinds of written work by pupils of the second and third grades, and may be suggestive to teachers in those grades studying the germination of the bean. All are selected from regular work of the pupils, and are printed as written, but with gross errors in spelling and English corrected by the author. All are from the Practice School of the Oswego Normal School.

The first illustrates class reproduction - with the bean personified. The statements were gained (mainly) from the class, arranged in order' by the class and teacher, written on the blackboard, and copied by the children. The other papers are individual papers. Where two are given under one title they are by pupils in the same room, writing at the same time, following the same line of thought, but showing considerable individuality. If space permitted, many others might be added from the same rooms.

The last paper (by Ethel Wilcox) illustrates well the proper order. The paper tells first about experiments and observations, and then gives conclusions based on these.

\section{The Bean's Story.}

"I am a little bean. I have been sleeping all winter in my little black coat. Don't you think that is a pretty long sleep? How long do you sleep? One day some little children put me in a box of earth and covered me up. Then they put some water on me. Soon Mother Nature said, 'Wake up! Wake up !' Soon I began to swell and my coat got tight. After awhile my coat burst and fell off. Then the sun kissed me and I began to grow."

Mamie Cuyler,

Third Grade. 


\section{Our Seed Babies.}

"We put some baby seeds to bed. They were bean babies and pea babies. Some sweet peas of ours came up too. We took off the seed's coat of a bean. We saw the head and foot coming out of the bean. We put some into a glass and they came up. The bean came up. I am going to make a picture of a bean and here it is. (Picture of seed.) I am going to make one more bean. (Picture of bean beginning to sprout.) The knees came up first."

\section{Darlene Stone, Second Grade.}

\section{Planting Beans.}

"We planted beans yesterday in a box with some soil in. We planted them a half inch deep and then covered them with soil.

"We then took some jars (and a piece of blotting paper, C. B. S.) and wet it and put it in the jars and then put beans in the jars. In the morning they were cracked.

"The beans grew in the garden last year. The pod looked like a cone. At first (when, C. B. S.) the bean grew the pods were green but when the sun came they turned white and when it rained it made them soft and then the men picked them. If the men did not pick them they would fall down to the ground and grow next year.

"We had some beans in the room in a bottle. We looked at them. They had grown a great deal. There was a little sprout on them. The sprout was green. It would be an inch long but it wasn't straight. It grew downward. Its cap is black."

\section{Robert Brennan, Third Grade.}

\section{The Bean.}

\section{(Part of a diary kept by members of the class.)}

"April 27, 1897. My bean is hard and the color is black and white. It is shaped like a boat and it has little dints in it. Yesterday we planted some beans and we put them in the ground an inch deep. After we planted them Miss Fuller got some little flags and stuck them in the ground for the row who planted them.

"April 29, 1897. Yesterday we put a sponge in a bottle and we put some water in it too (and some beans, C. B. S.). Then we looked at it (the bean, C. B. S.) this morning and it was soft. It was soft because there was water in it. The skin was coming off and it was all 
wrinkled and it was swelling. The bean wanted to get it wrinkled because it wanted to grow. -We had to replant our beans.

"May 7, 1897. Our beans are sprouted. The bean's sprout came out at the scar and at the place where it is called the little gate. The direction it came out was straight, then it went down because it was going to be the root. The sprout of the bean is longer than the sprout of the morning-glory."

Harold McCall, THIRD Grade.

\section{The Partis of Our Bean Plant.}

"The roots of the bean help the plant to grow. We measured the root and it was one inch and a half long. The central root has a lot of roots. The little roots have a lot of little hairlike roots. The little root bends out. My stem is white at the bottom. Then my stem was green at the top. My stem is got a lot of furry stuff on it. The root was big at the top and it was small at the bottom."

Walter Reynolds.

"The bean has three parts. One of the parts is the root and one of the parts is the leaves and one of the parts is the stem. The root is like a thread. The color of the root is yellowish white. The central root is sharp like a cylinder (cone?). On the central root I saw a great many little roots. We measured the root and it was a inch and one half long. On the root that was near the central root there are a great many new baby roots. On the root there are white spots. The root bends down near the ground. The stem is light green and down to the bottom it is whiter green. The stem is shaped like a cylinder. In the center were the cotyledons. The stem is about eight inches long."

Anna Carolin,

Second Grade.

\section{Root of Beans.}

"John Wells pulled up two plants. They were bean plants. One was bigger than the other. The littlest one pulled up harder than the other did. The littlest one came hard because it had roots on it and the big plant didn't have any roots on it. That is why it came up easier.

"The use of the root is to hold the plant firmly in the ground. If it didn't have the root when a hard wind or a hard rain-storm came it would blow it over. We call this root a fibrous root or a spreading root. 
"We put one bean plant in water. The color of this water was red. Then in a few days the roots turned red. Then in a little while the backs of the leaves turned red. The way they turned red was that the red water went up through the roots up through the stem into the leaves. The red gets into the root through the little hairs on the root.

"The root takes food to the leaves. The root takes in liquid food. The use of the stem to the leaves is that it takes up food through it. The sun makes the plant grow. Another use of the stem to the leaves is that it holds the leaves up to the sun. The food that the plant drinks is water. The food that it gets is all ground up in tiny pieces in the water."

Ethel Wilcox, Third Grade.

\section{GERMINATION OF THE MORNING GLORY.}

(Planned for the Third Grade.)

This is the substance of an outline prepared by Miss Kate Cambern, while a member of the author's class; it has been abridged and slightly modified by the author.

\section{LESSON I. THE LIFE IN THE SEED.}

Preparatory, observation. Previous observation for a week or more, with definite questions, of the early development of seeds planted on damp paper.

Step I. Protection during the winter. Read and discuss : -

" March nodded to Winter, 'Good-bye! good-bye !

Off to your home in the north you must hie.

$\mathrm{Oh}$ ! have you forgotten, under the snow,

The wee seeds are waiting, yes, waiting to grow?'

They are Spring's little babies, and soon she'll be here,

Whispering her welcome to each baby dear;

So I'll tidy the earth; I'll sweep and I'll blow,

Getting it cleared for the flowers to grow." 
Review how the seeds were taken from the seed-case last fall - (Cannot some tell how the seed-case looked. See Fig. $\mathrm{xxx}$ ); how many were gathered by people, while others dropped to the ground; how the dark color-so much like the color of the earth - and the hard coat have protected them from birds and insects and cold; how they have been covered with leaves and snow, until sun and rain have awakened them.

Step II. The awakening. Recall the size, shape, and hardness of the dry seed and its swelling and the softening of its coat when placed in water. The pupils should be able to tell, from their observations, how and where the little caulicle first appeared, always at the same part of the seed, coming through, or making a hole in the pointed end of the seed, and how it lengthened and thickened, perhaps bursting open the coat.

Compare development. of morning glory with that of the bean, if the children have studied the bean.

Read with them and discuss the following:-

"Down the little drops patter,

Making a musical clatter ;

Out of the clouds they throng.

Freshness of heaven they scatter

Little dark rootlets among.

'Coming to visit you, Posies, Open your hearts to us, Roses,'

That is the raindrop's song.

Up the little seed rises, Buds of all colors and sizes, Clamber out of the ground.

Gently the blue sky surprises

The earth with that soft rushing sound.

'Welcome,' the brown bees are humming;

'Come, for we wait for your coming,'

Whisper the wild flowers around." 


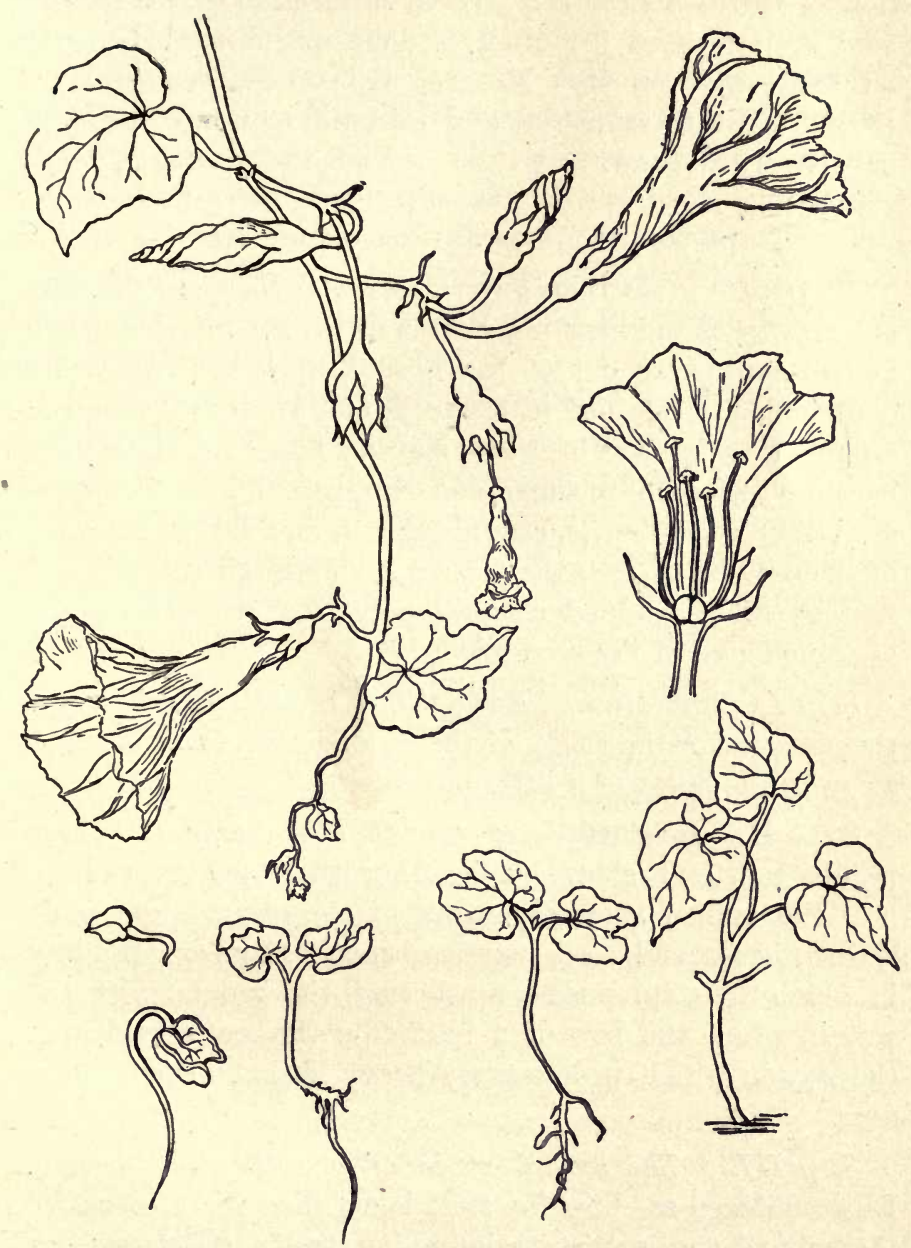

Fig. 69. Germination of Morning Glory. 
Step III. Summary. Have children draw the soaked seed and the seed beginning to develop. Some may write on "How Our (or My) Morning Glory Seed Waked Up," telling what the sunshine and rain did, and how the seed baby began to grow.

\section{LESSON II. BEGINNINGS OF GROWTH.}

Preparatory observations. Observe for a week or more the growth of the morning glories in the soil: how the stem arches and backs out of the ground, how the leaves are doubled and crumpled in the seed, and are partly wrapped around a little mass of white starch; how this white mass becomes soft, turns to sugar, and disappears; how the leaves get larger and greener, straighten out, and slowly back out of the seed coat; how the arched stem straightens, and carries up the leaves, and sometimes the seed coat on the tip of one or both of the seed leaves.

Step I. Literature. Read "The Seed," page 571 as a preparation for the study of the "wonderful things hidden away in the heart of a little brown seed."

Step II. First stage of growth above ground. Have pupils tell and show by bending their fingers exactly how the arched stem backs out of the ground, and pulls the seed-coat and seed leaves with it. Compare the way in which the stem pushes up through the ground with the way in which the bow of a boat cuts the water and with the way in which people carry heavy loads on their shoulders.

Step III. The second stage of growth above ground. Have children see how the stem has pulled the seed out of the ground and is now straightening itself. "But the seed baby's coat does not fit as well as it did before. It is all split down the sides. What is it we see peeping out?" 
"Some little yellow.(or green) crumpled things." "And what do you think they are?"

Bring out, by having children look at more advanced stage of morning glory that they are leaves. (These we can call seed-leaves, because any child can see that they are leaves. To call the cotyledons of the bean or pea seed leaves only confuses the children. They cannot grasp in a few weeks what it took botanists generations to comprehend, that the cotyledons of bean or pea are merely modified, greatly thickened leaves.)

Make sure that the children see the pellet of white starch, about which the leaves are partly rolled. If necessary, show this in seeds which have been soaked two or three days. Perhaps the pupils can discover, by tasting it, that it is changing to sugar. Note how early in the plant's development it disappears. Tell them that this (albumen) is the store of food the plant mother provided for her babies until they were old enough to get their own food. The leaves are wrapped around this food. At first it is dry, like starch. When the plant begins to grow, Mother Nature turns it to sugar, which dissolves in water, and can be absorbed by the leaves. When this food is gone the leaves have grown enough and have become strong enough to get along without the protecting seed coat.

Show how it is better for the seed to be pulled out as it is, and how it is better for the leaves to grow out backward.

Step IV. Summary. Have oral summary or blackboard reading lesson or individual written reproduction on "How Our (or My) Morning Glory Seed Came Out of the Ground," bringing out clearly, position and change in pos tion of stem, and reasons; position and changes in albumen, and use and reasons; position and growth of seed leaves, and reasons; pushing off of the seed coat, and why pushed off. 
LESSONS III. AND IV. GROWTH, USES, AND ADAPTATION OF ROOTS.

Preparatory work. Watch, if possible, growth of roots of seeds on damp blotting-paper in glasses. Note increase in length and formation of branches. Possibly the formation of root hairs may be seen. Dig up from soil a few plants two or three weeks old, being careful not to disturb the roots, and carefully wash off the soil. Try to show that the roots always grow downward, by experiment suggested in outline on bean. Mark with point of fine needle, dipped in ink, minute dots on the root, the first as near to the tip as possible, the others at intervals of an eighth of an inch or less. The experiment, if successful, will show that the root increases in length only just back of the tip. If it kept lengthening throughout its whole extent, it would be constantly disturbing or pulling out its branches. The success of these experiments depends largely on keeping the roots, and particularly their tips, always moist.

Step I. Growth of root. Trace its growth from the time the first little "foot" was pushed out until branches were formed on all sides. Impress fact of its always growing downward. Discuss (if it has been seen, but not otherwise) its manner of lengthening.

Step II. Appearance and parts. Draw on blackboard, directed by pupils, a well developed root, with branches (and if seen, root hairs).

Step III. Work or use or functions. Recall substances that dissolve in water, perhaps including the lime which forms the incrustation in the tea-kettle. Show how string or blotting-paper draws up water, with what is dissolved in it. The roots do the same. If the roots of young vigorous morning-glory plants are placed in water with some red dye, 
the dye may show, after several hours, in the veins of the leaves, proving that the roots have taken it in, and the stem has carried it to the leaves. So the roots take in water, and food dissolved in water, for the young plant. This is done by the fine rootlets and root hairs.

Have children show how their fingers help them to cling fast. Compare with rootlets and their use, bringing out fact that these also help the plant to hold fast in the ground.

Step IV. Adaptation to work. Summary. How roots are made or fitted for their work: by growing downward, by lengthening only near tips, by branching, by forming fine fibres and root hairs.

LESSON V. COMPARISON OF BEAN AND MORNING GLORY.

Note. This lesson is based on the assumption that the boys and girls are observing the development of both bean and morning glory. There should be some comparison constantly, but it is necessary to occasionally have a lesson devoted to gathering up the important points of resemblance and difference.

If a considerable number of seeds of both kinds are planted in late March or early April, several stáges in the development of both can usually be obtained a month after planting, on account of the unequal rate of growth of the seeds.

Step I. Comparison of soaked seeds. Different in size, shape, color, thickness and hardness of coat. Similar in having a scar, where fastened to seed-box, a little stem, two parts fastened to it (cotyledons), and a store of food. In one the food is within and part of the cotyledons, in the other the cotyledons are wrapped around the food.

Step II. Beginning growth. In both the caulicle grows first, pushes out through a certain place or hole in the coat, 
grows downward, turning and twisting if necessary, lengthens back of the tip, forms many branches.

Step III. Pushing out of the ground. Both come out with an arch, pulling cotyledons and seed-coat after them, and slowly straighten, lifting up the cotyledons.

Step IV. Development of cotyledons. In bean thick, slowly shrivelling up; in morning-glory leaf-like, turning green, and forming leaves. Why?

Step $V$. Store of food. Both have it. How do they differ in the position of the food and the way it is used? How alike in way of getting food from ground?

Step VI. Summary. Alike in being protected by coat, in having a little plant or embryo inside, with a stem and two cotyledons, and in having a store of food for the baby plant. Alike in sending down branching roots to get water and food in the ground, and in sending up green leaves into the air. Unlike in way seed food is stored and in character of seed leaves, or cotyledons.

\section{CHILDREN'S PAPERS ON GERMINATION.}

The Morning-Glory Seed.

"When the baby seed went to work for itself the mother fixed a box of food for it because it was not old enough to take care of itself. The food was inside of its little coat. We put the little seed in the earth and we put water on it. The little seed drank so much water it burst and the little stem and the leaves began to push out. The stem came out first. The stem was bent over when it came out and it came out to make a little place for the leaves. After awhile it straightened up. I could see the little leaves. There was two of them. They were green. They were doubled up. And at the end of them was the little coat."

Jessie Cardwell,

The Morning Glory.

Third Grade.

"The morning-glory seed is shaped like a quarter of an apple and they are very small. The color of them is black. It is hard and rough. 
"Then we got a dish of seeds with sprouts and they were swelled up because they were in water. The seeds were put in a dish and in the box April 27. The little gate is the place where the sprout comes out. It looks like a place where a pin was put in and took out again. It made a little hole. The skin of the morning-glory is loose.

"Then I went up to the box and saw that the morning-glory seed was up and the seed was at the end of the leaf and the leaves were shaped like a heart.

"The leaves were yellow at first, then they turned green. The stem is white. The seed pushed up and then it turned down to the ground and then the leaves were yellow. The leaves were down in the ground, then they straightened up.

"When the leaves were down in the ground they stuck together then when they came out they were spread out and we call them cotyledons. Before they straightened up the shucks fell off.

"The morning glory grow fast very fast."

Marguerite Brunead, Third Grade.

\section{Mr Little Squash Seeds.}

"My squash seed is shaped like a stone in a plum. The color is cream color. The one that has the sprout its life has come out. The sun has come and said 'Wake up and come out' so the second one has come out. But the first has never been planted so it can't until it is planted. There is a point where the little life comes out. And the other end is round like a ball. The use of the root is to send up the food and water. The color of the root is white and it has two little roots on it."

Blanche Martin.

WATCHING GERMINATION OF SEEDS OUT-DOORS.

Apply what is learned from bean and morning glory by leading children to observe carefully, and report how other seeds germinate. One or two field lessons to observe germination of any weed seeds or tree seeds will be helpful. Give pupils flower or garden seeds to plant on condition that they watch them carefully, and report what they see and learn. Try to have them observe the germination of some of the seeds whose formation and dissemination were studied last fall, such as the mallow, buttercup, dandelion, milk- 
weed, thistle, maple, burdock. The maple seedlings are particularly good for study.

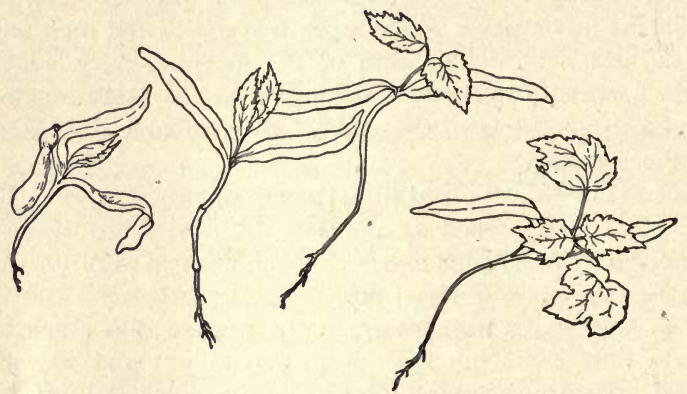

Fig. 70. Germination of Maple Seedlings.

\section{APRIL TREE AND BUD STUDY.}

It seems wise to centre the plant study during April about the seeds and their germination. Much of what was observed in March in the study of the buds forced in the schoolroom can be reviewed in April by out-door observation.

It will be well to observe also during April the formation from the flower and the early stages of growth of the winged seeds of the white maple and red maple. The sugar or rock maple or hard maple usually flowers during the latter part of April.

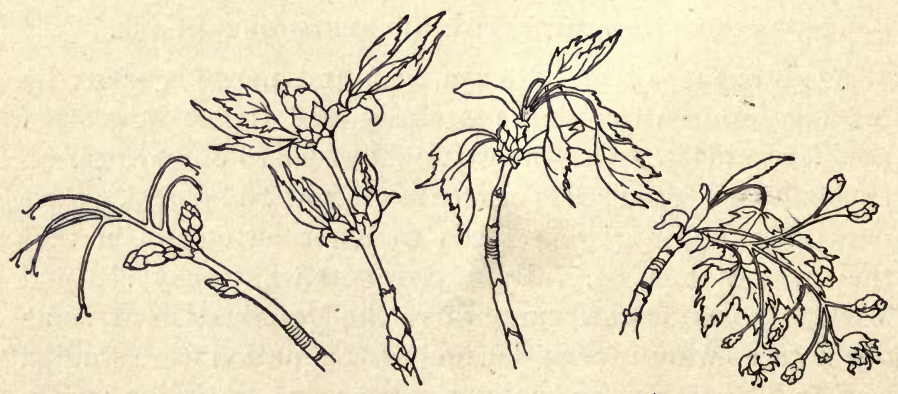

Fig. 71. Development of Buds of Norway Maple. 


\section{MAY PLANT STUDY.}

THE PLANT AT WORK.

For two months we have been studying beginnings, - the branch developing from the bud, the root and stem and leaf starting from the seed.

For two months our boys and girls have been discovering how much has been done for the plant, how the seeds and buds have been protected through the winter, how carefully provision was made long beforehand for their spring awakening and growth, how leaves and soil, snow and rain, sunshine and cloud, have all helped.

This side of plant life appeals to the child because it is like his own life, his own experience as a child.

But he has seen the protecting scales separate, and gradually fall off, and the warm woolly covering disappear. Uncovered, unprotected, the tiny delicate leaves unfold, grow thicker and stronger, separate, spread out to sun and sky and rain. What for? The stem strengthens and lengthens upward. What for? The delicate leaves one after another push out from the protection of their fellows, enlarge, unfold, spread their faces to the light. What for?

Why, they have all made a discovery. Pulsating and throbbing through the plant, from every root and stem, from every branch and leaf, comes the message: "We have a work to do. All these months Mother Nature has been getting us ready to do this work. She has cared for us and protected us. She has given us everything, done everything for us. Now she tells us we must work for ourselves."

During May and June our boys and girls will study the other side of the plant's life, - what it does, its work.

The Root at Work. Review observations on early growth 
of root. Review experiment showing that root always grows first, and always grows downward. The roots are determined to get into the earth. What do they do in the ground?

Carefully dig up by the roots a young bean or pea plant, shake it gently in water to remove the earth, and then place its roots in a vessel containing water in which a little red dye (eosine red is best) has been dissolved, coloring the water a bright red. After about twelve hours it will be found that all the fine veins in the leaves are stained a bright red, showing that the water, earrying the dye, has passed into and through the roots, up the stem, and into the leaves. (Laurie's " Food of Plants.")

The work of the root can be illustrated, not demonstrated, by showing the children how a piece of cloth or blottingpaper or a string draws up colored water.

The fine furry covering of "root-hairs" usually seen on peas raised on damp paper, under a glass, will help the ehildren to understand how or with what the root draws in water. Each hair is a tube with very thin walls and end, through which the water passes. It is not true that "the roots have hundreds of little mouths," as the children are sometimes told. They have no openings, but absorb through the thin walls. Hence they can take in only liquids and gases.

The main work of the roots is to take in food from the earth for the plants. Why are the roots formed first? Where does the little plant get its food while the roots are getting ready for work? How is it that they can grow so large without any earth?

The children will doubtless suggest another part of the work of the root, - to hold the plant in the ground. Notice how well they are fitted for this by the branching and direction of growth of the roots. 
The Stem at Work. The study of the germination of seeds and development of buds has shown the children one use of the stem - to support and separate the leaves.

As the beans planted on sawdust or paper get older, the children can be shown the skin enclosing the stem. What is its work? Compare with the use of the skin on their hand. Perhaps they will see the threads or fibres running lengthwise through the stem. If they do, tell them that in these threads are little tubes through which much of the water and food passes.

The Leaves and Their Work. There are many reasons for emphasizing leaf-study. Leaves are much more abundant and can be more easily obtained than flowers. Their study can be made as interesting and attractive as that of flowers. If leaves are studied more, our wild flowers will not be destroyed so rapidly, as the growing interest in nature study threatens.

We must study the leaves as living things, not as mere forms. The tendency to emphasize form and structure is particularly evident in the methods usually followed in studying leaves. Too often the leaf is nothing more than a form, supported by a skeleton. Too often the leaf is a means of giving the pupil practice in exact, concise description, and is nothing more. We are not going to neglect the careful observation and the clear, exact expression. In this we will find the leaves and flowers very helpful. But we must give our boys and girls more, - an interest in the world about them; a sympathy with nature; an appreciation of the beautiful in form, color, purpose, and relations. 
GERMINATION OF BEAN.

\section{(Continued from April. Planned for First Grade.)}

LESSON VI. THE LEAVES IN THE BEAN GETTING READY.

Preparation. Beginning with the two pale little leaves folded between the cotyledons lead children to watch : how they increase in size; how they push apart from one another, and push out from between the cotyledons, tip first; how their color changes to a deeper and deeper green; how the plant stem lengthens pushing them up, and the leaf stems lengthen pushing them apart, until they turn their faces to the sky; how between the bases of the two leaf stems a little knob appears, which slowly shows itself to be a bud.

When this stage is reached have a lesson. It will be much more successful if the children can have before them, during the lesson, beans (large Lima beans are best) just beginning their development, and others showing one or two stages in the emergence of the leaves.

Presentation. The lesson may be in four steps : first, the baby leaves in their seed cradle; second, the leaves climbing out of their cradle; third, looking up toward the sun; fourth, the parts of the leaf and what they do. The parts are: the leaf stem, to lift up and hold up the leaf; the leaf blade; the flat, thin green part (compare with a knife-blade); and the veins, to hold up the parts of the blade. (See Fig. 67.) Three blackboard sketches, showing these stages, and strongly emphasizing leaf development, drawn by the teacher as directed by the children, will lead the little folks to observe carefully, and will help to impress the main facts on their eyes and minds. It may be helpful to have the children cut the leaves in paper, or take an impress of them in clay. 
LESSON VII. MAKING NEW LEAVES TO HELP IN THE WORK.

Watch with the children the growth and unfolding of the bud. Why is it between the lower ends of the leaf stems? For better protection. Is it covered with scales, like the buds studied in March, which had been on the trees all winter? Why not? Note how its stem pushes it up from between the first two leaves, and how it unfolds until we see leaves quite unlike the first ones. They are divided into three parts, or leaflets. Note how they are folded in the bud and how they unfold.

When the most mature leaves are fairly well developed, have a lesson, having the children draw a leaf, with its three parts.

LESSON VIII. THE GREAT WORK OF THE LEAVES. MAKING THE WORLD BEAUTIFUL.

Mother Nature (who is Mother, Nature?) has been so very careful in covering and wrapping and folding these bean leaves; she has given them such a store of food; she sets the root and stem at work getting and carrying food for them, she brings them out so slowly and cautiously in the spring, - she must have a great work for them to do. What is it?

Try to have the little folks see how the green leaves give the main beauty to the bean plant. How bare a bean plant looks from which all the leaves have fallen! How much the leaves differ in size and outline, and how much better that is than having all alike! This thought will be impressed if children are led to try to find two leaves exactly alike. How much the plants in the window boxes, and mainly the leaves of these plants, brighten the windows and the room!

At this season, when all nature is dressed in richest 
green, turn the eyes and the thoughts of the children to the trees and lawns and fields. Gathered about the window (or, better, going out doors), with even one tree or lawn or bit of green in sight, cannot they see and begin to appreciate the fact that it is the leaves, not the flowers, which give the chief beauty to this world of ours. The leaves form nature's dress; the flowers are only the jewels scattered here and there.

Isn't it a great work to fill this world with life and beauty and brightness, to help bring joy and happiness to everybody? Will not some of the little men and women apply the thought? What would we and the birds and all the animals do without leaves? What a world this would be with nothing green!

In city schools, in a world of brick and stone and smoke, the leaf study may be the means of showing yearning, hungry eyes something of the world of beauty which seems so commonplace to the more favored children in village and country.

Bring out another use of the veins, - to carry water to every part of the leaf. Note how the veins come from the top of the leaf stem, branch again and again, and extend - to every part of the leaf. Compare with water pipes in the city, or with ditches or drains in the country, or with the blood vessels in the hands.

The children can understand that, if each leaf is giving out water, all together throw out into the air an enormous amount of water. Some trees are known to exhale several tons of water every day. Those children who have studied during the winter the forms of water can, perhaps, appreciate something of the use and value of leaves and of plants in keeping the air moist and thus helping in giving us frequent rains. 
LESSON IX. MORE WORK FOR THE LEAVES. THROWING OUT WATER.

Repeat or review the experiments suggested, showing that the roots drink in water with food dissolved in it, and that this is carried through the stem to the leaves. The roots must take in water every day, to get food for the plant. What becomes of the water?

Invert a clean dry fruit-can closely over a bean plant. Set the plant in the sunlight. Before very long the inner surface of the can becomes covered with moisture or water. If the leaves are removed, or the plant is not in the sunlight, little water will be seen.

The following simple experiment, from Goodale's "Physiological Botany," will help the children to see and understand what the leaves do:

"Take six or eight fresh, large, healthy leaves, two tumblers filled to within an inch of the top with water, two empty, dry, clean tumblers, and two pieces of card, each large enough to cover the mouth of the tumbler. Near the middle of each eard, bore three or four holes, each large enough to allow the stalk of a leaf to pass through. Put the leaf-stalks through the holes, far enough to hang quite deep in the water, turn the empty tumblers upside down, one over each card, so as to cover the broad part or blade of the leaves. Place one pair of tumblers in the sunlight, the other in a shady place. In five or ten minutes examine the inverted tumblers."

Thus the pupils will learn that one part of the work of the leaves is to throw out the water which the roots take in. The microscope shows us that each leaf has, mainly on its lower surface, thousands of little pores or mouths, much too small to be seen by the eye (each apple leaf is said to have about one hundred thousand of these pores), through which water passes. 
Compare the throwing out of water by the leaves (transpiration, the botanists call it) with the throwing out of water by the skin, or perspiration. Perhaps the children can discover, in old leaves, that the leaf, too, has a skin.

\section{LESSON $X$. HOW THE LEAVES AND THE SUN WORK TOGETHER.}

Study the leaves in relation to the light. Note how all the leaves of the bean turn toward the light. Turn the box around so that leaves face away from the light. How soon they twist around.

Any plants growing away from the window show how the leaves grow toward the light, often greatly lengthening their stems to get nearer the light.

Bean plants, whose leaves are shaded by other plants, or bean plants put in a dark place, soon lose their bright green color and look sickly.

Plants grown in a sunny window are much greener and much more thrifty looking than those which do not get the sun.

Evidently our bean leaves love the sun. Why? Does the sun help them? Show the children plants which have been in the cellar all winter. Ask them to turn over boards and stones, and see the color of the leaves under them which are hidden from the sun. How yellow or pale they look!

The sun helps the leaves by giving them their green color, and by keeping them healthy. A review of the experiments in the previous lesson, putting all emphasis on the difference, in the throwing out of water, between plants in the sun and those in the shade, will show even the little folks that the sun also helps the leaves throw out watersomewhat as it helps the water in lake and river and on street and walk to pass into the air or evaporate. 
This lesson may be applied by further observation by the children of house plants and weeds. Cannot they repeat the observations of last fall on the mallow-plant, and see again how the leaves face and follow the sun from morning to night? In the spring the leaves of many other plants do this. Perhaps they can see how the leaves of house plants, such as the geranium, arrange themselves so as to get as much light as possible; those that cannot get light fade and die.

LESSON XI. MORE WORK FOR THE LEAVES. PROTECTING THE BUDS.

Watch the further development of the new leaves. Note how the buds always grow where they are protected by the leaves. By the latter part of May flower buds are likely to appear.

This protective work of leaves is better shown by other plants. The mallow (see work for September) shows it very clearly, the young leaves being folded fan-like in the axils of the older leaves. In the common buttercup the stems of the older leaves are hollow toward the base, and enclose very securely the leaf and flower buds. The pea shows very clearly how buds and young leaves are protected by their older and stronger brothers and sisters.

There is material for several field lessons, related to and supplementary to the bean study, on "How baby leaves are protected by their older brothers and sisters."

The leaves have other functions, such as breathing for the plant and making plant food or starch out of water and air ; but these the teacher can only talk about, and the little children cannot see or comprehend, so it seems better to postpone the study of the other work of the leaves to later years. (See outline on morning glory.) The three uses given, - to beautify the world, to throw out water, to 
protect the younger leaves or the bud, - the smallest child can see and understand fairly well.

\section{LESSON XII. THE STORY OF THE LEAF AND OF ITS} WORK. A REVIEW.

Cannot the life and work of the leaf from infancy to maturity be summarized, more closely related, and more deeply impressed by a story, "The Story Our Bean Leaf Told" ? Let the children help by supplying to the teacher - who has forgotten (?) them - some of the main incidents of the story.

\section{GERMINATION OF MORNING GLORY.}

(Continued from April. Planned for Third Grade.)

The Morning-Glory Leaves and their Work. Follow much the same general line of work as outlined for the study of the bean.

Watch carefully the growth of the stem and the way in which it twines around the string provided for it, comparing its growth and manner of supporting itself with the bean or pea.

Observe the position of the bud, between the bases of the seed leaves, the protection, first appearance, and growth of the true leaves, the ways in which they differ from the seed leaves or cotyledons, the position and unfolding of new buds and leaves. Note how the seed leaves change color, and finally drop off.

Third-grade children should be able to draw the morningglory leaf with very little help. The best way to lead the children to observe the leaf, and to get a clear, exact idea of it, is to have each pupil draw a leaf.

Bring out by experiment - do not merely talk about the use of the morning-glory leaves. (See outline on bean.)

The third-grade children should be able to get a fair idea 
of the work of leaves in breathing and in making food for the plant.

Make sure that the children discover by observation the importance of sunlight to the leaves, the way in which they twist and turn and stretch to get the sunlight, and the effect of keeping leaves where they cannot get sunlight.

The Leaves as Breathing Organs. Begin the study of breathing by leading the children to see and tell how necessary breathing is for them. Let them see what is the effect of "holding their breath" and of breathing the air in a paper bag held tightly over mouth and nose. Tell the children that the lungs are two bags, with thousands of smaller bags or sacks opening into them (illustrate with paper bag), thus making a very large surface very much crumpled (like a paper bag compressed into a small space), that the walls of these sacs are full of blood vessels, and that the blood takes in the air from the bags, and throws out the poisonous gases of the body.

The leaves are to plants what the lungs are to the children. Each leaf is like one of these little sacs ; but instead of being in the plant, as our lungs are in the body, it is outside, somewhat as if our lungs with all their sacs might be turned" inside out." Each leaf has a network of veins and thousands of little "breathing-pores" too small to be seen by the eye, through which the useful gases, or beneficial parts of the air, pass into the leaf, and the injurious gases in the leaf pass into the air; that is, the leaves breathe in oxygen, and breathe out carbonic oxide (commonly called carbonic acid), much as we do.

The Leaves as Factories. The papers given below, written by third-grade children, show that they can get fairly clear ideas of the work of the leaves in manufacturing plant food or in making starch and sugar.

Lead the children to tell about some factory, dwelling on 
the difference between the raw material used and the manufactured product, and on the necessity of machinery and of an engine and furnace or other source of power. Tell them that the leaves are starch factories worked by sun power. Through the "breathing-pores" with which they breathe they take in parts of the air; through their roots they take in water; and out of these make, with the help of the sun, starch and other plant food. Like any other factory they cannot work without power to make them go. They only work in the daytime when they have the sun. Hence we see why every leaf tries to get out where it can see the sun and get sun power. Perhaps the children have discovered that those leaves which cannot get the sunlight turn yellow, and many finally die and drop off.

In these factories are millions of minute green bodies, each of which is a machine for making starch. When the leaf does not get the sunlight, these starch machines lose their green color and break down. Then the leaf loses its green color, and may wither and die.

What could plants do without leaves?

\section{The Leaves as Air Purifiers.}

Beginning with the experiment of breathing into a paper bag held tightly over mouth and nose, lead children to see that the air in the bag gets "bad," because we have breathed into our body the part of the air (oxygen) helpful to us, and have breathed out into the bag gases poisonous to us ("carbonic acid"). But this poisonous gas, which we and all animals breathe out, the leaves of the morning glory and of all other plants take in, and out of it and water make starch. So every leaf, as long as it has sun-power, is taking out of the air this poisonous gas, and making the air more fit for us and all animals to breathe. Nor is this all. In the process of making starch every leaf is setting free and throwing out 
the gas (oxygen) that we and all animals need to breathe. So the leaves, aided by the sun, purify the air for us in two ways.

What could we do without leaves?

The Leaves as Food.

Touch on the importance of leaves as food for animals, - horses, cows, rabbits, grasshoppers, caterpillars, etc.

\section{The Leaves as Homes.}

How much more secure the leaves make the birds'-nests hidden among them! Perhaps some leaf miners can be found in the yellow dock or other leaves, spending most of their life and getting their food between the upper and lower skin, or epidermis, of the leaves. Some of the children may find the "leaf-rollers," caterpillars or spiders, which have rolled leaves into tubes, in which they make their homes.

"There's never a leaf nor a blade too mean

To be some happy creature's palace."

What could animals do without leaves?

\section{CHILDREN'S PAPERS ON LEAVES. \\ What the Leaves Do.}

"There are channels in the leaves of the bean plant. The biggest channel is in the middle of the leaf. There is also a channel in the leaf stalk. The rain water falls on the leaves and passes through the channels down the stem and in the ground. The leaves of the bean spread out and point down. The leaves carry water to the roots. The roots take the water from the ground and send it to the leaves.

"Miss Schiller had a bottle of colored water and put a bean plant in it. After some time the plant turned red. The water soaked in the roots and passed through the stem then in the leaves. The water must pass through the plant to give it food."

Jennie Boyer, Third Grade. 


\section{The Work of the Leaves.}

"We got two pieces of grass and one was yellow and the other was green. The yellow piece of grass was under a stick and the green piece was out in the sun and light. The sun keeps the factories agoing. The leaf green factories make starch. They make starch and the starch factories do. They eat and drink like us and if they were in a dark place they would get pale and sick and so would we. The little pieces of grass make the starch out of air and water and they eat the starch. The light makes the engines go and the engines make the machines go."

Willie Allen, Third Grade.

What the Leaves Do.

"When we take up a board the grass under it is white. When our mothers put plants in the cellar they turn white. The cellar hides the light. We look at our beans. They are looking toward the window. The leaves get light for the plant. They can get light because they are large and they don't lap over each other. When they are one on each side of the stem they are opposite. When there is one and then another they are alternate. We need air to live, so do plants need air to live. Plants do not breathe good air, they breathe bad air. We breathe good air so there is not enough good air for the plants. They say that it is healthy for plants to be where there is a good many people. There is little holes in the back of the leaf and they breathe through them. If those little holes were closed they would die. We breathe through our lungs."

Carl Carter, Third Grade.

\section{What Leaves Do.}

"Miss Schiller got a piece of sod under a plank. The leaves on the grass was yellow because the sun didn't shine on it. And all plants in the dark the leaves turn yellow. The plants in the window box are green because the sun shines on them. In each leaf we find stuff called green leaf paste or jelly or paste which is leaf green. We called the leaf the kitchen. We call the sun the fire. The leaf green lives in all parts of the leaf. The leaf green works in the day. The sunlight colors the leaves green. The sun and the leaf green work together. Leaf green and the sun make their own food. The root soaks up the water and the bad air that we breathe out the leaf takes in. The sun and leaf green changes the water in the leaf and the air they breathe into food."

JAMES GRIGGs. 
"Miss Schiller had some sod that she found under a board. The sod was yellow because it grew in the dark and did not have the sun. The plants that are in the window box are green because they had sun. We find Leaf-green inside of each leaf. Leaf-green is something like green paste or jelly. We call the leaf the kitchen. The sun is the fire for the leaf. Leaf-green is a fairy and lives in every part of the leaf. The sun and Leaf-green are friends. They make food for the plant. The leaves take the bad air that we do not need. The roots take the water and send it to the leaves. Leaf-green and sun make food out of bad air and water. Leaf-green works in the day. When the sun goes down Leaf-green goes to bed."

Jennie Boyer, Third Grade.

\section{My Dandelion Leaf.}

"The dandelion leaf starts from the root. It resembles the horse chestnut a iittle in shape. The surface of the leaf in front is rough. On the back it is smoothest. The teeth curve in a little toward the end. The notches or teeth help support the plant by leaning against the grass. There are not so many veins in the dandelion leaf as there are in the horse chestnut. The middle rib holds the plant together. There is a little groove in the front of the main rib. This is for the water to run down to the root. The plant needs rain, sunshine, wind and a kind of food it gets from the ground. There are little teeth on the side of the big teeth. Toward the bottom the main rib is wider. On the back it is light green and on the front it is darker. The number of teeth on both sides of mine is eleven. The little veins come up to the main rib for food and drink. The main rib gets its food from the root. The little veins start from the main rib and run to the end of the teeth."

Richard Sheldon Ould.

"The shape of my dandelion leaf is like a horse-chestnut leaf, but it is not as strong and it is narrower. The front side of the dandelion leaf is rougher than the back side because it has a great many little fine hairs on it. The veins of the dandelion leaf start from the tip of the teeth. The great big rib that is in the centre of the leaf is for the water to run down through for the roots. On the back of the leaf it is light green and on the front it is dark green. It is dark green on the front because the sun shone on it. The number of the teeth on my dandelion is ten on one side and eleven on the other side."

\section{Marie Hapgood, Third Grade.}




\section{THE LEAVES. 1}

"We have a lilac branch. The leaves on this branch are arranged in twos. The two leaves come from the same part of the stem, but one leaf comes from one side of the stem and the other leaf from the opposite side of the stem, like this (drawing). We call this the opposite arrangement of leaves. The first leaves of our bean have an opposite arrangement.

The leaves of our plum branch are arranged in ones. There is a leaf near the bottom of the stem, then a little way up but not on the same side. It goes on like this until the sixth leaf is over the first. We call this the alternate arrangement. Our morning glories have an alternate arrangement of leaves. Mother Nature arranges them in a plan and this is the plan.

She put them out as far as she could get them out so she could let them get the sunlight and let their factories go. If their factories did not go they would die and we would not get so much air. Our bean plant got the sun in the front row but the ones (leaves, C. B. S.) in the back did not and so their stems began to grow and now they are tall and they can get the sun. The plants ought to get the sun so their factories can go and hey would die if they didn't go, so they don't want to die."

John Farrel, Third Grade.

1 The first two paragraphs are copied from a class reproduction. The remainder of the paper is an individual reproduction. 


\section{MAY BUD STUDY.}

\section{THE HORSE-CHESTNUT BUD.}

BRING in the ends of two or three branches showing what has developed from the buds. Note how the scales have turned back and how loosely they are attached. Observe the scar that each scale leaves when it has fallen off, and the ring about the twig formed by the dropping off of all the scales of each bud.

Note the green stem which has formed from the bud, its length (it usually grows much more rapidly on the twigs near the upper and outer parts of the tree), the woolly covering still adhering to it, and the way in which it has separated the leaves, which were so close together when they first appeared. Compare the stem and ring formed from the bud of this spring with those formed from previous buds. The growth of the twigs toward the top and outside of the tree is more rapid than that of those near the trunk!

The leaves have been separated by the growth of the stem and of the leaf stems. Try to get a fresh branch (not wilted) which has grown vertically, and let children look down on it, and discover how the three or four pairs of leaves have arranged themselves so that all can get as much light as is possible, the younger leaves filling the spaces between the stems of the older leaves. Each leaf - including one leaf stem and all the parts fastened to it - has five to seven divisions or leaflets, each division narrow at the base and broader toward the tip, shaped somewhat like a wedge. When all are spread out, each leaflet can get the sun.

Compare appearance and arrangement of leaves on a twig growing horizontally, or nearly so, with twig growing ver- 
tically. One leaf stem, the one growing downward, is usually very much elongated to push its leaflets out from under the leaves at the side. The stem of the leaf just opposite this, growing upward, has turned backward to put its leaflets in the position to get the most light, and has remained quite short.

Perhaps the children can discover how the young horsechestnut leaves sleep. At night, and sometimes on cold, stormy days, the leaflets droop or hang almost vertically, making each leaf look like a partly closed umbrella. In the morning they are lifted up and spread out like an open umbrella or somewhat like a fan.

As the younger leaves develop, notice how they fill the spaces between the stems of the older leaves, - some leaf stems lengthening, some remaining short, some turning and twisting, so that the younger leaves will not cover or be covered by the older leaves.

Why do they grow thus? Review what was shown in the work on the morning glory about the leaves as starch factories worked by sun-power. All the leaves arrange themselves, in general, so as to get, and allow others to get, the greatest amount of sunlight or of sun-power.

Watch the stages in the development of the flower cluster from the little "bunch of grapes" found in many buds. Note how the leaves are turned back to give the flower room; how the main stem and side stems of the flower cluster lengthen, separating the green balls; how each of these balls grows larger, opens at the tip, showing five (usually) teeth around a white interior; how this white part lengthens and opens; how growing from within it appear several brown knobs, each on a slender stem; how the mature flower finally appears. The outer green part of each ball or flower bud is the calyx, with five teeth; the white part is the corolla, separating into five handsome petals; 
the brown knobs are the ends of the stamens. In the ripe flower is a slender curved stem without a knob, growing from an enlarged base. The enlarged base is the seed box, or ovary.

Late in May, or early in June, the petals and stamens drop off, and some of the seed boxes enlarge, and become covered with green spines, the beginning of the horse chestnut. Watch the changes in it through June. In September the last stages in the development of the nut can be seen.

Before the close of school review, with the branches before the children, the whole story of the horse-chestnut bud and of its development from March to June.

\section{OTHER MAY BUD STUDY.}

The development of the lilac leaves, flowers, and fruit can be watched during May and June. Note how long the stem becomes; how the outermost scales drop off, and the inner leaf-like scales turn green, and form small leaves, which usually drop off; how the leaves are arranged (opposite) to get the most light; how new leaves form from the terminal bud; how the branches of the flower cluster are protected by a small leaf or bract; how the flowers unfold, and how and where the fruit forms.

The study of the pussy willow or poplar can be continued, dwelling on the growth of the seed boxes, or pistils, and of the seeds. Note how the scales and hairy covering drop off, how the stamenate catkins shrivel and disappear, how the "little green bottles" appear on the pistillate catkins, grow larger, split open, showing the cotton and seeds, and discharge of their plumed seeds. It is not wise to attempt with primary children any study of the parts of the flowers of willow or poplar. Merely watch the stages in the development of the seeds and of the leaves. 
The development of the maple bud shows very clearly the formation of the winged seeds and the arrangement of leaves to get the greatest possible amount of light. Relate to seed study of previous autumn.

The cherry buds are particularly good to show how the fruit is formed from the flower. Watch the turning back of the bud scales, the appearance and parts of the flowers, the falling of petals and later of the calyx and stamens, and the growth of the cherry and seed from the lower part of the blossom. There is no good reason why the second-and third-grade children should not study and understand the plan and parts of the flower, - the green calyx, cup-shaped with five teeth at the top; the white corolla with five or more petals; the many yellow thread-like stamens; the green seed box or pistil, concealed within by the calyx. Do not, however, allow the children to separate the parts of the flower, or to tear it into pieces.

This observation of the formation from the flower of seeds and fruits will both review the spring plant work and prepare for the fall study of seeds and fruits outlined for October and November.

\section{My Honse Chestnut Blossom.}

"The main stem is fastened to a little seat between the leaves. The shape of the stem is cylindrical and it has little notches on it. The length of my twig is about a half a foot long. The color of my twig is green a little lighter at the top than at the bottom. The little flowers are arranged almost opposite in pairs. The shape of my little stem is round and it has notches toward the end. The length of my little stem is about two inches long. The color of my little stem is a light green almost yellow but not quite. The calyx are under the corolla. Their color is light green. There are five of them (sepals, C. B. S.). There are five parts to the corolla. The parts are called petals. Their color is white with red and yellow spots in them. Those with the red in them are the older."

Margaret Becker, Third Grade. 
JUNE PLANT STUDY.

The Flowers and their Work.

"In all places, then, and in all seasons,

Flowers expand their light and soul-like wings, Teaching us, by most persuasive reasons,

How akin they are to human things."

"And with childlike, credulous affection

We behold their tender buds expand: Emblems of our own great resurrection,

Emblems of the bright and better land."

LONGFELLOW.

THe flowers. How shall we approach them? How shall we study them?

The flower is the summit of the plant kingdom. It is as perfect in detail, as marvellous in structure, as beautiful in color and form, as anything in nature. The flower was the favorite object lesson of the Great Teacher. It has been an inspiration to the poet, a messenger of peace to the troubled and anxious, a means of brightening and uplifting darkened hearts and homes.

Shall we consider the flower simply as something for boys and girls to pick to pieces and throw away? Shall we teachers in the elementary school follow the lead of so many in high school and college, and teach our pupils to regard the flower, mainly as something to be picked apart, or "analyzed," and described, and perhaps pressed out of shape and laid away, scarcely to be looked at again?

In the upper grades, more or less "analyzing" is necessary. Even this can be done, with older children, in such a way as to make the pupils more reverent toward the flowers.

If we make our flower study with our little folks a mere 
pulling into pieces and study of parts, we shall degrade the most beautiful of God's works. We shall miss the opportunity of all opportunities to open the child's eyes and mind to the beautiful, the uplifting and ennobling in the works of God, to the highest and best thoughts of man.

The study of flowers has been purposely left to the last. We want to impress very deeply the fact that plant study is not merely or mainly flower study. We want to preserve our wild flowers. We want our boys and girls - and their teachers - to realize that the flowers are the richest gems in the treasury of nature, which we are opening before their eyes.

\section{SUGGESTIONS FOR FLOWER STUDY.}

What shall we study in the flower?

First. Its development and unfolding, bringing out its relations to the plant.

Second. Its beauty and the beautiful thoughts it has inspired.

Third. Its work or function, to produce new plants.

Fourth. Its parts and plan, and how it is made or fitted for its work.

The observation in May of cherry or apple or horse-chestnut blossoms with some study of their parts, will prepare the children for the study of the flowers which form in the schoolroom.

The development of the flower can be best observed in the bean or pea or morning glory in the schoolroom window or yard. The bean has not finished its work. Roots have gone far into the ground. Stems have grown long and vigorous. Scores of leaves have unfolded and gone to work. Still the plant grows. What is it going to do now?

Watch the buds forming and enlarging just between the leaves or leaf stems and the plant stem. Watch this bud 
unfold, at first all green (the calyx, or outer covering), later opening at the top by five teeth (the sepals), and disclosing a whiter part within (the corolla, or crown). In time this white part unfolds, showing within it ten little yellow knobs or threads (stamens), and within these a slender, curved, pointed stem (the style, fastened to the seed box, or ovary, concealed in the base of the corolla). Do not be in a hurry to give the names of the parts. Careful observation and clear ideas first. After struggling for a time to express these ideas in their words, to tell about "the green cup," "the white part," "the little threads like pins," the children will welcome and correctly use any names which really help them to express their ideas.

Dwell on the beauty of the flower. Begin the lesson often with a bright, simple thought on flowers - a line or two on the blackboard - from the poet.

What is the work of the flower? Everything works for it. It is so well cared for. It unfolds so carefully. It is so beautiful and perfect. What does it do? Make the world look beautiful? Yes. Bring happiness to all about it? Yes. Make us think pure, beautiful thoughts? Yes. That is a great deal, isn't it?

But this is not all. "Do you know, boys and girls, that way down in the flower a wonderful secret is hidden? Well, there is - more wonderful than anything we have found yet. Shall we watch carefully? It may take several days. And when any one discovers it you will not tell the others, but just come and whisper it to me. We want all to discover it, each for himself." The children watch the development of the flower and the growth of the pod with the most intense interest. The writer has seen a roomful of unruly pupils transformed by a bean plant - and a wise teacher who knew how to make use of the plant. 
Will not such work (supplemented in later grades by a study of fertilization in the flower and of the development and life history of some animals) lay the foundation for a better understanding of the mystery of beginnings ? Through the flower, that emblem of all that is pure, cannot our boys and girls absorb a purer, holier conception of reproduction, of the origin of life?

For the little folks in the first grade it may be sufficient to merely watch the growth of the flower and the formation of the pod. There is no good reason why the children of the second and third grade should not know the names of the parts which they can easily see, - calyx, corolla, stamens, pistil, seed-box or ovary - and understand fairly well the plan of the flower.

It will be well to supplement these by studying the flowers of one or two other parts. The buttercup is excellent. The strawberry is good.

With the final work of the plant, the fruit or seed vessel, before the children try to gather up, as the last step in the work of the school year, the life and work of the plant during the year; the formation and protection and seattering of the seeds last summer or autumn; the long winter rest, and the ways the seeds were covered and preserved; the spring awakening, and the work of sun and rain and soil and of man; the development and work of root and stem and leaf and flower, and the beauty they added to the world, and the enjoyment they brought to us; the formation, protection, and ripening of the seed, and its importance to the plant, and to man, as a food.

How much all nature and man have done to help the seed ! Why? How carefully the plant mother protected and fed it! Why? How little the plant could do at first! How much it has done in making the world brighter and happier, in adding pleasure to our life and in helping to feed 
us, in preparing for another spring! Now its work is done, well done. Can the teacher ask for a better closing thought?

\section{CHILDREN'S PAPERS ON FLOWERS.}

Little Miss Buttercup.

"I am a little buttercup. My flower is bright yellow. They stand tall and straight. When the sun shines on them they look so pretty. If we were shut in a box and could not get air we would die. We have to drink water and milk. If we did not have it we would die. It is the same with the plant. When it rains the leaves send the water to the roots and the roots send it to the leaves again. The flower would die without the rain and so would we. God sends the rain and the sun to make us grow. He sends the rain and the sun for the flower too. If the flower did not get water in the summer it would die. Buttercups are wild flowers. But God likes them just as well as the flowers that are not wild." Ursula Kane, Second Grade.

\section{The Buttercur. ${ }^{1}$}

"It is called the buttercup because it looks like a dish of butter. We find them in pastures, meadows and fields. It grows in every kind of soil but swamp soil. It burns your tongue when you taste of it. And it tastes like pepper.

"It grows straight up in the air and it is a foot and 7 inches high so it can get the sun. It has a little slender branching stem and the blossoming is most in June. We can find it as late as October.

"It is attached by the root to the ground. The roots come from the same place and they are long and slender. There are a great many roots. They are from two to four inches long. They are very strong. The little branches get the water because they can get more water when they spread out. The use of the root is to hold it in the ground."

Willie Allen, Third Grade.

\section{The Buttercup (continued).}

"The buttercup we had this morning was 27 inches high. It is so high because it wants to get the sun or the little bees will come and get the honey.

1 The three papers on the buttercup were written in answer to a series of questions, all the members of the class writing answers to the questions, but each answering in his own way. The papers represent three days' written work, about half an hour each day. All wrote with the buttercup before them. 
"It is a hollow slender stem. She (Mother Nature ?) makes it hollow so that she will not waste any material. They (the leaves) are arranged alternate. It branches in the middle. The base of the leaves is like the half of a hollow cylinder. It (the leaf stem) is wrapped around the stem so that it will not hurt the other stem that is coming out.

"The buttercup has two kinds of leaves. One kind comes from the base of the stem. They look as if they come from the root and so we call them root leaves. The other kind comes from the stem and so we call them stem leaves.

"The root leaves are arranged around the base of the main stem. On our buttercup the stems of the leaves were one foot long. The base of the stem is shaped like a half a hollow cylinder. It is shaped like this so that it will fit around the stem and so that it will make a little bed to keep the little new stem warm.

"The general shape of the leaves is round. Our leaves have from three to six parts. Our buttercup leaf is simple because the divisions do not go quite down to the top of the stem. The general shape of one (division) is like a kite only it is divided so that it looks like a tree with branches."

Willie Allen, Third Grade.

\section{The Buttercup (Completed).}

"The blossoms are up on the top of the plant so the bees can see them and they will come and get honey.

"It is shaped like a ball (in the bud ? C. B. S.) and it has li"' hairs on the outside. The calyx is the green part. It has five parts. Each part's name is the sepal. They are shaped like spoons. 'The corolla is the yellow part. It has five parts. It (each part, C. B. S.) is shaped like a wedge. The name of the part is the petal. It protects the soldiers (stamens, C. B. S.).

"The soldiers (stamens, C. B. S.) are in the middle and there are forty five on my buttercup. They have some yellow dust on their head because they guard the plant so that the seeds can grow better. The seed boxes are under the soldiers."

Willie Allen, Third Grade.

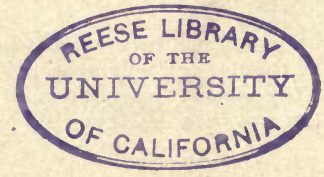



THIS BOOK IS DUE ON THE LAST DATE STAMPED BELOW

\section{AN INITIAL FINE OF 25 CENTS} WILL BE ASSESSED FOR FAILURE TO RETURN THIS BOOK ON THE PATE DUE. THL PENALTY WILL INCREASE TO $50^{\circ}$ CENTS ON THE FOURTH DAY AND TO \$1.0O ON THE SEVENTH DAY OVERDUE.

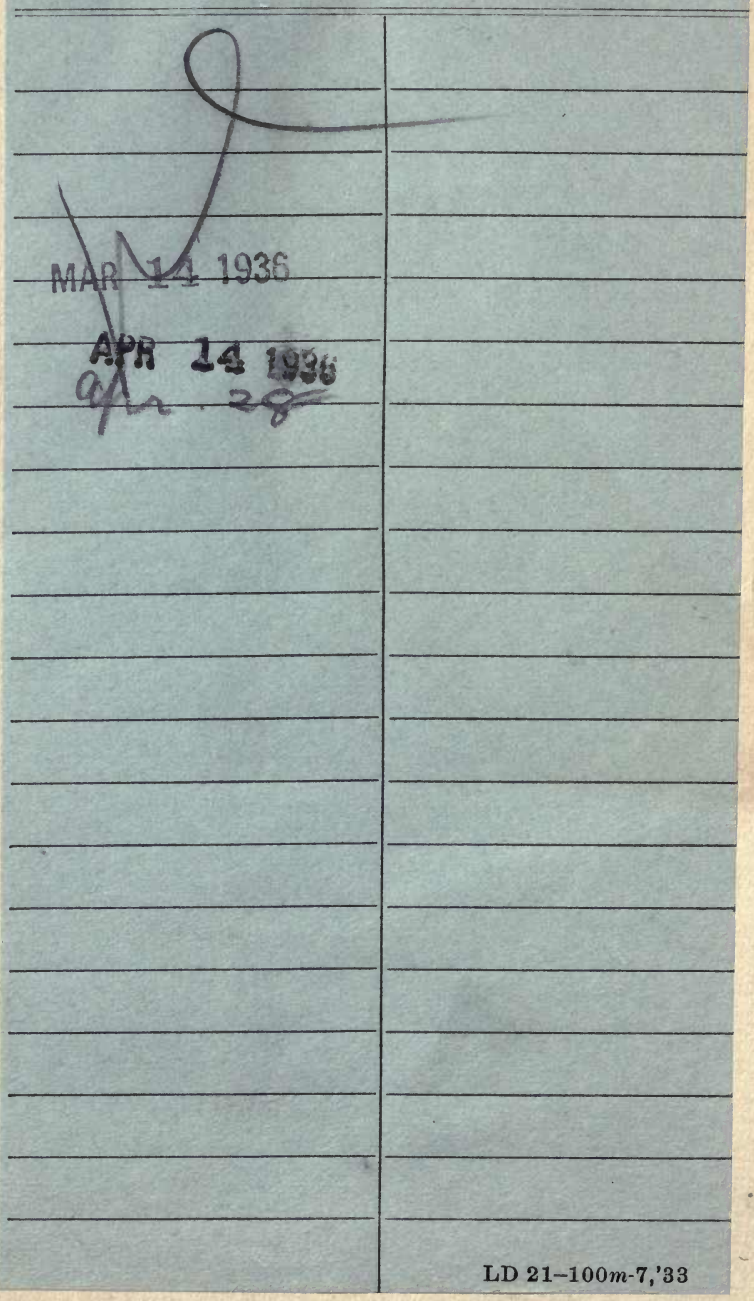




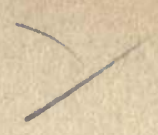

83010

istiat; 


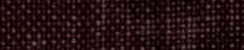
(4)

4. 30

(4)

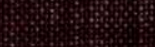

8

399

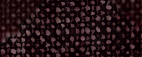

48.59

788

8093

\%

W.

$\%$

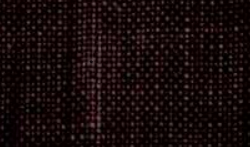

